\title{
Tank 241-T-111 Characterization Report
}

\author{
B. C. Simpson
}

Date Published

September 1994

Prepared for the U.S. Department of Energy

Office of Environmental Restoration and

Waste Management

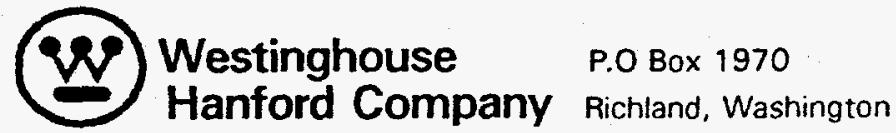

Hanford Operations and Engineering Contractor for the

U.S. Department of Energy under Contract DE-ACO6-87RL 10930

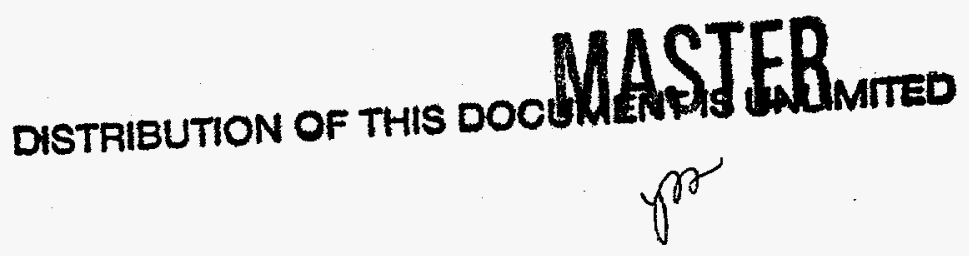

Approved for Public Release 


\section{RELEASE AUTHORIZATION}

Document Number: WHC-EP-0806

Document Title: Tank 241-T-111 Characterization Report

Release Date: $\quad$ October 6, 1994

This document was reviewed following the procedures described in WHC-CM-3-4 and is:

APPROVED FOR PUBLIC RELEASE

$* * * * * * * * * * * * *$

WHC Information Release Administration Specialist:

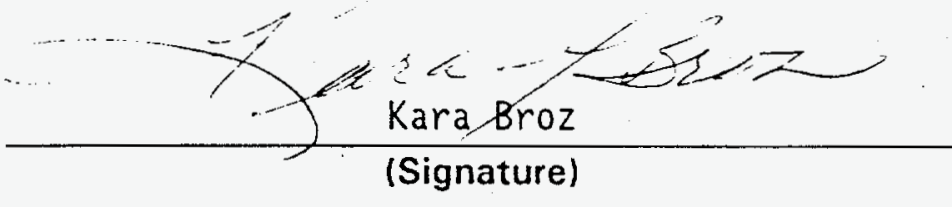

October 6, 1994

(Date) 


\section{DISCLAIMER}

This report was prepared as an account of work sponsored by an agency of the United States Government. Neither the United States Government nor any agency thereof, nor any of their employees, make any warranty, express or implied, or assumes any legal liability or responsibility for the accuracy, completeness, or usefulness of any information, apparatus, product, or process disclosed, or represents that its use would not infringe privately owned rights. Reference herein to any specific commercial product, process, or service by trade name, trademark, manufacturer, or otherwise does not necessarily constitute or imply its endorsement, recommendation, or favoring by the United States Government or any agency thereof. The views and opinions of authors expressed herein do not necessarily state or reflect those of the United States Government or any agency thereof. 


\section{DISCLAIMER}

Portions of this document may be illegible in electronic image products. Images are produced from the best available original document. 


\section{EXECUTIVE SUMMARY}

Single-shell tank 241-T-111 is a Hanford-Site High-Level Waste tank that was most recently sampled in late October and early November 1991. Analyses of materials obtained from tank 241-T-111 were conducted to support the Hanford Federal Facility Agreement and Consent Order $^{1}$ (Tri-Party Agreement) Milestone M-10-06 (now M-44-05). The waste in tank 241-T-111 is a complex material primarily made up of water and inorganic salts in a gel-like matrix. The insoluble solids are a mixture of phosphates, silicates, oxides, and hydroxides in combination with lanthanum, calcium, manganese, iron, bismuth, uranium, and chromium. The soluble analytes are primarily sodium, nitrate, sulfate, and fluoride (see Table ES-1).

Exotherms over -215 calldry gram were detected in the first two segments from each core. As a result of these analyses, tank 241-T-111 has been placed on the Organic Watch List'. The source of these exotherms remains under investigation; however, under present tank conditions, there is no possibility that a rapid exothermic reaction will occur. Another finding from the characterization analyses was that the present method for determining or measuring total organic carbon was not effective for the organic materials in this waste matrix. Further investigation of the method failure for this waste is underway and other assay methods are being considered.

\footnotetext{
'Ecology, EPA, and DOE, 1994, Hanford Federal Facility Agreement and Consent Order, 2 vols. as amended, Washington State Department of Ecology, U.S. Environmental Protection Agency, and U.S. Department of Energy, Olympia, Washington.

${ }^{2}$ Wicks, J. H. 1994, Tank T-111, (Internal Memo 94-003 to D. A. Turner, March 3) Westinghouse Hanford Company, Richland, Washington.
} 
Comparisons of the calculated bulk inventories for various analytes of concern show that tank 241-T-111 is within established operating safety requirements for heat-load, ferrocyanide, and plutonium inventory. From assessment of past and present surveillance data, tank 241-T-111 is considered an assumed leaking tank (see Table ES-2). Mitigation presently is taking place to remove the remaining free liquid in the tank in order to forestall any further leakage of tank contents to the environment. The free liquid is being transferred to tank 241-SY-102 as part of the overall single-shell tank stabilization effort ${ }^{3}$.

The results of the analyses have been compared to the dangerous waste codes in the "Washington Dangerous Waste Regulations" (WAC 173-303)". This assessment was conducted by comparing tank analyses against dangerous waste characteristics (" $D$ " waste codes) and against state waste codes. The comparison did not include checking tank analyses against " $U$, " $P$, " " $F$, or " $K$ " waste codes because application of these codes is dependent on the source of the waste and not on particular constituent concentrations. The results indicate that the waste in this tank is adequately described in the Dangerous Waste Permit Application for the Single-Shell Tank System; this permit is discussed in the Tank Characterization Reference Guide. ${ }^{5}$

${ }^{3}$ Jenkins, C. E. and D. B. Engleman, 1994, Engineering Report: Managing the Assumed Leak from Single-Shell Tank 241-T-111, WHC-SD-WM-ER-337, Westinghouse Hanford Company, Richland, Washington.

${ }^{4}$ WAC 173-303, "Dangerous Waste Regulations", Washington Administrative Code, as amended, Olympia, Washington.

${ }^{5}$ De Lorenzo, D. S., et al. 1994, Tank Characterization Reference Guide, WHC-SD-WM-TI-648, Rev. 0, Westinghouse Hanford Company, Richland, Washington. 
Analysis of the process history of the tank provided valuable information about the likely physical and chemical condition of the waste. Direct comparisons with historical tank reviews underway at Los Alamos National Laboratory are not possible at this time because the Los Alamos National Laboratory effort has not progressed to encompass tank 241-T-111. However, estimates and comparisons using the available process knowledge $e^{6}$ have been made. Further comparisons with the Los Alamos National Laboratory database will be made when it becomes available in 1995 . The available historical information, in combination with the analysis of the tank waste, supports the conclusion that a rapid exothermic reaction in tank 241-T-111 with the present tank conditions is not plausible because of the high moisture content of the waste and lack of any concentrated heat source. Therefore, the contents of tank 241-T-111 present no credible imminent threat to the workers at the Hanford Site, the public, or the environment. Because an exothermic reaction is not credible, the consequences of this accident scenario, as promulgated by the General Accounting Office, are not applicable. ${ }^{7}$ However, until the source and mechanism of the exotherm is further clarified, it was considered prudent to list the tank on the Organics Watch List, apply more rigorous access controls, and conduct further intrusive operations in tank 241-T-111 with greater care.

\footnotetext{
${ }^{6}$ Agnew, S. F., 1994, Hanford Defined Wastes: Chemical and Radionuclide Compositions, LA-UR-94-2657, Los Alamos National Laboratory, Los Alamos, New Mexico.

${ }^{7}$ Peach, J. D., 1990, Consequences of Explosion of Hanford's Single-Shell Tank are Understated, (Letter B-241479 to C. M. Synar, Chairman of Environment, Energy, and Natural Resources Subcommittee, Committee on Government Operations, House of Representatives), GAO/RCED-91-34, General Accounting Office, Washington, D.C.
} 
Table ES-1. Single-Shell Tank 241-T-111 Concentrations and Inventories for Critical List Analytes.

\begin{tabular}{|c|c|c|}
\hline \multicolumn{3}{|c|}{ Physical Properties } \\
\hline Density $\quad 1.16-1.28 \mathrm{~g} / \mathrm{mL}$ & $\mathrm{H}_{2} \mathrm{O} \quad 76.0 \%$ & $1,650,000 \mathrm{~kg}$ \\
\hline Temperature $16^{\circ} \mathrm{C}$ & Heat Load $81 \mathrm{w}$ & $(24 \mathrm{BTU} / \mathrm{hr})$ \\
\hline $\mathrm{pH} \quad 11.65$ & Total Waste Mass & $2,171,000 \mathrm{~kg}$ \\
\hline Chemical Constituents & $\begin{array}{c}\text { Average } \\
\text { Concentration } \\
(w t \%)\end{array}$ & $\begin{array}{l}\text { Bulk Inventory } \\
(\mathrm{kg})\end{array}$ \\
\hline Calcium $(\mathrm{Ca})$ & 0.242 & 5,260 \\
\hline Chromium $(\mathrm{Cr})$ & 0.198 & 4,290 \\
\hline Iron $(\mathrm{Fe})$ & 1.85 & 40,200 \\
\hline Manganese $(\mathrm{Mn})$ & 0.633 & 13,700 \\
\hline Sodium $(\mathrm{Na})$ & 3.70 & 80,300 \\
\hline Bismuth (Bi) & 2.60 & 56,300 \\
\hline Lanthanum (La) & 0.422 & 9,200 \\
\hline Silicon (Si) & 0.567 & 12,300 \\
\hline Uranium (U) & 0.355 & 7,700 \\
\hline Total Phosphate $\left(\mathrm{PO}_{4}^{-3}\right)$ & 3.23 & 70,100 \\
\hline Sulfate $\left(\mathrm{SO}_{4}{ }^{-2}\right)$ & 0.355 & 7,700 \\
\hline Nitrate $\left(\mathrm{NO}_{3}^{-}\right)$ & 4.13 & 89.700 \\
\hline Fluoride $(\mathrm{F})$ & 0.230 & 4,990 \\
\hline $\begin{array}{l}\text { Total Organic Carbon } \\
\text { (TOC) }\end{array}$ & 0.312 & 6.770 \\
\hline Radionuclides & $(\mu \mathrm{Ci} / \mathrm{g})$ & (Ci) \\
\hline Total Plutonium & 0.304 & 660 \\
\hline Am-241 & 0.0425 & 92.4 \\
\hline Sr-90 & 5.41 & 11,800 \\
\hline Cs- 137 & 0.166 & 360 \\
\hline
\end{tabular}


Table ES-2. Tank 241-T-111.

\begin{tabular}{|lr|}
\hline & Tank Description \\
\hline Type: & Single-Shell \\
Constructed: & 1944 \\
In Service: & 1945 \\
Diameter: & $75 \mathrm{ft}(22.9 \mathrm{~m})$ \\
Usable Depth: & $17 \mathrm{ft}(5.2 \mathrm{~m})$ \\
Operating Capacity: & $530,000 \mathrm{gal}$ \\
& $(2.01 \mathrm{E}+06 \mathrm{~L})$ \\
Bottom Shape: & Dished \\
Hanford Coordinates: & $43.347^{\circ}$ North \\
& $75.737^{\circ}$ West \\
Ventilation: & Passive \\
& \\
\hline \multicolumn{1}{|c|}{ Tank Status: } & as of May 1994 \\
\hline Contents: & Non-Complexed Waste \\
Total Waste: & 456,000 gal \\
& $(1.73 \mathrm{E}+06 \mathrm{~L})$ \\
Supernate Volume: & 0 gal \\
& $(0 \mathrm{~L})$ \\
Drainable Interstitial & 158.8 in. $(403.4 \mathrm{~cm})$ \\
Liquid: & Assumed Leaker \\
Manual Tape Surface Level & Organic \\
(under riser): & \\
Liquid Observation Well & \\
Level: & \\
Integrity Category: & \\
Watch List Status: & \\
& 51,000 gal $(193,000 \mathrm{~L})$ \\
\hline
\end{tabular}




\section{WHC-EP-0806}

Figure ES-1.

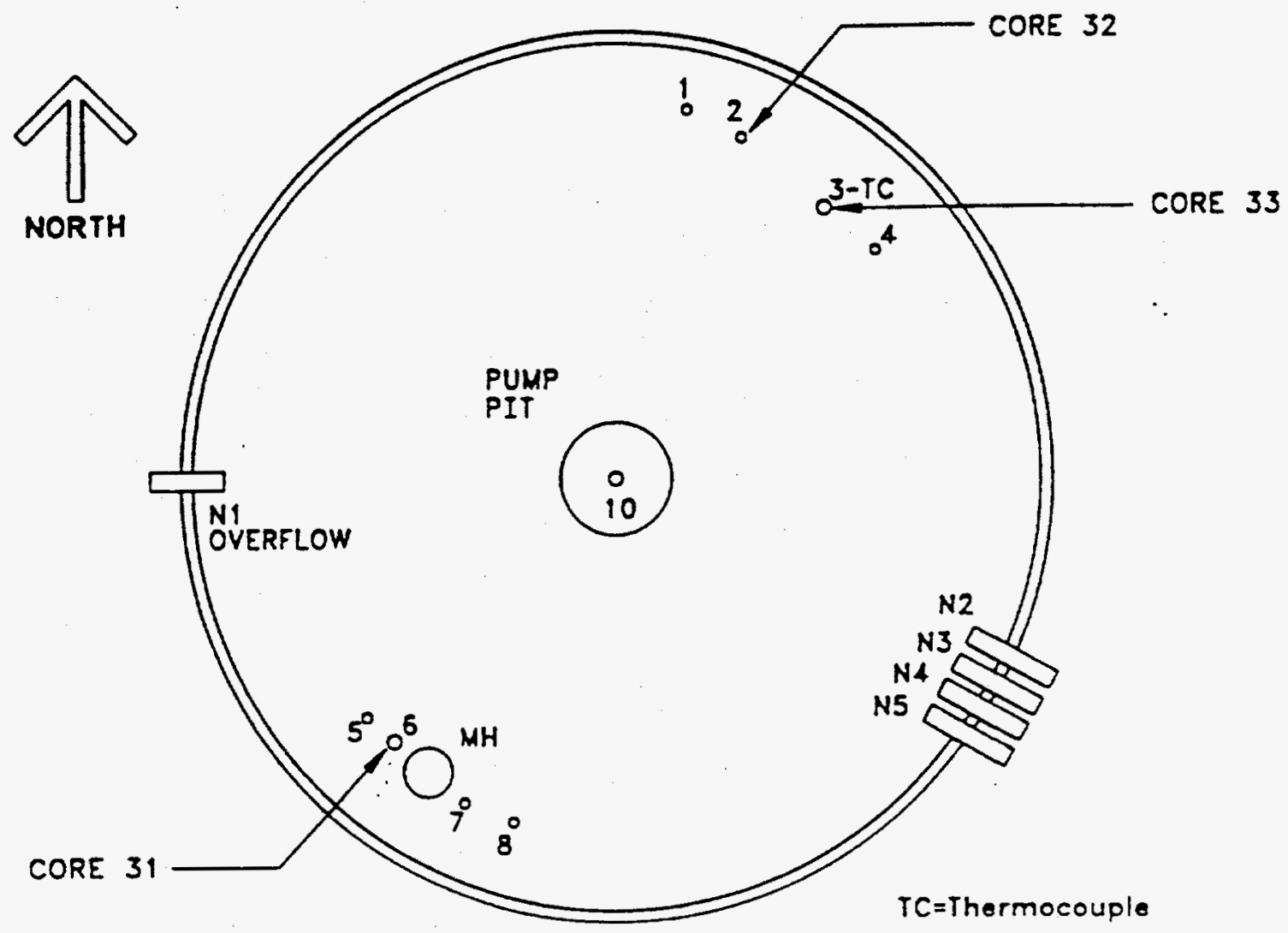

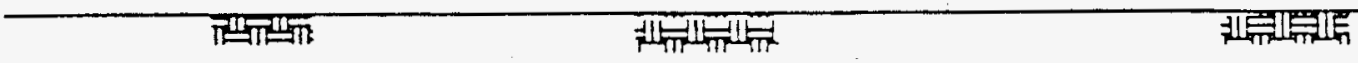

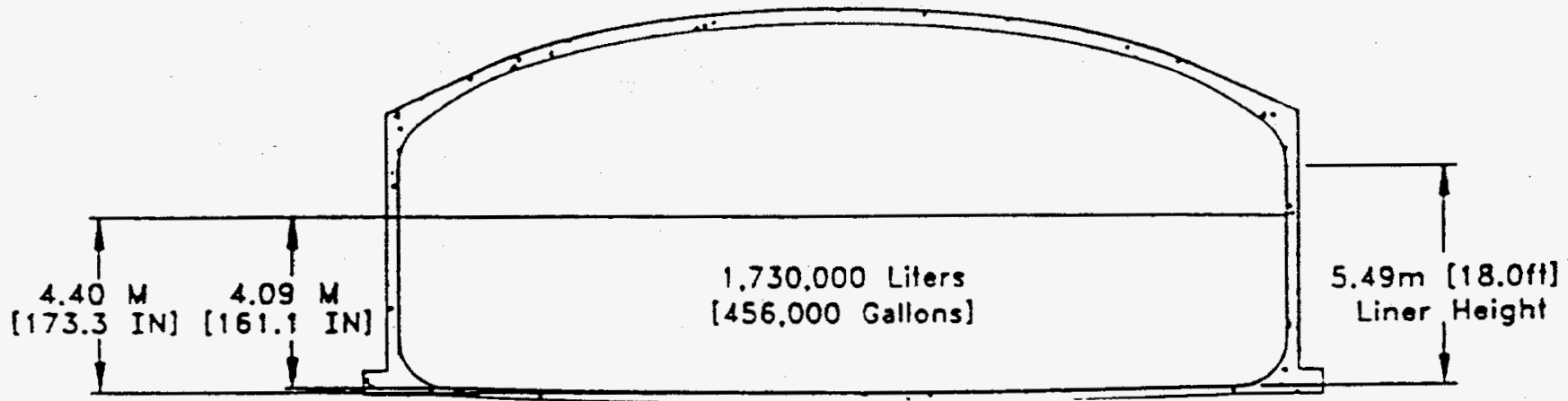




\section{CONTENTS}

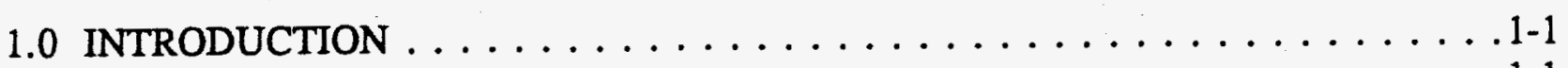

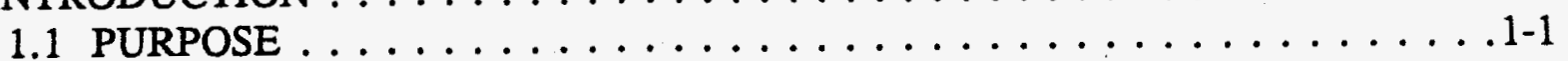

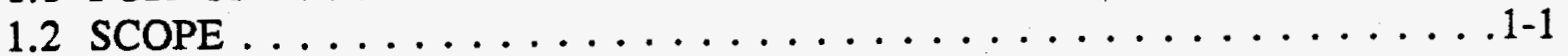

2.0 HISTORICAL TANK INFORMATION AND EVALUATION $\ldots \ldots \ldots \ldots .2-1$

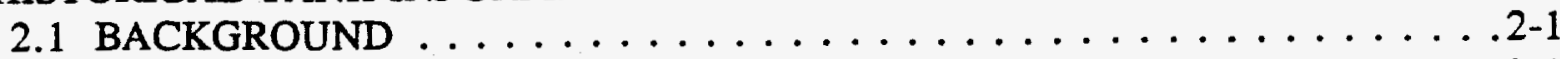

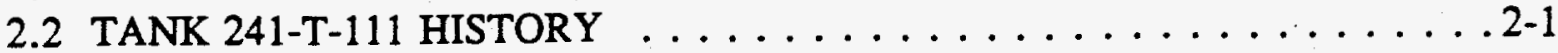

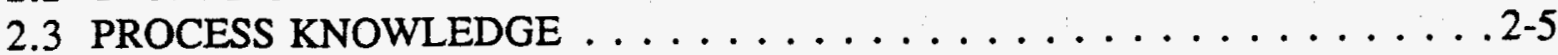

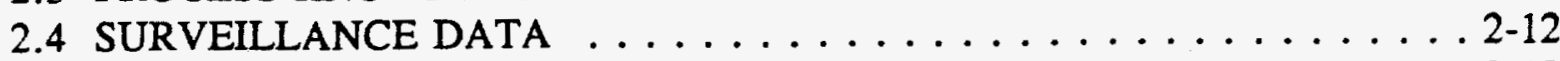

2.5 TANK STATUS $\ldots \ldots \ldots \ldots \ldots \ldots \ldots \ldots \ldots \ldots \ldots \ldots \ldots \ldots \ldots \ldots \ldots \ldots .12$

3.0 TANK SAMPLING OVERVIEW $\ldots \ldots \ldots \ldots \ldots \ldots \ldots \ldots \ldots \ldots \ldots \ldots \ldots$

3.1 DESCRIPTION OF SAMPLING EVENT $\ldots \ldots \ldots \ldots \ldots \ldots \ldots \ldots$

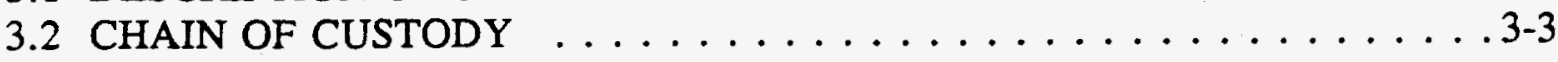

4.0 SAMPLE HANDLING AND ANALYTICAL SCHEME $\ldots \ldots \ldots \ldots \ldots \ldots$. . . . .

4.1 SAMPLE BREAKDOWN PROCEDURE $\ldots \ldots \ldots \ldots \ldots \ldots \ldots \ldots$ 4-1

4.2 TANK 241 -T-111 CORE SAMPLE DESCRIPTION $\ldots \ldots \ldots \ldots \ldots .4$. . . .

4.3 HOLD TIME CONSIDERATIONS $\ldots \ldots \ldots \ldots \ldots \ldots \ldots \ldots .6 \ldots$

4.4 SAMPLE PREPARATION $\ldots \ldots \ldots \ldots \ldots \ldots \ldots \ldots \ldots \ldots$

4.5 ANALYTICAL METHODS . . . . . . . . . . . . . . 4-8

4.5.1 Physical and Rheological Tests . . . . . . . . . . . . . 4-9

4.5.2 Chemical and Radionuclide Constituent Analysis . . . . . . . 4-10

4.5.3 Organic Constituent Analyses . . . . . . . . . . . 4-10

4.5.4 Segment-Level Analyses . . . . . . . . . . . . 4-12

5.0 ANALYTICAL RESULTS: TANK $241-\mathrm{T}-111 \ldots \ldots \ldots \ldots \ldots \ldots \ldots \ldots \ldots$

5.1 CHEMICAL ANALYSES . . . . . . . . . . . . . .

5.1.1 Analytical Results: Inductively Coupled

Plasma-Atomic Emission Spectroscopy . . . . . . . . . . . . . . 5-1

5.1 .2 Analytical Results--Anion Assays . . . . . . . . . . . . . . 5-9

5.2 ANALYTICAL RESULTS-RADIOCHEMISTRY . . . . . . . . 5-12

5.2.1 Radiochemistry Assays--General Comments . . . . . . . . . 5-12

5.2 .2 Gamma Energy Analysis Results . . . . . . . . . . . . 5-13

5.2 .3 Total Alpha Analysis and Uranium Assay . . . . . . . . 5-13

5.2 .4 Total Beta . . . . . . . . . . . . . . . . . 5-14

5.3 TANK 241-T-111 CORE SAMPLE RHEOLOGICAL/

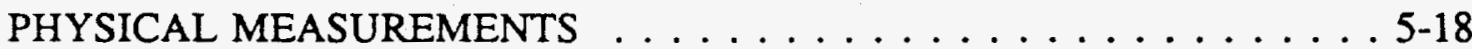

5.3 .1 Shear Strength . . . . . . . . . . . . . . . . 5-20

5.3.2 Shear Stress and Viscosity as Functions of Shear Rate . . . . . 5-21

5.3.3 Particle Size Measurement . . . . . . . . . . . . . . . 5-28

5.3.4 Settling Behavior of As-Received and Diluted Samples . . . . . . 5-30 


\section{CONTENTS (Continued)}

5.4 ANALYTICAL RESULTS--ENERGETICS . . . . . . . . . . . . 5-40

5.4.1 Remarks on the Interpretation of Differential Scanning Calorimetry/Thermogravimetric Analysis Data . . . . . . . . . 5-44

5.4.2 General Comments on the Differential Scanning Calorimetry/ Thermogravimetric Analysis Behavior of the Samples . . . . . . . 5-45

5.5 OVERALL ANALYTICAL DATA SUMMARY . . . . . . . . . 5-49

6.0 INTERPRETATION OF ANALYTICAL RESULTS . . . . . . . . . . . . . 6-1

6.1 Review of the Analyte Profiles . . . . . . . . . . . . . . . 6-2

6.1.1 Entrance, Exit, and Mixing Effects on Analyte Distribution . . . . . . . . . . . . . 6-4

6.1 .2 Waste Profile . . . . . . . . . . . . . . . . 6-5

6.2 WASTE SUMMARY AND CONDITIONS . . . . . . . . . . . 6-5

6.3 TWRS PROGRAM ELEMENT CHARACTERIZATION SYNOPSIS . . . 6-10

6.3.1 Retrieval Program Data Summary: Physical Properties . . . . . . . . 6-10

6.3.2 Final Disposal Program Data Summary . . . . . . . . . . . . 6-11

6.3.3 Waste Tank Safety Program Characterization Data Summary . . . . 6-13

7.0 QUANTITATIVE/STATISTICAL INTERPRETATION OF THE DATA $\ldots \ldots$. 7 -1

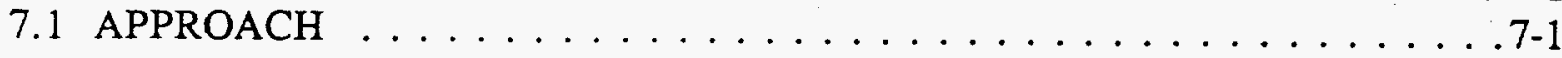

7.2 MEAN CONCENTRATION ESTIMATES . . . . . . . . . . 7-2

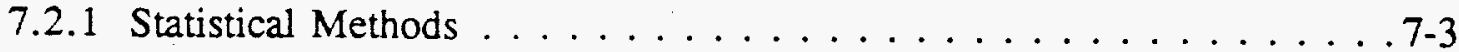

7.2 .2 Statistical Results . . . . . . . . . . . . . . . . . 7-3

7.3 COMPARISON OF THE VARIANCE COMPONENT ESTIMATES . . . . . 7-7

7.3.1 Statistical Methods . . . . . . . . . . . . . . . . 7-7

7.3.2 Statistical Results . . . . . . . . . . . . . . . . .7.8

7.4 MASS BALANCES . . . . . . . . . . . . . . . . . . 7-8

7.5 SUGGESTED COMPONENTS OF WASTE MATRIX $\ldots \ldots \ldots \ldots \ldots 7-14$

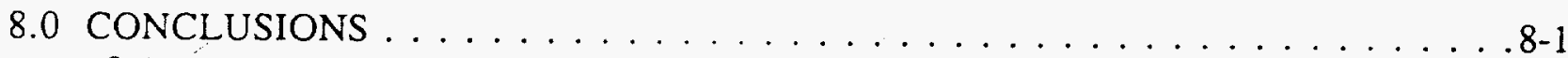

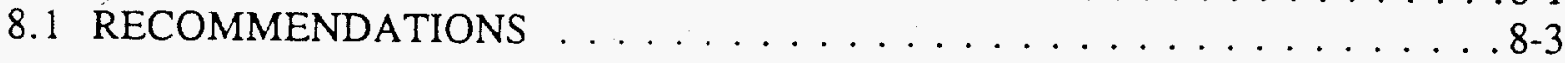

9.0 REFERENCES . . . . . . . . . . . . . . . . . . .9-1 


\section{APPENDICES}

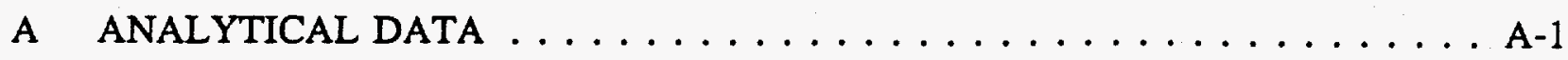

B STATISTICAL INTERPRETATION $\ldots \ldots \ldots \ldots \ldots \ldots \ldots$ B-1

C CALCULATIONS AND MISCELLANEOUS DATA $\ldots \ldots \ldots \ldots \ldots$ C-1 


\section{LIST OF FIGURES}

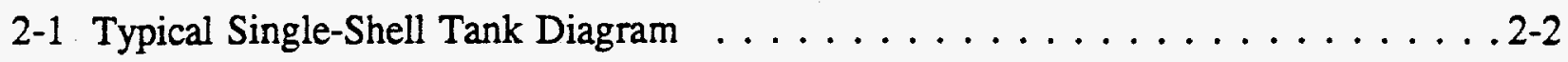

2-2 Fill and Transfer History of 241-T-111 . . . . . . . . . . . 2-4

2-3 241-T-111 Surveillance Photo- Collage $\ldots \ldots \ldots \ldots \ldots \ldots \ldots \ldots$. . . . . . . .

2-4 241-T-111 Surveillance Photo - Close up . . . . . . . . . . . . . . 2-9

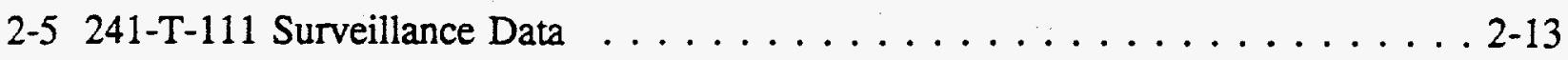

3-1 Tank 241-T-111 Riser Configuration $\ldots \ldots \ldots \ldots \ldots \ldots \ldots \ldots \ldots . \ldots \ldots$ 3-2

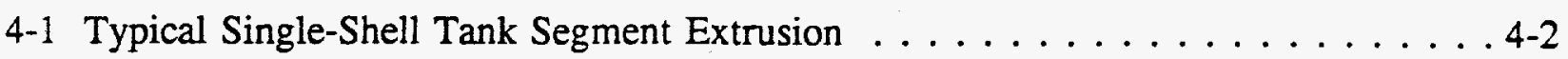

5-1 Current Condition of Tank 241-T-111 . . . . . . . . . . . . . 5-19

5-2 Shear Stress as a Function of Shear Rate: Direct Sample . . . . . . . . . . 5-23

5-3 Shear Stress as a Function of Shear Rate: 1 to 1 Dilution, Water to Sample . . 5-24

5-4 Shear Stress as a Function of Shear Rate: 1 to 1 Dilution, Water to Sample . . 5-25

5-5 Shear Stress as a Function of Shear Rate: 3 to 1 Dilution, Water to Sample . . 5-26

5-6 Viscosity as a Function of Time: 1 to 1 Dilution, Water to Sample . . . . . 5-27

5-7a Core 31 , Segment 1 , Particle Size: Number Density . . . . . . . . . 5-31

5-7b Core 31 , Segment 1 , Particle Size: Volume Density $\ldots \ldots \ldots$. . . . . . . 51

5-8a Core 31, Segment 2, Particle Size: Number Density . . . . . . . . . . 5-32

5-8b Core 31, Segment 2, Particle Size: Volume Density . . . . . . . . . 5-32

5-9a Core 31, Segment 3, Particle Size: Number Density . . . . . . . . . . . 5-33

5-9b Core 31, Segment 3, Particle Size: Volume Density . . . . . . . . . 5 5-33

5-10a Core 31, Segment 4, Particle Size: Number Density . . . . . . . . . . . . 5-34

5-10b Core 31, Segment 4, Particle Size: Volume Density . . . . . . . . . . 5-34 


\section{LIST OF FIGURES (Continued)}

5-11a Core 31, Segment 5, Particle Size: Number Density . . . . . . . . . 5-35

5-11b Core 31, Segment 5, Particle Size: Volume Density . . . . . . . . 5-35

5-12a Core 31, Segment 7, Particle Size: Number Density $\ldots \ldots \ldots$. . . . . 5-36

5-12b Core 31 , Segment 7, Particle Size: Volume Density . . . . . . . . . . 5-36

5-13a Core 31, Segment 8, Particle Size: Number Density . . . . . . . . . . 5-37

5-13b Core 31, Segment 8, Particle Size: Volume Density . . . . . . . . . . 5-37

5-14a Core 31, Segment 9, Particle Size: Number Density . . . . . . . . . . . 5 5-38

5-14b Core 31 , Segment 9 , Particle Size: Volume Density $\ldots \ldots \ldots \ldots$. . . . . .

5-15a Settling Rate Data for Tank 241-T-111 Core 31, Segment 2, 1 to 1 Dilution . . 5-41

5-15b Settling Rate Data for Tank 241-T-111

Core 31, Segment 2, 3 to 1 Dilution

5-16a Settling Rate Data for Tank 241-T-111 Core 31, Segment 4, 1 to 1 Dilution . . 5-42

5-16b Settling Rate Data for Tank 241-T-111 Core 31, Segment 4, 3 to 1 Dilution . . 5-42

5-17a Settling Rate Data for Tank 241-T-111 Core 31, Segment 8, 1 to 1 Dilution . . 5-43

5-17b Settling Rate Data for Tank 241-T-111 Core 31, Segment 8, 3 to 1 Dilution . . 5-43

6-1 Waste Profile of Tank 241-T-111 . . . . . . . . . . . 6-6 


\section{LIST OF TABLES}

2-1 Typical Waste Stream Compositions and Expected Sludge Compositions for Selected Analytes (Wet Basis) . . . . . . . . . . . . . . . . . 2-11

3-1 Core 31--Chain of Custody Summary $\ldots \ldots \ldots \ldots \ldots \ldots \ldots . . \ldots \ldots$

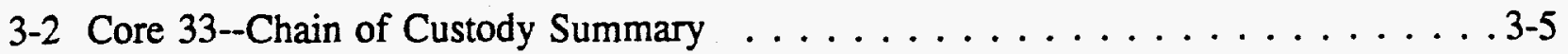

4-1 Tank 241-T-111 Core 31 Sample Description Summary . . . . . . . . . . . . 4-4

4-2 Tank 241-T-111 Core 33 Sample Description Summary . . . . . . . . . . . . 4-5

4-3 Analytical Methods for Physical and Rheological Testing . . . . . . . . . 4-9

4-4 Analytical Methods for Chemical and Radionuclide Analyses . . . . . . . . . 4-11

$4-5$ Analytical Methods For Organic Analytes . . . . . . . . . . . . . . 4-12

$4-6$ Segment-Level Analysis . . . . . . . . . . . . . . . . . . . 4-12

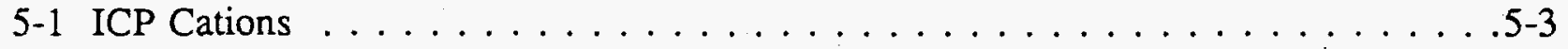

5-2 Tank 241-T-111 Core 33 ICP Selected Analyte Trending as a Function of Depth (Acid prep on segments) . . . . . . . . . . . . . . 5-6

5-3 Grab Sample/Water Digestion Data--ICP Average Values $\ldots \ldots \ldots \ldots$. . . . . 5-7

5-4 Comparison of Ion Chromatography and Water Digestion ICP Results for Selected Analytes

5-5 Anion Results--Composite Data (water leach) . . . . . . . . . . . . 5-10

5-6 Consolidated Radionuclide Concentration Results for 241-T-111 . . . . . . 5-15

5-7 Core Composite Uranium . . . . . . . . . . . . . . . . . . 5-16

5-8 Plutonium Concentration and Isotopic Distribution . . . . . . . . . . $\ldots$-17

5-9 Radiochemical Analyses of Grab Sample . . . . . . . . . . . . . . 5-17

5-10 Tank 241-T-111 Core 33 Radionuclide Analyte Trending as a Function of Depth (Acid prep on segments) . . . . . . . . . . 5-17 


\section{LIST OF TABLES (Continued)}

5-11 Tank 241-T-111 Core Sample Description Summary $\ldots \ldots \ldots \ldots \ldots$ 5-18

5-12 Tank 241-T-111 Core Sample Description Summary . . . . . . . . . . . . 5-20

5-13 Core 31 Particle Size Distribution by Number . . . . . . . . . . . . . . . 5-29

5-14 Core 31 Particle Size Distribution by Volume . . . . . . . . . . . . . . . 5-29

5-15 Grab Sample Physical Properties Summary . . . . . . . . . . . . . . . 5-39

5-16 Physical Properties Summary $\ldots \ldots \ldots \ldots \ldots \ldots \ldots \ldots$. . . . . . . . . . .

5-17 Settling Comparison for 1 to 1 and 3 to 1 dilutions for Core 31

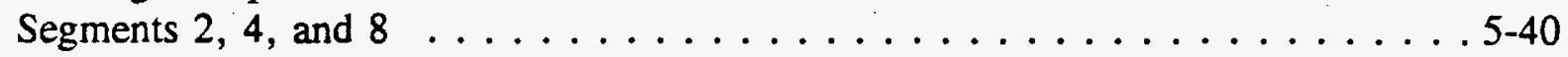

5-18 Percent Water Analyses Results from Tank 241-T-111 . . . . . . . . . . 5-45

5-19 Differential Scanning Calorimetry Energetics Results from

Tank 241-T-111, Core 31 (wet basis) . . . . . . . . . . . . 5-46

5-20 Differential Scanning Calorimetry Energetics Results from

Tank 241-T-111, Core 33 (wet basis) . . . . . . . . . . . . . . 5-47

5-21 Differential Scanning Calorimetry Energetics Results

from Tank 241-T-111, Core 33 (dry basis) . . . . . . . . . . . . . 5-48

5.22 Additional Segment-level Physical Properties

Measurements (1994) . . . . . . . . . . . . . . . . . . . . . . . . . . 5-49

$5-23$ Overall Data Summary and Inventory Estimates . . . . . . . . . 5-50

$6-1$ Retrieval Program ................... . . . . . . .

6-2 Concentrations and Solubility of Principal Waste Components . . . . . . . . 6-12

6-3 Tank 241-T-111 Comparison to Safety Screening Criteria . . . . . . . . . 6-13

6-4 Core Composite Uranium . . . . . . . . . . . . . . . 6-14

6-5 Plutonium Concentration and Isotopic Distribution $\ldots \ldots \ldots \ldots . . \ldots$ 6-14

6-6 Data Quality Objective Decision Limits for Organic Tanks . . . . . . . . . . 6-15 


\section{LIST OF TABLES (Continued)}

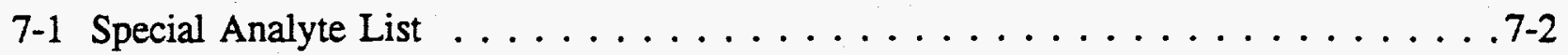

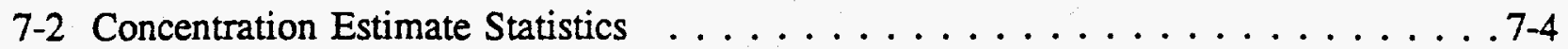

7-3 Variance Components Estimates . . . . . . . . . . . . . . . . . 7-9

7-4 Core 31 and Core 33 Mass and Charge Balance . . . . . . . . . 7-12

$7-5$ Probable Solids in the Waste Matrix $\ldots \ldots \ldots \ldots \ldots \ldots \ldots \ldots \ldots \ldots .15$

8-1 Comparison of Tank 241-T-111 Analyte Values to

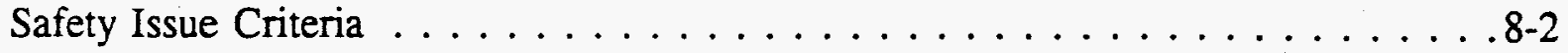




\section{LIST OF ACRONYMS/ABBREVIATIONS}

2C

224

AA

ANOVA

CI

DSC

GEA

IC

ICP

PNL

RPD

SST

TGA

TIC

TOC

Tri-Party

Agreement
Second-Cycle Decontamination Waste From The Bismuth Phosphate Process

Lanthanum Fluoride Waste

Atomic Absorption

Analysis Of Variance

Confidence Interval

Differential Scanning Calorimetry

Gamma Energy Analysis

Ion Chromatography

Inductively Coupled Plasma - Atomic Emission Spectroscopy

Pacific Northwest Laboratory

Relative Percent Difference

Single-Shell Tank

Thermogravimetric Analysis

Total Inorganic Carbon

Total Organic Carbon

Hanford Federal Facility Agreement And Consent Order 
This page intentionally left blank. 


\section{TANKK CHARACTERIZATION REPORT: TANK 241-T-111}

\subsection{INTRODUCTION}

In late October and early November of 1991, single-shell tank (SST) 241-T-111 was sampled and analyses were conducted on the materials obtained to complete Hanford Federal Facility Agreement and Consent Order (Tri-Party Agreement) Milestone M-10-00 (Ecology et al. 1992) to sample and analyze two cores from each tank. Other objectives that these measurements and inventory estimates support are as follows.

- Obtain estimates of both the concentration and total quantity of key analytes relating to safety issues, such as organics and radionuclides.

- $\quad$ Provide input to risk assessment-based disposal decisions for the waste.

- Implement physical property measurements, such as rheology, bulk density, and particle size. These measurements are necessary for the design and fabrication of retrieval, pretreatment, and vitrification systems.

\subsection{PURPOSE}

The purpose of the tank characterization report is to describe and characterize the waste in SST 241-T-111, based on information from various sources. This report summarizes the available information regarding the waste in tank 241-T-111, and arranges this information in a format useful to support management and technical decisions concerning this waste tank.

\subsection{SCOPE}

This report presents a broad background of information that was available before core sampling, which initially guided the development of the sampling and analysis program. This material includes process stream data, historical information about any previous characterization testing, transfer records, and observations from in-tank photographs. The results of tank 241-T-111 core-sample analyses are summarized and presented, along with a statistical interpretation of the data. The information obtained from historical sources will be compared and correlated with the actual waste measurements in this report. As characterization efforts proceed and additional information becomes available, this document will be revised periodically to reflect the new data set. 
This page intentionally left blank. 


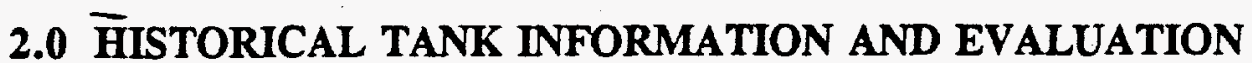

\subsection{BACKGROUND}

Radioactive wastes from defense operations have accumulated at the Hanford Site in underground waste tanks since the late 1940s. The original tank farms (B, C, T, and U) were built from 1943 to 1944 . Tank 241-T-111 was placed into service in 1945. Groups of waste tanks that were physically located together and built at the same time are called tank farms. Each original tank has a diameter of $22.9 \mathrm{~m}(75 \mathrm{ft})$, an operating depth of $5.2 \mathrm{~m}$ $(17 \mathrm{ft})$, and a nominal capacity of 2 million liters $(530,000$ gal). The basic design of a typical SST is shown in Figure 2-1. The tanks were constructed of reinforced concrete with a mild steel liner covering their bottoms and sides. The carbon steel liners were designed to receive and contain neutralized, mildly alkaline wastes. The tops of the tanks are concrete domes. Tanks such as 241-T-111 were all covered by at least $1.8 \mathrm{~m}(6 \mathrm{ft})$ of soil for shielding purposes (Anderson 1990). The tanks in the tank farms were connected in groups of three or four and overflowed from one to another in a configuration known as a cascade. Tank 241-T-111 is the middle tank in a cascade that includes 241-T-110 and 241-T-112. Cascades served several functions in Hanford-Site waste management operations. By cascading tanks, fewer connections needed to be made during waste disposal. Consequently, all three tanks were usable without having to connect the active waste transfer line directly to each individual tank. This handling method reduced the likelihood for personnel exposure to the waste and diminished the chances for a loss of tank integrity because of overfilling. Another benefit of the cascades was clarification of the wastes. When used in this manner, most of the solids in the waste slurries routed to the tanks settled in the first tank (241-T-110), and the clarified liquids cascaded on to the other tanks in the series (241-T-111 and 241-T-112). Supernate from the final tank in a cascade series was sometimes routed to a disposal trench. Since most radionuclides are insoluble in aqueous alkaline media, clarification reduced the potential amount of radiological contamination to the environment. However, historical sources report that cascade lines routinely clogged (Anderson 1990). When clogging occurred, very little could be done to resolve the problem, other than rerouting the effluent stream directly to the disposal tank. Cascading was a common practice in the early process history of the tanks, but became less frequent as time passed, virtually ceasing by the late 1950 s.

\subsection{TANK 241-T-111 HISTORY}

The first type of waste that tank 241-T-111 received and stored was second-cycle decontamination waste from the bismuth phosphate process (2C) (1945 to 1952). The tank was filled by a cascade of $2 \mathrm{C}$ waste in the fourth quarter of 1945 . The supernatant in the tank was disposed to a crib in the third and fourth quarters of 1947. The tank was then refilled with $2 \mathrm{C}$ waste in the second quarter of 1948. After the cascade was filled again in late 1948, tank 241-T-111 remained in active service. From 1953 to 1955 , tank 241-T-111 was 
Figure 2-1. Typical Single-Shell Tank Diagram.

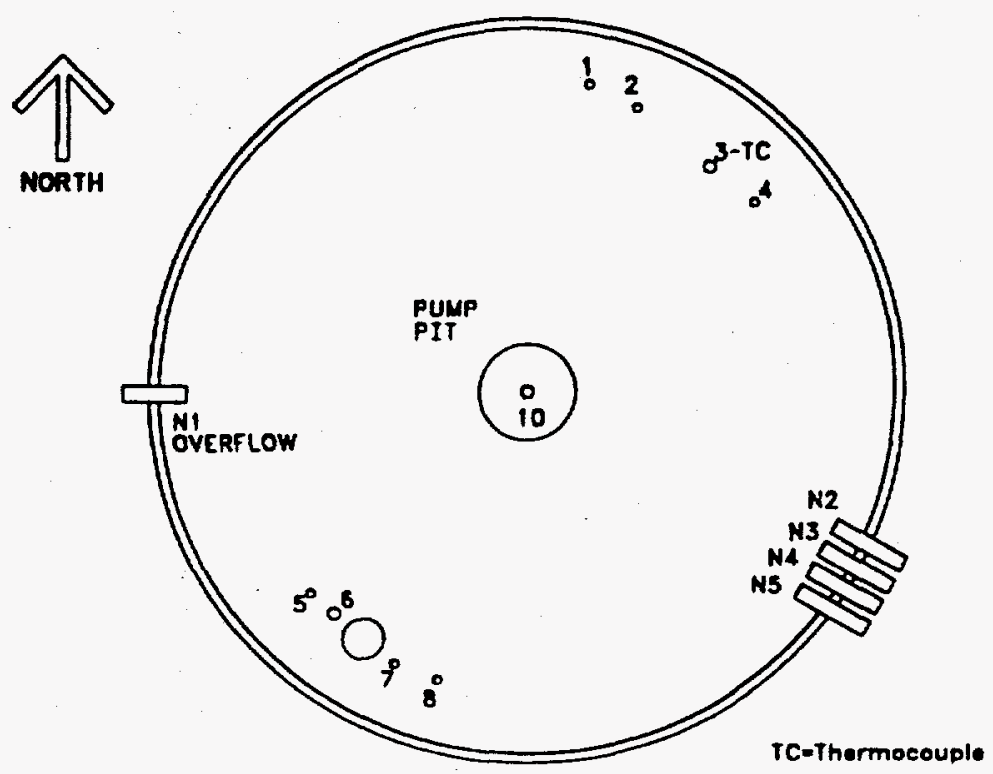

TANK RISER LOCATION

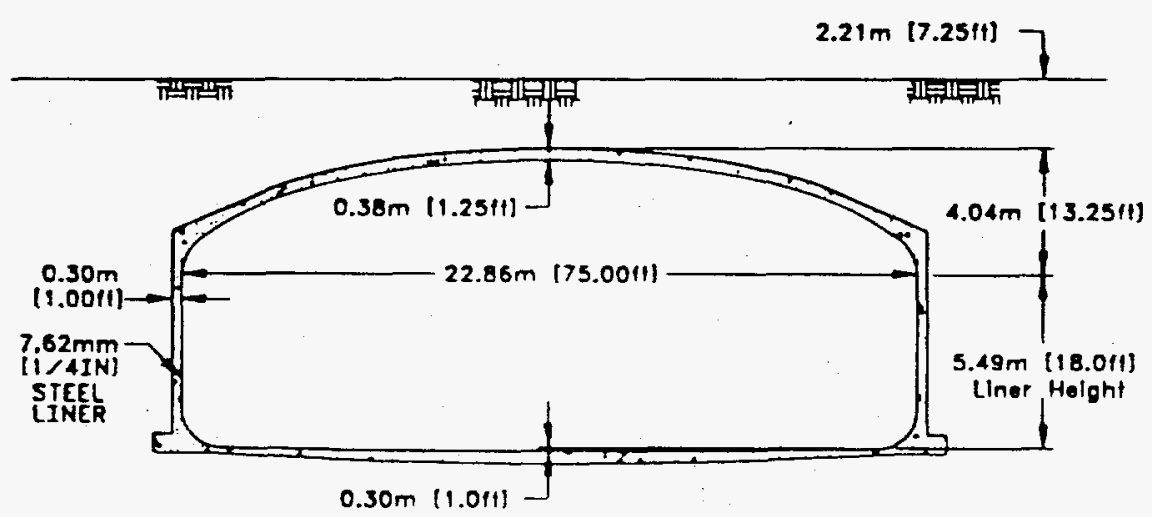

Note: Tank 241-T-111 has a dished bottom. 
used to cascade $\overline{2 \mathrm{C}}$ and lanthanum fluoride waste $(224)$ from the $\mathrm{LaF}_{3}$ finishing process in T Plant to a crib. In addition, Anderson (1990) reports that some 5-6 cell drainage out of B Plant was routed to the tank along with 224 waste in 1952.

After the end of the T-Plant cascade in 1955, the reported total waste volume remained relatively unchanged [between 1.98 and 2.12 million L (524,000 and 560,000 gal)] for the remainder of the tank's active service life. There was a residual heel of at least 1.85 million $\mathrm{L}(488,000 \mathrm{gal})$ left from previous waste management operations.

Tank 241-T-111 remained in $2 \mathrm{C}$ service through the third quarter of 1956 (T Plant ran BiPO until August 1956). Anderson (1990) notes that in 1952 the tank was also receiving 224 waste from the plutonium purification/concentration processes performed in the 224-T building.

T Plant initially was built as a bismuth phosphate processing plant, however that purpose was changed when it became an equipment decontamination facility. The tank would have also received miscellaneous decontamination chemicals from T-Plant decontamination operations performed in the 1960s. The records are not clear whether tank 241-T-111 always received waste as overflow from tank 241-T-110, or if waste was later routed directly to it. There is anecdotal evidence that the cascade overflow line plugged early in the service life of tank 241-T-110, and that a direct discharge line from T Plant was used to dispose of wastes to tank 241-T-111, however no reference confirming this fact can be found. Between 1964 and 1974 , the reported solids volume fluctuated widely between 1.93 and 0.88 million $\mathrm{L}$ $(510,000$ and $233,000 \mathrm{gal})$. A highly anomalous reading of $150,000 \mathrm{~L}$ ( $40,000 \mathrm{gal})$ is not considered credible and is believed to be the result of a transcription error. In that time period, the total volume reported rose slightly, then decreased from 2.06 million $\mathrm{L}$ to 1.85 million L (541,000 to 488,000 gal) (Anderson 1990). In the second quarter of 1974, there were two small transfers out of Tank 241-T-111: one of $106,000 \mathrm{~L}(28,000 \mathrm{gal})$ to tank $241-\mathrm{S}-110$ and one of $53,000 \mathrm{~L}(14,000 \mathrm{gal})$ to tank $241-\mathrm{T}-109$.

In the third quarter of the same year, dry wells 50-11-05 and 50-11-08 were drilled and in the fourth quarter of 1974 , tank 241-T-111 was removed from active service. In the first and second quarters of 1976, two minor transfers of 30,300 L and 19,000 L (8,000 and $5,000 \mathrm{gal})$, respectively, were made out of tank 241-T-111. Saltwell pumping commenced in the third quarter of 1976 as part of the tank stabilization effort, and no further waste receipts were made. In 1979, the integrity of the tank was questioned and dry well 50-11-11 was drilled in the third quarter. As a result of an observed level drop, tank 241-T-111 was declared an assumed leaker in 1984 (Hanlon 1994). Figure 2-2 illustrates the fill and transfer history of 241-T-111.

The wide fluctuation in the early reported solids level makes it difficult to derive any firm conclusions regarding the stratification in the tank on a strictly historical basis. Overall sludge volume in the tank may have decreased somewhat between 1956 and 1974 with further settling and compaction from the weight of overlying solids. The amount of sludge added since the end of the T-Plant cascade activity probably is negligible, because the transfer history of the tank was so limited. Floating suction pumps do not transfer solids 


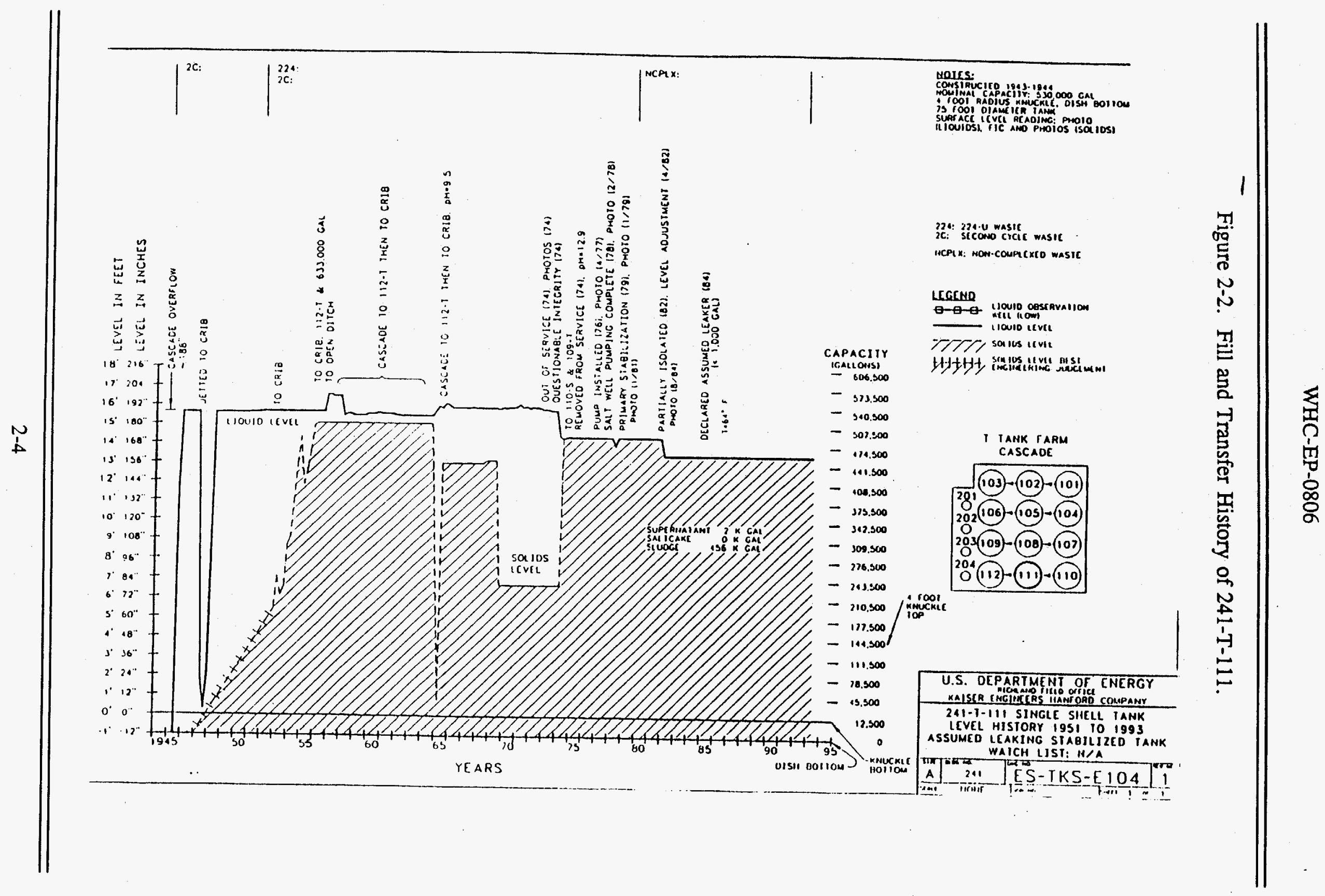


readily, and the movement of more than $950,000 \mathrm{~L}(250,000 \mathrm{gal})$ of solids in a quarter seems unlikely. However, the reported solids measurement in the fourth quarter of 1956 [1.93 million $L(510,000 \mathrm{gal})]$ and the reported solids measurement at the end of the tank's active service life in 1980 [1.85 million L (488,000 gal)] appears to be reasonable, a 4.5 percent difference, given the time and compaction processes ongoing in the tank, and the inherent uncertainties associated with early solids measurements in the tank farms.

\subsection{PROCESS KNOWLEDGE}

Process knowledge obtained from historical records can be used to predict the major constituents and some general physical properties of the waste matrix in the tanks. Tank 241-T-111 is expected to contain relatively soft sludge, which can be push-mode sampled. During its operating history, tank 241-T-111 was never subject to any of the various waste volume reduction or in-tank solidification processes. Consequently, there was no formation of hard salt cake on top of the sludge, as there was in the BY or TX Tank Farms (Anderson 1990). This expectation was supported by inspection of in-tank photographs that indicated a moist and pliant waste surface (see Figures 2-3 and 2-4). The effluents that were added to the tank during waste management operations were slurries consisting primarily of water (Schneider 1951). There was no mixing equipment in tank 241-T-111 to blend the layers of settled solids together and there were distinct differences in the composition of wastes directed to it over its operating life. Agnew (1994) predicts that $2 \mathrm{C}$ and 224 wastes are not identical in makeup, and analytically observable variations in composition are expected. Because of the lack of agitation or mixing in the tank, observable evidence of layering is expected in some of the segment-level analytical results.

Previous analytical data on tank $241-\mathrm{T}-111$ is scant. The results of some liquid samples taken in 1974 are provided in Appendix C. Because the tank has been pumped several times since those samples were taken, they are not considered representative of the present waste matrix. The lower solids in tank 241-B-110 should be similar to the lower solids in tank 241-T-111 (Borsheim 1994). Both tanks were filled at least twice with 2C.

Tank 241-B-110 was the first tank in the B-Plant 2C cascade while tank 241-T-111 was the second tank in the T-Plant $2 \mathrm{C}$ cascade. Further studies and comparisons of tank compositions will be forthcoming, pending additional analytical information on the various waste types and matrices that exist in the tank farms. The solids from the neutralized solution would have settled out in the tanks while the supernatant was disposed to cribs. The upper solids of tank 241-T-111 should have some similarity to the B and T 200-series tanks, because they all received 224 waste.

The estimated composition of neutralized $2 \mathrm{C}$ and 224 waste streams (i.e. unsettled) are given in Table 2-1 as determined from Schneider (1951). The Schneider (1951) process stream compositions are for the unsettled wastes being transferred from the separations plants. The 
This page intentionally left blank. 
Figure 2-3. 241-T-111 Surveillance Photo - Collage.

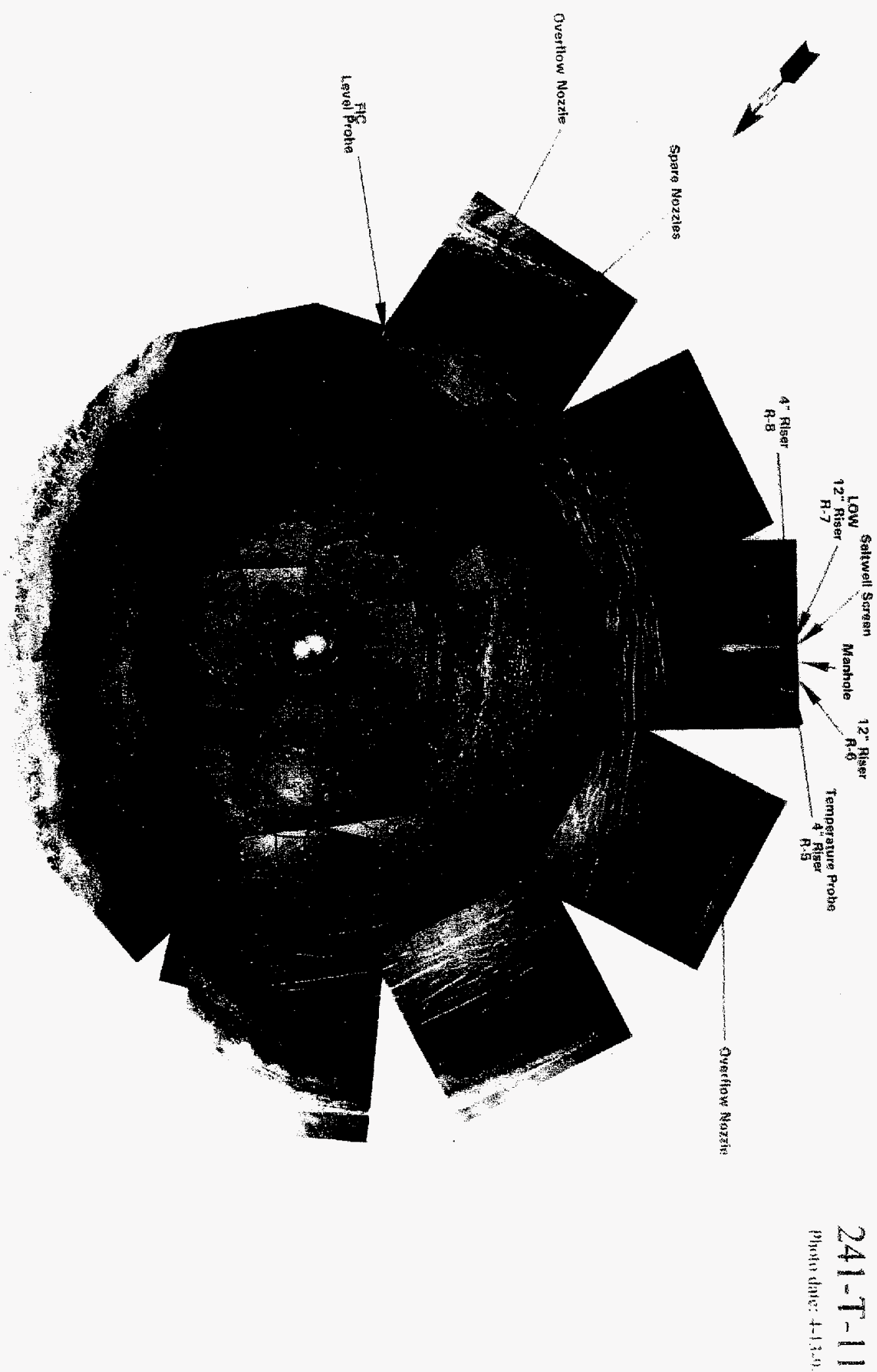


WHC-EP-0806

This page intentionally left blank. 
WHC-EP-0806

Figure 2-4. 241-T-111 Surveillance Photo - Close up.

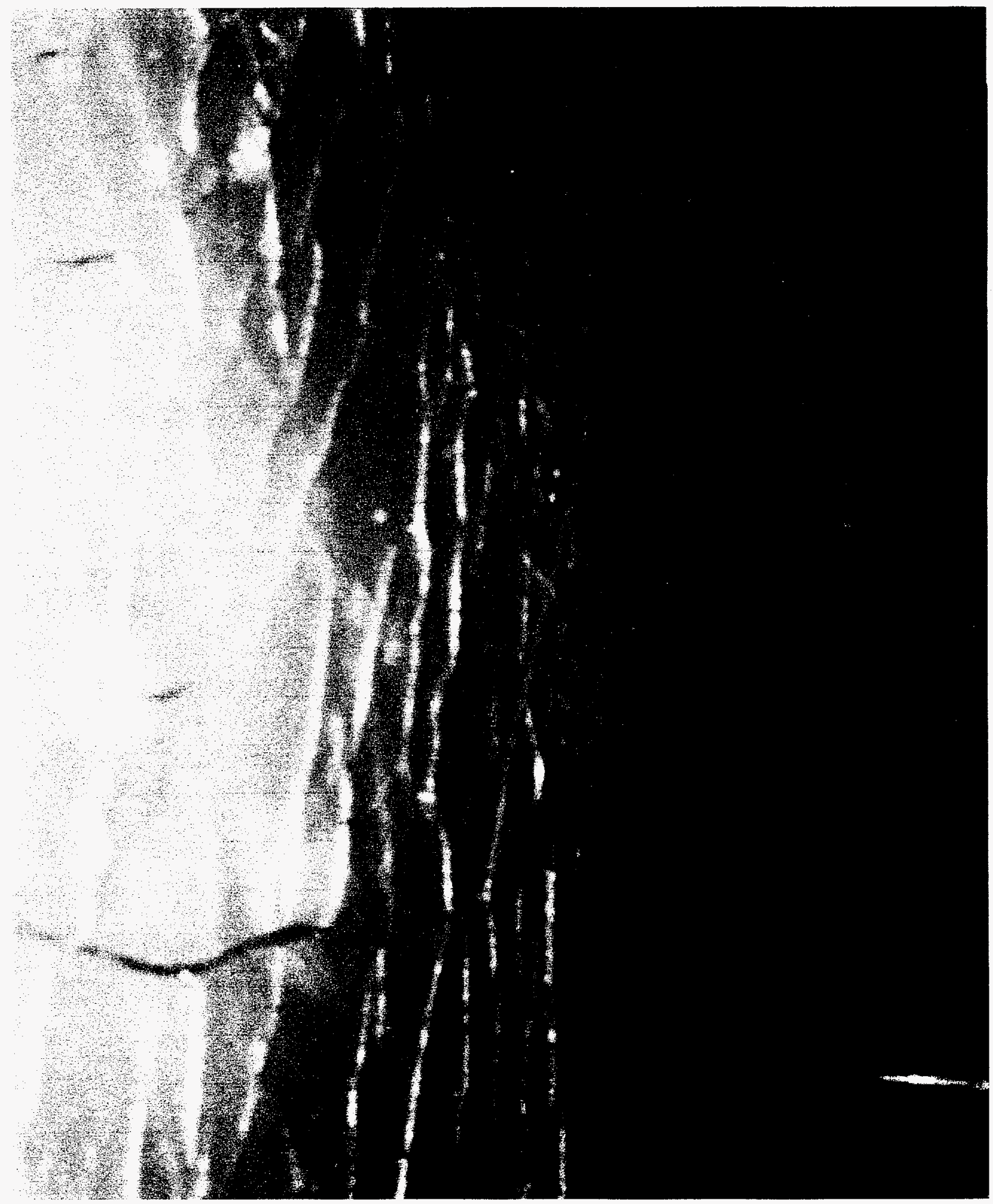


This page intentionally left blank. 
estimates using Agnew (1994) provide insight to the analyte concentrations of the settled sludge. How the waste settled, the solids content of the settled waste, and how it affected the waste inventory of the tank will be discussed further in Section 6.

Table 2-1. Typical Waste Stream Compositions and Expected Sludge Compositions for Selected Analytes (Wet Basis).

\begin{tabular}{|c|c|c|c|c|c|c|c|c|}
\hline \multirow{2}{*}{$\begin{array}{l}\text { Analyte } \\
\text { Cation } \\
\end{array}$} & \multicolumn{2}{|c|}{$\begin{array}{c}\text { Unsettled 2C } \\
\text { BiPO }_{4} \text { waste } \\
(\text { Schneider 1951) }\end{array}$} & \multicolumn{2}{|c|}{$\begin{array}{c}\text { Settled } 2 \mathrm{C} \mathrm{BiPO}_{4} \\
\text { waste, } \\
\text { (Agnew 1994) } \\
\text { average 1944-1951 } \\
\text { and 1951-1956 } \\
\text { compositions }\end{array}$} & \multicolumn{2}{|c|}{$\begin{array}{c}\text { Unsettled } \\
\text { BiPO }_{4}-\mathrm{LaF}_{3} 224 \\
\text { process waste } \\
\text { (Schneider 1951) }\end{array}$} & \multicolumn{2}{|c|}{$\begin{array}{l}\text { Settled } \mathrm{BiPO}_{4}-\mathrm{LaF}_{3} \\
224 \text { process waste } \\
\text { (Agnew 1994) }\end{array}$} \\
\hline & $\mathrm{Wt} \%$ & $(\mu \mathrm{g} / \mathrm{g})$ & Wt \% & $(\mu \mathrm{g} / \mathrm{g})$ & Wt \% & $(\mu \mathrm{g} / \mathrm{g})$ & Wt \% & $(\mu \mathrm{g} / \mathrm{g})$ \\
\hline$\overline{\mathrm{Bi}}$ & $\overline{0.12}$ & 1,200 & 2.55 & 25,500 & 0.11 & 1,100 & 2.07 & 20,690 \\
\hline$\overline{\mathrm{Cr}}$ & 0.006 & 60 & 0.0033 & 33 & 0.016 & 160 & 0.0035 & 35 \\
\hline $\mathrm{Na}^{*}$ & 3.5 & 35,000 & 6.46 & 64,600 & 3.39 & 33,900 & 8.50 & 85,000 \\
\hline $\mathrm{NH}_{4}^{+* *}$ & 0.16 & 1,600 & - & - & 0.011 & 110 & - & - \\
\hline $\mathrm{Fe}$ & 0.17 & 1,700 & 1.79 & 17,900 & - & - & 0 & 0 \\
\hline$\overline{M n}$ & - & - & 0 & 0 & 0.031 & 310 & 0.019 & 190 \\
\hline $\bar{K}$ & - & - & 0 & 0 & 0.79 & 7,900 & 0.779 & 7,790 \\
\hline $\mathrm{La}$ & - & - & 0 & 0 & 0.05 & 500 & 2.67 & 26,700 \\
\hline \multicolumn{9}{|l|}{ Anions } \\
\hline $\mathrm{PO}_{4}^{3-}$ & 2.2 & 22,000 & 5.63 & 56,300 & 0.28 & 2,800 & 1.25 & 12,500 \\
\hline $\mathrm{SO}_{4}{ }^{2-}$ & 0.34 & 3,400 & 0.276 & 2,760 & 0.032 & 320 & 0 & 0 \\
\hline $\mathrm{NO}_{3}{ }^{-}$ & 5.8 & 58,000 & 4.28 & 42,800 & 3.91 & 39,100 & 6.16 & 61,600 \\
\hline $\mathrm{F}^{-}$ & - & - & 0.494 & 4,940 & 0.52 & 5,200 & 4.66 & 46,600 \\
\hline $\mathrm{SiF}_{6}^{2-}$ & 0.35 & 3,500 & - & - & - & - & - & - \\
\hline $\mathrm{C}_{2} \mathrm{O}_{4}{ }^{2-}$ & - & - & - & 0 & 0.12 & 1,200 & 1.52 & 15,200 \\
\hline$\overline{\mathrm{H}_{2} \mathrm{O}}$ & 87.3 & 873,000 & 76.0 & 760,000 & 90.75 & 907,500 & 69.0 & 689,600 \\
\hline
\end{tabular}

*Analytes listed in italics are mostly soluble.

${ }^{* *} \mathrm{NH}_{4}{ }^{+}$probably has dissipated over time and is believed to be no longer present. 


\subsection{SURVEILLĀNCE DATA}

The most recent waste inventory measurement for tank 241-T-111 reports approximately 1.73 million L $(456,000 \mathrm{gal})$ of solid waste with an estimated $193,000 \mathrm{~L}(51,000 \mathrm{gal})$ of drainable liquids (Hanlon 1994). The most recent surveillance data shows a discernable downward trend over the past 18 months, nearly a $3.8 \mathrm{~cm}$ drop in surface level, after a very long, gradual, but minor upward trend over the last ten years (see Figure 2-5). This recent behavior possibly indicates further settling, or leaking has taken place. These figures translate to a waste depth of $408.9 \mathrm{~cm}$ (161.1 in.) underneath the riser and $440.2 \mathrm{~cm}$ (173.3 in.) at the tank centerline. The tank has not been fully interim stabilized yet, and is an assumed leaker. The recent waste temperature in tank 241-T-111, taken from a thermocouple tree is approximately $16^{\circ} \mathrm{C}\left(60.5^{\circ} \mathrm{F}\right)$ (Rios 1994), and the estimated heat load in the tank is less than $2.93 \mathrm{~kW}(10,000 \mathrm{Btu} / \mathrm{hr})$.

\subsection{TANK STATUS}

Tank 241-T-111 was a non-watch list SST, with no historical indication of any potential safety issue. However, during the review of the energetics data that was done in support of characterization, exotherms in excess of $-125 \mathrm{cal} / \mathrm{dry}$ gram of waste were noticed in the top 3 segments of core 31 and the top 2 segments of core 33. Additional follow-up work has been done confirming the initial observation and as a result, 241-T-111 has been added to the Organic Tank Watch List (Wicks 1994). The exotherms were not predicted from the process history of the tank and the known characteristics of the $2 \mathrm{C}$ and 224 waste streams disposed there. 
Figure 2-5. 241-T-111 Surveillance Data.

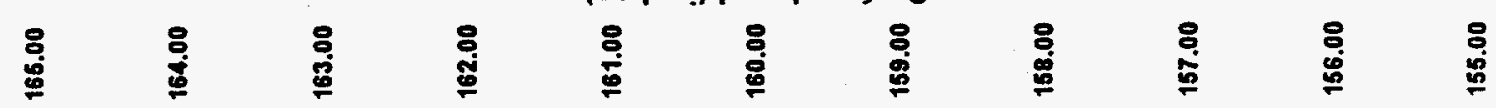

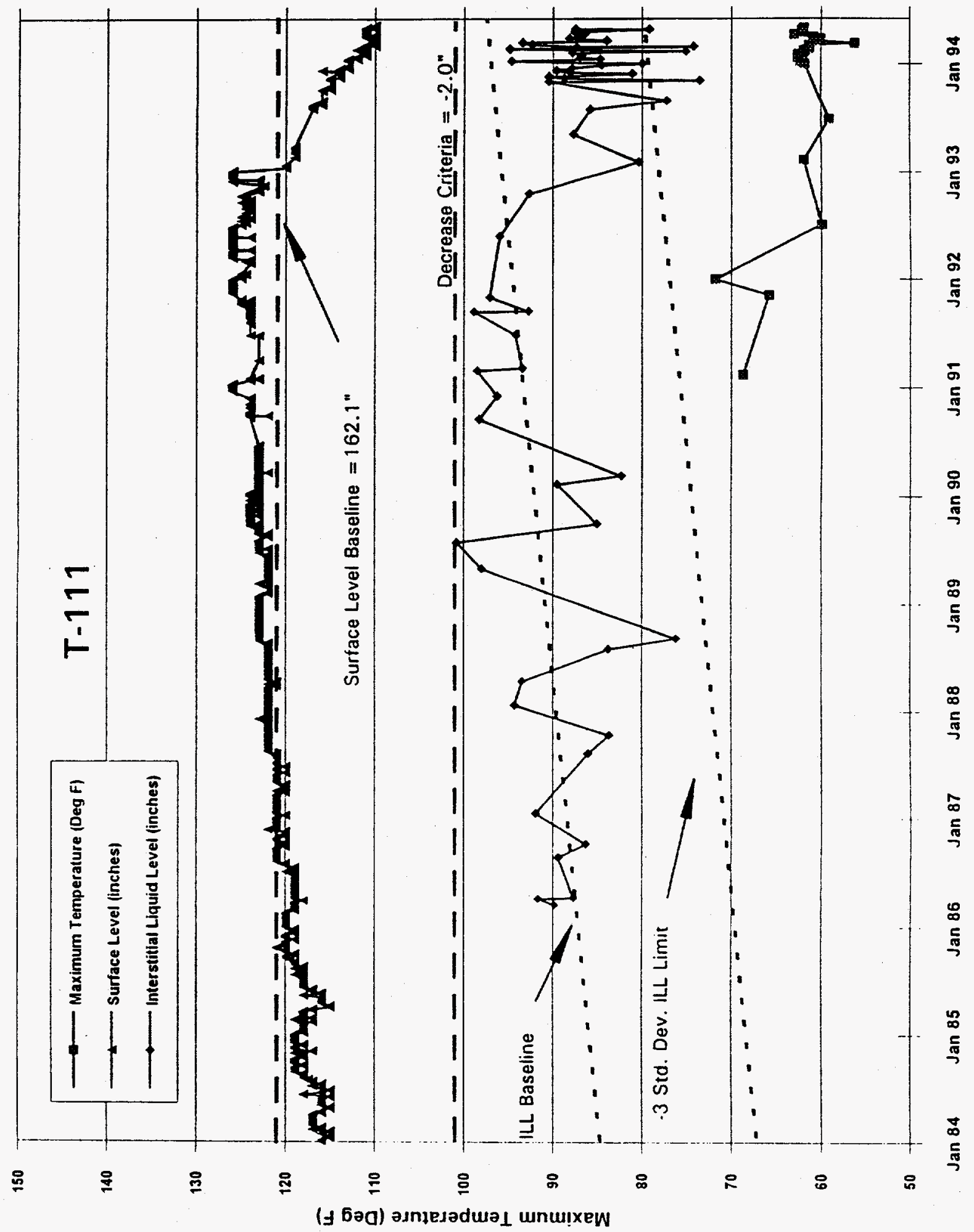


This page intentionally left blank. 


\subsection{TANK SAMPLING OVERVIEW}

\subsection{DESCRIPTION OF SAMPLING EVENT}

Tank 241-T-111 was push-mode core sampled through three risers during a period from October 22, 1991 to November 7, 1991. The core samples were obtained using a specially designed core sampling truck. Access to the interior of the tank is provided by various tank risers. Risers are pipes of various diameters leading into the tank dome from the ground. The riser configuration for tank 241-T-111 is given in Figure 3-1. A review of the tank farm operating records and a field inspection of the tank risers determine which risers can be used in the sampling operation. During sampling, a riser is opened and the truck is positioned over the riser. The sampler is lowered into the tank through the drill string and pushed into the waste. Further information regarding the core sampling operation can be found in Tank Farm Operating Procedure (Ross 1993). Nine segments were expected from each core sample. Each segment is approximately $48 \mathrm{~cm}$ (19 in) long. Core 31 was obtained from riser 6 on October 22, 1991. Core 32 was obtained from riser 2 from October 24, 1991 to October 25, 1991. Core 33 was obtained from riser 3 on November 5, 1991 to November 7, 1991.

The sampler is constructed of stainless steel and is $48 \mathrm{~cm}$ (19 in) long, with a 2.2-cm (7/8-in) inside diameter, and has a volume of $187 \mathrm{~mL}(0.05 \mathrm{gal})$. A hydrostatic fluid of normal paraffin hydrocarbons, similar to kerosene, was used in establishing a head balance while taking these cores. Objections involving sample degradation and contamination have been raised regarding the use of this fluid, and the practice has since been discontinued. However, for cores 31 and 33 , nearly full recovery was achieved in every case. There were little or no drainable liquids observed in the sample liners or in the samplers upon extrusion of the samples, and although hydraulic permeability measurements were not taken as part of the characterization effort, the waste did not appear porous. Thus, sample contamination from the hydrostatic fluid is not deemed to be a significant issue with the analysis of the sample or the interpretation of the results.

The casks were transported to the 222-S Laboratory for characterization analysis. This facility is operated by Westinghouse Hanford Company in the 200 West Area of the Hanford Site. Further physical and radiochemical characterization was performed at the 325 Laboratory. Specific analyses aimed at identifying and resolving the unusual energetics observed (Bean 1994) are also being done at 325 Laboratory. That facility is operated by Battelle Pacific Northwest Laboratory (PNL), and is located in the 300 Area of the Hanford Site.

Before the most recent stabilization effort, a series of liquid grab samples were taken and analyzed to ensure waste compatibility with the tank receiving the 241-T-111 liquid waste. These grab samples were acquired using a sampling method known as "bottle-on-a-string," in which a weighted bottle with a shuttered mouth is lowered into the liquid waste. The bottle's 
Figure 3-1. Tank 241-T-111 Riser Configuration.
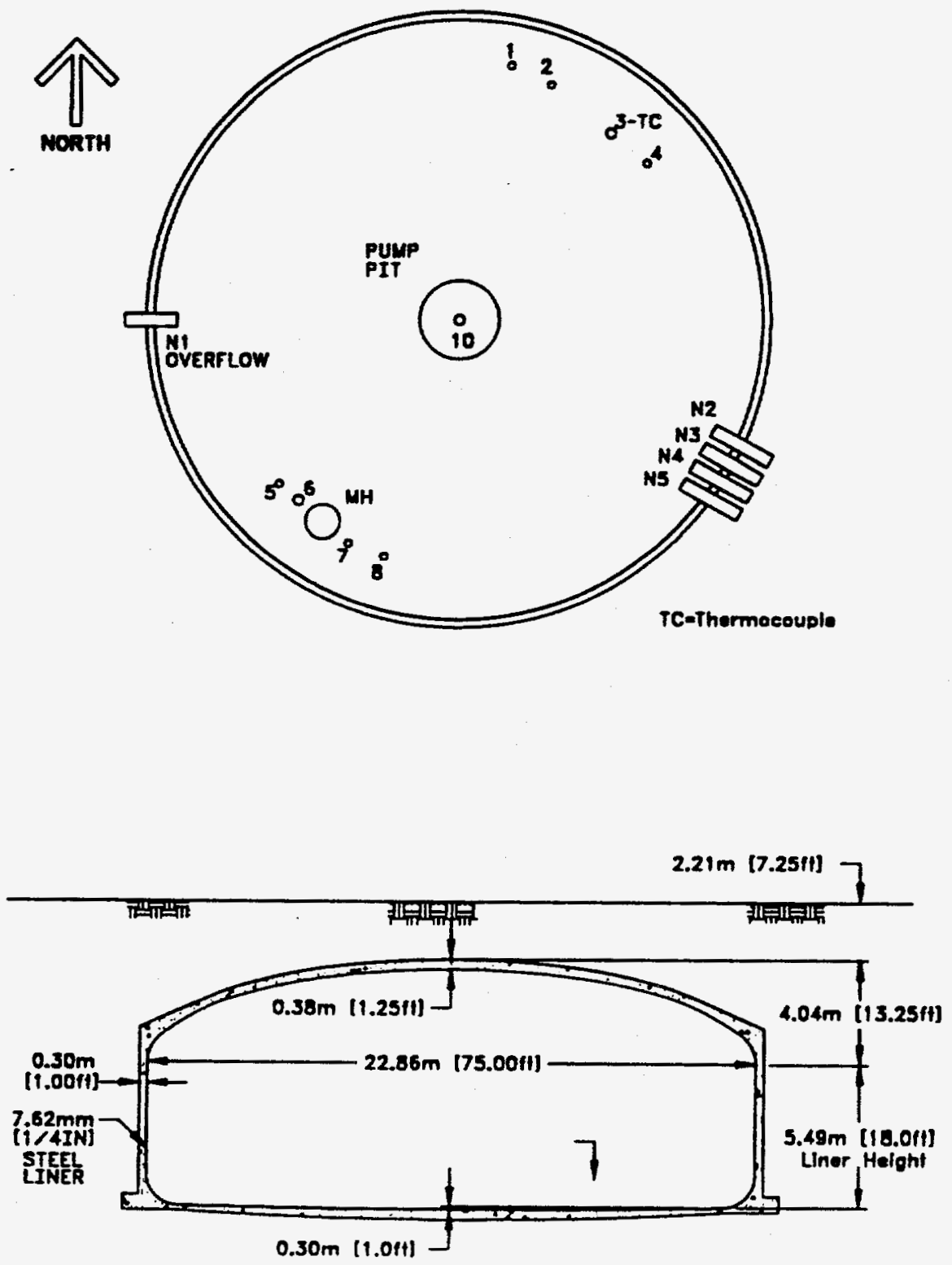
mouth is opened, it fills with liquid, the mouth is closed, and the sample is retrieved and transported to the 222-S Laboratory. Winters et al. (1990a and 1990b) has a more detailed description of this sample method.

\subsection{CHAIN OF CUSTODY}

A chain-of-custody record was kept during the sampling event for each segment that was sampled. The chain-of-custody form is a one-page record that is used to ensure that (1) the sample is safely and properly transported from the field to the laboratory, and (2) the correct personnel are involved in the sampling operation and transportation of the sample to the laboratory.

One of the additional functions of the chain-of-custody record is to provide radiation survey data. This is a record of the radiation dose that is emitted from the shipping cask. The dose rates in mrem/hour are measured from the top, sides, and bottom of the cask. These values are recorded on the chain-of-custody record and represent the radiation being emitted directly from the sample. The last item recorded under the radiation survey data is the smearable contamination. Smearable contamination represents the radiation from waste material that is not sealed within the shipping cask; values greater than $100 \mathrm{mrem} /$ hour are considered unsafe. Measurements are made both in the field and in the laboratory. No smearable contamination was found with these samples.

The chain-of-custody has several other important functions: (1) to provide a modest description of the cask, sampler, and the expected contents of the sampler (shipment, sample, and cask serial numbers for the specific sampling event); (2) to provide summary information about the analytical suite that the sample will undergo or reference the salient documentation; (3) to provide traceability for the sample during transport; and (4) to ensure sample integrity on arrival at the laboratory. This information is provided to ensure that each sample can be uniquely identified. A summary of the most pertinent data contained in the chain-of-custody forms for the tank 241-T-111 samples is presented in Tables 3-1 and 3-2.

Copies of the chain-of-custody forms are available in the full data package and through Hanford-Site Central Files. From inspection of the chain-of-custody records, there appear to be irregularities in the sampling and transport of tank 241-T-111 samples. Valve failures were observed in individual segments in all three core samples, and core 32 was considered to be completely compromised and non-representative. Each segment was almost entirely aqueous, containing at most a small amount of suspended solids. Liquid was also found in some of the liners surrounding the samplers from core 32, and was assumed to be leakage from the sampler. These irregularities merit a sampling concern, sample integrity concem, and potential safety concern (i.e., sample containment was compromised). However, the double-containment strategy employed in the handling of the samples was successful in preventing any excessive radiological exposure to personnel and no material escaped confinement. Further investigation and refinement of the sampling process, procedures, and sampler design is in progress. 
Table 3-1. Core 31--Chain of Custody Summary.

\begin{tabular}{|c|c|c|}
\hline Sample & Core 31 & \\
\hline Place Taken & 241-T-111 Riser 6 & \\
\hline Date Taken & $10 / 22 / 91$ & \\
\hline Date Released & $10 / 23 / 91$ & \\
\hline Time Released & 9:35 P.M. & \\
\hline Sender. & D. C. Hartley & \\
\hline Receiver & V. Johansen & \\
\hline Place Received & 222-S Laboratory & \\
\hline Time Received & 10:00 P.M. & \\
\hline Sample Number & Smearable Contamination & $\begin{array}{l}\text { Dose Rate Through the } \\
\text { Drill String }\end{array}$ \\
\hline $91-090$ (Segment 1) & $\begin{array}{l}<\text { DL alpha } \\
<\text { DL beta-gamma }\end{array}$ & $4.5 \mathrm{mR} / \mathrm{hr}$ \\
\hline 91-091 (Segment 2) & $\begin{array}{l}<\mathrm{DL} \text { alpha } \\
<\mathrm{DL} \text { beta-gamma }\end{array}$ & $2.4 \mathrm{mR} / \mathrm{hr}$ \\
\hline $91-092$ (Segment 3) & $\begin{array}{l}<\mathrm{DL} \text { alpha } \\
<\mathrm{DL} \text { beta-gamma }\end{array}$ & $2.5 \mathrm{mR} / \mathrm{hr}$ \\
\hline 91-093 (Segment 4) & $\begin{array}{l}<\text { DL alpha } \\
<\text { DL beta-gamma }\end{array}$ & $2.0 \mathrm{mR} / \mathrm{hr}$ \\
\hline 91-094 (Segment 5) & $\begin{array}{l}<\text { DL alpha } \\
<\text { DL beta-gamma }\end{array}$ & $1.5 \mathrm{mR} / \mathrm{hr}$ \\
\hline 91-095 (Segment 6) & $\begin{array}{l}<\text { DL alpha } \\
<\text { DL beta-gamma }\end{array}$ & $1.5 \mathrm{mR} / \mathrm{hr}$ \\
\hline $91-096$ (Segment 7) & $\begin{array}{l}<\text { DL alpha } \\
<\text { DL beta-gamma }\end{array}$ & $0.5 \mathrm{mR} / \mathrm{hr}$ \\
\hline 91-097 (Segment 8) & $\begin{array}{l}<\mathrm{DL} \text { alpha } \\
<\mathrm{DL} \text { beta-gamma }\end{array}$ & $1.5 \mathrm{mR} / \mathrm{hr}$ \\
\hline 91-098 (Segment 9) & $\begin{array}{l}<\text { DL alpha } \\
<\text { DL beta-gamma }\end{array}$ & $0.3 \mathrm{mR} / \mathrm{hr}$ \\
\hline
\end{tabular}

$<\mathrm{DL}=$ below detection limit 
WHC-EP-0806

Table 3-2. Core 33--Chain of Custody Summary

\begin{tabular}{|c|c|c|c|}
\hline Sample & \multicolumn{2}{|l|}{ Core 33} & \\
\hline Place Taken & \multicolumn{2}{|l|}{ 241-T-111 Riser 3} & \\
\hline Dates Taken & \multicolumn{2}{|l|}{$11 / 5 / 91$ to $11 / 6 / 91$} & \\
\hline Dates Released & \multicolumn{2}{|l|}{$11 / 6 / 91$ to $11 / 7 / 91$} & \\
\hline Sender & \multicolumn{2}{|l|}{ D. C. Hartley } & \\
\hline Receiver & \multicolumn{2}{|l|}{ V. Johansen } & \\
\hline Place Received & \multicolumn{2}{|l|}{\begin{tabular}{|l|} 
222-S Laboratory \\
\end{tabular}} & \\
\hline Times Received & \multicolumn{2}{|l|}{ See Below } & \\
\hline $\begin{array}{l}\text { Sample Number/ } \\
\text { Date Sampled }\end{array}$ & $\begin{array}{l}\text { Date Released/ } \\
\text { Time Released/ } \\
\text { Time Received }\end{array}$ & $\begin{array}{c}\text { Smearable } \\
\text { Contamination }\end{array}$ & $\begin{array}{l}\text { Dose Rate Through the Drill } \\
\text { String }\end{array}$ \\
\hline $\begin{array}{l}91-108 \\
\text { (Segment 1) } \\
11 / 5 / 91\end{array}$ & \begin{tabular}{|l|}
$11 / 6 / 91$ \\
$10: 10$ \\
$10: 55$ \\
\end{tabular} & $\begin{array}{l}<\text { DL alpha } \\
<\text { DL beta-gamma }\end{array}$ & $3 \mathrm{mR} / \mathrm{hr}$ \\
\hline $\begin{array}{l}91-109 \\
\text { (Segment 2) } \\
11 / 5 / 91\end{array}$ & \begin{tabular}{|l|}
$11 / 6 / 91$ \\
$10: 10$ \\
$10: 55$ \\
\end{tabular} & $\begin{array}{l}<\text { DL alpha } \\
<\text { DL beta-gamma }\end{array}$ & $2.5 \mathrm{mR} / \mathrm{hr}$ \\
\hline $\begin{array}{l}91-110 \\
\text { (Segment 3) } \\
11 / 5 / 91\end{array}$ & \begin{tabular}{|l|}
$11 / 6 / 91$ \\
$10: 10$ \\
$10: 55$ \\
\end{tabular} & $\begin{array}{l}<\text { DL alpha } \\
<\text { DL beta-gamma }\end{array}$ & $10 \mathrm{mR} / \mathrm{hr}$ \\
\hline $\begin{array}{l}91-111 \\
\text { (Segment 4) } \\
11 / 5 / 91\end{array}$ & $\begin{array}{l}11 / 6 / 91 \\
14: 10 \\
14: 30 \\
\end{array}$ & $\begin{array}{l}<\text { DL alpha } \\
<\text { DL beta-gamma }\end{array}$ & $5 \mathrm{mR} / \mathrm{hr}$ \\
\hline $\begin{array}{l}91-112 \\
\text { (Segment 5) } \\
11 / 6 / 91\end{array}$ & \begin{tabular}{|l|}
$11 / 6 / 91$ \\
$14: 10$ \\
$14: 30$ \\
\end{tabular} & $\begin{array}{l}<\text { DL alpha } \\
<\text { DL beta-gamma }\end{array}$ & $<0.5 \mathrm{mR} / \mathrm{hr}$ \\
\hline $\begin{array}{l}91-113 \\
\text { (Segment 6) } \\
11 / 6 / 91\end{array}$ & \begin{tabular}{|l|}
$11 / 6 / 91$ \\
$14: 10$ \\
$14: 30$ \\
\end{tabular} & $\begin{array}{l}<\mathrm{DL} \text { alpha } \\
<\mathrm{DL} \text { beta-gamma }\end{array}$ & $2 \mathrm{mR} / \mathrm{hr}$ \\
\hline $\begin{array}{l}91-114 \\
\text { (Segment } 7) \\
11 / 6 / 91\end{array}$ & $\begin{array}{l}11 / 7 / 91 \\
10: 10 \\
10: 35 \\
\end{array}$ & $\begin{array}{l}<\text { DL alpha } \\
<\text { DL beta-gamma }\end{array}$ & $1.5 \mathrm{mR} / \mathrm{hr}$ \\
\hline $\begin{array}{l}91-115 \\
\text { (Segment } 8) \\
11 / 6 / 91\end{array}$ & \begin{tabular}{|l|}
$11 / 7 / 91$ \\
$10: 10$ \\
$10: 35$ \\
\end{tabular} & $\begin{array}{l}<\text { DL alpha } \\
<\text { DL beta-gamma }\end{array}$ & $1 \mathrm{mR} / \mathrm{hr}$ \\
\hline $\begin{array}{l}91-116 \\
\text { (Segment 9) } \\
11 / 6 / 91\end{array}$ & \begin{tabular}{|l|}
$11 / 7 / 91$ \\
$10: 10$ \\
$10: 35$ \\
\end{tabular} & $\begin{array}{l}<\text { DL alpha } \\
<\text { DL beta-gamma }\end{array}$ & $1 \mathrm{mR} / \mathrm{hr}$ \\
\hline
\end{tabular}


This page intentionally left blank. 


\subsection{SAMPLE HANDLING AND ANALYTICAL SCHEME}

The primary objective for these waste analyses was to meet requirements of the Hanford Federal Facility Agreement and Consent Order (Ecology et al. 1992, Ecology et al. 1994). Two composites from each core were built and analyzed in accordance with the complete baseline case core composite scenario detailed in WHC-EP-0210 (Winters et al. 1990a, Winters et al. 1990b) and as amended by Hill et al. (1991). However, there are other concerns and interests for this data. First, this information will help to evaluate whether constituent concentrations are within safe operating limits by determining whether they are flammable or explosive. Second, analyte concentrations of interest to the various Hanford-Site technical programs can be determined.

Because tank 241-T-111 initially was identified as a non-watch-list tank, extensive analytical measurements were not specified to resolve any previously identified safety concerns associated with this tank. The analysis horizon for characterization was determined to be on the core composite level with selected analyses being performed on a segment-level basis. However, after the discovery of substantial exotherms in the top $100 \mathrm{~cm}$ (40 in) of the waste, additional testing on a segment level basis was done on those samples exhibiting reactive behavior. This additional testing, with an emphasis on providing resolution to the safety issues raised by the presence of the exotherms in the waste is still underway at the time of the writing of this report. This report will be updated to reflect the new data or root causes of the energetics when that information becomes available.

\subsection{SAMPLE BREAKDOWN PROCEDURE}

In order to obtain the sample, the sampler is shipped in a vertical position and removed from the shipping cask directly into the hot cell. At this time, the sampler must be placed in the horizontal position. The sample is then loaded into the mechanical extruder and removed by pushing it out from the back of the sampler with a piston. In this case, the sampler is pressed against a fixed piston, forcing the sample into the extrusion tray. If a full sample is captured, the material nearest the valve will be from a deeper part of the tank. The material near the piston is closer to the surface. The sample and any liquids are collected on a metal tray. Next, the mass of the segment and the approximate length are recorded. From this information, the gross bulk densities of the segments can be estimated until further physical properties work is performed. The sample volume is determined by measuring the length of the extruded sample using a linear unit volume of $9.85 \mathrm{~mL} / \mathrm{in}$. Figure $4-1$ illustrates how the SST segment sample was extruded. Color photographs documenting the extrusions of each of the segments from tank 241-T-111 were taken and are on file at the 222-S Laboratory. 
Figure 4-1. Typical Single-Shell Tank Segment Extrusion.

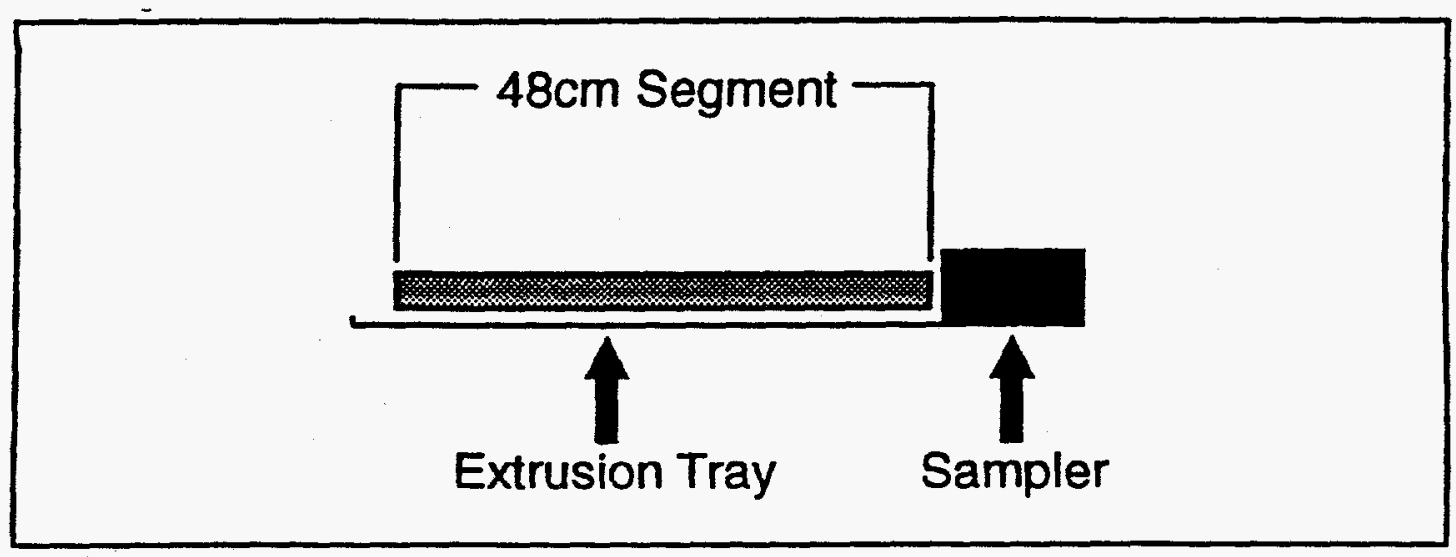

29409011.1 
Several different styles of nomenclature presently are used for distinguishing core samples, sample segments, and subsegments in the existing literature. Two major conventions are used in the documentation relating to core sampling in general. The first is designating the segment with the last two digits of the calendar year (92-) and then numbering the segments sequentially $(-001,-002$, etc.). This system resets itself every calendar year. The second system distinguishes the tank, core, segment (and subsegment, if necessary), with segment 1 being the at the top of the core sample and having the number increase as a function of depth in the tank so that segment 9 is at the bottom of the tank in 241-T-111. An example of this naming protocol for the second segment of the first core is 241-T-111-Core 31-Segment 2. Where no tank identification is given in this report, it is understood to mean tank 241-T-111.

\subsection{TANK 241-T-111 CORE SAMPLE DESCRIPTION}

The location of the risers, the dished bottom of the tank, and safety margins in the sampling protocol preclude obtaining samples from the entire waste depth in the tank. In addition, the sampling protocol establishes that segments will be calculated from the bottom up. Thus, depending on the waste depth, maximum recovery for the top segment from tank 241-T-111 is not necessarily going to be a full 48-cm (19-in) segment. However, for cores 31 and 33, sample recovery was excellent; overall recoveries were in excess of 80 percent. Segment recoveries were based on the maximum recoverable volume for the segment regardless of solid/liquid ratio. The core recoveries reported in the data package are determined based on a visual inspection of the sample length and apparent volume at the time the samples are extruded. Further study of the color photographs taken after extrusion can aid in clarifying a rough sample volume. Tables 4-1 and 4-2 present the initial measurements and observations regarding the core samples on extrusion, and an estimated range of the core recovery on a volume basis for cores 31 and 33 .

Although samples for core 32 were taken from riser 2, the materials obtained at all levels appeared to be particulate suspended in an aqueous solution, with slight traces of normal paraffin-hydrocarbon contamination observed in a few samples. These samples did not correspond to the observed conditions in the tank and were considered non-representative. The results of the core- 32 sampling exercise were attributed to sampler failure, and because no acceptable samples were acquired, no assays were performed. Therefore, no results for core 32 will be reported. Valve failures were reported routinely for all three core samples at deeper positions in the tank. The full data package (McKinney et al. 1993) containing all of the assay results is available from the Hanford-Site Central Files.

General characteristics of tank 241-T-111 waste materials are as follows.

- Very little drainable liquid was associated with these samples either in the liner or in the extruder.

- Core samples generally were dark brown or black in color. The brown solids were streaked through with grey/white material. 


\begin{tabular}{|c|c|c|c|c|}
\hline $\begin{array}{c}\text { Core } \\
\text { number } \\
\text { (Riser 6) }\end{array}$ & Segment & $\begin{array}{l}\text { Core recovery } \\
\text { (Vol. basis) }\end{array}$ & $\begin{array}{c}\text { Total } \\
\text { mass }(g)\end{array}$ & Comments \\
\hline 31 & 1 & $27 \%$ & 64.0 & $\begin{array}{l}\text { Sampler was neantly empty; cootuined approximately } 50 \mathrm{~mL} \text { of bleck/brown low viscosity solida. Apparently } \\
\text { homogencous. }\end{array}$ \\
\hline 31 & 2 & $80-100 \%$ & 182.8 & $\begin{array}{l}\text { Sampler was atmost completely filled with solids. Agsin, the material is dent brown or black with a fuid or } \\
\text { gel-like consistency, and appears to be homogeneous. A small amount of liner liquid was observed. The } \\
\text { liquid was observed to be two phase (NPH and aquecous phases). }\end{array}$ \\
\hline 31 & 3 & $95-100 \%$ & 162.2 & $\begin{array}{l}\text { Sampler was almost completely filled with solids. The waste is dert browns with a thick, viscous consistency, } \\
\text { and appears to be completely homegeneous. }\end{array}$ \\
\hline 31 & 4 & $80-100 \%$ & 153.5 & $\begin{array}{l}\text { Sampler was almost completely filled with solids. The waste is dantk brown with a thick, viscous consistency, } \\
\text { and appears to be completely homogeneous. The top eighth contuined waste manterial that appeared to be more } \\
\text { fluid than the rest of the sample. No sampler liquid or liner liquid was observed. }\end{array}$ \\
\hline 31 & 5 & $100 \%$ & 190.9 & Similar to previous observations; no sampler or liner liquid. \\
\hline 31 & 6 & $0 \%$ & NA & Sumpler emply. \\
\hline 31 & 7 & $90-100 \%$ & 186.4 & $\begin{array}{l}\text { Sampler was almost completely filled with solids. The whaste is dart brown with a thick, viscous consistency, } \\
\text { and appears to be completely bomogeneous. }\end{array}$ \\
\hline 31 & 8 & $100 \%$ & 186.4 & Similar to previous observations; no sampler or liner liquid. \\
\hline 31 & 9 & $100 \%$ & 203.1 & 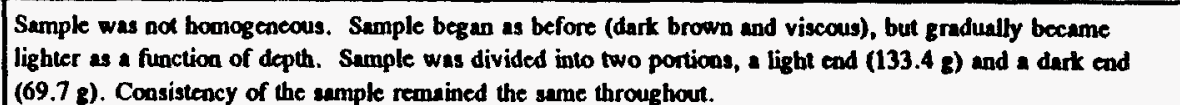 \\
\hline
\end{tabular}




\begin{tabular}{|c|c|c|c|c|}
\hline $\begin{array}{l}\text { Core } \\
\text { number } \\
\text { (Riser 3) }\end{array}$ & Segment & $\begin{array}{c}\text { Core recovery } \\
\text { (Vol. basis) }\end{array}$ & $\begin{array}{c}\text { Total mass } \\
(\mathrm{g})\end{array}$ & Comments \\
\hline 33 & 1 & $100 \%$ & 159.16 & $\begin{array}{l}\text { Sampler was full of black/brown low viscosity solids. Apparently homogencous, with no drainable } \\
\text { liquid. }\end{array}$ \\
\hline 33 & 2 & $100 \%$ & 207.59 & $\begin{array}{l}\text { Sampler was completely filled with solids. Agtin, the material is dart brown or bleck with a } \\
\text { viscous consistency, end appears to be homogeneous. }\end{array}$ \\
\hline 33 & 3 & $87-100 \%$ & 167.9 & $\begin{array}{l}\text { Sampler was nearly filled with solids. The waste is derk brown with a thick, viscous consistency, } \\
\text { and appears to be completely homogeneous. }\end{array}$ \\
\hline 33 & 4 & $75-85 \%$ & 182.05 & $\begin{array}{l}\text { Sampler was } 75-85 x \text { filled with solids. The waste is dart brown with a thick, viscous } \\
\text { consistency, and appears to be complectly homogeneous. The valve was observed to be open prior } \\
\text { to extrusion. No sampler liquid or liner liquid was observed. }\end{array}$ \\
\hline 33 & 5 & $88 \%$ & 174.3 & $\begin{array}{l}\text { Similar to previous observation, the valve was observed open, the sampler had approximalely } 88 x \\
\text { solids, and no drainable or liner liquid was seen. }\end{array}$ \\
\hline 33 & 6 & $100 \%$ & 217.37 & $\begin{array}{l}\text { Samplet was aimost conpletely filled with solids. The waste is dentk brown with a thick, viscous } \\
\text { consistency, and appears to be completely homogencous. }\end{array}$ \\
\hline 33 & 7 & $100 \%$ & 196.91 & $\begin{array}{l}\text { Samples was atmost complearly filled with solids. The waste is dark brown with a thick, viscous } \\
\text { consistency, and appears to be completely homogencous. }\end{array}$ \\
\hline 33 & 8 & $100 \%$ & 199.8 & Similar to previous observations. No sampler or liner liquid. \\
\hline 33 & 9 & $100 \%$ & 191.01 & 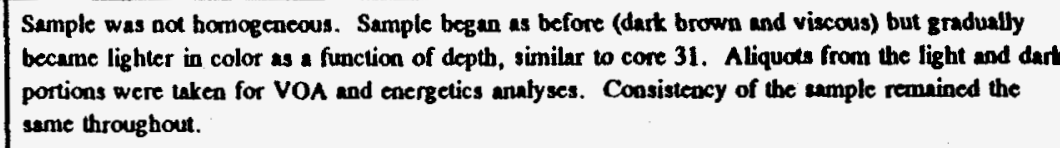 \\
\hline
\end{tabular}


- The samples had a viscous or gel-like consistency. They were thick, relatively smooth sludges (swamp mud was the descriptive term used by the hot-cell observer). The core materials all appeared to be saturated with liquid, which did not drain.

\subsection{HOLD TIME CONSIDERATIONS}

All analytes have a predetermined maximum allowable holding time set by the Environmental Protection Agency (EPA 1986), during which the analysis should be completed. Completion of analysis during the maximum allowable holding time enhances the regulatory defensibility of the data. The length of the holding time varies for each analyte. For example, analyses performed on volatile and semivolatile organic compounds, many of which decompose or dissipate quickly, have shorter holding times. On the other hand, persistent analytes such as metals (except mercury), do not readily decompose or dissipate, and therefore have much longer acceptable holding times. Nearly all of the analyses of cores 31 and 33 exceeded their respective maximum allowable holding times. The only analyses that came close to meeting holding-time criteria were radiochemistry and metal analyses. Both of these analyses were completed about six months after sampling, and six months is the maximum hold time for these analyses. Although exceeding the maximum allowable holding times weakens the defensibility of the analytical results for some uses, it is anticipated that the overall effect on the analytical results for tank 241-T-111 waste relative to waste management and disposal information needs is minimal. Further discussion of holding times can be found in Winters et al. (1990a).

\subsection{SAMPLE PREPARATION}

Sample preparation procedures are conducted in order to optimize the recovery of each analyte of interest from the tank waste. Water digestion, acid digestion, and potassium hydroxide fusion commonly are used to extract metals and several radioisotopes from solid samples, and in some cases digestions are performed on liquid samples to improve analytical resolution. Many separations are specific to a particular analysis and are described within the corresponding analytical methods referenced in Section 4.5. In order to verify analyte recoveries resulting from separation techniques, laboratory control samples, carriers, spikes, tracers, and surrogates are analyzed concurrently with the characterization samples.

In some cases no sample preparation is necessary or desired. Direct analyses are assays performed on the sample matrix with little or no sample preparation. Several direct analyses were performed relating to the physical or energetic properties of the waste: density, thermogravimetric analysis (TGA), differential scanning calorimetry (DSC), and gravimetric weight percent water. 
Water leach (or water digestion) analyses are assays performed after the sample matrix has been digested in distilled/deionized water. The water is then analyzed for soluble analytes. The soluble anions are determined by ion chromatography (IC). The primary anions analyzed in this manner are fluoride, chloride, nitrate, nitrite, phosphate, and sulfate. In addition, free cyanide and $\mathrm{pH}$ were also analyzed from water digestion samples. Note that IC assays use a 1 to 100 sample to water digestion, where $\mathrm{pH}$ measurements use a 1 to 1 sample to water ratio. Selected radionuclides were measured on some of the water digestion samples to determine the type and number of water soluble radionuclides. Inductively coupled plasma-atomic emission spectroscopy (ICP) and atomic absorption (AA) spectroscopy were also performed on some of the water digestion samples. These assays were performed to determine the amount of soluble metal cations (ICP) or arsenic, mercury, or selenium (AA). In many cases, these analytes were below the detection limits in the water digestion samples, suggesting that most of the analytes are not water soluble.

Acid digestion is a preparation method in which the sample is dissolved in a mixture of nitric and hydrochloric acids. This preparation brings most of the insoluble metals into a solution with a minimum amount of dilution, and usually is best for the detection of trace and some major metals. These properties are the reason that acid digestion generally is used as the sample preparation for the homogenization tests in SW-846-based environmental sampling. However, experience with Hanford-Site tank-waste matrices has shown that acid digestion does not always provide complete solubilization, and that a more rigorous dissolution preparation, such as fusion, may be necessary to get adequate quantitation. The analyses performed on this preparation were the ICP, gamma energy analysis (GEA), and AA analysis (the AA analysis used nitric acid only). IC analysis was not performed with the acid digestion preparation solution because that method introduces additional $\mathrm{Cl}^{-}$or $\mathrm{NO}_{3}{ }^{-}$anions, confounding the results for that sample.

Analyses that were performed on fusion-prepared samples were ICP and GEA for radionuclides. Fusion dissolution analyses are assays performed on the sample matrix after it has been fused with potassium hydroxide in a nickel crucible and dissolved in acid. This preparation dissolves the entire sample, whereas other sample preparation procedures may not completely dissolve the sample matrix. However, one significant disadvantage of fusion preparation is that large amounts of potassium hydroxide are required to bring a sample into solution. Because of this high dilution factor, trace elements are less likely to be quantified correctly, if they are detected at all. Another limitation of the preparation method is if the sample contains substantial quantities of potassium or nickel, these analytes will not be quantifiable because the procedure uses potassium hydroxide and a nickel crucible. This limitation can be overcome using alternate preparation methods if potassium or nickel are analytes critical to interpretation of the data. Elements that occur in abundance, such as major metals, or that are highly insoluble are likely to be detected better by the fusion results than by any other sample preparation.

Generally, fusion dissolution is the preferred method of analyzing radionuclide content, with the exception of ${ }^{14} \mathrm{C},{ }^{129} \mathrm{l}$, and ${ }^{3} \mathrm{H}$ (tritium). However, the sample preparation specified in the test instructions for ${ }^{14} \mathrm{C}$ (water digestion) probably is not best for the high-level waste 
matrices. Difficulty with dissolving the sample with a water leach, and volatility associated with a fusion preparation, potentially will bias the ${ }^{14} \mathrm{C}$ results low for both sample preparation types if they are associated with the water insoluble solid materials, and similar difficulties are encountered for the other radionuclides mentioned. However, none of these analytes are expected to be significant contributors to the radionuclide content of the waste.

Major metal components that were detected well with fusion ICP analysis for tank 241-T-111 were calcium, chromium, iron, manganese, sodium, bismuth, and lanthanum. Phosphorous, sulfur, and silicon are non-metallic analytes detected by ICP. In the case of these elements, the fusion result is the preferred method of analysis because it is believed to provide more complete dissolution of the waste, and therefore, more complete quantitation of the analytes. Comparisons of these results with the IC results can provide insight to the solubility characteristics of the waste. Some of the primary radionuclides that are measured using this sample preparation are ${ }^{237} \mathrm{~Np},{ }^{239 / 240} \mathrm{Pu},{ }^{90} \mathrm{Sr},{ }^{137} \mathrm{Cs}$, and ${ }^{99} \mathrm{Tc}$. A total alpha and total beta count were performed on the fusion dissolution samples as well.

As previously noted, chemical and radiological analyses were done largely on core composites, and in these previous characterization efforts, the core composites were built using quantities of segments based on a proportion of the total weight of sample for the core (Winters et al. 1990a, Winters et al. 1990b). This method assumed that the sample obtained is representative of what is in the tank. However, when partially filled segments are obtained, this procedure assumes that the tank does not contain any waste in this area. Incomplete recovery for a segment probably is the result of sampling problems rather than voids in the waste. The approach used in this analysis effort was to composite equal quantities of the homogenized segment material and assume that whatever is obtained in a partial segment is representative of a whole segment. Some inaccuracies may be introduced from this method because of density differences between segments. However, the inaccuracies introduced from density differences probably are small. In general, those deviations are minimal compared to the other errors inherent in core sampling and analysis. If full segments are obtained for the entire core, and the homogenization procedure is satisfactory, there will be little difference between the two approaches.

\subsection{ANALYTICAL METHODS}

This section briefly describes the analyses used to characterize the waste in tank 241-T-111. The analyses were split between the Westinghouse 222-S Laboratory and PNL. Several of the analytical tests performed on the composites were also performed on the segments, but on a much more limited scope. There were no free liquids from cores 31 and 33, thus there are no separate liquid core composite results. However, in March 1994, a series of liquid grab samples were taken and analyzed for compatibility considerations (Carothers et al. 1994) before the start of stabilization. These results will be presented with the water digestion results and comparisons and conclusions will be made. 


\subsubsection{Physical and Rheological Tests}

Physical tests completed at the 222-S Laboratory included particle size analysis, TGA, DSC, specific gravity, and percent water analyses. Duplicates were performed for the percent water analyses. The physical properties measured at PNL included weight percent solids, settling behavior, and weight percent dissolved solids. Rheological testing on these samples were performed at PNL and included shear strength and shear stress as a function of shear rate. Rheological properties were measured in duplicate. Table 4-3 lists the analytical methods used for physical and rheological testing. Three segments from Core 31 (segments 2, 4, and 8) were selected to perform the full suite of rheological and physical measurements, in addition to the particle size assay done on each segment. Viscosity, settling properties, fluid behavior, and shear strength were some of the primary characteristics investigated. The samples tested for these properties were not homogenized before analysis.

Table 4-3. Analytical Methods for Physical and Rheological Testing.

\begin{tabular}{|l|l|}
\hline \multicolumn{1}{|c|}{ Analyte } & \multicolumn{1}{c|}{ Procedure } \\
\hline Particle size & T044-A-01712F \\
\hline Thermogravimetric analysis & LA-560-112 \\
\hline $\begin{array}{l}\text { Differential scanning } \\
\text { calorimetry }\end{array}$ & LA-514-113 \\
\hline Specific gravity & LA-510-112 \\
\hline Percent water & LA-564-101 \\
\hline Rheology & $\begin{array}{l}\text { PNL-ALO-501 } \\
\text { PNL-ALO-502 }\end{array}$ \\
\hline Physical properties & N/A \\
\hline
\end{tabular}

Scanning TGA and DSC are useful in determining the thermal stability or reactivity of a material. TGA measures the mass of a sample while the temperature of the sample is increased at a constant rate. In DSC analysis, the heat absorbed/evolved over and above the usual heat capacity of the substance is measured while the substance is exposed to a linear increase in temperature. The gravimetric weight percent water was determined by drying the sample for 12 to 24 hours in an oven at 103 to $105^{\circ} \mathrm{C}$ and measuring the difference in the weight of the sample. 


\subsubsection{Chemical and Radionuclide Constituent Analysis}

Most of the chemical and radionuclide analyses were performed at the 222-S Laboratory. The uranium and plutonium isotopic analyses, however, were performed at PNL. Duplicate analyses were performed on every tank sample. Table 4-4 lists the analytical methods used (Winters et al. 1990a, Winters et al. 1990b).

\section{Sample Homogenization}

The segment and core composite samples were homogenized using a mechanical mixer before analysis. This was done so that aliquots removed for analysis would be representative of the entire segment or core composite. Aliquots of the homogenized tank waste from core 33 , segments $1,3,5,7$, and 9 , were taken to determine the efficacy of the homogenization procedure. The samples were split into duplicates, acid digested, and assayed by ICP and GEA. This procedure is done to determine if the degree of mixing achieved by the as-planned homogenization procedure was sufficient to achieve sample homogeneity. Since the homogenization samples are evaluated concurrently or after the other core samples, the results provide only an estimate of subsampling error (or variation). They were not used in this case to ensure that homogenization was achieved before analysis. However, after review of the results, it appears that homogenization of the samples was satisfactory.

\subsubsection{Organic Constituent Analyses}

All organic analyses of the samples from tank 241-T-111 were performed at PNL. An EPA contract-laboratory-procedure-type organics-speciation analysis was performed on the core composites. No levels of organic compounds above the contract required quantitation limit were found in any of the samples, and they were not expected to contribute to the sample matrix. The organic analyses performed were volatile organic analyses, semi-volatile organic analyses, total organic halides, and extractable organic halides. Duplicates were performed for all of these analyses. Table 4-5 lists the analyses and procedure numbers.

At the 222-S Laboratory, the initial total organic carbon assays were done using a furnace oxidation procedure of a water digested sample. At PNL, the total organic carbon content for the solids was determined using the hot persulfate method. That method dissolves a sample in a $90{ }^{\circ} \mathrm{C}+$ sulfuric acid solution to liberate inorganic carbon (carbonate). $\mathrm{K}_{2} \mathrm{~S}_{2} \mathrm{O}_{8}$ is then added, and organic carbon is converted to $\mathrm{CO}_{2}$, which is measured coulometrically. As stated in the "Executive Summary," these methods did not provide satisfactory results for the tank 241-T-111 waste samples. Later, furnace oxidation tests done at PNL gave results much higher than those from the 222-S Laboratory and more in line with the observed exothermic activity. 
Table 4-4. Analytical Methods for Chemical and Radionuclide Analyses.

\begin{tabular}{|c|c|c|}
\hline Analyte & Method & Procedure number \\
\hline $\mathrm{Hg}$ & Cold vapor atomic absorption & LA-325-102 \\
\hline $\mathrm{F}, \mathrm{Cl}^{-}, \mathrm{NO}_{3}^{-}, \mathrm{NO}_{2}^{-}, \mathrm{PO}_{4}^{3-}, \mathrm{SO}_{4}{ }^{2-}$ & Ion chromatography & LA-533-105 \\
\hline $\mathrm{CN}^{-}$ & $\begin{array}{c}\text { Distillation/spectrometric } \\
\text { analysis }\end{array}$ & $\begin{array}{l}\text { LA-695-101 } \\
\text { LA-695-102 }\end{array}$ \\
\hline$\overline{\mathrm{U}}$ & Laser fluorimetry & LA-925-106 \\
\hline $\begin{array}{l}\text { Total Alpha } \\
\text { Total Beta }\end{array}$ & Proportional counting & LA-508-101 \\
\hline${ }^{238} \mathrm{Pu},{ }^{239 / 240} \mathrm{Pu},{ }^{241} \mathrm{Am}$ & Alpha spectrometry & LA-503-156 \\
\hline${ }^{237} \mathrm{~Np}$ & Alpha proportional counting & LA-933-141 \\
\hline Total Cations & Inductively coupled plasma & LA-505-151 \\
\hline${ }^{90} \mathrm{Sr}$ & Beta proportional counting & LA-220-101 \\
\hline $\begin{array}{l}{ }^{99} \mathrm{Tc} \\
{ }^{79} \mathrm{Se} \\
{ }^{14} \mathrm{C} \\
{ }^{3} \mathrm{H}\end{array}$ & Liquid scintillation & $\begin{array}{l}\text { LA-438-101 } \\
\text { LA-365-132 } \\
\text { LA-348-104 } \\
\text { LA-218-114 }\end{array}$ \\
\hline $\begin{array}{l}{ }^{129} \mathrm{I} \\
{ }^{59} \mathrm{Ni}\end{array}$ & Low energy gamma analysis & $\begin{array}{c}\text { LA-378-104 } \\
\text { PNL-ALO-464 }\end{array}$ \\
\hline${ }^{63} \mathrm{Ni}$ & Liquid scintillation & PNL-ALO-474 \\
\hline${ }^{154} \mathrm{Eu},{ }^{155} \mathrm{Eu},{ }^{241} \mathrm{Am},{ }^{137} \mathrm{Cs},{ }^{60} \mathrm{Co}$ & Gamma energy analysis & LA-548-121 \\
\hline $\mathrm{NO}_{2-}^{-}$ & Spectrophotometry & LA-645-001 \\
\hline $\mathrm{H}+$ & $\mathrm{pH}$ & LA-212-103 \\
\hline $\begin{array}{l}\text { As } \\
\text { Se }\end{array}$ & $\begin{array}{c}\text { Graphite furnace atomic } \\
\text { absorption }\end{array}$ & $\begin{array}{l}\text { PNL-ALO-214 } \\
\text { PNL-ALO-215 }\end{array}$ \\
\hline $\mathrm{Pu}$ Isotopic & $\begin{array}{c}\text { Fusion } \\
\text { mass spectrometry }\end{array}$ & $\begin{array}{l}\text { PNL-ALO-423 } \\
\text { PNL-MA-597 }\end{array}$ \\
\hline U Isotopic & $\begin{array}{c}\text { Mass spectrometry } \\
\text { uranium laser }\end{array}$ & $\begin{array}{l}\text { PNL-MA-597 } \\
\text { PNL-ALO-445 } \\
\end{array}$ \\
\hline TOC & Total organic carbon & $\begin{array}{c}\text { LA-344-105 } \\
\text { PNL-ALO-380 } \\
\text { PNL-ALO-381 }\end{array}$ \\
\hline $\mathrm{CO}_{3} / \mathrm{C}$ & Total inorganic carbon & LA-622-102 \\
\hline
\end{tabular}


Table 4-5. Analytical Methods For Organic Analytes.

\begin{tabular}{|l|l|l|}
\hline \multicolumn{1}{|c|}{ Analysis } & \multicolumn{1}{|c|}{ Method } & Procedure Number \\
\hline Volatile organic analysis & $\begin{array}{l}\text { Gas chromatography/mass } \\
\text { spectrometry }\end{array}$ & PNL-ALO-335 \\
\hline Semi-volatile organic analysis & $\begin{array}{l}\text { Gas chromatography/mass } \\
\text { spectrometry }\end{array}$ & PNL-ALO-345 \\
\hline Extractable organic halides & Microcoulometric titration & PNL-ALO-320.2 \\
\hline Total organic halides & Microcoulometric titration & PNL-ALO-321 \\
\hline
\end{tabular}

\subsubsection{Segment-Level Analyses}

The objectives of segment-level analyses are to provide (1) information as a function of depth pertaining to the overall waste energetics (water content and chemical reactivity) and (2) the particle size distribution and other general rheological information. To accomplish these goals, the limited suite of analyses listed in Table 4-6 were performed on each homogenized segment. These analyses were conducted using the analytical procedures identified in Tables 15-1 and I5-2 of WHC-EP-0210, Rev. 3 (Hill et al. 1991). In addition, where appropriate, the information obtained from the segment-level homogenization tests will be used to enhance the interpretation of the data.

Table 4-6. Segment-Level Analysis.

\begin{tabular}{|c|c|}
\hline Direct & Acid dissolution* $^{*}$ \\
\hline Thermogravimetric analysis & Inductively coupled plasma \\
differential scanning calorimetry & (metals) \\
Wt\% $\mathrm{H}_{2} \mathrm{O}$ & gamma energy analysis $\left({ }^{137} \mathrm{Cs}\right)$ \\
particle size** & total alpha \\
\hline
\end{tabular}

*Acid dissolution assays were performed on the homogenization test segments.

**Particle size was done on non-homogenized segment material. 


\subsection{ANALYTICAL RESULTS: TANK 241-T-111}

\subsection{CHEMICAL ANALYSES}

\subsubsection{Analytical Results: Inductively Coupled Plasma-Atomic Emission Spectroscopy}

Online inter-element corrections were performed for matrix interferences. The ICP has a built-in correction capability to adjust for moderate matrix interferences; however, there may be performance degradation on samples containing weight-percent quantities of iron, aluminum, or uranium. Corrections were made for moderate levels of aluminum, calcium, chromium, and magnesium in the samples. Corrections were made for high iron concentrations as well. Process or preparation blank values have not been subtracted from the results. In the water digestion and liquid grab sample assays, the single most prevalent element is sodium by at least an order of magnitude. Relative percent differences (RPDs) for water digestion results were high for some analytes (i.e. above the 20 percent acceptance criteria), but there was no consistent trend observed between cores 31 and 33 .

In the fusion assays, some elements can appear to be at high concentrations because of the large dilution factors required for fusion samples. These high dilution factors propagate errors. Those analytes actually may be present only in concentrations marginally above the detection limit. For several analytes, higher quantitation was found in the acid digestion results. For purposes of determining inventories and making comparisons, the highest reliable average analytical result will be used between acid and fusion preparations.

In reviewing the data, a subtle bias or gradient was observed between the results for cores 31 and 33 , with core 31 having slightly higher values overall than core 33 . Although not readily discernable among the first tier analytes (sodium, bismuth, iron, and phosphorus), the difference between cores 31 and 33 is more evident in the second tier analytes (aluminum, lead, and magnesium). The RPDs between the individual core composite samples and their replicates were small, suggesting that the gradient is real and not an analytical artifact, however, this observation could be the result of the compositing procedure. There were nine segments used in the core 33 composites, but only eight segments in the core 31 composites (segment 6 was absent in core 31). Furthermore, sample variability may contribute or be wholly responsible for the observed difference.

RPDs for most elements were within the 20-percent acceptance criteria for acid and fusion results, and generally were less than 10 percent for the major analytes. Potential sample contamination for boron and silicon exists because of the caustic nature of the samples and the glass vials used to store the samples in the laboratory; however, silicon routinely demonstrated a low bias. Calcium and magnesium for blank and spike recovery results may have been biased high by the powder used on the analysts' gloves when performing the assays. With the small sample sizes used in the assay, even trace amounts of powder have 
the potential to impact the analyses. Low spike recoveries were noted for several analytes for differing reasons. Silver recoveries are commonly low because of the precipitation of silver chloride in the sample digestion. Poor spike recoveries of iron, magnesium, and calcium accompany high preparation blank results, but the overall correlation is poor. Spike failures frequently are noted for major elements when the spike concentration is insignificant compared to the analyte concentration in the waste matrix. Spike and standard results outside the acceptance criteria for these analytes do not necessarily invalidate the sample results for the ICP in general, or for those analytes in particular. Individual analyte failures need to be evaluated on a case by case basis. All of these behaviors could affect, and are considered in the interpretation of the results.

The detection limit for each analyte is provided for comparison with the results to aid in interpretation. All ICP analytes are reported in the data tables; however, those consistently contributing significant (i.e generally greater than approximately 0.2 weight percent) amounts to the composition of the waste matrix generally are relevant to bulk characterization. The fusion/acid ratio, which can be compared in the table, for most analytes indicates near total dissolution for the acid digestion assay. Average values for the analytes are reported to three significant figures. The full range of ICP analytical results can be found in the full data packages (McKinney et al. 1993). All reported concentration values are based on grams of wet sample, unless otherwise specified. Table 5-1 provides ICP analyte concentration information on the core composites as a function of the sample preparation. Table 5-2 provides ICP analyte concentrations as a function of depth for Core 33. Table 5-3 compares the water digestion core composite ICP values with the results from the grab sample.

\section{Core 31}

The most significant analytes measured by the water digestion of the core composite were sodium and phosphorous (probably as a soluble phosphate), and sulfur (probably as a soluble sulfate). Much smaller amounts of iron, chromium, and silicon also were measured. RPDs were elevated for these samples (between 10 and 20 percent), but were generally within the 20 -percent acceptance criteria. For analytes with results outside the acceptance criteria, no clear trend between the two composites can be established. The water digestion result for core 31, composite 1 had several analytes with high RPDs, many of which are significant contributors to the waste: iron, lead, manganese, silver, bismuth, lanthanum, and strontium. Core 31, composite 2 had few analytes with results outside the acceptance criteria: barium, calcium, lead, and vanadium. All of the analytes noted are largely insoluble and that characteristic probably is contributing to the observed variability.

The results from the acid digestion preparation of the core composite samples had sodium, phosphorous, sulfur, calcium, chromium, iron, manganese, bismuth, and lanthanum as major analytes. RPDs are very good in general for most of the major analytes (generally between 5 and 10 percent), well within the 20 percent acceptance criteria. Analytes outside the acceptance criteria for core 31 , composite 1 were antimony and boron (56 percent and 27 percent, respectively). However, neither of those analytes are substantial contributors to the waste matrix, and for analytes near the detection limit, reproducibility is not expected. 
Table 5-1. ICP Cations. (4 pages)

\begin{tabular}{|c|c|c|c|c|c|c|c|}
\hline Analyte & $\begin{array}{l}\text { Acid-water } \\
\text { digestion }\end{array}$ & $\begin{array}{c}\text { Fusion } \\
\text { digestion }\end{array}$ & $\begin{array}{l}\text { Prep } \\
\text { type }\end{array}$ & $\begin{array}{l}\text { Core } 31 \\
\text { comp. } 1\end{array}$ & $\begin{array}{l}\text { Core } 31 \\
\text { comp. } 2\end{array}$ & $\begin{array}{l}\text { Core } 33 \\
\text { comp. } 1\end{array}$ & $\begin{array}{l}\text { Core } 33 \\
\text { comp. } 2\end{array}$ \\
\hline & $\begin{array}{l}\text { Detection } \\
\text { limit }\end{array}$ & $\begin{array}{l}\text { Detection } \\
\text { limit }\end{array}$ & & $\begin{array}{c}\text { Average } \\
\text { concentration }\end{array}$ & $\begin{array}{c}\text { Average } \\
\text { concentration }\end{array}$ & $\begin{array}{c}\text { Average } \\
\text { concentration }\end{array}$ & $\begin{array}{c}\text { Average } \\
\text { concentration }\end{array}$ \\
\hline & $(\mu g / g)$ & $(\mu g / g)$ & & $(\mu g / g)$ & $(\mu g / g)$ & $(\mu g / g)$ & $(\mu g / g)$ \\
\hline \multirow[t]{3}{*}{ Al } & \multirow[t]{2}{*}{2.4} & & Water & 6.71 & 10.3 & 15.5 & 11.0 \\
\hline & & & Acid & 584 & 705 & 472 & 405 \\
\hline & & 12.0 & Fusion & 644 & 693 & 484 & 459 \\
\hline \multirow[t]{3}{*}{$\mathrm{Sb}$} & \multirow[t]{2}{*}{17.7} & & Water & 17.7 & 17.7 & 17.7 & 17.7 \\
\hline & & & Acid & 30.4 & 36.5 & 35.9 & 22.6 \\
\hline & & 85.5 & Fusion & 88.6 & 88.3 & 109 & 88.4 \\
\hline \multirow[t]{4}{*}{ As } & \multirow[t]{2}{*}{3.0} & & Water & 3.0 & 3.0 & 2.99 & 3.0 \\
\hline & & & Acid & 3.15 & 2.92 & 3.45 & 3.06 \\
\hline & 3.3 & & $\mathrm{GFAA}^{1}$ & 3.3 & 3.3 & 3.3 & 3.2 \\
\hline & & 15.0 & Fusion & 15.0 & 15.0 & 15.0 & 15.0 \\
\hline \multirow[t]{3}{*}{$\mathrm{Ba}$} & \multirow[t]{2}{*}{.3} & & Water & 0.305 & 0.416 & 0.547 & 0.516 \\
\hline & & & Acid & 57.0 & 64.9 & 66.8 & 87.3 \\
\hline & & 1.5 & Fusion & 58.8 & 60.6 & 65.4 & 73.7 \\
\hline \multirow[t]{3}{*}{$\mathrm{Be}$} & \multirow[t]{2}{*}{0.1} & & Water & 0.10 & 0.10 & 0.10 & 0.10 \\
\hline & & & Acid & 0.105 & 0.097 & 0.117 & 0.104 \\
\hline & & 0.5 & Fusion & 0.501 & 0.499 & 0.499 & 0.499 \\
\hline \multirow[t]{3}{*}{$\mathrm{Cd}$} & \multirow[t]{2}{*}{.4} & & Water & 0.40 & 0.40 & 0.4 & 0.4 \\
\hline & & & Acid & 7.22 & 7.86 & 4.4 & 3.72 \\
\hline & & 2.0 & Fusion & 8.25 & 10.7 & 6.42 & 7.17 \\
\hline \multirow[t]{3}{*}{$\mathrm{Ca}$} & \multirow[t]{2}{*}{4.4} & & Water & 50.8 & 61.6 & 66.4 & 67.5 \\
\hline & & & Acid & 2,200 & 2,480 & 1,490 & 1,350 \\
\hline & & 22.0 & Fusion & 2,760 & 2,660 & 2,220 & 2,050 \\
\hline \multirow[t]{3}{*}{$\mathrm{Cr}$} & \multirow[t]{2}{*}{0.9} & & Water & 209 & 229 & 224 & 211 \\
\hline & & & Acid & 1,860 & 1,840 & 2,060 & 2,140 \\
\hline & & 4.5 & Fusion & 1,890 & 1,700 & 1,790 & 1,820 \\
\hline
\end{tabular}

${ }^{1}$ GFAA: Graphite furnace atomic absorption 
Table 5-1. ICP Cations. (4 pages)

\begin{tabular}{|c|c|c|c|c|c|c|c|}
\hline Analyte & $\begin{array}{l}\text { Acid-water } \\
\text { digestion }\end{array}$ & $\begin{array}{l}\text { Fusion } \\
\text { digestion }\end{array}$ & $\begin{array}{l}\text { Prep } \\
\text { type }\end{array}$ & $\begin{array}{l}\text { Core } 31 \\
\text { comp. } 1\end{array}$ & $\begin{array}{l}\text { Core } 31 \\
\text { comp. } 2\end{array}$ & $\begin{array}{l}\text { Core } 33 \\
\text { comp. } 1\end{array}$ & $\begin{array}{l}\text { Core } 33 \\
\text { comp. } 2\end{array}$ \\
\hline & $\begin{array}{c}\text { Detection } \\
\text { limit }\end{array}$ & $\begin{array}{l}\text { Detection } \\
\text { limit }\end{array}$ & & $\begin{array}{c}\text { Average } \\
\text { concentration }\end{array}$ & $\begin{array}{c}\text { Average } \\
\text { concentration }\end{array}$ & $\begin{array}{c}\text { Average } \\
\text { concentration }\end{array}$ & $\begin{array}{c}\text { Average } \\
\text { concentration }\end{array}$ \\
\hline & $(\mu g / g)$ & $(\mu \mathrm{g} / \mathrm{g})$ & & $(\mu \mathrm{g} / \mathrm{g})$ & $(\mu \mathrm{g} / \mathrm{g})$ & $(\mu \mathrm{g} / \mathrm{g})$ & $(\mu \mathrm{g} / \mathrm{g})$ \\
\hline \multirow[t]{3}{*}{ Co } & \multirow[t]{2}{*}{0.8} & & Water & 0.8 & 0.825 & 0.821 & 0.825 \\
\hline & & & Acid & 3.4 & 7.16 & 3.13 & 2.91 \\
\hline & & 4.0 & Fusion & 10.1 & 10.8 & 13.3 & 11.8 \\
\hline \multirow[t]{3}{*}{$\mathrm{Cu}$} & \multirow[t]{2}{*}{.4} & & Water & 0.4 & 0.4 & 0.4 & 0.4 \\
\hline & & & Acid & 25.2 & 79.6 & 16.4 & 13.0 \\
\hline & & 2.0 & Fusion & 36.3 & 34.2 & 22.1 & 24.6 \\
\hline \multirow[t]{3}{*}{$\mathrm{Fe}$} & \multirow[t]{2}{*}{1.0} & & Water & 79.6 & 140 & 132 & 159 \\
\hline & & & Acid & 19,200 & 20,000 & 17,500 & 17,300 \\
\hline & & 5.0 & Fusion & 20,500 & 19,600 & 15,900 & 16,100 \\
\hline \multirow[t]{3}{*}{$\mathrm{Pb}$} & \multirow[t]{2}{*}{6.2} & & Water & 7.05 & 7.93 & 6.24 & 6.19 \\
\hline & & & Acid & 475 & 543 & 201 & 168 \\
\hline & & 31.0 & Fusion & 440 & 484 & 267 & 269 \\
\hline \multirow[t]{3}{*}{$\mathrm{Mg}$} & \multirow[t]{2}{*}{0.3} & & Water & 2.94 & 3.95 & 3.84 & 3.83 \\
\hline & & & Acid & 435 & 479 & 305 & 290 \\
\hline & & 1.5 & Fusion & 438 & 443 & 268 & 272 \\
\hline \multirow[t]{3}{*}{$\mathrm{Mn}$} & \multirow[t]{2}{*}{0.2} & & Water & 14.7 & 25.1 & 25.4 & 33.8 \\
\hline & & & Acid & 6,190 & 6,140 & 6,710 & 6,280 \\
\hline & & 1.0 & Fusion & 6,380 & 5,940 & 6,220 & 6,590 \\
\hline \multirow[t]{3}{*}{$\mathrm{Ni}$} & \multirow[t]{2}{*}{1.7} & & Water & 1.7 & 1.7 & 1.7 & 1.7 \\
\hline & & & Acid & 151 & 157 & 110 & 108 \\
\hline & & 8.5 & Fusion & NR & NR & ${ }^{\wedge} \mathrm{NR}$ & NR \\
\hline \multirow[t]{3}{*}{ K } & \multirow[t]{2}{*}{11.2} & & Water & 734 & 783 & 712 & 648 \\
\hline & & & Acid & 1,100 & 1,210 & 1,210 & 1,020 \\
\hline & & 56.0 & Fusion & NR & NR & NR & NR \\
\hline \multirow[t]{4}{*}{$\mathrm{Se}$} & \multirow[t]{2}{*}{7.6} & & Water & 7.6 & 8.01 & 7.58 & 7.59 \\
\hline & & & Acid & 7.98 & 7.4 & 10.3 & 7.79 \\
\hline & 1.5 & & GFAA & 1.5 & 1.5 & 1.5 & 1.5 \\
\hline & & 38.0 & Fusion & 38.0 & 37.9 & 38.0 & 38.0 \\
\hline
\end{tabular}


Table 5-1. ICP Cations. (4 pages)

\begin{tabular}{|c|c|c|c|c|c|c|c|}
\hline Analyte & $\begin{array}{l}\text { Acid-water } \\
\text { digestion }\end{array}$ & $\begin{array}{l}\text { Fusion } \\
\text { digestion }\end{array}$ & $\begin{array}{l}\text { Prep } \\
\text { type }\end{array}$ & $\begin{array}{l}\text { Core } 31 \\
\text { comp. } 1\end{array}$ & $\begin{array}{l}\text { Core } 31 \\
\text { comp. } 2\end{array}$ & $\begin{array}{l}\text { Core } 33 \\
\text { comp. } 1\end{array}$ & $\begin{array}{l}\text { Core } 33 \\
\text { comp. } 2\end{array}$ \\
\hline & $\begin{array}{c}\text { Detection } \\
\text { limit }\end{array}$ & $\begin{array}{l}\text { Detection } \\
\text { limit }\end{array}$ & & $\begin{array}{c}\text { Average } \\
\text { concentration }\end{array}$ & $\begin{array}{c}\text { Average } \\
\text { concentration }\end{array}$ & $\begin{array}{c}\text { Average } \\
\text { concentration }\end{array}$ & $\begin{array}{c}\text { Average } \\
\text { concentration }\end{array}$ \\
\hline & $(\mu g / g)$ & $(\mu g / g)$ & & $(\mu g / g)$ & $(\mu \mathrm{g} / \mathrm{g})$ & $(\mu g / g)$ & $(\mu \mathrm{g} / \mathrm{g})$ \\
\hline \multirow[t]{3}{*}{ Ag } & \multirow[t]{2}{*}{0.5} & & Water & 0.639 & 1.16 & 0.553 & 0.499 \\
\hline & & & Acid & 203 & 227 & 44.3 & 30 \\
\hline & & 2.5 & Fusion & 214 & 221 & 39.5 & 37.1 \\
\hline \multirow[t]{3}{*}{$\mathrm{Na}$} & \multirow[t]{2}{*}{3.1} & & Water & 34,000 & 35,000 & 30,800 & 32,000 \\
\hline & & & Acid & 37,600 & 38,700 & 35,000 & 36,300 \\
\hline & & 15.5 & Fusion & 39,800 & 39,000 & 33,900 & 35,200 \\
\hline \multirow[t]{3}{*}{$\mathrm{V}$} & \multirow[t]{2}{*}{0.5} & & Water & 0.5 & 0.707 & 0.5 & 0.8 \\
\hline & & & Acid & 12.7 & 21.4 & 13.9 & 9.99 \\
\hline & & 2.5 & Fusion & 12.1 & 16.5 & 15.3 & 14.7 \\
\hline \multirow[t]{3}{*}{$\mathrm{Zn}$} & \multirow[t]{2}{*}{0.3} & \multirow[b]{2}{*}{ • } & Water & 0.3 & 0.3 & 0.3 & 0.3 \\
\hline & & & Acid & 79.4 & 101 & 44.2 & 35 \\
\hline & & 1.5 & Fusion & 104 & 106 & 105 & 110 \\
\hline \multirow[t]{3}{*}{$\mathrm{Bi}$} & \multirow[t]{2}{*}{7.5} & & Water & 115 & 191 & 231 & 270 \\
\hline & & & Acid & 23,600 & 23,300 & 28,500 & 28,400 \\
\hline & & 37.5 & Fusion & 20,900 & 20,100 & 26,500 & 26,700 \\
\hline \multirow[t]{3}{*}{ B } & \multirow[t]{2}{*}{0.6} & & Water & 3.31 & 3.19 & 5.54 & 4.25 \\
\hline & & & Acid & 27.1 & 23.4 & 29.4 & 32.2 \\
\hline & & 3.0 & Fusion & 3.0 & 2.99 & 4.84 & 4.84 \\
\hline \multirow[t]{3}{*}{$\mathrm{Ce}$} & \multirow[t]{2}{*}{10.1} & & Water & 10.1 & 10.1 & 10.1 & 10.1 \\
\hline & & & Acid & 32.6 & 28.6 & 37.8 & 35.8 \\
\hline & & 50.5 & Fusion & 50.6 & 50.4 & 50.4 & 50.4 \\
\hline \multirow[t]{3}{*}{ La } & \multirow[t]{2}{*}{1.4} & & Water & 6.02 & 8.52 & 13.8 & 15.8 \\
\hline & & & Acid & 3,720 & 3,620 & 4,640 & 4,890 \\
\hline & & 7.0 & Fusion & 3,690 & 3,410 & 4,510 & 4,810 \\
\hline \multirow[t]{3}{*}{$P$} & \multirow[t]{2}{*}{5.8} & & Water & 5,760 & 5,960 & 5,300 & 5,700 \\
\hline & & & Acid & 10,100 & 9,960 & 9,860 & 11,300 \\
\hline & & 29 & Fusion & 11,600 & 11,100 & 9,070 & 9,910 \\
\hline \multirow[t]{3}{*}{$\mathrm{Si}$} & \multirow[t]{2}{*}{1.3} & & Water & 438 & 560 & 669 & 620 \\
\hline & & & Acid & 482 & 471 & 528 & 394 \\
\hline & & 6.5 & Fusion & 5,960 & 5,840 & 5,460 & 5,410 \\
\hline
\end{tabular}


Table 5-1. ICP Cations. (4 pages)

\begin{tabular}{|c|c|c|c|c|c|c|c|}
\hline Analyte & $\begin{array}{l}\text { Acid-water } \\
\text { digestion }\end{array}$ & $\begin{array}{c}\text { Fusion } \\
\text { digestion }\end{array}$ & $\begin{array}{l}\text { Prep } \\
\text { type }\end{array}$ & $\begin{array}{l}\text { Core } 31 \\
\text { comp. } 1\end{array}$ & $\begin{array}{l}\text { Core } 31 \\
\text { comp. } 2\end{array}$ & $\begin{array}{l}\text { Core } 33 \\
\text { comp. } 1\end{array}$ & $\begin{array}{l}\text { Core } 33 \\
\text { comp. } 2\end{array}$ \\
\hline & $\begin{array}{c}\text { Detection } \\
\text { limit }\end{array}$ & $\begin{array}{c}\text { Detection } \\
\text { limit }\end{array}$ & & $\begin{array}{c}\text { Average } \\
\text { concentration }\end{array}$ & $\begin{array}{c}\text { Average } \\
\text { concentration }\end{array}$ & $\begin{array}{c}\text { Average } \\
\text { concentration }\end{array}$ & $\begin{array}{c}\text { Average } \\
\text { concentration }\end{array}$ \\
\hline & $(\mu \mathrm{g} / \mathrm{g})$ & $(\mu g / g)$ & & $(\mu g / g)$ & $(\mu \mathrm{g} / \mathrm{g})$ & $(\mu \mathrm{g} / \mathrm{g})$ & $(\mu \mathrm{g} / \mathrm{g})$ \\
\hline \multirow[t]{3}{*}{$\mathrm{Sr}$} & \multirow[t]{2}{*}{0.3} & & Water & 1.21 & 2.13 & 2.18 & 2.34 \\
\hline & & & Acid & 282 & 280 & 305 & 334 \\
\hline & & 1.5 & Fusion & 303 & 280 & 291 & 317 \\
\hline \multirow[t]{3}{*}{$S$} & \multirow[t]{2}{*}{2.7} & & Water & 1,190 & 1,200 & 1,060 & 1,140 \\
\hline & & & Acid & 1,230 & 1,260 & 1,140 & 1,220 \\
\hline & & 13.5 & Fusion & 1,350 & 1,310 & 1,080 & 1,160 \\
\hline \multirow[t]{2}{*}{ Sn } & \multirow[t]{2}{*}{1.6} & & Water & 1.6 & 1.6 & 1.6 & 1.6 \\
\hline & & & Acid & 4.21 & 2.44 & 1.81 & 1.61 \\
\hline & & 8.0 & Fusion & 8.01 & 7.98 & 7.99 & 7.99 \\
\hline \multirow[t]{2}{*}{$\mathrm{Ti}$} & \multirow[t]{2}{*}{0.4} & & Water & 0.4 & 0.4 & 0.4 & 0.4 \\
\hline & & & Acid & 29.4 & 33 & 8.9 & 6.46 \\
\hline & & 2.0 & Fusion & 72.9 & 72.4 & 22.3 & 24.1 \\
\hline \multirow[t]{3}{*}{$\mathrm{Zr}$} & \multirow[t]{2}{*}{ NR } & & Water & 0.8 & 0.799 & 0.798 & 0.798 \\
\hline & & & Acid & 0.84 & 0.778 & 0.913 & 0.816 \\
\hline & & NR & Fusion & 4.00 & 3.99 & 4.00 & 4.00 \\
\hline $\mathrm{Hg}$ & 0.125 & NR & $\mathrm{CVAA}^{2}$ & 1.59 & 1.83 & 1.20 & 1.08 \\
\hline
\end{tabular}

Table 5-2. Tank 241-T-111 Core 33 ICP Selected Analyte Trending as a Function of Depth (Acid prep on segments).

\begin{tabular}{|c|c|c|c|c|c|c|c|c|c|c|c|}
\hline Segment & $\begin{array}{c}\mathrm{C} \\
\left(\mu \mathrm{g}^{\prime} \mathrm{g}\right)\end{array}$ & $\begin{array}{c}\mathrm{Cr} \\
(\mu \mathrm{g} / \mathrm{g})\end{array}$ & $\begin{array}{c}\mathrm{Fe} \\
(\mu \mathrm{g} / \mathrm{g})\end{array}$ & $\begin{array}{c}M n \\
(\mu g / g)\end{array}$ & $\begin{array}{c}\mathrm{Ni} \\
(\mu \mathrm{g} / \mathrm{g})\end{array}$ & $\begin{array}{c}\mathrm{Na} \\
(\mu \mathrm{g} / \mathrm{g})\end{array}$ & $\begin{array}{c}\mathrm{Bi} \\
(\mu \mathrm{g} / \mathrm{g})\end{array}$ & $\underset{(\mu \mathrm{g} / \mathrm{g})}{\mathrm{La}}$ & $\begin{array}{c}P \\
(\mu g / g)\end{array}$ & $\begin{array}{c}S i \\
(\mu g / g)\end{array}$ & $\begin{array}{c}S \\
(\mu g / g)\end{array}$ \\
\hline 1 & 4,800 & 490 & 17,300 & 23,900 & 240 & 22,400 & 760 & 3 & 4,400 & 380 & 800 \\
\hline 3 & 1,100 & 1,200 & 11,700 & 3.800 & 70 & 25,800 & 24,200 & 3,900 & 4,800 & 430 & 720 \\
\hline 5 & 1.300 & 2.000 & 16.100 & 2,800 & 90 & 32,100 & 33,400 & 5,100 & 9,100 & 400 & 1.100 \\
\hline 7 & 1.100 & 2,500 & 18,100 & 4,200 & 70 & 36,000 & 34,700 & 4,900 & 12,200 & 450 & 1.200 \\
\hline 9 & 950 & 2,000 & 16,600 & 4,600 & 90 & 40,700 & 24,100 & 4,200 & 15,300 & 450 & 1,400 \\
\hline
\end{tabular}

${ }^{2}$ CVAA: Cold vapor atomic absorption 
Table 5-3. Grab Sample/Water Digestion Data--ICP Average Values.

\begin{tabular}{|l|c|r|r|r|r|}
\hline Analyte & $\begin{array}{c}\text { Grab sample avg. } \\
\text { concentration } \\
(\mu \mathrm{g} / \mathrm{g} \text { sample })\end{array}$ & $\begin{array}{r}\text { Core 31, } \\
\text { comp. 1 } \\
(\mu \mathrm{g} / \mathrm{g} \text { sample })\end{array}$ & $\begin{array}{c}\text { Core 31, } \\
\text { comp. 2 } \\
(\mu \mathrm{g} / \mathrm{g} \text { sample })\end{array}$ & $\begin{array}{c}\text { Core 33, } \\
\text { comp. 1 } \\
(\mu \mathrm{g} / \mathrm{g} \text { sample })\end{array}$ & $\begin{array}{c}\text { Core 33, } \\
\text { comp. 2 } \\
(\mu \mathrm{g} / \mathrm{g} \text { sample })\end{array}$ \\
\hline $\mathrm{Ca}$ & $<\mathrm{DL}$ & 51 & 62 & 66 & 68 \\
\hline $\mathrm{Cr}$ & 230 & 210 & 230 & 220 & 210 \\
\hline $\mathrm{Fe}$ & $<\mathrm{DL}$ & 80 & 140 & 130 & 160 \\
\hline $\mathrm{Ni}$ & $<\mathrm{DL}$ & 15 & 25 & 25 & 34 \\
\hline $\mathrm{Na}$ & 24,800 & 34,000 & 35,000 & 30,800 & 32,000 \\
\hline $\mathrm{Bi}$ & $<\mathrm{DL}$ & 120 & 190 & 230 & 270 \\
\hline $\mathrm{La}$ & $<\mathrm{DL}$ & 6 & 9 & 14 & 16 \\
\hline $\mathrm{P}$ & 3,200 & 5,800 & 6,000 & 5,300 & 5,700 \\
\hline $\mathrm{Si}$ & 60 & 440 & 560 & 670 & 620 \\
\hline $\mathrm{S}$ & 750 & 1,200 & 1,200 & 1,100 & 1,100 \\
\hline
\end{tabular}

$<\mathrm{DL}=$ below detection limit

This behavior is true in general for analytes with these characteristics. The silicon RPD is marginal at 19.26 percent, but acceptable. For core 31, composite 2, cobalt, copper, silicon, and tin were outside the acceptance criteria. Again, cobalt, copper, and tin were not significant contributors to the waste, and thus have little influence on the interpretation of the data. The only clear trend for this assay is for silicon. The variation observed for silicon was attributed to the solubility of the waste matrix (i.e. the waste is not completely solubilized by the acid), and therefore, the fusion results will be reviewed to quantitate silicon. Based on a ratio of the acid and water digestion results, most of the analytes are not water soluble, except as noted earlier, however, approximately 10 percent of the chromium is water soluble.

The results from the fusion preparation core composite had sodium, phosphorous, bismuth, manganese, lanthanum, silicon, iron, calcium, and chromium as major analytes. Nickel was detected in substantial quantities, but the results are considered unreliable because of sample contamination (the method uses a nickel crucible to perform the fusion), and nickel was not detected in significant quantity in the acid digestion assay. RPDs were quite low, generally less than eight percent for most analytes, demonstrating excellent agreement. The only analyte with an RPD outside the acceptance criteria for core 31 , composite 1 was cadmium, which is not a large contributor to the waste and is near the detection limit. The only analytes with excessive RPDs for core 31 , composite 2 were cadmium and nickel. Both of these analytes have problems associated with them that make these results suspect for this test method (proximity to the detection limit for cadmium and cross-contamination from the 
crucible for nickel). Comparisons with the acid digestion results indicate that the samples were well dissolved by the acid preparation, but in some cases, and with silicon especially, the fusion dissolution was necessary to obtain reliable, quantitative results for the analyte.

\section{Core 33}

Sodium, phosphorus (probably as a soluble phosphate), and sulfur (probably as a soluble sulfate) were the most significant analytes measured by the water digestion of the core composite. Much smaller amounts of iron, chromium, and silicon were the other main analytes. RPDs were elevated for these samples (between 10 and 20 percent), but generally were within the 20 percent acceptance criteria. For analytes with results outside the acceptance criteria, no clear trend between the two composites or between cores can be established firmly, but there was some correspondence between the cores and their respective composites (i.e. there was some agreement between cores 31 and 33 composite 1 , etc.), but the connection was quite tenuous. The water digestion result for core 33, composite 1 had several analytes with high RPDs, many of which are significant contributors to the waste. These analytes are aluminum, barium, iron, manganese, bismuth, and lanthanum. For core 33 , composite 2 , only calcium and vanadium were outside the acceptance criteria. The degree of variability observed for this particular sample preparation is not unexpected. Most of these analytes probably are in a form that is not readily water soluble and, depending on the sample matrix exposure to the solution media, substantial differences may be observed.

The results from the acid digestion preparation of the core composite samples are quite similar to core 31 . They had sodium, phosphorous, sulfur, calcium, chromium, iron, manganese, bismuth, and lanthanum as major analytes, the RPDs decline significantly in comparison to the water digestion results, both in the number of analytes outside the acceptance criteria and the overall magnitude of the RPDs themselves. The RPDs are very good in general for most of the major analytes (between 5 percent and 10 percent), well within the 20 percent acceptance criteria. Analytes outside the acceptance criteria for core 33, composite 1 were antimony and selenium ( 88.5 percent and 33.0 percent, respectively). For core 33 , composite 2 , antimony and silicon were outside the acceptance criteria (31.2 percent and 48.7 percent, respectively). The results for antimony and selenium are not surprising. They are not far above their respective detection limits and neither is a substantial contributor to the waste matrix. The silicon RPD result is not unexpected, because the waste has solubility properties that make it resistant to acid digestion, making this assay marginal at best. Based on a ratio of the acid and water digestion results, most of the analytes are not water soluble, except as noted earlier; however, approximately 10 percent of the chromium is water soluble. In this case, for several analytes, some consistency is seen between composite replicates and cores. As noted earlier, core 33 sample results are, in several cases, about 25 percent or more lower than core 31 . Significant changes in analyte concentration were observed in the ICP acid digestion results as a function of depth for core 33. The results are shown in Table 5-2. The changes observed for some analytes are notable, ranging from factors of 3 and 4 for calcium, chromium, and phosphorous to orders of magnitude for manganese, bismuth, and lanthanum. These swings 
in concentration suggest the waste is heterogenous on a tank-wide scale and that the waste in the tank is layered.

Properties and major analytes for the fusion digestion results are similar to core 31 , however the differences observed between the analytical results of cores 31 and 33 become much less consistent with this group of assay results. RPDs were generally low, less than 12 percent, with most analyte results substantially less than that. Antimony, calcium, and boron had RPDs outside the acceptance criteria for core 33, composite 1. In core 33, composite 2, cobalt and nickel, which are not large contributors to the waste, had RPDs outside the acceptance level and antimony, boron, and cobalt are near their respective detection limits. Several of these analytes have problems associated with them that make these results suspect for this test method. However, the variation seen for calcium is not expected and there is no reason for its behavior. In this case, no consistency was observed between composites or cores, except for nickel in cores 31 and 33, composite 2, and the nickel results for this test method are suspect.

\subsubsection{Analytical Results--Anion Assays}

\section{Core 31 Ion Chromatography Results:}

Major anions detected are $\mathrm{NO}_{3}{ }^{-}$and $\mathrm{PO}_{4}{ }^{3}$, with smaller, but still substantial amounts of $\mathrm{F}$ and $\mathrm{SO}_{4}{ }^{-2}$. Nitrite and chloride are minor contributors to the waste. Indeed, the IC results for nitrite are considered an estimated result; however, the magnitude and range of concentration is confirmed by a spectrophotometric analysis. All RPDs for quantitated results are well within the 20 percent acceptance criteria, and generally are less than 10 percent. Comparisons of phosphorous and sulfur water-digestion ICP results with ion-chromatography results for $\mathrm{PO}_{4}{ }^{3-}$ and $\mathrm{SO}_{4}{ }^{-2}$ give good agreement (RPDs are less than 10 percent) and show that phosphorous is about 48 to 56 percent soluble (as phosphate) and sulfur is about 90 to 100 percent soluble (as sulfate). Table 5-4 illustrates the comparison between the water digestion ICP and IC results, and the relationship to the total amount of phosphorous and sulfur in the matrix. Table 5-5 presents the summary results for the IC analytes and other anions.

\section{Core 33 Ion Chromatography Results:}

Major analytes were the same as those found in core 31. RPDs for the minor analytes, F, $\mathrm{Cl}^{-}$, and $\mathrm{NO}_{2}{ }^{-}$, were much higher in composite 1 than in composite 2 , or in either of core 31 's composites, exceeding 15 percent, but within the 20 percent acceptance criteria. Core 33, composite 2 had superior RPDs, all were less than 8 percent. Comparison of the phosphorous and sulfur water-digestion ICP results with IC for $\mathrm{PO}_{4}{ }^{3-}$ and $\mathrm{SO}_{4}{ }^{-2}$ gives good 
Table 5-4. Comparison of Ion Chromatography and Water Digestion ICP Results for Selected Analytes.

\begin{tabular}{|l|c|c|c|c|c|c|c|c|c|c|}
\hline Sample ID & \multicolumn{2}{|c|}{$\begin{array}{c}\mathrm{PO}_{4}{ }^{3-} \\
\text { Concentration } \\
(\mu \mathrm{g} / \mathrm{g})\end{array}$} & $\begin{array}{c}\mathrm{PO}_{4}{ }^{3-} \\
\mathrm{RPD}\end{array}$ & $\begin{array}{c}\mathrm{SO}_{4}{ }^{-2} \\
\text { Concentration } \\
(\mu \mathrm{g} / \mathrm{g})\end{array}$ & $\begin{array}{l}\mathrm{SO}_{4}{ }^{-2} \\
\mathrm{RPD}\end{array}$ & \multicolumn{2}{|c|}{$\begin{array}{c}\mathrm{PO}_{4}{ }^{3-} \\
\text { Solubility* }\end{array}$} & \multicolumn{3}{|c|}{$\begin{array}{c}\mathrm{SO}_{4}{ }^{-2} \\
\text { Solubility* }\end{array}$} \\
\hline & $(\mathrm{IC})$ & (ICP.w) & & (C) & (ICP.w) & & (IC) & (ICP.w) & (IC) & (ICP.w) \\
\hline Core 31-C1 & 16,200 & 17,300 & 6.7 & 3,690 & 3,570 & -3.3 & 50.8 & 54.2 & 100.4 & 97.1 \\
\hline Core 31-C2 & 17,400 & 17,900 & 2.8 & 3,740 & 3,600 & -3.7 & 54.5 & 56.1 & 101.8 & 97.9 \\
\hline Core 33-C1 & 13,600 & 15,900 & 16.9 & 3,290 & 3,420 & -3.3 & 42.6 & 49.8 & 89.5 & 93.1 \\
\hline Core 33-C2 & 15,100 & 17,100 & 13.2 & 3,470 & 3,660 & -1.4 & 47.3 & 53.6 & 94.4 & 99.6 \\
\hline
\end{tabular}

*Solubility is a ratio of the IC/ICP.w result to $31,900 \mu \mathrm{g} / \mathrm{g} \mathrm{PO}_{4}{ }^{3-}$ and $3,675 \mu \mathrm{g} / \mathrm{g}$ $\mathrm{SO}_{4}{ }^{2-}$, the tank average of the converted fusion results

ICP.w $=$ Notation for ICP water digestion result

Table 5-5. Anion Results--Composite Data (water leach).

\begin{tabular}{|c|c|c|c|c|c|c|}
\hline \multirow[t]{2}{*}{ Analyte } & \multirow[t]{2}{*}{$\begin{array}{c}\text { Detection } \\
\text { limit } \\
(\mu \mathrm{g} / \mathrm{g})\end{array}$} & \multicolumn{2}{|c|}{$\begin{array}{c}\text { Core } 31 \\
(\mu \mathrm{g} / \mathrm{g})\end{array}$} & \multicolumn{2}{|c|}{$\begin{array}{l}\text { Core } 33 \\
(\mu \mathrm{g} / \mathrm{g})\end{array}$} & \multirow{2}{*}{$\begin{array}{c}\begin{array}{c}\text { Grab } \\
\text { sample } \\
(\mu \mathrm{g} / \mathrm{g})\end{array} \\
\text { Average }\end{array}$} \\
\hline & & Composite 1 & Composite 2 & Composite 1 & Composite 2 & \\
\hline $\mathrm{NO}_{3}^{\circ}$ & 100 & 44,300 & 43,800 & 36,900 & 40,100 & 30,300 \\
\hline $\mathrm{PO}_{4}{ }^{3-}$ & 100 & 16,200 & 17,400 & 13,600 & 15,100 & 8,400 \\
\hline $\mathrm{SO}_{4}^{2-}$ & 100 & 3,690 & 3,740 & 3,290 & 3,470 & 2,900 \\
\hline $\mathrm{Cl}^{-}$ & 10 & 470 & 497 & 401 & 432 & 490 \\
\hline $\bar{F}$ & 10 & 3,090 & 3,130 & 1,370 & 1,630 & 2,100 \\
\hline $\mathrm{NO}_{2}{ }^{\circ}$ & 50 & 952 & 525 & 878 & 817 & 1,320 (IC) \\
\hline TOC $^{\circ}$ & 500 & 3,490 & 3,990 & 2,000 & 3,000 & 420 \\
\hline TIC $^{\circ}$ & 500 & 650 & 824 & 823 & 950 & 670 \\
\hline Free $\mathrm{OH}^{-}$ & $\mathrm{NM}$ & NM & NM & $\mathrm{NM}$ & NM & 3,000 \\
\hline $\mathrm{pH}^{*}$ & NA & 10.18 & 9.93 & 10.05 & 9.77 & 11.65 \\
\hline $\begin{array}{l}\mathrm{NH}_{3} / \\
\mathrm{NH}_{4}^{+}\end{array}$ & 4,500 & $<\mathrm{DL}$ & $<\mathrm{DL}$ & $<\mathrm{DL}$ & $<\mathrm{DL}$ & 400 \\
\hline
\end{tabular}


Table 5-5. Anion Results--Composite Data (water leach).

\begin{tabular}{|l|c|c|c|r|r|c|}
\hline Analyte & $\begin{array}{c}\text { Detection } \\
\text { limit } \\
(\mu \mathrm{g} / \mathrm{g})\end{array}$ & \multicolumn{2}{|c|}{$\begin{array}{c}\text { Core 31 } \\
(\mu \mathrm{g} / \mathrm{g})\end{array}$} & \multicolumn{2}{|c|}{$\begin{array}{c}\text { Core 33 } \\
(\mu \mathrm{g} / \mathrm{g})\end{array}$} & $\begin{array}{c}\text { Grab } \\
\text { sample } \\
(\mu \mathrm{g} / \mathrm{g})\end{array}$ \\
\hline & & Composite 1 & Composite 2 & Composite 1 & Composite 2 & Average \\
\hline $\begin{array}{l}\text { Direct } \\
\text { Cyanide }^{1}\end{array}$ & 5 & $<\mathrm{DL}$ & $<\mathrm{DL}$ & $<\mathrm{DL}$ & $<\mathrm{DL}$ & $<\mathrm{DL}$ \\
\hline
\end{tabular}

$\mathrm{NM}=$ No measurement $\quad \mathrm{NA}=$ Not applicable

$<\mathrm{DL}=$ Below detection limit

Note: All IC results are obtained from a water leach preparation and are reported on a wet basis.

Direct Cyanide, $\mathrm{NH}_{3} / \mathrm{NH}_{4}{ }^{+}, \mathrm{pH}$, total organic carbon (TOC), and total inorganic carbon (TIC) are not IC analyses, but are grouped with the anions for convenience. $\mathrm{NO}_{2} \cdot$ results reported are from spectrophotometric methods. At the 222-S Laboratory, TOC and TIC assays were done on water digested samples. When 325 performed segment level assays for these analytes, they did them on direct solid samples.

agreement, however, phosphorous shows a higher, but still acceptable variability, with RPDs of 13 to 17 percent, than sulfur as $\mathrm{SO}_{4}^{-2}$, with RPDs of -1.4 to -3.3 . Phosphorous is approximately 50 percent soluble as phosphate, whereas sulfur as sulfate is almost entirely soluble. Table 5-4 illustrates the comparison between the water digestion ICP and IC results, and the relationship to the total amount of phosphorous and sulfur in the bulk tank matrix. Note the ICP results are converted to phosphate and sulfate for comparison.

Core 31 and 33 Additional Anion Results:

- Nitrite, as determined from spectrophotometry, has good agreement between composites and acceptable RPDs. Concentrations between cores are observed to agree well also.

- The $\mathrm{pH}$ of the solids is measured using a water dilution of a solids aliquot. The $\mathrm{pH}$ of the mixture is measured and reported. The results for tank 241-T-111 waste from this method are consistent, ranging from 9.8 to 10.5 , but are of limited utility because the sample preparation and assays only marginally represent the conditions in the tank. The $\mathrm{pH}$ as determined from a grab sample taken in 1994 (see Appendix C) is between 11.5 and 11.8, and is considered more reliable and more representative of the waste tank conditions. 
- Ammonia/ammonium results for the solids were all below the detection limit for the method. This is not unexpected. Over time, ammonia probably was slowly released to the vapor space and removed by passive ventilation. A small amount of this analyte remains in the liquids, but the liquid is being removed.

- Total organic carbon (TOC) results indicate a substantial difference between cores 31 and 33 (core 31 's TOC concentration is 33 percent higher than core 33's), but results for the individual core composites are very consistent. Core 31 composite 1 and composite 2 RPDs are negligible. Core 33, composite 1 and composite 2 RPDs are low, well within the acceptance criteria, but noticeable.

- Total inorganic carbon (TIC) results were a factor of three to four times lower than the TOC results and were near the detection limit. Therefore, they are not considered wholly reliable, however the results did provide acceptable reproducibility. TOC results are also considered questionable, especially when contrasted with the calorimetry results from segment-level data from both cores (segments 1-3 particularly), and a fumace oxidation value of 4.1 weight percent (dry), for core 33, segment 2 (Baldwin 1994).

The gradient observed in the ICP results remains noticeable for the anions, especially for TOC and $F^{-}$, but the overall effect is much less pronounced. This effect is expected and ascribed to the nature of the assay (i.e. water digestion assay results for soluble analytes in a mostly water matrix are expected to be reasonably homogeneous). TOC and F probably are present in insoluble forms, and thus are not as amenable to detection and are more likely to exhibit variations in concentration.

\subsection{ANALYTICAL RESULTS--RADIOCHEMISTRY}

\subsubsection{Radiochemistry Assays--General Comments}

Analyses appear to be consistent. Total beta measurements calculated using ${ }^{60} \mathrm{Co}$ detector efficiencies are largely in agreement with the sum of the major beta emitters, ${ }^{90} \mathrm{SrY}$ and ${ }^{137} \mathrm{Cs}$ [i.e. beta emission values must be adjusted by 1.42 and 1.51 , respectively, the ratio of ${ }^{90} \mathrm{SrY}$ and ${ }^{137} \mathrm{Cs}$ to ${ }^{60} \mathrm{Co}$ detector efficiencies (Winters 1991)]. However, the total alpha values show only marginal agreement with the sum of the neptunium, plutonium, and americium/curium values. This behavior was attributed to the low activity of the samples and a recently discovered equipment problem. Technicians at the 222-S Laboratory identified an electronic problem with their alpha detection system involving the degree of discrimination between beta and alpha emissions. These two conditions are thought to contribute to the observed high bias of the total alpha measurements. Detection and quantitation of ${ }^{137} \mathrm{Cs}$ and most other radionuclides was based on the presumed ability of the fusion sample preparation to completely dissolve the waste. Water preparation samples were 
done on selected analytes as directed in the test plan. GEA measurements show good agreement with alpha energy analysis for ${ }^{241} \mathrm{Am}$. GEA analytical values are not corrected to account for decay, however most of the radionuclides present are long-lived enough and low enough in concentration so that any correction at this point would be modest.

\subsubsection{Gamma Energy Analysis Results}

The GEA data from the replicate samples of the core composites for cores 31 and 33 prepared by caustic fusion agree reasonably well with each other (RPDs generally were within 10 percent). However, there is a discernable gradient between cores 31 and 33 for ${ }^{137} \mathrm{Cs}$. This follows the general pattern observed for several other analytes, but in this case ${ }^{241} \mathrm{Am}$ does not appear to be affected. Review of the segment-level homogenization data for core 33 indicates that in general, the ${ }^{137} \mathrm{Cs}$ content is lowest in the bottom segments and highest in the upper segments, increasing in concentration from bottom to top. This behavior indicates that the ${ }^{137} \mathrm{Cs}$ is concentrated in the upper portion of the tank. However, the overall radionuclide content of tank $241-\mathrm{T}-111$ is extremely low. The ${ }^{154} \mathrm{Eu}$ and ${ }^{155} \mathrm{Eu}$ content is above the detection limits only in segments 1 and 3, suggesting that these isotopes are in the upper portions of cores 31 and 33. However because of the limited segment level data, too many conclusions should not be drawn from these observations. Grab sample results for ${ }^{137} \mathrm{Cs}$ is more than a factor of four lower than those obtained from fusion assays, indicating that the radionuclides, ${ }^{137} \mathrm{Cs}$ in particular, are very insoluble. Agreement between the same top and bottom aliquots in the homogenization check samples prepared by acid digestion were very good for analytes above the detection limit, with RPDs generally less than 10 percent and usually much less than that, indicating sample homogeneity and/or relatively complete dissolution.

\subsubsection{Total Alpha Analysis and Uranium Assay}

Total alpha, plutonium, ${ }^{237} \mathrm{~Np},{ }^{241} \mathrm{Am}$, and ${ }^{244} \mathrm{Cm}$ analyses were performed on the fusion prepared samples of the core composites and selected assays were done on the liquid grab sample. Total alpha measurements were also performed on the homogenization check samples from segments $1,3,5,7$, and 9 from core 33 . The total alpha activity was determined by drying a small aliquot of prepared sample on a counting plate and assayed with an alpha proportional counter. The plutonium and americium fractions were separated by solvent extraction or ion exchange and similarly counted.

The plutonium analyses are reported as total alpha ${ }^{239 / 240} \mathrm{Pu}$. The process blank was two to three orders of magnitude lower that the samples, indicating little contamination occurred during sample preparation. The total alpha concentration frequently tends to be somewhat lower than the sum of the individual alpha emitters. The difference is probably caused by absorption by the salt residue on the counting mounts. However, in this case, substantial differences are observed between the total alpha measurements and the sum of the individual alpha emitters. The total alpha emissions are believed to be lower than the measurement 
indicates because of a bias caused by beta emissions confounding the detector. The activity of the samples is so low that the offset used to discriminate between alpha and beta plateaus was not sufficient to provide accurate readings. Furthermore, analyses from PNL indicate a potential low bias for plutonium in the samples. The degree of discrepancy ranges from over a factor of two to nearly a factor of five. This degree of disagreement warrants further attention. Isotope content was determined by thermal-ionization mass spectroscopy. Little variation in the plutonium isotopic composition was observed between cores. Total alpha measurements vary widely as a function of depth, but exhibit a general decreasing trend the deeper the samples are in the waste. Segment 5 was an exception to this trend. The anomalous total alpha reading in segment 5 may be indicative of a process upset or change in waste management operations, such as the 5-6 waste that Anderson (1990) notes was co-mingled with the $2 \mathrm{C}$ waste in 1952.

Uranium measurements were obtained from laser fluorimetry of the fusion-prepared sample from the two core composites and their replicates. The assays show good agreement between duplicates for each individual core composite, but there is not good agreement between the core 31 and 33 replicates. Additionally, the gradient observed in the other assays is not evident here. Furthermore, analyses from PNL indicate a potential low bias for uranium in the samples. The degree of discrepancy is nearly a factor of two for corresponding samples, and thus warrants further study. Differences in concentration as a function of the water content of the samples is not deemed to be an issue because the additional characterization work done in resolving the energetics question indicates that little or no water is lost while the samples are stored. Time lag is also not considered relevant, since the difference in time between the two assays was small in comparison to the half-lifes involved. No general trend of the uranium concentration as a function of depth can be established because there is no segment-level data for this analyte.

\subsubsection{Total Beta}

Total beta, ${ }^{90} \mathrm{Sr}$, and ${ }^{99} \mathrm{Tc}$ analyses were performed on the liquid grab sample and fusion prepared samples of the core composites. The total beta activity was determined by drying a small aliquot of prepared sample on a planchet and assaying it with a beta proportional counter. The ${ }^{90} \mathrm{Sr}$ fraction was separated by solvent extraction or ion exchange and counted. The ${ }^{99} \mathrm{Tc}$ fraction was separated similarly, but assayed using liquid scintillation. There generally is good agreement (RPDs were less than 10 percent) between duplicates, and preparation blank beta activities are orders of magnitude lower than the levels found in the samples, again indicating little contamination from preparation in the hot cell. Most of the beta activity in the tank samples is from ${ }^{90} \mathrm{SrY}$ and ${ }^{137} \mathrm{Cs}$. There is also a trace of ${ }^{99} \mathrm{Tc}$. The ${ }^{90} \mathrm{SrY},{ }^{99} \mathrm{Tc}$, and ${ }^{137} \mathrm{Cs}$ data are consistent between the fusion core composites and their replicates, but in this case the gradient between cores 31 and 33 is observed for ${ }^{90} \mathrm{Sr}$ and ${ }^{137} \mathrm{Cs}$. There is no data to determine if ${ }^{90} \mathrm{Sr}$ content varies as a function of depth. 
Tables 5-6, 5-7, 5-8, and 5-9 show the average radionuclide concentrations found in the core composite samples. Table 5-10 shows average fission product concentration and total alpha concentrations as a function of depth.

Table 5-6. Consolidated Radionuclide Concentration Results for 241-T-111.

\begin{tabular}{|r|c|c|c|c|c|}
\hline $\begin{array}{c}\text { Analyte } \\
\text { method }\end{array}$ & Detection limit & $\begin{array}{c}\text { Core 31, } \\
\text { composite 1 }\end{array}$ & $\begin{array}{c}\text { Core 31, } \\
\text { composite 2 }\end{array}$ & $\begin{array}{c}\text { Core 33, } \\
\text { composite 1 }\end{array}$ & $\begin{array}{c}\text { Core 33, } \\
\text { composite 2 }\end{array}$ \\
\hline GEA analytes & $(\mu \mathrm{Ci} / \mathrm{g})$ & $(\mu \mathrm{Ci} / \mathrm{g})$ & $(\mu \mathrm{Ci} / \mathrm{g})$ & $(\mu \mathrm{Ci} / \mathrm{g})$ & $(\mu \mathrm{Ci} / \mathrm{g})$ \\
\hline${ }^{60} \mathrm{Co} . \mathrm{f}$ & $(\mathrm{DL}=4.07 \mathrm{E}-04)$ & $<\mathrm{DL}$ & $<\mathrm{DL}$ & $<\mathrm{DL}$ & $<\mathrm{DL}$ \\
\hline${ }^{137} \mathrm{Cs} . \mathrm{f}$ & $(\mathrm{DL}=3.70 \mathrm{E}-04)$ & 0.211 & 0.237 & 0.114 & 0.103 \\
\hline${ }^{154} \mathrm{Eu} . \mathrm{f}$ & $(\mathrm{DL}=1.20 \mathrm{E}-03)$ & 0.00108 & 0.00324 & $<\mathrm{DL}$ & $<\mathrm{DL}$ \\
\hline${ }^{155} \mathrm{Eu} . \mathrm{f}$ & $(\mathrm{DL}=5.95 \mathrm{E}-04)$ & $<\mathrm{DL}$ & $<\mathrm{DL}$ & 0.00307 & $<\mathrm{DL}$ \\
\hline${ }^{241} \mathrm{Am} . \mathrm{f}$ & $(\mathrm{DL}=1.14 \mathrm{E}-04)$ & 0.0459 & 0.0409 & 0.0387 & 0.0443 \\
\hline Beta emitters & & & & & \\
\hline Total beta.f & $(\mathrm{DL}=9.35 \mathrm{E}-02)$ & 20.6 & 21.5 & 9.59 & 8.83 \\
\hline${ }^{\text {Total beta }}$ & $\mathrm{Calculated}$ & 20.7 & 21.5 & 10.5 & 9.9 \\
\hline${ }^{33} \mathrm{H} . \mathrm{w}$ & $(\mathrm{DL}=3.15 \mathrm{E}-04)$ & $<\mathrm{DL}$ & $<\mathrm{DL}$ & $<\mathrm{DL}$ & $<\mathrm{DL}$ \\
\hline${ }^{14} \mathrm{C} . \mathrm{w}$ & $(\mathrm{DL}=2.25 \mathrm{E}-04)$ & $<\mathrm{DL}$ & $<\mathrm{DL}$ & $<\mathrm{DL}$ & $<\mathrm{DL}$ \\
\hline${ }^{59} \mathrm{Ni.a}$ & $(\mathrm{DL}=4.00 \mathrm{E}-06)$ & $8.3 \mathrm{E}-05$ & $3.33 \mathrm{E}-05$ & $4.44 \mathrm{E}-05$ & $4.07 \mathrm{E}-05$ \\
\hline${ }^{63} \mathrm{Ni.a}$ & $(\mathrm{DL}=4.00 \mathrm{E}-06)$ & 0.0093 & 0.00358 & 0.00545 & 0.00459 \\
\hline${ }^{79} \mathrm{Se} . \mathrm{f}$ & $(\mathrm{DL}=1.40 \mathrm{E}-04)$ & $<\mathrm{DL}$ & $<\mathrm{DL}$ & $<\mathrm{DL}$ & $<\mathrm{DL}$ \\
\hline${ }^{90} \mathrm{Sr} . f$ & $(\mathrm{DL}=2.15 \mathrm{E}-03)$ & 7.16 & 7.43 & 3.65 & 3.43 \\
\hline${ }^{99} \mathrm{Tc} . \mathrm{f}$ & $(\mathrm{DL}=4.60 \mathrm{E}-03)$ & 0.00514 & 0.00473 & 0.0114 & 0.0104 \\
\hline${ }^{129} \mathrm{I} . f$ & $(\mathrm{DL}=6.40 \mathrm{E}-03)$ & $<\mathrm{DL}$ & $<\mathrm{DL}$ & $<\mathrm{DL}$ & $<\mathrm{DL}$ \\
\hline
\end{tabular}


Table 5-6. Consolidated Radionuclide Concentration Results for 241-T-111.

\begin{tabular}{|c|c|c|c|c|c|}
\hline $\begin{array}{l}\text { Analyte } \\
\text { method }\end{array}$ & Detection limit & $\begin{array}{c}\text { Core } 31, \\
\text { composite } 1\end{array}$ & $\begin{array}{c}\text { Core } 31, \\
\text { composite } 2\end{array}$ & $\begin{array}{c}\text { Core } 33, \\
\text { composite } 1\end{array}$ & $\begin{array}{c}\text { Core } 33, \\
\text { composite } 2\end{array}$ \\
\hline \multicolumn{6}{|l|}{$\begin{array}{l}\text { Uranium and } \\
\text { transuranics }\end{array}$} \\
\hline $\begin{array}{r}\text { Total U.f } \\
(\mu \mathrm{g} / \mathrm{g}) \\
(325)\end{array}$ & $(\mathrm{DL}=3.40 \mathrm{E}-02)$ & $\begin{array}{l}2,180 \\
4,000\end{array}$ & $\begin{array}{l}3,880 \\
5,200\end{array}$ & $\begin{array}{l}3,180 \\
4,500\end{array}$ & $\begin{array}{l}1,950 \\
3,500\end{array}$ \\
\hline Total alpha.f & $(\mathrm{DL}=7.01 \mathrm{E}-03)$ & 0.358 & 0.359 & 0.377 & 0.379 \\
\hline Total alpha & Calculated (Range) & $0.179-0.669$ & $0.179-0.608$ & $0.172-0.357$ & $0.195-0.416$ \\
\hline${ }^{237} \mathrm{Np.f}$ & $(\mathrm{DL}=3.40 \mathrm{E}-02)$ & $<\mathrm{DL}$ & $<\mathrm{DL}$ & $<\mathrm{DL}$ & $<\mathrm{DL}$ \\
\hline${ }^{238} \mathrm{Pu} . \mathrm{f}$ & $(\mathrm{DL}=1.00 \mathrm{E}-02)$ & $<\mathrm{DL}$ & $<\mathrm{DL}$ & $<\mathrm{DL}$ & $<\mathrm{DL}$ \\
\hline $\begin{array}{r}{ }^{239 / 240} \mathrm{Pu} . \mathrm{f} \\
\text { (325) }\end{array}$ & $(\mathrm{DL}=3.50 \mathrm{E}-03)$ & $\begin{array}{l}0.138 \\
0.628\end{array}$ & $\begin{array}{l}0.136 \\
0.565\end{array}$ & $\begin{array}{l}0.134 \\
0.319\end{array}$ & $\begin{array}{l}0.147 \\
0.368\end{array}$ \\
\hline${ }^{241}$ Am.f & $(\mathrm{DL}=3.00 \mathrm{E}-03)$ & 0.0414 & 0.0431 & 0.0382 & 0.0478 \\
\hline${ }^{244} \mathrm{Cm} . \mathrm{f}$ & $\begin{array}{l}\text { (DL }=\text { Not } \\
\text { Reported) }\end{array}$ & $<\mathrm{DL}$ & $<\mathrm{DL}$ & $<\mathrm{DL}$ & $<\mathrm{DL}$ \\
\hline
\end{tabular}

$<\mathrm{DL}=$ below detection limit

Analyte. $\mathrm{f}=$ fusion digestion

Analyte. $\mathrm{a}=$ acid digestion

Analyte. $w=$ water digestion

Total beta calculated determined by:

$1.42(2)\left({ }^{90} \mathrm{Sr}\right)+1.51\left({ }^{137} \mathrm{Cs}\right)$

Total alpha calculated determined by:

${ }^{239 / 240} \mathrm{Pu}+{ }^{241} \mathrm{Am}$

Table 5-7. Core Composite Uranium.

\begin{tabular}{|l|c|c|c|c|}
\hline Core number & $\begin{array}{c}\mathrm{U}_{\mathrm{FL}}(222-\mathrm{S}) \\
(\mu \mathrm{g} / \mathrm{g})\end{array}$ & $\begin{array}{c}\mathrm{U}_{\mathrm{FL}}(325) \\
(\mu \mathrm{g} / \mathrm{g})\end{array}$ & $\begin{array}{c}{ }^{238} \mathrm{U} \\
\text { mass percent }\end{array}$ & $\begin{array}{c}{ }^{235} \mathrm{U} \\
\text { mass percent }\end{array}$ \\
\hline Core 31, composite 1 & 2,180 & 4,000 & 99.3074 & 0.6755 \\
\hline Core 31, composite 2 & 3,880 & 5,200 & 99.3098 & 0.6761 \\
\hline Core 33, composite 1 & 3,180 & 4,500 & 99.3125 & 0.6761 \\
\hline Core 33, composite 2 & 1,950 & 3,500 & 99.3161 & 0.6717 \\
\hline
\end{tabular}

$\mathrm{FL}=$ Uranium measurement by laser fluorimetry.

222-S Assay date: $4 / 92$

325 Assay date: 9/92 
Table 5-8. Plutonium Concentration and Isotopic Distribution.

\begin{tabular}{|l|c|c|c|c|c|c|c|}
\hline Core number & $\begin{array}{c}\text { Total } \mathrm{Pu} \\
\alpha(222-\mathrm{S}) \\
(\mu \mathrm{Ci} / \mathrm{g})\end{array}$ & $\begin{array}{c}\text { Total } \mathrm{Pu} \\
\alpha(325) \\
(\mu \mathrm{Ci} / \mathrm{g})\end{array}$ & $\begin{array}{c}{ }^{238} \mathrm{Pu} \\
\text { mass } \\
\text { percent }\end{array}$ & $\begin{array}{c}{ }^{239} \mathrm{Pu} \\
\text { mass } \\
\text { percent }\end{array}$ & $\begin{array}{c}{ }^{240} \mathrm{Pu} \\
\text { mass } \\
\text { percent }\end{array}$ & $\begin{array}{c}{ }^{441} \mathrm{Pu} \\
\text { mass } \\
\text { percent }\end{array}$ & $\begin{array}{c}{ }^{242} \mathrm{Pu} \\
\text { mass } \\
\text { percent }\end{array}$ \\
\hline Core 31, C1 & 0.138 & 0.628 & 0.005 & 96.7199 & 3.2109 & 0.0352 & 0.0151 \\
\hline Core 31, C2 & 0.136 & 0.565 & 0.0105 & 96.6351 & 3.2834 & 0.0496 & 0.0215 \\
\hline Core 33, C1 & 0.134 & 0.319 & 0.004 & 96.7540 & 3.1046 & 0.1071 & 0.0683 \\
\hline Core 33, C2 & 0.147 & 0.368 & 0.0105 & 96.5499 & 3.3436 & 0.0621 & 0.0337 \\
\hline
\end{tabular}

222-S Assay date: 4/92 C1 = Composite 1

325 Assay date: $9 / 92 \quad \mathrm{C} 2=$ Composite 2

Table 5-9. Radiochemical Analyses of Grab Sample.

\begin{tabular}{|l|l|l|}
\hline \multicolumn{1}{|c|}{ Analyte } & $\begin{array}{c}\text { Average concentration } \\
(\mu \mathrm{Ci} / \mathrm{mL})\end{array}$ & $\begin{array}{c}\text { Average concentration } \\
(\mu \mathrm{Ci} / \mathrm{g})^{1}\end{array}$ \\
\hline${ }^{90} \mathrm{Sr}$ & 0.001 & 0.001 \\
\hline${ }^{137} \mathrm{Cs}$ & 0.090 & 0.087 \\
\hline${ }^{239 / 240} \mathrm{Pu}$ & $6.83 \mathrm{E}-05$ & $6.58 \mathrm{E}-05$ \\
\hline Total Alpha & 0.0024 & 0.0023 \\
\hline Total Beta & 0.233 & 0.224 \\
\hline
\end{tabular}

${ }^{1}$ Density of $1.036 \mathrm{~g} / \mathrm{mL}$ used for conversion.

Table 5-10. Tank 241-T-111 Core 33 Radionuclide Analyte Trending as a Function of Depth

(Acid prep on segments).

\begin{tabular}{|c|c|c|c|c|c|c|}
\hline Segment & $\begin{array}{c}{ }^{137} \mathrm{Cs} \\
(\mu \mathrm{Ci} / \mathrm{g})\end{array}$ & $\begin{array}{c}{ }^{154} \mathrm{Eu} \\
(\mu \mathrm{Ci} / \mathrm{g})\end{array}$ & $\begin{array}{c}{ }^{155} \mathrm{Eu} \\
(\mu \mathrm{Ci} / \mathrm{g})\end{array}$ & $\begin{array}{c}{ }^{241} \mathrm{Am} \\
(\mu \mathrm{Ci} / \mathrm{g})\end{array}$ & $\begin{array}{c}{ }^{60} \mathrm{Co} \\
(\mu \mathrm{Ci} / \mathrm{g})\end{array}$ & $\begin{array}{c}\text { Total alpha } \\
(\mu \mathrm{Ci} / \mathrm{g})\end{array}$ \\
\hline 1 & 0.403 & 0.021 & 0.027 & 0.138 & 0.006 & 0.649 \\
\hline 3 & 0.140 & $9.05 \mathrm{E}-04$ & 0.002 & 0.014 & 0.0005 & 0.166 \\
\hline 5 & 0.088 & $<\mathrm{DL}$ & $<\mathrm{DL}$ & 0.020 & $<\mathrm{DL}$ & 0.527 \\
\hline 7 & 0.023 & $<\mathrm{DL}$ & $<\mathrm{DL}$ & 0.014 & 0.0005 & 0.350 \\
\hline 9 & 0.013 & $<\mathrm{DL}$ & $<\mathrm{DL}$ & 0.050 & $<\mathrm{DL}$ & 0.262 \\
\hline
\end{tabular}




\subsection{TANK 241-T-111 CORE SAMPLE RHEOLOGICAL/ PHYSICAL MEASUREMENTS}

Physical and rheological assays consume substantial quantities of material. Tables 5-11 and 5-12 provide a breakdown of the total amount of sample available at the outset of the analylical effort. Figure 5-1 shows the location where the core samples were taken and the waste depth. Measurements of physical characteristics such as shear strength, viscosity, particle size, and settling properties were taken. These measurements are necessary for the design and fabrication of retrieval, pretreatment, and final waste disposal systems. Rheological assays were performed on samples from core 31 , segments 2,4 , and 8 . Particle size measurements were done on each segment of core 31 . The data from segment 4 is not considered valid for these assays because it had dried before the measurements were taken. The drying process irreversibly changed the physical properties of the sample under investigation, and thus the sample is not considered representative. Therefore, the results from most of these assays will not be presented. However, in some cases it is useful to compare and contrast the results from the "representative" samples with the samples that dried.

Table 5-11. Tank 241-T-111 Core Sample Description Summary.

\begin{tabular}{|c|c|c|c|c|c|l|}
\hline $\begin{array}{c}\text { Core } \\
\text { number }\end{array}$ & $\begin{array}{c}\text { Segment } \\
\text { number }\end{array}$ & $\begin{array}{c}\text { Solid sample } \\
\text { mass }(\mathrm{g})\end{array}$ & $\begin{array}{c}\text { Liquid sample } \\
\text { mass }(\mathrm{g})\end{array}$ & $\begin{array}{c}\text { Approximate } \\
\text { solid sample } \\
\text { volume }(\mathrm{mL})\end{array}$ & $\begin{array}{c}\text { Liquid } \\
\text { sample } \\
\text { volume } \\
(\mathrm{mL})\end{array}$ & $\begin{array}{c}\text { Approximate } \\
\text { solid sample } \\
\text { length }\end{array}$ \\
\hline 31 & 1 & 18.74 & 45.26 & Not Recorded & $\sim 50$ & Not Resolved \\
\hline 31 & 2 & 178.68 & 4.12 & 150 & NA & 15 in. $(38 \mathrm{~cm})$ \\
\hline 31 & 3 & 162.2 & NA & 177 & NA & 18 in. $(46 \mathrm{~cm})$ \\
\hline 31 & 4 & 153.47 & NA & 148 & NA & 15 in. $(38 \mathrm{~cm})$ \\
\hline 31 & 5 & 190.94 & NA & 187 & NA & 19 in. $(48 \mathrm{~cm})$ \\
\hline 31 & 6 & 0 & NA & 0 & NA & No Sample \\
\hline 31 & 7 & 186.44 & NA & 177 & NA & 18 in. $(46 \mathrm{~cm})$ \\
\hline 31 & 8 & 186.44 & NA & 187 & NA & 19 in. $(48 \mathrm{~cm})$ \\
\hline 31 & 9 & 203.08 & NA & 187 & NA & 19 in. $(48 \mathrm{~cm})$ \\
\hline
\end{tabular}


Figure 5-1. Current Condition of Tank 241-T-111.
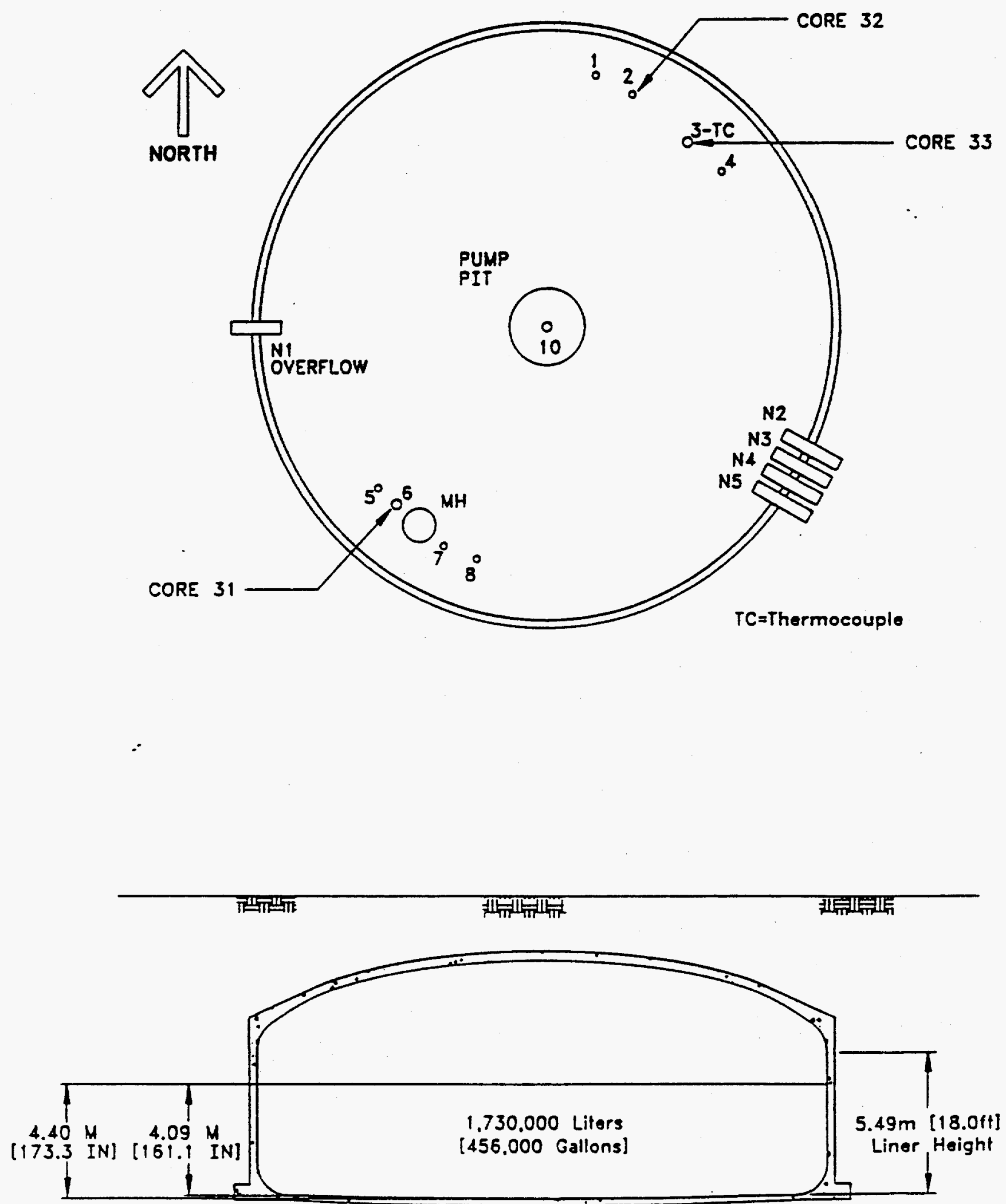
Table 5-12. Tank 241-T-111 Core Sample Description Summary.

\begin{tabular}{|c|c|c|c|c|c|c|}
\hline $\begin{array}{c}\text { Core } \\
\text { number }\end{array}$ & $\begin{array}{c}\text { Segment } \\
\text { number }\end{array}$ & $\begin{array}{c}\text { Solid } \\
\text { sample } \\
\text { mass }(\mathrm{g})\end{array}$ & $\begin{array}{c}\text { Liquid } \\
\text { sample } \\
\text { mass }(\mathrm{g})\end{array}$ & $\begin{array}{c}\text { Approximate } \\
\text { solid sample } \\
\text { volume }(\mathrm{mL})\end{array}$ & $\begin{array}{c}\text { Liquid sample } \\
\text { volume }(\mathrm{mL})\end{array}$ & $\begin{array}{c}\text { Approximate } \\
\text { solid sample } \\
\text { length }\end{array}$ \\
\hline 33 & 1 & 159.16 & 0 & 137 & NA & 14 in. $(36 \mathrm{~cm})$ \\
\hline 33 & 2 & 209.59 & 0 & 187 & NA & 19 in. $(48 \mathrm{~cm})$ \\
\hline 33 & 3 & 167.9 & 0 & 163 & NA & 16 in. $(41 \mathrm{~cm})$ \\
\hline 33 & 4 & 182.05 & 0 & 167 & NA & 16 in. $(41 \mathrm{~cm})$ \\
\hline 33 & 5 & 174.3 & 0 & 167 & NA & 17 in. $(43 \mathrm{~cm})$ \\
\hline 33 & 6 & 217.37 & 0 & 187 & NA & 19 in. $(48 \mathrm{~cm})$ \\
\hline 33 & 7 & 196.91 & 0 & 187 & NA & 19 in. $(48 \mathrm{~cm})$ \\
\hline 33 & 8 & 199.8 & 0 & 187 & NA & 19 in. $(48 \mathrm{~cm})$ \\
\hline 33 & 9 & 191.01 & 0 & 187 & NA & 19 in. $(48 \mathrm{~cm})$ \\
\hline
\end{tabular}

\subsubsection{Shear Strength}

The shear strength of the waste from tank 241-T-111 was measured on the unhomogenized segment samples from core 31 (segments 2,4 , and 8 ). The shear strength measurements were made at ambient temperatures using a shear vane connected to a viscometer and rotated at $0.3 \mathrm{rpm}$. Shear strength $\left(\tau_{\mathrm{s}}\right)$ is a semiquantitative measurement of the force required to move the sample. Because shear strength is dependent on sample handling, the measurement was taken without any sample homogenization. Small aliquots from the segments 2,4 , and 8 from core 31 were taken and assayed. The aliquots were transferred to a sample jar and allowed to settle for several weeks so that they could recover from the disturbance of sampling and extrusion. The extended delay between sample and analysis was permitted because it is believed that the longer the sample sits undisturbed, the closer it will resemble its original condition; therefore, the shear measurement is likely to be more representative. The shear stress $\left(S_{\tau}\right)$ of the sample was recorded as a function of time and the shear strength was calculated using Equation 1.

$$
\tau_{s}=\frac{[\% \tau / 100] * S_{\tau} * 4.9 E+05}{\frac{\pi * H_{v} * D_{v}^{2}}{2}+\frac{\pi * D_{v}^{3}}{6}}
$$


where:

$$
\begin{aligned}
& \% \tau / 100=\begin{array}{l}
\text { The ratio of the total torque to the maximum torque of the } \\
\text { viscometer head, measured as a percentage of the full scale on the } \\
\text { plot of the shear stress versus time diagram (dimensionless) }
\end{array} \\
& \mathrm{S}_{\tau}=\text { Instrument reading proportional to the torque (dimensionless) } \\
& 4.9 \mathrm{E}+05=\text { maximum torque of the viscometer head (dyne } \mathrm{cm}) \\
& \mathrm{H}_{\mathrm{v}}=\text { shear vane height }(0.635 \mathrm{~cm}) \\
& \mathrm{D}_{\mathrm{v}} \quad=\text { shear vane diameter }(0.635 \mathrm{~cm})
\end{aligned}
$$

The shear strength for segments 2 and 8 were found to range $5,000 \pm 2,300$ dynes $/ \mathrm{cm}^{2}$. Segment 4 is not reported because of sample drying. Although relatively low, the shear stress of the material exceeded the baseline value for the measurement system $\left(200\right.$ dynes $/ \mathrm{cm}^{2}$ ). Therefore, the values are considered to be valid and representative. Some additional drying of the sample may have occurred during the settling time, causing the shear stress to be higher than expected.

\subsubsection{Shear Stress and Viscosity as Functions of Shear Rate}

Shear stress measurements, as functions of shear rate, were performed on the as-received, 1 to 1 and 3 to 1 water to sample dilution of the sample at ambient hot-cell temperatures [ranging from 27 to $34^{\circ} \mathrm{C}\left(81\right.$ to $\left.93{ }^{\circ} \mathrm{F}\right)$ ] and at $95^{\circ} \mathrm{C}\left(203{ }^{\circ} \mathrm{F}\right)$. Drying the as-received sample at $95^{\circ} \mathrm{C}$ posed difficulties in measurement; therefore no results of the rheograms for the samples run under those conditions are presented. In addition, the results from segment 4 are not presented because the drying that occurred compromised the sample properties, as discussed previously.

A rheogram for a material with a yield stress has two sections. The first section is a straight line beginning at the origin and climbing up the ordinate. This portion of the rheogram records the material as it acts like a solid or gel. When sufficient force is applied to the material to make it yield, the rheogram breaks sharply to the right; recording the material's behavior as a fluid. The point on the rheogram at which the sample's behavior transfers from a solid or gel to a fluid is the yield point or yield stress. This minimum shear stress must be exceeded to initiate fluid behavior. The tank wastes demonstrate both elastic and plastic behavior, depending on the amount of shear acting on them. The samples are elastic under low shear conditions (less than $50 \mathrm{~s}^{-1}$ ), and plastic under high shear conditions (greater than $300 \mathrm{~s}^{-1}$ ).

Viscosity measurements as a function of shear rate for the 1 to 1 diluted samples had viscosities near the limits of detection of the system $(2 \mathrm{cP})$ for over the broad range of shear 
rates; however, some qualitative and quantitative information was obtained from the measurement trials. Even though the measurements were at the limits of detection, the qualitative and quantitative behavior was consistent and reproducible. Viscosity was observed to increase slightly, then decrease with increasing shear rates. The 1 to 1 dilution of the segment 2 and segment 8 samples exhibited tendencies toward yield-pseudoplastic behavior. In fact, the general behavior exhibited by the wastes is best described by a yield-pseudoplastic model, however the system was not modeled and empirical model parameters were not determined because the system was at the detection limits. No other measurements of the viscosity as a function of shear rate were made on the 1 to 1 dilution samples at $95^{\circ} \mathrm{C}\left(203^{\circ} \mathrm{F}\right)$ or the 3 to 1 dilution samples.

Figures 5-2 to 5-6 are general illustrations of the rheograms. They are not to scale and do not fully capture all of the nuances and detail that is contained in each measurement trial. However, when coupled with the description underneath each diagram, much insight can be obtained about the flow properties of the waste. If more detailed rheological information is required, the data package should be consulted. Note that in the figures, Point $A$ is where the sample begins to register movement. Point $B$ represents the behavior of the sample at the maximum shear rate of the viscometer. 
Figure 5-2. Shear Stress as a Function of Shear Rate: Direct Sample.

Shear Stress (Pa)
$A=$ Yield Stress

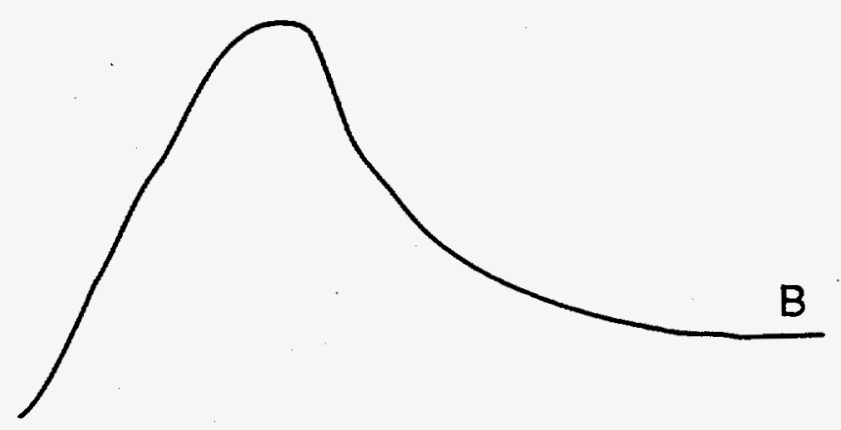

Elastic Behavior

Region $\left(<50 \mathrm{~s}^{-1}\right)$
Plastic Behavior

Region ( $>300 \mathrm{~s}^{-1}$ )

Shear Rate $\left(\mathrm{s}^{-1}\right)$

Shear Stress as a Function of Shear Rate: Direct Sample.

\begin{tabular}{|l|c|c|c|l|c|}
\hline $\begin{array}{l}\text { Sample: } \\
\text { core 31 }\end{array}$ & $\begin{array}{l}\text { Sample } \\
\text { number }\end{array}$ & $\begin{array}{c}\text { Temperature } \\
\left({ }^{\circ} \mathrm{C}\right)\end{array}$ & $\begin{array}{c}\text { Point A shear } \\
\text { stress range } \\
(\mathrm{Pa})\end{array}$ & $\begin{array}{c}\text { Qualitative behavior } \\
\text { of rheogram }\end{array}$ & $\begin{array}{c}\text { Point B } \\
\text { shear stress } \\
(\mathrm{Pa})\end{array}$ \\
\hline Segment 2 & 80701 & 34 & $88-220$ & $\begin{array}{l}\text { Wide variation at low } \\
\text { shear, converging to a } \\
\text { single value at high shear. }\end{array}$ & 165 \\
\hline Segment 2 & 80703 & 33 & $200-680$ & Same & 70 \\
\hline Segment 8 & 123201 & 33 & $36-108$ & Same & 77 \\
\hline Segment 8 & 123202 & 33 & $0-108$ & Same & 50 \\
\hline
\end{tabular}


Figure 5-3. Shear Stress as a Function of Shear Rate: 1 to 1 Dilution, Water to Sample.

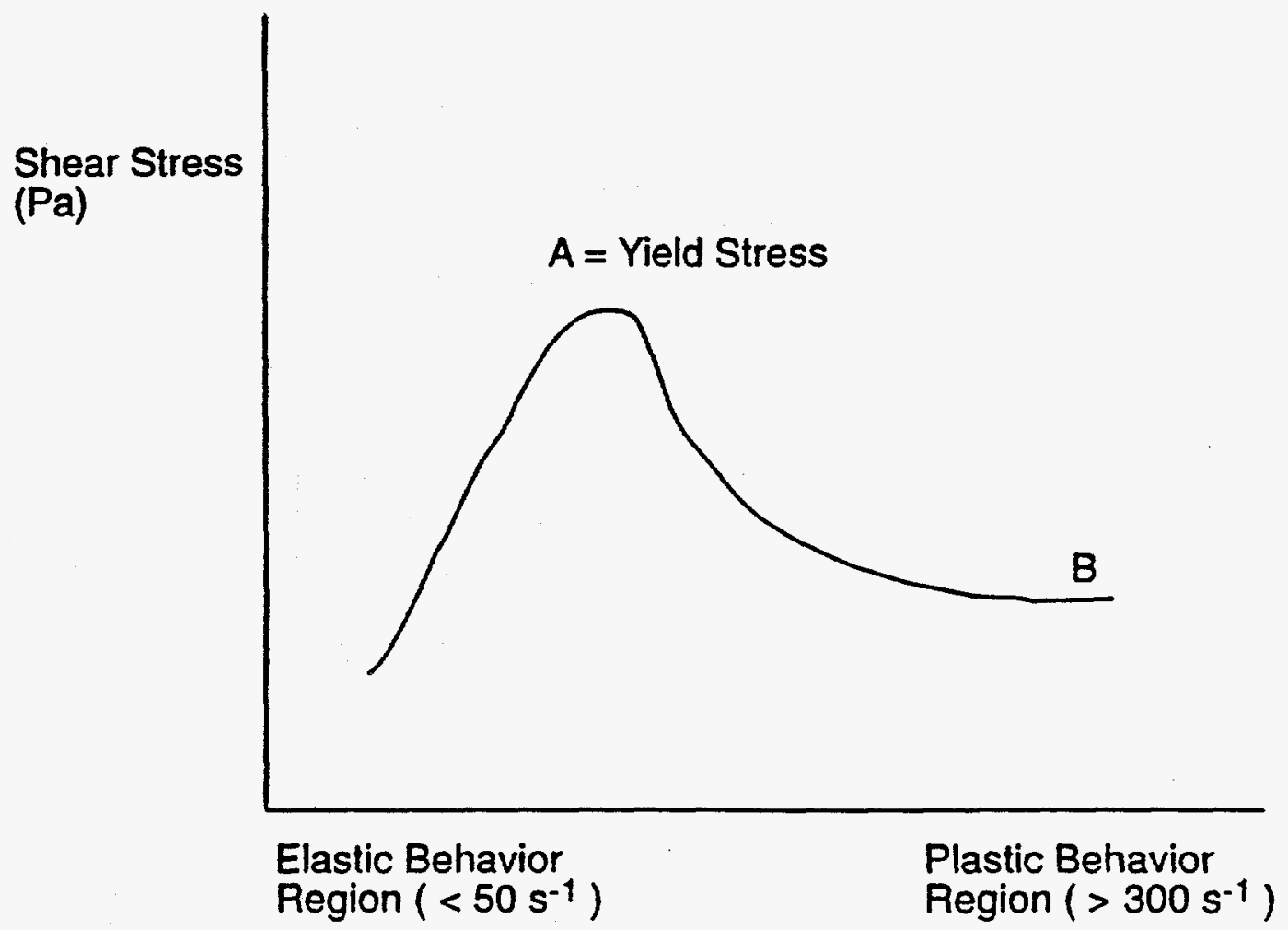

Shear Rate $\left(s^{-1}\right)$

Shear Stress as a Function of Shear Rate: 1 to 1 Dilution, Water to Sample.

\begin{tabular}{|l|c|c|c|l|c|}
\hline $\begin{array}{l}\text { Sample: } \\
\text { core 31 }\end{array}$ & $\begin{array}{c}\text { Sample } \\
\text { number }\end{array}$ & $\begin{array}{c}\text { Temperature } \\
\left({ }^{\circ} \mathrm{C}\right)\end{array}$ & $\begin{array}{c}\text { Point A } \\
\text { shear stress } \\
\text { range (Pa) }\end{array}$ & $\begin{array}{c}\text { Qualitative behavior } \\
\text { of rheogram }\end{array}$ & $\begin{array}{c}\text { Point B } \\
\text { shear } \\
\text { stress (Pa) }\end{array}$ \\
\hline Segment 2 & 1 & 27 & $0.6-4.2$ & $\begin{array}{l}\text { Wide variation at low shear, } \\
\text { converging to a single value at } \\
\text { high shear. }\end{array}$ & 2.4 \\
\hline Segment 2 & 2 & 27 & 1.2 & Linear & 2.8 \\
\hline Segment 2 & 3 & 95 & $1.0-7.0$ & $\begin{array}{l}\text { Wide variation at low shear, } \\
\text { converging to a single value at } \\
\text { high shear. }\end{array}$ & 2.0 \\
\hline Segment 2 & 4 & 95 & $0.7-1.1$ & Linear & $1.2-1.4$ \\
\hline Segment 2 & 5 & 95 & $1.0-2.4$ & Linear & 2.2 \\
\hline
\end{tabular}


Figure 5-4. Shear Stress as a Function of Shear Rate: 1 to 1 Dilution, Water to Sample.

Shear Stress

(Pa)

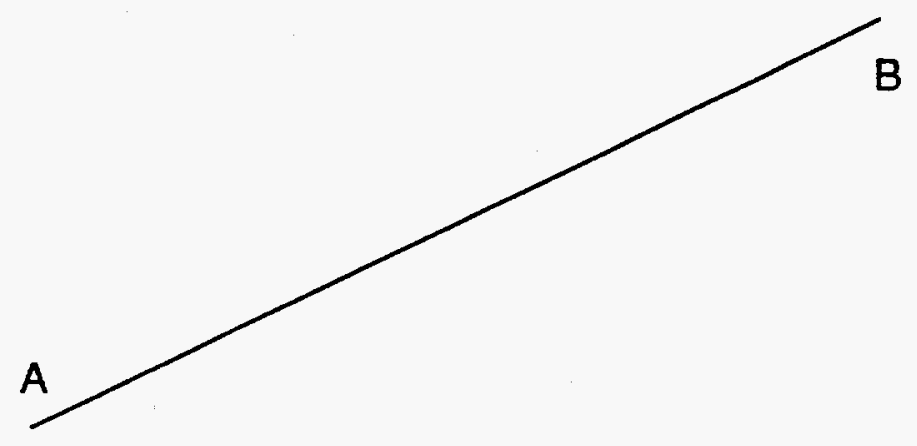

0

Shear Rate $\left(s^{-1}\right)$

Shear Stress as a Function of Shear Rate: 1 to 1 Dilution, Water to Sample

\begin{tabular}{|l|c|c|c|l|c|}
\hline $\begin{array}{c}\text { Sample: } \\
\text { core 31 }\end{array}$ & $\begin{array}{c}\text { Sample } \\
\text { number }\end{array}$ & $\begin{array}{c}\text { Temperature } \\
\left({ }^{\circ} \mathrm{C}\right)\end{array}$ & $\begin{array}{c}\text { Point A shear } \\
\text { stress range } \\
(\mathrm{Pa})\end{array}$ & $\begin{array}{c}\text { Qualitative behavior } \\
\text { of rheogram }\end{array}$ & $\begin{array}{c}\text { Point B } \\
\text { shear stress } \\
(\mathrm{Pa})\end{array}$ \\
\hline Segment 8 & 1 & 27 & $0.4-0.6$ & Linear & 2.8 \\
\hline Segment 8 & 2 & 27 & 0.6 & Linear & 2.8 \\
\hline Segment 8 & 3 & 95 & 0.6 & Linear & 2.0 \\
\hline Segment 8 & 4 & 95 & $2.0-5.0$ & Erratic, non-linear & 2.0 \\
\hline Segment 8 & 5 & 95 & 0.2 & Linear & $0.7-0.9$ \\
\hline
\end{tabular}


Figure 5-5. Shear Stress as a Function of Shear Rate: 3 to 1 Dilution, Water to Sample.

Shear Stress

(Pa)

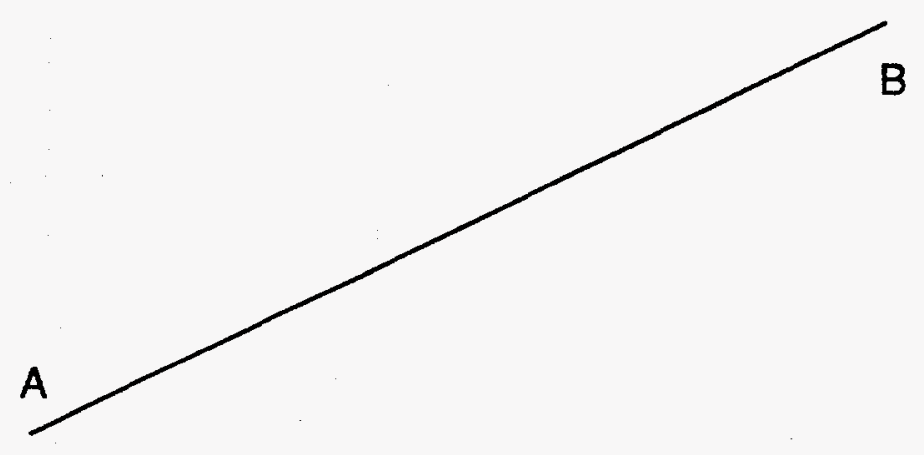

0

Shear Rate $\left(\mathrm{s}^{-1}\right)$

Shear Stress as a Function of Shear Rate: 3 to 1 Dilution, Water to Sample.

\begin{tabular}{|l|c|c|c|l|c|}
\hline $\begin{array}{c}\text { Sample: } \\
\text { core 31 }\end{array}$ & $\begin{array}{c}\text { Sample } \\
\text { number }\end{array}$ & $\begin{array}{c}\text { Temperature } \\
\left({ }^{\circ} \mathrm{C}\right)\end{array}$ & $\begin{array}{c}\text { Point A shear } \\
\text { stress range } \\
(\mathrm{Pa})\end{array}$ & $\begin{array}{l}\text { Qualitative behavior } \\
\text { of rheogram }\end{array}$ & $\begin{array}{c}\text { Point B } \\
\text { shear stress } \\
(\mathrm{Pa})\end{array}$ \\
\hline Segment 2 & 1 & 27 & $0.05-0.25$ & Linear & $0.75-1.1$ \\
\hline Segment 2 & 2 & 27 & $0.2-0.35$ & Linear & 1.2 \\
\hline Segment 2 & 3 & 95 & 0.2 & Linear & 0.8 \\
\hline Segment 2 & 4 & 95 & 0.3 & Linear & 1.0 \\
\hline Segment 8 & 3 & 95 & Not defined & Erratic, non-linear & 0.4 \\
\hline Segment 8 & 4 & 95 & 0.3 & Linear & 1.0 \\
\hline
\end{tabular}


Figure 5-6. Viscosity as a Function of Time: 1 to 1 Dilution, Water to Sample.

\section{Viscosity} (mPa)

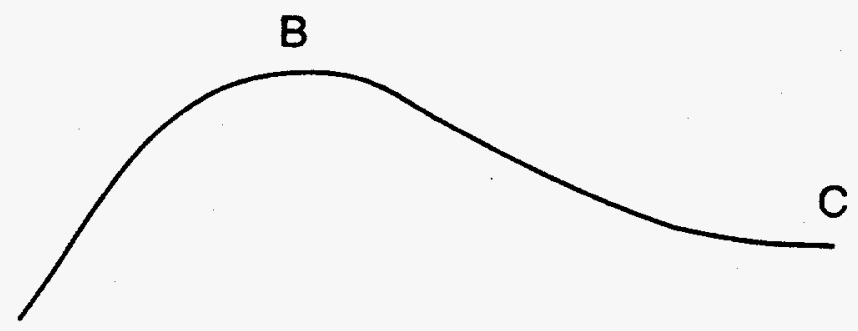

A

0

Time (seconds)

Viscosity as a Function of Shear Rate: 1 to 1 Dilution, Water to Sample

\begin{tabular}{|l|c|c|c|l|c|c|}
\hline $\begin{array}{c}\text { Sample: } \\
\text { core 31 }\end{array}$ & $\begin{array}{c}\text { Sample } \\
\text { number }\end{array}$ & $\begin{array}{c}\text { Temperature } \\
\left({ }^{\circ} \mathrm{C}\right)\end{array}$ & $\begin{array}{c}\text { Point A } \\
\text { viscosity } \\
(\mathrm{mPa})\end{array}$ & $\begin{array}{l}\text { Qualitative description } \\
\text { of rheogram }\end{array}$ & $\begin{array}{c}\text { Point B } \\
\text { viscosity } \\
(\mathrm{mPa})\end{array}$ & $\begin{array}{c}\text { Point C } \\
\text { viscosity } \\
(\mathrm{mPa})\end{array}$ \\
\hline Segment 2 & 1 & 30 & 0.65 & $\begin{array}{l}\text { Rises, levels off, then } \\
\text { gradually declines }\end{array}$ & $\begin{array}{c}1.8- \\
2.0\end{array}$ & $1.5-1.7$ \\
\hline Segment 2 & 2 & 30 & 0.56 & Slightly sinusoidal & 0.6 & 0.6 \\
\hline Segment 2 & 3 & 30 & 0.80 & $\begin{array}{l}\text { Rises, levels off, then } \\
\text { gradually declines }\end{array}$ & 1.0 & 0.9 \\
\hline Segment 8 & 3 & 30 & 0.75 & $\begin{array}{l}\text { Flattened exponential } \\
\text { growth and decay curve }\end{array}$ & 1.0 & 0.75 \\
\hline Segment 8 & 4 & 30 & 0.85 & $\begin{array}{l}\text { Flattened exponential } \\
\text { growth and decay curve }\end{array}$ & 0.95 & 0.9 \\
\hline
\end{tabular}




\subsubsection{Particle Size Measurement}

Particle size is analyzed by placing a small amount of sample in a dispersant, which is the liquid used to disperse and suspend the particles from the solid sample. Samples from each segment of core 31 were prepared and assayed. The prepared sample was placed in a particle size analyzer. The apparatus measures particle size by passing a thin beam of laser light through the dispersant. The diameter of a particle in the dispersant can be determined by the amount of light that it blocks as it passes through the beam. The dimension measured by this method is the value across the short diameter of the particle. This means that if a particle is oblong, the machine estimates the shortest length across the particle. The term "diameter" throughout this text will be used to describe any linear profile of any shape.

An important consideration involving the analysis of particle size is the dispersant used. The primary concern involved with the dispersant is that it may dissolve the particle. Any particles existing in the tank that are soluble in the dispersant will dissolve or decrease in size during the analysis. Depending on the dispersant, the particle size analysis may not represent the true particle size distribution in the tank. In the case of tank 241-T-111, water was used as the dispersing medium. If a true particle size distribution is required, the mother liquor, or drainable liquid of the tank should be used if possible because the tank particulates are already in equilibrium with the tank's mother liquor. The insolubility of the waste matrix suggests that the particle size data acquired should be acceptable.

The mean particle size in the number distribution runs in a narrow range from 0.93 to 1.23 microns in diameter for tank 241-T-111 waste samples. Table 5-13 presents the summary results of the measurements. 
Table 5-13. Core 31 Particle Size Distribution by

Number.

\begin{tabular}{|r|c|c|c|}
\hline Segment & $\begin{array}{c}\text { Mean } \\
(\mu \mathrm{m})\end{array}$ & $\begin{array}{c}\text { Standard } \\
\text { deviation }\end{array}$ & $\begin{array}{c}\text { Median } \\
(\mu \mathrm{m})\end{array}$ \\
\hline 1 & 1.23 & 0.89 & 0.94 \\
\hline 2 & 1.13 & 0.80 & 0.88 \\
\hline 3 & 1.17 & 1.00 & 0.91 \\
\hline 4 & 0.93 & 0.60 & 0.80 \\
\hline 5 & 0.95 & 0.63 & 0.81 \\
\hline 6 & - & - & - \\
\hline 7 & 0.97 & 0.60 & 0.83 \\
\hline 8 & 1.02 & 0.85 & 0.82 \\
\hline 9 & 1.02 & 0.83 & 0.83 \\
\hline
\end{tabular}

Table 5-14 presents the summary results of the volume distribution measurements. Assuming that the density of the solid material within the tank is constant, the volume distribution is also the best estimation of the mass particle size distribution of the tank.

Table 5-14. Core 31 Particle Size Distribution by Volume.

\begin{tabular}{|c|c|c|c|}
\hline Segment & $\begin{array}{c}\text { Mean } \\
(\mu \mathrm{m})\end{array}$ & $\begin{array}{c}\text { Standard } \\
\text { deviation }\end{array}$ & $\begin{array}{c}\text { Median } \\
(\mu \mathrm{m})\end{array}$ \\
\hline 1 & 28.56 & 35.92 & 5.81 \\
\hline 2 & 14.91 & 20.76 & 4.79 \\
\hline 3 & 64.99 & 46.19 & 58.69 \\
\hline 4 & 24.87 & 34.15 & 5.63 \\
\hline 5 & 37.87 & 47.91 & 12.31 \\
\hline 6 & - & - & - \\
\hline 7 & 7.95 & 11.88 & 4.02 \\
\hline 8 & 24.72 & 28.18 & 10.02 \\
\hline 9 & 59.69 & 49.04 & 58.97 \\
\hline
\end{tabular}

The number density graph is plotted over the acquisition range of the device (from 0.5 to 150 microns). The numbers of particles in each size range, shown as a percentage of the whole, are graphed against their respective size ranges to form a distribution curve. The figures show that the modes for particle size range between the origin and 2.0 microns. In 
fact, over 80 percent of the measured particles fit within this narrow band. As with the number distribution, the volume distribution is represented by a probability volume density graph. The average particle size in the volume distribution is considerably larger than in the number distribution. The particle size in the volume distribution ranges over the full scale of the device, 0.0 microns to 150 microns in diameter, between the eight segments (core 31 segment 6 was empty, but the nomenclature for the other samples held). The analyzer calculates particle volume as the cube of the diameter.

In core 31 , approximately 70 percent of particle measurements for segments $1,2,4,5,7$, and 8 fall into the range between 0.0 and 24.0 microns, and tend to be dispersed towards the smaller particle sizes. Segments 3 and 9 were exceptions to this rule. They had a distribution over the broad spectrum of particle sizes, with the particles generally much larger and more widely scattered over the 0.0 to 150.0 micron range and a slight tendency towards the smaller end of the scale. In segment 3,23 percent of the particles were less than 24 microns. In segment 9,40 percent of the particles were less than 24 microns.

The disparity between the segment measurements possibly indicates a difference in waste type, or perhaps a transitional layer between two waste types that individually are physically similar, but when commingled, may precipitate larger particulate materials. In segments 1 , $2,4,5,7$, and 8 , over 60 percent of the particles in the sample have a diameter of less than 24.0 microns. In segments 3 and 9 , over 50 percent of the particles have a diameter of greater than 24.0 microns. In the retrieval and subsequent treatment of the tank wastes, it may be desirable to design pumping or filtration systems for the tank particulate. Therefore, the volume distribution of the particles should not be neglected (i.e., particles with diameters of over 20 microns should be considered in these designs). In addition, variation in particle size distribution is believed to have an impact on analytical precision, especially with small sample sizes, and thus, should be considered when evaluating analytical results. Plots of the probability number and volume density for each core are presented as Figures 5-7a to 5-14b.

\subsubsection{Settling Behavior of As-Received and Diluted Samples}

This section analyzes the settling behavior and physical properties of the grab samples and the as-received 1 to 1 and 3 to 1 water to sample dilutions. The physical properties reported here include settling rates and volume percent for settled solids and weight percent and volume percent for centrifuged solids. The experimental procedures used to take these measurements were reported previously (McKinney et. al 1993). The physical properties of the grab samples are reported in Table 5-15. The properties for core 31 samples are summarized in Table 5-16. 
Figure 5-7a. Core 31, Segment 1, Particle Size: Number Density.

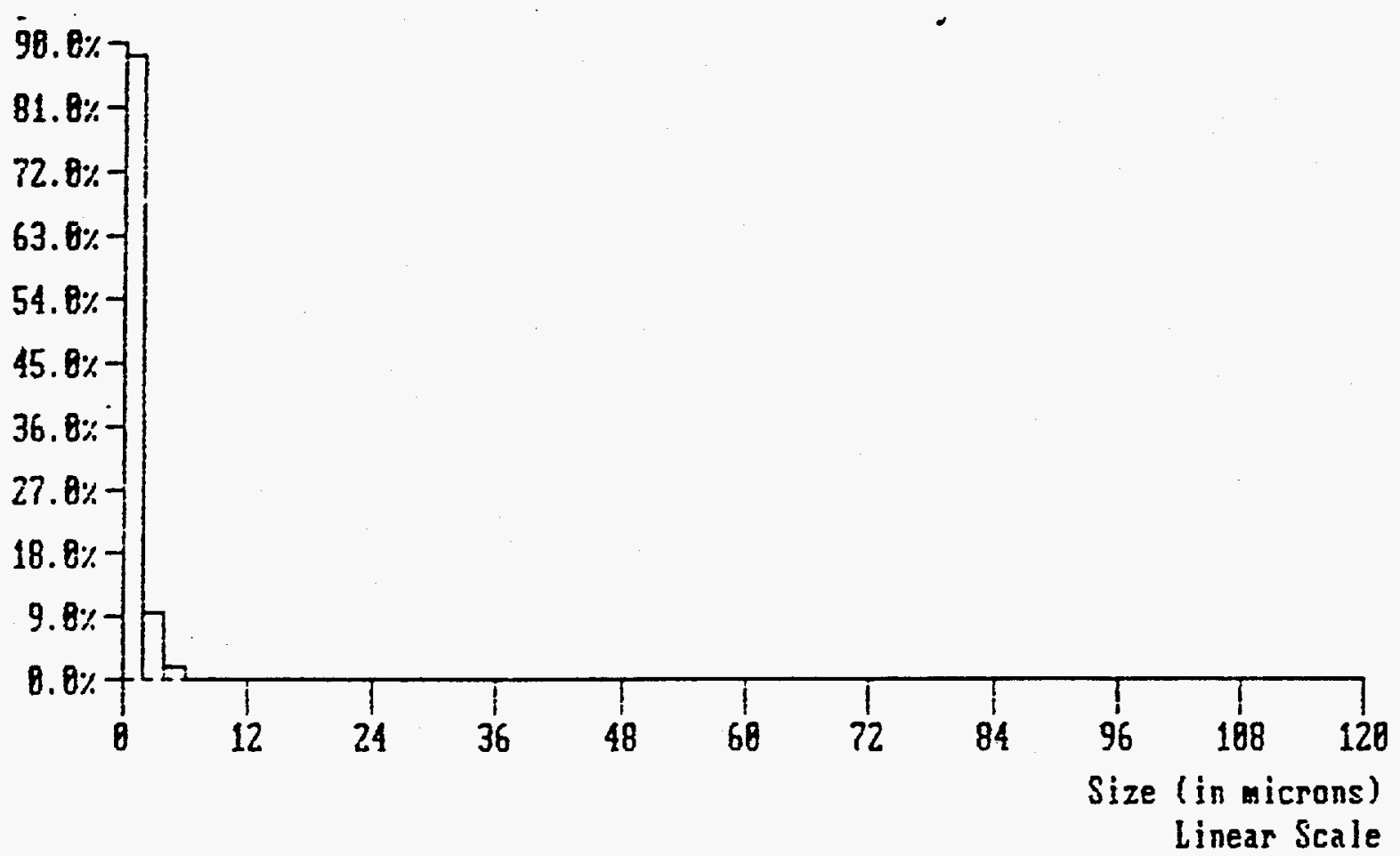

Figure 5-7b. Core 31, Segment 1, Particle Size: Volume Density. $25.8 \% 7$

$22.5 \%-1$

$28.8 \%$
$17.5 \%$
$15.8 \%$
$12.5 \%$

$10.8 \%-7$

$3.5 \%$

$\begin{aligned} & 5.8 \% \\ & 2.5 \% \\ & 8.8 \%\end{aligned}-1$

$8.8 \%$

12

48

72

84096

Size (in wicrons)

Linear Scale 
Figure 5-8a. Core 31, Segment 2, Particle Size: Number Density.

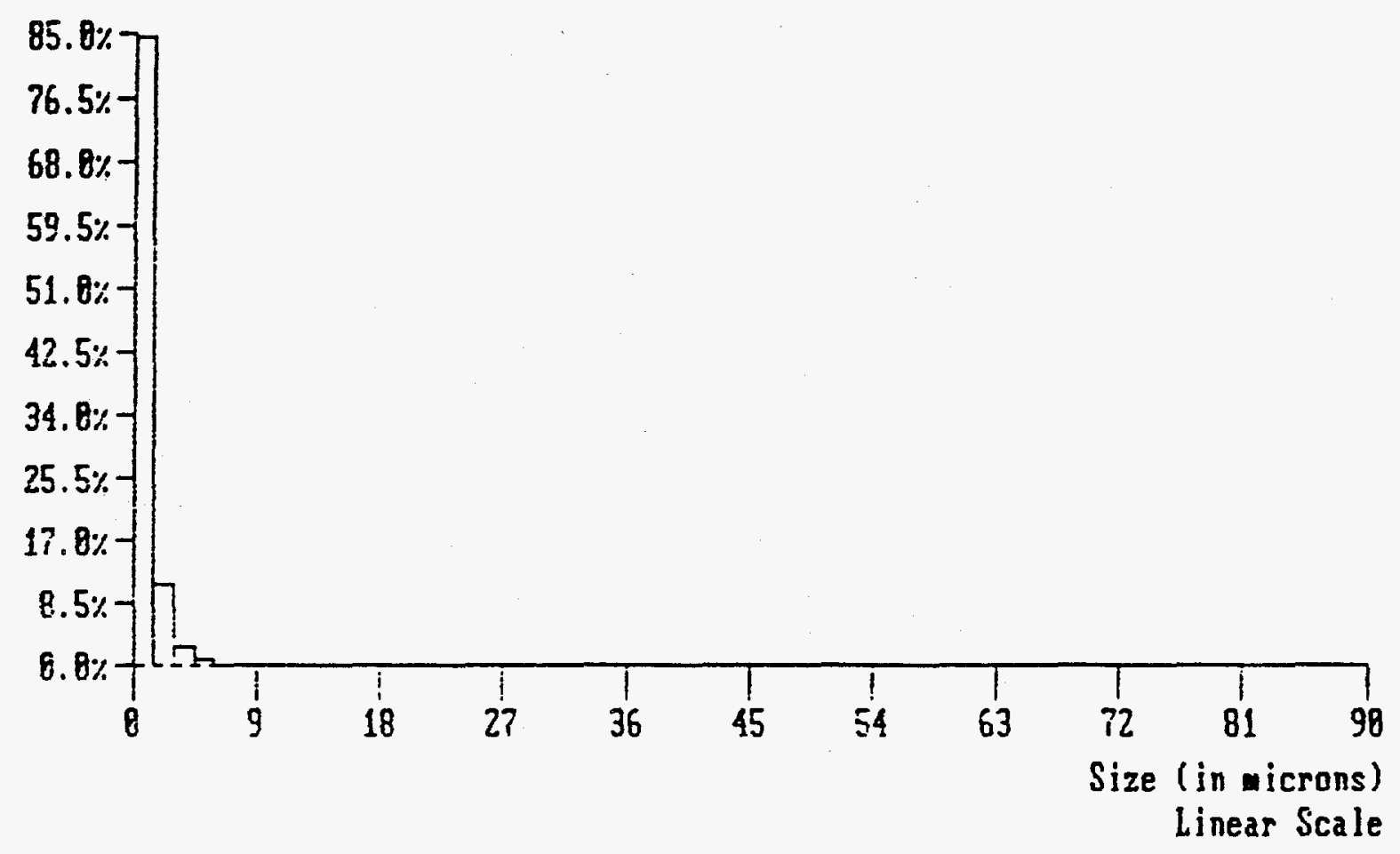

Figure 5-8b. Core 31, Segment 2, Particle Size: Volume Density.

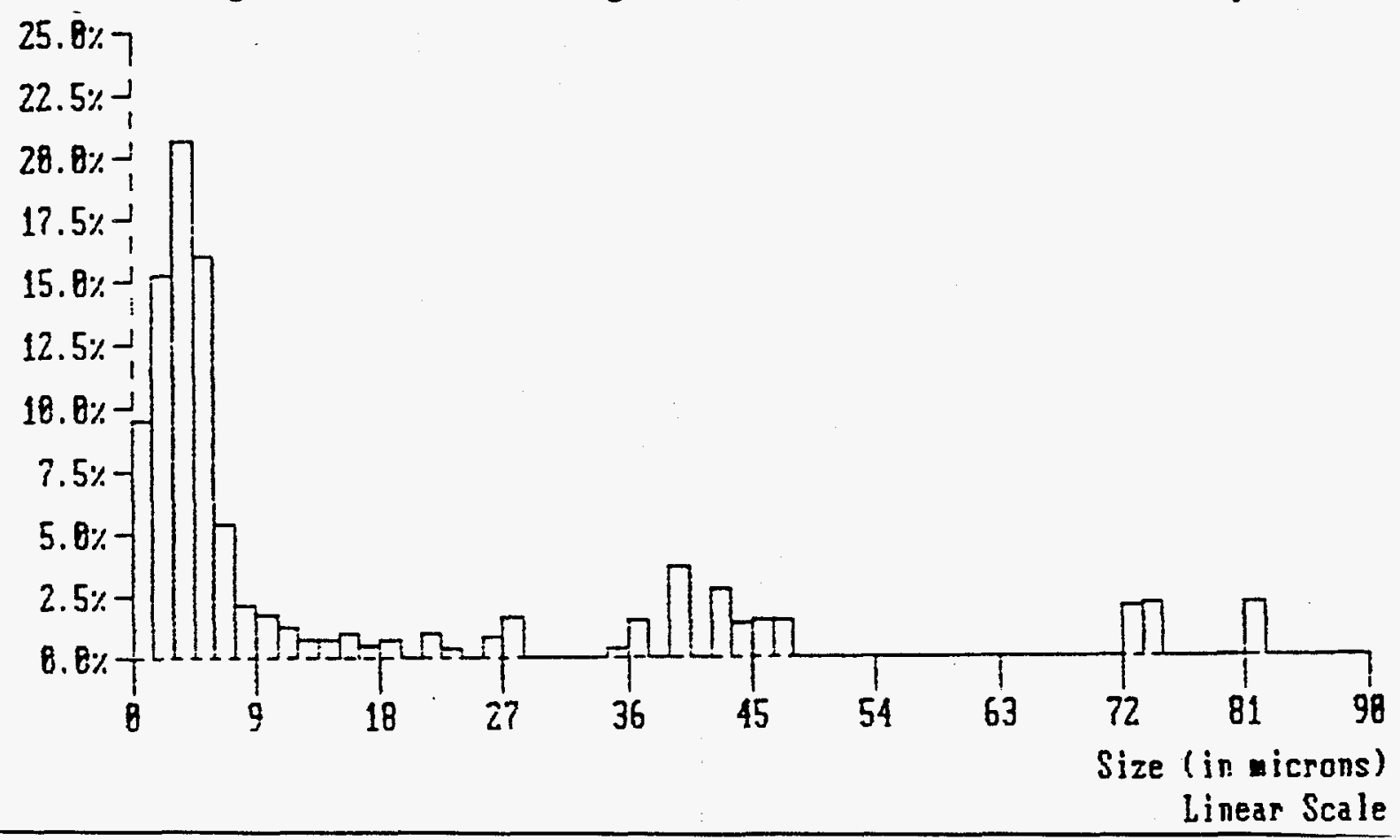


Figure 5-9a. Core 31, Segment 3, Particle Size: Number Density.

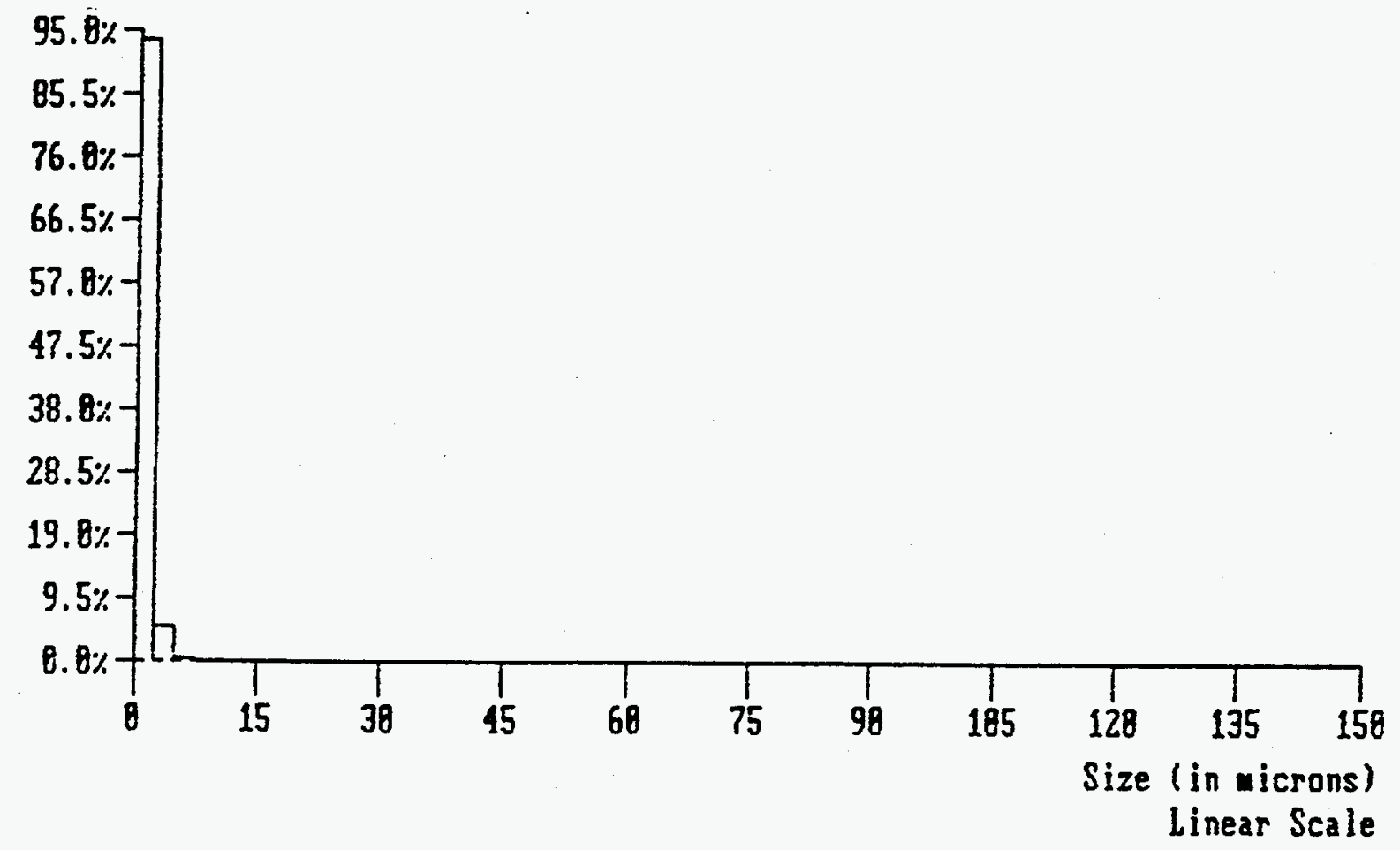

Figure 5-9b. Core 31, Segment 3, Particle Size: Volume Density.

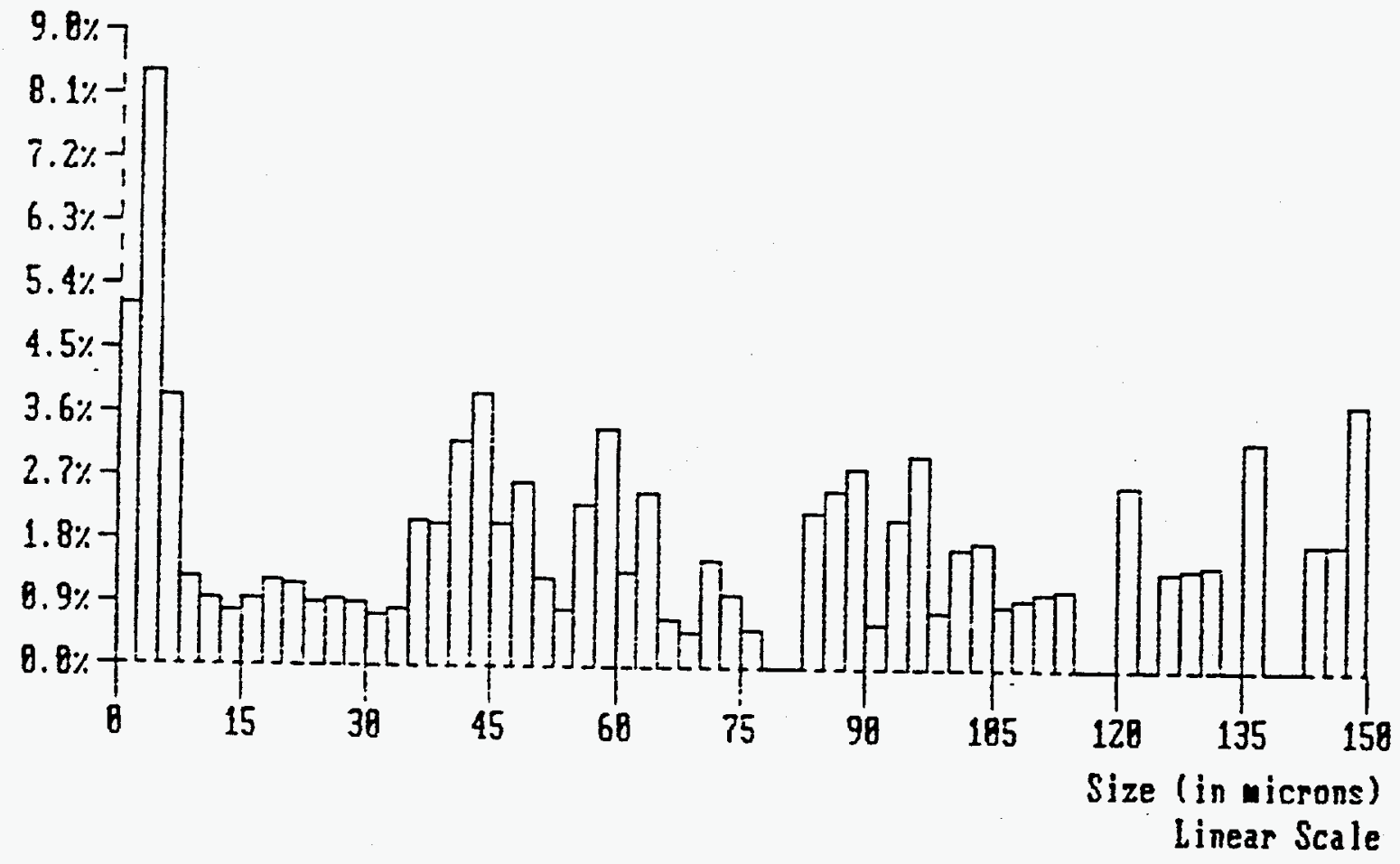


Figure 5-10a. Core 31, Segment 4, Particle Size: Number Density.

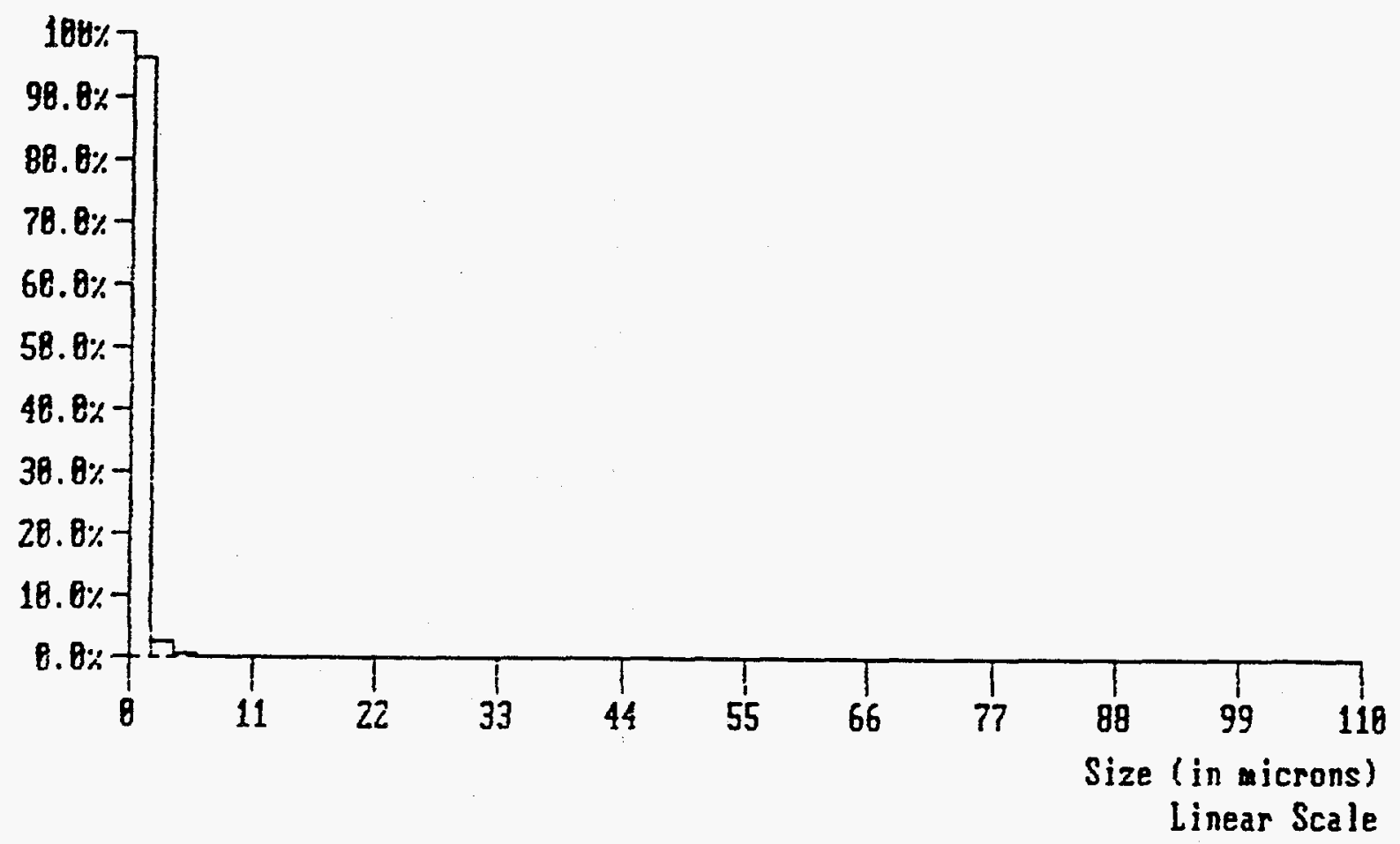

Figure 5-10b. Core 31, Segment 4, Particle Size: Volume Density.

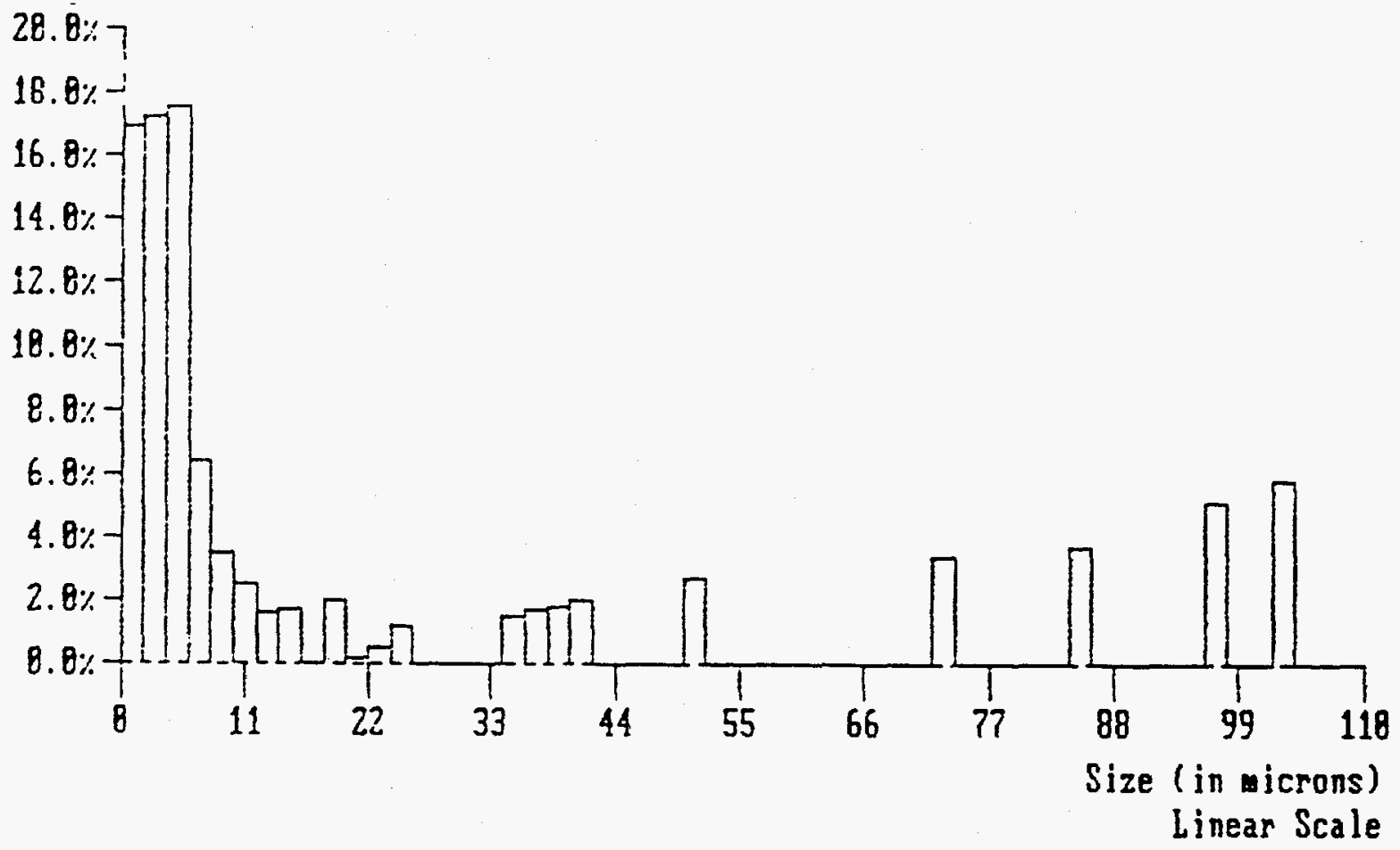


Figure 5-11a. Core 31, Segment 5, Particle Size: Number Density.

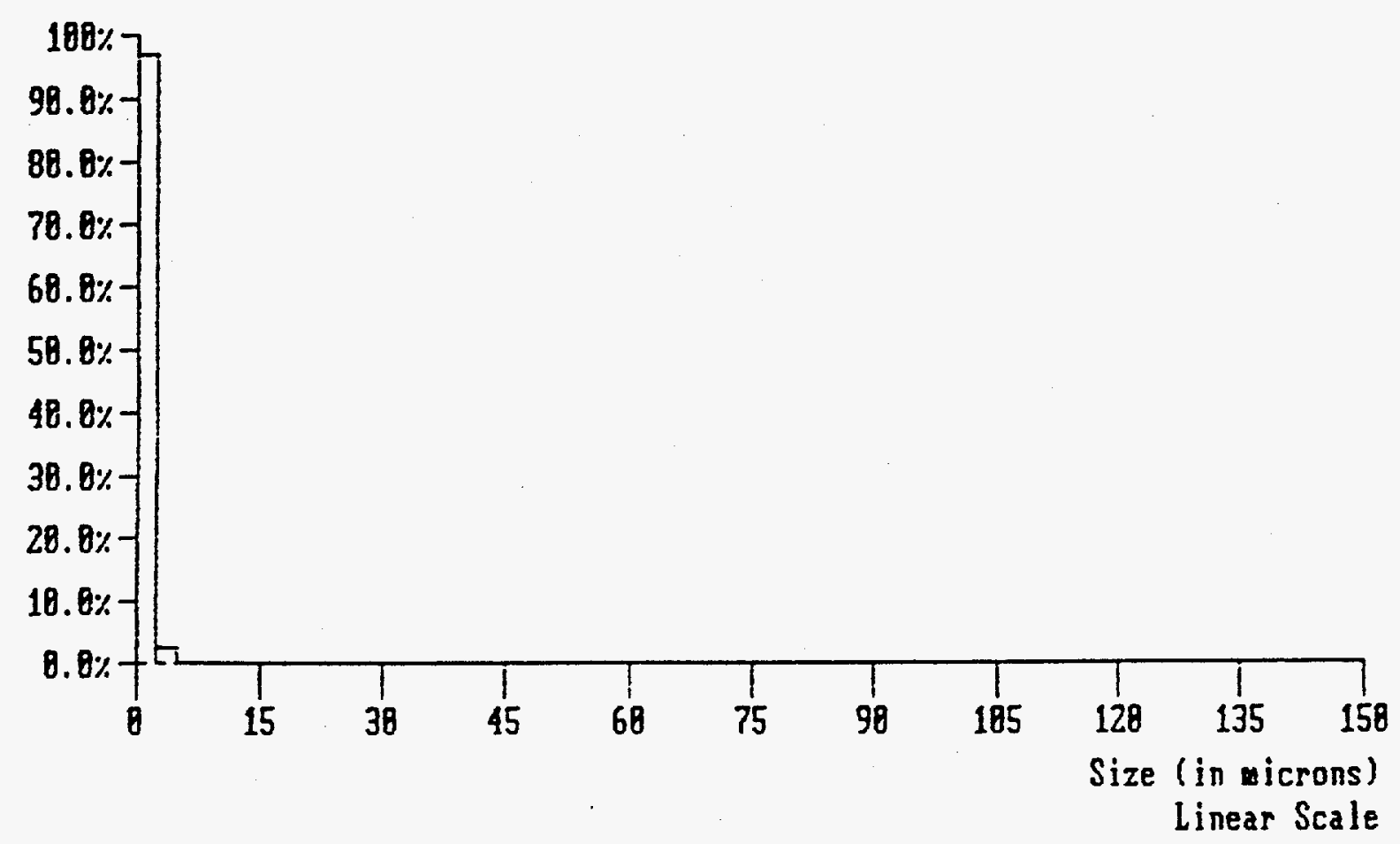

Figure 5-11b. Core 31, Segment 5, Particle Size: Volume Density.

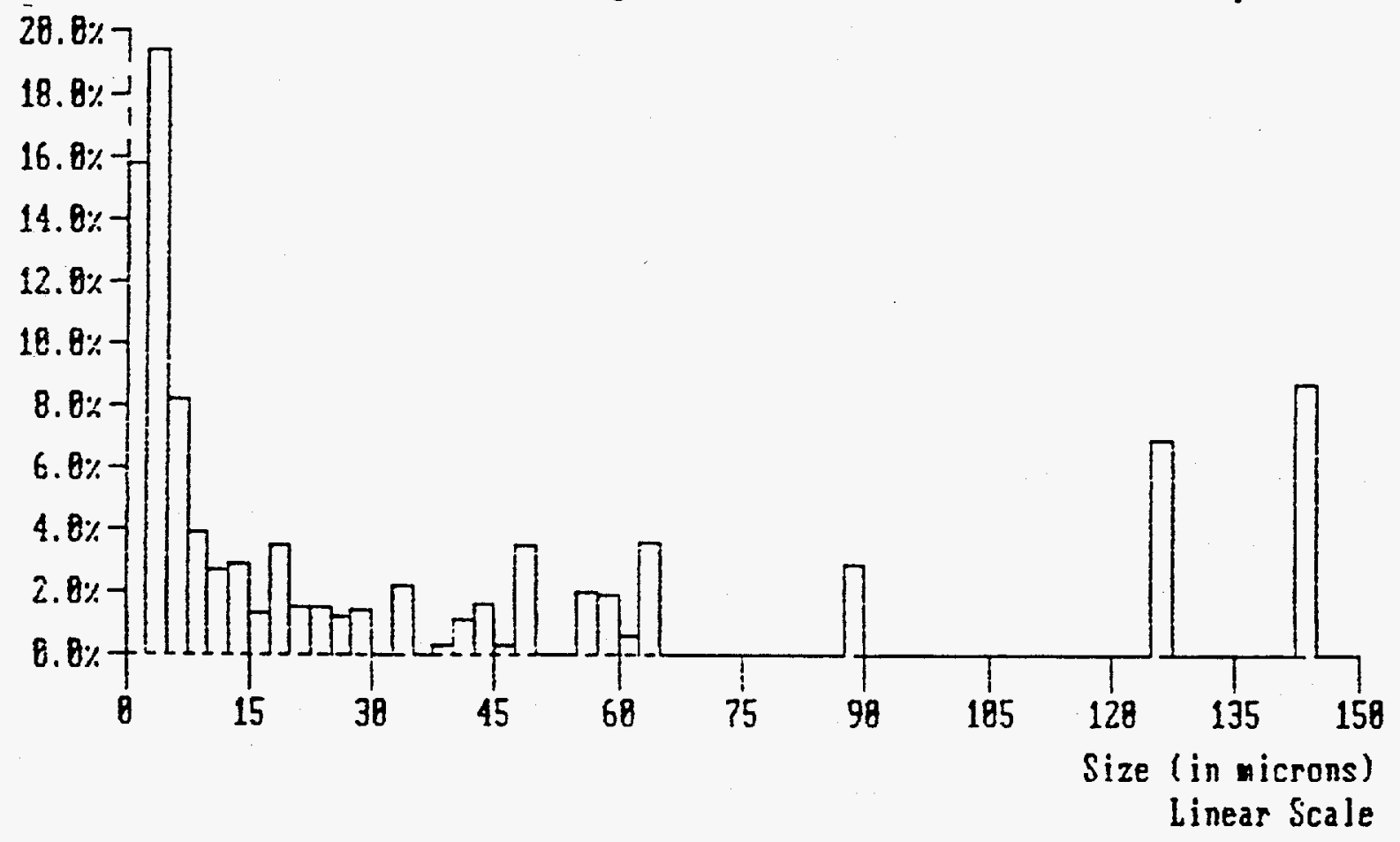


Figure 5-12a. Core 31, Segment 7, Particle Size: Number Density.

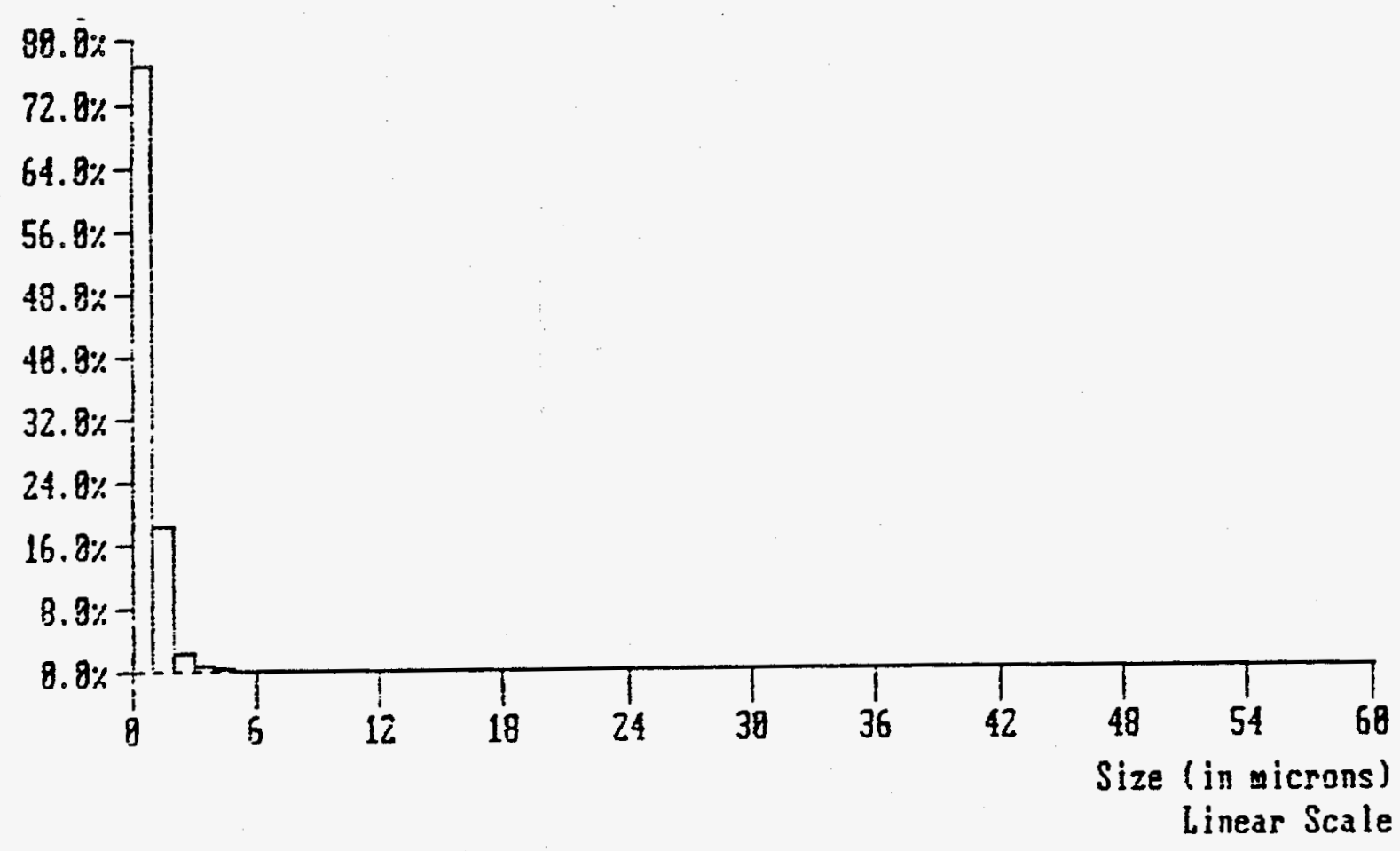

Figure 5-12b. Core 31, Segment 7, Particle Size: Volume Density.

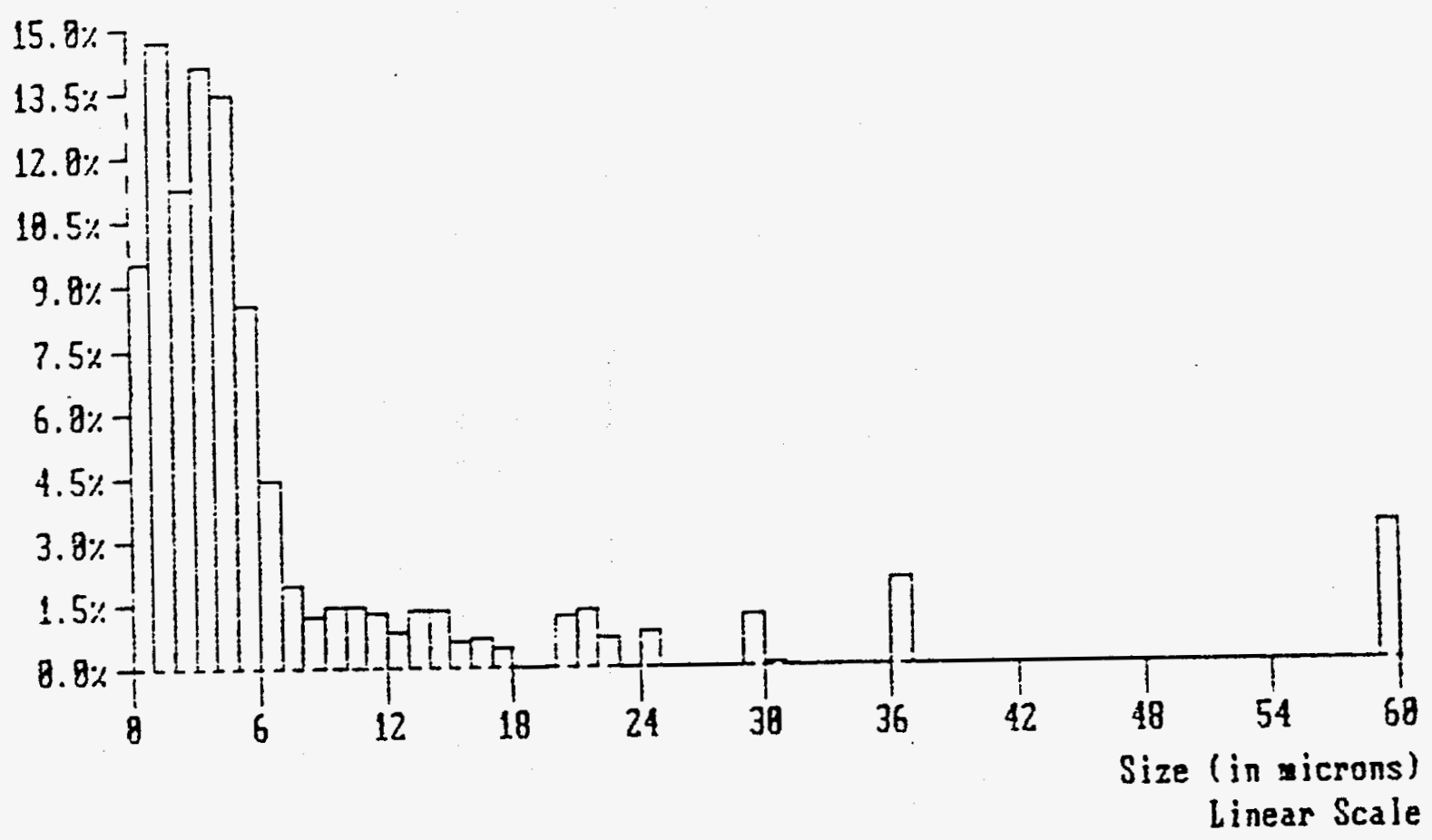


Figure 5-13a. Core 31, Segment 8, Particle Size: Number Density.

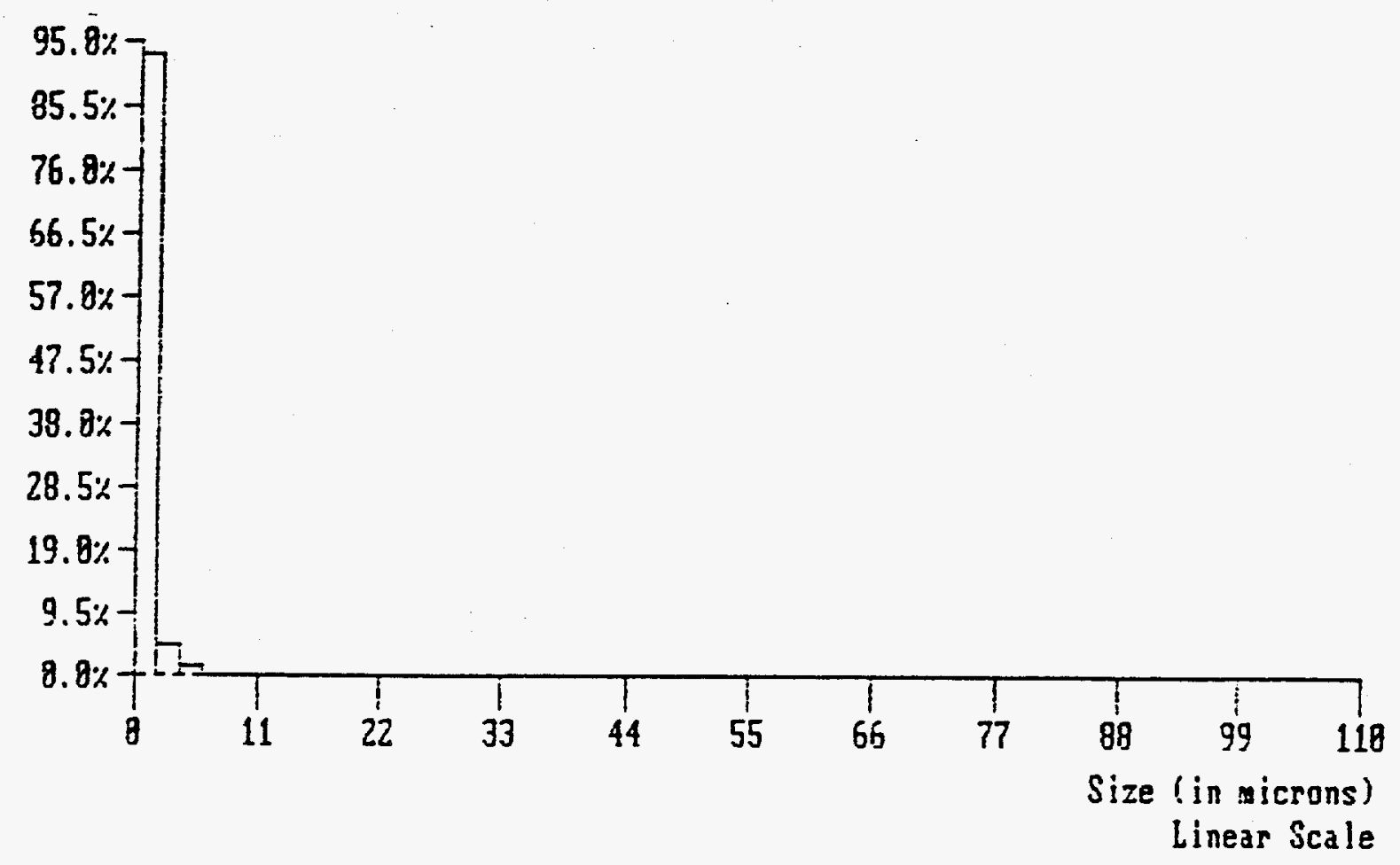

Figure 5-13b. Core 31, Segment 8, Particle Size: Volume Density.

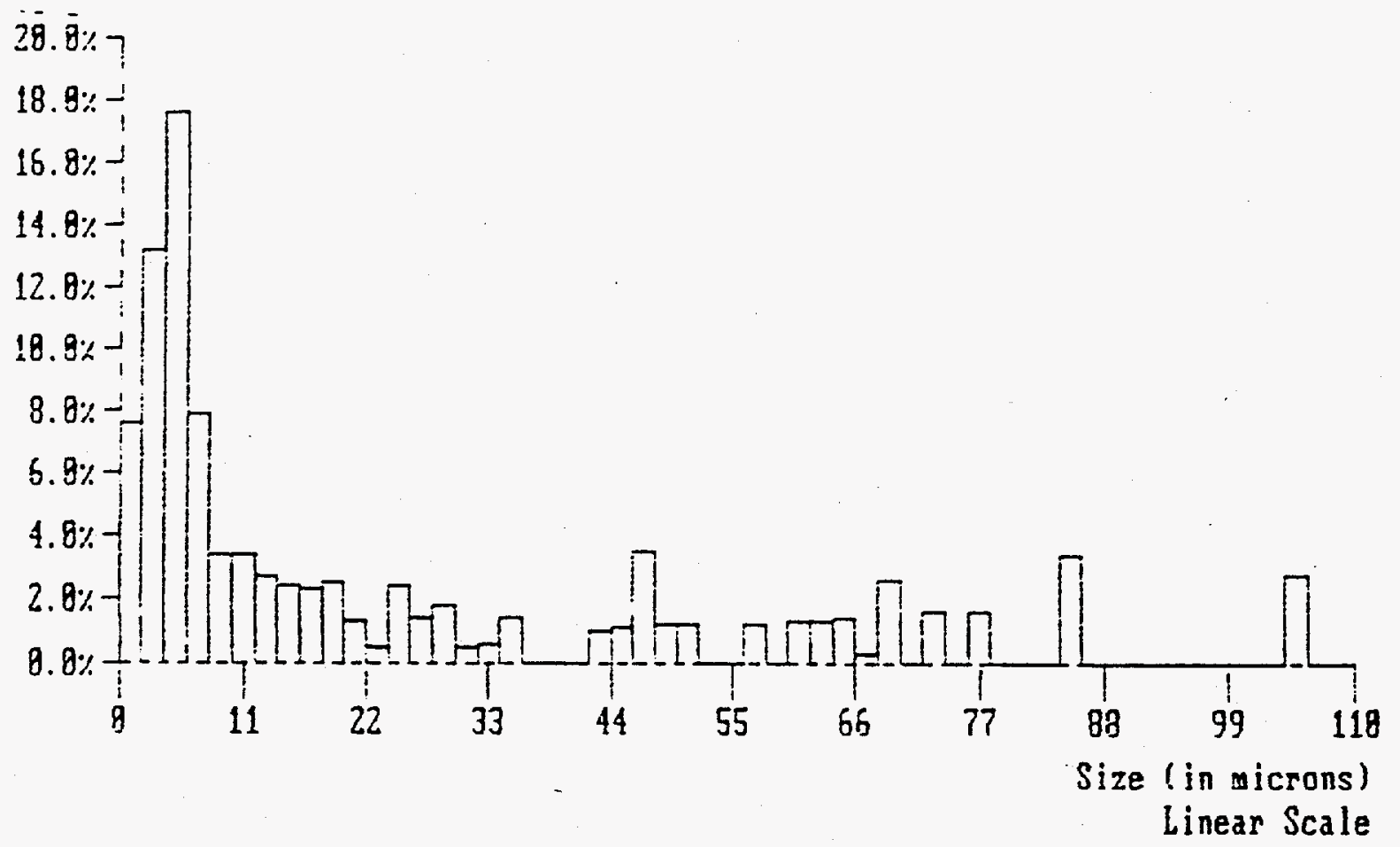


Figure 5-14a. Core 31, Segment 9, Particle Size: Number Density.

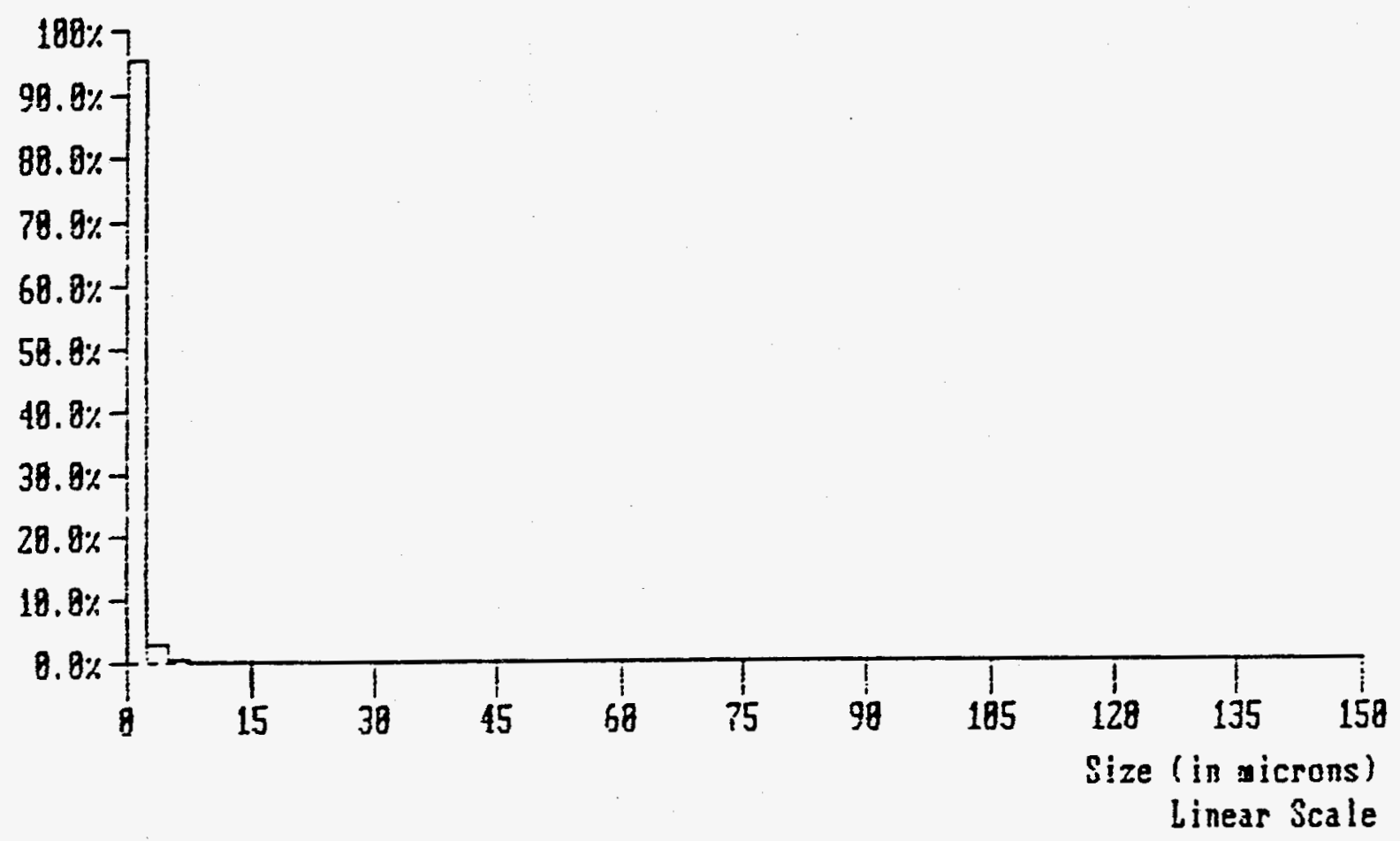

Figure 5-14b. Core 31, Segment 9, Particle Size: Volume Density.

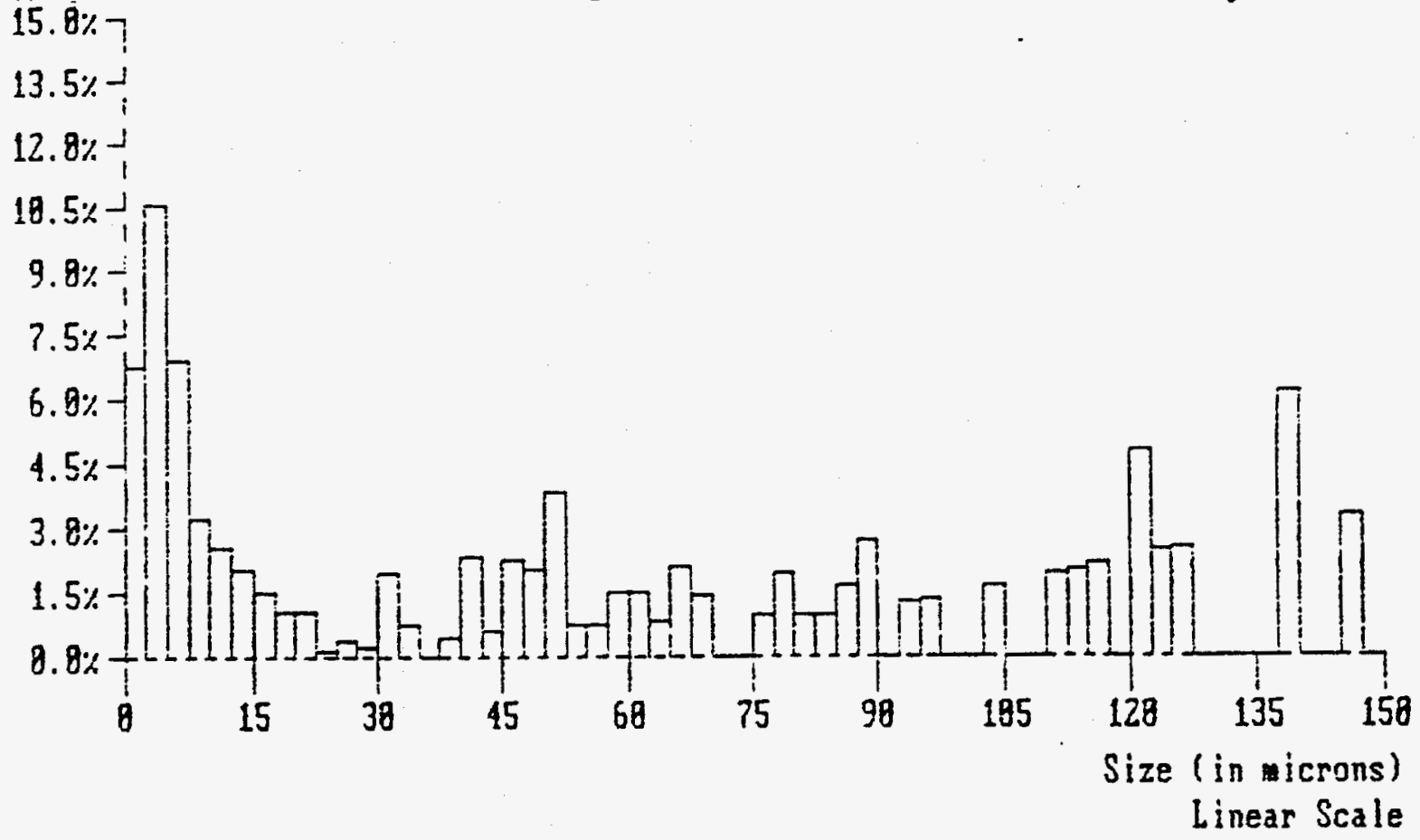


Table 5-15. Grab Sample Physical Properties Summary.

\begin{tabular}{|l|c|c|c|c|}
\hline \multicolumn{1}{|c|}{ Property } & Grab sample \#1 & Grab sample \#2 & Grab sample \#3 & Average value \\
\hline Specific gravity & 1.036 & 1.038 & 1.033 & 1.036 \\
\hline $\mathrm{pH}$ & 11.57 & 11.59 & 11.78 & 11.65 \\
\hline $\mathrm{Wt} \% \mathrm{H}_{2} \mathrm{O}$ & 92.70 & 92.90 & 92.90 & 92.83 \\
\hline $\mathrm{Wt} \% \mathrm{H}_{2} \mathrm{O}$ (TGA) & 91.17 & 91.73 & 90.24 & 91.05 \\
\hline $\begin{array}{l}\text { Settled solids } \\
\text { (vol\%) }\end{array}$ & $<1 \%$ & $<1 \%$ & $<1 \%$ & $<1 \%$ \\
\hline
\end{tabular}

The grab samples were clear yellow liquids with no particulate.

Table 5-16. Physical Properties Summary.

\begin{tabular}{|c|c|c|c|}
\hline \multirow[b]{2}{*}{ Property } & & \multicolumn{2}{|c|}{ Sample } \\
\hline & & $\begin{array}{l}\text { Core } 31, \\
\text { segment } 2\end{array}$ & $\begin{array}{l}\text { Core } 31, \\
\text { segment } 8\end{array}$ \\
\hline Settled solids (vol\%) & \multirow{4}{*}{ As-Received } & $100 \%$ & $100 \%$ \\
\hline Wt\% Solids & & 22.4 & 29.3 \\
\hline Wt\% Undissolved solids & & 19.0 & 25.4 \\
\hline Density $(\mathrm{g} / \mathrm{mL})$ & & 1.19 & 1.28 \\
\hline \multicolumn{4}{|l|}{ Centrifuged samples } \\
\hline Vol\% & \multirow{4}{*}{$\begin{array}{l}1 \text { hour at } \\
1,000 \\
\text { gravities }\end{array}$} & 65.8 & 71.9 \\
\hline $\mathrm{Wt} \%$ & & 67.3 & 75.9 \\
\hline $\begin{array}{l}\text { Centrifuged supernate } \\
\text { density }(\mathrm{g} / \mathrm{mL})\end{array}$ & & 1.07 & 1.10 \\
\hline $\begin{array}{l}\text { Centrifuged solid density } \\
(\mathrm{g} / \mathrm{mL})\end{array}$ & & 1.22 & 1.34 \\
\hline
\end{tabular}

No settling was observed in the as-received segment samples over a period of three days, and there was no standing liquid obtained from the samples. Two dilutions of 1 to 1 and 3 to 1 water to sample ratios, respectively were prepared, and the volume-percent settled solids for each of the dilutions are plotted as a function of settling time.

The 1 to 1 dilution for segment 2 reaches a final volume percent settled solids of 85 to 87 percent. Settling is observed throughout the three-day period, but the majority of the settling is observed in the first 10 hours. The 3 to 1 dilution reaches a final volume-percent settled solids of approximately 52 percent. Again, settling is observed over three days, and the first 10 hours is when the majority of the solids settle. Qualitatively, the settling behavior for both sample dilutions is a steep, nearly linear relationship between the initial 
fluidization of the material and the first 10 hours of settling. After that, the final 10 percent of the suspended solids take up almost the rest of the time settling in a long, gradual decline, before coming to equilibrium.

The 1 to 1 and 3 to 1 dilutions for segment 4 were compromised by drying the sample before its assay. However, some observations and contrasts with the other samples are appropriate. Settling is mostly completed after 3 to 4 hours, and is complete after 10 hours. This is in sharp contrast to the other samples for which there is a long, asymptotic-like settling behavior observed for a substantial portion of the suspended solids (10 to 15 percent), after the initial settling phase. This behavior is suggestive of a colloid or gel for segments 2 and 8. In contrast, segment 4 appears to be a collection of discrete particles with no interaction between them.

The 1 to 1 dilution for segment 8 reaches a final volume-percent settled solids of about 80 percent (see Figure 5-17a). Settling is observed throughout the three-day period, but the majority of the settling is observed in the first 10 hours. The 3 to 1 dilution reaches a final volume-percent settled solids of approximately 40 percent. Again, settling is observed over three days and the first 10 hours is when the majority of the solids settle. Qualitatively, the settling behavior for both sample dilutions is a shallow, nearly linear relationship between the initial fluidization of the material and the first 10 hours of settling. The slope of this line is much more gradual than that of segment 2 for the corresponding dilutions. After the first 10 hours, the final 15 percent of the suspended solids take up almost the rest of the time settling in a long, gradual decline before coming to equilibrium. Table 5-17 summarizes the settling behavior for the samples investigated. Figures 5-15a through 5-17b illustrate the setting behavior over time.

Table 5-17. Settling Comparison for 1 to 1 and 3 to 1 dilutions for Core 31 Segments 2,4 , and 8 .

\begin{tabular}{|l|c|c|c|c|c|c|}
\hline Analyte & \multicolumn{2}{|c|}{ Segment 2} & \multicolumn{2}{c|}{ Segment 4} & \multicolumn{2}{c|}{ Segment 8} \\
\hline Dilution: water to sample & $1: 1$ & $3: 1$ & $1: 1$ & $3: 1$ & $1: 1$ & $3: 1$ \\
\hline Final volume \% solids & 87 & 52 & 22 & 22 & 80 & 40 \\
\hline
\end{tabular}

\subsection{ANALYTICAL RESULTS--ENERGETICS}

TGA and DSC were performed on subsegment and core-composite material from tank 241-T-111. These two thermal analysis techniques are used to determine the thermal stability or reactivity of a material. In DSC analysis, heat flow over and above the usual heat capacity of the substance is measured while the substance is exposed to a linear increase in temperature, i.e., the change in temperature, divided by the time elapsed is constant $\left(\mathrm{dT} / \mathrm{dt}=\right.$ constant). While the substance is being heated, a cover gas (usually air or $\mathrm{N}_{2}$ ) is passed over the waste material to remove any gases being released. The onset temperature 
Figure 5-15a. Settling Rate Data for Tank 241-T-111 Core 31, Segment 2, 1 to 1 Dilution.

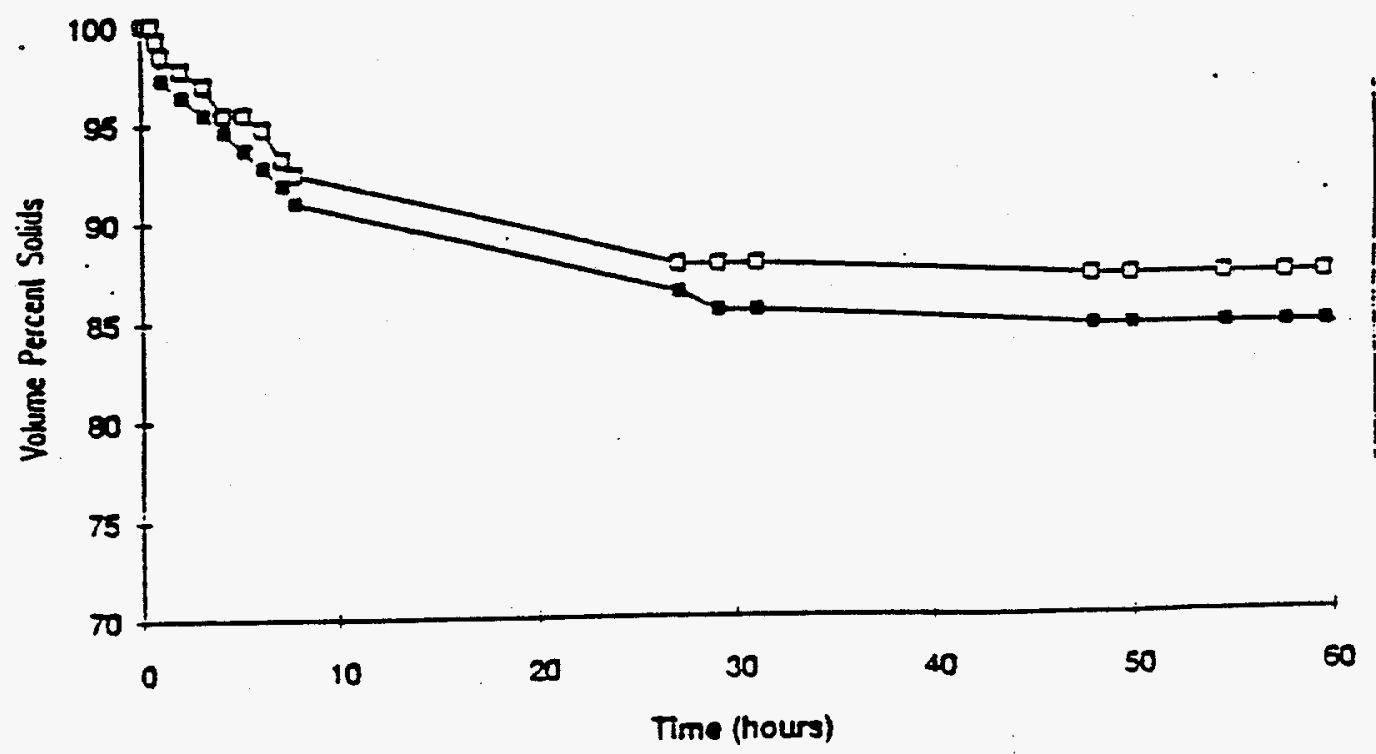

Figure 5-15b. Settling Rate Data for Tank 241-T-111

Core 31 , Segment 2, 3 to 1 Dilution.

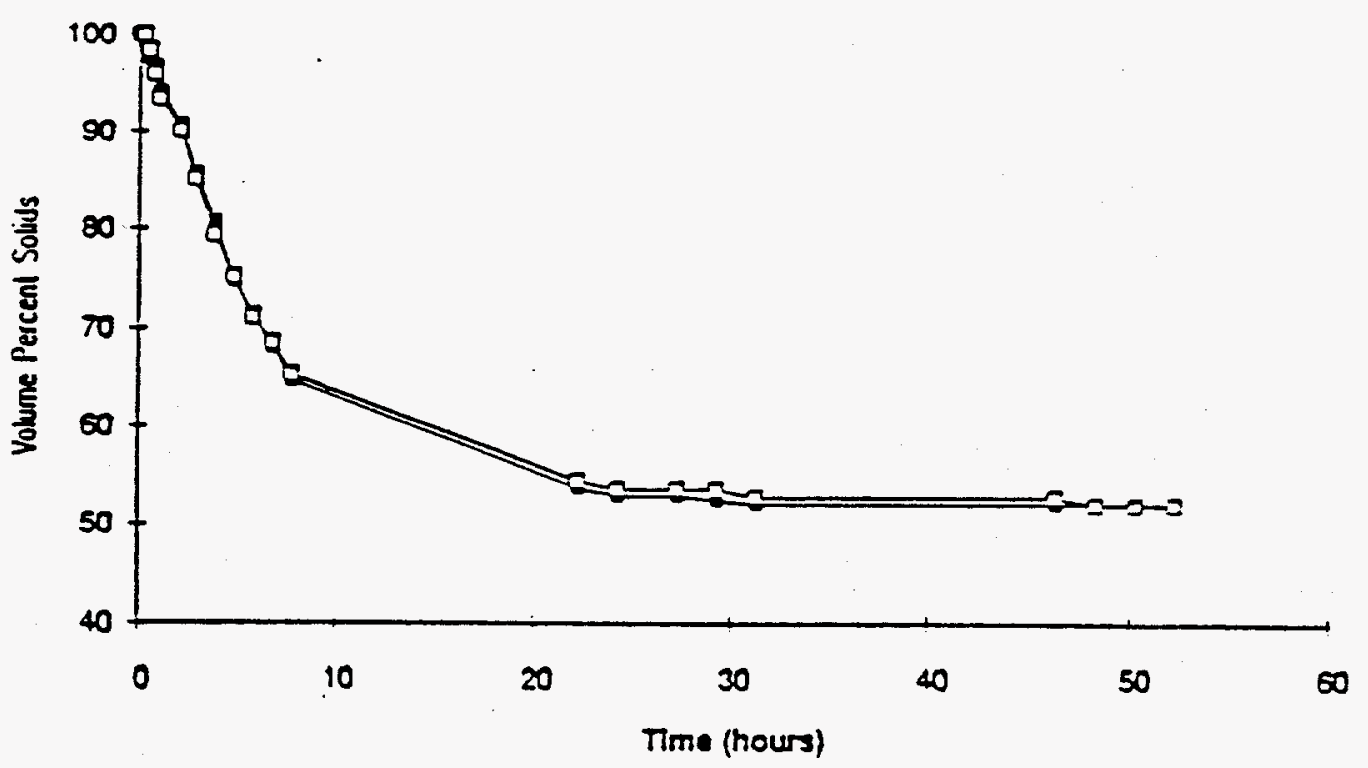


Figure 5-16a. Settling Rate Data for Tank 241-T-111 Core 31, Segment 4, 1 to 1 Dilution.

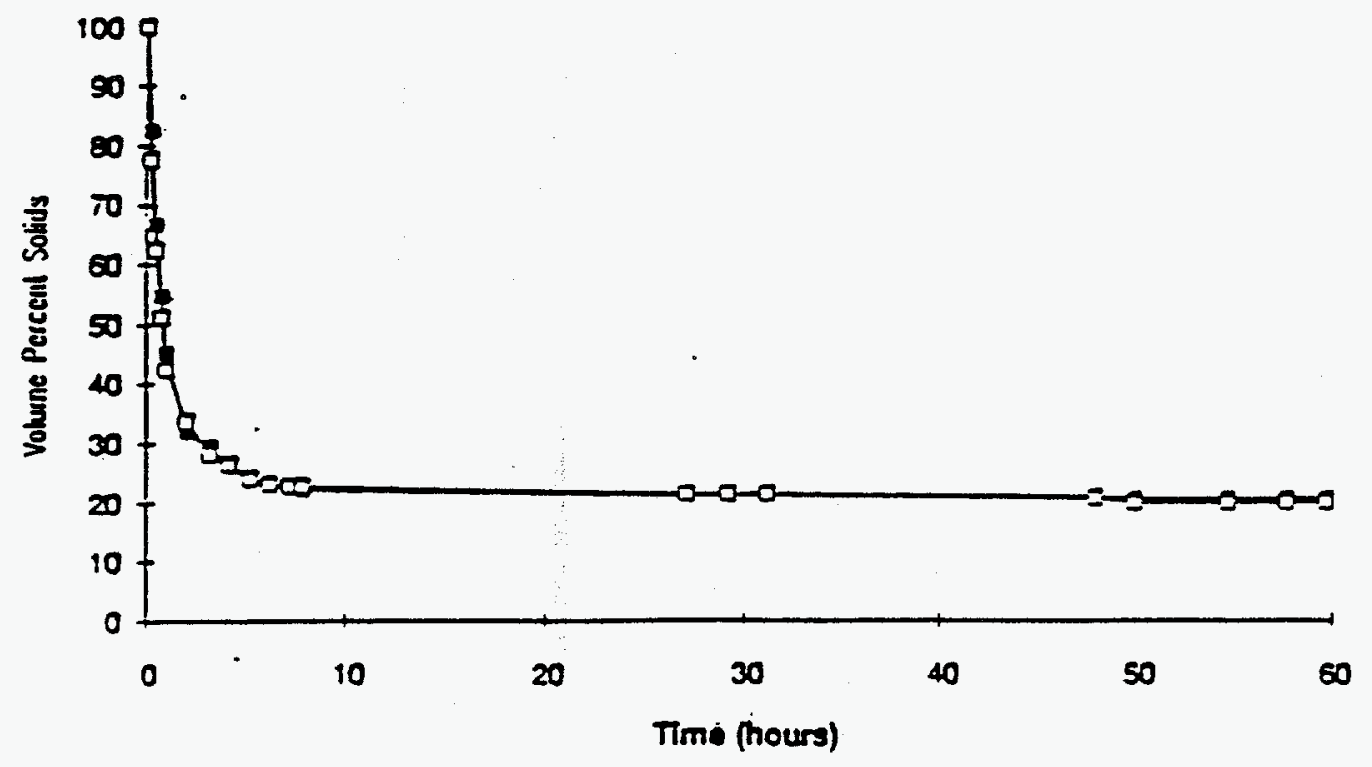

Figure 5-16b. Settling Rate Data for Tank 241-T-111 Core 31, Segment 4, 3 to 1 Dilution.

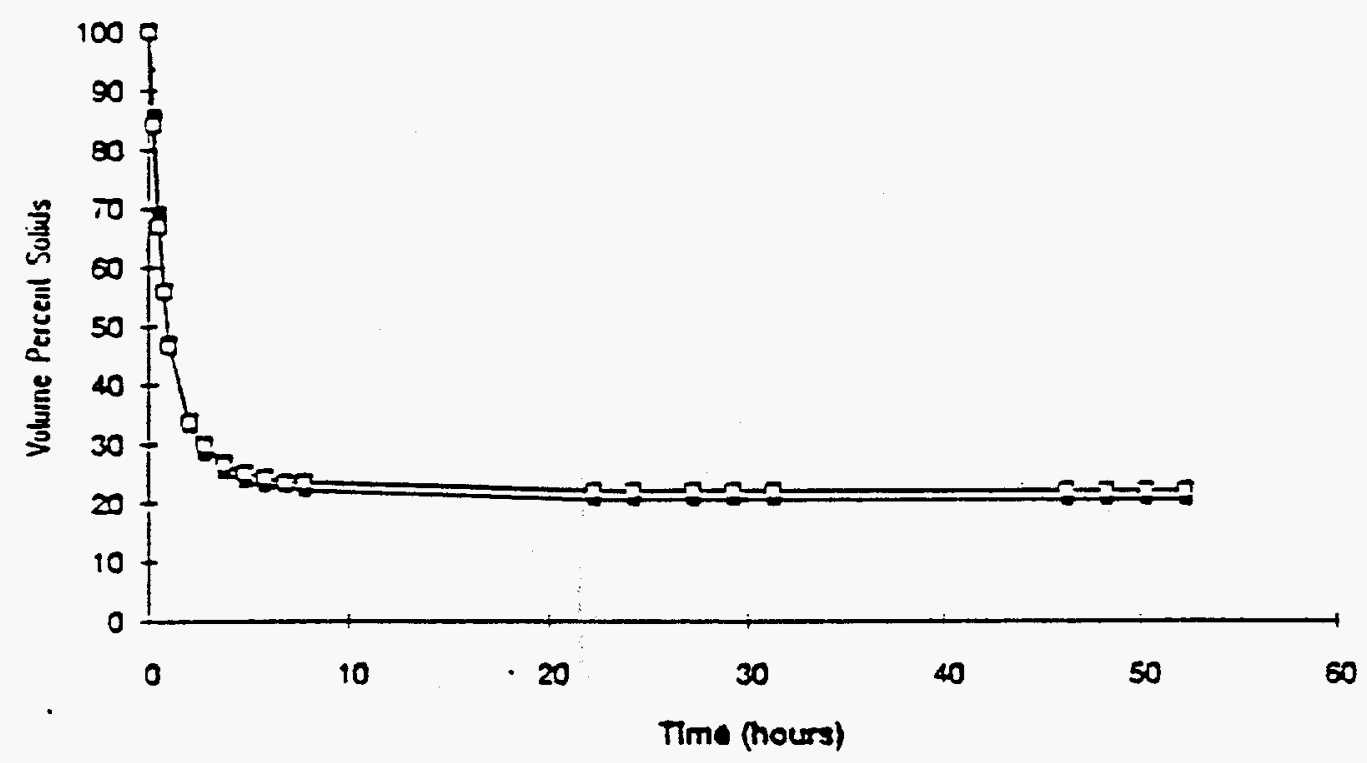


Figure 5-17a. Settling Rate Data for Tank 241-T-111 Core 31, Segment 8, 1 to 1 Dilution.

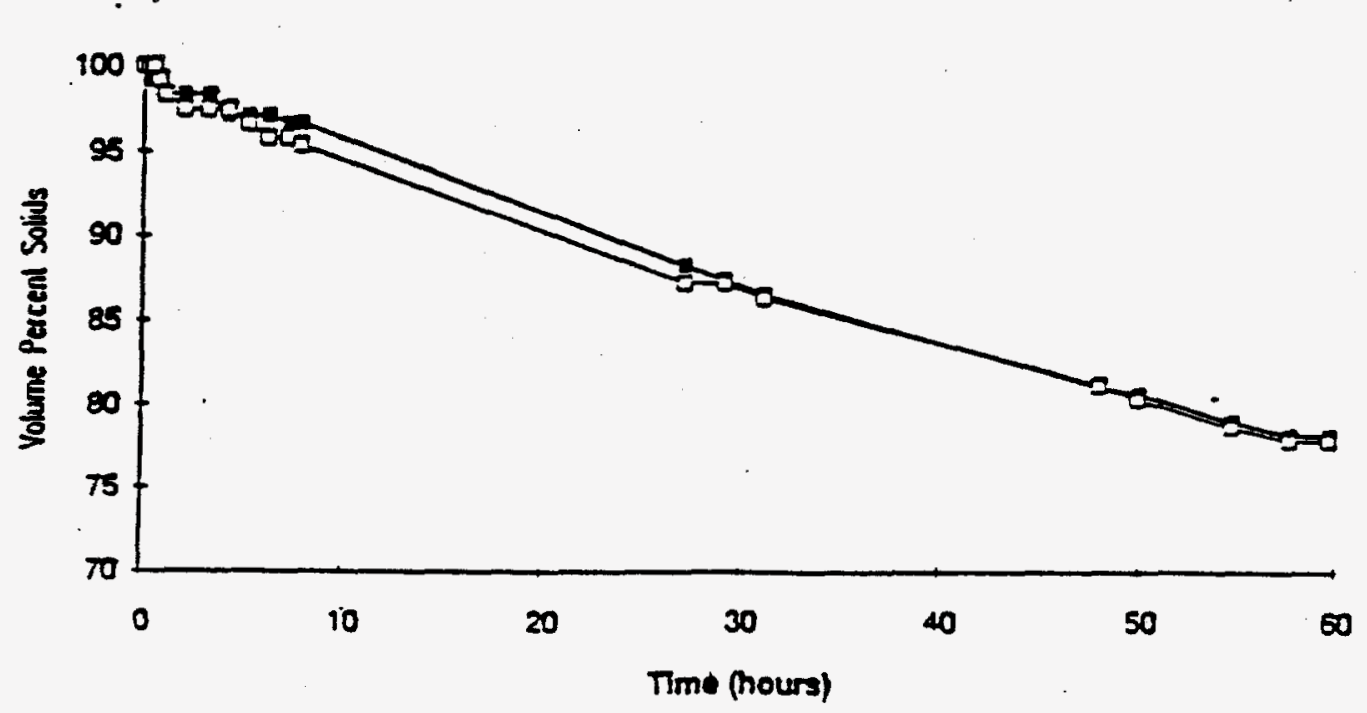

Figure 5-17b. Settling Rate Data for Tank 241-T-111 Core 31, Segment 8, 3 to 1 Dilution.

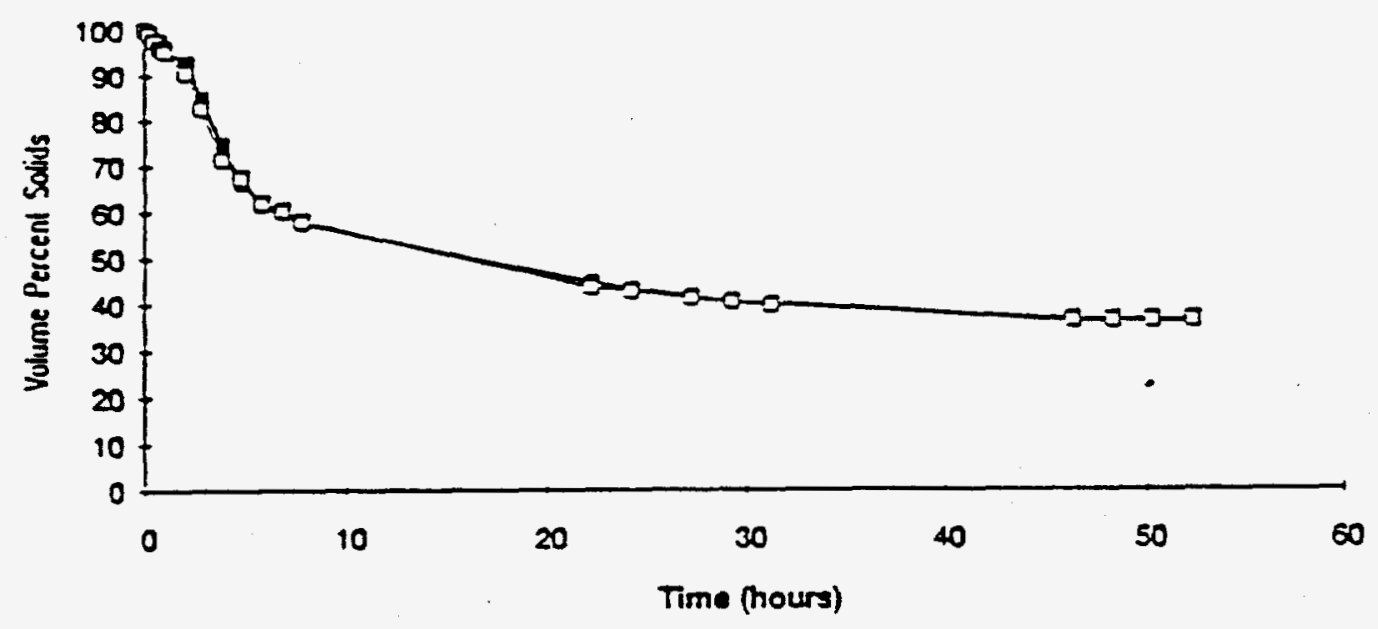


for an endothermic or exothermic event on a DSC is determined graphically. The endpoints of the event are determined and a line is drawn between them to establish a base. A line tangent to the initial side of the event is drawn until it intersects the base. From that point of intersection, a vertical line is constructed to the temperature scale at the bottom of the DSC curve. That temperature is the onset temperature of the event.

TGA measures the mass of a sample while the temperature of the sample is increased at a constant rate. The $\mathrm{X}$-axis is representative of the running time of the analysis as well as the temperature increase of the sample during analysis. The $\mathrm{Y}$-axis represents the weight percent of the sample and is effectively unitless. As with the DSC, a cover gas is passed over the sample during heating. Any decrease in the weight percent of the sample represents a loss of gaseous matter from the sample either through evaporation or a reaction that forms gas phase products.

DSC is often used to measure thermal decomposition temperatures, heats of reaction, reaction temperatures, melting points, and solid-solid transition temperatures. TGA is used to measure thermal decomposition temperatures, water content, and reaction temperatures. The two methods often provide complementary information.

\subsubsection{Remarks on the Interpretation of Differential Scanning Calorimetry/Thermogravimetric Analysis Data}

Tables 5-18, 5-19, and 5-20 summarize the results of the thermal analyses performed. Although DSC assays were performed on the grab samples, the results were uniformly negative (i.e. no exotherms were observed). Where exotherms were observed, there are two significant features seen on the DSC and one on the TGA plots. The endothermic DSC event overlaps the area where the substantial majority of the sample mass is lost as recorded by the TGA, suggesting that this endotherm is a result of the evaporation of water from the sample. The values presented in the tables may not exactly match the values derived from the DSC and TGA plots, especially exotherm magnitudes. This is because interpreting these semi-quantitative analyses requires considerable experience and judgement on the part of the analyst, and differences in perception and judgement between readers can be expected in a semi-quantitative analysis. Appendix A contains copies of all of the DSC and TGA traces and results.

Additional physical properties work was performed to expand the understanding of the exothermic behavior of some of the segments (WHC 1994, Delegard 1994). Table 5-21 presents additional energetics results for core 33 , segments 1 and 2 . These samples were dried under a vacuum at $60^{\circ} \mathrm{C}$ before analysis, using either air or nitrogen as a cover gas. Even after drying, the samples retained 10 to 12 weight percent water. Table 5-22 presents a brief summary of the analytical results for the average sample properties as-received after centrifuging samples from core 31 , segments 3 and 7 , and core 33 , segments 1 and 7 , at 500 gravities for 113 hours. 


\subsubsection{General Comments on the Differential Scanning Calorimetry/ Thermogravimetric Analysis Behavior of the Samples}

The first transition in each sample is endothermic, begins at the lower temperature limit of the analysis $\left(30^{\circ} \mathrm{C}\right)$, and essentially is complete between 140 and $180^{\circ} \mathrm{C}$. The most likely phenomenon occurring in this region is the release of the bulk and interstitial water in the core sample material. The endotherms exhibited in this region are substantial (typically in excess of $1,000 \mathrm{~J} / \mathrm{g}$ ). These values are per gram of wet sample. If divided by the mass fraction lost during analysis, they range from 1,600 to $1,900 \mathrm{~J} / \mathrm{g}$ (dry) and correspond roughly with the heat of vaporization of water $(2,260 \mathrm{~J} / \mathrm{g})$. The TGA water content corresponds reasonably well with the water loss observed in a gravimetric weight percent solids determination; however, the gravimetric weight percent water assay is consistently lower.

Table 5-18. Percent Water Analyses Results from Tank 241-T-111.

\begin{tabular}{|l|r|r|r|r|}
\hline Sample I.D. & $\begin{array}{c}\text { Core 31 average } \\
\text { gravimetric } \\
\text { Wt\% loss }\end{array}$ & $\begin{array}{c}\text { Core 31 average } \\
\text { TGA transition 1 } \\
\text { Wt\% loss }\end{array}$ & $\begin{array}{c}\text { Core 33 average } \\
\text { gravimetric Wt\% } \\
\text { loss }\end{array}$ & $\begin{array}{c}\text { Core 33 average } \\
\text { TGA transition 1 } \\
\text { Wt\% loss }\end{array}$ \\
\hline Segment 1 & 80.3 & 87.0 & 80.4 & NM \\
\hline Segment 2 & 82.4 & 87.0 & 85.7 & 80.6 \\
\hline Segment 3 & 86.0 & 85.0 & 81.8 & 88.5 \\
\hline Segment 4 & 77.3 & 82.8 & 79.9 & 89.5 \\
\hline Segment 5 & 80.9 & 88.0 & 78.2 & 88.8 \\
\hline Segment 6 & No sample & No sample & 75.8 & 84.4 \\
\hline Segment 7 & 76.8 & 84.8 & 71.7 & 85.8 \\
\hline Segment 8 & 76.6 & 85.6 & 75.4 & 84.8 \\
\hline Segment 9 & 75.8 & 71.0 & 76.0 & 85.2 \\
\hline Segment 9B & 70.4 & 72.1 & NA & NA \\
\hline Composite 1 & 74.6 & 73.3 & 76.5 & 81.6 \\
\hline Composite 2 & 75.9 & 70.2 & 77.1 & 80.8 \\
\hline
\end{tabular}


Table 5-19. Differential Scanning Calorimetry Energetics Results from

Tank 241-T-111, Core 31 (wet basis).

\begin{tabular}{|l|c|c|c|c|c|c|}
\hline \multirow{2}{*}{$\begin{array}{c}\text { Core sample } \\
31\end{array}$} & \multicolumn{3}{|c|}{ Transition 1 } & \multicolumn{3}{c|}{ Transition 2 } \\
\cline { 2 - 7 } & $\begin{array}{c}\text { Range } \\
\left({ }^{\circ} \mathrm{C}\right)\end{array}$ & $\begin{array}{c}\text { Avg. } \\
\text { onset } \\
\left({ }^{\circ} \mathrm{C}\right)\end{array}$ & $\begin{array}{c}\Delta \mathrm{H} \text { range } \\
(\mathrm{J} / \mathrm{g})\end{array}$ & $\begin{array}{c}\text { Range } \\
\left({ }^{\circ} \mathrm{C}\right)\end{array}$ & $\begin{array}{c}\text { Avg. } \\
\text { onset } \\
\left({ }^{\circ} \mathrm{C}\right)\end{array}$ & $\begin{array}{c}\Delta \mathrm{H} \text { range } \\
(\mathrm{J} / \mathrm{g})\end{array}$ \\
\hline Segment 1 & $43-141$ & 43 & 1,088 to 1,406 & $200-387$ & 200 & -259 to -273 \\
\hline Segment 2 & $46-149$ & 46 & 1,108 to 1,643 & $200-398$ & 225 & -256 to -264 \\
\hline Segment 3 & $45-160$ & 50 & 1,210 to 1,233 & $195-405$ & 198 & -263 to -448 \\
\hline Segment 4 & $44-165$ & 44 & 1,235 & $200-390$ & 200 & -55.7 \\
\hline Segment 5 & NR & -- & Endotherm NR & NA & NA & No Exotherm \\
\hline Segment 6 & NA & -- & --- & --- & -- & NA \\
\hline Segment 7 & $50-164$ & 50 & 1,488 & $165-400$ & NA & No Exotherm \\
\hline Segment 8 & $50-153$ & 50 & 1,534 & $154-400$ & NA & No Exotherm \\
\hline Segment 9 & $61-158$ & 61 & 1,437 & $159-400$ & NA & No Exotherm \\
\hline Composite 1 & NR & -- & Endotherm NR & $256-339$ & 257 & -23.6 to -37.0 \\
\hline Composite 2 & NR & -- & Endotherm NR & $260-334$ & 262 & -18.5 to -22.9 \\
\hline
\end{tabular}

NOTE: To convert from J to cal, divide by 4.18.

NOTE: Negative $\Delta \mathrm{H}$ indicates an exotherm.

NA $=$ Not applicable.

$\mathrm{NR}=$ Not resolved. 
Table 5-20. Differential Scanning Calorimetry Energetics Results from Tank 241-T-111, Core 33 (wet basis).

\begin{tabular}{|l|c|c|c|c|c|c|}
\hline \multirow{2}{*}{ Core Sample } & \multicolumn{3}{|c|}{ Transition 1 } & \multicolumn{3}{c|}{ Transition 2 } \\
\cline { 2 - 7 } & Range $\left({ }^{\circ} \mathrm{C}\right)$ & $\begin{array}{c}\text { Avg. } \\
\text { onset } \\
\left({ }^{\circ} \mathrm{C}\right)\end{array}$ & $\begin{array}{c}\Delta \mathrm{H} \text { range } \\
(\mathrm{J} / \mathrm{g})\end{array}$ & Range $\left({ }^{\circ} \mathrm{C}\right)$ & $\begin{array}{c}\text { Avg. onset } \\
\left({ }^{\circ} \mathrm{C}\right)\end{array}$ & $\begin{array}{c}\Delta \mathrm{H} \text { range } \\
\text { (J/g) }\end{array}$ \\
\hline Segment 1 & $49-168$ & 49 & 958 to 1,604 & $168-374$ & 184 & -218 to -293 \\
\hline Segment 2 & $45-179$ & 50 & $\begin{array}{c}1,346 \text { to } \\
1,496\end{array}$ & $168-438$ & 174 & -454 to -645 \\
\hline Segment 3 & NA & -- & $\begin{array}{c}\text { Endotherm } \\
\text { NR }\end{array}$ & $237-400$ & 237 & -49.3 \\
\hline Segment 4 & NA & -- & $\begin{array}{c}\text { Endotherm } \\
\text { NR }\end{array}$ & NA & -- & $\begin{array}{c}\text { No } \\
\text { Exotherm }\end{array}$ \\
\hline Segment 5 & NA & -- & $\begin{array}{c}\text { Endotherm } \\
\text { NR }\end{array}$ & NA & -- & $\begin{array}{c}\text { No } \\
\text { Exotherm }\end{array}$ \\
\hline Segment 6 & NA & - & $\begin{array}{c}\text { Endotherm } \\
\text { NR }\end{array}$ & NA & -- & $\begin{array}{c}\text { No } \\
\text { Exotherm }\end{array}$ \\
\hline Segment 7 & NA & -- & $\begin{array}{c}\text { Endotherm } \\
\text { NR }\end{array}$ & NA & -- & $\begin{array}{c}\text { No } \\
\text { Exotherm }\end{array}$ \\
\hline Segment 8 & NA & -- & $\begin{array}{c}\text { Endotherm } \\
\text { NR }\end{array}$ & NA & -- & $\begin{array}{c}\text { No } \\
\text { Exotherm }\end{array}$ \\
\hline Segment 9 & NA & -- & $\begin{array}{c}\text { Endotherm } \\
\text { NR }\end{array}$ & NA & -- & $\begin{array}{c}\text { No } \\
\text { Exotherm }\end{array}$ \\
\hline Composite 1 & NA & -- & $\begin{array}{c}\text { Endotherm } \\
\text { NR }\end{array}$ & NA & -- & $\begin{array}{c}\text { No } \\
\text { Exotherm }\end{array}$ \\
\hline Composite 2 & NA & -- & $\begin{array}{c}\text { Endotherm } \\
\text { NR }\end{array}$ & NA & -- & $\begin{array}{c}\text { No } \\
\text { Exotherm }\end{array}$ \\
\hline
\end{tabular}

NOTE: To convert from J to cal, divide by 4.18.

NOTE: Negative $\Delta H$ indicates an exotherm.

NA $=$ Not applicable.

$\mathrm{NR}=$ Not resolved. 
Table 5-21. Differential Scanning Calorimetry Energetics Results from Tank 241-T-111, Core 33 (dry basis).

\begin{tabular}{|c|c|c|c|c|c|c|}
\hline \multirow[b]{2}{*}{$\begin{array}{l}\text { Laboratory-core } \\
\text { sample-air } / \mathbf{N}_{2}\end{array}$} & \multicolumn{3}{|c|}{ Transition 1} & \multicolumn{3}{|c|}{ Transition 2} \\
\hline & $\begin{array}{l}\text { Range } \\
\left({ }^{\circ} \mathrm{C}\right)\end{array}$ & $\begin{array}{l}\text { Avg. } \\
\text { onset } \\
\left({ }^{\circ} \mathrm{C}\right)\end{array}$ & $\underset{(\mathrm{J} / \mathrm{g})}{\Delta \mathrm{H} \text { range }}$ & $\begin{array}{l}\text { Range } \\
\left({ }^{\circ} \mathrm{C}\right)\end{array}$ & $\begin{array}{l}\text { Avg. onset } \\
\left({ }^{\circ} \mathrm{C}\right)\end{array}$ & $\Delta \mathrm{H}$ range $(\mathrm{J} / \mathrm{g})$ \\
\hline $\begin{array}{l}222-\mathrm{S} \\
\text { core } 33 \text {, seg. 1, Air }\end{array}$ & -- & --- & NR--Dried & $158-405$ & NR & $-1,857$ to $-1,882$ \\
\hline $\begin{array}{l}222-S \\
\text { core } 33, \text { seg. } 2 \text {, Air }\end{array}$ & -- & $\ldots$ & NR--Dried & $130-425$ & NR & -251 to -269 \\
\hline $\begin{array}{l}222-\mathrm{S} \\
\text { core, } 33 \text { seg. } 2, \mathrm{~N}_{2}\end{array}$ & -- & $-\cdots$ & NR--Dried & $130-430$ & NR & -288 to -309 \\
\hline $\begin{array}{l}222-\mathrm{S} \\
\text { core } 33, \text { seg. } 2, \mathrm{~N}_{2}\end{array}$ & --- & $\cdots$ & NR--Dried & $128-418$ & NR & -180 to -187 \\
\hline $\begin{array}{l}222-\mathrm{S} \\
\text { core } 33, \text { seg. } 2, \mathrm{~N}_{2}\end{array}$ & - & -- & NR--Dried & $123-421$ & NR & -163 to -175 \\
\hline $\begin{array}{l}222-\mathrm{S} \\
\text { core } 33 \text {, seg. } 2, \mathrm{~N}_{2}\end{array}$ & -- & -- & NR--Dried & $121-438$ & NR & -336 \\
\hline $\begin{array}{l}325 \\
\text { core } 33, \text { seg. } 2, \mathrm{~N}_{2}\end{array}$ & $\overline{---}$ & $\cdots$ & NR--Dried & $107-394$ & 199 & -836 to -898 \\
\hline
\end{tabular}

NOTE: To convert from J to cal, divide by 4.18 .

NOTE: Negative $\Delta \mathrm{H}$ indicates an exotherm.

NA $=$ Not applicable.

$\mathrm{NR}=$ Not resolved. 
Table 5-22. Additional Segment-level Physical Properties Measurements (1994).

\begin{tabular}{|c|c|c|c|c|c|c|c|c|}
\hline \multirow[t]{2}{*}{ Analyte } & \multicolumn{2}{|c|}{$\begin{array}{l}\text { Core } 31 \text {, } \\
\text { segment } 3\end{array}$} & \multicolumn{2}{|c|}{$\begin{array}{l}\text { Core } 31 \text {, } \\
\text { segment } 7\end{array}$} & \multicolumn{2}{|c|}{$\begin{array}{l}\text { Core } 33 \text {, } \\
\text { segment } 1\end{array}$} & \multicolumn{2}{|c|}{$\begin{array}{l}\text { Core } 33 \text {, } \\
\text { segment } 7\end{array}$} \\
\hline & $\begin{array}{c}\text { As- } \\
\text { received }\end{array}$ & Centrifuged & $\begin{array}{c}\text { As- } \\
\text { received }\end{array}$ & Centrifuged & $\begin{array}{c}\text { As- } \\
\text { received }\end{array}$ & Centrifuged & $\begin{array}{c}\text { As- } \\
\text { received }\end{array}$ & Centrifuged \\
\hline $\begin{array}{l}\text { Gravimetric } \\
\text { water } \\
\text { (\%) }\end{array}$ & 79.53 & 64.96 & 74.72 & 62.06 & 79.56 & 65.49 & 74.07 & 59.95 \\
\hline $\begin{array}{l}\text { TGA } \\
(\%)\end{array}$ & 76.72 & 55.36 & 74.06 & 55.83 & 78.08 & 51.37 & 78.1 & 45.15 \\
\hline $\begin{array}{l}\text { Density } \\
(g / m L)\end{array}$ & 1.24 & 1.09 & 1.19 & 1.20 & 1.16 & 1.19 & 1.20 & 1.29 \\
\hline $\begin{array}{l}\Delta H \text { exotherm } \\
\text { range }(\mathrm{J} / \mathrm{g})\end{array}$ & $\begin{array}{l}-112 \text { to } \\
-191\end{array}$ & $\begin{array}{l}-465.3 \text { to } \\
-546.9\end{array}$ & $\begin{array}{l}-10.2 \text { to } \\
-33.1\end{array}$ & 10 & $\begin{array}{l}-249 \text { to } \\
-254\end{array}$ & $\begin{array}{l}-822.4 \text { to } \\
-838.1\end{array}$ & $\begin{array}{l}-37.5 \text { to } \\
-41.4\end{array}$ & 0 \\
\hline
\end{tabular}

When there is a second transition it is usually substantial and the energetic behavior is readily quantifiable in all of the samples analyzed where exotherms are observed. Any weight loss in the second transition region (generally temperatures above $200^{\circ} \mathrm{C}$ ) was not readily quantifiable, whether exotherms were observed or not. The results for the samples from segments 1,2 , and 3 , which are from the upper portion of the tank, indicate significant differences in thermal behavior compared to other samples from deeper in the tank, further suggesting a difference in waste type. In addition, because of the observed exothermic behavior for the top 3 segments from cores 31 and 33 and the results from Baldwin (1994), the present TOC assay is not considered capable of measuring the TOC in the waste. Resolution of the actual magnitude of the exotherm, its reaction mechanism, and speciation of the fuel is still continuing.

\subsection{OVERALL ANALYTICAL DATA SUMMARY}

Several characterization and safety issues are defined by certain bulk amounts or weight percent of a given analyte. Table 5-23 presents the nominal concentration and calculated bulk amounts of the analytes in the waste matrix. The gross waste inventory in the tank is estimated to be $2,171,000 \mathrm{~kg}$ wet solid. It is assumed that by the publication of this report, no drainable liquid will remain in the tank. Appendix $C$ presents the data, assumptions, and calculations used to determine the following values. 
Table 5-23. Overall Data Summary and Inventory Estimates. (3 pages)

\begin{tabular}{|c|c|c|c|c|c|}
\hline GROUP & $\begin{array}{l}\text { Process history } \\
\text { (Agnew } 1994) \\
\text { P }^{1}\end{array}$ & 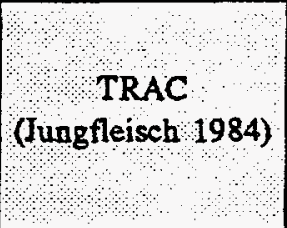 & $\begin{array}{l}\text { Analytical data range } \\
\text { (most quantitative assay) }\end{array}$ & $\begin{array}{c}1992 \text { cores } 31 \\
\text { and } 33 \\
\text { average }\end{array}$ & $\begin{array}{c}\text { Tank } \\
\text { inventory } \\
\text { based on } \\
1992 \text { core } \\
\text { data }\end{array}$ \\
\hline CATIONS & $\mu g / g$ & $\mu \mathrm{g} / \mathrm{g}$ & $\mu g / g$ & $\mu g / g$ & kgs \\
\hline Be.f & - & - & $<\mathrm{DL}$ & $<D L$ & $<0.22$ \\
\hline$\overline{B . a}$ & $\cdots$ & $\cdots$ & $23.4-32.2$ & 28 & 60.8 \\
\hline Na.f & 74,200 & 0 & $33,900-39,800$ & 37,000 & 80,300 \\
\hline Mg.a & -- & $\cdots$ & $290-479$ & 377 & 820 \\
\hline Al.f & 0 & 0 & $459-693$ & 570 & 1,240 \\
\hline Si.f & 2,800 & 0 & $5,410-5,960$ & 5,670 & 12,300 \\
\hline P.f & (as $\mathrm{PO}_{4}{ }^{3-}$ ) & $\left(\right.$ as $\left.\mathrm{PO}_{4}{ }^{3-}\right)$ & $9,070-11,600$ & 10,400 & 22,600 \\
\hline S.f & (as $\left.\mathrm{SO}_{4}{ }^{2-}\right)$ & $\left(\right.$ as $\left.\mathrm{SO}_{4}{ }^{2}\right)$ & $1,080-1,350$ & 1,230 & 2,660 \\
\hline K.a & 3,700 & 0 & $1,020-1,210$ & 1,140 & 2,460 \\
\hline Ca.f & 0 & 0 & $2,050-2,760$ & 2,420 & 5,260 \\
\hline Ti.f & -- & $\cdots$ & $22.3-72.9$ & 48 & 104 \\
\hline V.f & $\cdots$ & $\cdots$ & $12.1-16.5$ & 14.5 & 31.5 \\
\hline Cr.a & 33 & 719 & $1,840-2,140$ & 1,980 & 4,290 \\
\hline Mn.a & 90 & 507 & $6,140-6,710$ & 6,330 & 13,700 \\
\hline Fe.f & 9,400 & 10,300 & $15,900-20,500$ & 18,500 & 40,200 \\
\hline Ni.a & 0 & 0 & $108-151$ & 132 & 285 \\
\hline Co.f & -- & -- & $10.1 \cdot 13.3$ & 4.5 & 9 \\
\hline Cu.f & -- & -- & $22.1-36.3$ & 29.3 & 63 \\
\hline Zn.f & $\cdots$ & $\cdots$ & $104 \cdot 110$ & 106 & 231 \\
\hline As.a & $\cdots$ & $\cdots$ & $<\mathrm{DL}$ & $<3.3$ & $<7.2$ \\
\hline Se.a & $\overline{--}$ & $\cdots$ & $<\mathrm{DL}$ & $<1.5$ & $<3.3$ \\
\hline Sr.f & 0 & $\cdots$ & $280-334$ & 300 & 651 \\
\hline Zr.f & 0 & 0 & 4 & NR & $\cdots$ \\
\hline Ag.f & -- & 0 & $37.1-221$ & 130 & 278 \\
\hline Cd.f & -- & $\cdots$ & $6.42-10.7$ & 5.8 & 12.6 \\
\hline Sn.a & -- & $\cdots$ & $1.61-4.21$ & 2.5 & 5.4 \\
\hline Sb.a & -- & $\cdots$ & $22.6-36.5$ & 31.4 & 70 \\
\hline Ba.a & -- & 0 & $57.0-87.3$ & 69 & 150 \\
\hline La.a & 12,700 & 512 & $3,620-4,890$ & 4,220 & 9,160 \\
\hline
\end{tabular}


Table 5-23. Overall Data Summary and Inventory Estimates. (3 pages)

\begin{tabular}{|c|c|c|c|c|c|}
\hline GROUP & $\begin{array}{l}\text { Process history } \\
\text { (Agnew 1994) } \\
\text { (A) }\end{array}$ & $\begin{array}{c}\text { TRAC } \\
\text { (Jungfleisch 1984) } \\
\text { (1) }\end{array}$ & $\begin{array}{l}\text { Analytical data range } \\
\text { (most quantitative assay) }\end{array}$ & $\begin{array}{c}1992 \text { cores } 31 \\
\text { and } 33 \\
\text { average } \\
\text { anas }\end{array}$ & $\begin{array}{l}\text { Tank } \\
\text { inventory } \\
\text { based on } \\
1992 \text { core } \\
\text { data }\end{array}$ \\
\hline CATIONS & $\mu g / g$ & $\mu g / g$ & $\mu g / g$ & $\mu g / g$ & kgs \\
\hline Ce.a & 0 & 0 & $28.6-37.8$ & 33.7 & 73.2 \\
\hline Hg.CVAA & - & - & $1.08-1.83$ & 1.43 & 3.1 \\
\hline $\mathrm{Pb} . \mathrm{f}$ & 0 & 0 & $267-484$ & 365 & 792 \\
\hline Bi.a & 23,200 & 963,000 & $23,300-28,500$ & 26,000 & 56,300 \\
\hline U.LF & 140 & - & $1,950-5,200$ & 3,550 & 7,700 \\
\hline \multicolumn{6}{|c|}{ RADIONUCLIDES } \\
\hline Analyte & $\mu \mathrm{Ci} / \mathrm{g}$ & $\mu \mathrm{Ci} / \mathrm{g}$ & $\mu \mathrm{Ci} / \mathrm{g}$ & $\mu \mathrm{Ci} / \mathrm{g}$ & $\mathrm{Ci}$ \\
\hline Total Alpha & $\cdots$ & - & $0.166-0.649$ & 0.368 & $\mathbf{N A}$ \\
\hline Total Beta & - & - & $8.83-21.5$ & 15.1 & NA \\
\hline${ }^{241} \mathrm{Am}$ & - & 0.0092 & $0.0382-0.0478$ & 0.0425 & 92.4 \\
\hline${ }^{239 / 240} \mathrm{Pu}$ & 0.009 & 0.055 & $0.134-0.628$ & 0.304 & 660 \\
\hline${ }^{137} \mathrm{Cs}$ & 0.086 & 0 & $0.103-0.237$ & 0.166 & 360 \\
\hline${ }^{99} \mathrm{Tc}$ & - & 0 & $0.00473 \cdot 0.0114$ & 0.0079 & 17.2 \\
\hline${ }^{59} \mathrm{Ni}$ & $\cdots$ & $\cdots$ & $3.35 E-05-9.4 E-05$ & $5.04 E-05$ & 0.11 \\
\hline${ }^{63} \mathrm{Ni}$ & $\cdots$ & $\cdots$ & $0.0036-0.011$ & 0.0057 & 12.4 \\
\hline${ }^{90} \mathrm{Sr}$ & 0.176 & 1.84 & $3.43-7.43$ & 5.41 & 11,800 \\
\hline${ }^{14} \mathrm{C}$ & - & 0 & $<\mathrm{DL}$ & $<\mathrm{DL}$ & - \\
\hline${ }^{3} \mathrm{H}$ & $\cdots$ & -- & $<\mathrm{DL}$ & $<\mathrm{DL}$ & - \\
\hline \multicolumn{6}{|l|}{ ANIONS } \\
\hline Analyte & $\mu g / g$ & $\mu g / g$ & $\mu g / g$ & $\mu g / g$ & kgs \\
\hline $\mathrm{OH}^{-}$ & 8,900 & 15,700 & $3,300-6,000^{2}$ & $\overline{--}$ & $\cdots$ \\
\hline $\mathrm{NH}_{3}$ & $\cdots$ & $\overline{-}$ & $<\mathrm{DL}$ & $<D L$ & $\cdots$ \\
\hline$F$ & 24,600 & 0 & $1,370-3,130$ & 2,300 & 4,990 \\
\hline $\mathrm{Cl}^{-}$ & 0 & 0 & $400-500$ & 450 & 977 \\
\hline $\mathrm{NO}_{2}^{-}$ & 0 & 0 & $525-952$ & 793 & 1,720 \\
\hline $\mathrm{NO}_{3}^{-}$ & 51,600 & 0 & $36,900-44,300$ & 41,300 & 89,660 \\
\hline $\mathrm{CO}_{3}^{-}$ & 0 & 0 & as TIC & 812 & 1,760 \\
\hline Total $\mathrm{PO}_{4}^{-3}$ & 35,400 & 438,000 & $27,800-35,500$ & 31,900 & 70,100 \\
\hline
\end{tabular}


Table 5-23. Overall Data Summary and Inventory Estimates. (3 pages)

\begin{tabular}{|c|c|c|c|c|c|}
\hline GROUP & $\begin{array}{l}\text { Process history' } \\
\text { (Agnew } 1994) \\
\text { Po }\end{array}$ & $\begin{array}{l}\text { ') } \\
\text { (Jungfleisch } 1984)\end{array}$ & $\begin{array}{l}\text { Analytical data range } \\
\text { (most quantitative assay) }\end{array}$ & $\begin{array}{c}1992 \text { cores } 31 \\
\text { and } 33 \\
\text { average }\end{array}$ & $\begin{array}{c}\text { Tank } \\
\text { inventory } \\
\text { based on } \\
1992 \text { core } \\
\text { data }\end{array}$ \\
\hline CATIONS & $\mu \mathrm{g} / \mathrm{g}$ & $\mu \mathrm{g} / \mathrm{g}$ & $\mu g / g$ & $\mu g / g$ & kgs \\
\hline \multicolumn{6}{|l|}{ ANIONS } \\
\hline $\mathrm{SO}_{4}^{-2}$ & 1,450 & 0 & $3,290-3,690$ & 3,680 & 7,990 \\
\hline \multicolumn{6}{|c|}{ CARBON-BEARING SPECIES } \\
\hline Analyte & $\mu g / g$ & $\mu g / g$ & $\mu g / g$ & $\mu g / g$ & Kgs \\
\hline TOC & 2,000 & - & $2,000-3,990$ & 3,120 & 6,770 \\
\hline TIC & $\cdots$ & 0 & $650-950$ & 812 & 1,760 \\
\hline $\mathrm{C}_{2} \mathrm{H}_{3} \mathrm{O}_{2}^{-}$ & 0 & 0 & NM & - & - \\
\hline $\mathrm{C}_{2} \mathrm{O}_{4}{ }^{2-}$ & 7,200 & -- & $\mathbf{N M}$ & - & - \\
\hline $\mathrm{C}_{6} \mathrm{H}_{5} \mathrm{O}_{7}$ & 0 & 0 & $\overrightarrow{N M}$ & - & - \\
\hline $\mathrm{Fe}(\mathrm{CN})_{6}^{4 *}$ & 0 & 0 & $\mathrm{NM}$ & - & - \\
\hline EDTA & 0 & 0 & $\mathrm{NM}$ & - & -- \\
\hline HEDTA & 0 & 0 & $\mathbf{N M}$ & -- & $\cdots$ \\
\hline \multicolumn{6}{|c|}{ PHYSICAL PROPERTIES } \\
\hline $\begin{array}{l}\text { Wt\% Water } \\
\text { (Grav.) }\end{array}$ & $72.5 \%$ & $\cdots$ & $74.6-77.1$ & $76.0 \%$ & $1.65 \mathrm{E}+06 \mathrm{~kg}$ \\
\hline $\begin{array}{l}\text { Wi\% Water } \\
\text { (TGA) }\end{array}$ & $72.5 \%$ & $\cdots$ & $70.2-81.6$ & $76.5 \%$ & $1.66 \mathrm{E}+06 \mathrm{~kg}$ \\
\hline $\begin{array}{l}\text { Bulk } \\
\text { Density } \\
\left(\mathrm{g} / \mathrm{cm}^{3}\right)\end{array}$ & 1.21 & 1.8 & $1.19 \cdot 1.28$ & 1.24 & --- \\
\hline $\begin{array}{l}\text { Supernatant } \\
\text { Density } \\
\left(\mathrm{g} / \mathrm{cm}^{3}\right)\end{array}$ & 1.058 & $-\cdots$ & $1.033-1.038$ & 1.036 & -- \\
\hline
\end{tabular}

'Process history estimates are determined using a simple linear combination based on the proportions of $2 \mathrm{C}$ and 224 waste contributed.

${ }^{2} \mathrm{OH}$ is estimated from mass and charge imbalance. 


\section{$\overline{6} .0$ INTERPRETATION OF ANALYTICAL RESULTS}

Tank 241-T-111 had a relatively straightforward process history as documented in the transfer records. It received very few major types of waste that were likely to deposit solids during its operating history. The waste types, in chronological order, were as follows:

- $2 \mathrm{C}$ waste

- 224 Waste

- Decontamination streams from T Plant (221-T).

The purpose of this section is to attempt to identify and reconcile the location of the tank waste solids, thereby estimate the tank inventory for various analytes of importance.

The waste profile was identified by examining the available segment level assays for analytes or characteristics distinct to the waste types that were disposed in the tank, and then combining that information with what is known regarding the tank's process history. The first waste placed in the tank through the cascade inlet from tank 241-T-110 was $2 \mathrm{C}$ waste. Study of the process stream compositions indicates that this waste would be comparatively high in bismuth and phosphate in addition to the ubiquitous sodium, nitrate, and iron found in nearly all waste types. Elevated levels of fluoride, chromium, and sulfate are also expected. Qualitatively, the waste has been observed to be a gelatinous material. Anecdotal reports during this time also indicate that the cascade lines may have clogged in tank 241-T-111 and in other tank cascades receiving this type of waste. The $2 \mathrm{C}$ solids volume was measured to be between $723,000 \mathrm{~L}(191,000 \mathrm{gal})$ and $931,000(246,000 \mathrm{gal})$ in 1953 (Anderson 1990).

The tank then received 224 waste. The solids from this waste are high in manganese, lanthanum, and fluoride, however, the 224 waste may have been combined with the $2 \mathrm{C}$ waste before being discharged to the tank. The estimated solids volume contribution for this waste type in tank 241-T-111 at the end of bismuth phosphate production in T Plant was between 594,000 and $802,000 \mathrm{~L}$ (157,000 and 212,000 gal).

The last major waste type disposed in the tank was T-Plant decontamination waste. Much of the physical and chemical composition of this waste is unknown because it was a catch-all, consisting of various process residues, unused stock solutions, and aqueous decontamination solutions that contained surfactants (such as Turco $0^{\circ}$ ). Few predictions can be made from

Turco is a registered trademark of Turco Products, Inc. 
studying the historical process flowsheets in this case. Lack of analytical data and/or transfer records with regard to T-Plant effluents later in tank 241-T-111's service life are a great source of uncertainty regarding the waste near the surface. One observation is that slightly higher TOC values may be anticipated near the surface because of the use of detergents in the decontamination waste stream and its chronological discharge sequence with respect to the other wastes. This waste stream is estimated to occupy the top segment of waste, or $198,000 \mathrm{~L}(53,000 \mathrm{gal})$. The sum of the wastes would range between 1.52 million $\mathrm{L}$ and 1.93 million $\mathrm{L}$ (401,000 gal and 511,000 gallons), well within the reported range described in Anderson (1990). This waste volume would measure between 389.4 to $491.0 \mathrm{~cm}$ (153.3 to $193.3 \mathrm{in}$ ), measured from the centerline and distributed evenly across the tank. The present surveillance level status is almost exactly in the middle of this range 1.73 million L $(456,000 \mathrm{gal})$ and $440.2 \mathrm{~cm} \pm 1.3 \mathrm{~cm}(173.3 \pm 0.5 \mathrm{in})$ (Rios 1994).

Two common characteristics of all these waste types are high water content and relatively low activity. None of the waste streams disposed in this tank were concentrated through the evaporator; therefore, the waste tank would not have any salt cake. The uranium, plutonium, and fission product content of these wastes are uniformly low.

\subsection{Review of the Analyte Profiles}

The following conclusions are drawn from review of the available composite and segment analyses presented in Section 5, and the historical information presented in Section 2.

\section{Core 31}

The chemical analyses of core 31 indicate there are at least two primary types of material in distinct layers in the tank. The DSC traces for segments 1,2, and 3 show exotherms far out of proportion to the measured organic content in the wastes. The temperature range where the wastes begin to show reactions are from 170 to $400^{\circ} \mathrm{C}$, but do not appear to be self-sustaining. Instead, the overall energy profile is highly endothermic, probably caused by the large amount of bound water (70 to 80 weight percent) that is evaporated from the sample before a reaction is initiated. The overall physical and chemical properties of the waste in the tank roughly correspond to the expected behavior and composition of $2 \mathrm{C}$ waste, with large quantities of bismuth, iron, and phosphorous, and no exothermic behavior. But, there is a substantial contribution of manganese and lanthanum in the composites. However, these analytes can be found in 224 waste, and historical data indicates that 224 waste was added to tank 241-T-111 later in its service life. Therefore, the analytical and historical data correspond reasonably well, except for the anomalous energetic results. At this time, there is no adequate explanation for the observed exotherms in the upper segments of tank 241-T-111 waste. 


\section{Core 32}

Every segment of core 32 was compromised during the sampling process in some fashion. When the sampler operated properly, liquids were the only material recovered from this core. However, the sampler valve failed repeatedly. Photographs taken before and after the sampling event reveal that there was a plastic bag in the vicinity of the sampling area before coring operations. After core sampling, the bag can not be seen. It is surmised that the sampling drill string was obstructed by the bag during core sampling operations, causing the corruption of the samples. All samples from core 32 were rendered unusable or categorized as non-representative. Therefore, no assays were performed and no analytical results are. reported.

\section{Core 33}

The chemical analyses of core 33 indicate there probably are three primary types of material in distinct layers in the tank. The extremely high manganese values in the top first segment of the tank are attributed to a combination of T-Plant decontamination waste (i.e. the result of a final process flush during the decontamination of $T$ Plant) and 224-waste solids deposited late in the tank's service life. Proceeding deeper into the tank, beneath the first segment, the distribution of bismuth, manganese, lanthanum, and chromium in the composites and the analyte profiles from the homogenization results through segment 3 support the conclusion that this material is still 224 waste. Segment 3 itself is suspected to be a transition layer, containing the boundary between the 224 waste and the $2 \mathrm{C}$ waste, based on the exothermic behavior of the waste as a function of depth. The TOC analysis indicates moderate amounts of residual organics in the waste.

Cesium - 137 concentrations between the core composites vary within a factor of two, and the variation in the ${ }^{241} \mathrm{Am}$ is less than 13 percent. But the change in concentration as a function of depth for each of these analytes is much more significant. Both analyte profiles show a decreasing trend as a function of depth in core 33 . The ${ }^{137} \mathrm{Cs}$ concentration decreases by more than a factor of 30 over the depth of the tank, and ${ }^{241} \mathrm{Am}$ decreases by a factor of 10 through segment 7 before rebounding somewhat in segment 9 . The ${ }^{137} \mathrm{Cs}$ and ${ }^{241} \mathrm{Am}$ concentrations as a function of depth in core 33 show profiles consistent with the wastes believed to be associated with the segments: low overall ${ }^{137} \mathrm{Cs}$ and ${ }^{241} \mathrm{Am}$ values. But the relative radionuclide concentrations for the suspected 224 and T-Plant decontamination wastes are higher than the $2 \mathrm{C}$ wastes. The ${ }^{90} \mathrm{Sr}$ concentration is also low, and ${ }^{90} \mathrm{Sr}$ is similar to ${ }^{137} \mathrm{Cs}$ in the magnitude of the change in concentration and as a function of location for both cores. However, there are no high radionuclide values anywhere in the tank, and the tank temperature further confirms the tank's low radionuclide content.

Lanthanum and phosphate/phosphorus demonstrate an increasing concentration profile as a function of depth. Between segments 1 and 3 and 3 and 5 there is an abrupt change in the concentrations of calcium, chromium, manganese, bismuth, lanthanum, and phosphorous, although after segment 5 , the analyte concentrations tend to plateau, mirroring the behavior 
of the radionuclides. In addition, the DSC traces for segments 1,2 , and 3 show exotherms far out of proportion to the measured organic content in the waste. The temperatures where the wastes begin to show reactions range from 170 to $400^{\circ} \mathrm{C}$, but these reactions do not appear to be self-sustaining. Instead, the overall energy release is highly endothermic, probably from the large amount of bound water that is evaporated from the sample before a reaction is initiated.

In conclusion, the physical and chemical properties of the waste in the bottom half of the tank correspond to the expected behavior and composition of $2 \mathrm{C}$ waste, and the upper half of the tank is suspected to be 224 waste with a high manganese layer located in segment 1. Therefore, the analytical and historical data correspond well with the historical fill pattern, except for the anomalous energetic results. Presently there is no adequate explanation for the observed exotherms in the upper segments of tank 241-T-111 waste.

\subsubsection{Entrance, Exit, and Mixing Effects on Analyte Distribution}

Figure 5-1 shows an elevation and plan view of where the core samples were taken. Important items to note are the arrangement and location of the risers and cascade lines (inlet and outlet). Their configuration can have a substantial impact on the distribution of waste in the tank, and observations with regard to sampling. However, the waste entrance and exit points for the tank over its service life are not well documented, therefore the spatial relationship and proximity to the sample risers is not known. The decant "float and flex" pump contained a $6.1-\mathrm{m}(20-\mathrm{ft})$ section of flexible hose that could traverse a relatively wide area under and around the pumpout riser. The cascade fill line where $2 \mathrm{C}$ waste entered the tank is closer to the core 33 sample point than to the core 31 sample point. There was very limited discharge/transfer traffic from the other separations plants within $\mathrm{T}$ farm or with the tank farms as a whole, so no highly enriched layer of radioactive material is expected to lie on top of the waste as has been observed in other tanks sampled. However, the relative concentration of radionuclides is observed to be higher in the upper portions of the tank.

As new wastes entered the tank and were distributed across it, the material under and around the tank pumpout could have been disturbed, and occasionally solids could have been transferred, in behavior similar to the last in, first out principle. It is believed that the material beneath the waste inlets, the cascades and perhaps a riser, would have been disturbed initially, but over time, large stratified layers resistant to mixing eventually would have built up. No deliberate mixing of the wastes was performed; therefore, where segment-level data is available, distinctions between waste types can be made. Some of the larger particulate materials discharged to the tank initially may have settled out near the inlet because they were not as flocculent or as easily suspended as some of the other solids. This settling behavior may have provided a slight degree of separation. Therefore, the influence of the waste inlet and outlet locations can provide insight to the analyte distribution and waste profiles between cores 31 and 33 . These factors may account for the nominally observed lateral heterogeneity between cores 31 and 33; however, it must be noted that this lateral 
heterogeneity is very slight and there may be several other factors contributing to this observation.

\subsubsection{Waste Profile}

Given the historical and analytical data, it is possible to develop a rough representation of the wastes as they presently are configured in tank 241-T-111. Figure 6-1 shows a representation of the overall waste profile of tank 241-T-111 and the assumed volumes, boundaries, and positions of the various individual layers as they are believed to exist.

\subsection{WASTE SUMMARY AND CONDITIONS}

Historically, 241-T-111 was a non-watch list single-shell tank with no previous indication of a potential safety issues. All waste receipts were $2 \mathrm{C}$ waste, 224 waste, or residues from the T-Plant cleanout. Flowsheet records indicate that small amounts of oxalate are present in 224 waste (at $0.028 \underline{\mathrm{M}}$ ) (Schneider 1951). As a result of DSC measurements, tank 241-T-111 was added to the Organic Watch List on March 4, 1994 and further concerns have been raised about the tank's integrity.

When tank 241-T-111 was sampled, normal paraffin hydrocarbon was used as a hydrostatic fluid, presenting a potential contamination source and bias for the DSC. However, when taking the first segment, no normal paraffin hydrocarbon was used, and sample recovery for the other segments in the cores was excellent. No voids or separable liquid layer were observed on extrusion of the samples, and results from the gas chromatograph/mass spectrometer for normal paraffin hydrocarbons components showed only trace amounts, precluding significant sample contamination from the hydrostatic head fluid. Furthermore, experiments have demonstrated that normal paraffin hydrocarbons steam distill away before reaching the reaction temperatures observed in DSC assays of the samples. In the deeper segments and in the composites, core 31 demonstrates some activity, but not to the extent shown in the upper segments. In core 33, no significant exotherms are evident in the composite. The photographs of the extruded waste material demonstrated that the all of the core samples were viscous, gel-like materials with very little free liquid, and that they held their shape relatively well. During the physical testing of the core 31 , segment 2 solid sample, when the sample was centrifuged, there was some separation of free water from the gel. Later physical testing did show some separation of liquid from the waste matrix for segment 7, but again, no separable phase was observed in the liquid (Delegard 1994). In each case, the liquid did not appear to have any distinct layers, therefore no liquid organics are considered to contribute to this waste matrix. In addition, although historically there have been problems with both volatile and semi-volatile organics analysis methods and 
WHC-EP-0806

Figure 6-1. Waste Profile of Tank 241-T-111.

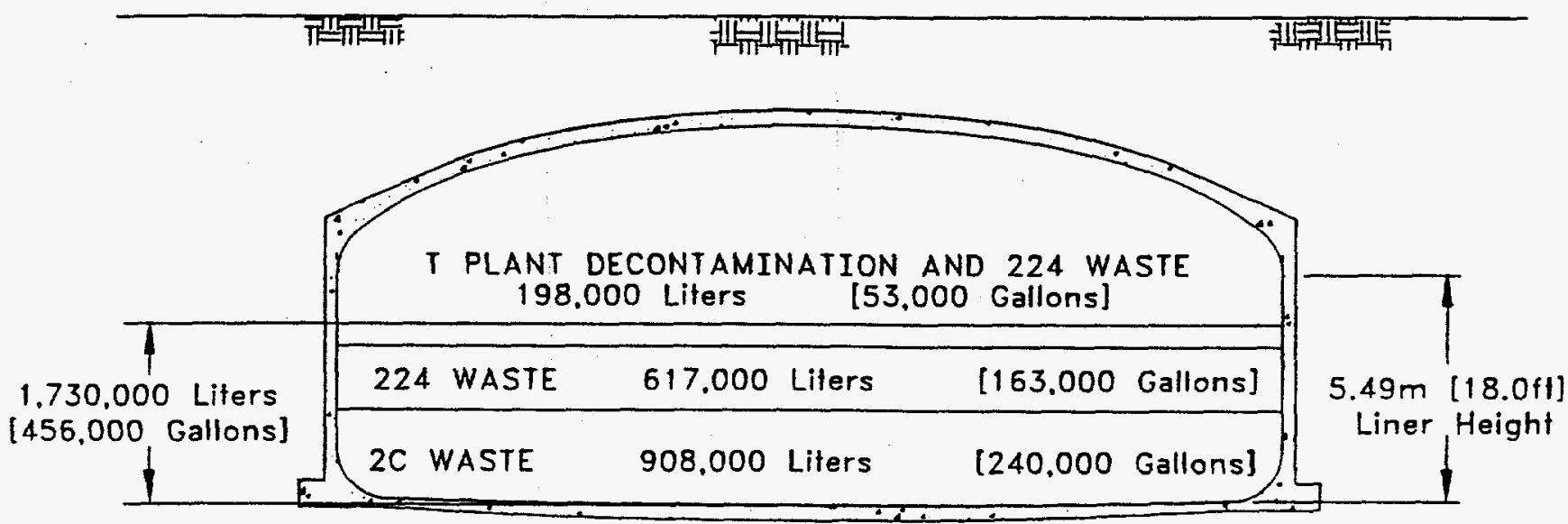

- Dished bottom and tank layer 1: 2C, 908,000 L (240,000 gal)

- Tank layer 2: 224 waste, $617,000 \mathrm{~L}(163,000 \mathrm{gal})$

- Tank layer 3: T-Plant decontamination and 224 wastes, 198,000 L (53,000 gal) 
holding times on these samples, all of the results from these assays show levels of these compounds below EPA contract laboratory procedure quantitation limits.

This information, coupled with data from the organic vapor monitor taken during the recent liquid sample effort (Appendix C), supports the contention that there are no substantial liquid organics in the tank. The organic vapor monitor results from the vapor space of tank 241-T-111 show a reading of 9.2 parts per million over a three minute monitoring interval: a detectable concentration, but far below the established safety criterion of 20 percent of the lower flammability limit. This result from the organic vapor monitor is not unexpected because small quantities of ammonia were observed in the grab samples and historically ammonia was used as a process chemical in the tank wastes. Over time, the ammonia is believed to have dissipated slowly to the levels observed today. It is also believed that the vapor space of this tank is relatively homogenous, and therefore, large concentration gradients for organics and other materials in the vapor space are not plausible. Differences of 2 to 10 times are within the realm of possibility (10 times being an extreme). Factors higher than that are not considered credible. For comparison, the vapor space of tank 241-C-103, which has a known organic liquid layer, was found to be $200 \mathrm{ppm}$.

Furthermore, a simplified modeling scenario of tank $241-\mathrm{T}-111$ shows that if normal-paraffin-hydrocarbon-type liquid organics were present, they would be in much greater quantities than detected in the organic vapor monitor (see Appendix C).

To conclude, the waste in tank $241-\mathrm{T}-111$ is a complex material, primarily made up of water and organic and inorganic salts in a gel-like matrix. The insoluble solids are a mixture of phosphates, silicates, hydrated oxides, and hydroxides in combination with calcium, chromium, lanthanum, iron, bismuth, manganese, and uranium. The soluble analytes are primarily sodium, nitrate, sulfate, and fluoride. Phosphorous is nearly evenly divided between its soluble and insoluble forms. Substantial exotherms were detected in segments 1 , 2 , and 3 , with the reactivity tailing off in segment 4 of core 31 and in segments 1 , and 2 , with the reactivity tailing off in segment 3 of core 33 . The exotherms were reported to be similar in size and temperature range. It is important to note that no exotherms are observed until the sample has been dried and heated to approximately $180^{\circ} \mathrm{C}$. The exotherms themselves do not appear to be kinetically fast, thus the reaction may not be able to sustain itself without being thermally driven, as they are in the DSC apparatus. The organics present appear to be in the form of slightly soluble salts, contributing to a gel or sol-like structure. This behavior would be consistent with the very high moisture content observed in these tanks and with the types of organics historically indicated to be in the waste: aqueous decontamination solutions using surfactants, not normal paraffin hydrocarbons or TBP-type organics. This would help explain their low volatility and reactivity, their presence in the solid phase, and their relative absence in the liquids. These materials are carbon-bearing and will, if given enough impetus in the form of a thermal driver, react; however, the reaction does not appear rapid or self-sustaining, and will not occur without first removing the water from the gel. No other safety issue was found after critically reviewing the analytical, historical, and surveillance data. 


\section{Hypotheses Regarding Recent Behavior of 241-T-111}

Recently, surveillance data indicated that there had been a relatively abrupt level change in tank 241-T-111 over the past 16 to 18 months. Approximately $2.5 \mathrm{~cm}(1 \mathrm{in})$ of gradual sludge growth was observed over the last eight-year period, followed by an approximately 4.1-cm (1.6-in) decrease in surface level over 16 months. This situation is cause for concern. Tank 241-T-111 is an assumed leaker, therefore there is the possibility that the tank has leaked again and waste is being lost to the environment. This is not an acceptable condition. Tank Farm Operating Procedures (Boyles 1992) specify that when a level drop in a tank is observed, the observation must be accompanied by certain actions, and that a leaking tank must be pumped to eliminate any remaining drainable liquid to prevent further environmental contamination. However, the observed level decrease was not large enough to trigger action past investigation under present guidelines (Boyles 1992), and it was not resolved that a leak was the only explanation for the observed behavior. In fact, there were observers who believed there was another safety issue requiring consideration involved. The final outcome of the review, however, was the decision to pump the liquid in the saltwell of tank 241-T-111 to tank 241-SY-102 (Jenkins and Engelman 1994). This section recaps some of the alternative explanations presented for the surveillance data and provides some of the strongest and weakest points of the arguments put forth.

- Tank is a "Re-leaker"

Evidence supporting this point of view is strong and it is one of the most favored explanations for the observed level drop. Tank integrity was questionable for a long period of time, and the tank was declared a leaker in 1984. Corrosion of tank liner is also evident from in-tank photographs. However, the change in surface level could be a localized phenomenon and in-tank photographs and observations of the extruded core material indicate that the waste is viscous and cohesive. Substantial damage to the tank liner and shell would be necessary for the evacuation of over 11,000 L (3,000 gal) of material and this condition is not indicated.

- Long Cycle Gas-Release Tank

This proposition is more speculative, but warrants consideration. Cyclic, gas generating behavior previously has been observed in Hanford-Site waste tanks. Specifically, tank 241-T-110, the cascade source for tank 241-T-111, is on the Gas-Generation Watch List. Viscous waste material, such as that observed in tank 241-T-111, also appears to be able to retain generated gases. However, overall tank information, specifically the analytical chemistry results, indicate tank conditions necessary for gas generation as currently understood (i.e. high radionuclide and complexant levels), do not exist. 
- Intrinsic Waste Matrix Changes

This explanation is even more tenuous than the previous one, but again, the present understanding of the high-level waste tank matrices is very limited, so it is within the realm of possibility. Composition and structure of the waste (small particles, high water content, high ionic strength solution, and possible organic surfactants), may be similar to an emulsion. Over time, the low-level radiolytic action and thermal cycling of the waste may break down the colloidal characteristics of the matrix. The breakdown may be uneven, and there may even be a slurry-growth phase before the separation of the emulsion and the loss of free water through pinhole corrosion. However, that same degree of uncertainty regarding the content and structure of the waste matrix makes this hypothesis highly speculative without much more characterization information than currently exists.

- Structural Subsidence of the Waste

This particular condition may be a contributing factor to the observed behavior, since it is acknowledged that the overall configuration of the waste generally is not very well known (and that the surfaces of the waste beds can be highly irregular), however it is not considered the main cause. After disposal into the tank, irregularities in the waste bed may have formed. The shifting of the waste bed over time as a result of gravitational compression is potentially responsible for the sudden drop in waste level. However, this rationale does not adequately explain the observed increase in tank level without involving another agent (i.e. a slow tank intrusion). Also, further slumping of the waste was not observed in the recent in-tank photographs, and the waste surface was observed to be reasonably uniform.

- Other Possibilities or Combinations of the Preceding Agents

There may be more than one mechanism involved in the observed behavior, such as a long-term slow intrusion coupled with a subsequent upset and relatively rapid loss of material, especially of liquid, because the matrix appears to be quite viscous. There are a limited number of measurements taken and their location is fixed; therefore, local irregularities may be exacerbated. In addition, measurement error and bias also are significant when considering the magnitude of the drop in comparison with the error band. 


\subsection{TWRS PROGRAM ELEMENT CHARACTERIZATION SYNOPSIS}

This section provides selected results obtained from core sampling for some of the most pertinent analytes for the various TWRS program elements, including vitrification, Retrieval, Pretreatment, and Waste Tank Safety. Analytes of interest will be reported on a level of resolution commensurate with the available data and program direction. Watch-list tanks will have segment or subsegment level analyses reported, while non-watch-list tanks are analyzed on a core composite basis. Analytes of interest to multiple programs generally will be reported only in one section. Further detail can be found in the body of the report or in the data packages.

\subsubsection{Retrieval Program Data Summary: Physical Properties}

A major objective of the characterization program is to measure the physical properties of the waste to support waste retrieval technology development. The analytical methods to determine the physical properties of the waste as it actually exists in the tank require 50 to $100 \mathrm{~g}$ of unhomogenized sample. In some cases, the limited amount of sample recovered constrains the number of analyses that can be performed. At the time of the sampling and analysis of tank 241-T-111 waste, no data quality objective existed to define the scope of the analyses. However, several analytes that specifically relate to physical properties were determined to be of interest to the program and are summarized here. The physical characteristics of tank waste are required to develop design criteria for waste retrieval equipment, provide a basis for simulated waste development, and to provide a basis for validation of equipment testing using design criteria and simulated waste. Selected rheological and physical properties are presented in Table 6-1. Further information regarding these analytes can be found in Section 5.3.

Table 6-1. Retrieval Program.

\begin{tabular}{|l|l|}
\hline \multicolumn{1}{|c|}{ Analyte } & \multicolumn{1}{|c|}{ Data range } \\
\hline $\begin{array}{l}\text { Specific gravity (g/mL) } \\
\text {--solids } \\
\text {--liquids (grab sample) }\end{array}$ & $1.19-1.28$ \\
\hline Shear strength & $5,000 \pm 2,300$ dynes $/ \mathrm{cm}^{2}$ \\
\hline $\begin{array}{l}\text { Viscosity (mPa } \bullet \text { s) } \\
--1: 1 \text { dilution @ 29 }{ }^{\circ} \mathrm{C}\end{array}$ & Less than $2 \mathrm{mPa} \bullet \mathrm{s}(\mathrm{cP})$ \\
\hline Settled solids (Vol \%) & $100 \%$ \\
\hline Weight \% solids & 22.4 to 29.3 \\
\hline $\begin{array}{l}\text { Weight \% undissolved } \\
\text { solids }\end{array}$ & 19.0 to 25.4 \\
\hline $\begin{array}{l}\text { Particle size }(\mu \mathrm{m}) \\
\text {--number distribution } \\
\text {--volume distribution }\end{array}$ & $85 \%<2 \mu \mathrm{m}$ \\
\hline
\end{tabular}




\subsubsection{Final Disposal Program Data Summary}

\section{Bulk Constituent Concentrations for Pretreatment}

Programmatic decisions pertaining to the design of pretreatment and final disposal systems shall be based upon the average characteristics of the tank waste. Therefore, the majority of the laboratory analyses shall be conducted on representative core composites. However, as noted in other documentation (Bell 1993), segment, subsegment, and additional analyses will be performed when directed. The constituent concentrations and inventories shall be calculated by either treating the core samples as random samples and averaging the results, or by using a spatial model. The calculated values will include an estimated total quantity of each selected analyte and its corresponding confidence interval (CI) based upon analytical and sampling variability. Again, no data quality objective existed to define the scope of the analyses at the time tank 241-T-111 was sampled and analyzed. However, several analytes relating specifically to the most significant chemical and radiological contributors and their solubility properties were determined to be of interest to the program and are summarized here. Chemical analytes of interest are presented in Table 6-2. Trace analytes and more comprehensive chemical and radiological characterization information can be found in Section 5.

\section{Low-level and High-Level Vitrification Program}

The final disposal option for Hanford-Site wastes has been determined to be vitrification after partitioning into low-level and high-level fractions. This program has characterization needs in addition to those described for core sampling. The vitrification process will be performed after the solids have been pretreated. Therefore, the core sample information will provide preliminary bounding design conditions for the vitrification plant. Further characterization for technology development and regulatory compliance will be necessary on the pretreated waste that will be fed to the vitrification plant. Although the data requirements for this option are not formally defined, the analytical requirements for the previous Hanford Waste Vitrification program generally are applicable and are identified in the Hanford Waste Vitrification Plant Feed Characterization Requirements, Revision 4 (Wagner 1992). These requirements are quite similar to the pretreatment program requirements, and therefore are presented together in this section (see Table 6-2). For more specific information on a particular analyte not given in this table, consult the data package (McKinney, et al. 1993) or the appropriate table in Section 5.

The analytical program for vitrification not only entails determining if a waste type is suitable for disposal as glass, but also includes determining the physical and chemical characteristics of the glass for process-control purposes and to ensure regulatory compliance. Sampling and analysis plans will be developed on an individual basis for each tank or process batch. The characterization needs for these efforts include analyses for metals, water-soluble anions, radionuclides, semi-volatile organics, and rheological and physical testing for both the feed and vitrified product. 
Table 6-2. Concentrations and Solubility of Principal Waste Components.

\begin{tabular}{|l|r|c|c|}
\hline \multicolumn{1}{|c|}{ Analyte } & $\begin{array}{c}\text { Tank average } \\
\text { concentration } \\
\text { water prep: }(\mu \mathrm{g} / \mathrm{g})\end{array}$ & $\begin{array}{c}\text { Tank average } \\
\text { concentration } \\
\text { fusion prep: } \\
(\mu \mathrm{g} / \mathrm{g})\end{array}$ & $\begin{array}{c}\text { \% Water } \\
\text { soluble }\end{array}$ \\
\hline Calcium & 61.8 & 2,420 & 2.55 \\
\hline Chromium & 218.3 & 1,980 & 11.03 \\
\hline Iron & 127.7 & 18,500 & 0.69 \\
\hline Aluminum & 10.9 & 570 & 1.91 \\
\hline Sodium & 33,000 & 37,000 & 89.19 \\
\hline Bismuth & 201.8 & 26,000 & 0.78 \\
\hline Lanthanum & 11.0 & 4,220 & 0.26 \\
\hline Silicon & 571.8 & 5,670 & 10.08 \\
\hline Uranium & No measurement & 3,550 & -- \\
\hline Zirconium & 0.8 & 4.0 & 20.00 \\
\hline Phosphate & $15,600(\mathrm{IC})$ & 32,300 & 48.29 \\
\hline Sulfate & $3,550(\mathrm{IC})$ & 3,680 & 96.47 \\
\hline Nitrate & 41,300 & Not Applicable & --- \\
\hline Fluoride & 2,300 & Not Applicable & -- \\
\hline TOC & 3,120 & Not Applicable & -- \\
\hline Radionuclides & $(\mu \mathrm{Ci} / \mathrm{g})$ & $(\mu$ Ci/g) & \\
\hline 90 Sr & $0.00097(\mathrm{Grab})$ & 5.41 & 0.018 \\
\hline${ }^{137} \mathrm{Cs}$ & $0.087(\mathrm{Grab})$ & 0.166 & 52.33 \\
\hline
\end{tabular}

Tank 241-T-111 presently is not scheduled as an early feed for pretreatment and vitrification. The following characterization objectives need to be addressed in a data quality objective supporting the design of retrieval, pretreatment, and final disposal systems for early feed tanks.

- Provide extensive characterization of the chemical and radiological contents of the waste (solids and supernate) as it currently exists in the tanks to evaluate how it can be processed and to verify if the composition variability study envelope coverage for key analytes is adequate. 
- Estimate the waste fraction that will remain after sludge wash pretreatment and estimate the feeds for the low-level and high-level streams for vitrification.

- Simulate sludge washing pretreatment on the waste material. This will provide a detailed understanding of the sludge wash process and obtain empirical data on soluble species removal.

- Determine the physical and rheological properties of the waste before and after simulated sludge washing to support the design of a waste retrieval system.

- Provide a supply of sludge washed material to be used as feed material for a laboratory scale vitrification.

- Satisfy the general characterization requirements for physical, chemical, and radiological analytes.

\subsubsection{Waste Tank Safety Program Characterization Data Summary}

\section{Safety Screening}

The tank safety screening data quality objective will be used to classify 149 SSTs and 28 double-shell tanks that contain high-level radioactive waste into specific safety categories for issues dealing with the presence of ferrocyanide, organics, flammable gases, and criticality (Babad and Redus 1994). The analytes used to make this classification are fuel energy value, total alpha concentration, weight percent moisture, and gas composition. The following table presents the analytes of concern, the criterion for classification, and the analytical result from the tank, where available. Further information on the tank contents are presented in subsequent sections. Because of the exothermic response of the waste material from the upper portions of tank 241-T-111, it has been placed on the Organic Watch List, and further studies trying to resolve the nature of the observed reaction are continuing. Table 6-3 provides a comparison of the tank values with the safety screening criteria.

Table 6-3. Tank 241-T-111 Comparison to Safety Screening Criteria.

\begin{tabular}{|l|l|l|}
\hline \multicolumn{1}{|c|}{ Analyte } & \multicolumn{1}{|c|}{ Safety issue/criteria } & \multicolumn{1}{c|}{ Tank result } \\
\hline $\begin{array}{l}\text { Fuel energy value } \\
\text { (cal/dry g) }\end{array}$ & $\begin{array}{l}\text { Organics, ferrocyanide, } \\
\text { flammable gas; }-125 \mathrm{cal} / \mathrm{dry} \mathrm{g}\end{array}$ & $\begin{array}{l}\text { Greater than } \\
-215 \mathrm{cal} / \mathrm{dry} \mathrm{g}\end{array}$ \\
\hline Total alpha concentration & Criticality; $1 \mathrm{~g}{ }^{239} \mathrm{Pu} / \mathrm{L}$ & $0.0053 \mathrm{~g} / \mathrm{L}$ \\
\hline Percent moisture & $\begin{array}{l}\text { Organics, ferrocyanide, } \\
\text { flammable gas; } 17 \mathrm{wt} \%\end{array}$ & $76 \mathrm{wt} \%$ \\
\hline Gas composition & $25 \%$ lower flammability limit & NA \\
\hline
\end{tabular}

$\mathrm{NA}=$ Not available 


\section{Criticality Safety}

The criticality safety program has indicated that plutonium and uranium isotopic analyses on each core composite and the bottom six inches of each core is required to alleviate the concern for the potential of tank criticality. Therefore, upon extruding the last segment in a core, the waste to be tested shall be homogenized before a small aliquot is taken and analyzed for plutonium and uranium isotopic analyses by mass spectroscopy. The analyses will indicate whether the fissile species have settled in a concentrated layer at the bottom of a tank. However, this analytical criterion was established after the sampling and analysis of tank 241-T-111 waste. Tables 6-4 and 6-5 present a summary of the core composite data for uranium and plutonium concentration. After reviewing the data, the isotopic analyses from both cores 31 and 33 were found to be very consistent with regard to composition, and the total alpha content indicated from the core 33, segment 9 homogenization data is extremely low $(0.262 \mu \mathrm{Ci} / \mathrm{g})$. Therefore further re-analysis and isotopic resolution of the core sample material from the lower portion of cores 31 and 33, segment 9 is not warranted. For this tank to exceed established operating limits for fissile material in the tank farms, a concentration of $1.58 \mu \mathrm{Ci} / \mathrm{g}{ }^{239 / 240} \mathrm{Pu}$ was calculated as a threshold limit value (see Appendix C).

Table 6-4. Core Composite Uranium.

\begin{tabular}{|l|c|c|c|c|}
\hline \multicolumn{1}{|c|}{ Core No. } & $\begin{array}{c}\mathrm{U}_{\mathrm{FL}}(222-\mathrm{S}) \\
(\mu \mathrm{g} / \mathrm{g})\end{array}$ & $\begin{array}{c}\mathrm{U}_{\mathrm{FL}}(325) \\
(\mu \mathrm{g} / \mathrm{g})\end{array}$ & $\begin{array}{c}{ }^{238} \mathrm{U} \\
\text { mass percent }\end{array}$ & $\begin{array}{c}{ }^{235} \mathrm{U} \\
\text { mass percent }\end{array}$ \\
\hline Core 31, composite 1 & 2,180 & 4,000 & 99.3074 & 0.6755 \\
\hline Core 31, composite 2 & 3,880 & 5,200 & 99.3098 & 0.6761 \\
\hline Core 33, composite 1 & 3,180 & 4,500 & 99.3125 & 0.6761 \\
\hline Core 33, composite 2 & 1,950 & 3,500 & 99.3161 & 0.6717 \\
\hline
\end{tabular}

$\mathrm{FL}=$ Uranium measurement by laser fluorimetry.

Table 6-5. Plutonium Concentration and Isotopic Distribution

\begin{tabular}{|c|c|c|c|c|c|c|c|}
\hline $\begin{array}{c}\text { Core } \\
\text { number }\end{array}$ & $\begin{array}{c}\text { Total Pu } \\
\alpha(222-\mathrm{S}) \\
(\mu \mathrm{Ci} / \mathrm{g})\end{array}$ & $\begin{array}{c}\text { Total Pu } \\
\alpha(325) \\
(\mu \mathrm{Ci} / \mathrm{g})\end{array}$ & $\begin{array}{c}{ }^{238} \mathrm{Pu} \\
\text { mass } \\
\text { percent }\end{array}$ & $\begin{array}{c}{ }^{239} \mathrm{Pu} \\
\text { mass } \\
\text { percent }\end{array}$ & $\begin{array}{c}{ }^{240} \mathrm{Pu} \\
\text { mass } \\
\text { percent }\end{array}$ & $\begin{array}{c}{ }^{241} \mathrm{Pu} \\
\text { mass } \\
\text { percent }\end{array}$ & $\begin{array}{c}{ }^{242} \mathrm{Pu} \\
\text { mass } \\
\text { percent }\end{array}$ \\
\hline Core 31 C1 & 0.138 & 0.628 & 0.005 & 96.7199 & 3.2109 & 0.0352 & 0.0151 \\
\hline Core 31 C2 & 0.136 & 0.565 & 0.0105 & 96.6351 & 3.2834 & 0.0496 & 0.0215 \\
\hline Core 33 C1 & 0.134 & 0.319 & 0.004 & 96.7540 & 3.1046 & 0.1071 & 0.0683 \\
\hline Core 33 C2 & 0.147 & 0.368 & 0.0105 & 96.5499 & 3.3436 & 0.0621 & 0.0337 \\
\hline
\end{tabular}




\section{Organic Tanks}

The following characterization objectives support resolution of this unreviewed safety question and safety issue and support retrieval, pretreatment, and final disposal systems design. Table 6-6 provides a comparison of the tank core composite values with the Organic Data Quality Objective Criteria.

- Determine the overall waste energetics and properties governing waste reactivity behavior in the tanks.

- Determine the spatial distribution of ${ }^{137} \mathrm{Cs}$ and ${ }^{90} \mathrm{Sr}$.

- Determine the concentration of TOC and the speciation of organics present in the waste.

- Satisfy the general characterization requirements for physical, chemical, and radiological analytes.

Table 6-6. Data Quality Objective Decision Limits for Organic Tanks. (Babad 1994)

\begin{tabular}{|l|l|l|}
\hline \multicolumn{1}{|c|}{ Analyte } & \multicolumn{1}{|c|}{ Decision threshold } & \multicolumn{1}{c|}{ Tank result } \\
\hline TOC (Dry wt\%) & $>5 \mathrm{wt} \%$ (dry basis) & $\begin{array}{l}1.3 \mathrm{wt} \% \text { (tank) } \\
4.1 \mathrm{wt} \% \text { (Core 33, Seg. 2) }\end{array}$ \\
\hline Moisture content (wt\%) & $<17 \mathrm{wt} \%$ & $76 \mathrm{wt} \%$ \\
\hline Presence of organic layer & Yes $/$ No & No \\
\hline Tank temperature $\left({ }^{\circ} \mathrm{C}\right.$ ) & $90^{\circ} \mathrm{C}$ & $16{ }^{\circ} \mathrm{C}$ \\
\hline Total fuel content & $-125 \mathrm{cal} / \mathrm{dry} \mathrm{g}$ & In excess of $-215 \mathrm{cal} / \mathrm{dry} \mathrm{g}$ \\
\hline
\end{tabular}

Further analysis and secondary analytes for measurement were found to be unwarranted for the tank composites; however, the first two segments of core 31 and three segments of core 33 will undergo additional study. The results from this series of assays will be incorporated into the revision of this characterization report as they become available. 
This page intentionally left blank. 


\subsection{QUAN̄TITATIVE/STATISTICAL INTERPRETATION OF THE DATA}

This section contains the results of the statistical analysis of data from two core samples obtained from tank 241-T-111. Section 7.1 contains a description of the core-sample data used in the statistical analyses and some general observations regarding the data. Section 7.2 contains mean concentration estimates, and the associated 95 percent CIs, for each of the analytes in tank 241-T-111 waste. Section 7.3 contains estimates of the spatial variability (variability between cores), and estimates of the analytical error from the core composite data in tank 241-T-111. Further information can be found in Jensen (1994).

Two types of analytical error were estimated from the core composite data: variability between composite samples within the same core and variability between the primary and duplicate analyses within each core composite sample. Estimates of the analytical measurement error were used to test the significance of the spatial and compositing variability. Spatial variability was significant (i.e. substantially greater than zero at the 0.05 significance level) in 40 out of 79 analytes in the tank. The compositing variance was significant for 38 out of the 79 analytes.

\subsection{APPROACH}

Cores 31 and 33 were the two valid core samples taken from tank 241-T-111. The segment recoveries for each core were given previously in Section 4 . Two core composite samples were made for each core from the homogenized solid segment waste. Primary and duplicate results were obtained from each core composite.

The ICP acid digestion, ICP fusion dissolution, ICP water leach, IC water leach analyses, selected radiochemistry, and other GEA were performed on all composite core samples. These were the analytical results used in the statistical treatment of the data. In the tables in Appendix B, the data are identified by the analysis method, the type of dissolution, and analyte; e.g., the notation ICP.a.Al refers to aluminum, acid digestion, and an ICP analysis. The core composite sample results used also are contained in Appendix B, together with ratios of the mean of each sample and duplicate divided by the detection limit for that pair. The data package for tank 241-T-111 (McKinney et al. 1993) contains a complete report of the sample results along with the laboratory quality control data. The core composite data for each analyte are illustrated in Appendix B.

Statistics were calculated for analytes with concentrations greater than 10 times their detection limits (DL). Personnel within the TWRS Information Management Systems have identified a list of analytes that have exception to this rule. Table 7-1 lists the analytes specified. Statistics were calculated for the analytes from this list if the concentrations were greater than three times their DL. For a number of analytes, the concentrations of some samples were greater than a particular limit ( 3 or 10 times the DL), while the other samples were less than that limit. In these cases the statistics were calculated using all of the data 
whether it was above or below the particular limit (3 or $10 \mathrm{DL})$. The above rules do not apply to alpha or beta/gamma counting methods. The ratios (mean/DL) reported in Appendix $\mathrm{B}$ are provided to show how large the analyte concentrations are relative to the DL.

Table 7-1. Special Analyte List.

\begin{tabular}{|ll|}
\hline Aluminum & Nitrate \\
Bismuth & Nitrite \\
Calcium & Phosphate \\
Chromium & Carbonate \\
Iron & Fluoride \\
Silicon & Chloride \\
Sodium & TOC \\
Zirconium & Cyanide \\
\hline
\end{tabular}

A close examination of the figures in Appendix B reveals several outlier data points in the core composite data:

ICP.a.Co: The primary result for core 31 , composite 2 of $11.7 \mathrm{ug} / \mathrm{g}$ is over three times the duplicate result. The other results for ICP.a.Co all fall in the range $2.7 \mathrm{ug} / \mathrm{g}$ to $3.8 \mathrm{ug} / \mathrm{g}$. The detection limit for ICP.a.Co is $0.8 \mathrm{ug} / \mathrm{g}$.

ICP.a.Cu: The duplicate result for core 31 , composite 2 of $127 \mathrm{ug} / \mathrm{g}$ is about four times the primary result of $31.7 \mathrm{ug} / \mathrm{g}$. The detection limit for ICP.a.Cu is $0.4 \mathrm{ug} / \mathrm{g}$.

$\mathrm{NO}_{2}: \quad$ Both the primary and duplicate results from composite 2 of core 31 are about half the results for core 31 , composite 1 . The average of the results for core 31 , composite one is $952 \mathrm{ug} / \mathrm{g}$; the average for composite two is $525 \mathrm{ug} / \mathrm{g}$. The detection limit for $\mathrm{NO}_{2}$ by water digestion spectrophometric analysis is $50 \mathrm{ug} / \mathrm{g}$.

\subsection{MEAN CONCENTRATION ESTIMATES}

One of the tasks outlined as part of the waste characterization effort (Bell 1993, Winters et al. 1990a, Winters et al. 1990b), is to estimate the constituent inventories in the waste. The inventories are estimated by computing mean concentrations and 95 percent CIs on the mean concentrations for each constituent. The estimate of the inventory and $\mathrm{CI}$ on the inventory of an analyte in the tank are equal to the corresponding mean concentration estimates and CI multiplied by the volume of waste in the tank. 


\subsubsection{Statistical Methods}

The concentration estimates are given in the form of 95 percent CIs on the mean concentration. It is assumed that each sample and its duplicate are analyzed independently of one another. The two analytical results are used to estimate the analytical measurement error. Because of the hierarchical structure of the data, the analytical measurement error alone is not the appropriate error term to use in computing the CIs. A linear combination of the analytical measurement variance and the spatial variance is the appropriate variance of the mean for the Cls. Appendix B contains a description of the statistical model and formulas used to calculate estimates of the mean, variance of the mean, and the $\mathrm{CI}$ on the mean.

\subsubsection{Statistical Results}

Table 7-2 contains the summary statistics by analyte for ICP acid digestion, ICP water leach, ICP fusion dissolution, IC, and selected radiochemical and physical analyses. The summary statistics are as follows:

$\bar{y} \quad$ mean of the concentration data

$\hat{\sigma}^{2}(\bar{y}) \quad$ estimated variance of $\bar{y}$

df degrees of freedom

$95 \% \mathrm{LL}$ lower limit to the 95 percent $\mathrm{CI}$ on the mean

$95 \%$ UL upper limit to the 95 percent $\mathrm{CI}$ on the mean.

For some analytes the lower confidence limit ( 95 percent $L L$ ) was negative. Because concentrations are greater than or equal to zero, any negative 95 percent LL values were set equal to zero.

The CIs in Table 7-2 are wide relative to the range of the data. The CIs are wide because only two cores were used to estimate the spatial variability. A minimum of two core samples is needed to estimate a tank's spatial variability. 
Table 7-2. Concentration Estimate Statistics. (4 pages)

(Units $\mu \mathrm{g} / \mathrm{g}$ Except Radionuclides $\mu \mathrm{Ci} / \mathrm{g}$ )

\begin{tabular}{|l|c|c|c|c|c|}
\hline \multicolumn{1}{|c|}{ Analyte } & $\overline{\mathrm{y}}$ & $\hat{\sigma}^{2}(\overline{\mathrm{y}})$ & $\mathrm{df}$ & $95 \% \mathrm{LL}$ & $95 \% \mathrm{UL}$ \\
\hline ICP.a.Ag & $1.26 \mathrm{E}+02$ & $7.86 \mathrm{E}+03$ & 1 & 0.00 & $1.25 \mathrm{E}+03$ \\
\hline ICP.a.Al & $5.41 \mathrm{E}+02$ & $1.06 \mathrm{E}+04$ & 1 & 0.00 & $1.85 \mathrm{E}+03$ \\
\hline ICP.a.B & $2.80 \mathrm{E}+01$ & $7.56 \mathrm{E}+00$ & 1 & 0.00 & $6.30 \mathrm{E}+01$ \\
\hline ICP.a.Ba & $6.90 \mathrm{E}+01$ & $6.46 \mathrm{E}+01$ & 1 & 0.00 & $1.71 \mathrm{E}+02$ \\
\hline ICP.a.Bi & $2.59 \mathrm{E}+04$ & $6.38 \mathrm{E}+06$ & 1 & 0.00 & $5.80 \mathrm{E}+04$ \\
\hline ICP.a.Ca & $1.88 \mathrm{E}+03$ & $2.12 \mathrm{E}+05$ & 1 & 0.00 & $7.72 \mathrm{E}+03$ \\
\hline ICP.a.Cd $\star$ & $5.80 \mathrm{E}+00$ & $3.03 \mathrm{E}+00$ & 1 & 0.00 & $2.79 \mathrm{E}+01$ \\
\hline ICP.a.Co & $4.30 \mathrm{E}+00$ & $1.63 \mathrm{E}+00$ & 1 & 0.00 & $2.05 \mathrm{E}+01$ \\
\hline ICP.a.Cr $\star$ & $1.98 \mathrm{E}+03$ & $1.63 \mathrm{E}+04$ & 1 & $3.57 \mathrm{E}+02$ & $3.60 \mathrm{E}+03$ \\
\hline ICP.a.Cu & $3.35 \mathrm{E}+01$ & $3.53 \mathrm{E}+02$ & 1 & 0.00 & $2.72 \mathrm{E}+02$ \\
\hline ICP.a.Fe & $1.85 \mathrm{E}+04$ & $1.21 \mathrm{E}+06$ & 1 & $4.55 \mathrm{E}+03$ & $3.25 \mathrm{E}+04$ \\
\hline ICP.a.K & $1.14 \mathrm{E}+03$ & $2.24 \mathrm{E}+03$ & 1 & $5.34 \mathrm{E}+02$ & $1.74 \mathrm{E}+03$ \\
\hline ICP.a.La & $4.22 \mathrm{E}+03$ & $3.00 \mathrm{E}+05$ & 1 & 0.00 & $1.12 \mathrm{E}+04$ \\
\hline ICP.a.Mg & $3.77 \mathrm{E}+02$ & $6.36 \mathrm{E}+03$ & 1 & 0.00 & $1.39 \mathrm{E}+03$ \\
\hline ICP.a.Mn & $6.33 \mathrm{E}+03$ & $2.68 \mathrm{E}+04$ & 1 & $4.25 \mathrm{E}+03$ & $8.41 \mathrm{E}+03$ \\
\hline ICP.a.Na & $3.69 \mathrm{E}+04$ & $1.56 \mathrm{E}+06$ & 1 & $2.10 \mathrm{E}+04$ & $5.27 \mathrm{E}+04$ \\
\hline ICP.a.Ni & $1.32 \mathrm{E}+02$ & $5.12 \mathrm{E}+02$ & 1 & 0.00 & $4.19 \mathrm{E}+02$ \\
\hline ICP.a.P & $1.03 \mathrm{E}+04$ & $1.21 \mathrm{E}+05$ & 1 & $5.90 \mathrm{E}+03$ & $1.47 \mathrm{E}+04$ \\
\hline ICP.a.Pb & $3.47 \mathrm{E}+02$ & $2.64 \mathrm{E}+04$ & 1 & 0.00 & $2.41 \mathrm{E}+03$ \\
\hline ICP.a.S & $1.21 \mathrm{E}+03$ & $1.06 \mathrm{E}+03$ & 1 & $8.00 \mathrm{E}+02$ & $1.63 \mathrm{E}+03$ \\
\hline ICP.a.Si & $4.69 \mathrm{E}+02$ & $9.17 \mathrm{E}+02$ & 1 & $8.40 \mathrm{E}+01$ & $8.54 \mathrm{E}+02$ \\
\hline ICP.a.Sr & $3.00 \mathrm{E}+02$ & $3.75 \mathrm{E}+02$ & 1 & $5.39 \mathrm{E}+01$ & $5.46 \mathrm{E}+02$ \\
\hline ICP.a.Ti & $1.95 \mathrm{E}+01$ & $1.39 \mathrm{E}+02$ & 1 & 0.00 & $1.69 \mathrm{E}+02$ \\
\hline ICP.a.V & $1.45 \mathrm{E}+01$ & $6.58 \mathrm{E}+00$ & 1 & 0.00 & $4.71 \mathrm{E}+01$ \\
\hline ICP.a. $\mathrm{Zn}$ & $6.50 \mathrm{E}+01$ & $6.46 \mathrm{E}+02$ & 1 & 0.00 & $3.88 \mathrm{E}+02$ \\
\hline
\end{tabular}


Table 7-2. Concentration Estimate Statistics. (4 pages)

(Units $\mu \mathrm{g} / \mathrm{g}$ Except Radionuclides $\mu \mathrm{Ci} / \mathrm{g}$ )

\begin{tabular}{|c|c|c|c|c|c|}
\hline Analyte & $\bar{y}$ & $\hat{\sigma}^{2}(\bar{y})$ & $\mathrm{df}$ & $95 \%$ LL & 95\% UL \\
\hline ICP.f.Ag & $1.28 \mathrm{E}+02$ & $8.05 E+03$ & 1 & 0.00 & $1.27 \mathrm{E}+03$ \\
\hline ICP.f.Al & $5.70 \mathrm{E}+02$ & $9.70 \mathrm{E}+03$ & 1 & 0.00 & $1.82 E+03$ \\
\hline ICP.f.Ba & $6.46 \mathrm{E}+01$ & $2.45 \mathrm{E}+01$ & 1 & $1.73 E+\infty 0$ & $1.28 \mathrm{E}+02$ \\
\hline ICP.f.Bi & $2.36 \mathrm{E}+04$ & $9.08 \mathrm{E}+06$ & 1 & 0.00 & $6.18 \mathrm{E}+04$ \\
\hline ICP.f.Cat & $2.42 \mathrm{E}+03$ & $8.27 \mathrm{E}+04$ & 1 & 0.00 & $6.07 \mathrm{E}+03$ \\
\hline ICP.f.Cd $\star$ & $8.12 E+00$ & $1.76 \mathrm{E}+\infty 0$ & 1 & 0.00 & $2.50 \mathrm{E}+01$ \\
\hline ICP.f.Cr & $1.80 \mathrm{E}+03$ & $1.56 \mathrm{E}+03$ & 1 & $1.30 \mathrm{E}+03$ & $2.30 \mathrm{E}+03$ \\
\hline ICP.f.Cu & $2.93 E+01$ & $3.56 \mathrm{E}+01$ & 1 & 0.00 & $1.05 E+02$ \\
\hline ICP.f.Fe & $1.80 E+04$ & $4.05 \mathrm{E}+06$ & 1 & 0.00 & $4.36 \mathrm{E}+04$ \\
\hline ICP.f.La & $4.11 E+03$ & $3.08 \mathrm{E}+05$ & 1 & 0.00 & $1.12 \mathrm{E}+04$ \\
\hline ICP.f.Mg & $3.55 \mathrm{E}+02$ & $7.31 \mathrm{E}+03$ & 1 & 0.00 & $1.44 \mathrm{E}+03$ \\
\hline ICP.f.Mn & $6.28 \mathrm{E}+03$ & $1.88 \mathrm{E}+04$ & 1 & $4.54 \mathrm{E}+03$ & $8.02 \mathrm{E}+03$ \\
\hline ICP.f.Na & $3.70 E+04$ & $6.00 \mathrm{E}+06$ & 1 & $5.82 \mathrm{E}+03$ & $6.81 E+04$ \\
\hline ICP.f.Ni & $8.14 E+03$ & $6.41 E+06$ & 1 & 0.00 & $4.03 E+04$ \\
\hline ICP.f.P & $1.04 \mathrm{E}+04$ & $8.42 \mathrm{E}+05$ & 1 & 0.00 & $2.21 \mathrm{E}+04$ \\
\hline ICP.f.Pb $\star$ & $3.65 E+02$ & $9.38 \mathrm{E}+03$ & 1 & 0.00 & $1.60 \mathrm{E}+03$ \\
\hline ICP.f.S & $1.23 \mathrm{E}+03$ & $1.13 \mathrm{E}+04$ & 1 & 0.00 & $2.58 \mathrm{E}+03$ \\
\hline ICP.f.Si & $5.67 \mathrm{E}+03$ & $5.41 E+04$ & 1 & $2.71 \mathrm{E}+03$ & $8.62 E+03$ \\
\hline ICP.f.Sr & $2.98 \mathrm{E}+02$ & $6.24 \mathrm{E}+01$ & 1 & $1.97 \mathrm{E}+02$ & $3.98 E+02$ \\
\hline ICP.f.Ti & $4.79 \mathrm{E}+01$ & $6.09 E+02$ & 1 & 0.00 & $3.62 \mathrm{E}+02$ \\
\hline ICP.f. $\mathrm{Zn} \star$ & $1.06 \mathrm{E}+02$ & $7.17 \mathrm{E}+00$ & 1 & $7.22 \mathrm{E}+01$ & $1.40 \mathrm{E}+02$ \\
\hline ICP.w.Al $\bullet$ & $1.09 \mathrm{E}+01$ & $5.75 \mathrm{E}+00$ & 1 & 0.00 & $4.14 \mathrm{E}+01$ \\
\hline ICP.w.Bi & $2.02 E+02$ & $2.40 \mathrm{E}+03$ & 1 & 0.00 & $8.24 \mathrm{E}+02$ \\
\hline ICP.w.Ca & $6.16 \mathrm{E}+01$ & $3.32 \mathrm{E}+01$ & 1 & 0.00 & $1.35 E+02$ \\
\hline ICP.w.Cr & $2.18 \mathrm{E}+02$ & $2.45 \mathrm{E}+01$ & 1 & $1.55 \mathrm{E}+02$ & $2.81 E+02$ \\
\hline ICP.w.Fe & $1.28 \mathrm{E}+02$ & $3.11 E+02$ & 1 & 0.00 & $3.52 E+02$ \\
\hline
\end{tabular}


Table 7-2. Concentration Estimate Statistics. (4 pages)

(Units $\mu \mathrm{g} / \mathrm{g}$ Except Radionuclides $\mu \mathrm{Ci} / \mathrm{g}$ )

\begin{tabular}{|c|c|c|c|c|c|}
\hline Analyte & $\overline{\mathrm{y}}$ & $\hat{\sigma}^{2}(\bar{y})$ & $\mathrm{df}$ & $95 \% \mathrm{LL}$ & $95 \%$ UL \\
\hline ICP.w.K & $7.19 \mathrm{E}+02$ & $1.54 E+03$ & 1 & $2.21 E+02$ & $1.22 \mathrm{E}+03$ \\
\hline ICP.w.Lat & $1.10 \mathrm{E}+01$ & $1.42 \mathrm{E}+01$ & 1 & 0.00 & $5.89 \mathrm{E}+01$ \\
\hline ICP.w.Mg & $3.64 \mathrm{E}+00$ & $5.45 \mathrm{E}-02$ & 1 & $6.75 \mathrm{E}-01$ & $6.61 E+00$ \\
\hline ICP.w.Mn & $2.47 \mathrm{E}+01$ & $2.36 \mathrm{E}+01$ & 1 & 0.00 & $8.65 E+01$ \\
\hline ICP.w.Na & $3.30 \mathrm{E}+04$ & $2.44 E+06$ & 1 & $1.31 E+04$ & $5.28 \mathrm{E}+04$ \\
\hline ICP.w.P & $5.68 \mathrm{E}+03$ & $3.24 E+04$ & 1 & $3.39 \mathrm{E}+03$ & $7.97 \mathrm{E}+03$ \\
\hline ICP.w.S & $1.15 E+03$ & $2.38 E+03$ & 1 & $5.29 \mathrm{E}+02$ & $1.77 \mathrm{E}+03$ \\
\hline ICP.w.Si & $5.72 E+02$ & $5.35 E+03$ & 1 & 0.00 & $1.50 \mathrm{E}+03$ \\
\hline IC.w.Cl' & $4.50 \mathrm{E}+02$ & $1.11 E+03$ & 1 & $2.56 \mathrm{E}+01$ & $8.74 E+02$ \\
\hline IC.w.F & $2.30 \mathrm{E}+03$ & $6.46 \mathrm{E}+05$ & 1 & 0.00 & $1.25 E+04$ \\
\hline IC.w.NO ${ }_{2} \star$ & $8.97 \mathrm{E}+02$ & $2.10 \mathrm{E}+04$ & 1 & 0.00 & $2.74 E+03$ \\
\hline IC.w. $\mathrm{NO}_{3}^{-}$ & $4.12 E+04$ & $7.77 \mathrm{E}+06$ & 1 & $5.82 E+03$ & $7.67 \mathrm{E}+04$ \\
\hline IC.W.PO ${ }_{4}{ }^{3-}$ & $1.55 \mathrm{E}+04$ & $1.53 E+06$ & 1 & 0.00 & $3.13 \mathrm{E}+04$ \\
\hline IC. w. $\mathrm{SO}_{4}{ }^{2-}$ & $3.54 \mathrm{E}+03$ & $2.85 E+04$ & 1 & $1.40 \mathrm{E}+03$ & $5.69 E+03$ \\
\hline GEA.Am-241 & $4.24 \mathrm{E}-02$ & $2.61 \mathrm{E}-06$ & 1 & $2.19 \mathrm{E}-02$ & $6.29 E-02$ \\
\hline GEA.Co-60 & $3.64 \mathrm{E}-04$ & $2.68 \mathrm{E}-10$ & 1 & $1.56 \mathrm{E}-04$ & $5.72 \mathrm{E}-04$ \\
\hline GEA.Cs-137 & $1.66 \mathrm{E}-01$ & $3.35 \mathrm{E}-03$ & 1 & 0.00 & $9.02 \mathrm{E}-01$ \\
\hline Gross.alpha & 3.73E-01 & $1.96 \mathrm{E}-04$ & 1 & $1.95 \mathrm{E}-01$ & $5.51 \mathrm{E}-01$ \\
\hline Gross.beta & $1.51 \mathrm{E}+01$ & $3.48 E+01$ & 1 & 0.00 & $9.00 \mathrm{E}+01$ \\
\hline TGA.Percent. $\mathrm{H}_{2} \mathrm{O}$ & $7.65 E+01$ & $2.23 \mathrm{E}+01$ & 1 & $1.64 \mathrm{E}+01$ & $1.37 \mathrm{E}+02$ \\
\hline $\mathrm{NO}_{2}^{-}$ & $7.93 E+02$ & $8.76 \mathrm{E}+03$ & 1 & 0.00 & $1.98 E+03$ \\
\hline Percent. $\mathrm{H}_{2} \mathrm{O}$ & $7.60 \mathrm{E}+01$ & $5.81 \mathrm{E}-01$ & 1 & $6.63 E+01$ & $8.57 \mathrm{E}+01$ \\
\hline Pu-239/240 & $1.39 \mathrm{E}-01$ & $9.19 E-06$ & 1 & $1.00 \mathrm{E}-01$ & $1.77 \mathrm{E}-01$ \\
\hline Sr-90 & $5.41 \mathrm{E}+00$ & $3.53 \mathrm{E}+00$ & 1 & 0.00 & $2.93 E+01$ \\
\hline$\overline{\text { TOC } \star}$ & $3.12 \mathrm{E}+03$ & $3.83 E+05$ & 1 & 0.00 & $1.10 \mathrm{E}+04$ \\
\hline Tc-99• & $7.92 \mathrm{E}-03$ & $8.90 \mathrm{E}-06$ & 1 & 0.00 & $4.58 \mathrm{E}-02$ \\
\hline
\end{tabular}


Table 7-2. Concentration Estimate Statistics. (4 pages)

(Units $\mu \mathrm{g} / \mathrm{g}$ Except Radionuclides $\mu \mathrm{Ci} / \mathrm{g}$ )

\begin{tabular}{|l|c|c|c|c|c|}
\hline \multicolumn{1}{|c|}{ Analyte } & $\overline{\mathrm{y}}$ & $\hat{\sigma}^{2}(\overline{\mathrm{y}})$ & $\mathrm{df}$ & $95 \% \mathrm{LL}$ & $95 \% \mathrm{UL}$ \\
\hline $\mathrm{U \star}$ & $2.79 \mathrm{E}+03$ & $2.01 \mathrm{E}+05$ & 1 & 0.00 & $8.50 \mathrm{E}+03$ \\
\hline $\mathrm{pH}$ & $9.98 \mathrm{E}+00$ & $7.79 \mathrm{E}-03$ & 1 & $8.86 \mathrm{E}+00$ & $1.11 \mathrm{E}+01$ \\
\hline
\end{tabular}

-: Analytes with a portion of the data below 3 times the DL.

$\star$ : Analytes with a portion of the data below 10 times the DL.

\subsection{COMPARISON OF THE VARIANCE COMPONENT ESTIMATES}

Using the hierarchical structure of the core composite data, estimates of the between-core spatial variability, the compositing variability, and the analytical-measurement variability can be obtained. The spatial variance is a measure of the variability between cores. The compositing variance measures the variability between composite samples within the same core. The analytical-measurement variance is a measure of the difference between the analytical results from the sample and duplicate samples. This variance includes, among other things, the sample handling error and the chemical analysis error.

The estimate of the variance of the mean is a linear function of the spatial, compositing, and analytical-measurement variances. To help evaluate the magnitude of these three variance components, estimates of each variance component are given.

\subsubsection{Statistical Methods}

Estimates of the spatial variance $\left(\hat{\sigma}^{2}(S)\right)$, compositing variance $\left(\hat{\sigma}^{2}(C)\right)$, and analytical-measurement variance $\left(\hat{\sigma}^{2}(\mathrm{~A})\right)$, were obtained for each analyte using restricted maximum likelihood estimation methods. Restricted maximum likelihood estimation is discussed by Harville (1977).

To test the significance of the variance components, an analysis of variance (ANOVA) was calculated using the hierarchical statistical model described in Appendix B. The mean square error terms in the ANOVA table were used to perform an F-test on the spatial variability and the composite variability. The $p$-values given in Table 7-3 were derived from the results of these tests. 


\subsubsection{Statistical Results}

The restricted maximum likelihood estimates of each component of variability along with the $\mathrm{p}$-values (significance level) from the F-tests also are given in Table 7-3. P-values less than 0.05 indicate that $\sigma^{2}(S)$ or $\sigma^{2}(C)$ is significantly different from zero at the 0.05 significance level.

The p-values from the tests on $\sigma^{2}(S)$ were less than 0.05 for 40 out of the 79 analytes in tank 241-T-111 waste. Thus, for these 40 cases, differences between the results in the two cores were statistically significant"*. The p-values from the tests on $\sigma^{2}(C)$ were less than 0.05 for 38 out of the 79 analytes in tank 241-T-111 waste. This indicates that, relative to the analytical error, differences between composite samples were significantly greater than zero in 38 cases. Conversely, for 41 out of 79 cases, differences between composite samples were not statistically significant. The number of analytes (and the amount that they contribute to the waste) for which $\sigma^{2}(S)$ and $\sigma^{2}(C)$ were statistically significant further suggests that the waste is heterogeneous.

\subsection{MASS BALANCES}

A method to help ensure the data are consistent and reasonable is to perform a mass and charge balance on the core composite sample data. This activity is a rough quality control check and provides insight to some of the properties of the matrix. To do this, the assumption in performing the mass balance is that the anions, cations, and water are all associated in some manner, but the exact chemistry of the association is not considered. Analytes contributing less than 0.2 weight percent, generally trace ICP analytes, AA analytes, and radionuclides, are considered negligible in this assessment. The assays that will contribute analytes to the mass balance are ICP acid or fusion (whichever gives higher quantitation), IC, TOC, and the gravimetric weight-percent water measurement.

Without considering the physical and chemical properties of the waste matrix and the context of the process history, the mass balances produced from these assays may be biased low. However, this bias is expected because it is known that there are analytes present that were not measured in the analysis of the samples. The IC anions only measure the water-soluble components; there is a substantial insoluble residue that must contain additional anions. Bias may be impacted substantially by chemical form, accountability, and variability in oxide or hydroxide content. Assumptions regarding the chemical combination of some of the analytes will be made and inserted into the mass/charge balance, presented in Table 7-4. Generally, this consists of assuming that some analytes are precipitated as an oxide or hydroxide, and that the shortfall indicated from the charge balance in microequivalent [ $\mu$ equ.] is present as one of those two analytes.

"Statistically significant for the purposes of this analysis means substantially greater than zero at the 0.05 level of significance. 


\section{WHC-EP-0806}

Table 7-3. Variance Components Estimates. (3 pages)

\begin{tabular}{|l|c|r|r|r|r|}
\hline \multicolumn{1}{|c|}{ Analyte } & $\hat{\sigma}^{2}(\mathrm{~S})$ & $\begin{array}{c}\text { Test: } \\
\sigma^{2}(\mathrm{~S})=0 \\
\mathrm{p} \text {-value }\end{array}$ & $\hat{\sigma}^{2}(\mathrm{C})$ & $\begin{array}{c}\text { Test: } \\
\sigma^{2}(\mathrm{C})=0 \\
\text { p-value }\end{array}$ & $\hat{\sigma}^{2}(\mathrm{~A})$ \\
\hline ICP.a.Ag & $1.56 \mathrm{E}+04$ & 0.001 & $1.94 \mathrm{E}+02$ & 0.000 & $3.16 \mathrm{E}+00$ \\
\hline ICP.a.Al & $1.89 \mathrm{E}+04$ & 0.055 & $4.79 \mathrm{E}+03$ & 0.000 & $1.06 \mathrm{E}+01$ \\
\hline ICP.a.B & $1.25 \mathrm{E}+01$ & 0.093 & $9.28 \mathrm{E}-01$ & 0.387 & $8.59 \mathrm{E}+00$ \\
\hline ICP.a.Ba & $6.91 \mathrm{E}+01$ & 0.263 & $1.20 \mathrm{E}+02$ & 0.000 & $3.54 \mathrm{E}-01$ \\
\hline ICP.a.Bi & $1.27 \mathrm{E}+07$ & 0.000 & $6.25 \mathrm{E}+03$ & 0.360 & $3.75 \mathrm{E}+04$ \\
\hline ICP.a.Ca & $4.10 \mathrm{E}+05$ & 0.010 & $2.17 \mathrm{E}+04$ & 0.074 & $9.95 \mathrm{E}+03$ \\
\hline ICP.a.Cd $\star$ & $5.96 \mathrm{E}+00$ & 0.004 & $1.90 \mathrm{E}-01$ & 0.039 & $5.34 \mathrm{E}-02$ \\
\hline ICP.a.Co & $8.92 \mathrm{E}-01$ & 0.376 & $8.08 \mathrm{E}-01$ & 0.389 & $7.84 \mathrm{E}+00$ \\
\hline ICP.a.Cr & $3.17 \mathrm{E}+04$ & 0.007 & $1.36 \mathrm{E}+03$ & 0.081 & $6.75 \mathrm{E}+02$ \\
\hline ICP.a.Cu & $3.39 \mathrm{E}+02$ & 0.290 & $1.67 \mathrm{E}+02$ & 0.369 & $1.14 \mathrm{E}+03$ \\
\hline ICP.a.Fe & $2.33 \mathrm{E}+06$ & 0.013 & $1.55 \mathrm{E}+05$ & 0.063 & $6.25 \mathrm{E}+04$ \\
\hline ICP.a.K & $2.45 \mathrm{E}-24$ & 0.911 & $8.86 \mathrm{E}+03$ & 0.000 & $1.75 \mathrm{E}+02$ \\
\hline ICP.a.La & $5.91 \mathrm{E}+05$ & 0.003 & $1.63 \mathrm{E}+04$ & 0.019 & $2.88 \mathrm{E}+03$ \\
\hline ICP.a.Mg & $1.25 \mathrm{E}+04$ & 0.005 & $5.18 \mathrm{E}+02$ & 0.001 & $1.58 \mathrm{E}+01$ \\
\hline ICP.a.Mn & $2.97 \mathrm{E}+04$ & 0.254 & $4.29 \mathrm{E}+04$ & 0.030 & $1.00 \mathrm{E}+04$ \\
\hline ICP.a.Na & $2.76 \mathrm{E}+06$ & 0.057 & $6.73 \mathrm{E}+05$ & 0.016 & $1.05 \mathrm{E}+05$ \\
\hline ICP.a.Ni & $1.02 \mathrm{E}+03$ & 0.000 & $6.13 \mathrm{E}+00$ & 0.091 & $3.38 \mathrm{E}+00$ \\
\hline ICP.a.P & $2.37 \mathrm{E}-22$ & 0.608 & $4.77 \mathrm{E}+05$ & 0.000 & $1.25 \mathrm{E}+04$ \\
\hline ICP.a.Pb & $5.20 \mathrm{E}+04$ & 0.003 & $1.41 \mathrm{E}+03$ & 0.000 & $1.91 \mathrm{E}+01$ \\
\hline ICP.a.S & $1.11 \mathrm{E}+03$ & 0.268 & $1.94 \mathrm{E}+03$ & 0.003 & $1.25 \mathrm{E}+02$ \\
\hline ICP.a.Si & $2.57 \mathrm{E}-31$ & 0.946 & $7.61 \mathrm{E}-14$ & 0.418 & $7.34 \mathrm{E}+03$ \\
\hline ICP.a.Sr & $6.38 \mathrm{E}+02$ & 0.079 & $2.18 \mathrm{E}+02$ & 0.004 & $1.54 \mathrm{E}+01$ \\
\hline ICP.a.Ti & $2.75 \mathrm{E}+02$ & 0.001 & $4.69 \mathrm{E}+00$ & 0.000 & $7.83 \mathrm{E}-02$ \\
\hline ICP.a.V & $1.83 \mathrm{E}+00$ & 0.423 & $2.25 \mathrm{E}+01$ & 0.000 & $2.30 \mathrm{E}-01$ \\
\hline ICP.a.Zn & $1.22 \mathrm{E}+03$ & 0.021 & $1.35 \mathrm{E}+02$ & 0.008 & $1.42 \mathrm{E}+01$ \\
\hline ICP.f.Ag & $1.61 \mathrm{E}+04$ & 0.000 & $6.23 \mathrm{E}+00$ & 0.295 & $1.83 \mathrm{E}+01$ \\
\hline ICP.f.Al & $1.90 \mathrm{E}+04$ & 0.005 & $6.78 \mathrm{E}+02$ & 0.030 & $1.57 \mathrm{E}+02$ \\
\hline
\end{tabular}


Table 7-3. Variance Components Estimates. (3 pages)

\begin{tabular}{|c|c|c|c|c|c|}
\hline Analyte & $\hat{\sigma}^{2}(S)$ & $\begin{array}{c}\text { Test: } \\
\sigma^{2}(S)=0 \\
\text { p-value }\end{array}$ & $\hat{\sigma}^{2}(C)$ & $\begin{array}{c}\text { Test: } \\
\sigma^{2}(C)=0 \\
\text { p-value }\end{array}$ & $\hat{\sigma}^{2}(A)$ \\
\hline ICP.f.Ba & $3.99 \mathrm{E}+01$ & 0.102 & $1.71 E+01$ & 0.012 & $2.19 \mathrm{E}+00$ \\
\hline ICP.f.Bi & $1.81 \mathrm{E}+07$ & 0.001 & $2.88 E+04$ & 0.392 & $2.94 \mathrm{E}+05$ \\
\hline ICP.f.Cat & $1.51 \mathrm{E}+05$ & 0.008 & $2.07 \mathrm{E}-19$ & 0.804 & $5.86 \mathrm{E}+04$ \\
\hline ICP.f.Cd $\star$ & $2.17 \mathrm{E}+00$ & 0.126 & $1.21 \mathrm{E}-20$ & 0.649 & $5.38 \mathrm{E}+00$ \\
\hline ICP.f.Cr & $3.72 \mathrm{E}-15$ & 0.994 & $5.63 \mathrm{E}+03$ & 0.013 & $1.21 \mathrm{E}+03$ \\
\hline ICP.f.Cu $t$ & $6.97 \mathrm{E}+01$ & 0.005 & $2.00 \mathrm{E}+00$ & 0.119 & $1.43 \mathrm{E}+00$ \\
\hline ICP.f.Fe & $8.00 E+06$ & 0.003 & $1.68 \mathrm{E}+05$ & 0.079 & $8.13 E+04$ \\
\hline ICP.f.La & $5.96 \mathrm{E}+05$ & 0.010 & $3.82 \mathrm{E}+04$ & 0.012 & $4.98 \mathrm{E}+03$ \\
\hline ICP.f.Mg & $1.46 \mathrm{E}+04$ & 0.000 & $5.15 \mathrm{E}-44$ & 0.913 & $1.60 \mathrm{E}+02$ \\
\hline ICP.f.Mn & $1.66 \mathrm{E}-11$ & 0.553 & $7.02 \mathrm{E}+04$ & 0.011 & $9.70 \mathrm{E}+03$ \\
\hline ICP.f.Na & $1.17 \mathrm{E}+07$ & 0.007 & $5.43 \mathrm{E}+05$ & 0.044 & $1.65 \mathrm{E}+05$ \\
\hline ICP.f.Ni & $1.17 \mathrm{E}+07$ & 0.033 & $4.18 \mathrm{E}-12$ & 0.498 & $4.39 E+06$ \\
\hline ICP.f.P & $1.57 \mathrm{E}+06$ & 0.028 & $1.95 \mathrm{E}+05$ & 0.049 & $6.45 \mathrm{E}+04$ \\
\hline ICP.f.Pb $\star$ & $1.85 \mathrm{E}+04$ & 0.003 & $4.35 E+02$ & 0.030 & $1.02 \mathrm{E}+02$ \\
\hline ICP.f.S & $2.15 E+04$ & 0.017 & $2.00 \mathrm{E}+03$ & 0.008 & $2.13 \mathrm{E}+02$ \\
\hline ICP.f.Si & $1.06 \mathrm{E}+05$ & 0.005 & $1.00 \mathrm{E}+03$ & 0.369 & $6.83 E+03$ \\
\hline ICP.f.Sr & $6.12 \mathrm{E}-16$ & 0.661 & $1.15 \mathrm{E}+02$ & 0.222 & $2.69 \mathrm{E}+02$ \\
\hline ICP.f.Ti & $1.22 \mathrm{E}+03$ & 0.000 & $2.66 \mathrm{E}-01$ & 0.331 & $1.12 \mathrm{E}+00$ \\
\hline ICP.f. $\mathrm{Zn} \star$ & $5.69 \mathrm{E}-23$ & 0.440 & $1.10 \mathrm{E}-22$ & 0.839 & $5.74 E+01$ \\
\hline ICP.w.Al• & $7.35 \mathrm{E}+00$ & 0.208 & $6.93 E+00$ & 0.061 & $2.72 E+00$ \\
\hline ICP.w.Bi & $3.90 \mathrm{E}+03$ & 0.102 & $1.30 \mathrm{E}+03$ & 0.123 & $9.66 \mathrm{E}+02$ \\
\hline ICP.w.Ca & $1.86 \mathrm{E}-11$ & 0.144 & $1.69 \mathrm{E}-22$ & 0.862 & $2.66 \mathrm{E}+02$ \\
\hline ICP.w.Cr & $5.66 \mathrm{E}-20$ & 0.979 & $9.52 \mathrm{E}+01$ & 0.001 & $5.62 \mathrm{E}+00$ \\
\hline ICP.w.Fe & $6.16 \mathrm{E}+01$ & 0.436 & $9.05 \mathrm{E}+02$ & 0.077 & $4.29 \mathrm{E}+02$ \\
\hline ICP.w.K & $2.28 \mathrm{E}+03$ & 0.148 & $1.57 \mathrm{E}+03$ & 0.001 & $4.73 \mathrm{E}+01$ \\
\hline ICP.w.La & $2.71 \mathrm{E}+01$ & 0.015 & $1.34 \mathrm{E}+00$ & 0.226 & $2.23 E+00$ \\
\hline ICP.w.Mg ${ }^{\prime}$ & $3.04 \mathrm{E}-21$ & 0.597 & $1.61 \mathrm{E}-01$ & 0.098 & $1.14 \mathrm{E}-01$ \\
\hline
\end{tabular}


Table 7-3. Variance Components Estimates. (3 pages)

\begin{tabular}{|c|c|c|c|c|c|}
\hline Analyte & $\hat{\sigma}^{2}(S)$ & $\begin{array}{c}\text { Test: } \\
\sigma^{2}(S)=0 \\
\text { p-value }\end{array}$ & $\hat{\sigma}^{2}(C)$ & $\begin{array}{c}\text { Test: } \\
\sigma^{2}(C)=0 \\
\text { p-value }\end{array}$ & $\hat{\sigma}^{2}(A)$ \\
\hline ICP.w.Mn & $2.51 \mathrm{E}+01$ & 0.266 & $3.19 \mathrm{E}+01$ & 0.130 & $2.51 \mathrm{E}+01$ \\
\hline ICP.w.Na & $4.53 E+06$ & 0.030 & $6.84 \mathrm{E}+05$ & 0.002 & $2.88 \mathrm{E}+04$ \\
\hline ICP.w.P & $3.98 \mathrm{E}+04$ & 0.222 & $3.94 \mathrm{E}+04$ & 0.089 & $2.13 E+04$ \\
\hline ICP.w.S & $3.95 \mathrm{E}+03$ & 0.091 & $1.50 \mathrm{E}+03$ & 0.014 & $2.13 E+02$ \\
\hline ICP.w.Si & $8.53 E+03$ & 0.113 & $1.98 \mathrm{E}+03$ & 0.272 & $4.72 \mathrm{E}+03$ \\
\hline IC.w.Cl & $1.99 \mathrm{E}+03$ & 0.043 & $1.15 \mathrm{E}-10$ & 0.509 & $9.66 \mathrm{E}+02$ \\
\hline IC.w.F- & $1.28 \mathrm{E}+06$ & 0.001 & $1.37 \mathrm{E}+04$ & 0.102 & $8.44 \mathrm{E}+03$ \\
\hline IC.w. $\mathrm{NO}_{2}{ }^{-\star}$ & $3.99 \mathrm{E}+04$ & 0.015 & $5.22 \mathrm{E}-16$ & 0.510 & $8.64 E+03$ \\
\hline IC.w. $\mathrm{NO}_{3}^{-}$ & $1.42 \mathrm{E}+07$ & 0.038 & $2.46 \mathrm{E}+06$ & 0.013 & $3.44 \mathrm{E}+05$ \\
\hline IC.w.PO ${ }_{4}^{3-}$ & $2.59 \mathrm{E}+06$ & 0.082 & $8.54 \mathrm{E}+05$ & 0.030 & $1.99 \mathrm{E}+05$ \\
\hline IC. $\mathrm{w}^{-\mathrm{SO}_{4}{ }^{2-}}$ & $5.27 \mathrm{E}+04$ & 0.032 & $7.04 E+03$ & 0.071 & $3.14 \mathrm{E}+03$ \\
\hline GEA.Am-241 & $2.99 \mathrm{E}-32$ & 0.786 & $8.13 E-06$ & 0.062 & $4.59 \mathrm{E}-06$ \\
\hline GEA.Co-60 & $3.58 \mathrm{E}-10$ & 0.046 & $5.14 \mathrm{E}-36$ & 0.813 & $7.12 \mathrm{E}-10$ \\
\hline GEA.Cs-137 & $6.61 \mathrm{E}-03$ & 0.003 & $1.87 \mathrm{E}-04$ & 0.000 & $1.88 \mathrm{E}-06$ \\
\hline Gross.alpha & $3.42 \mathrm{E}-04$ & 0.065 & $7.74 \mathrm{E}-05$ & 0.098 & $4.58 \mathrm{E}-05$ \\
\hline Gross.beta & $6.93 \mathrm{E}+01$ & 0.000 & $3.14 \mathrm{E}-01$ & 0.026 & $6.62 \mathrm{E}-02$ \\
\hline TGA. $\% . \mathrm{H}_{2} \mathrm{O}$ & $3.17 \mathrm{E}+01$ & 0.008 & $3.78 \mathrm{E}-33$ & 0.935 & $5.18 \mathrm{E}+01$ \\
\hline $\mathrm{NO}_{2}{ }^{\circ}$ & $1.92 \mathrm{E}-14$ & 0.789 & $3.46 \mathrm{E}+04$ & 0.000 & $9.50 \mathrm{E}+02$ \\
\hline Percent $\mathrm{H}_{2} \mathrm{O}$ & $8.99 \mathrm{E}-01$ & 0.128 & $2.55 \mathrm{E}-01$ & 0.259 & $5.46 \mathrm{E}-01$ \\
\hline $\mathrm{Pu}-239 / 240$ & $2.49 \mathrm{E}-28$ & 0.736 & $2.01 \mathrm{E}-05$ & 0.171 & $3.33 \mathrm{E}-05$ \\
\hline Sr -90 & $7.04 \mathrm{E}+00$ & 0.000 & $1.79 \mathrm{E}-02$ & 0.209 & $2.61 \mathrm{E}-02$ \\
\hline TOC $\star$ & $6.10 \mathrm{E}+05$ & 0.113 & $2.98 \mathrm{E}+05$ & 0.006 & $2.72 \mathrm{E}+04$ \\
\hline Tc-99・ & $1.76 \mathrm{E}-05$ & 0.001 & $2.63 \mathrm{E}-07$ & 0.027 & $5.75 \mathrm{E}-08$ \\
\hline $\mathrm{U \star}$ & $6.24 \mathrm{E}-06$ & 0.831 & $7.91 \mathrm{E}+05$ & 0.001 & $2.99 \mathrm{E}+04$ \\
\hline$\overline{\mathrm{pH}}$ & $7.11 \mathrm{E}-28$ & 0.601 & $3.06 \mathrm{E}-02$ & 0.001 & $1.19 \mathrm{E}-03$ \\
\hline
\end{tabular}

-: Analytes with a portion of the data below 3 times the DL.

$\star$ : Analytes with a portion of the data below 10 times the DL. 
Table 7-4. Core 31 and Core 33 Mass and Charge Balance. (2 pages)

\begin{tabular}{|c|c|c|c|c|c|}
\hline Analyte & $\begin{array}{c}\text { Core } 31 \\
\text { average } \\
\text { concentration } \\
(\mu \mathrm{g} / \mathrm{g})\end{array}$ & $\begin{array}{c}\text { Core } 31 \\
\text { charge } \\
(\mu \text { equ/g) }\end{array}$ & $\begin{array}{c}\text { Core } 33 \\
\text { average } \\
\text { Concentration } \\
(\mu \mathrm{g} / \mathrm{g})\end{array}$ & $\begin{array}{l}\text { Core } 33 \\
\text { charge } \\
(\mu \text { equ/g) }\end{array}$ & $\begin{array}{l}\text { Core } \\
31 / 33 \\
\text { RPD }\end{array}$ \\
\hline $\mathrm{Ca}^{+2}$ & 2,710 & 135.50 & 2,140 & 107.00 & 23.51 \\
\hline $\mathrm{Cr}^{+3}$ & 1,850 & 106.73 & 2,100 & 121.15 & -12.66 \\
\hline $\mathrm{Fe}^{+2}$ & 20,100 & 717.86 & 16,000 & 571.43 & 22.71 \\
\hline $\mathrm{Mn}^{+4}$ & 6,160 & 448.00 & 6,400 & 465.45 & -3.82 \\
\hline $\mathrm{Na}^{+}$ & 39,400 & $1,713.04$ & 34,600 & $1,504.35$ & 12.97 \\
\hline$\overline{\mathrm{Bi}^{+3}}$ & 23,500 & 337.32 & 28,500 & 409.09 & -19.23 \\
\hline $\mathrm{La}^{+3}$ & 3,670 & 79.21 & 4,770 & 102.95 & -26.07 \\
\hline $\mathrm{Si}^{+4}$ & 5,900 & 842.86 & 5,440 & 777.14 & 8.11 \\
\hline $\mathrm{U}^{+6}$ & 3,820 & 96.30 & 3,280 & 82.69 & 15.21 \\
\hline $\mathrm{PO}_{4}^{3-}$ & 30,100 & -950.53 & 31,700 & -1001.05 & -5.18 \\
\hline $\mathrm{SO}_{4}{ }^{2-}$ & 3,650 & -76.04 & 3,460 & -72.08 & 5.34 \\
\hline $\mathrm{NO}_{3}^{-}$ & 44,100 & -711.29 & 38,500 & -620.97 & 13.56 \\
\hline $\mathrm{F}^{-}$ & 3,110 & -163.68 & 1,500 & -78.95 & 69.85 \\
\hline TOC & 3,740 & -85.00 & 2,500 & -56.82 & 39.74 \\
\hline \multicolumn{6}{|c|}{ Anion reconciliation } \\
\hline $\mathrm{O}_{2}^{4}$ & 17,116 & $-2,139.50$ & 16,926 & $-2,115.75$ & \\
\hline$\overline{\mathrm{OH}^{-}}$ & 5,965 & -350.88 & 3,325 & -195.59 & \\
\hline \multicolumn{6}{|c|}{ Water content } \\
\hline $\mathrm{H}_{2} \mathrm{O}$ & 735,000 & 0 & 790,000 & $\overline{0}$ & -7.21 \\
\hline $\mathrm{H}_{2} \mathrm{O}$ Calc. & 785,109 & 0 & 798,859 & $\overline{0}$ & -1.74 \\
\hline
\end{tabular}


$-$

Table 7-4. Core 31 and Core 33 Mass and Charge Balance. (2 pages)

\begin{tabular}{|l|c|c|c|c|c|}
\hline Analyte & $\begin{array}{c}\text { Core 31 } \\
\text { average } \\
\text { concentration } \\
(\mu \mathrm{g} / \mathrm{g})\end{array}$ & $\begin{array}{c}\text { Core 31 } \\
\text { charge } \\
(\mu \mathrm{equ} / \mathrm{g})\end{array}$ & $\begin{array}{c}\text { Core 33 } \\
\text { average } \\
\text { Concentration } \\
(\mu \mathrm{g} / \mathrm{g})\end{array}$ & $\begin{array}{c}\text { Core 33 } \\
\text { charge } \\
(\mu \mathrm{equ} / \mathrm{g})\end{array}$ & $\begin{array}{c}\text { Core } \\
31 / 33 \\
\mathrm{RPD}\end{array}$ \\
\hline Total & 949,891 & -0.10 & 991,141 & 0.05 & \\
\hline $\begin{array}{l}\text { Percent } \\
\text { difference* }\end{array}$ & -5.01 & & -0.89 & & \\
\hline
\end{tabular}

$\mathrm{O}_{2}^{4}:$ Represents the overall mass and charge of oxygen added to manganese, uranium, silicon, TOC, and chromium as part of the assumptions given in Section 7.4. This notation is not meant to imply actual chemical form.

$\mathrm{OH}:$ Represents hydroxide amount calculated to reconcile charge balance

NOTE: Neither of these analytes (oxygen or $\mathrm{OH}^{-}$) are analytically determined.

Relative Percent Difference $(R P D)=\frac{\text { Core } 31 \text { value }- \text { Core } 33 \text { value }}{\left(\frac{\text { Core } 33 \text { value }+ \text { Core } 33 \text { value }}{2}\right)} \times 100$

*Percent difference is determined from a Total of $1.0 \mathrm{E}+06 \frac{\mu \mathrm{g}}{\mathrm{g}}$ i.e.,

Percent Difference $=\frac{\text { sum of analytical values in a core }-1,000,000}{1,000,000} \times 100$

A significant source of error can be reduced by assuming all phosphorous is present as $\mathrm{PO}_{4}{ }^{3}$. The water digestion ICP values for phosphorous (converted to $\mathrm{PO}_{4}{ }^{3-}$ ) and $\mathrm{PO}_{4}{ }^{3 \cdot}$ values from the IC agree well. The ratio of soluble to insoluble phosphorous (taken as phosphate) indicates that it is only about 50 percent soluble. The process history of the tank also indicates that large amounts of phosphate were used to encourage precipitate formation. Therefore, an assumption that the phosphorus determined by ICP in the fusion acid/assay (and converted to phosphate) represents total $\mathrm{PO}_{4}{ }^{3}$ is not unwarranted. The phosphorus in the ICP fusion assay is converted to $\mathrm{PO}_{4}{ }^{3-}$ and added to the other anions in the charge balance. This step will avoid double counting in the mass and charge balance calculations.

The following other assumptions will be made for the purposes of simplifying the calculations: manganese is assumed present as $\mathrm{MnO}_{2}$, uranium is present as $\mathrm{UO}_{2}(\mathrm{OH})_{2}$, silicon is present as $\mathrm{SiO}_{3}{ }^{-}, \mathrm{TOC}$ as $\mathrm{C}_{2} \mathrm{O}_{4}{ }^{2-}$, and chromium as $\mathrm{Cr}_{2} \mathrm{O}_{3}$. These forms are not the 
only likely speciation of the analytes; however, the waste matrices are too complicated to represent every possible, or even probable compound present.

In the case of these waste materials, the disparity between the gravimetric water measurement and the TGA water content suggests (1) drying of the sample before the gravimetric assay; (2) incomplete drying during the gravimetric test, which biases the results low; or (3) one or more endothermic events occurring in the same temperature range (chemical reactions or phase transitions resulting in the loss of mass). One or more of these factors may be responsible for the observed trend. However, in this case, the analytical results and chemical assumptions that were made with regard to the waste matrix reconcile well.

\subsection{SUGGESTED COMPONENTS OF WASTE MATRIX}

The actual composition of the waste matrix is quite complex and trace amounts of various compounds probably exist in the tank. However, with some simple assumptions regarding how the anions and cations will combine, a list of the most probable compounds that exist in the waste matrix and contribute significantly to its overall makeup can be developed.

Table 7-5 is a condensed version of a more general chart found on page D-147 in the Handbook of Chemistry and Physics $64^{\text {th }} \mathrm{Ed}$. (Weast 1984). It provides solubility data on some of the most common anions and cations. The oxidation state shown in the table for the cations is the most stable. However, precipitates may form for multivalent cations under varying conditions, and so precipitates are reported as likely, if conditions and anions in the assessment of the analyst warrant it.

From the chromatographic data, suspected solubility behavior, and process information, chloride, nitrite, and carbonate will not be significant mass contributors to the waste matrix. Sodium, $\mathrm{SO}_{4}{ }^{2-}$, and $\mathrm{NO}_{3}{ }^{-}$are highly soluble, and thus probably do not contribute much to the insoluble solids. However, they contribute significantly to the overall solids content of the waste (dissolved + insoluble solids). Phosphorous is one of the most prevalent analytes, is approximately 50 percent soluble, and contributes substantially to both the soluble and insoluble solids. No analytical measurement of hydroxide was made for the solids (although there was an $\mathrm{OH}^{-}$assay of the grab sample), but it is known that in the process history of tank $241-T-111$, basic solutions were added routinely to the tank. The following are likely candidates for the insoluble solids:

- $\quad$ Bismuth phosphate, $\mathrm{BiPO}_{4}$

- Bismuth hydroxide, $\mathrm{Bi}(\mathrm{OH})_{3}$

- Calcium fluoride, $\mathrm{CaF}_{2}$
- Bismuth fluoride, $\mathrm{BiF}_{3}$

- Bismuth trioxide, $\mathrm{Bi}_{2} \mathrm{O}_{3}$

- Calcium phosphate, $\mathrm{Ca}_{3}\left(\mathrm{PO}_{4}\right)_{2}$ 
Table 7-5. Probable Solids in the Waste Matrix.

\begin{tabular}{|l|c|c|c|c|c|c|c|c|}
\hline & $\mathrm{NO}_{3}{ }^{-}$ & $\mathrm{PO}_{4}{ }^{-}$ & $\mathrm{SO}_{4}{ }^{2-}$ & $\mathrm{F}$ & $\mathrm{OH}^{-}$ & $\begin{array}{c}\mathrm{Si} \\
\left(\mathrm{Ss}_{3}{ }^{2}{ }^{-}\right)\end{array}$ & $\begin{array}{c}\text { Oxide } \\
2\end{array}$ & $\mathrm{CO}_{3}{ }^{2-}$ \\
\hline $\mathrm{Bi}^{+3}$ & & PPT & & PPT & PPT & & PPT & \\
\hline $\mathrm{Ca}^{+2}$ & & PPT & PPT & PPT & & PPT & PPT & PPT \\
\hline $\mathrm{Cr}^{+3}$ & & PPT & PPT & PPT & PPT & & PPT & \\
\hline $\mathrm{Fe}^{+3}$ & & PPT & & PPT & PPT & & PPT & PPT \\
\hline $\mathrm{Na}^{+}$ & & & & & & & & \\
\hline $\mathrm{La}^{+3}$ & & & PPT & PPT & PPT & & PPT & PPT \\
\hline $\mathrm{Mn}^{+4}$ & & PPT & & PPT & PPT & PPT & PPT & PPT \\
\hline $\mathrm{U}^{+6}$ & $\mathrm{NL}$ & PPT & PPT & NL & PPT & & PPT & \\
\hline
\end{tabular}

PPT $=$ Precipitate forms.

$\mathrm{NL}=$ Precipitate formation not likely under tank conditions.

- Calcium carbonate, $\mathrm{CaCO}_{3}$

- Calcium oxide, $\mathrm{CaO}$

- Calcium sulfate, $\mathrm{CaSO}_{4}$

- Chromium(II) fluoride, $\mathrm{CrF}_{2}$

- Chromium phosphate, $\mathrm{CrPO}_{4} \bullet 2 \mathrm{H}_{2} \mathrm{O}$

- Chromium dioxide, $\mathrm{CrO}_{2}$

- Chromium oxide, $\mathrm{Cr}_{2} \mathrm{O}_{3}$

- Iron(III) fluoride, $\mathrm{FeF}_{3}$

- Iron(III) hydroxide, $\mathrm{Fe}(\mathrm{OH})_{3}$

- Iron(III) phosphate, $\mathrm{FePO}_{4}$

- Lanthanum oxide, $\mathrm{La}_{2} \mathrm{O}_{3}$

- Manganese diflouride, $\mathrm{MnF}_{2}$

- Manganese phosphate, $\mathrm{MnPO}_{4} \bullet \mathrm{H}_{2} \mathrm{O}$

- Manganese dioxide, $\mathrm{MnO}_{2}$

- Manganese(III) hydroxide, $\mathrm{MnO}(\mathrm{OH})$

- Uranyl hydroxide, $\mathrm{UO}_{2}(\mathrm{OH})_{2}$
- Calcium chromite, $\mathrm{CaCr}_{2} \mathrm{O}_{4}$

- Calcium silicate, $\mathrm{CaSiO}_{3}$

- Calcium hydroxide, $\mathrm{Ca}(\mathrm{OH})_{2}$

- Chromium(III) fluoride, $\mathrm{CrF}_{3}$

- Chromium hydroxide, $\mathrm{Cr}(\mathrm{OH})_{2}$

- Chromium monoxide, $\mathrm{CrO}$

- Iron(II) fluoride, $\mathrm{FeF}_{2}$

- Iron(II) hydroxide, $\mathrm{Fe}(\mathrm{OH})_{2}$

- Iron(II) phosphate, $\mathrm{Fe}_{3}\left(\mathrm{PO}_{4}\right)_{2}$

- Lanthanum hydroxide, $\mathrm{La}(\mathrm{OH})_{3}$

- Lanthanum fluoride, $\mathrm{LaF}_{3}$

- Manganese triflouride, $\mathrm{MnF}_{3}$

- Manganese hydroxide, $\mathrm{Mn}(\mathrm{OH})_{2}$

- Manganese oxide, $\mathrm{Mn}_{3} \mathrm{O}_{4}$

- Uranyl phosphate, $\mathrm{UO}_{2} \mathrm{HPO}_{4} \bullet 4 \mathrm{H}_{2} \mathrm{O}$

- Uranyl sulfate, $2\left(\mathrm{UO}_{2} \mathrm{SO}_{4}\right) \bullet 7 \mathrm{H}_{2} \mathrm{O}$.

Insoluble aluminosilicates are suspected of binding the ${ }^{137} \mathrm{Cs}$. ${ }^{90} \mathrm{Sr}$ may be held by several possible insoluble ionic compounds. There are many more possible and complex compounds that conceivably could exist in the waste matrix. This list is not meant as authoritative or exhaustive, and the alkaline nature of the media may substantially alter the phase equilibria for some of these materials. However, it does provide a reasonable starting point for any further speciation work. 
This page intentionally left blank. 


\subsection{CONCLUSIONS}

Analyses of the waste show a very small number of analytes comprising a disproportionate majority of the waste. Water is the single largest analyte, making up over 75 percent of the solids mass. Less than one percent of the total mass of the tank waste is drainable liquid. Calcium, chromium, iron, manganese, sodium, lanthanum, bismuth, and silicon constitute approximately 10.7 percent of the solids mass. $\mathrm{PO}_{4}{ }^{3-}$ and $\mathrm{NO}_{3}{ }^{-}$constitute approximately 7.4 percent of the total (i.e. soluble and insoluble) solids mass. The fraction of the total anions that nitrate and phosphate represent cannot be determined adequately because the analytical method measured only soluble anions and it is known that there are insoluble oxides and hydroxides that are not assayed at this time. The TOC was measured and found to be less than 1.3 weight percent (dry basis) in each core and for the tank as a whole. However, the TOC assay method is believed to biased low for this waste matrix and individual segment results have been observed to be higher than the bulk value for the tank.

The only significant gamma emitter found in the waste was ${ }^{137} \mathrm{Cs}$, and it was found at very low levels. No meaningful regional concentrations (hot spots) of radioisotopes or fuel were detected along the vertical axis in either core. The ${ }^{137} \mathrm{Cs}$ concentration was relatively constant between individual core composites and their replicates; however, the concentrations between core 31 and core 33 differed by a factor of 2 . In addition, the ${ }^{137} \mathrm{Cs}$ concentration decreased by a factor of nearly 3 as a function of depth between segment 1 and segment 9 of core 33. The major source of radiological activity was ${ }^{90} \mathrm{Sr}$, which was also at a very low level. The bulk waste temperature in the tank, obtained from a thermocouple tree, ranges between 16 to $20^{\circ} \mathrm{C}\left(61\right.$ to $\left.68^{\circ} \mathrm{F}\right)$. The radiological activity of tank $241-\mathrm{T}-111$ waste material was quite low, ranging from 0.3 to $10 \mathrm{mR} / \mathrm{hr}$, measured through the drill string. No significant radiological activity was found in the drainable liquid in the tank or in the water digestion of the samples, but radionuclides were liberated readily in the acid digestion sample preparation, as indicated from the homogenization data. This suggests that ${ }^{90} \mathrm{Sr}$ and ${ }^{137} \mathrm{Cs}$ are insoluble.

Cores 31 and 33 appear to have a T-Plant process flush disposed on top of 224 waste, overlying a $2 \mathrm{C}$ waste heel. ${ }^{241} \mathrm{Am}$ and ${ }^{137} \mathrm{Cs}$ decrease substantially as a function of depth, thus their profiles nominally agree with fill histories, although individual batches and process upsets can show characteristics contrary to the general trend. These observations are consistent with the historical information regarding the transfer history, and the ICP element distribution through the segments. Discernable exothermic behavior was detected in the upper segments of both cores 31 and 33, even though the magnitude of the exotherms did not agree with the TOC present. This lack of an identifiable fuel source was attributed to the inability of the persulfate oxidation method to adequately quantitate TOC in this waste matrix. Another hypothesis under investigation is the potential contribution of an exothermic inorganic reaction that has not been identified.

Historical data indicated that $2 \mathrm{C}$ and 224 wastes were not expected to give any exothermic response at all, and could not create a propagating hazard. This prediction has been upheld 
for $2 \mathrm{C}$ wastes as no exotherms were observed. In the 224 wastes, even though some small amounts of oxalate were indicated in the flowsheets, no reaction was expected. Calculations of the bulk waste inventory and inventories for several analytes of interest to the various safety issues [organics (as $\mathrm{TOC}$ ), $\mathrm{NO}_{3},{ }^{137} \mathrm{Cs},{ }^{90} \mathrm{Sr}$, plutonium, and water] were made. The calculated TOC by weight percent was smaller than the watch list criterion on a bulk basis, but the energetics results do not reconcile well with that interpretation, and indicate that the organic content in the tank may be disproportionately partitioned between the upper $100 \mathrm{~cm}$ of waste and the remainder of the tank. However, it is important to note that the organics concentration, even in this hypothesized enriched layer, may be too low to support a self-sustaining reaction in its present state. Reactions were observed only after all water had been removed from the waste matrix, and water makes up over 75 weight percent of the waste, providing an enormous heat sink to be overcome before reactions can be initiated. Both the historical and analytical data from tank 241-T-111 strongly indicate that the waste lacks the fuel concentration needed to sustain any propagating exothermic behavior or a heat source intense enough to trigger a reaction. None of the other calculated bulk inventory values exceeded any level of concern (see Table 8-1).

Experimental and analytical evidence from tank 241-T-111 waste suggests the risk from organic compounds in this particular Hanford-Site high-level waste tank is acceptable and that a propagating exothermic reaction under current and near-term tank operating conditions is not credible.

Table 8-1. Comparison of Tank 241-T-111 Analyte Values to Safety Issue Criteria.

\begin{tabular}{|l|l|l|}
\hline \multicolumn{1}{|c|}{ Analyte } & \multicolumn{1}{|c|}{$\begin{array}{c}\text { Safety issue } \\
\text { criteria }^{1}\end{array}$} & \multicolumn{1}{c|}{$\begin{array}{c}\text { Calculated/ } \\
\text { measured value }\end{array}$} \\
\hline$\Delta \mathrm{H}$ (dry basis) & $-75 \mathrm{cal} / \mathrm{g}$ & $\begin{array}{l}\text { In excess of }-215 \\
\text { cal/g }\end{array}$ \\
\hline $239 / 240 \mathrm{Pu}$ & $50 \mathrm{~kg}$ & $9.2 \mathrm{~kg}$ \\
\hline Temperature & $300^{\circ} \mathrm{F}\left(149^{\circ} \mathrm{C}\right)$ & $16^{\circ} \mathrm{C}\left(60.5^{\circ} \mathrm{F}\right)$ \\
\hline Heat load & $11.72 \mathrm{kw}$ & $0.08 \mathrm{kw}$ \\
\hline $\begin{array}{l}\text { Organic content } \\
\text { (roC, Dry basis) } \\
\text { (10\% sodium acetate equivalent) }\end{array}$ & $3.0 \mathrm{wt} \%$ TOC & $\begin{array}{l}1.3 \mathrm{wt} \% \text { TOC } \\
\text { (This result is likely } \\
\text { biased low) }\end{array}$ \\
\hline
\end{tabular}

'(Lindsey 1986, RHO 1988, Boyles 1992, Reep 1992) 


\subsection{RECOMMENDATIONS}

The following recommendations are made based on the data and analyses presented in this report and the goals of the characterization effort.

- Investigate the potential existence of alternate transfer paths from T-Plant.

- Examine more closely the chemical behavior, reactivity, and composition of Turco decontamination agent.

- Continue to characterize tank 241-T-111 sample matrices at PNL.

- Investigate the possible kinship between tank 241-T-111 and other tanks.

- Research and develop improved assay methods for TOC.

- Investigate observed discrepancy for alpha-emitting radionuclides (especially ${ }^{239 / 240} \mathrm{Pu}$ and $\mathrm{U}$ ). 
This page intentionally left blank. 


\subsection{REFERENCES}

Agnew, S. F., 1994, Hanford Defined Wastes: Chemical and Radionuclide Compositions, LA-UR-94-2657, Los Alamos National Laboratory, Los Alamos, New Mexico.

Anderson, J. D., 1990, A History of the 200 Area Tank Farms, WHC-MR-0132, Westinghouse Hanford Company, Richland, Washington.

Babad, H. and K. S. Redus, 1994, Tank Safety Screening Data Quality Objectives, WHC-SD-WM-SP-004, Rev. 0, Westinghouse Hanford Company, Richland, Washington.

Babad, H., 1994, Data Quality Objective to Support Resolution of the Organic Fuel Rich Tank Safety Issue, WHC-SD-WM-DQO-006, Rev. 0, Westinghouse Hanford Company, Richland, Washington.

Baldwin, D. L., 1994, Final T-111 (Core 33, Segment 2) Dry/As-received TOC results from two methods, Rev. 2, (Letter to R. M. Bean, January 14), Pacific Northwest Laboratory, Richland, Washington.

Bean, R. M., 1994, Tank 241-T-111 Reactive Component Issue, WHC-SA-2418-VA, Presentations for Tank Waste Chemical Reactions Sub Panel Meeting April 11-13, Westinghouse Hanford Company, Richland, Washington.

Bell, K. E., 1993, Tank Waste Remediation System Tank Characterization Plan, WHC-SD-WM-PLN-047, Rev. 0, Westinghouse Hanford Company, Richland, Washington.

Borsheim, G. L., 1994, Bismuth Phosphate 224 Building Waste Data, Internal Memo 7E320-94, February 24, Westinghouse Hanford Company, Richland, Washington.

Boyles, V. C., 1992, Operating Specifications for Single-Shell Waste Storage Tanks, OSD-T-151-00013, Rev. D-1, Westinghouse Hanford Company, Richland, Washington.

Carothers, K., D. A. Reynolds, and N. W. Kirch, 1994, Data Quality Objective for Waste Compatibility Program, WHC-SD-WM-DQO-001, Rev. 7, Westinghouse Hanford Company, Richland, Washington.

Delegard, C. H., 1994, Centrifugation and Analysis of Sludge from Tank 241-T-111, (Internal Memo 8E110-PCL-046, June 9), Westinghouse Hanford Company, Richland, Washington. 
DeLorenzo, D. S., J. H. Rutherford, D. J. Smith, D. B. Hiller, K. W. Johnson, and B. C. Simpson 1994, Tank Characterization Reference Guide, WHC-SD-WM-TI-648, Rev. 0, Westinghouse Hanford Company, Richland, Washington.

Ecology, EPA, and DOE, 1992, Hanford Federal Facility Agreement and Consent Order, 2 vols., Washington State Department of Ecology, U.S. Environmental Protection Agency, U.S. Department of Energy, Olympia, Washington.

Ecology, EPA, and DOE, 1994, Hanford Federal Facility Agreement and Consent Order, 2 vols., as amended, Washington State Department of Ecology, U.S. Environmental Protection Agency, U.S. Department of Energy, Olympia, Washington.

EPA, 1986, Test Methods for Evaluating Solid Waste, SW-846, 3rd Edition, U.S. Environmental Protection Agency, Washington, D.C.

Hanlon, B. M., 1994, Tank Farm Surveillance and Waste Status Summary Report for April 1994, WHC-EP-0182-73, Westinghouse Hanford Company, Richland, Washington.

Harville, D. A., 1977, "Maximum Likelihood Approaches to Variance Component Estimation and to Related Problems," Journal of the American Statistical Association, p.p. $320-340$.

Hill, J. G., W. I. Winters, B. C. Simpson, J. W. Buck, P. J. Chamberlain, and V. L. Hunter, 1991, Waste Characterization Plan for the Hanford Site Single-Shell Tanks "Appendix I: Test Plan for Sampling and Analysis of Ten Single-Shell Tanks," WHC-EP-0210, Rev. 3, Westinghouse Hanford Company, Richland, Washington.

Jenkins, C. E., and D. B. Engleman, 1994, Engineering Report: Managing the Assumed Leak from Single-Shell Tank 241-T-111, WHC-SD-WM-ER-337, Rev. 0, Westinghouse Hanford Company, Richland, Washington.

Jensen, L., 1994, Statistical Characterization Report for Single-Shell Tank 241-T-111, WHC-SD-WM-TI-650, Rev. 0, Westinghouse Hanford Company, Richland, Washington.

Jungfleisch, F. M., 1984, TRAC: A Preliminary Estimation of the Waste Inventories in Hanford Tanks Through 1980, SD-WM-TI-057, Rockwell Hanford Operations, Richland, Washington.

Lindsey, D. W., 1986, Operating Specifications for Single-Shell Waste Storage Tanks, OSD-T-151-00013, Rockwell Hanford Operations, Richland, Washington. 
McKinney, S. G., L. R. Webb, L. P. Markel, M. A. Bell, 1993, Single-Shell Tank Characterization Project and Safety Analysis Project Core 31 and 33, Validation Report Tank 241-T-111, WHC-SD-WM-DP-024, Rev. 0, Westinghouse Hanford Company, Richland, Washington.

Reep, I. E., 1992, Status Report on Resolution of Waste Tank Safety Issues at the Hanford Site, WHC-EP-0600, Westinghouse Hanford Company, Richland, Washington.

RHO, 1988, Criticality Prevention Specifications for Waste Storage Tanks and Associated Equipment, CPS-T-149-00010, Rockwell Hanford Operations, Richland, Washington.

Rios, R. R., 1994, Computer Automated Surveillance System, Westinghouse Hanford Company, Richland, Washington.

Ross, L., 1993, Tank Farm Operating Procedure--Perform Core Sampling, TO-020-450, Westinghouse Hanford Company, Richland, Washington.

Schneider, K. J. 1951, Flow Sheets and Flow Diagrams of Precipitation Separations Process, HW-23043, General Electric Company, Richland, Washington.

Wagner, R. N., 1992, Hanford Waste Vitrification Plant Feed Characterization Requirements, WHC-SD-HWV-SM-001, Rev. 4, Westinghouse Hanford Company, Richland, Washington.

Weast, R., 1984, Handbook of Chemistry and Physics, 64th Ed., CRC Press, Boca Raton, Florida.

WHC, 1994, Tank 241-T-111 Reanalyses, WHC-SD-WM-DP-058, Rev. 0, Westinghouse Hanford Company, Richland, Washington.

Wicks, J. H., 1994, Tank T-111, (Internal Memo 94-003, March 3), Westinghouse Hanford Company, Richland, Washington.

Winters, W. I., 1991, Evaluation of SST Data, (Internal Memo 28200-91-55, July 30), Westinghouse Hanford Company, Richland, Washington.

Winters, W. I., L. Jensen, L. M. Sasaki, R. L. Weiss, J. F. Keller, A. J. Schmidt, and M. G. Woodruff, 1990a, Waste Characterization Plan for the Hanford Site Single-Shell Tanks, WHC-EP-0210, Rev. 1, Westinghouse Hanford Company, Richland, Washington.

Winters, W. I., L. Jensen, L. M. Sasaki, R. L. Weiss, J. F. Keller, A. J. Schmidt, and M. G. Woodruff, 1990b, Waste Characterization Plan for the Hanford Site Single-Shell Tanks, WHC-EP-0210, Rev. 2, Westinghouse Hanford Company, Richland, Washington. 
This page intentionally left blank. 


\section{DISTRIBUTION}

\section{Number of Copies}

\section{OFFSITE}

1 Sandia National Laboratory

P. O. Box 5800

MS-0744, Dept. 6404

Albuquerque, NM 87815

D. Powers

$1 \quad$ Nuclear Consulting Services Inc.

P. O. Box 29151

Columbus, $\mathrm{OH}$ 43229-01051

J. L. Kovach

1 Chemical Reaction Sub-TAP

202 Northridge Court

Lindsborg, Kansas 67456

B. C. Hudson

1 Tank Characterization Panel

Senior Technical Consultant

Contech

6301 Indian School Road NE, Suite 614

Albuquerque, NM 87110

J. Arvizu

2 U.S. Department of Energy - Headquarters Office of Environmental Restoration

and Waste Management EM-563

12800 Middlebrook Road

Germantown, MD 20874

K. T. Lang

J. A. Poppitti 


\section{DISTRIBUTION (continued)}

\section{Number of Copies}

\section{OFFSITE}

$\underline{\text { SAIC }}$

2030 Centry Boulevard

Suite 200-B

Germantown, MC 20874

H. Sutter

6

Los Alamos Laboratory

CST-14 MS-J586

P. O. Box 1663

Los Alamos, NM 87545

S. F. Agnew

5

Los Alamos Technical Associates

750 Swift Blvd. Suite 4

Richland, WA 99352

A. T. DiCenso

1

Ogden Environmental

101 East Wellsian Way

Richland, WA 99352

R. J. Anema

1

CH2M Hill

P. O. Box 91500

Bellevue, WA 98009-2050

M. McAfee

1

Tank Advisory Panel

102 Windham Road

Oak Ridge, TN 37830

D. O. Campbell 


\section{DISTRIBUTION (continued)}

\section{Number of Copies}

\section{ONSITE}

H. Babad

S7-30

D. A. Barnes

R1-51

A. L. Boldt

H5-49

G. L. Borsheim

R2-11

D. R. Bratzel

S7-31

T. M. Brown

R2-12

T. H. Bushaw

T6-30

M. P. Campbell

R2-86

R. J. Cash

S7-15

G. M. Christensen

H4-21

W. L. Cowley

H4-61

M. L. Deffenbaugh

R2-86

C. Defigh-Price

S7-30

R. A. Dodd

R1-51

G. L. Dunford

R2-50

S. J. Eberlein

S7-31

D. B. Engelman

R1-49

K. O. Fein

H4-63

J. S. Garfield

H5-49

K. D. Gibson

H4-61

C. E. Golberg

H5-49

J. M. Grigsby

H4-62

R. D. Gustavson

R1-51

C. S. Haller

R2-12

H. W. Heacock

S7-81

D. L. Herting

T6-09

B. A. Higley

H5-49

G. Jansen

L0-14

G. D. Johnson

S7-15

K. K. Kawabata

T6-50

N. W. Kirch

R2-11

M. J. Kupfer

H5-49

G. A. Meyer

S4-54

W. C. Miller

S4-55

W. C. Mills

C. T. Narquis 
DISTRIBUTION (continued)

\section{Number of Copies}

\section{ONSITE}

Westinghouse Hanford Company (continued)

$\begin{array}{ll}\text { R. H. Palmer } & \text { R2-58 } \\ \text { M. A. Payne } & \text { S7-14 } \\ \text { S. H. Rifaey } & \text { S2-45 } \\ \text { R. R. Rios } & \text { R1-80 } \\ \text { D. A. Reynolds } & \mathrm{R} 2-11 \\ \text { P. Sathyanarayana (2) } & \mathrm{R} 2-12 \\ \text { F. A. Schmittroth } & \mathrm{H} 0-35 \\ \text { J. S. Schofield } & \mathrm{R} 1-51 \\ \text { P. Segall } & \mathrm{H} 4-19 \\ \text { M. H. Shannon } & \mathrm{H} 4-61 \\ \text { E. J. Shen } & \mathrm{S} 4-58 \\ \text { B. C. Simpson (10) } & \mathrm{R} 2-12 \\ \text { G. L. Smith } & \mathrm{H} 4-61 \\ \text { M. J. Sutey } & \mathrm{T} 4-07 \\ \text { L. D. Swenson } & \mathrm{G} 3-20 \\ \text { J. D. Thomson } & \mathrm{R} 2-76 \\ \text { G. L. Troyer } & \mathrm{T} 6-50 \\ \text { D. A. Turner } & \mathrm{S} 7-15 \\ \text { C. J. Udell } & \mathrm{L} 6-12 \\ \text { D. J. Washenfelder } & \mathrm{L} 4-75 \\ \text { M. S. Waters } & \mathrm{S} 6-30 \\ \text { G. R. Wilson } & \mathrm{S} 7-14 \\ \text { TFIC (Tank Farm Information Center) } & \mathrm{R} 1-20 \\ \text { Central Files } & \mathrm{L} 8-04 \\ \text { EDMC } & \mathrm{H} 6-08 \\ \text { OSTI (3) } & \mathrm{L} 8-07 \\ \text { Document Processing } & \\ \text { and Distribution (2) } & \mathrm{L} 8-15 \\ \text { ICF - Kaiser Hanford Company } & \\ \text { C. H. Brevick } & \\ \text { L. A. Gaddis } & \mathrm{G} 7-56 \\ \text { R. B. Johnson } & \mathrm{G} 7-57 \\ \text { W. W. Pickett } & \mathrm{G} 7-57 \\ & \mathrm{G} 7-57\end{array}$




\section{DISTRIBUTION}

\section{Number of Copies}

\section{ONSITE}

U.S. Department of Energy - Richland Operations

4

J. M. Clark

S7-54

R. E. Gerton

$57-54$

J. R. Noble-Dial

S7-54

14

Pacific Northwest Laboratory

W. J. Apley

S7-71

R. M. Bean

P8-08

S. F. Bobrowski

K7-28

P. G. Eller

B1-40

E. J. Eschbach

K7-15

J. G. Hill

K7-97

L. K. Holton

P7-43

B. M. Johnson

K1-78

G. J. Lumetta

P7-25

B. D. McVeety

K6-63

R. C. McVeety

$\mathrm{K} 7-22$

P. J. Mellinger

P7-22

A. F. Noonan

B1-40

L. R. Pederson

K2-44

4

Washington State

Department of Ecology

A. B. Stone

N1-05 
This page intentionally left blank. 
WHC-EP-0806

-

Appendix A: Analytical Data 
WHC-EP-0806

This page intentionally left blank. 


\section{Introduction}

The analyses in this data package were performed by the Westinghouse Hanford 222-5 Laboratory or the 8attelle Pacific Northwest Laboratory (PNL) under the guidance provided in the Waste Characterization Plan for the Hanford Site single Shell Tanks" (WHC-EP-0210) and the "Sampling and Analysis of Ten Single Shell Tanks" (HHC-SOW-91-0006). The quality control for single shell tanks is described in appendix 0 of UHC-EP-0210. Additional support data can be found in append $i x$ I of WHC-EP-0210. Laboratory operations at 222-5 are performed according to the Quality Assurance Project Plan for the Analysis of Highiy Radioactive Samples in Support of Environmental Activities on the Hanford Site" (WHC-SD-CP-QAPP-002) unless superseded by the waste characterization plan, appendix D, the associated SOW, or the Technical Project Plan (TPP).

Tank 241-T-111 (referred to as T-111 in the remainder of this package) is a single shell tank built in 1944 with an operating capacity of 500,000 gallons. T-1Il received 488,000 gallons of ${ }^{\circ} 2 C^{\circ}$ and ${ }^{\prime} 224^{\circ}$ type wastes through February 1976, and is classified as EHW (extremely hazardous waste). During early remediation efforts, ending in 1978, nearly 25,100 gallons of liquid was pumped out of $T-111$. The " $2 C$ " waste was from the second decontamination eycle of the bismuth phosphate process at the $B$ and $T$ plants. This waste consists of the liquid remaining after precipitation of the plutonium. The " $224^{\text {" waste }}$ was from the final decontamination and concentration stage of the bismuth phosphate process. In this stage, first the by-products and then the piutonium are precipitated with lanthanum fluoride. Historical data indicates the major components and estimated concentrations of these waste streams are as follows.

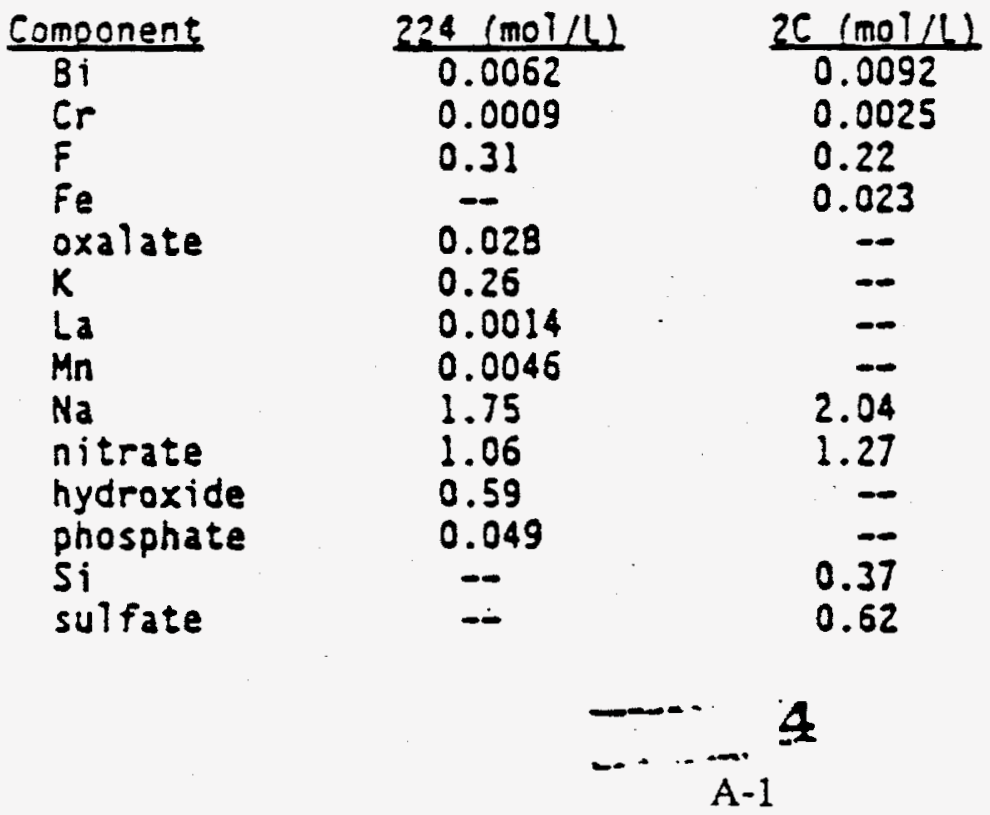


WHC-EP-0806

WHC-SO-WM-DP-024 ADOENDUM 2, REY 0

Based on prior knowledge, cores from T-111 were expected to contain 8.5 segments. The first segment is normally the partial segment. Three cores were obtained from $T-111$ - cores 31,32 , and 33 . Core 32 was not analyzed as the recovered material, all liquid, was considered not representative of the tank. No drainable liquids were recovered from cores 31 and 33 . Drainable liquids are defined as quantities greater than $25 \mathrm{~mL}$. Less than $25 \mathrm{~mL}$ quantities are blended back into the sample. Homogenization tests were performed on segments $1,3,5,7$ and 9 from core 33. Two composite samples were prepared for core 31 and core 33. Sample identification is obtained from the "sample point section on the analytical card. A sample from core 31 , segment 1 is designated "TIII-C31-5I". Similarly, a sample from composite 1 , core 33 is designated "TII1-C33-C1", and a homogenization sample from core 33 , segment 5 is designated "TI11-C33-55H*.

All of the segments, with the exception of segment 9 of each core, were a homogeneous brown-black aud-like material. The botton half of segment 9 had a white layer. The homogenization test for segment 9 used the entire segment (both phases) from core 33. Additional analysis (acid digest, water digest, ICP, GEA, TA and IC) were requested for the white layer on material from core 31. This sample is designated "TI11-[31-598*. All samples from T-111 exceeded the six month holding time limit.

Fifteen samples were sent to PNL. Volatile Organic Analysis (VOA) were requested on odd numbered segment samples for both cores and rheology on even numbered segment samples for core 31. The VOA requested for segment 9 is on the white phase only. Samples from both composites from each core were submitted for semi-VOA, Extractable Organic Halides (EOX). As, Se, Ni-63, Pu and $U$ isotopic analyses. These samples and the requested anaiyses are as follows.

VOA: core 31 , segments $1,3,5,7,9$. core 33 , segments $1,3,5,7,9$.

Semt-YOA, EOX, As, Se: core 31, composites 1, 2. core 33, composites 1, 2.

Ni-63, Pu and U isotopic: core 31, composites 1, 2. core 33, composites 1, 2. VOA, semi-VOA: hot cell blank. field biank.

Rheology 3 Physical: core 31, segments 2, 4, 8.

The required $Q C$ is listed in table $0-5$ of appendix 0 , WHC-EP-0210. In sumary, the requirements are:

- one laboratory control standard per analytical batch,

- one blank per analytical batch,

- one matrix spike per core or per matrix change,

- $100 \%$ duplicates on all homogenization test samples and core composite samples,

- one duplicate per analytical batch for direct segment samples, 
WHC-EP-0806

WHC-SD-WM-DP-024 ADDENDUM 2, REV 0

- a duplicate to verify each detected exotherm for OSC analysis.

The exceptions to the above guidelines are:

- water is always ran in duplicate,

- Sr-90, Se-79, TC-99, I-129, Pu and Am have a spike or carrier added to each sample, so no additional matrix spikes are required.

- GEA and pH do not require a spike,

๘

- a matrix spike for $N p$ is requested on each sample,

- ICP. HYA, CVAA, and IC require additional, method specific QC. Instrument calibration and check standards are run according to spectfic procedure protocols.

Sample analysis are repeated at least once if the spike recovery is outside of $100 \% \pm 25 \%$ (provided the spike concentration is at least $25 \%$ of the sample concentration), or the duplicates have a relative $\%$ difference greater than 20 * (provided the analytical results are greater than 5 times the detection

imit). If the original problem remains after one re-run, and the chemist has no explanation or "fix", additional re-runs are not required. These situations should be described in the "Analytical Batch Sumary Sheet" described below. The entire batch does not have to be re-run uniess the standard or blank for the batch failed.

A "Characterization Change Notice" was implemented during the T-111 analysis. The intent of the form is to document minor changes in analyses and deviations from the sow or waste characterization plan. These are attached at the end of the sumary section.

A "Chemist's Batch Surmary Sheet" form was introduced for T-111 sample analysis and appears at the end of the analytical batch. Since this form was introduced after analysis started, one may not accompany each sample batch. The intent of this form is to document the chemist's initial data evaluation, and to provide a means of obtaining descriptive results from the chemist and chemical technologist on each sample batch. While not required as part of the final package, these forms will aid in preparing this narrative and provide insight into some of the problems encountered during sample analysis.

All analytical data for the package appears in a sumary section. The sumaries are lotus spread sheets intended to aid in review of anaiytical data, and may not include all of the associated laboratory control standards, dates, or laboratory identification numbers ( $J$ numbers). The spread sheet sumaries display analytical results, blank data, detection limits, LMCS recoveries and spike recoveries, and using this data, calculates averages for duplicates, the relative percent difference between the duplicates, a mass and charge balance (described below), a ratio of the result to the detection limit, and varfous inter-comparisons throughout the summary. Secondary spread sheets are supplied that compare the core composite and homogenization duplicate and average results. Since a spike is not required for each sample, spike data is copied with each associated sample. "Less than" values are not used in any of the spread sheet calculations.

$$
-A-3 \quad 6
$$


WHC-EP-0806

WHC-SD-WM-DP-024 ADDENDUM-2, REV 0

All analytical resuits are "wet weight" values, based on the actual extrusion weights. To convert to dry weight, divide the "weight wet value by the weight fraction of solids $(100$ - : water $/ 100)$. All the preparation bianks and detection limits are reported in the same untts as the sample results by assuming a typical sample size. This is done to provide a direct comparison of the background and degree of contamination present in the method to the sample results. Since the sample size is estimated, a "less than value provided for a sample could be slightly lower than the given detection liait or blank value.

A charge balance is calculated for each core composite sample in the analytical summary. The charge balance is calculated by ratioing the equivalent charge of the eations to the anions. As an example, the equivaient charge of sulfate is calculated as follows:

\section{averace ug/a sulfate \\ ailliequivalent weight of sulfate $\cdot 1000$}

Only the major components are used for these calculations, those with a concentration greater than $1000 \mathrm{ug} / \mathrm{g}$. The cations used are $\mathrm{Ca}, \mathrm{Cr}, \mathrm{Fe}, \mathrm{Mn}, \mathrm{X}$, $\mathrm{Na}, \mathrm{Bi}$, and La from the acid digested ICP results. The anions used are fluoride, nitrate, phosphate (ealculated from the $P$ on the acid digested ICP resuit), sulfate (calculated from the $S$ on the acid digested ICP result), and acetate (calculated from the TOC results). The ratio ranges from $1.3-1.5$. Proper incorporation of hydroxide would probably improve these ratios, since there is a relatively large uncertainty in the assumed molecular speciation mode1.

A mass balance is calculated for each core composite sample in the analytical summary, using an "oxide model" as the basts for the calculattons for metals and the anions were present in their normal forms. The mass balance is the sum of the weight fractions of the major constituents (those with a concentration greater than $1000 \mathrm{ug} / \mathrm{g})$. As an example, the weight fraction calculation for $\mathrm{CaO}$ is as follows:

$$
\frac{\text { Lug/e of } \left.\mathrm{Ca}_{\mathrm{a}} \text { molecular weight of } \mathrm{CaO}\right)}{\text { (atomic wt of } \mathrm{Ca} \cdot 1000000)}
$$

The components used in caleulating the mass balance are $8 \mathrm{i}, \mathrm{Ca}, \mathrm{Cr}$. Fe, Mn, $\mathrm{Na}, U, F$, nitrate, phosphate, sulfate, water, $K$, and $L 2$. It was assumed that aif but $K, \mathrm{Na}$, and $\mathrm{F}$ were present as oxides. The ratio ranged between 0.93 and 0.96 .

\section{SECTION I: EXTRUSION AND SAMPLE DATA}

\section{Visual}

A sumary of the extrusion data, entitied "Physical Properties Sumary", is provided with the segment data. This is a compilation of all the recoveries for each segment of each core, with an assoctated percent recovery, penetrometer reading, and density. Photographs of the extruded segment are included in the data pacxage. All volumes given that are less than $180 \mathrm{~mL}$ (100 * recovery) are estimates provided by the hot cell chemist. Segments. marked with an asterisk on the sumary sheet were recovered from sample 
contalners with the valves left in the "open" position (the waste was thick enough to remain in the container, even though the valve was not closed). The extruston data for core 32 will be included in the core 31 package.

\section{Core 31}

Segment 1: The sampler was almost empty. It contained about $50 \mathrm{aL}$ of homogeneous, black-brown, low viscous solids. The entire sample was used in VOA and DSC/TEA sampling. There was a tiny amount of liquid, not enough to observe characteristics.

Segment 2: The sampler was completely full of homogeneous, dark brown to biack solids with the conststency of swamp mud. There were no drainable liquids.

Segment 3: The sampler was completely full of homogeneous, dark brown solids that had the consistency of swamp mud. There were no drainable iqquids.

Segment 4: Most of the sampler was full of the same dark brown homogeneous solids. The top $1 / 8$ of the extruder was filled with a nore ilquidy" solids than the rest. There were no drainable liquids.

Segment 5: The sampler was completely full of the same dark brown homogeneous solids and contained no dratnable liquids.

Segment 6: This sampler was empty, the valve was left in the open position.

Segment 7: The sampler was completely full of the same dark brown homogeneous solids and contained no drainable liquids.

Segment 8: The sampler was completely full of the same dark brown homogeneous solids and contained no drainable liquids.

Segment 9: The sampler was completely full of solids, the same dark brown solid material at the top, but gradually whitened down the segment. While the color varied, the consistency of the material was the same as all the other segments in this core.

Core 32

Segment 1: Contained about $50 \mathrm{~mL}(58.70 \mathrm{~g})$ of "dark dishwater grey aqueous" liquid with about a $2 \mathrm{~mm}$ layer on the surface. There was a layer of bubbles covering the thin top layer, and adhering to the sides of the jar. No solids were collected.

Segment 2: Contained about $170 \mathrm{~mL}(88.35 \mathrm{~g})$ of dark grey liquid with dark grey particles suspended in the liquid. There were only minimal solids (enough for a VOA sample) that had the consistency of loose mud or pudding and was dark brown/black in color.

Segment 3: Contained 180.90 grams of dark grey aqueous material. No solids were present. Ho volume was recorded. 
Segment 4: Tontained 182.48 grams of dark grey aqueous material. No solids were present. No volume was recorded.

Segment 5: Contained 191.05 grams of dark grey aqueous matertal. No solids were present. Ho volume was recorded.

Segment 6: Contained 185.52 grams of dark grey aqueous material. No solids were present. No volume was recorded.

Segment 7: The sampler was empty, the valve was left in the open posjtion.

Segment 8: The sampler was empty, the valve was left in the open position.

Segment 9: Contained 158.24 grams of llquid, with about $150 \mathrm{ml}$ of aqueous phase and $8 \mathrm{~mL}$ of $\mathrm{NPH}$.

No samples were taken from core 32 as the material was judged to be nonrepresentative of the material in the tank when compared to cores 31 and 33 .

No photographs were taken for segments $1,3,4,5,6,7,8,9$.

Core 33

Segment 1: The sampler was completely full of nearly black homogeneous solids, and contained no drainable liquids.

Segment 2: The sampler was completely full of the same nearly black homogeneous solids, and contained no drainable liquids.

Segment 3: The sampler was completely full of the same nearly black homogeneous solids, and contained no drainable liquids.

Segment 4: The vaive was left open on this core assembly. The extruder was about $75 x$ full dark brown/nearly black homogeneous solids, and contained no drainable liquids. Color was slightly lighter than previous segment.

Segment 5: The valve was left open on this core assembiy. The extruder was about $7 / 8$ full of the same dark brown homogeneous solids, and contained no drainable liquids.

Segment 6: The sampler was nearly full of the same dark brown homogeneous solids, and contained no drainable liquids.

Segnent 7: The sampler was nearly full of the same dark brown homogeneous solids, and contained no drainable liquids.

Segment 8: The sampier was nearly full of the same dark brown homogeneous solids, and contained no drainable liquids.

Segment 9: The sampler was completely full of solids, the same dark brown solid material at the top, but the botton 5-6 inches was light colored. While the color varied, the consistency of the material was the same as all the other segments in this core. The segment

$$
\text { A-6 } 9
$$




\section{WHC-EP-0806}

WHC-SD-WM-DP-024 ADOENDUM 2 , REV 0

was divided into two parts, one was the bottom 5 inches of the segment which contained most of the white material. A VOA sample was taken from the top, and a DSC/TGA taken from the bottom. These samples were later combined for the homogenization test.

A field blank and a hot cell blank were also taken for T-111.

Sub-samoles for T-111

The following numbers are the $\cdot J$ numbers assigned as tracking numbers by the 222-5 laboratory. The analytical batches may contain information from other sample numbers because of the way the samples were grouped for analysis.

Results from other samples should be ignored, since they will be included in the data package for that specific segment.

CORE 31

J308, J309

J310

Segment 2

Segment 3

Segment 4

Segment 5

Segment 6

Segment 7

Segment 8

Segment 9

Segment 98

J311

$\mathrm{J} 312$

J313, J315

none (empty)

J315, 3316

J317

J318

J412, J413, J414

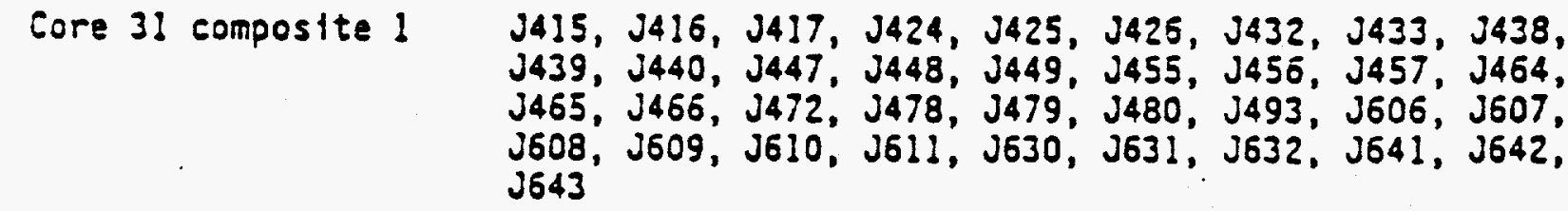

CORE 33

J319, J320

J321, J323

$J 324$

3325

J326, J327

J328, J329

J330

J331

J332, J333

NA
CORE 33 (Homog. Tests) J396, J397, J398, J399

NA

$J 400, J 401, J 402, J 403$

NA

J404, J405

MA

J406, J407, J408, J409

NA

3410,3411

NA

Core 31 composite 2 J418, J419, J427, J434, J441, J450, J459, J467, J475, 3485

Core 33 composite 1 J420, J421, J428, J429, J430, J435, J436, J442, J443, J445, J451, J452, J453, J460, J461, J462, J468, J469, J470, J476, J487, J488, J489

Core 33 composite 2 J422, J423, J431, J437, J446, J454, J463, J471, J477 
WHC-EP-0806

WHC-SD-WM-DP-024 ADDENDUM 2, REV 0

Hot cell biank

IGA
J494, J495, J496, J498, J499, J500, J502, J503, J504, J506, J508, J513, J517

Thermogravimetric Analyses and Differential Scanning Caiorimetry (DSC) are performed on every visible phase of the waste, prior to homogenization, to evaluate the thermal properties of the waste. The TGA results give a measure of the weight loss with increasing temperature. The result obtained ifrom TGA is - weight $x$ water. The TGA $x$ water (percent weight loss at 100 degrees $C$ ) may vary considerabiy, due to a combination of the small sample size and sample heterogeneity. The procedure number for DSC, T042 A-01712F, has been changed to LA-514-113, Rev. A-0. The procedure number for TGA, T045 A-00712F, has been ehanged to LA-560-112, Rev. A-0. These procedures are routine Analytical Operations now, rather than Process Chemistry procedures.

The TGA results were $5-7 \%$ higher than the gravimetric wt 8 water, and ranged from 70-87x. Where duplicates were ran, there was good agreement, and results were consistent over all segment samples

\section{x Vater}

More representative : water measurements are obtained with the gravimetric measurements, also reported in the sumaries. Duplicate $\%$ water analysis were requested for all segment samples. However, the duplicates for segments 2,3 , $4,5,8,9$ from core 31 and segments $1,3,4,5,7$, and 9 from core 33 were not requested until one month after the original samples were run. These latter values are added to the sumary sheet, but due to the summary sheet format, the LMCS standard results are not included. The duplicate values for segments 2 and 4 from core 31 (32.60\% and $59.60 \%$ ) are probably low due to the sample drying out between analysis, or from a non-homogeneous "soupy sample" that would cause uneven sampling. There is no more sample for a re-run. However, the original sample results and the TGA agree quite well. There was no sample for a duplicate analysis of segment 8 from core 33 .

\section{DSC}

DSC is used to identify the potential of exothermic reactions from the waste upon heating. In all cases, the identified exotherms were 3 to 4 times smaller than the detected endothems. The calibration frequency of the instrument is determined by the chemist and is based on the instrument performance on laboratory standards.

Core 31: Exotherms were detected on the sample and duplicate for segments 1, 2, and 3. A very small exotherm, nearly an order of magnitude smaller, was detected for segment 4 , and was not verified with a duplicate. No exotherms were detected for segments $5,7,8,9$, and 98 (the white layer). The temperature ranges for the exotherms were between 200 and $405{ }^{\circ} c$, with the energy around $300 \mathrm{~J} / \mathrm{g}$. The small exotherm had an energy of $55.7 \mathrm{~J} / \mathrm{g}$.

Core 33: Exotherms were detected on the sample and duplicate for segments 1 and 2 , and only the sample for segment 3. The duplicate did not show an exotherm. The temperature ranges for the exotherms were from $179^{\text {to }} 438^{\circ} \mathrm{C}$,

\section{A-8 11}




$$
\begin{aligned}
& \text { WHC-EP-0806 } \\
& \text { WHC-SD-WM-DP-024 ADDENDUY 2, REV } 0
\end{aligned}
$$

with the energy around $300 \mathrm{~J} / \mathrm{g}$. The exotherm for segment 3 was small, about $50 \mathrm{~J} / 9$. No exotherms were detected for segments $4-9$.

\section{Particle size}

Particle size analyses are performed on every segment from every core to support the evaluation of potential waste retrieval methods. Small aliquots of the wastes were suspended in a water matrix using sonification before measuring the particle size by laser technology. The data are summarized in a table and four plots of probability number and probability volume density and distribution graphs. The procedure number for particle size analysis listed in the Technical Project Plan (WHC-SD-CP-TP-070, rev O) is incorrect, and should be T044-A-01712F.

\section{Penetrometer}

Penetrometer readings are taken for each segment at extrusion. All of the segments were soft, with readings $<100$ psi.

Seqment 98 (white laver)

In addition to the above analyses requested for each segment, ICP, IC, GEA, and TA were requested on the white portion of segment $g$ of core 31 . The sample was taken after the white layer had been homogenized. The ICP and TA resemble the homogenized segment data, and the IC resembles the core composite data. The spike recoveries for the ICP were biased low. There were no exotherms detected, and the $x$ water was $70 \times$, about 5-10 $\times$ lower than the other segments.

General comments

Because of the qualitative nature of TGA, OSC, particle size, and penetrometer analyses, no detection $l i m i t s$ or precision and aceuracy statements are required.

\section{SECTION III: HOMOGENIZATION TEST ANALYSES}

\section{Introduetion}

Waste tank samples have a wide range of physical characteristics. Methods for homogenizing waste samples are limited by their applicability to hot cell operations and how well they lend themselves to remote operation and decontamination for reuse. Homogenization tests have been incorporated into the single shell tank characterization program to obtain estimates of the errors resulting from homogenization techniques employed during analysis. The evaluation of this data will support decisions made using the data and identify areas where homogenization procedures may be improved.

\section{Homogenization Tests}

Homogenization tests are performed on segments. After the segment has gone through the homogenization procedure, two sub-samples are taken from two different (top/bottom, left/right) locations in the homogenized segment. Each of the sub-samples are analyzed in duplicate to obtain estimates of the 
WHC-EP-0806

WHC-SD-WM-DP-024 ADDENDUM $z$, REV 0

analytical error. The differences in the results obtained on the two subsamples will provide homogenization error. A statistical analysis (beyond the scope of this narrative) of the vartance must be performed to differentiate between the analytical and homogenization errors. Each homogenization sample was analyzed by GEA, ICP, and TA on an acid digested sample. The acid digestion is the same as that used for normal ICP analysis.

\section{Sub-samples}

Homogenization tests were performed on segments 1, 3, 5, 7, and 9 from core 33. See the listing above for the $J$ numbers assigned to the homogenization samples. The results are compiled in the sumaries entitled "T-III Homogenization Analyses" and "Homogenization Test Sumary". One spike was considered suffieient for the homogenized sample data. A comparison of the RPD's of the duplicate results of each sample to the RPD of the averages of the two samples (see summary) shows virtually no difference for those elements well above their detection lintts. This tank probabiy is not a good test of homogenization procedures, as the segment material was very uniform at extrusion. Even the white material in segment 9 was chemically similar to the rest of the segments, with the exception of segment 1. Segment 1 has much higher concentrations of $\mathrm{Mn}, \mathrm{Pb}, \mathrm{Ag}$, and $\mathrm{In}$ when compared to the other segments, while 81 and $L a$ are much lower. The spike for the gross alpha on segment 5 was consistently high even after several re-runs.

\section{SECTION IV: CORE COMPOSITE ANALYSES}

\section{Samols Preparation}

Samples are prepared for core composite analyses using an acid and water digestion, and a KOH fusion. ICP and HYAA are run on the acid preparation, ICP. IC, nitrite by spectrophotometry, PH, ammonia, TOC, TIC, carbon-14, and tritium on the water digestion, and ICP and the other radioctemical analyses on the fuston preparation. The $\mathrm{XOH}$ fuston is contaninated with Ni from the crucibles used. LMCS standards for the acid digestion go through the sample preparation procedure. Standards for the water digestion and fusion are not run through the sample preparation procedures.

\section{IC?}

The ICP data is reported using a CLP software pacxage from WARO Scientific L:d (WARDS), and is used to generate the spread sheet summaries instead of the analytical cards. The caleulations on the analytical cards are preliminary calculations performed by the instrument technician to access instrument operation and are not used in the final report.

WAROS utilizes the concept of a sample delfvery group (SDG), and batches spike, duplicate, instrument control standards, blanks, serial dilutions, interference checks, and narrative information for each sample group. If the result is below the detection limit, the CLP report format will return a 200\% RPD for duplicates and a 100\% for serial dilutions. On all pages except the "duplicate" page (form VI-IN), any values less than the detection limit are replaced with the instrument detection limit, and should be interpreted as a "less than" value. The duplicate page (form VI-IN) reports what the instrument measures, and may include negative numbers. Since it is this page

$$
\text { A-10 } 13
$$


that is used to generate the "result 1" and "result 2" columns in the summary sheets, negative values are included.

On the page in the HAROS pacxage designated "COVER PAGE - IN", the answer to the third question, '...were raw data generated before application of background corrections?" has been changed to "no" based on the chemist's interpretation. This change does not affect the data or evaluation of the data in any of the HAROS packages generated in support of the 5ST program. The WARDS package Sample Delivery Group (SOG) number has a "* suffix, where the * is " $N$ " for no sample preparation. " $W$ " for water digestion, " $F$ " for fusion, and " $A$ " for acid digestion. This was not implemented until after analysis began on T-111, and so most of the WARDS packages will not have this identifier. The ease narrative provided with each batch flags areas that would not neet CLP criteria. The HAROS package is configured to report all elements requested in the sow except $T$, Th, and $U$, and report the additional elements B, Ce, La, P, Sr, S, and TH. Form I-IN will not show negative resuits for individual determinations, while form VI-IN does. The WAROS results used in compiling the master sumaries are taken from the VI-IN form.

ICP analyses are ran on acid and water digests, and a KOH fusion. In the data sumaries for the T-111 package, the preparation blank and the detection limit values for ICP have been converted from $u g / L$ to $u g / g$ by estimating the typical sample size and dilution involved in the preparation procedure. The acid and water blank and detection limit results (ug/h) were divided by a factor of 10 because the actd and water preparation procedures dissolve approximately $1 \mathrm{~g}$ of original sample in $100 \mathrm{~mL}$ of liquid. The fusion blank and detection limit results were divided by 2 , as this preparation procedure dissolves approximately $0.5 \mathrm{~g}$ of sample in $250 \mathrm{~mL}$ of liquid.

The units for the "SA" column (spike added) on form V-IN are "ing/kg" for the pre-digestion spiked acid sample preparation, and "ug/L" for the post digestion spiked water and fusion sample preparations. Spike concentrations must be at least $25 \%$ of the sample concentration for proper evaluation.

Failure criteria for an entire WARDS package are under development. Since each ICP run generates results for 32 elements, there will always be some failures on each run. These failures are identified in the narrative assoctated with each HARDS package. Failure criteria should be based on the absolute fallure rate of either spikes, duplicates, LMCS standards, and calibration standards, but tempered by the relative importance of the individual element that failed. For example, LMCS and spike recoveries may be generally high for $\mathrm{Na}, \mathrm{Ca}_{\text {, }}$ and $\mathrm{Fe}$ from contamination of the blank and sample during preparation, and $S i$ and $B$ from the use of glass containers during sample preparation. Spike or LMCS failures noted for these elements should not invalidate the entire WARDS package.

Several factors noted in the WARDS packages for T-111 create low spike recoveries and were noted by the ICP chemist. Silver recoveries are comnoniy low due to the precipitation of Silver Chloride. Poor recoveries of Iron, Magnesium, and Calcium accompany high Preparation Blank values, but the correlation is poor. Spike failures for major elements are frequently caused by a high element concentration in the sample. When the added spike concentration is insignificant compared to the concentration of the element present in the sample, a failure generally occurs. 
WHC-EP-0806

WHC-SO-WM-DP-024 ADDENDUM 2, REV $O$

The major elements detected by ICP analysis of the acid digestion were $C a, C r$. $\mathrm{Fe}, \mathrm{Mn}, \mathrm{K}, \mathrm{Na}, \mathrm{B1}, \mathrm{La}, \mathrm{P}$, and $\mathrm{S}$ (all greater than $1000 \mathrm{ug} / \mathrm{g}$ ). $\mathrm{Cr}$, and $\mathrm{Pb}$ concentrations $(1.86 E+3$ and $4.75 E+2 \mathrm{ug} / \mathrm{g}$ respectively) would both exceed the $100 \mathrm{ug} / \mathrm{g}$ TCLP limit, assuming $100 \%$ leachability. The WARDS package performs inter-element corrections for $\mathrm{Al}, \mathrm{Ca}, \mathrm{Fe}, \mathrm{Mg}$, and $\mathrm{Cr}$. Calcium and magnesium contamination often occurs as a result of the powder on the gloves used by laboratory personnel. The ICP analysts of the fused sample is used to evaluate the completeness of the acid digestion procedure, and to identify any acid insoluble compounds. The $K$ results in the WARDS package often over ranges on the fuston, giving the impression that no $X$ was in the sample. Ratios of the ICP results for major elements appear in the data summaries, and are used to estimate consistency and speciation. The fusion/acid ratio shows good agreement for $\mathrm{Al}$. Fe, $\mathrm{Na}, \mathrm{P}$ and $\mathrm{Sr}$. St and $\mathrm{Tt}$ are an order of magnitude higher in the fuston, whtie $B i$ is slightiy higher in the acid digestions. Based on the ratlo of the acid and watar ICP data, about $10 \%$ of the $\mathrm{Cr}$ is water soluble (CrVI). Most of the $\mathrm{Ka}_{2}$ is soluble, but only $50 \%$ of the phosphate, and essentially none of the Mn is solubie. There was no La reported for the water digested composite LuCS standard for core 33, and no Ir detection limits reported for the core composite samples. The Si results for ICP on all T-111 analyses are known to be biased low due to an undetermined interference.

\section{CYAA and HYAS}

Coid vapor atonic absorption (CVAA) was used for $\mathrm{Hg}$ analyses. The $\mathrm{Hg}$ results for T-111 ranged from $1.02-1.88 \mathrm{ug} / \mathrm{g}$. The soike for core 31 was high (122\%) and low for core 33 (82x). However, both were within the plus or minus $25 \%$ limits. All RPD's were less than 13\%. Due to instrument and sample matrix problems, the As and Se elemental analyses were performed at PNL by graphite furnace $A$.

\section{Anion and Wet Chemical Analys is}

Anions were determined on a water digestion of the sample. Ion chromatography (IC) was used to determine F, Cl, nitrate, nitrite, phosphate, and sulfate. All duplifates were within limits $(<20 \times R P O)$ and the results were consistent over 2 li the compostte samples. Post digestion spikes are used because of the high concentrations of the anions. Nitrate, phosphate, and $F$ concantrations were high, consistent with the historical data available on T-111 waste. Soike recoveries were biased low for 3 of the 4 composite samples, but within the 75-125X limits. The S deterwined on the acid ICP, converted to sulfate, agrees very well with the sulfate determined by $I C$, while the same comparison of $P$ with the phosphate shows the converted $P$ a factor of 2 higher than the phosphate. This indicates that only $50 \%$ of the phosphate is soluble. The pH is very consistent at about 10, while only "less than" values wera obtained for amonia. All the TIC results were near the detection limit, with good reproducibility and spike recoveries. TOC results were nearly an order of magnitude higher $(2000-3000 \mathrm{ug} / \mathrm{g})$. All analytical units were ehanged to ug/g for the data summaries, and may not agree with what is on the analytical card. All cyanide results obtained were "less than" values. Both the $\%$ water and TGA results were between 75 and 80 * with good precision over all the core composite samples. 


\section{Radiochemical Analysis}

Most of the radionuclides are determined on the fusion due to the acid Insolubility of actinide and $\mathrm{Sr}$ compounds. Tritfum and $\mathrm{C}-14$ are determined on the water digestion, and Ni-63 (analyzed at PNL laboratories) is determined on the acid digestion. There are indications that I-129 is lost during the actdification of the fused sample, which will require the development of an alternate digestion procedure for future work. In the cases where two spike recoveries are reported in the analytical summaries, one under the other, the spike recovery is used to correct for chemical yield. The second spike (bottom) corresponds to the duplicate result. Pu-238 is reported as part of the Pu-239 analysis, using the spike data from the Pu-239 procedure. Can-244 would be reported only if seen on the An-24! mount. The relative counting error reported is based on gross counts, and will under-estimate the counting error in those samples close to the detection Timit (where the gross counts and the background counts are nearly the same). Calibration data for GEA labeled as detector " $14^{\prime \prime}$ is data for detector " 4 ".

During calibration updates, the new calibration file name for individual detectors have a " 1 " added (4 to 14) to avoid erasing the old calibration data prior to validation of the new calibration data. For T-111, the new calibration file nawe was not changed back to "4". Calibration of the alpha proportional counters (APC) is performed as follows. A standard source is prepared by the standards laboratory and used to calibrate one of the three detectors. Since the calibration standard is not durable enough for daily use, a secondary source is prepared and the $d / m$ value of the secondary source is assigned using the calibrated detector. The secondary source is counted daily on all three APC's and tracked using the LMCS system. The detectors pass the daily check if the calculated efficiency for each detector is within $50 \% \pm 0.25 \%$ (100\% "recovery"). The LMCS data for the APC's and EDP codes are listed in the "Precision and Accuracy Statement" section.

Poor spike recoveries were obtained for uranium on core 33, but the data across all the core composite samples was consistent (between 2000-3000 ug/g).

Total alpha and total beta RPD's were normally under $5 \%$ with good recovery on the spikes. The total alpha results were twice the sum of the $P u$ and $A m$ results, indicating 1) the potential presence of undetermined alpha emitters, 2) beta cross-talk (unlikely due to the beta activity present), or 3) incorrect $\mathrm{Pu}$ or Am recoveries (incomplete exchange with the spike). This last scenario is unlikely due to the consistency of the ratios, and the excellent agreement between the Am-24l results abtained by gamma spectroscopy and aipha spectroscopy. The ratio of the total beta to the sum of the Sr/Y and Cs-137 results show good agreement $(.991$ to 1.00$)$ for the activity balance of the beta emitters. When sample " $J-470$ " was rerun for poor spike recovery, a blank was not included in the analytical batch.

Sr-90 spike recoveries were consistently 90-95\%. Results for core 31 were around $7 \mathrm{uCl} / \mathrm{g}$ while core 33 was around $3.5 \mathrm{uCl} / \mathrm{g}$. These results vary more than the elemental Sr results from the fusion IC?, where the results are consistent across both cores $(280-310 \mathrm{ug} / \mathrm{g})$. Tc-9g results were low, within a factor of 5 of the detection. limits but spike recoveries were adequate (6774\%). The results for Se-79, $\mathrm{H}-3$, and $\mathrm{C}-14$ were at or below detection limits, while spike recoveries ranged from 85-95\%. No standard material is available 
WHC-EP-0806

WHC-SD-WM-DP-024 ADDENDUM \&, REV 0

for Se-79. The tritiun procedure LA-218-113 was changed to LA-218-114 for T111 analysis. This procedure uses microdistillation columns in place of the normal glass distillation equipment.

The Pu spike recoveries ranged from 50\% to 90\%, while An recoveries were poor. 10-20\%. No Pu-238, Np-237 or Ca-244 were present above detection levels. Spike recoveries for Np-237 were consistently low at around $70 \%$.

Am-241 and Cs-137 were the only isotopes that were consistently found at quantifiable concentrations by gamma spectroscopy. No spikes were requested for gama spectroscopy. As stated above. the beta activity based on the Cs137 results from gamma spectroscopy agreed with the gross beta determination, and the An-241 results from gamma spectroscopy agreed with the alpha spectroscopy results for An. I-129 results were all - less than" values, therefore no counting error could be deterwined. The preparation blank for I129 for core 33 was invalid based on spike recovery, but was not re-run as all results were "less than values. The spike recoveries ranged from 39\% to 57\%.

\section{Physical Measurements}

DSC, TGA, and weight $\&$ water was performed on each core composite. Exotherms were observed (in duplicate) for both composite samples from core 31 , but no exotherms were observed for core 33. This is not surprising, as the exotheres were small on the segment analysis and were done prior to homogenization.

TGA and $\%$ water results are in the same range as found on the segment samples, 75-85\%, with the TGA results being consistently higher than the * water.

TChP Resuits

A TCLP extraction was perfortaed on the waste using a TCLP procedura scaled down a factor of 10 for radioactive samples. The matrix spike was added before the TCLP extract was preserved and acidified (per SW-846 procedure), recognizing that possible precipitation of the spike material could result in low spike recoveries. In order to meet the duplicate, spike, and blank requirements of appendtx 0 , the following sampling and digestion scheme was used on T-111. Composite 1 and composite 2 from core 31 , composite 1 from core 33, and a biank were run through the TCLP digestion procedure. The composite 1 TCLP digests from core 31 and core 33 were spitit into two subsamoles, and one sub-sample from each digestion was spiked with the TCLP metals. All sub-samples were acidified. Each sub-sample was acid digested in preparation for analysis, with the unspiked sub-samples from both cores again prepared in duplicate (split into two samples prior to acid digestion) to deteraine analytical error. The composite 2 and blank TCLP digests from above were acidiffed, acid digested and submitted for analysis (no spike or oupifcate measurements).

The RPD's were high for As, Ba, and $\mathrm{Pb}$, but these analytes were present in concentrations less than 6 times the detection limit. Cd was the only element with spike recoveries within acceptable limits (greater than $75 \%$ ). A comparison of spiking procedures is being performed on the next single shell tank $(6-110)$. Cr and Se both exceeded the TCLP limit. Good agreement was obtained for those elements well above the detection limits. 
Field blanks are prepared by fllling a sample container in the field, shipping it to the labs with the samples, extruding in the hot cell and collecting as drainable liquids. The hot cell blank is a rinse of the extruder tray. The required analysis for these samples are ICP, GEA, HYAA (As, Se), CVAA (Hg), $T A, T B, T D C, I C$, and VOA and semi-YOA. The raw data for the field blank and the hot celi blank is included at the end of the core 31 data package. No duplicate samples or spikes were required on the blanks. The ICP was ran on direct sample, so no corrections were made on the preparation blanks pr detection limits. The ICP LMCS standard did not include Sr. There was insuffictent sample for duplicate ICP analysis for the hot cell blank.

Hot cell blank: The major constituents in the ICP analysis were $\mathrm{Na}$ at $5 \mathrm{ug} / \mathrm{mL}$, $B$ at $1.5 \mathrm{ug} / \mathrm{mL}$ and $S i$ at $4.75 \mathrm{ug} / \mathrm{mL}$. All the rest were less than I ug/mL. The balance of the analytes deterwined (F, Cl, NO2, NO3, SO4, PO4, As, Se, Hg, TOC, TA, TB, and GEA) were "less than" values.

Field blank: The major constituents in the ICP analysis for the field blank were simflar to the hot cell blank. The $\mathrm{Na}$ was at $8.07 \mathrm{ug} / \mathrm{mL}, B$ at 1.76 $\mathrm{ug} / \mathrm{mL}$, and $S t$ at $4.47 \mathrm{ug} / \mathrm{mL}$. The rest of the constituents were less than 1 ug/mL. Results greater than the detection 1 imits were obtained for F, N03, and PO4 on the IC, TB, and Cs-137 on the GEA. These levels of contamination are insignificant when compared to the concentrations of these analytes in the T-111 samples.

\section{Accuracy and Prectsfon Statements}

Accuracy and prectston estimates for the procedures used in analyzing T-111 core samples were complied from the $222-5$ Laboratory Measurement Control System (LMCS) data base over the period of April 1, 1992 through July 22, 1992 (the time period that the samples were ran in the iaboratory). The average percent recovery and standard deviation for each analyte are determined from multiple analysis of standards containing those constituents. Each analyte and analytical system has a specific EDP code. A different EDP code is used for each parameter, instrument, method, or standard used in the system. When more than one EDP code is provided, then more than one analytical system was monitored. If no data was availabie for an EDP code for the time frame of interest, the historical values based on earlier data has been provided. In these cases, the number of measurements noted as " $n$ " is recorded as " 0 ". Historical data typicaliy is based on 50 measurements.

No standard Se-79 material is available from commereial suppliers of isotopes for the preparation of a standard. The LMCS standard data for DSC only indicates that an exotherm is detected, and $100 \times$ recovery is noted. The results do not reflect errors caused by sample matrices, or special sampie preparation procedures used prior to applying some of the methods. 
WHC-SD-WM-DP-024 ADOENDUMP2, REV 0

The accuracy and preciston estimates for T-111 are as follows.

\begin{tabular}{|c|c|c|c|c|c|c|}
\hline$\frac{\text { Method }}{\text { ICP }}$ & Analvte & EDP & $n$ & $\begin{array}{c}\text { Average } \\
\times \text { Recovery } \\
\end{array}$ & $\begin{array}{l}\text { Relative } \\
\text { Std. Dev. }\end{array}$ & Comments \\
\hline$L A-505-151$ & $\begin{array}{l}\text { Al } \\
S b \\
A s \\
B a \\
B e \\
C d \\
C a \\
C r \\
C o \\
C u \\
F e \\
P b \\
H g \\
M n \\
N 1 \\
K \\
S e \\
A g \\
N a \\
Y \\
Z n \\
B 1 \\
B \\
L a \\
P \\
S 1 \\
S r \\
S \\
S n \\
T i \\
Z r \\
C e\end{array}$ & $\begin{array}{l}5102 \\
5104 \\
5106 \\
5108 \\
5110 \\
5116 \\
5118 \\
5122 \\
5124 \\
5126 \\
5130 \\
5134 \\
5138 \\
5140 \\
5148 \\
5152 \\
5156 \\
5160 \\
5162 \\
5182 \\
5184 \\
5112 \\
5114 \\
5132 \\
5150 \\
5158 \\
5164 \\
5166 \\
5174 \\
5176 \\
5186 \\
5120 \\
5150\end{array}$ & $\begin{array}{l}46 \\
50 \\
5 \\
35 \\
50 \\
21 \\
42 \\
56 \\
6 \\
18 \\
39 \\
35 \\
30 \\
33 \\
31 \\
37 \\
5 \\
17 \\
49 \\
12 \\
36 \\
23 \\
9 \\
14 \\
31 \\
23 \\
24 \\
32 \\
9 \\
13 \\
9 \\
4\end{array}$ & $\begin{array}{l}96.7 \\
100.2 \\
99.6 \\
96.9 \\
102.3 \\
98.5 \\
96.5 \\
100.3 \\
98.6 \\
96.5 \\
98.5 \\
98.3 \\
98.1 \\
95.0 \\
98.9 \\
99.3 \\
100.1 \\
99.1 \\
96.1 \\
98.9 \\
99.0 \\
100.1 \\
95.8 \\
103.2 \\
96.9 \\
94.4 \\
96.3 \\
100.1 \\
97.1 \\
98.1 \\
101.4 \\
103.9\end{array}$ & $\begin{array}{l}4.9 \\
3.0 \\
2.5 \\
2.6 \\
3.2 \\
3.5 \\
3.5 \\
3.0 \\
2.0 \\
1.8 \\
2.7 \\
4.7 \\
3.7 \\
2.8 \\
2.7 \\
2.9 \\
4.9 \\
3.5 \\
2.3 \\
1.4 \\
2.4 \\
4.7 \\
3.0 \\
3.0 \\
4.2 \\
5.1 \\
2.2 \\
3.2 \\
4.6 \\
2.2 \\
3.8 \\
1.3\end{array}$ & $\begin{array}{r}\text { Historical } \\
\text { ( }\end{array}$ \\
\hline
\end{tabular}


WHC-SD-WM-DP-024 ADDENDUM 2, REV 0

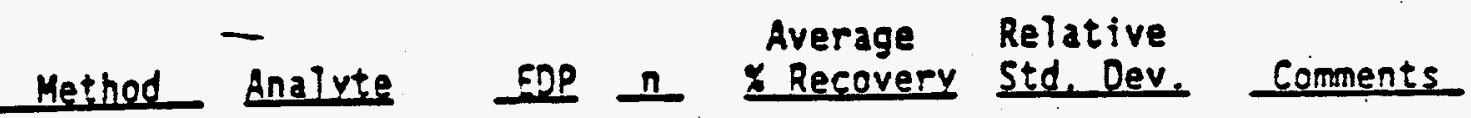

CYAA

LA-325-102 $\mathrm{Hg}$

$\begin{array}{lll}R 716 & 18 & 102.8\end{array}$

6.0

IC

C1

$\mathrm{NO3}$

$\mathrm{NO2}$

PO4

SO4

R974 $18 \quad 101.4$

5.9

297220

99.0

$\begin{array}{lll}R 978 & 22 & 96.8\end{array}$

R968 22

101.2

R976 - $18 \quad 97.5$

R970 $21 \quad 96.9$

4.4

3.9

4.9

3.7

SPEC

$\begin{array}{lll}5215 & 88 & 99.6\end{array}$

4.0

TOC/TIC

LA-622-102 TOC

$\begin{array}{lll}5223 & 74 & 103.8\end{array}$

3.6

LA-344-105 CO3

5346

Dist/SPEC

LA-695-101 CK

$\begin{array}{lll}S 242 & 29 & 99.4 \\ 5244 & 9 & 99.5\end{array}$

3.5

LA-695-102

2.0

Dist/Titrate

LA-634-102 $\mathrm{NH3}$

$\begin{array}{lll}5235 & 70 \quad 99.6\end{array}$

$\begin{array}{lll}5236 & 70 \quad 99.6\end{array}$

6.4

6.4

Fluorimeter

LA-925-106 U

$\begin{array}{lll}5267 & 111 & 100.8\end{array}$

8.2

ATpha

LA-508 $8-101$ Tot Alpha

$\begin{array}{lll}5510 & 62 & 103.8\end{array}$

8.8

LA-508-104

APC 1

APC 2

APC 3

LA-508-114 Det 14

Det 16

col] $112 \quad 99.9$

0.11

Col2 $112 \quad 100.0$

0.09

6013111

99.5

$\begin{array}{lll}\text { CI42 } & 176 & 99.7\end{array}$

$\begin{array}{lll}162 & 169 & 103.5\end{array}$

0.10

4.8

5.3

Beta

LA-508-101

LA-508-114

Tot Beta

$\begin{array}{lll}5515 & 59 & 98.3\end{array}$

C143 $176 \quad 99.0$

$\begin{array}{lll}\text { C163 } 170 \quad 99.7 & \end{array}$

4.4

Det 16

3.1

7.4

Gamma

LA-548-12]

GEA CS-137

$R 901 \quad 28 \quad 101.9$

2.4 Co-60

R9OS $28 \quad 100.6$

2.3

ATpha Spec LA-503-156

$P u-239$
Am-241

R211 $20 \quad 99.0$

R20I $31 \quad 94.2$

5.3

8.2 


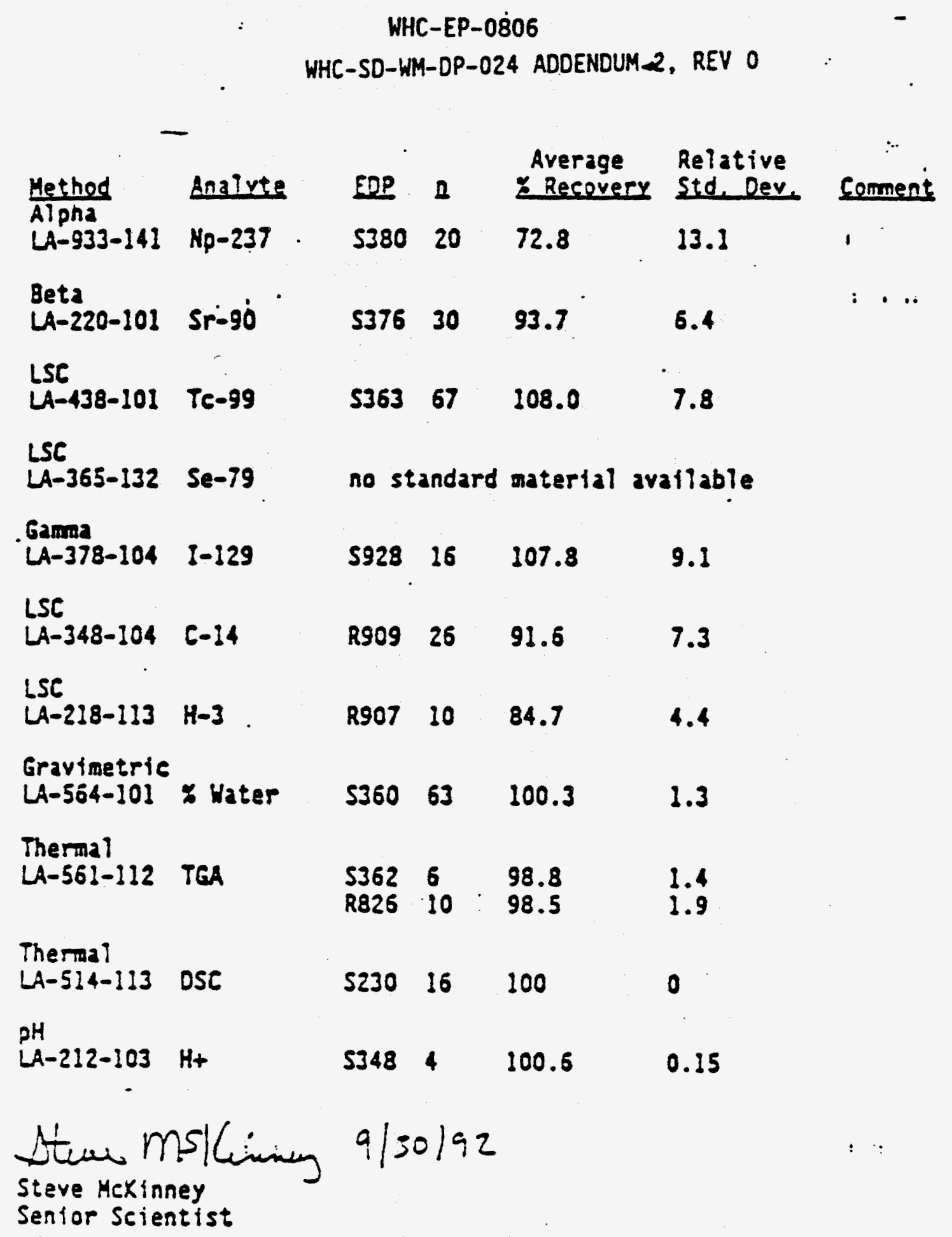


Battelle Psctíc Vortnwert Liooratones

WHC-SD-WM-DP-024

ADDENDUM 5, REV O-A

Proves Numer

internal Qistnounon

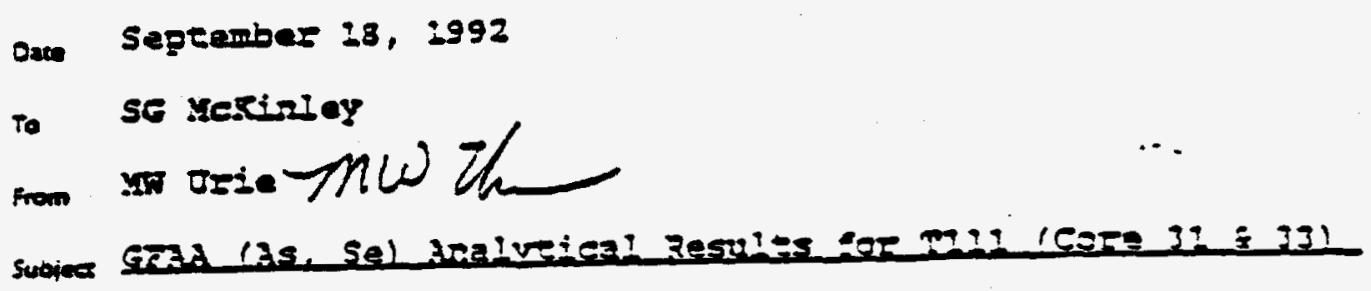

Graphite pumace dtsmis Absopption analyses were peforsed saptember

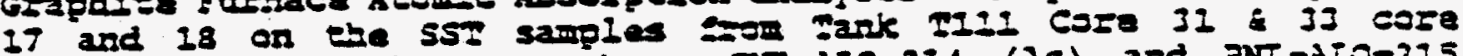

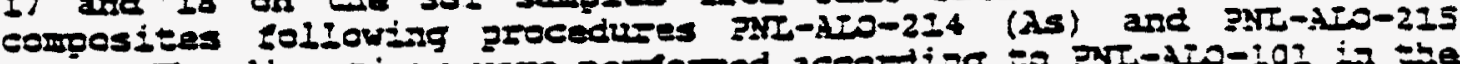

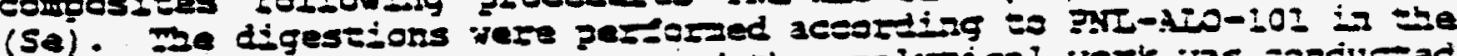

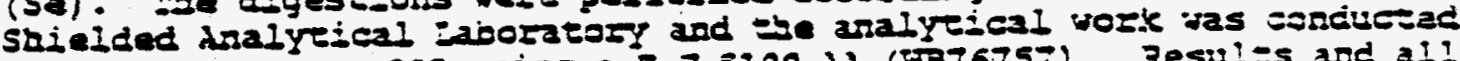

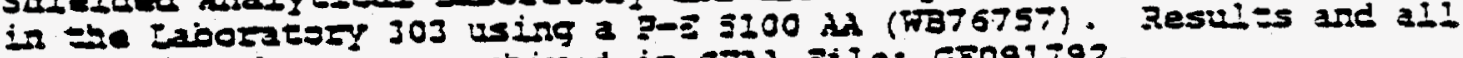

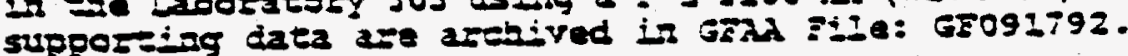

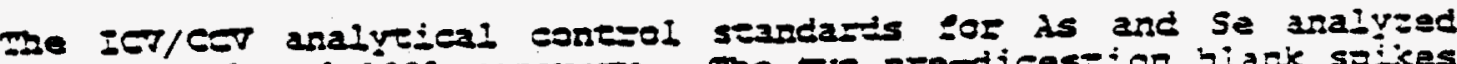

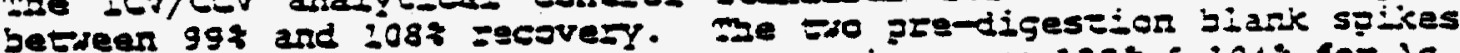

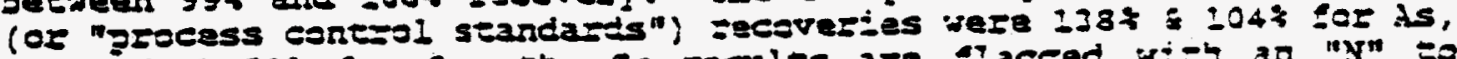
and $57 \%$ i $58 \%$ fer se; be se zesules are slagged wis an "N"

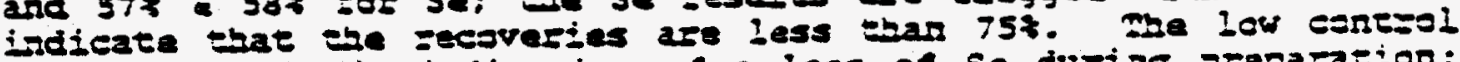
zecovery on $\mathrm{se}$ is isdicarive of a loss of se durias jpeparation:

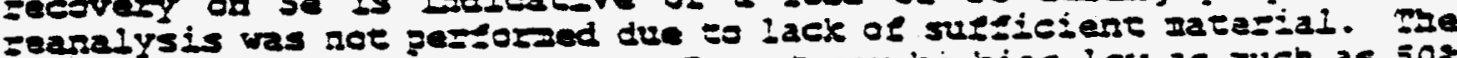

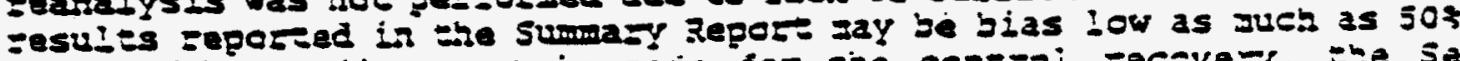

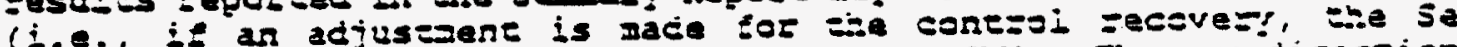

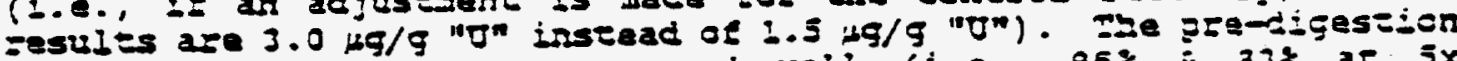
spixed sampies lof is zecovered dell (1.a., $95 \%$ i 337 at $5 x$

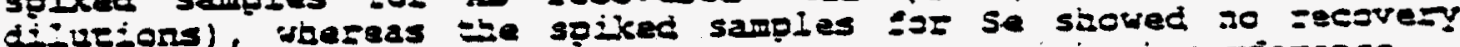
(i.e., at iox dilutions) ijdicazing a severe rat=ix infeziezance.

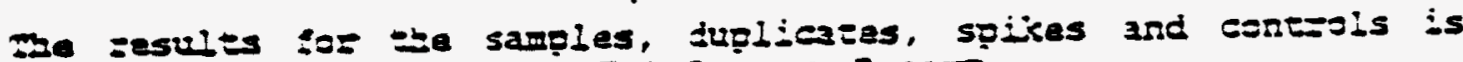

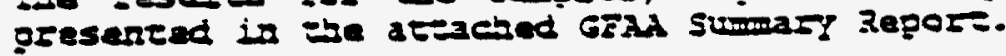

concer:

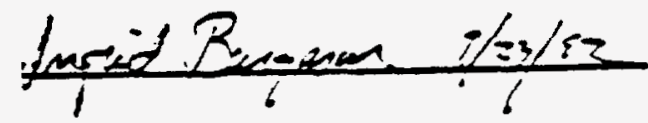




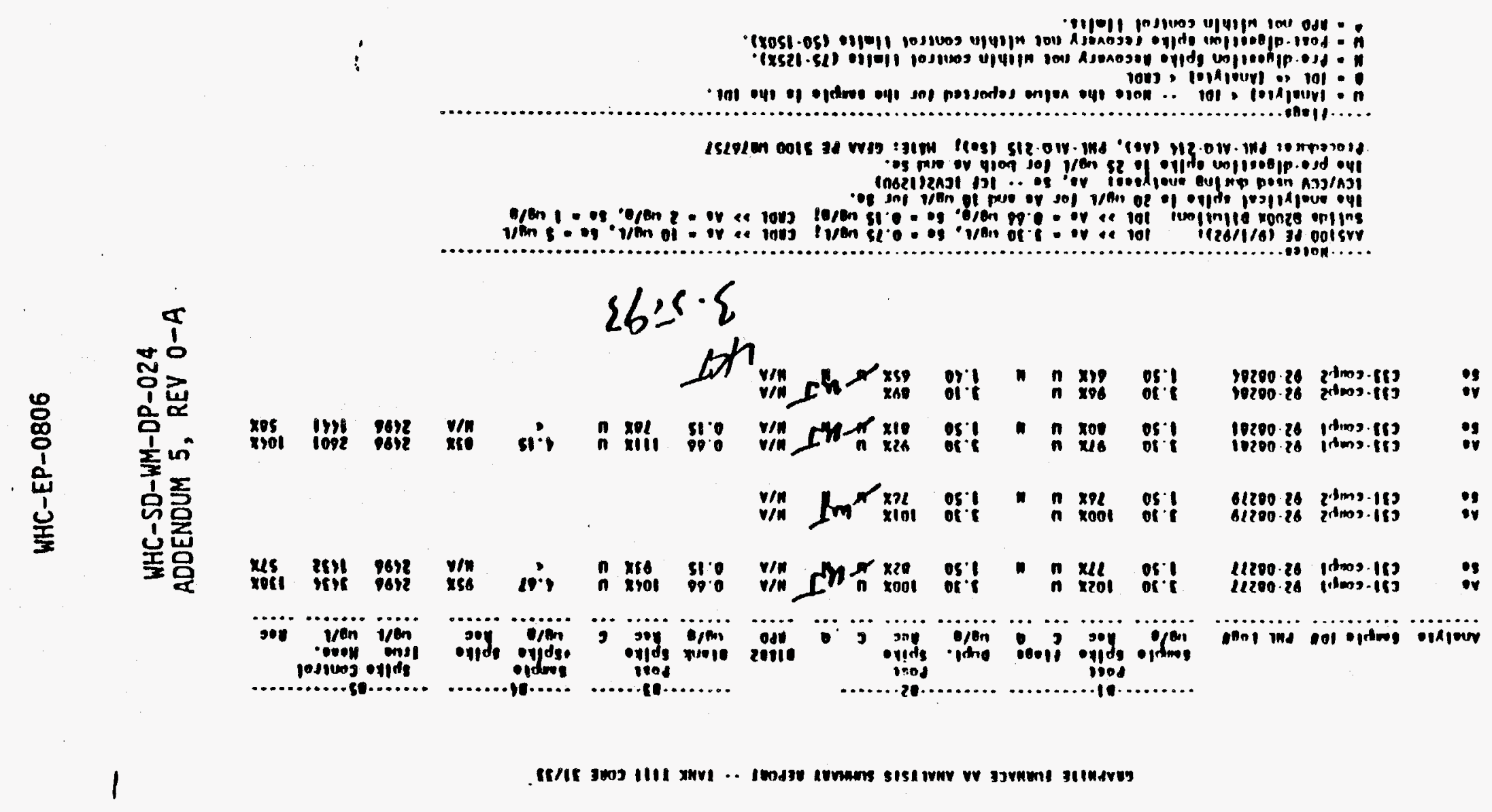




\section{WHC-EP-0806}

WHC-SD-WM-DP- 024

ADOENDUM 5 REY OA

Susan Mexinley

Octover 9, 1992

Page 2 $\therefore \quad \cdot A$

The relative pereent difference (RPO) is calculatad with sampie $92-08290-1 / 2$ and its duplicate to indicate the overall analytical precision (3\% for ${ }^{23 i}$ and 20 for ${ }^{3} \mathrm{Ni}_{1}$ ).

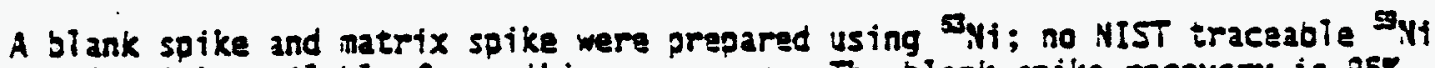
was (or is) available for soiking purposes. The blank spike reesvery is $95 \%$. The matrix spike recovery is 91\%. Thus the average bated bias is -7\%.

A: \WPS1\TI11C313.RPT 
WHC-EP-0806

HHC-SD-WM-DP-026

ADOENDUM 5 REY OA

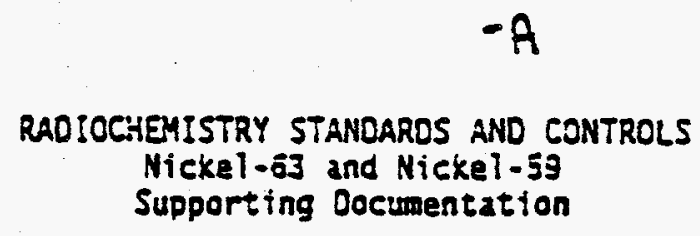

This page indicates the location for supporting documentation for

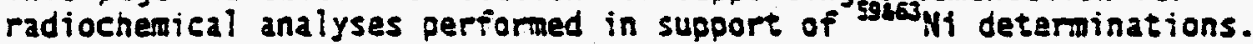

Detector Controis

- LEPS detec:or background, control counts, and efficiency determination, see control and background files for MatE $\$$ Diode A, Diode 3 , and Diode D.

- LSC detector background and control counts, see instrument log, Packard $2250 \times 6$, lab 54 , $3 i d g 325$.

Solution siandards:

- ${ }^{53}$ Mi standard \$54124-16-0, LRB 54124, page 16, Bidg. 329, room 10.

- Nickel (sible) earrier solution for yield determination, see LRB 53293 , page 30.

Flourescence on the ${ }^{59} \mathrm{Ni}$ i-ray peak

- ALO office, 1015Y \$9663ini report

Performance sheeks of pipets and balances, see LRB $53647 \mathrm{pg} .33,85, \& 36$ and $4.2 B 54371,2 g .41$.

$6 r 34 c: 12.3 \mathrm{p} p$ 

WHC-EP-0806

HHC-SD-HM-DP-026

ADOEHOUM 5 REY OA

Projes Nunber

Inoma Ciscibuten

L. R. Greenwood

Dem October 9, 1992

File/LS

To Susan MeKiniey

from s. H. Kaye G.4.S.4

swoina Analvtical Results for Ni-59 and $N i-63$ in Tank IIIL Cores 31 and 33

Nine core composite samples were received from the hot cell for ${ }^{\text {sack }} \mathrm{yl}$ analysis (92-08278-il, -H2, - H3; 92-08280-H1, - H2; 92-08282-H1, - H2; and $32-$ 08284-HI and -H2). These reoresent fused comoosite samples and dupi icates, and a fused hot cell biank from Tank TIII, Cores 31 and 33 . These samoles were analyzed with their corresoonding $Q C$ samples (two reagent bianks, a blank soike, a matrix spike, and a sample duplicate) aceording to procedures PNLALO-473, Revision-!, Nickel Separation from Radioactive Solutions, PNL-ALO464, Procadure for Gama Counting and Oata Reduction in the Low-Level Counting Room, and PNL-ALO-474, Liquid Scintiliation Counting.

Revision I of PNL-ALO-473 has been submitted to the ALO office. In this revised procedure, the option of 3 dimethylglyoxime precipitations was used. This was followed by anion exchange and the remainder of the procadure (steps 5.1 througi 5.5 , then steps 5.13 to end).

A sumary of the results obtained is given in the attached table.

Chemical yieids are determined by ICP measurement of stable Ni on an aliquat of the Final solution preparad for LSC. The yield based on gravimetric means is detarmined but is not used for caleulation of results. It is performed to determine if electroplating was sucsessful. The error in the IC? neasurements is quoted at $=15 \%$ relative; however $=5 \%$ is a better estimate of the error based on typical performance eriteria with ICP analysis on ideal matrices such as presented with the samoles submitted for analysis ( 2 volume percent nitric acid and no interfering ions). The daca are therefore calculaced with the error of $=5 \%$ applied to the ICP deteraination.

The fusion biank is used to aonitor contamination due to hot call operations; the reagent bianiks are used to inonitor contanination due to the laboratory analysis. The fusion bianx and reagent bianks are ealeulated similarly to the composite fusion sawoles in order to provide a value which can be comoared to the samoles. The iusion blank gave a sligintly positive result for ${ }^{3}$ ili, bue this is insignificant comoared to the samole resuits. A mean samole size or 0.5006 grans was used for the reagent blanks. A value of jo mi was usad for the samble volume analyzed for the reagent bianks, as this amount was used for seven out of the eleven samole volumes.

Detection limit estimates for the reagent bianks were approximateiy $4 E-06$ for both ${ }^{\mathrm{Ni}} \mathrm{i}$ and $\mathrm{si}_{\mathrm{Ni}}$. 


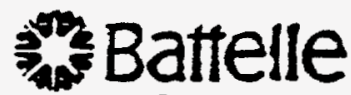

Pacifie Northwest Laboratories
Projece Numen

Imans Jisubuen

FiTe/LB

September 30, 1992

To SE Mexiniey

Fon co Harrey 60 throm

surex Radiochemical Results for TII (Core 31 \& 33)

The radiochemical analyses were performed on four core composites, two each from Core 31 and 33 . The solid core composite was preparsd by potassium hydrexide (XCH) fusion, following procesdure PNL-ALO-103. Duplicate samoles and a single process blank were analyzed. The samples were analyzed for jotal Alpha Plutonium, Uranium and for isotopic composition of the $P y$ and $U$. There was generaliy good agreement between duplicates for Uranium excapt for samples 92-08z80-HI and H2. However, the results wers verified by re-analysis. The agreement of duplicates for pu was poor, differing by a factor of approximately two. The dupilicates for samples $92-08278$ and $92-08290$ wer: ranalyzed with good agreement with the original aeasurement, indicating acsaptable analytical perforuance. The results of the individual analysis are included with the data. The average of the analyses is reported in the sumary tables. The reason for the disagreement is unkiown.

The Mickel-o3 analysis are not complete and will be reported at a later date.

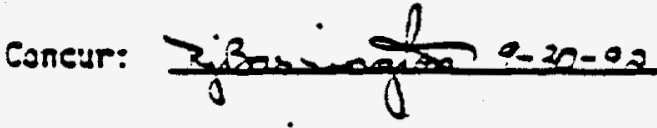


WHC-EP-0806

WHE-SO-WM-OP-OZ4
ADOENDUM S REV OA



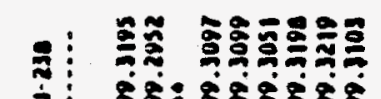

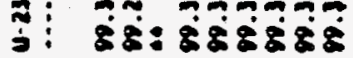

ว

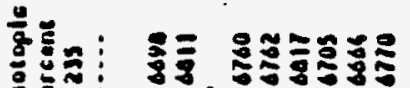

-0.0040.

ב:

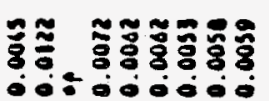

$\frac{3}{3}$

(3)

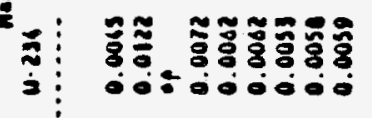

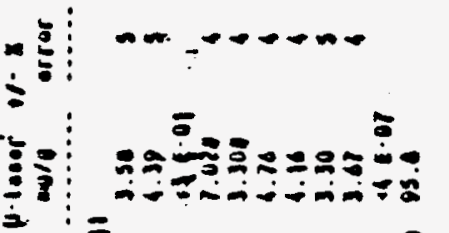
$\equiv$

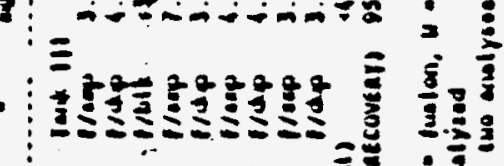

:

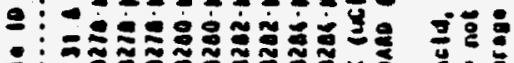

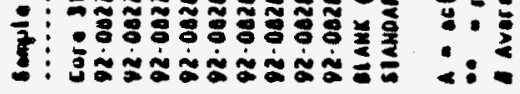


Nickol-63 and Nickol-69 Plesulls. Tank T-111, Cores 31 und 33

\begin{tabular}{|c|c|}
\hline Al.O 8 ample ID & Bamplo Typo \\
\hline $82-0827 \theta-111$ & Cornposile I luston, Core 31 \\
\hline $82-08278-112$ & Cunupasile I lusiton, Core 31 \\
\hline 82-08278-113 & Fuglon Blank \\
\hline $02-08280-111$ & Composile 2 luslon. Core 31 \\
\hline $82-08280-112$ & Composile 2 lublon, Core 31 \\
\hline $02-08280-112$ & 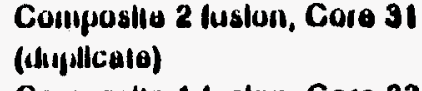 \\
\hline$-00202-111$ & Comingosile I luslon,، Core 33 \\
\hline $82-08282-112$ & Conluposile I lustori, Core 33 \\
\hline $02-00204-111$ & Composilte 2 lustorl, Cort 33 \\
\hline $82-00204-112$ & 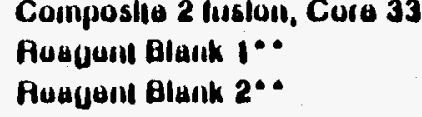 \\
\hline
\end{tabular}

Huaguill Blanik $2 \cdot 0$

\begin{tabular}{|c|c|}
\hline $\begin{array}{r}N 1-63 \\
\text { (iulcroCW0) }\end{array}$ & $\begin{array}{l}+1-0018 \\
\text { clomias }\end{array}$ \\
\hline 7.34E-03 & 4.0E-04 \\
\hline 1.13E-02 & 6.2E -04 \\
\hline 6.17E-06 & 1.4E-06 \\
\hline 7.32E-03 & 4.0E-04 \\
\hline $3.62 E-03$ & 2.0E-04 \\
\hline 3.63E-03 & $1.8 E-04$ \\
\hline 6.36E-03 & 3.6E-04 \\
\hline 4.64E-03 & 2.6E-04 \\
\hline 4.26E-03 & $2.3 E-04$ \\
\hline 1.82E-03 & 2.7E-04 \\
\hline $\begin{array}{l}<5 E-1 \\
<6 E-1\end{array}$ & \\
\hline
\end{tabular}
Auded t-one (Hpoli) ugana*

APD

\section{Blank Splke (NII-63)}

Mallix Splke (NII-63)
Racovered (upoiv)
1- one Racavery algma* (perceni)

$\begin{array}{lll}735 & 40 & 85 \\ 704 & 77 & 81\end{array}$

- One slgma uncerlalinles aro based on propagaflon of usass, volurne, counilug, and yleld determinallon uncertalniles.

- Two reagent blanke were used lor lils balch of analyses. The resulis liave been normallzed relativo to line garinglo voluines uillized.

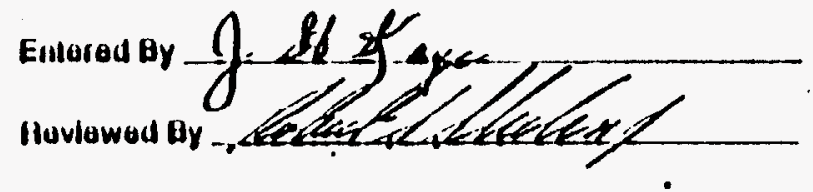

Da10 $10 / 8 / 92$ 
WHC-SD-WM-DP-024

ADDENDUM 5, REV O-A

\section{ORGANIC COMPOUND ANALYSIS REPORT}

SEMNOLATLE COMPOUNDS

\section{SAMPI E ANALYSTS REPORTED}

Analysis of 551 samples from Cores 31 and 33 Comoosites, 3uilding 2225 Hot Call 3ianks, and Field Blanks for semivoiatile organic esmpounds by gas chromatography/mass spestrametry (GE/MS) is the subject of in is report.

SAMPI E DESERTPTION AND TQEDARATION

Sample io

Core 31 Composite!

Core 31 Composite 2

Cors 33 Composite!

Core 33 Composite?

2225 Hot Cell Blank

Field slank
ACl 1 sis Vumeer

$92-08277$

$92-08279$

$92-08291$

$92-08293$

$92-08285$

92-08286

The sambies were received on 07/30/92. Extractions of both samples and soiked samples wera periormed acsording to the following orocadures.

- Extraction procadure

PNL-ALO-120 for the solids

PNL-ALO-122 for the water sample

- Ertraction location

oartitioning

- Extrzesion type

Analytical Chemistry Hot Calls and labs $306 / 308,325$ building

Sonication, medium level soil for eare sampies

Sesaratory funnel, nedium level water for samies 2z25 Hot Cell 3lank and Fieid 37 ank

- Samole/Extract szorage $4{ }^{\circ}\left(+1-2^{\circ}\right)$ :amperature

The jrocadure used to extract the aatrix spiked care samole resuited in a Jwo jhase exirace eoncantrate. The second shase was eliminated by adding

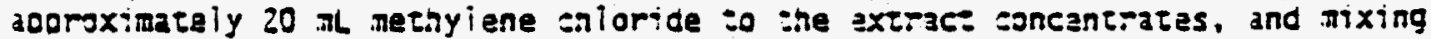
eace of shese solutions with 20 grams sodiun suifate for aoout jo ainutes.

\section{ANAL YSTS METHOD}

- GC/MS procedure:

PNL-ALO-345.

- Gejms instrumentation:

HP-5890/5970 GE'MS (H838473)

- GS/MS iocation: Lab 325,325 buididing. 


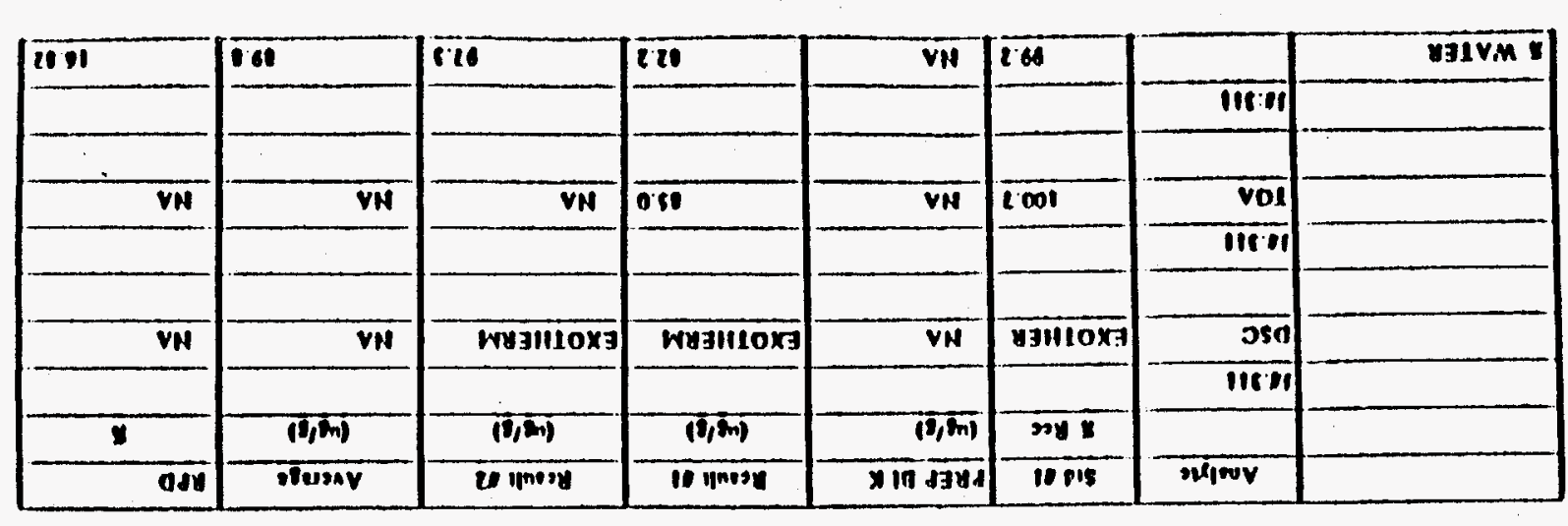

twoels

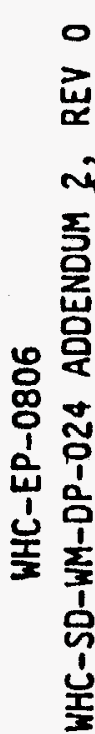

\begin{tabular}{|c|c|c|c|c|c|c|c|}
\hline 100 & F16 & Dit & $120 \Omega$ & VH & 16 & & G91VM \\
\hline & & & & & & oir'or & \\
\hline VH & VN & VH & 00 & VH & $C$ & vol & \\
\hline & & & & & & olfon & \\
\hline & & & & & & & \\
\hline $\mathrm{VN}$ & Vn & Druatioxa & mestilloxa & VN & 93110 3 & $\sin$ & \\
\hline & & & & & & orren & \\
\hline 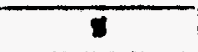 & $(1 /(m)$ & (Dका & $(3,(n)$ & $(0,(m)$ & $\operatorname{son} 1$ & & \\
\hline adi & obunay & Thinom & 10 1nement & Ty: 894d & 1009 & nolory & \\
\hline
\end{tabular}

trosests

\begin{tabular}{|c|c|c|c|c|c|c|c|}
\hline n21 & 100 & 10 & 10 & vin & 208 & & BaIVM $x$ \\
\hline & & & & & & $\cos 11$ & \\
\hline 210 & 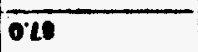 & 190 & 020 & VN & 1001 & vol & \\
\hline & & & & & & $\cos 01$ & \\
\hline VN & VW & 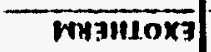 & musilioxa & $\overline{\mathrm{VN}}^{-}$ & B1110x7 & 3xi & \\
\hline & & & & & & $\cos \cdot 1$ & \\
\hline $\bar{x}$ & $(1,(m)$ & $(\pi, m)$ & $(2,(m)$ & $n(m, m)$ & myx & & \\
\hline$\overline{0+8}$ & DTumar & u ymory & 101 inesu & X्रा9 898. & 10018 & oxprov & \\
\hline
\end{tabular}

$103 m+2 x$ 
WHC-SO-WM-DP-024 ADDENDUM 2, REV $O$
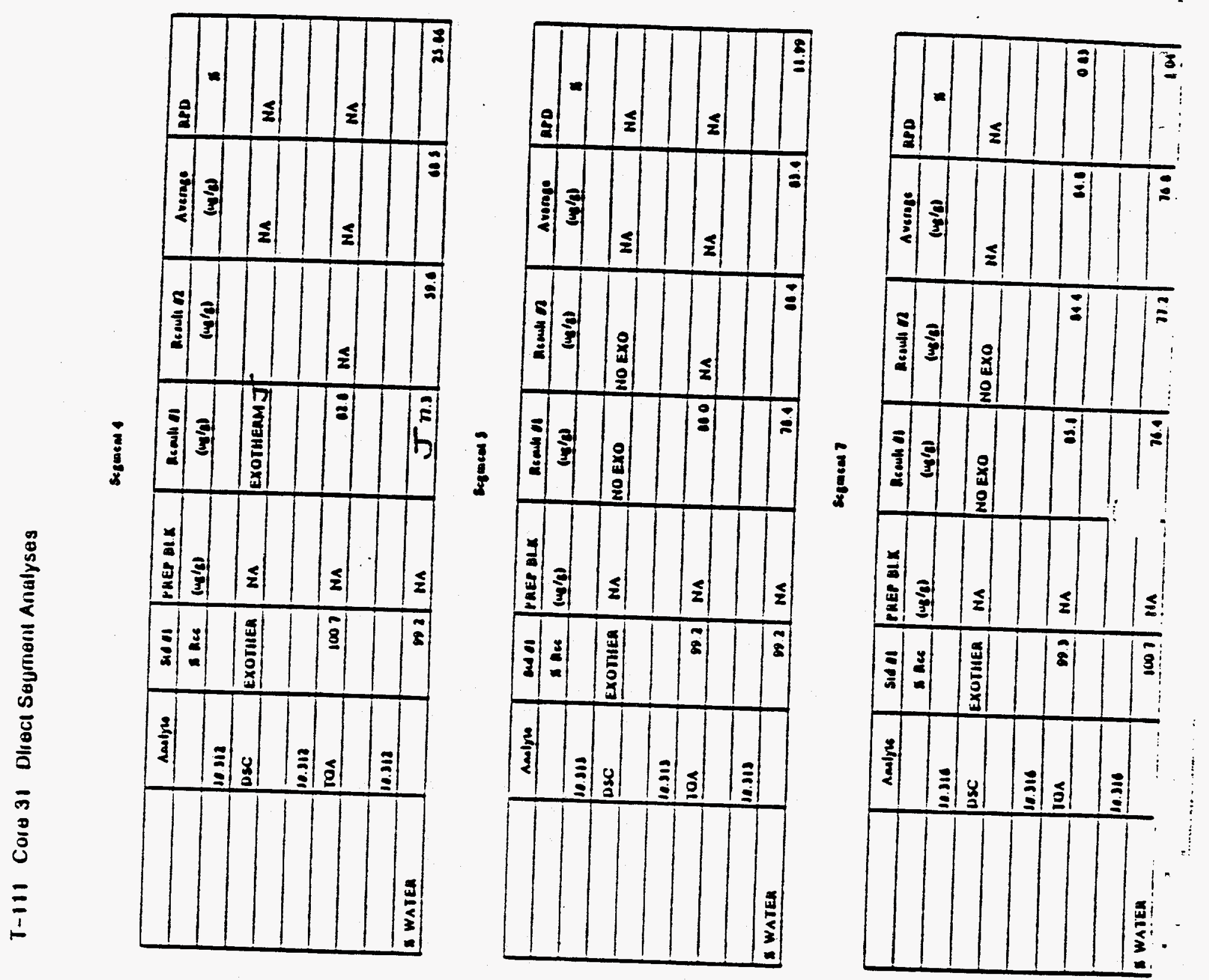
WHC-SD-WM-DP-024 ADDENDUM,2, REV 0
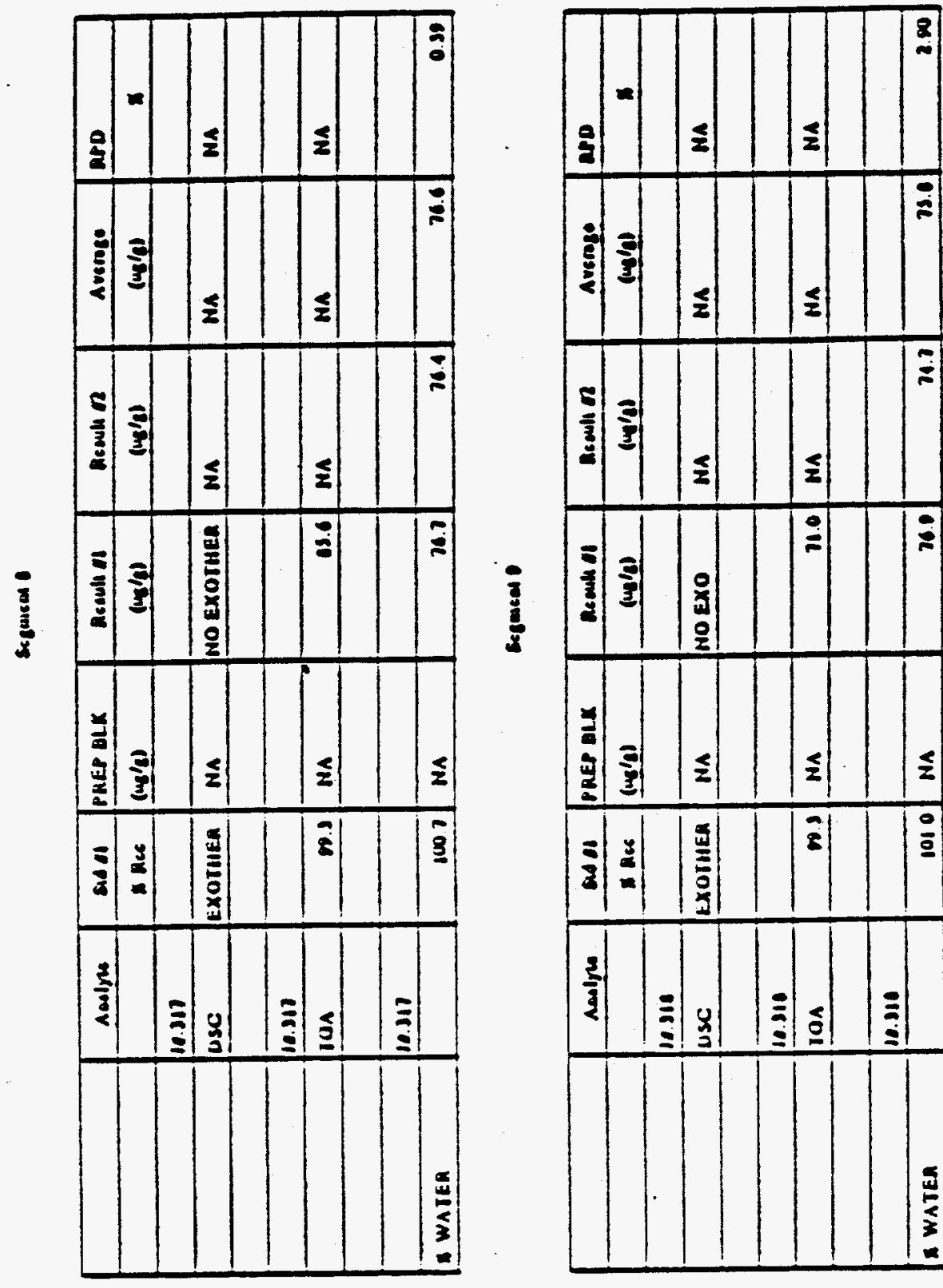

$\frac{2}{3}$

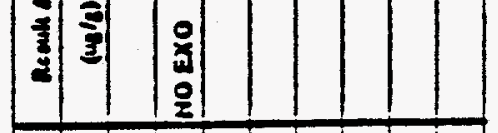

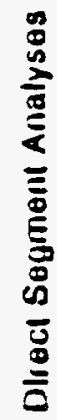

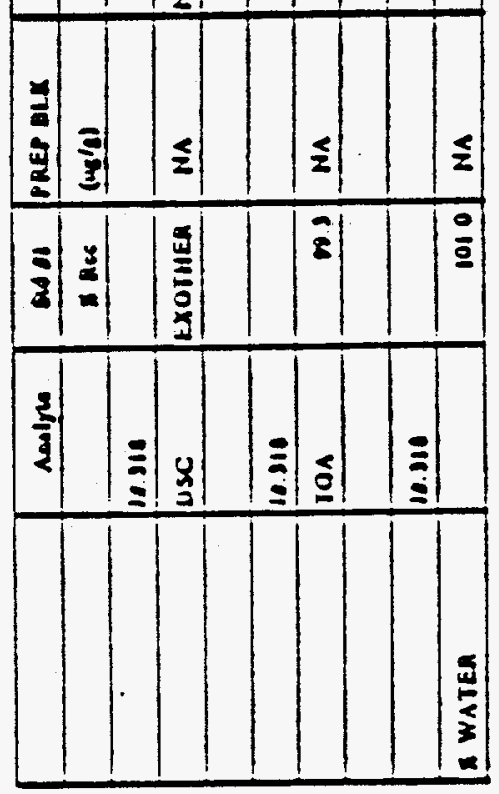

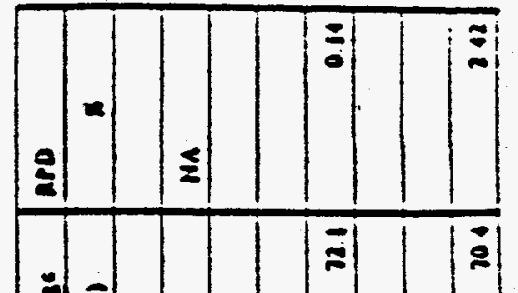

בै:

$\S$

(1)

$\frac{2}{5}$

势

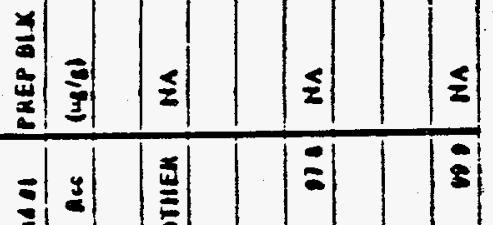

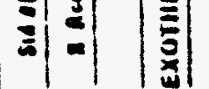

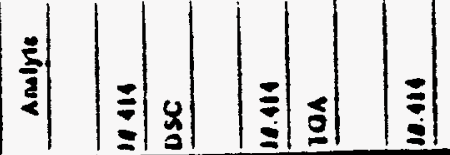


Speclal Arialysls of Segmenll 8 (whillo layer)

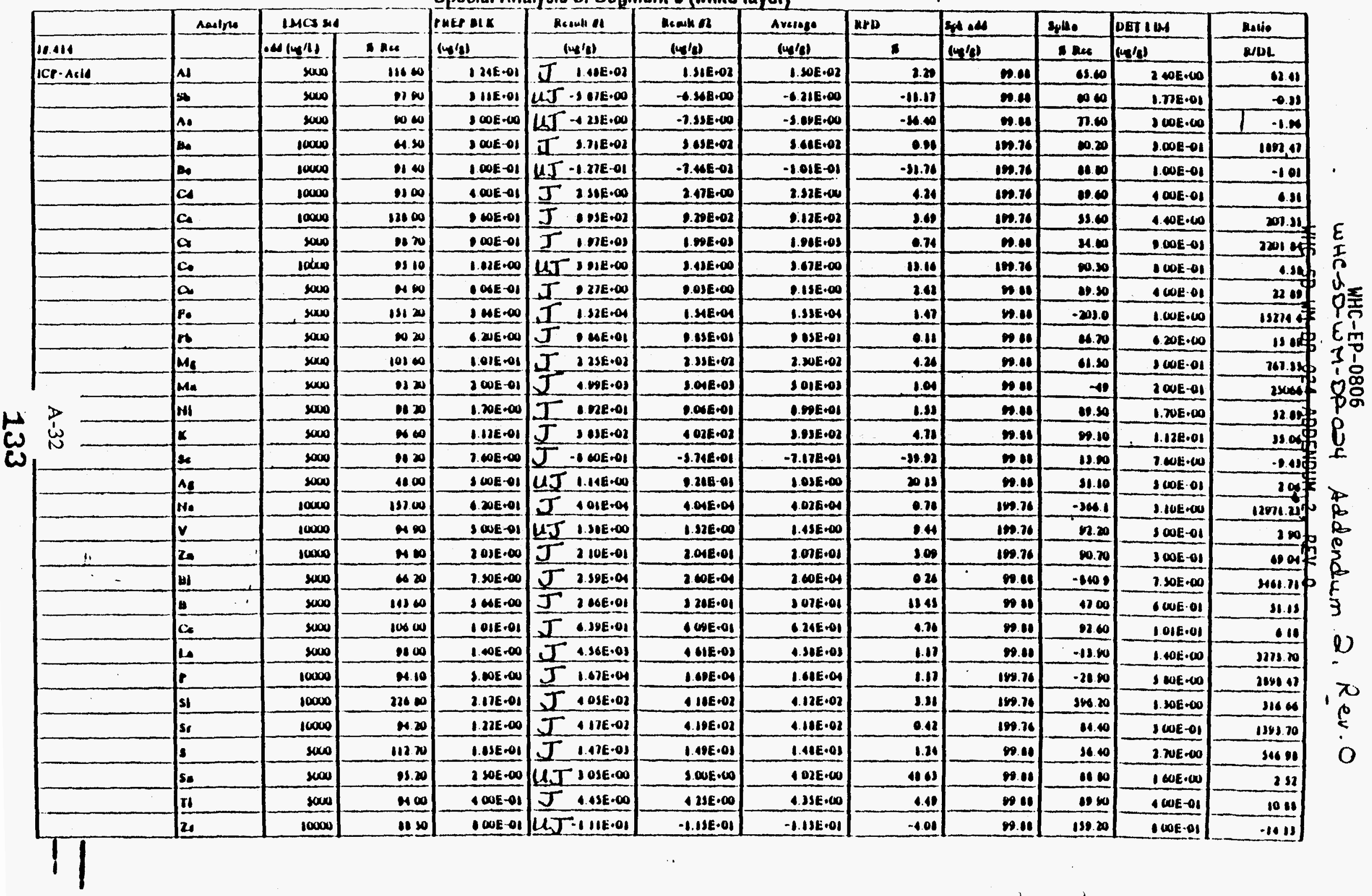


Speclal Analysls of Seginent 8 (whille layer)

\begin{tabular}{|c|c|c|c|c|c|c|c|c|c|c|c|}
\hline & Asosipe & use! & PKEP AIC & Acoull ol & Acoull a & Aresose & ApD & splle & DeE LAM & monto & \\
\hline & 10.414 & 1 Ace & $\operatorname{mos}(1)$ & $(4 / 1)$ & $(4 a / 6)$ & $(4 / 2)$ & $s$ & Snec & $(4 / 1)$ & NDL. & \\
\hline \multirow[t]{8}{*}{ ic-Wour } & $p$ & 10700 & $\triangle 100 E-01$ & I ARE-OS & 4.24E.03 & C.S1E.01 & 11.76 & 1110.00 & 1.00E.01 & 450.50 & \\
\hline & a & $\ldots 10$ & S1.00E-01 & I. OJE-OQ? & $7.33 E \cdot 02$ & 1.41E.02 & 22.41 & n. & 1.00E-01 & 4.60 & \\
\hline & mos & 0100 & $\triangle 1.00 E \cdot 02$ & $\tau$ C IIENOA & S.41E.04 & S.0EE.04 & 11.03 & 111.00 & $1.00 E \cdot 02$ & 80000 & \\
\hline & Hon & 101.00 & $\leq 1.00 E-02$ & II O.12E.02 & 0.565 .02 & 3.40E.02 & 24.03 & 00.20 & 1.006002 & 1.00 & \\
\hline & ros & $\infty$ & $\leq 1.00 E-02$ & I I ONE & $202 E-01$ & 2.235 .04 & 0.45 & on.0 & 1.00E.02 & Bss.00 & \\
\hline & 304 & 000 & $\angle 100 E \cdot 02$ & I D.J1E.03 & 1.22E.01 & $3.1216-03$ & 18.4 & 100.00 & 1.005 .02 & 31.13 & \\
\hline & pros & & & & & $1.00 \cdot 00$ & & & & & \\
\hline & wsor & & & & & 1.06E-01 & & & & & \\
\hline$>\quad 8$ & की & $41:$ & काष & की & कि & mPl? & 14\%? & Pमी। & $\$ 4+1$ & min & $\because \quad \because$ \\
\hline & & sendI & pater aux & Acantel & Acoull n & Average & RPD & 20140 & WEET LAM & Molis & $\triangle$ arT ENa \\
\hline & 101.416 & Date & $\left(\omega \mathrm{C} \mu_{1}\right)$ & (ucila) & $\left(w c_{i} /\right)_{1}$ & $\left(\mu C v_{0}\right)$ & $s$ & Den & $(\Delta \subset \mathrm{C} / \mathrm{w})$ & NDL & \\
\hline \multirow{3}{*}{ RAD-PMO. } & TA & $10+6$ & SOIIE-4 & 1.JJE-01 & 1.01E-01 & 1.00E-01 & 17.4 & 111.40 & $0.706-01$ & 260.25 & $2 x$ \\
\hline & & & $\therefore$ & $\therefore$ & $\because \div$ & 0 & 301 & man & 4 & $\because \quad:$ & \\
\hline & 10.414 & & & & & & & & & & \\
\hline \multirow[t]{5}{*}{ ogn } & $c_{1-131}$ & 10300 & $<2 E-3$ & 103E-02 & D.UE-03 & $1.00 E-02$ & $\$ .70$ & MA & 7.206-0s & 138.41 & 200 \\
\hline & $E=19$ & NA & Q 221E-4 & Q 41EE-1 & Q.22E-4 & NA & MA & NA & $2.40 E-04$ & NA & \\
\hline & $E N-13 s$ & NA & <1.12E-4 & Q.11E-4 & CI.OPE-A & MA & MA & NA & 1.10E-OS & MA & \\
\hline & Aan-211 & HA & Q Q 62E-4 & 2 UNE-02 & 204E-02 & 2.COE-02 & 1.00 & $M A$ & $2201-01$ & 125.04 & 200 \\
\hline & Co- 60 & 10100 & $<1$ ASE- 2 & <.7.7E-s & O.GHE-S & MA & NA & Ma & D ISE-OS & MA & \\
\hline
\end{tabular}


WHC-SD-WM WHC-EP-0806 ndum 2, Rev.O

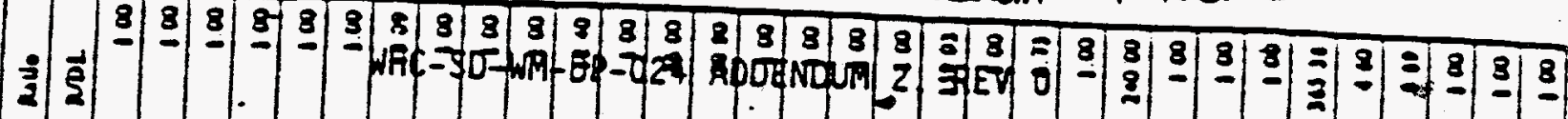

全

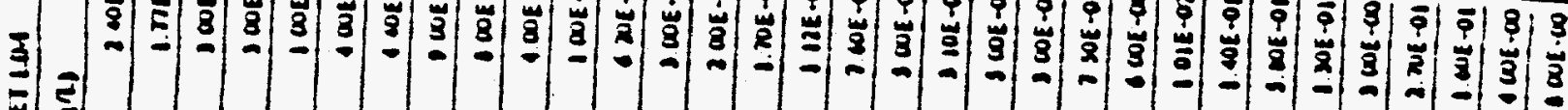
a)

천.

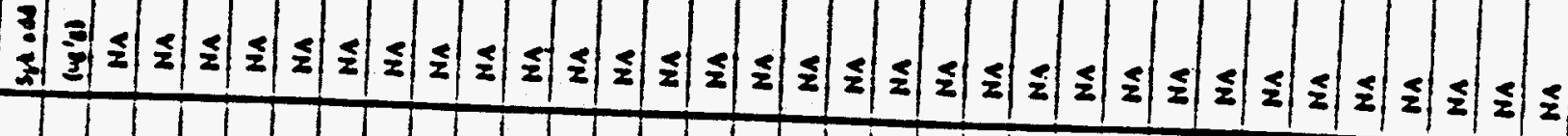

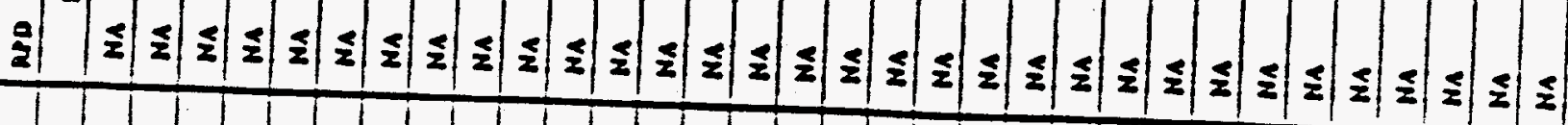

(2)

$(2$

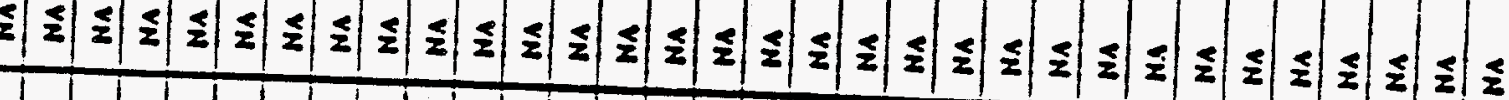

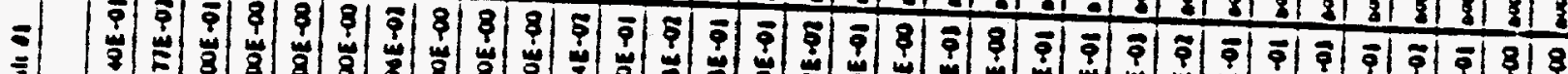

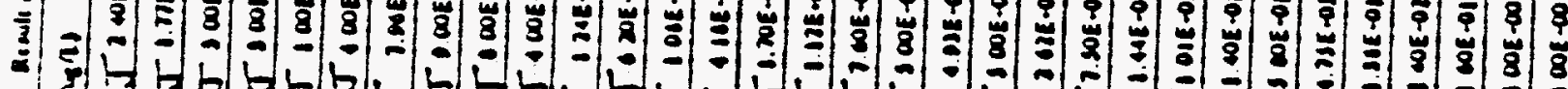

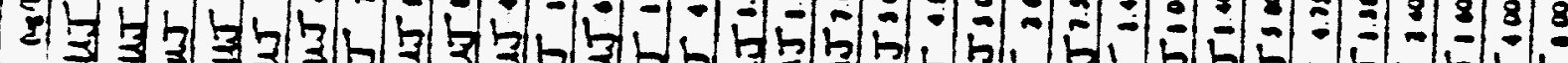

क्रF

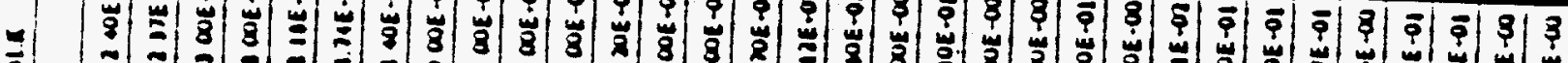

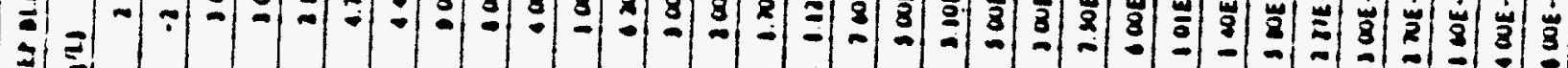

\& 3

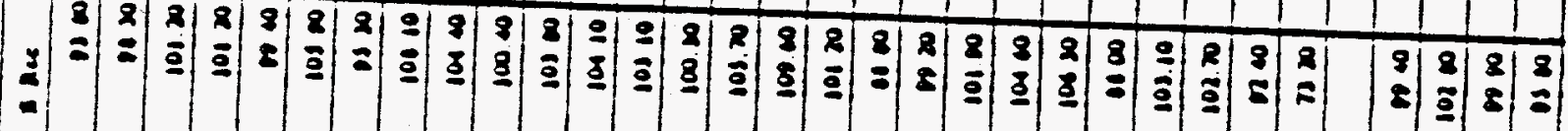

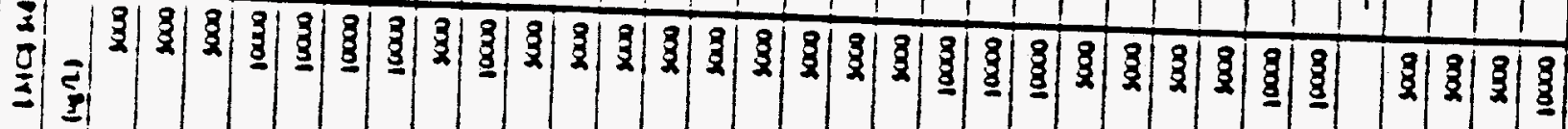
3

?

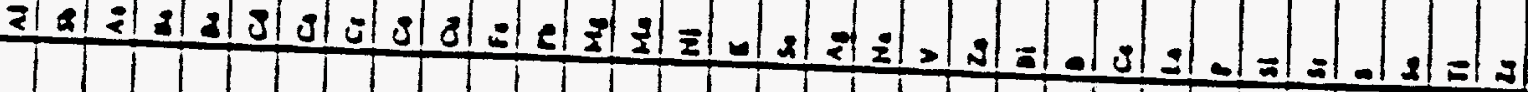




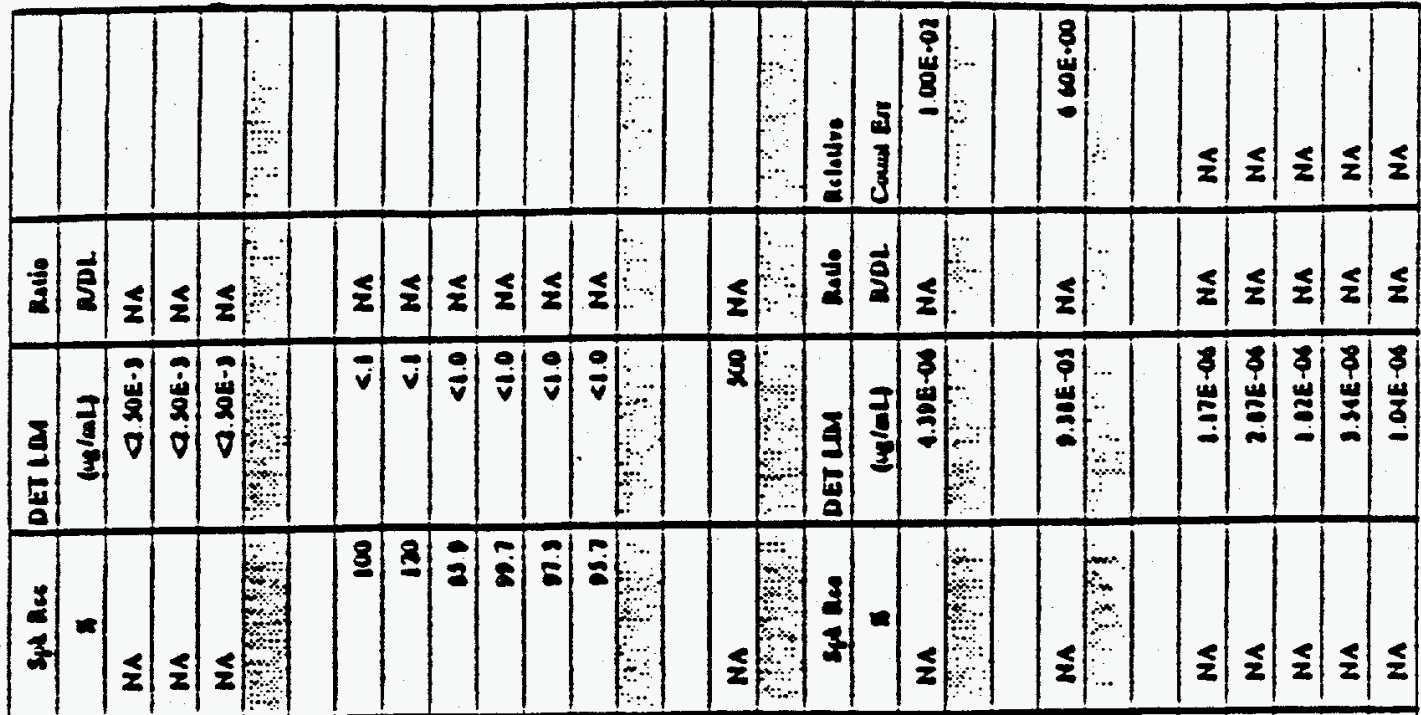

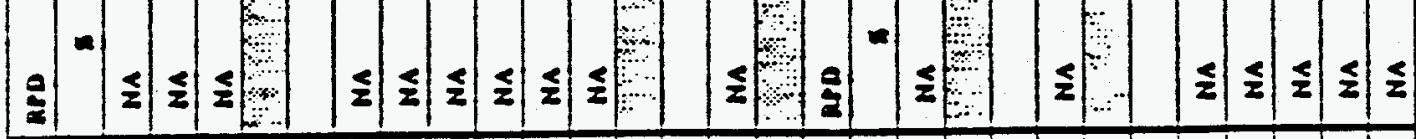

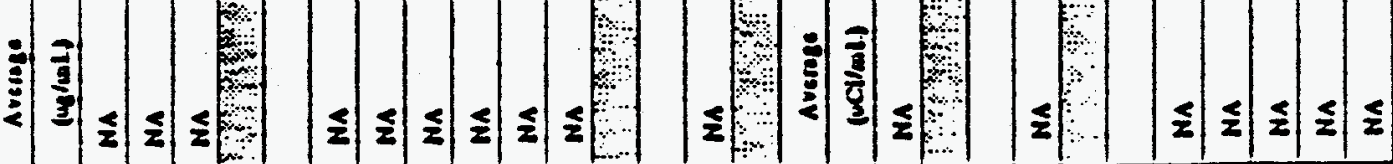

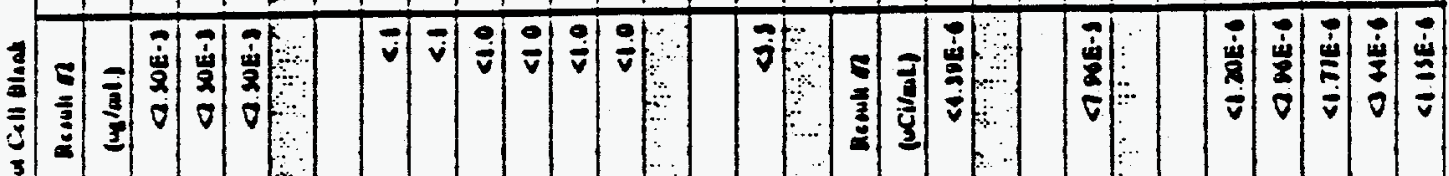
3

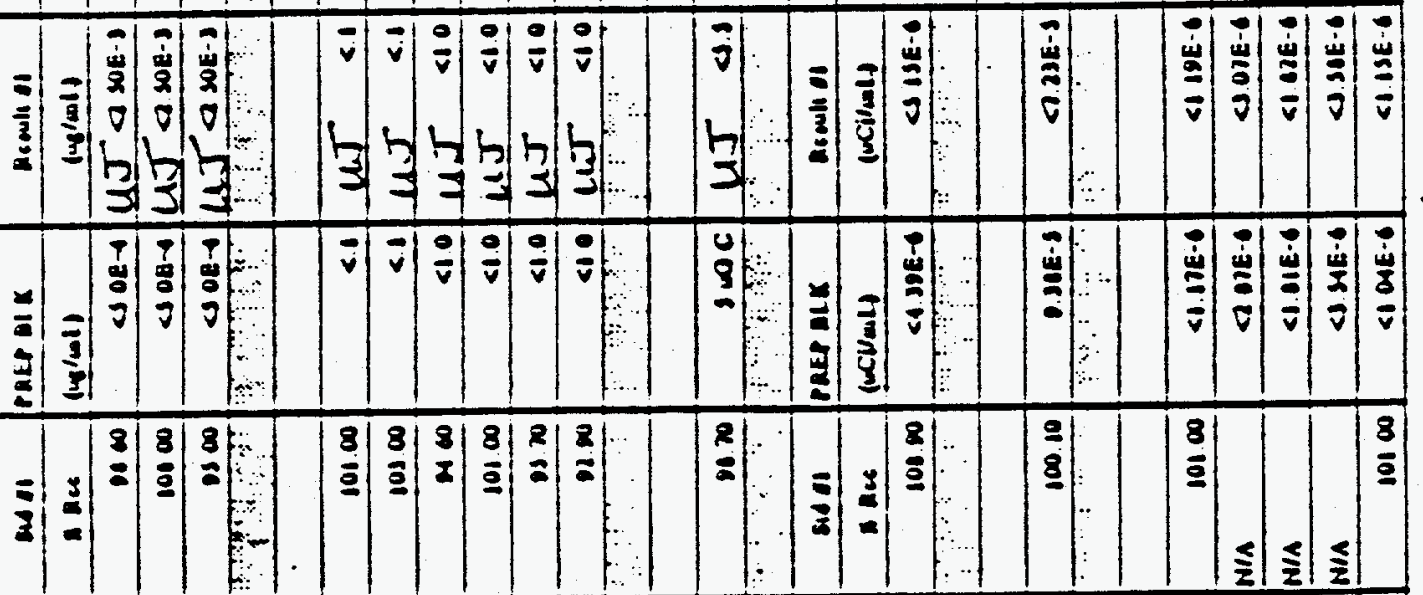

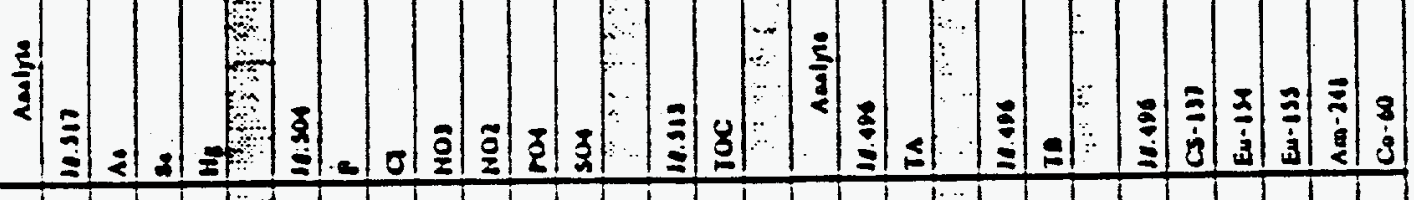

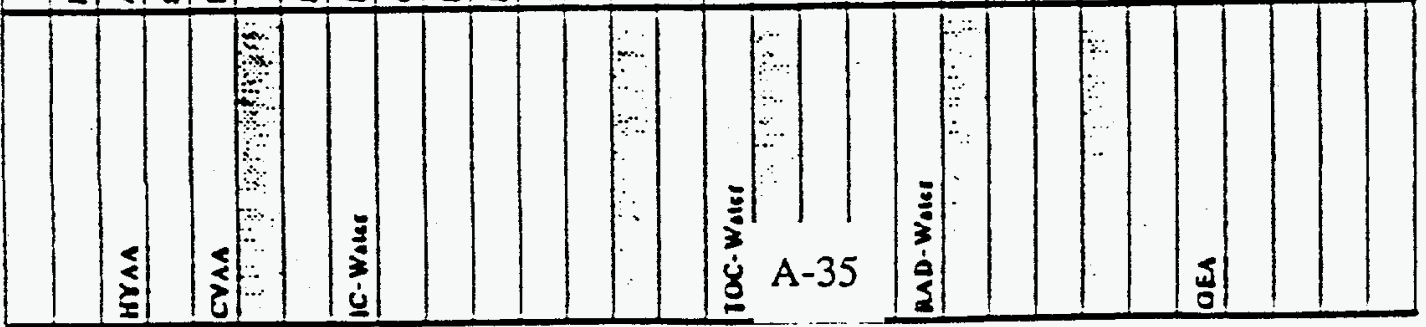




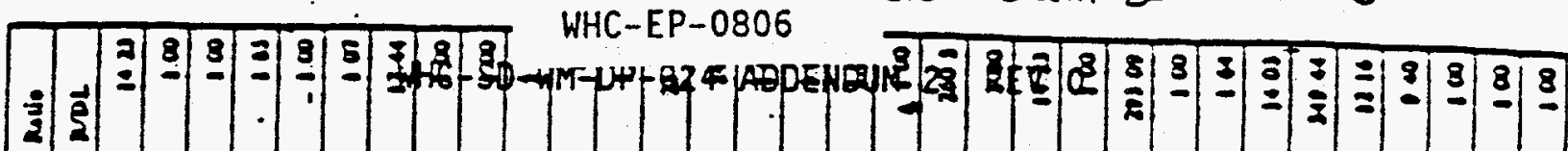

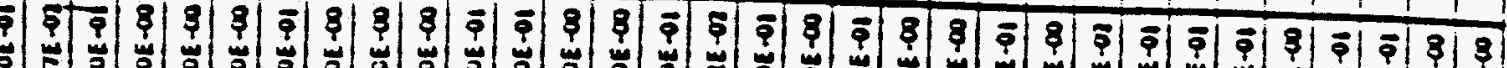

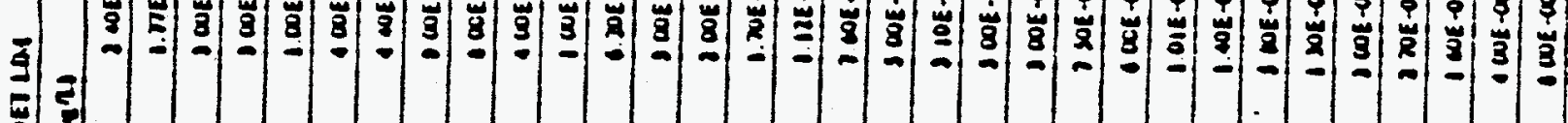

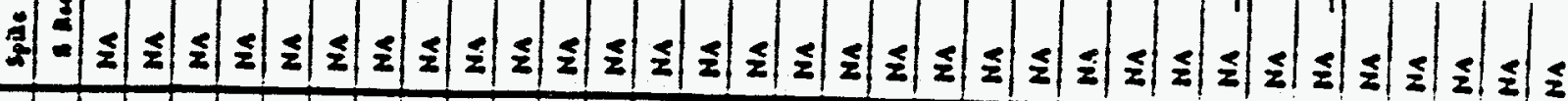

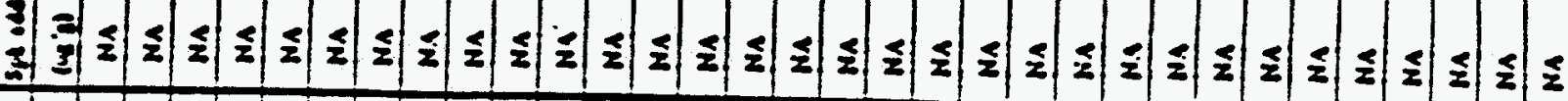
a $-$

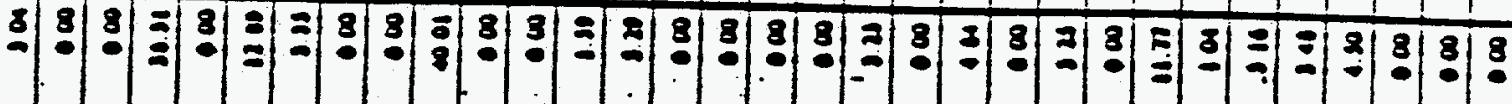

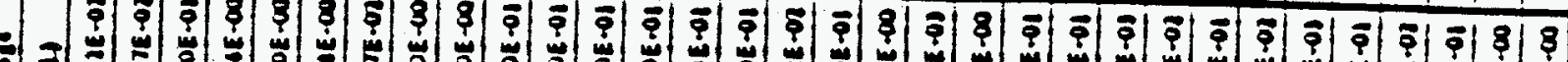

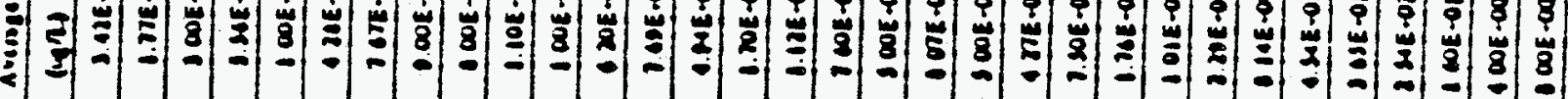

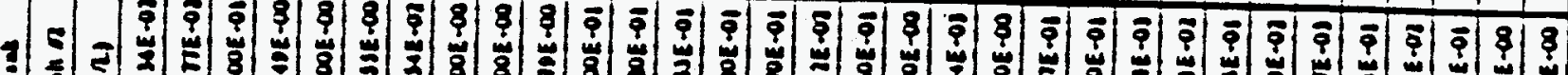

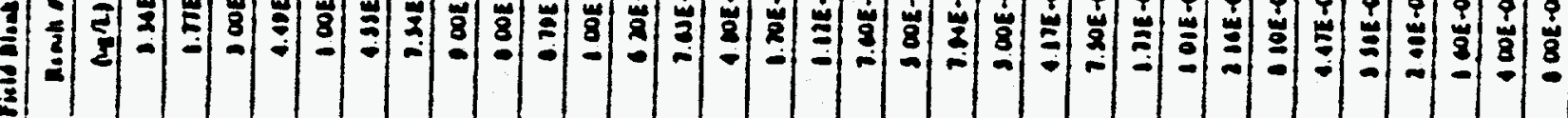

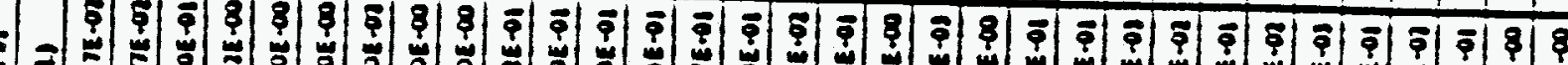

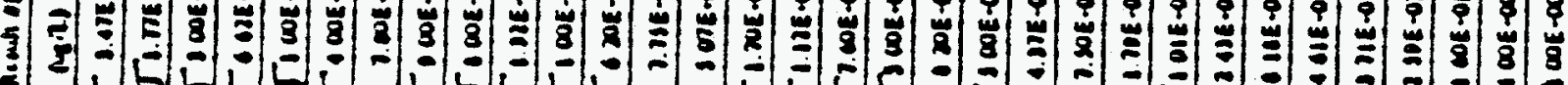

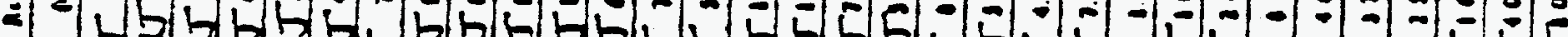

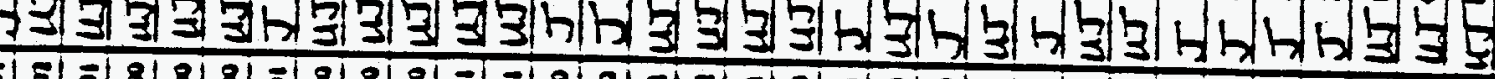

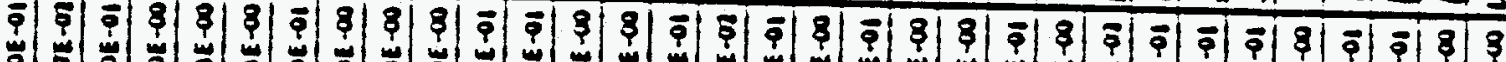

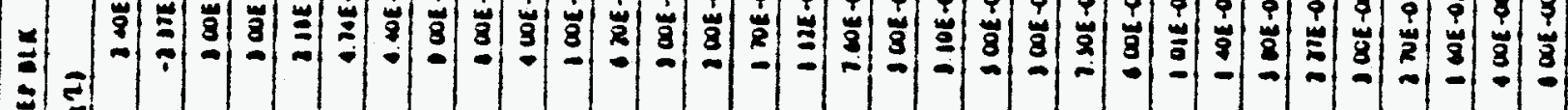
3

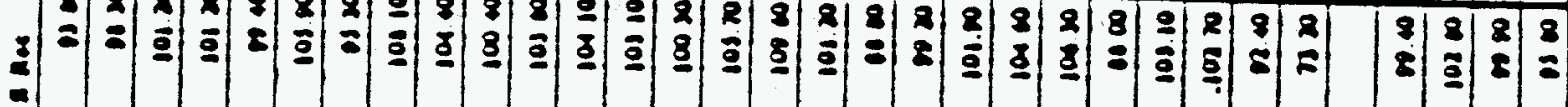

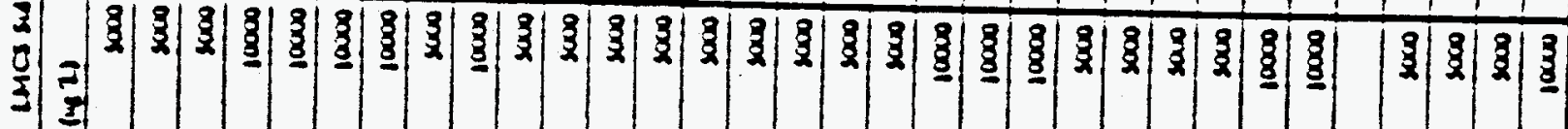
子

?

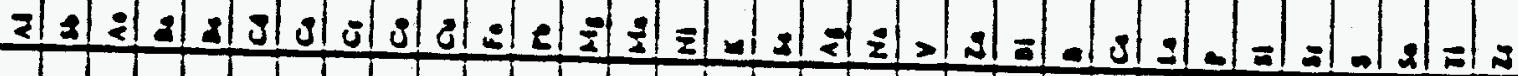




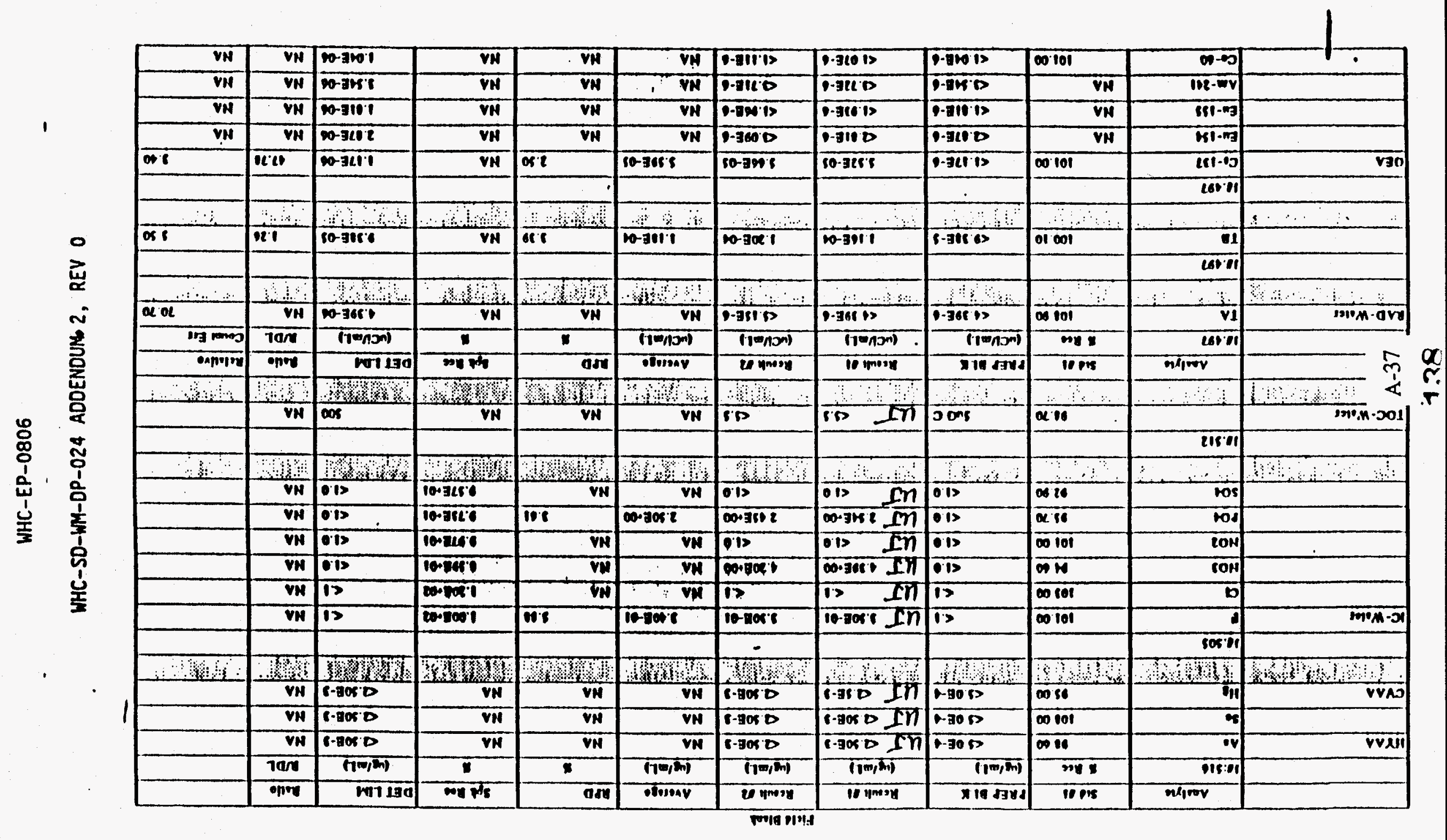

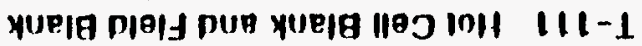




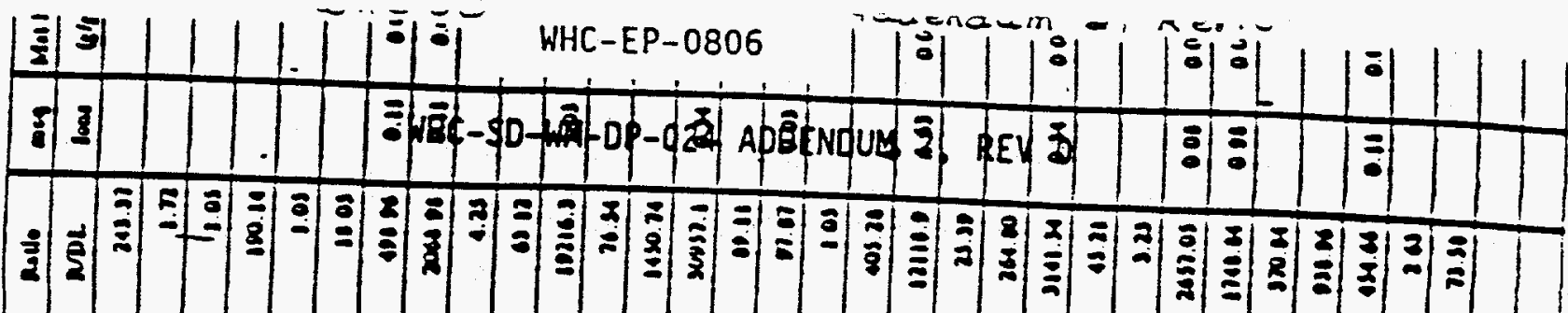
$\$$

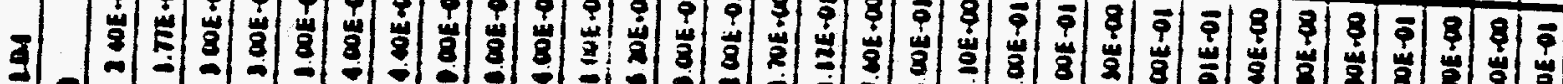

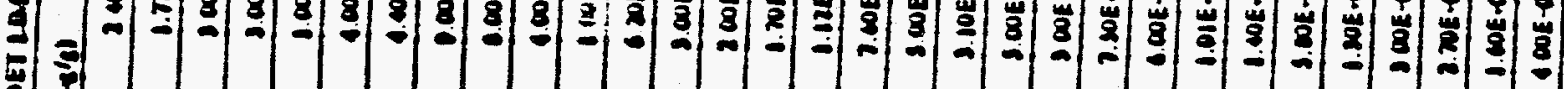

势

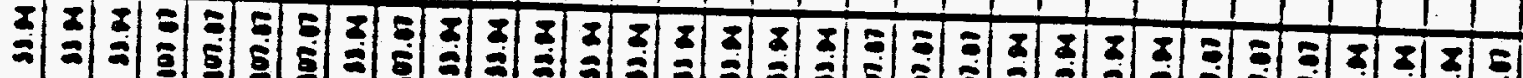
3

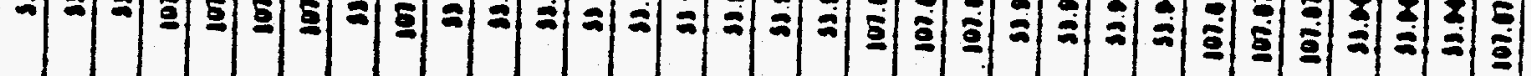

초 3

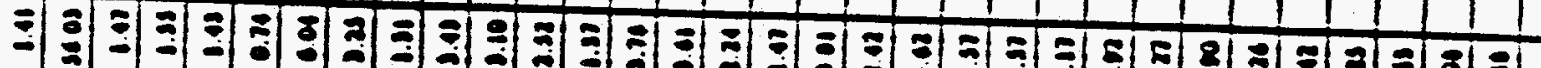

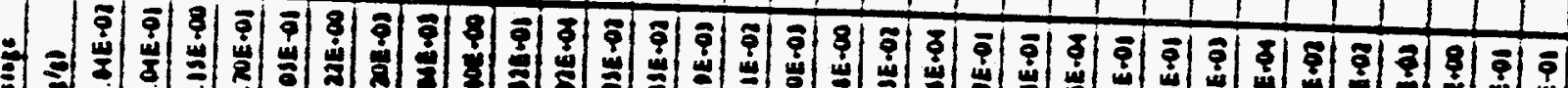

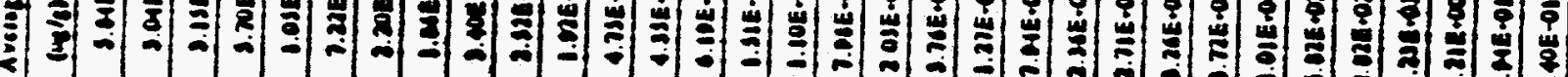

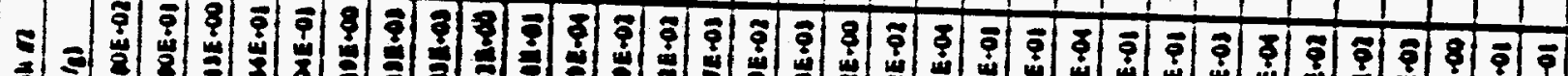

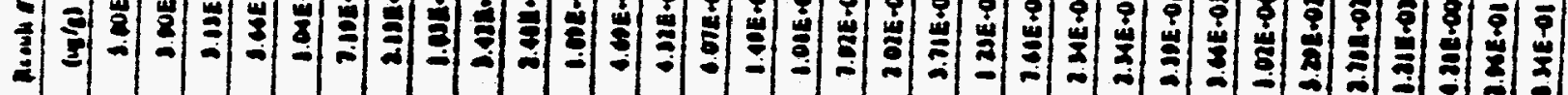

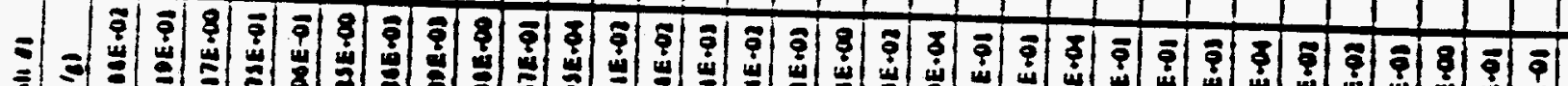

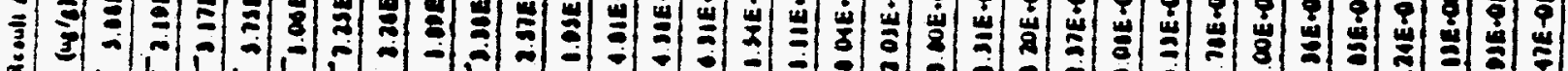

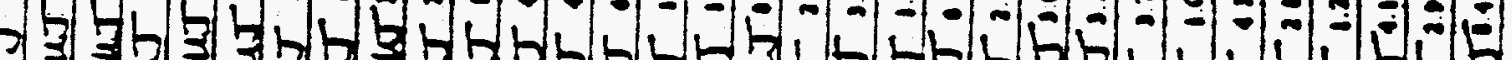

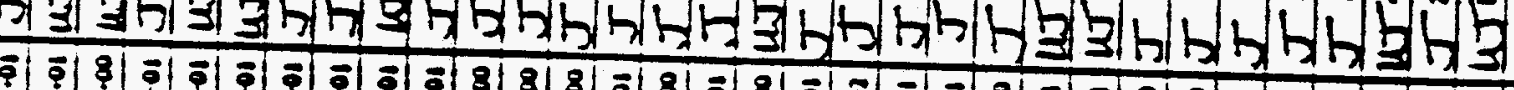

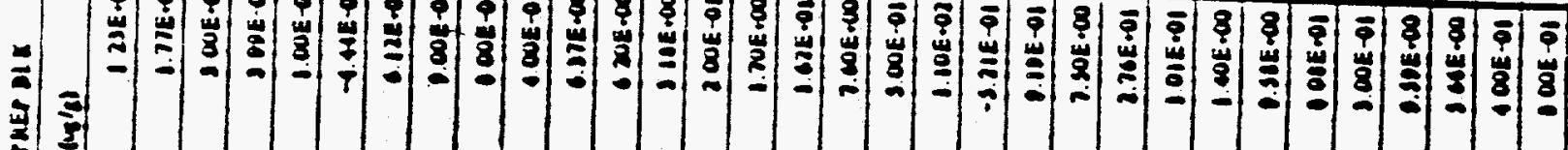

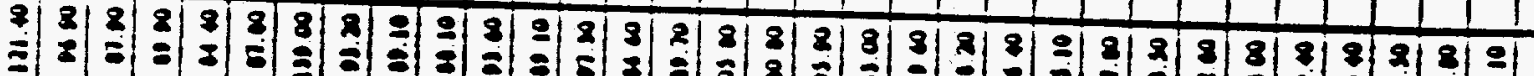

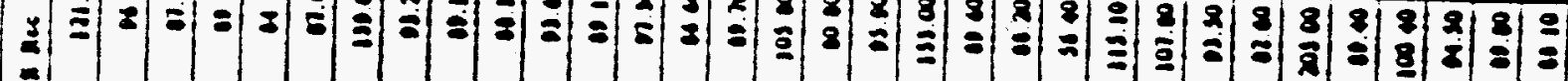

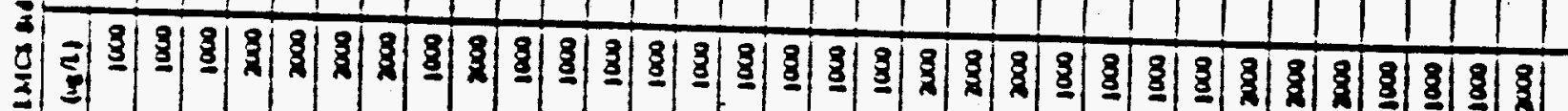
3

:

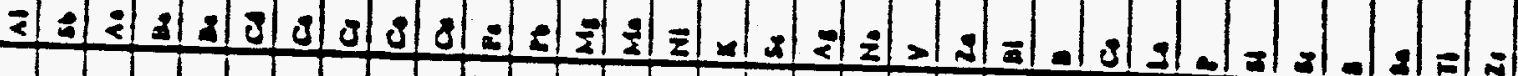


WHC-EP=0806

WHC-SD-WM-DP-024 ADDENDUM 2, REV 0

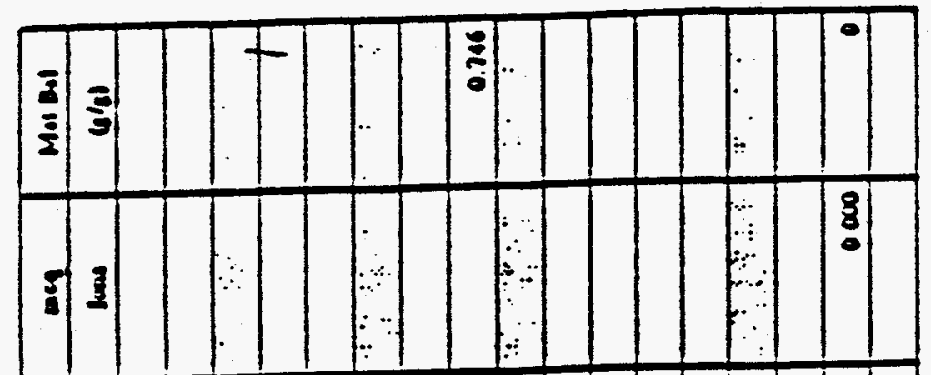

$\frac{1}{2}$ है

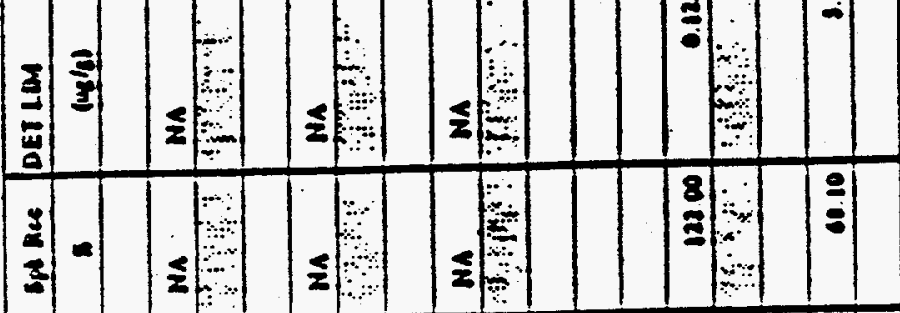

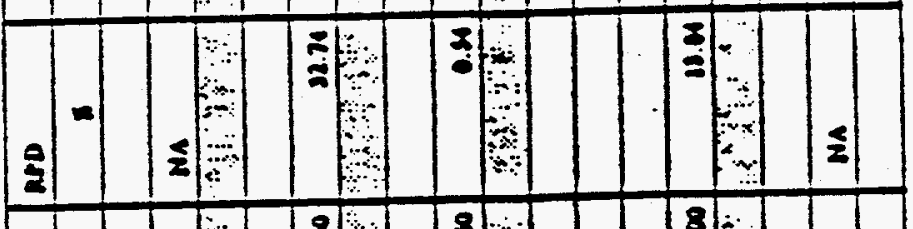

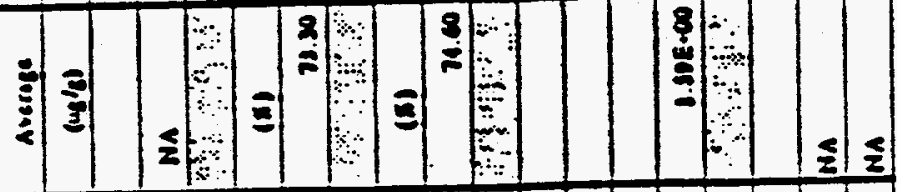

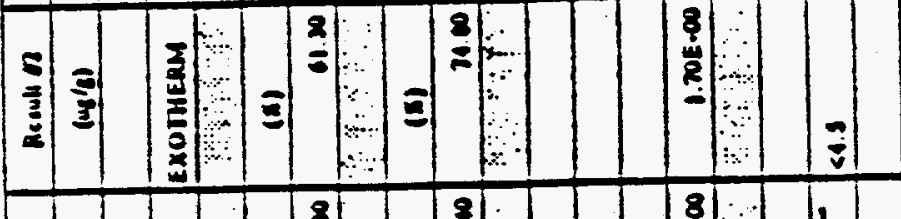

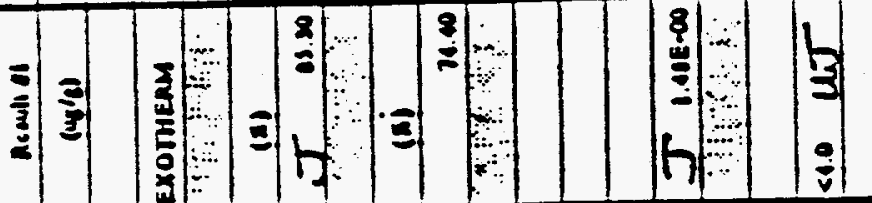

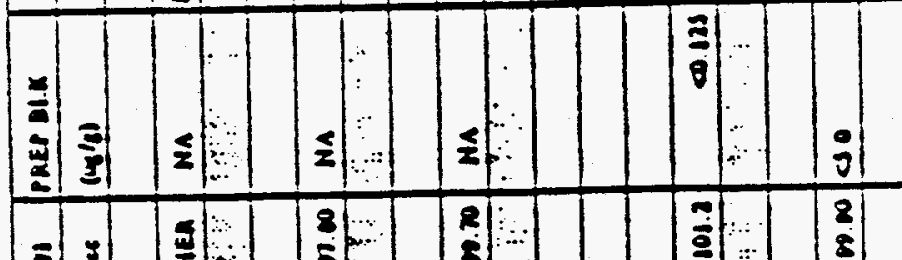

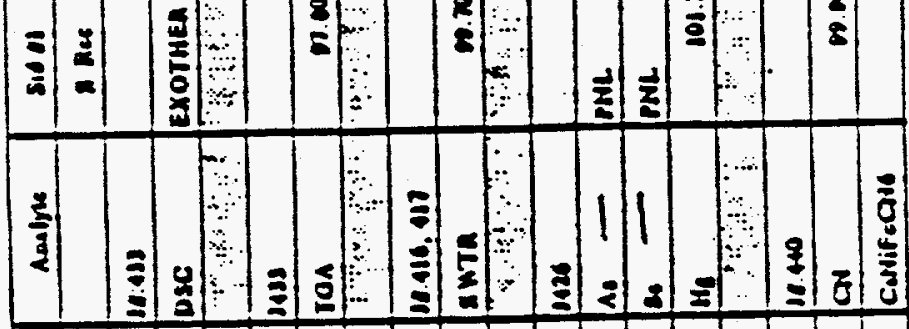

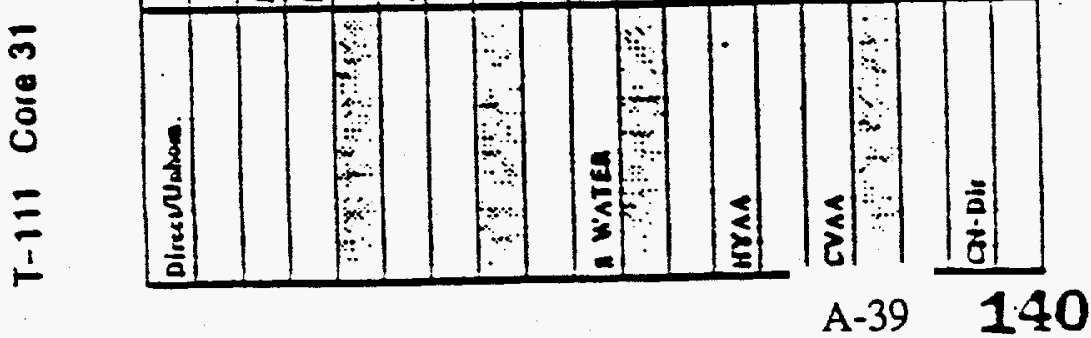




\begin{tabular}{|c|c|c|c|c|c|c|c|c|c|c|c|c|c|}
\hline 1 & $0 \times 00$ & 0000 & $\mathbf{V N}$ & 20.3008 & os sot & $\mathbf{V H}$ & $\mathbf{V A}$ & $2 \cdot 3005$ & $\cos 300,1 n$ & $\cos 1$ & irol & 100 & 190.0 .54 \\
\hline \multirow{28}{*}{$\begin{array}{l}0 \\
0 \\
0 \\
0 \\
1 \\
1 \\
0 \\
1 \\
1 \\
\underline{1} \\
\frac{1}{3}\end{array}$} & & & & & & & & & & & & cston & \\
\hline & 3 & & 10 & $\because \because \quad \because 3$ & $\therefore$ & 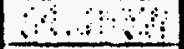 & $\because$ & 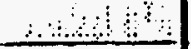 & 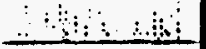 & $\because \quad \because$ & 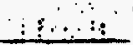 & 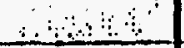 & $4 \quad 0,3$ \\
\hline & $\infty$ & 1020 & & & & & & & & $6 \cdot 3 \mathrm{Cl}$ & & G na19y & \\
\hline & & & 101 & 20.3008 & on 10 & 6001 & 100.36018 & 10.3019 & $10-3018 I$ & 0503 & 010 & 301 & $\mid n 1, n-x-201$ \\
\hline & & & & & & & & & & & & 28001 & \\
\hline & $:$ & $\therefore \ldots$ & $\therefore \%$ & $\because \because \quad \because \quad$ & & an & $\because \because \vdots$ & $\because$ & $\therefore$ & & & $\therefore$ & $\because \therefore$ \\
\hline & & & VH & $10-3006$ & 0010 & VN & VH & $000+3$ & In cosis & 00813 & 0010 & IHN & $m, n-1 K N$ \\
\hline & & & & & & & & & & & & 6001 & \\
\hline & . & $\begin{array}{r}80 \\
4\end{array}$ & 31 & 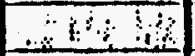 & $4 \quad 3$ & 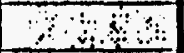 & $\because \quad \therefore \quad \therefore$ & $\vdots \quad \cdots \quad i \quad: \quad$ & $: 1: 4: 1$ & 1 & & $\therefore$ & $\therefore$ \\
\hline & & & $\begin{array}{r}\mathbf{N} \\
\end{array}$ & $\mathrm{VN}$ & VH & 060 & 1101 & 1101 & 2101 & $\mathrm{VN}$ & CMI & $\mathrm{NA}^{-1}$ & Hd \\
\hline & & & & & & & & & & & & (150) & -1 \\
\hline & $\begin{array}{llll}\vdots & \ddots & \vdots\end{array}$ & $4 x+4$ & $\therefore \mathrm{H}^{3}$ & $1.4 \times 94$ & 40 & $1 \%$ & $\therefore \therefore \therefore$ & 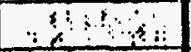 & 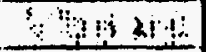 & $\because \quad \because \quad \because$ & $\because: 1$ & $\therefore \quad \therefore$ & : \\
\hline & & & & & & & $\infty 6$ & & & & 691 & 20NU60 $20 \mathrm{~N}$ & \\
\hline & & & & & & & 160 & & & & & CONULO $\mathrm{CON}$ & \\
\hline & mo & & 10.01 & $10 \cdot 3006$ & an & 100 & tondte! & 800000 & co-36r. II & 1.1005 & .001 & 20H & monesong \\
\hline & & & & & & & & & & & & esonen & \\
\hline & $\therefore \therefore$ & : & $3 m$ & $4 \ldots \mathrm{a}$ & $1 \%$ & $31 x^{2}$ & $x ! 1 !$ & 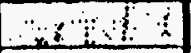 & $1, n$ & 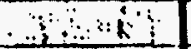 & 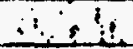 & $5 x$ & $l_{4} \ldots$ \\
\hline & & & & & & & $10-3116$ & & & & & Or/d31 GJV I & \\
\hline & & & & & & & $\infty 003261$ & & & & & aver and & \\
\hline & 100 & & $\infty x$ & $20 \cdot 3001$ & a.10 & $\infty 0$ & 10034918 & $100.369 t$ & $10 \cdot 3001 工$ & $2 \cdot 30013$ & $\alpha$ & 200 & \\
\hline & 100 & & 06101 & 10.3001 & 000 & 100 & 0.3101 & 100.3961 & $00-31011$ & 1.30013 & $\sigma x$ & not & \\
\hline & $\infty 0$ & & $V A$ & $20+3001$ & $0 \times 01$ & VH & VH & 030118 & rians is In & $2 \cdot 30013$ & 010 & ton & \\
\hline & $m 0$ & 120 & os 16 & 20.3001 & 00101 & 060 & $10-3100$ & mo.360. & 00.31101 & 2.30017 & ass & ION & \\
\hline & $\infty$ & & $10 \%$ & $10 \cdot 3001$ & onoll & ati & 10.3000 & 10.3180 & $(n+3 n+1$ & $\mid .30015$ & 0101 & 0 & \\
\hline & $\infty 0$ & 110 & 05100 & 10.3001 & $\infty 211$ & es? & 100.3608 & 10.31118 & $1003106 I$ & $\mid \cdot 3 m 11$ & $\alpha M$ & d & $190 m-31$ \\
\hline & & & & & & & & & & & & estor & \\
\hline & $(0, \pi)$ & -001 & $70 \mathrm{da}$ & $(2,(n)$ & 7 & 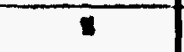 & $(\pi, m)$ & $18,(m)$ & $(1, m)$ & (19, & ne 1 & & \\
\hline & $\log 1064$ & be & oniy & mitad & काल & ant & gitena & 80 1nosn & $10 \ln 1004$ & $108 \times 4$ & 10018 & nilowy & \\
\hline
\end{tabular}




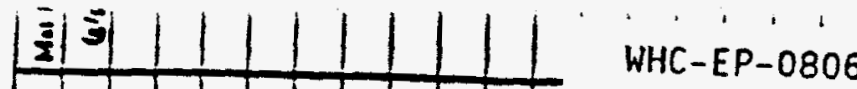

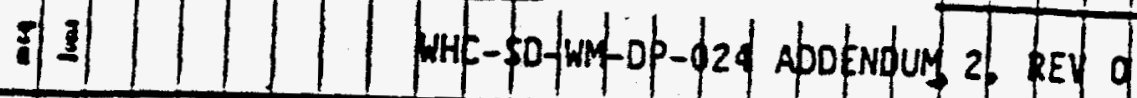

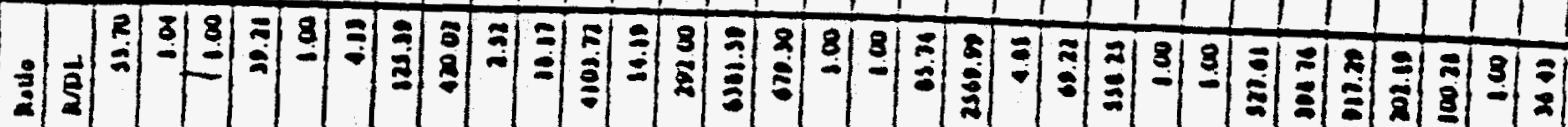

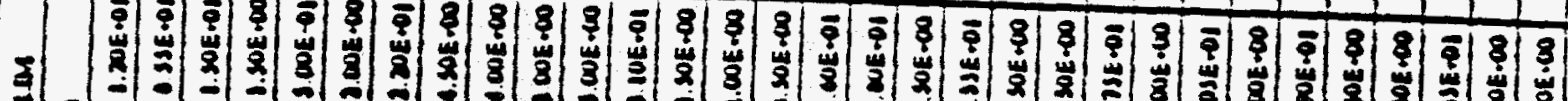

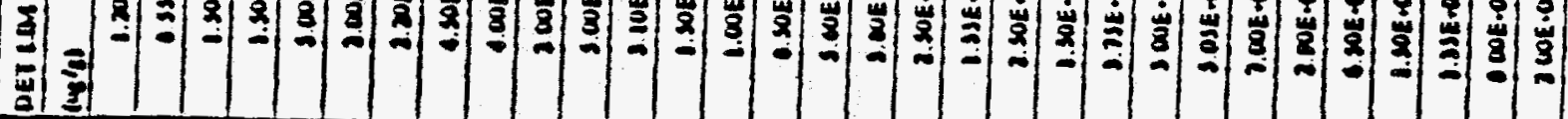

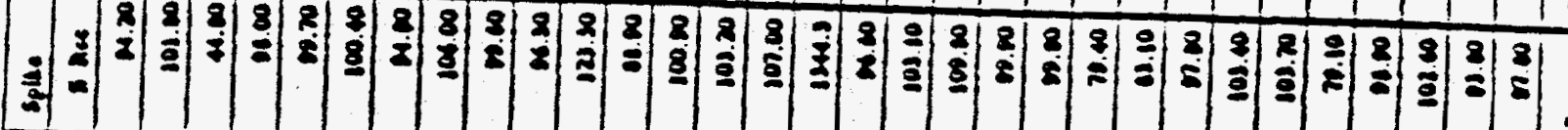

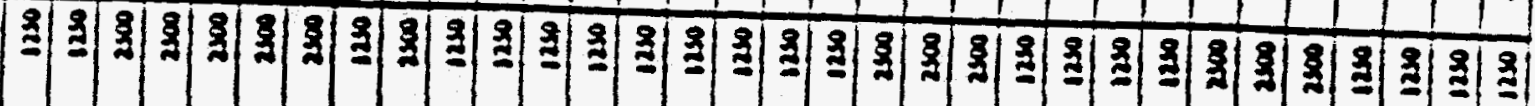
3. $=$

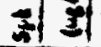

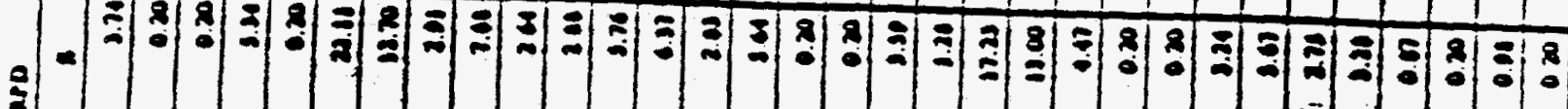

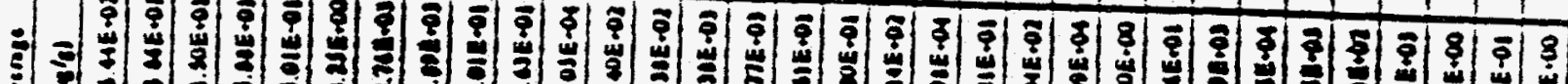

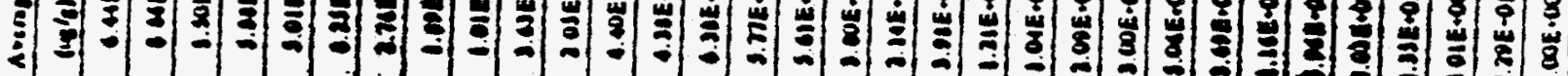

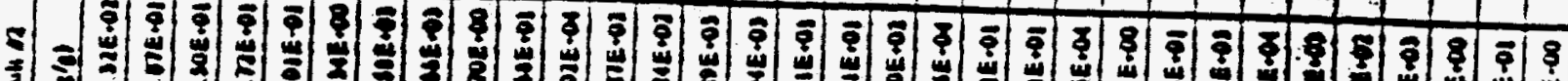

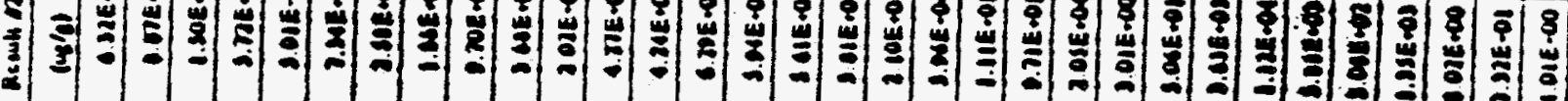

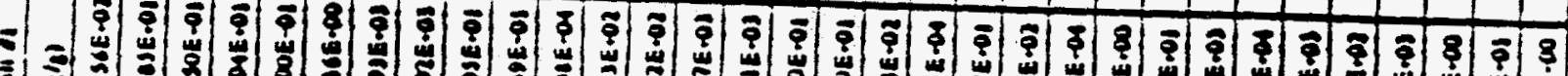

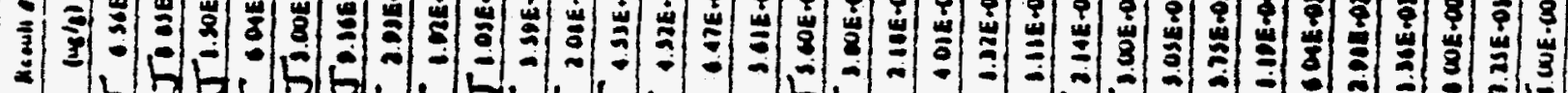

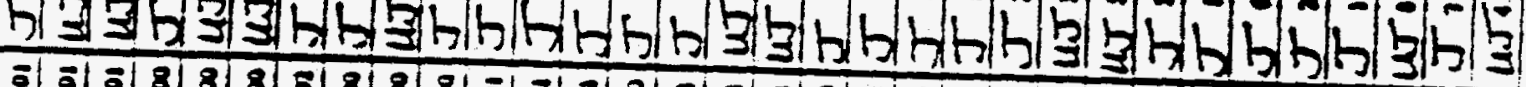

5.

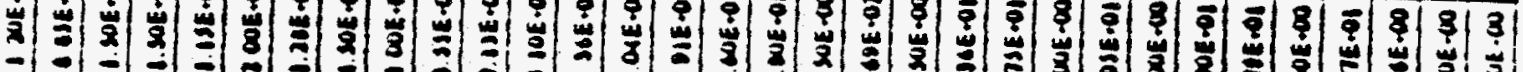

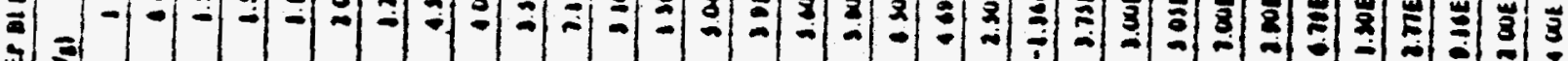

缕

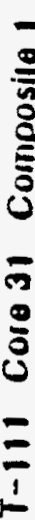

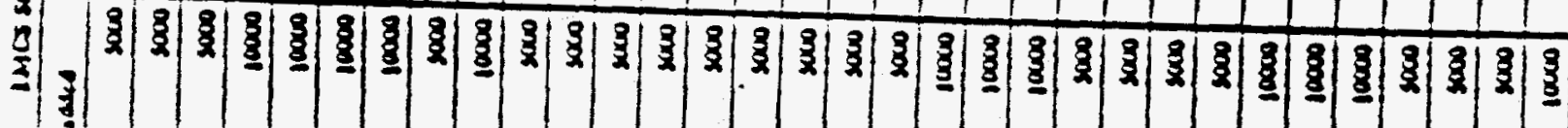

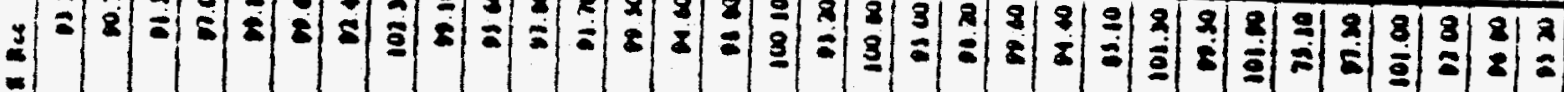

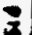

3.

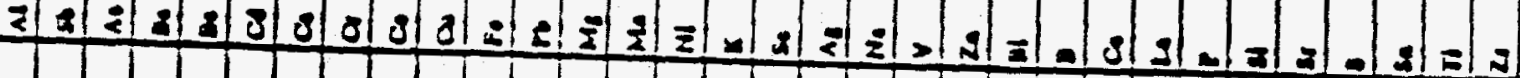

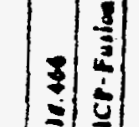

A-42 
WHC-SD-WM-DP-024 ADDENDUM 2, REV 0

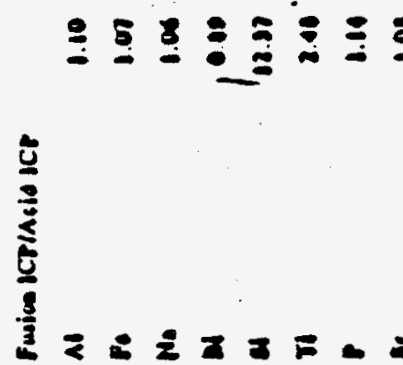

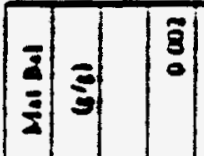

.)

힘

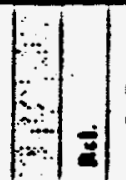

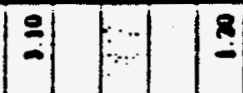

$-1=$

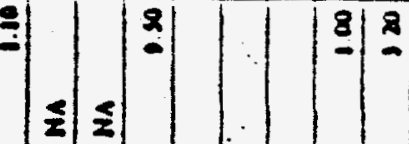

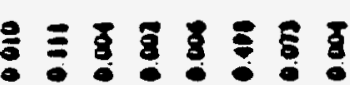

है

है

일

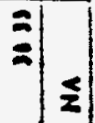

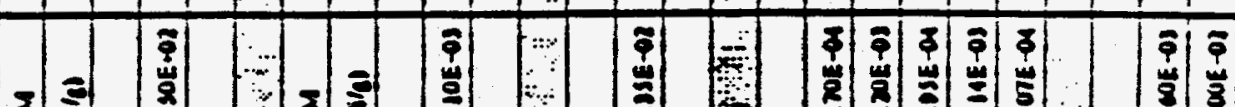

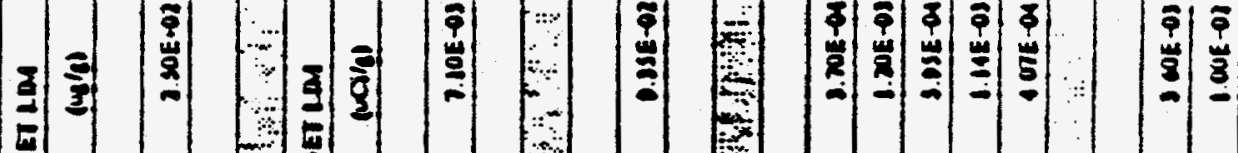

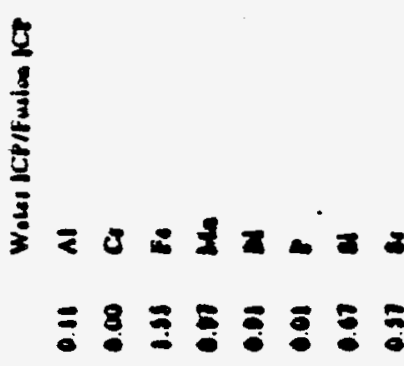

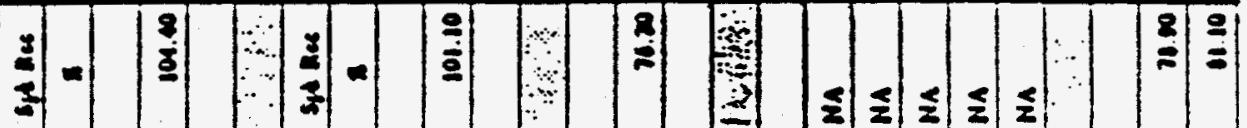

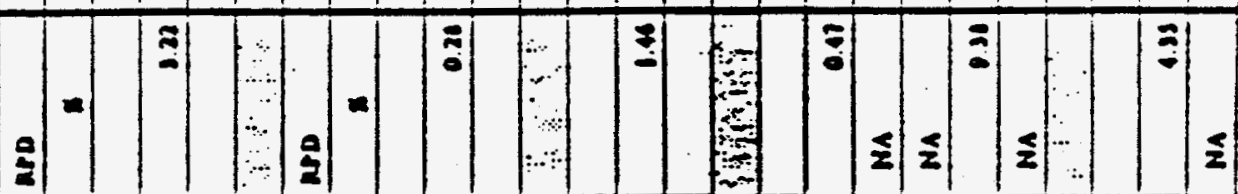

\begin{tabular}{|c|c|c|c|c|c|c|c|c|c|c|c|c|c|c|}
\hline 8 & 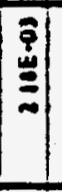 & & 15 & $\bar{\vdots}$ & 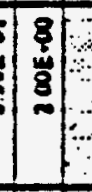 & & & & $\overline{\underline{9}}$ & $\overline{9}$ & $\bar{x}$ & & $\therefore$ & $\mid \begin{array}{l}\bar{a} \\
\vdots \\
0\end{array}$ \\
\hline (3) & $\left|\begin{array}{l}0 \\
\vdots \\
\vdots \\
\vdots\end{array}\right|$ & & 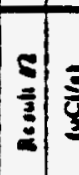 & & & & & & & $\widetilde{\xi}$ & 立 & & & $\bar{q}$ \\
\hline
\end{tabular}

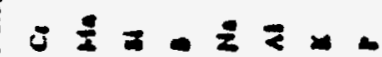

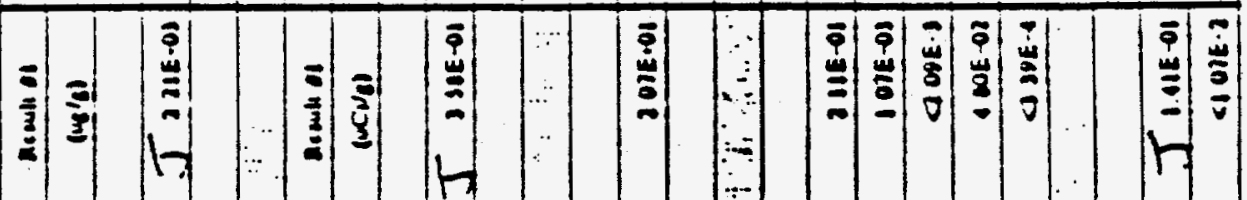

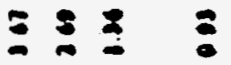

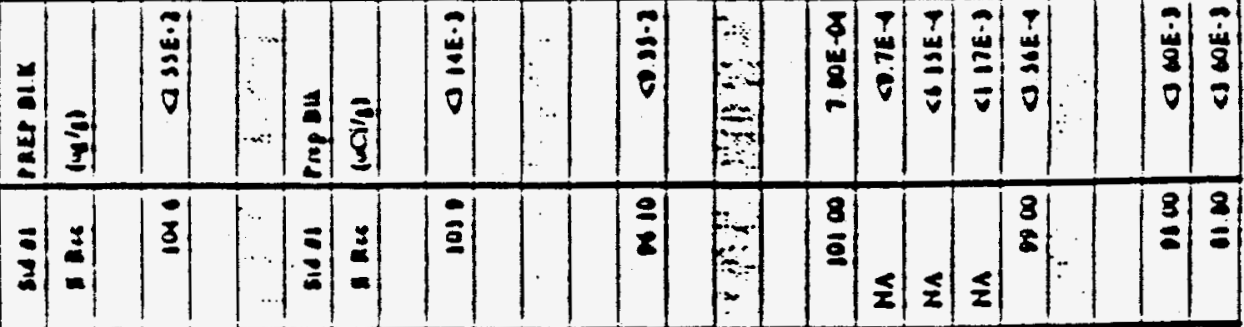

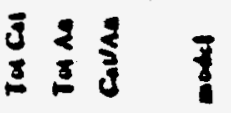

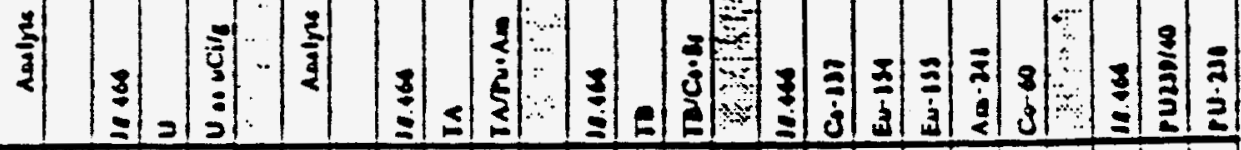

$\overline{0}$
$\overline{0}$
$\overline{0}$
$\overline{1}$
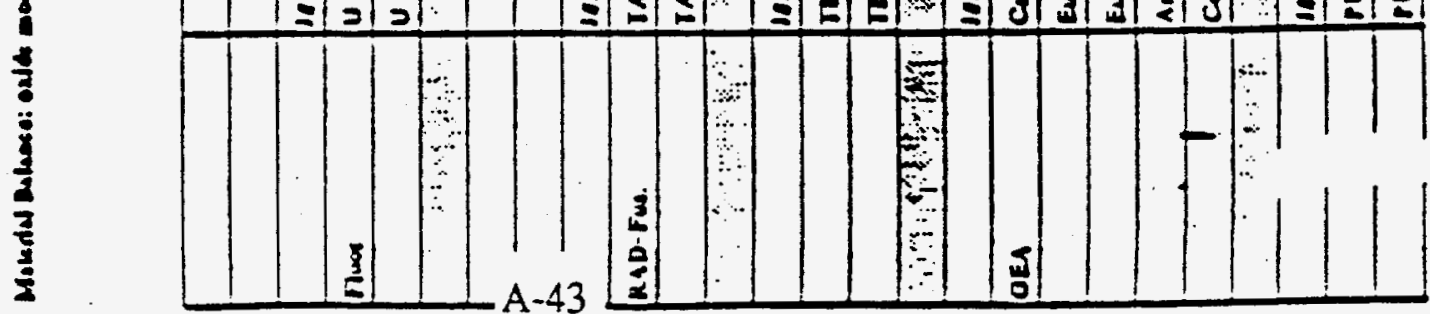
WHC-EP-0806

WHC-SD-WM-DP-024 ADOENDUM 2, REV 0

\begin{tabular}{|c|c|c|c|c|c|c|c|c|c|c|}
\hline \pm & & 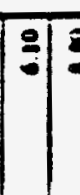 & - & 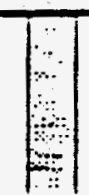 & 8 & 8 & $\therefore$ & & & 1. \\
\hline$\frac{\circ}{2}$ & & a) & $\leq$ & 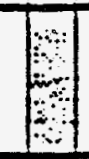 & 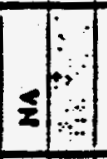 & $\bar{a}$ & 3 & & & $\because$ \\
\hline $\begin{array}{l}\bar{z} \\
\bar{a}\end{array}$ & & \begin{tabular}{|l|}
$\vec{q}$ \\
$\vec{a}$ \\
$\vec{a}$ \\
\end{tabular} & & 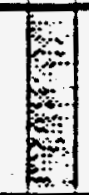 & 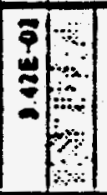 & 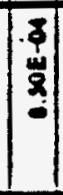 & 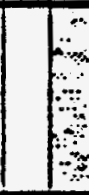 & & & 8 \\
\hline $\begin{array}{l}8 \\
3 \\
3\end{array}$ & & 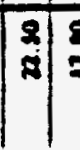 & & $*$ & $=9$ & $\stackrel{8}{=}$ & 8 & 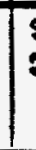 & & $=8$ \\
\hline$\vec{\xi}$ & & \begin{tabular}{|l|l|}
6 \\
$\vdots$
\end{tabular} & $\leq$ & $=$ & 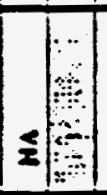 & 3 & 5 & & & $1 \%$ \\
\hline
\end{tabular}

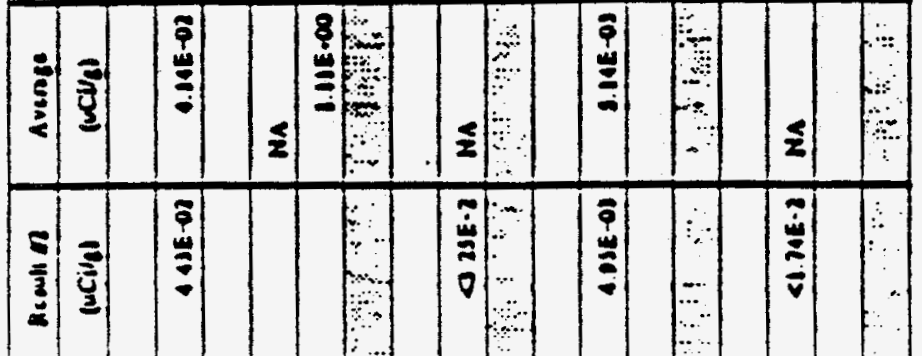

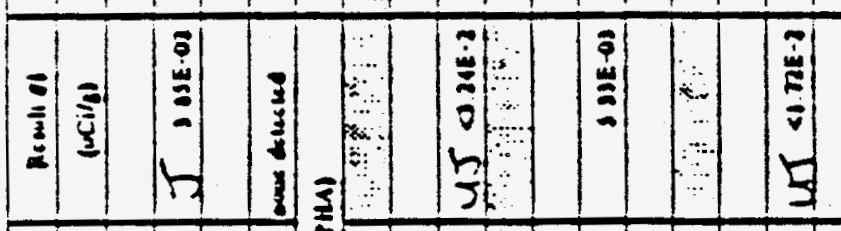

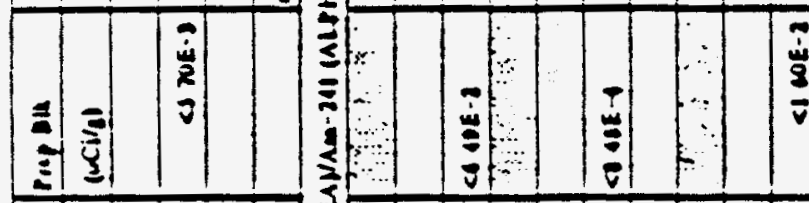

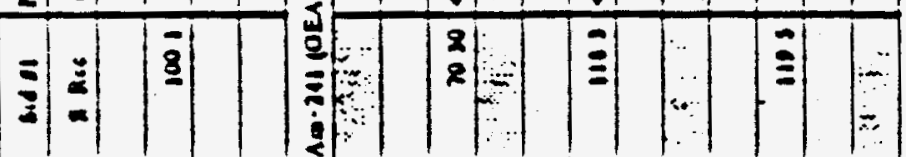

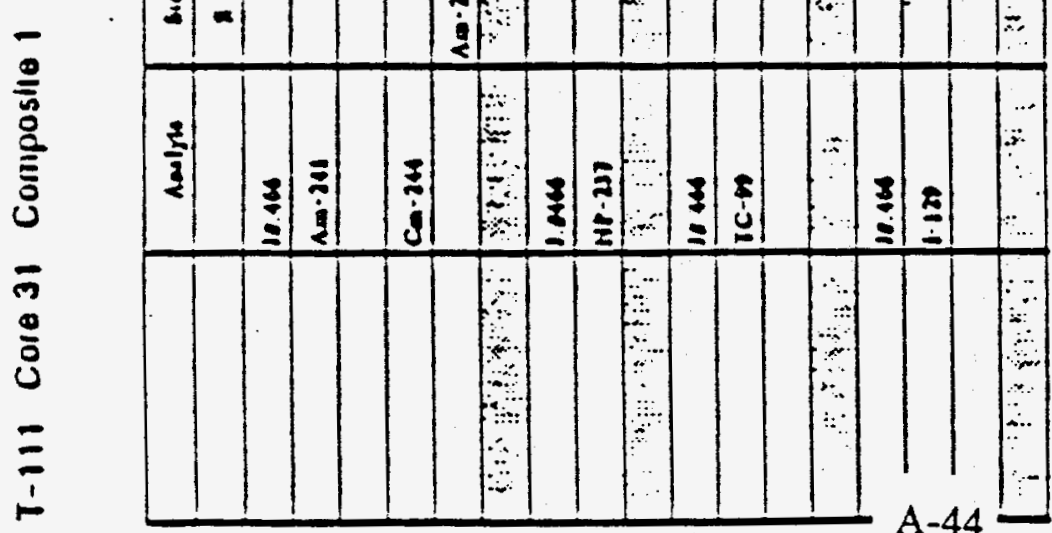


WHC-SD-WM-DP-024 ADDENDUM 2, REV 0

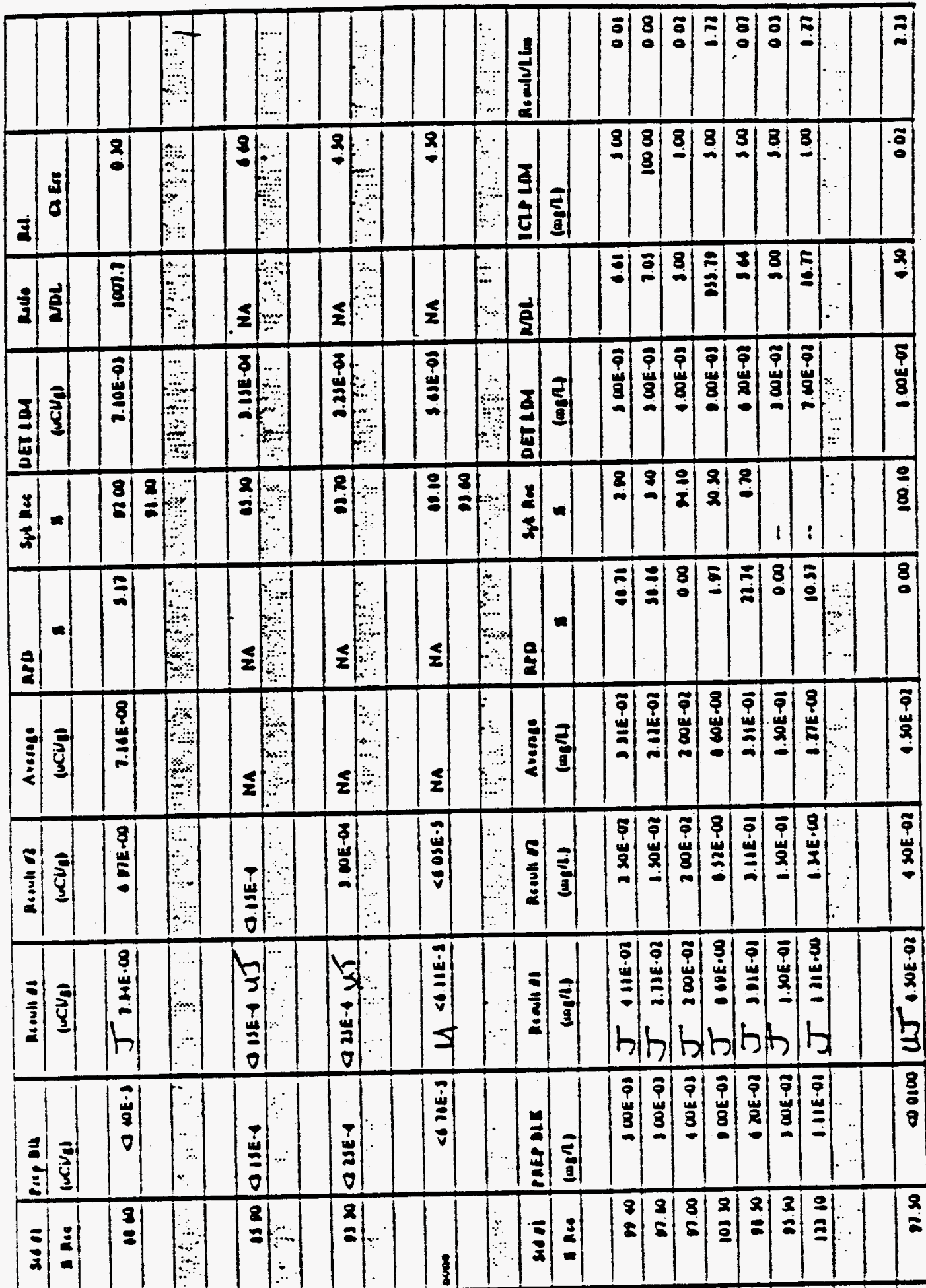

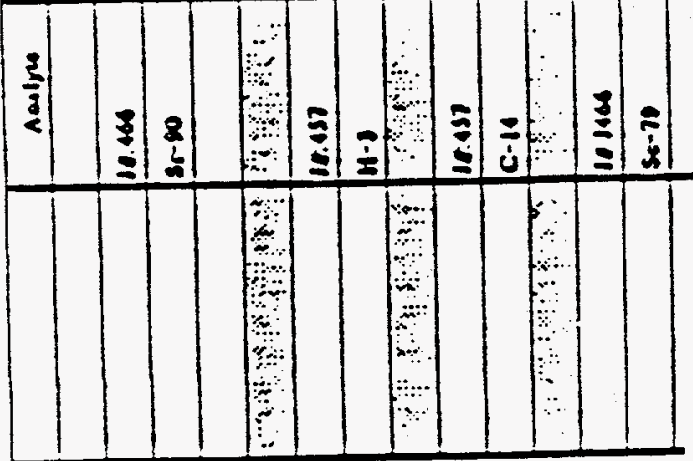




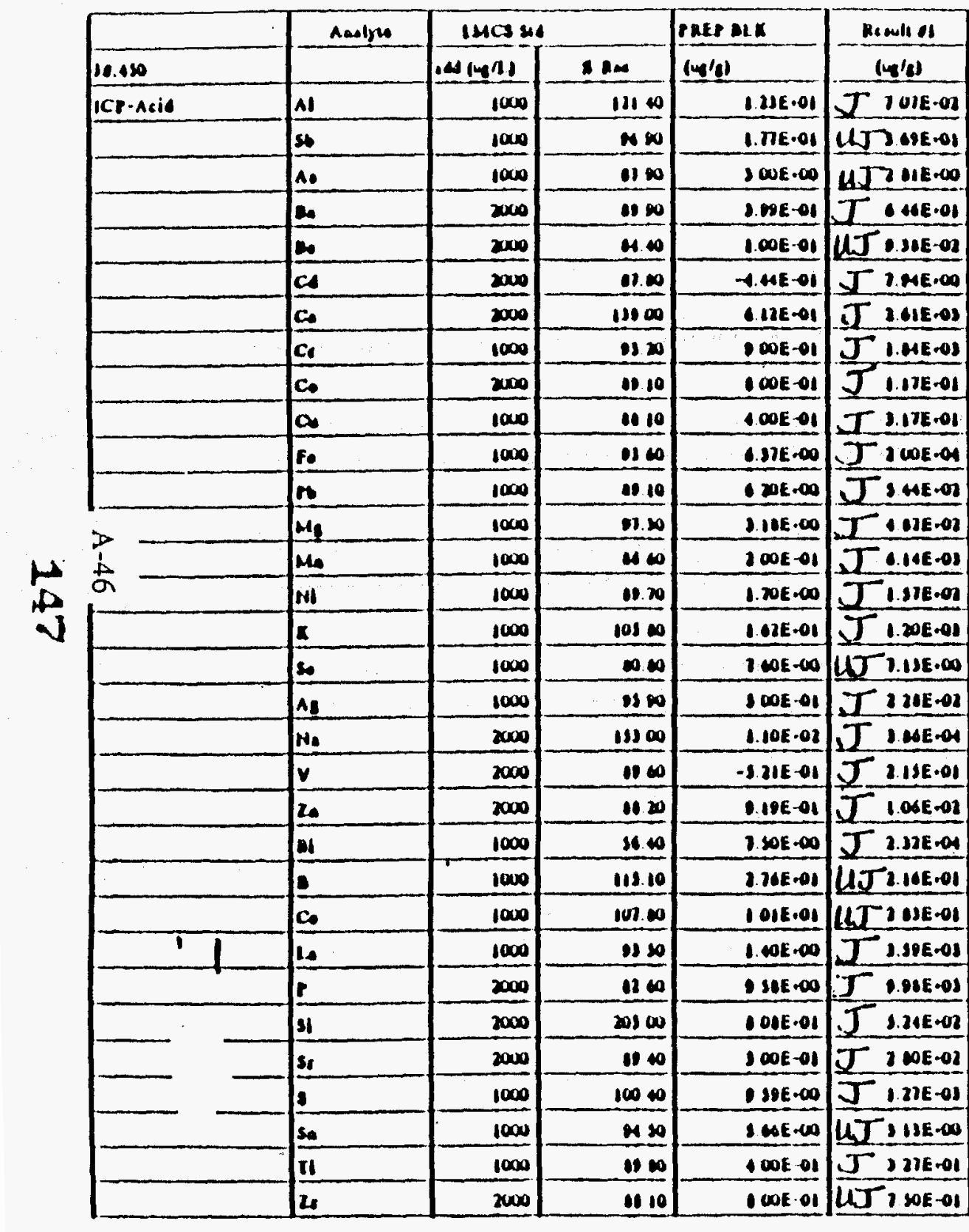

\begin{tabular}{|c|c|}
\hline Asoun nn & Avereget \\
\hline$\left(\mathrm{m}^{\prime} / \mathrm{l}\right)$ & $(x / 4)$ \\
\hline $1.01 E-01$ & 2015E.01 \\
\hline B.UE.01 & jose-01 \\
\hline DO2E.00 & $1.02 E \cdot 00$ \\
\hline C.SIE-OI & $0.00 E-01$ \\
\hline $1.015-01$ & ..73E-Q \\
\hline $1.10 E \cdot \infty$ & D. $\omega 6$ - $-\infty$ \\
\hline $2.48 E-01$ & $2.40 E-03$ \\
\hline 1.00E-OS & D.ME.03 \\
\hline $3.00=-\infty$ & 7.76E.+0 \\
\hline $1.0 \mathrm{me} \cdot 0$ & 1.00E-0I \\
\hline $2015-01$ & $2.00 E .000$ \\
\hline $3.42 E-02$ & D.43E. DO \\
\hline C.7sE-02 & $4.70 E-02$ \\
\hline (111E-0) & $(100.0)$ \\
\hline D.SIENOO & 1.532 .02 \\
\hline 1.21E-03 & 1.21E-0S \\
\hline 1 NENDO & 1.40E.00 \\
\hline 2215.02 & 1.20E-02 \\
\hline $1010-04$ & 1070.04 \\
\hline 2.11E-01 & 2.14E.01 \\
\hline 0.61 Enol & 1.01E-0? \\
\hline 8.13JENOS & 2.JuE.0S \\
\hline $2.83 E \cdot 01$ & 1.HE-OI \\
\hline $2.00 E=01$ & 2.46E-01 \\
\hline BME.03 & $3.02 E .013$ \\
\hline D.ME-OS & OQSE-0) \\
\hline $110 E-0\}$ & S.71E-01 \\
\hline $20 \mathrm{E}-03$ & 200E.01 \\
\hline 1.20E-01 & 1.26E.03 \\
\hline $1.21 E-\infty$ & $2.41 E \cdot 00$ \\
\hline D AE.OI & D.XE.01 \\
\hline $1005-01$ & D.ME-OI \\
\hline
\end{tabular}

\begin{tabular}{|c|c|c|c|}
\hline Ard & $3+.4$ & soine & DETIA \\
\hline 1 & (s)/2) & inese & $(y / 2)$ \\
\hline 0.51 & $11 . \mathrm{N}$ & 11.0 & 2.005 .00 \\
\hline 1.0 & 31.4 & 100.00 & 1. ME-01 \\
\hline 0.10 & 33.4 & 67.00 & 1000.00 \\
\hline 0.10 & 100.0 & 01.20 & S OWE-OI \\
\hline 1.19 & 100.0 & H.10 & 1.00E-01 \\
\hline 201 & $101 n$ & 0.00 & $1.000-01$ \\
\hline 10.80 & 100.0 & +10.6 & 4. $10 E .00$ \\
\hline 0.20 & $11 . \mathrm{m}$ & 0.10 & $0.00 E-01$ \\
\hline 102.20 & 100.0 & 0.0 & $1.00 E-01$ \\
\hline 1204 & 31.04 & 0.00 & $100 \mathrm{E}-01$ \\
\hline $0 . n$ & 11.4 & -600.4 & $1.00 E-\infty 0$ \\
\hline 0.4 & 31.94 & 2000 & C.2OE.CO \\
\hline 1.41 & 210.4 & 13.80 & 100E-01 \\
\hline 008 & IIN & -254.8 & $2000-01$ \\
\hline 0.11 & 81.4 & 4.20 & $1.70 E-\infty 0$ \\
\hline 1.41 & SIN & 10.20 & 1.121 .01 \\
\hline 1.01 & 32.4 &.$\infty$ & 7. COE. . \\
\hline 0.26 & 31.04 & n..00 & $200 E-01$ \\
\hline ‥n & 100.01 & -3138.8 & $3.10 E-00$ \\
\hline 1.08 & 101.01 & $\infty .10$ & S.00E-O1 \\
\hline 0.10 & $100 . .11$ & 1120 & $100 E-01$ \\
\hline 013 & 21.4 & -31100 & $1.50 E-\infty$ \\
\hline 18.73 & 11.4 & 25.00 & $1005-02$ \\
\hline 211 & 23.4 & n.p & 1018.01 \\
\hline 1.20 & 31.94 & -10.60 & $1.00 E \cdot 00$ \\
\hline 0.40 & 107.0 & 483.10 & $1.0 \mathrm{E} \cdot 00$ \\
\hline$\underline{n} \omega$ & 101.01 & 1.0 & 1. $30 \mathrm{E} \cdot 00$ \\
\hline 003 & 101.01 & 11.0 & $100 E-01$ \\
\hline 100 & 31.4 & 110 & $0.20 E-00$ \\
\hline 31.20 & IIN & 01.6 & $1 \cos -\infty$ \\
\hline 2.10 & 1110 & 11.80 & C. COE-OI \\
\hline 110 & 10101 & 00 & - \\
\hline
\end{tabular}

\begin{tabular}{|c|c|c|}
\hline Rosile & en & Hal A \\
\hline NDL & bou & (6/1) \\
\hline 201.58 & & \\
\hline 200 & & \\
\hline $0 \Omega$ & & \\
\hline 21d.12 & & \\
\hline on & & \\
\hline 104 & & \\
\hline $\operatorname{sen} 41$ & 0.11 & $0 . \alpha$ \\
\hline 2046.07 & $\infty$ & on \\
\hline 0.20 & 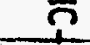 & \\
\hline 19080 & $n$ & \\
\hline 200420 & u & $\Sigma !$ \\
\hline D.s. & & ริ \\
\hline esess do & $\bar{i}$ & $m$ \\
\hline 200111.0 & $\$$ & 1 \\
\hline n.20 & & 品 \\
\hline 10020 & gas & $\sigma$ \\
\hline an & $\underline{m}$ & \\
\hline 433.11 & 号 & \\
\hline 12014.8 & $6 \pi$ & o. or \\
\hline 424 & - & \\
\hline 336.14 & $\boldsymbol{g}$ & \\
\hline 3101.11 & $0 \pi$ & o. os \\
\hline 3004 & & \\
\hline 2.13) & & \\
\hline 2318.32 & 001 & 000 \\
\hline 1716.4 & $0 n$ & 0.01 \\
\hline $202 \pi$ & & 1 \\
\hline 032.73 & & \\
\hline 467.42 & 0.12 & 000 \\
\hline 138 & & \\
\hline ass & & \\
\hline & & \\
\hline
\end{tabular}




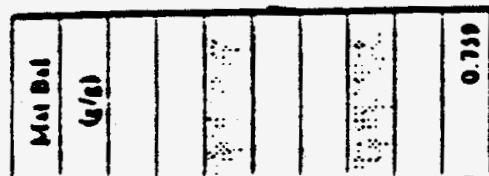

8

$:$

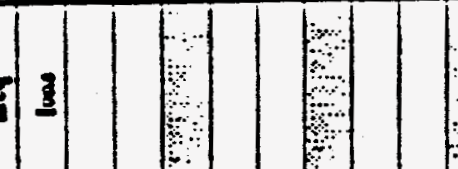

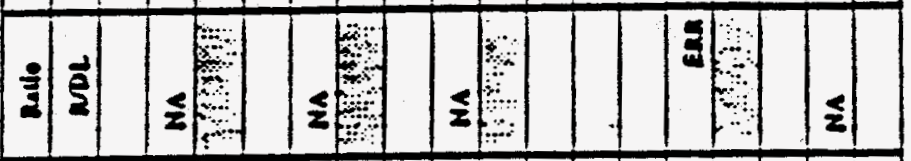

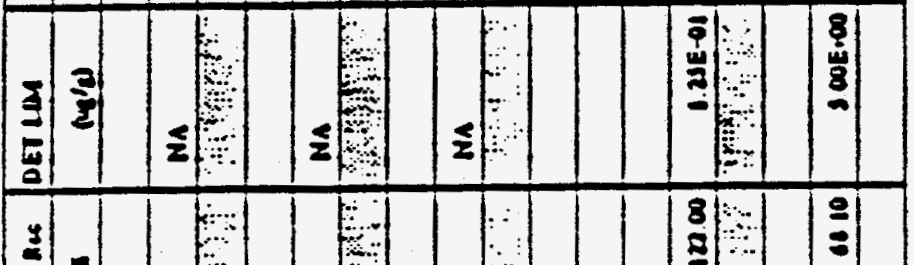

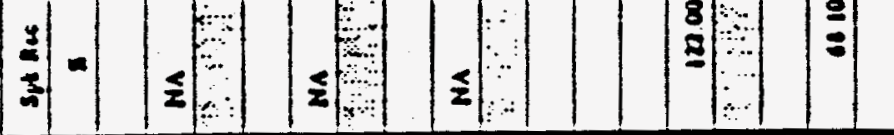

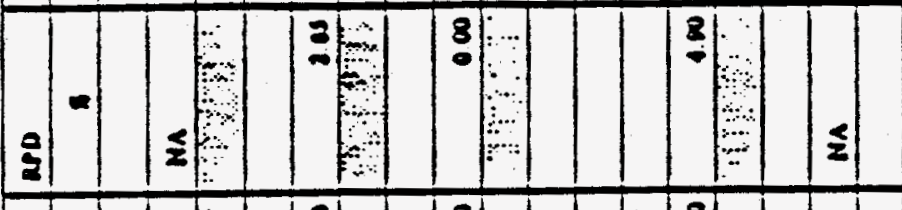

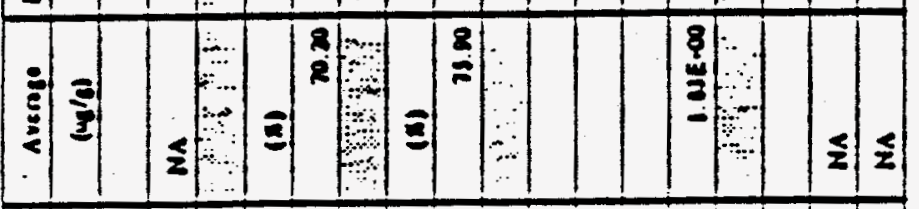

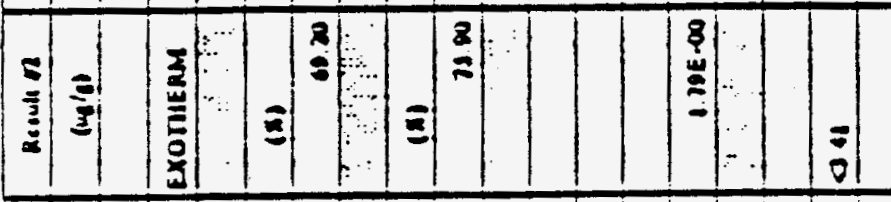

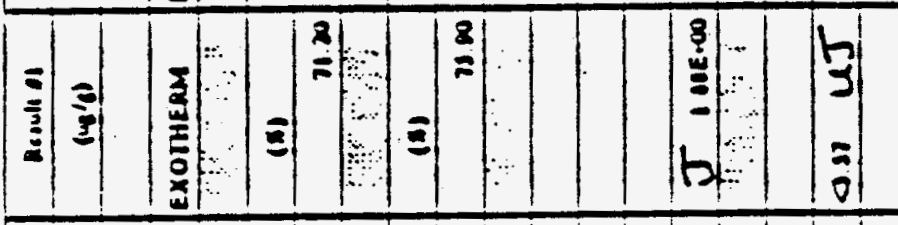

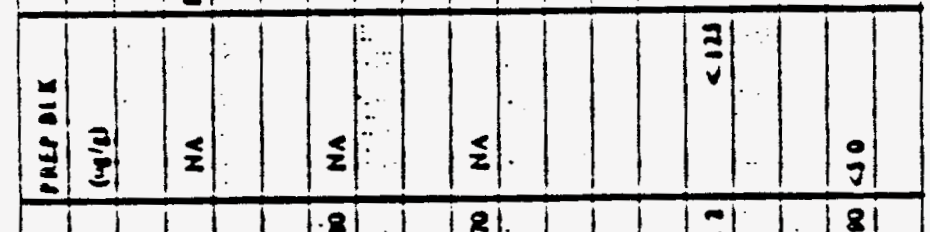

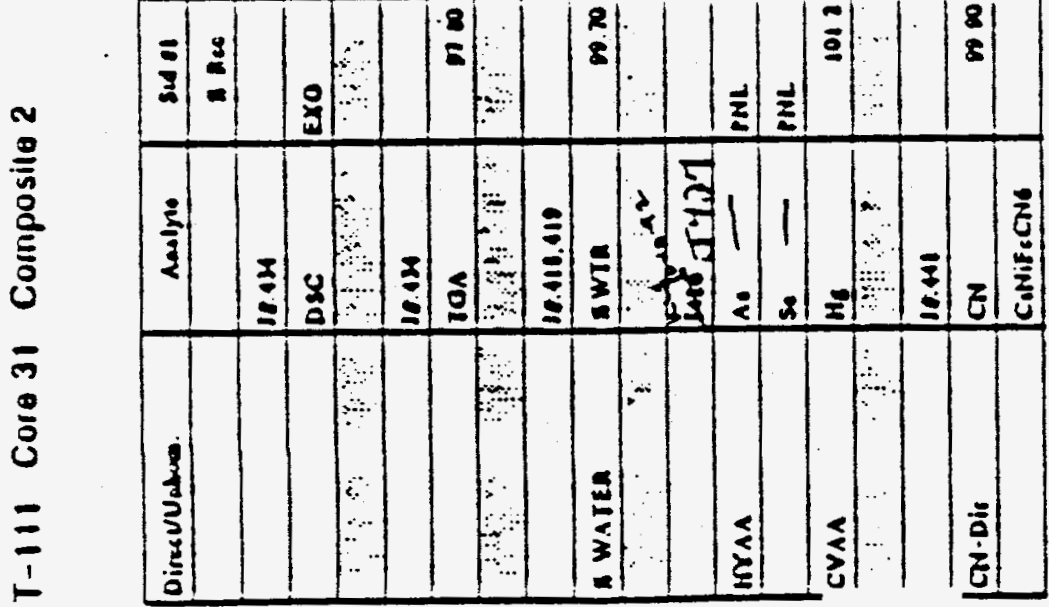




\begin{tabular}{|c|c|c|c|c|c|c|c|c|c|c|c|c|}
\hline \multirow[b]{2}{*}{10.450} & \multirow[t]{2}{*}{ Anolyu } & \multicolumn{2}{|c|}{ IAICS sid } & \multirow{2}{*}{ 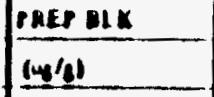 } & \multirow{2}{*}{$\frac{\text { Hecull al }}{\text { (uses) }}$} & \multirow{2}{*}{$\frac{\text { Aroun } n}{\log (s)}$} & \multirow{2}{*}{$\frac{\text { Aosroge }}{\text { (ugles) }}$} & \multirow{2}{*}{ aro } & \multirow{2}{*}{$\frac{(b+10)}{(s a)}$} & \multirow{2}{*}{$\frac{\text { spis. }}{\text { Ines }}$} & \multirow{2}{*}{ 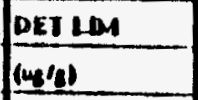 } & \multirow{2}{*}{ nento } \\
\hline & & odsce & 1 Ans & & & & & & & & & \\
\hline ICP-Nolies & Al & Now & 0160 & $200 E \cdot 00$ & $4 J_{1} 102 E \cdot 01$ & 101E.01 & IOIE-O1 & 1.14 & 1250 & $\infty .80$ & $2.40 E+00$ & 10 \\
\hline & st & sow & 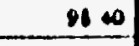 & InE.01 & UJ, nE-OI & $1 . n E-01$ & I.JIE-01 & 0.00 & 1250 & 24.10 & I.TEE-0S & 100 \\
\hline & A. & 2000 & $21 \omega$ & $100 \mathrm{E} \cdot 00$ & $4 L I=00 E \cdot 00$ & $3005 \cdot 00$ & $1.00 E-00$ & $0 \omega$ & 2800 & 420 & $300 E \cdot 00$ & $\$ 00$ \\
\hline & D. & socou & 010 & SOEE-OI & $14 J, 32 E-01$ & $100 E-01$ & 4165.01 & 33.4 & $2 \times 00$ & 10.0 & 2 WOE.01 & 130 \\
\hline$\ldots$ & Bes & 1000 & 수 & 1 wor 01 & UST,00E-0I & $\triangle O A E-02$ & OOEEOL & 0.00 & 2500 & 10 & $1.00 E-01$ & 100 \\
\hline 1 & ca & 10000 & 110 & $100 E-01$ & $U$ J $100 E-01$ & $1000-01$ & $\triangle$ DOE-OS & 000 & 2500 & n1.0. & $1.00 E-01$ & 100 \\
\hline & $c_{0}$ & 10000 & $20 \pi 0$ & $2.10 E-01$ & HTOAOE-O1 & 1.4JE +01 & $\angle 16 E-01$ & 23.13 & 2500 & 01.00 & $4.40 E .00$ & 1400 \\
\hline & $c_{6}$ & 3000 & 1000 & WOE-OI & 1230602 & $230 \mathrm{E}-02$ & $2.20 E-02$ & on & 1250 & $n \infty$ & WOE-01 & 2410 \\
\hline 1 & c. & $100 \times 0$ & $\infty \infty$ & 0 ONE 01 & UJ: SIE.OL & I WUE-0I & $121 t-01$ & 623 & 2860 & n..6 & OWE.01 & 103 \\
\hline$i$ & $\infty$ & x<10 & 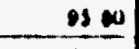 & QWE-OI & $11 \Gamma_{1}$ COE OL & 1 COE-OL & $\triangle$ WOE-OI & 00 & 1250 & 00 & 1 COE-OI & 100 \\
\hline - & re & $x \times 0$ & $\underline{n} \infty$ & $100 \mathrm{k} \cdot 00$ & STIS1E.01 & $1000 \cdot 01$ & $1.00[0.01$ & 1319 & $12 \times 0$ & 0.20 & 1 WOE. WO & 14041 \\
\hline$\therefore$ & $r$ & sow & ov 50 & - XEE - - & $u r \cdot 0,00$ & $\triangle B E-\infty 0$ & 2.03E $\infty$ & 23.10 & 1250 & 11.20 & 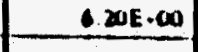 & 1.21 \\
\hline & $M_{1}$ & 8000 & $0 x$ & C COE-OI & $I+21 E \cdot \infty$ & SUE - & DUSE. OO & 14.41 & 1210 & 0.70 & 1.00E -01 & 1310 \\
\hline$P$ & He & xou & $11 \infty$ & $200 \mathrm{E}-01$ & $\Sigma 220 \mathrm{E}-01$ & 2 UIE.01 & 2.11E.01 & 13n & 1250 & 03.20 & $200 E-01$ & 12310 \\
\hline$\stackrel{\phi}{\infty}$ & NI & 2000 & 0.20 & $1.20 \mathrm{E} \cdot 00$ & LI $1.00 \mathrm{E} \cdot 00$ & $1.20 E+\infty$ & $1 . x 0=00$ & 0.00 & 1250 & 10.10 & $1.20 \mathrm{E} \cdot 0$ & 100 \\
\hline & $\kappa$ & $x$ & 10110 & $1.12 E-01$ & $I$ 1.01E-02 & $101 \mathrm{E} \cdot 02$ & 2.01E-02 & 0.08 & 1280 & 0110 & $1.12 E \cdot 01$ & 09.83 \\
\hline 4 & S. & 3000 & 110 & $2.00 E-00$ & HL: $: 04 E-\infty$ & $2.30 E \cdot 00$ & 1016.00 & 10.81 & 1210 & 101.00 & $1.00 E+\infty 0$ & 1.03 \\
\hline 3 & AL & 2000 & 10100 & $100 E-01$ & 4 J $1.07 \varepsilon-\infty$ & $1.26 E+\infty 0$ & $1.10 E+\infty 0$ & 16.42 & 1230 & 102.50 & $100 E-01$ & 2.11 \\
\hline & $M_{0}$ & 10000 & $\infty \infty$ & $2005-01$ & I B.30E-04 & S.SIE.04 & 3.SOE-OS & 0.14 & 2500 & -21.20 & 3 10E.00 & $11 \times 01.6$ \\
\hline & $v$ & Inxo & os 30 & S00E-01 & LT $20 \mathrm{E}-01$ & INE-OI & $2.01 E-01$ & 11.00 & 2500 & 01.0 & $\operatorname{sic}-01$ & 111 \\
\hline & 20 & joxke & 17.0 & .5406 .00 & UT $300 E-01$ & SOOE-01 & $100 \mathrm{k}-01$ & 000 & 2500 & 01.00 & 100E-01 & 1.00 \\
\hline & ui & 2000 & 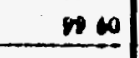 & 2505.00 & I 20SE.02 & 1.766 .01 & $1.918 \cdot 03$ & 1342 & 1250 & 20.00 & $1.50 E \cdot 00$ & 2541 \\
\hline & 2 & saxo & 1120 & 1 WOE.01 & $\tau^{2}, 11 E \cdot \infty$ & $3.21 \mathrm{E} \cdot 00$ & IDE.WO & 412 & 1230 & 6.10 & 6001.01 & 311 \\
\hline & $c_{4}$ & 2000 & $+\infty$ & $101 E \cdot 01$ & $4 T^{\top}: 018.01$ & $101 E+01$ & $1.016-01$ & 00 & 1180 & 90.00 & $1.01 E-01$ & 100 \\
\hline & 10 & 2000 & $\infty 10$ & $140 E \cdot 00$ & I OLSE-00 & $2.69 E \cdot \infty 0$ & $1.326 \cdot 00$ & 18.18 & 1230 & 100.50 & $1.40 E .00$ & $\operatorname{sog}$ \\
\hline$\rightarrow$ & e & 100000 & 93.00 & S.00E.00 & $J^{-}, 11 E \cdot 03$ & $2.01 \mathrm{E} \cdot 03$ & S.08E-03 & 101 & $23 \times 4$ & 02.0 & S. $00 \mathrm{E}: 00$ & 1021 as \\
\hline & si & 10500 & 000 & $1.10 E \cdot \infty$ & I : OOE -02 & S..00E-02 & $300[-01$ & $10 \leftrightarrow 1$ & 2000 & 20.10 & $1.00 E \cdot 00$ & 130.18 \\
\hline & si & 10000 & $\because \cdots$ & 100E-01 & I $220 E \cdot \omega 0$ & $1.21 E \cdot 00$ & $2115 \cdot \infty$ & 1190 & 2500 & now & $1000-01$ & 2.10 \\
\hline & 1 & 1000 & 21.10 & $200 E-\infty$ & I $131 E-03$ & $1.10 E-03$ & 1.20E-03 & 00 & 1230 & 13.0 & $220 \mathrm{E} \cdot 10$ & 444 \\
\hline & sin & $\$ 000$ & 11.20 & $100 E \cdot \omega$ & LI, $60 \mathrm{E} \cdot 00$ & $1605+00$ & 1 NOE. 00 & 000 & 1250 & $01 \infty$ & $1 \cos -\infty$ & 100 \\
\hline & II & $2 \times 0$ & $\| \infty$ & $4 \cos -01$ & $\angle \omega+00 E-01$ & $100 \mathrm{E}-01$ & $\triangle 00 E-01$ & 0.00 & 1250 & 040 & S.00E-01 & 100 \\
\hline & 21 & 10000 & $08 \times$ & $100 E$ O1 & UI T WE-OL & 2 NDE- a & IWE OI & $0 \omega$ & $\because$ & $\cdots$ & $\cdots$ & \\
\hline
\end{tabular}


T-111 Core 31 Composile 2

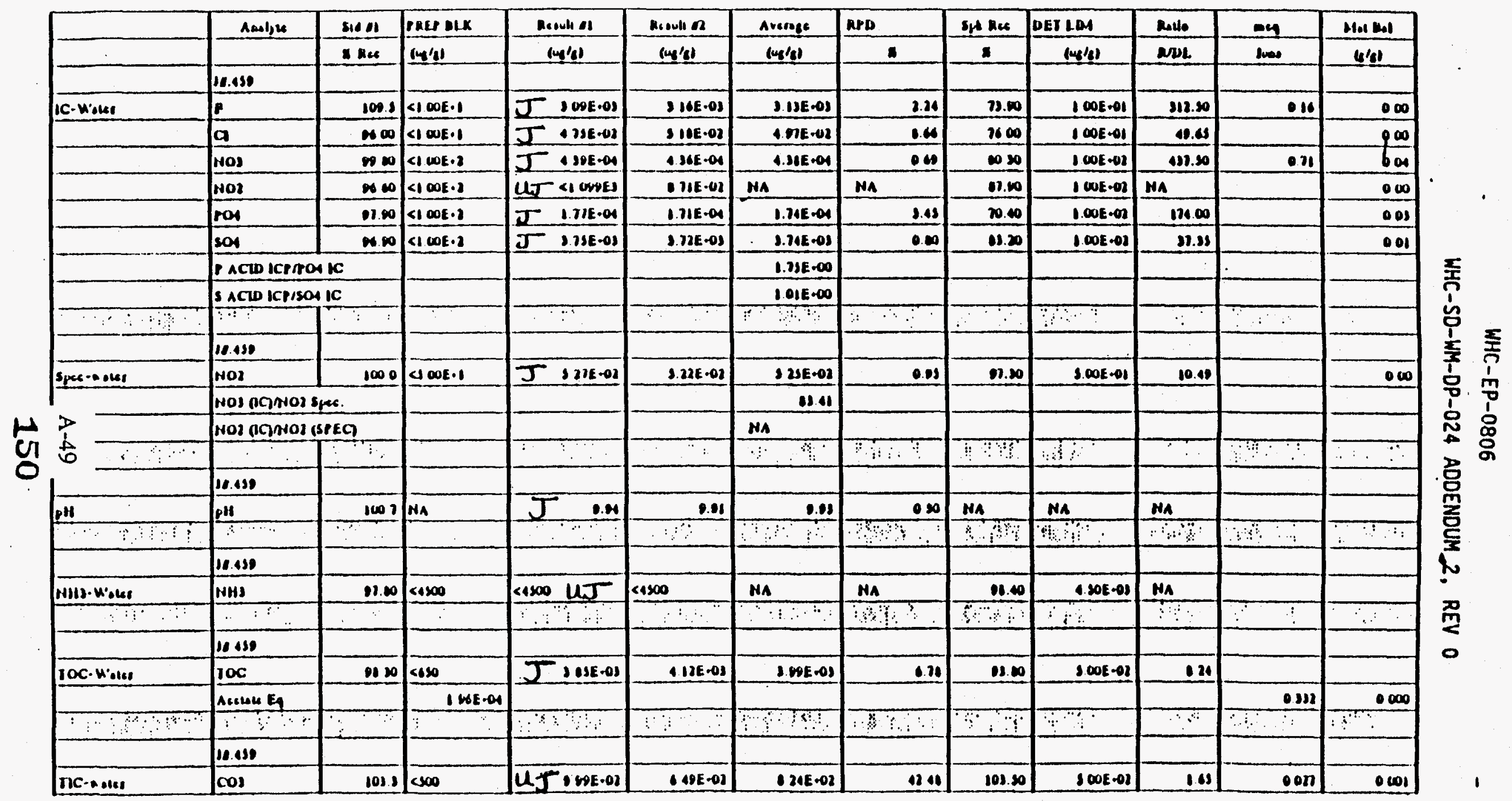


T-111 Core 31 Composile 2

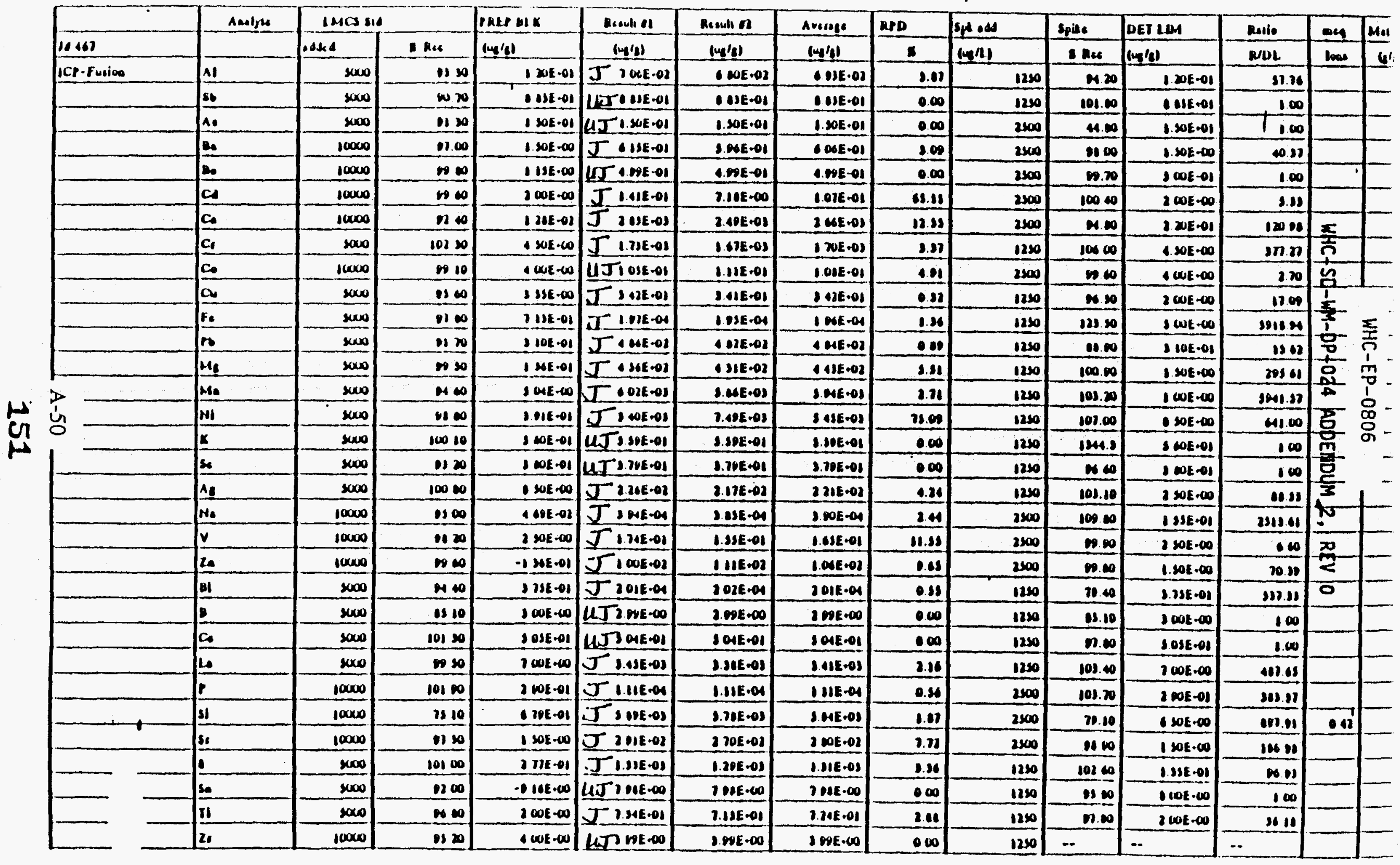




\begin{tabular}{|c|c|c|c|c|c|c|c|c|}
\hline & & & \multicolumn{2}{|c|}{ W'alci ICP/Acid ICP } & \multicolumn{2}{|c|}{ W'suc ICRfFusion ICP } & \multicolumn{2}{|c|}{ Fuidon ICPIAsio ICP } \\
\hline & & & $c_{1}$ & 0.12 & Al & pols & AI & - 00 \\
\hline \multirow[t]{4}{*}{ Cosone B.1 } & Tal cal & 370 & Ma & 000 & c & o1ss & Fo & 0,00 \\
\hline & Tot Aa & 270 & $8 i$ & 200 & Fo & $0 \infty 1$ & $\mathrm{H}_{0}$ & 0.01 \\
\hline & CovAs & 100 & 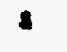 & 0.05 & M & 0.004 & ou & 10.01 \\
\hline & & & No & 0.01 & 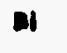 & 0000 & 81 & 12.10 \\
\hline \multirow{3}{*}{\multicolumn{2}{|c|}{ 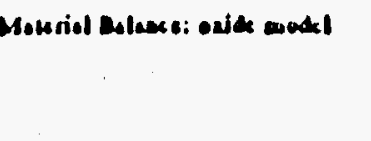 }} & ons & Al & 0.01 & P & 038 & $\boldsymbol{n}$ & 2.10 \\
\hline & & & $x$ & o.s & 81 & 0.006 & P & 0.12 \\
\hline & & & 1 & 0.10 & si & 0.001 & 8 & 1.00 \\
\hline
\end{tabular}

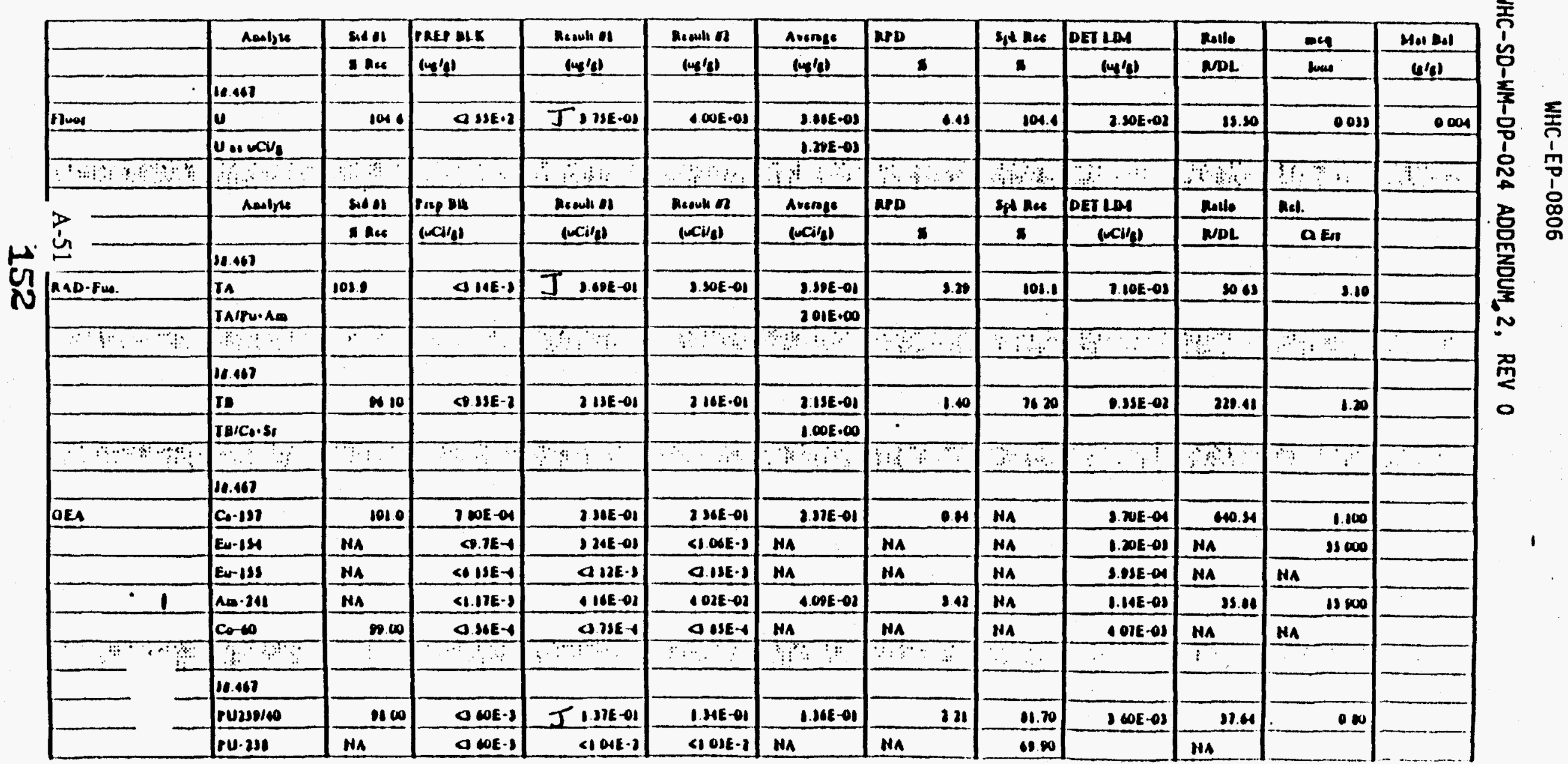




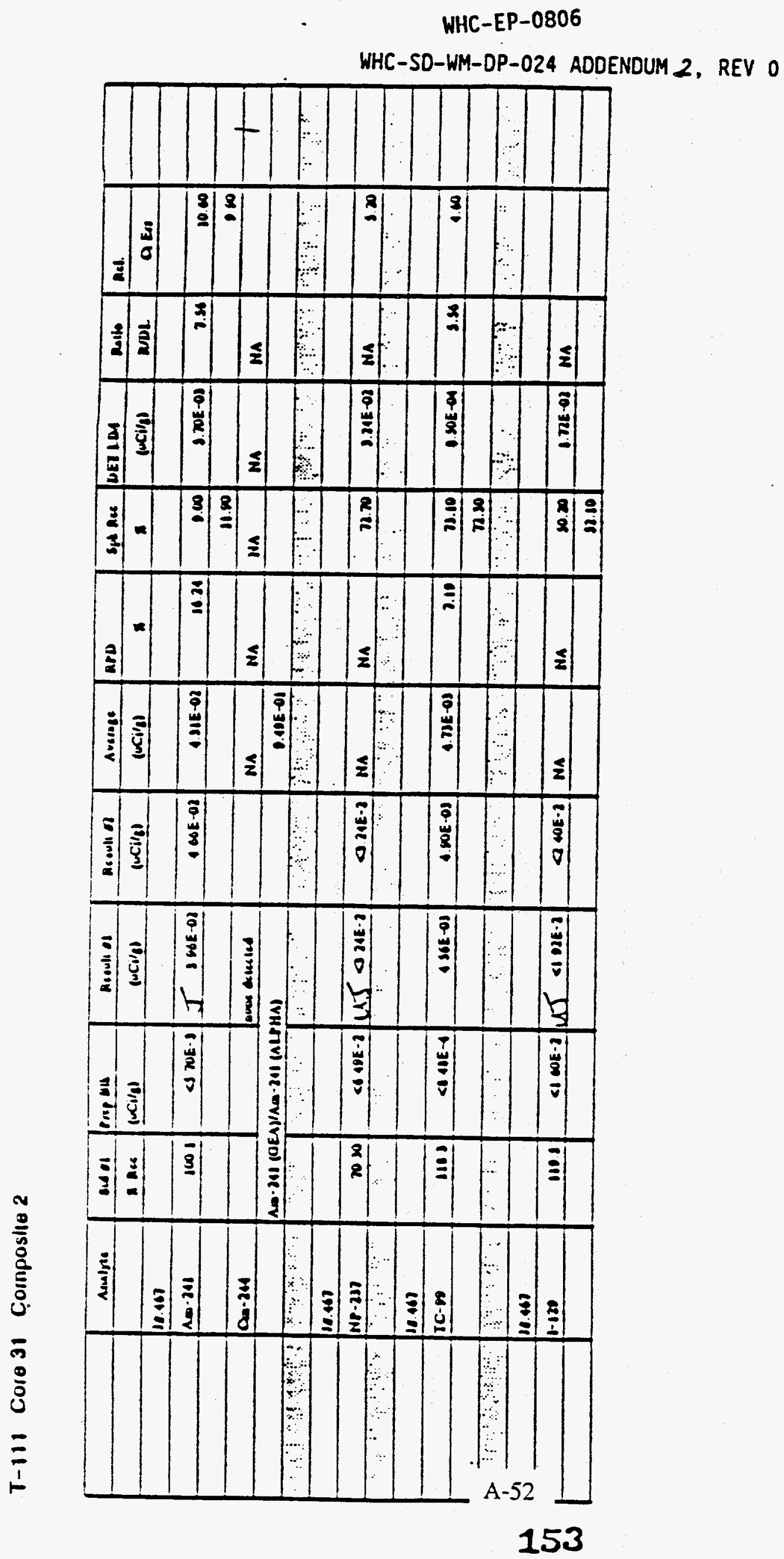


WHC-SD-WM-DP-024 ADDENDUM-2, REV 0

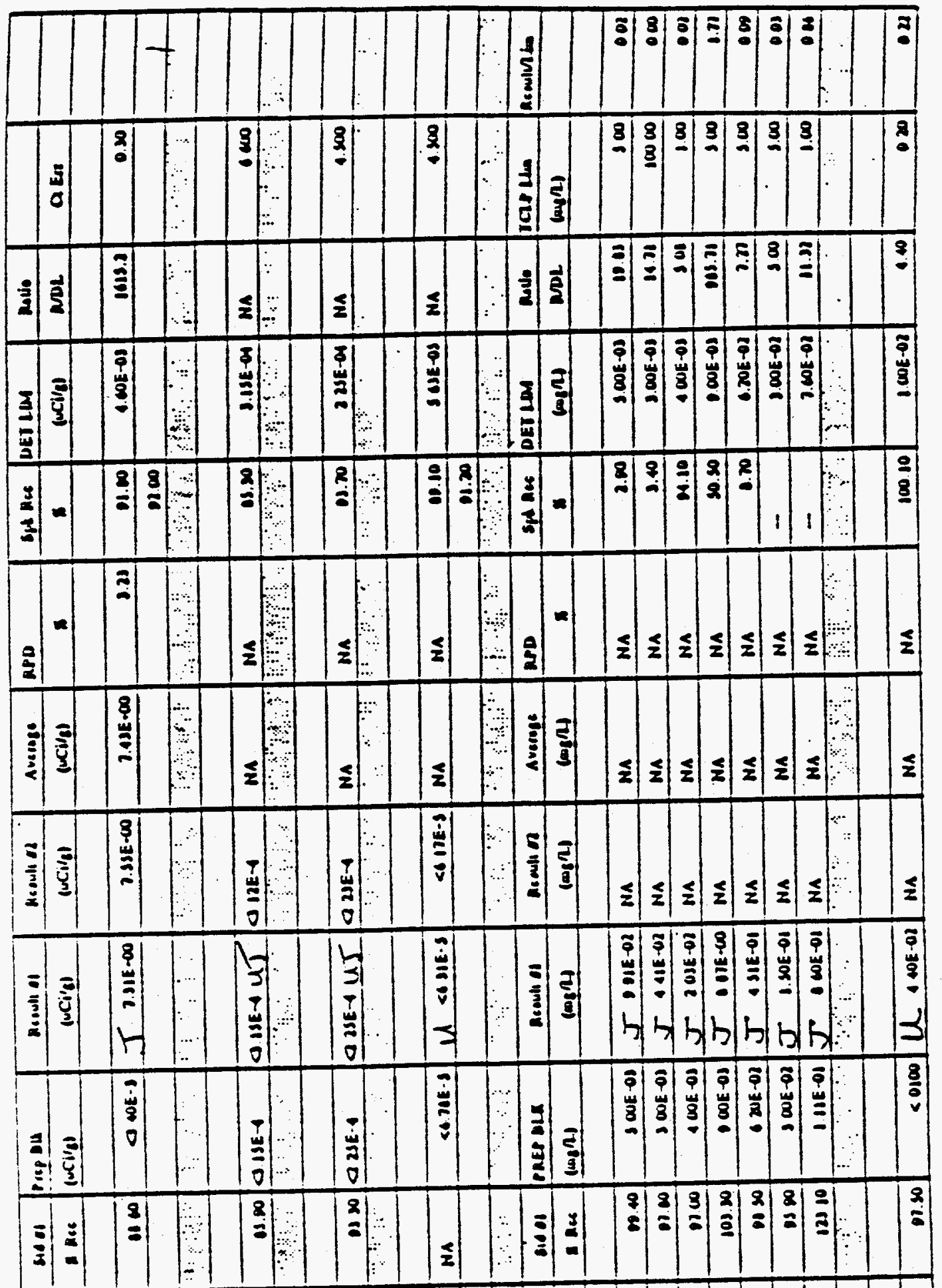

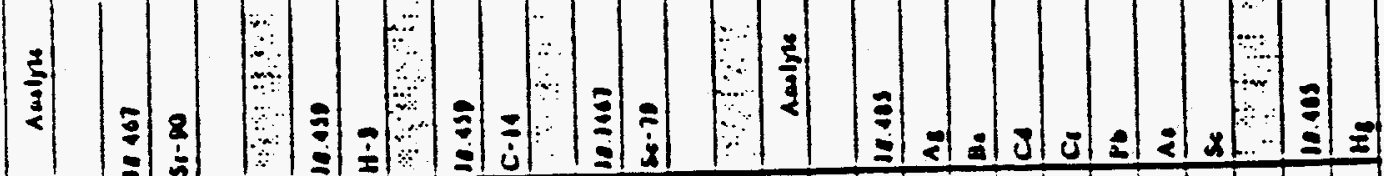

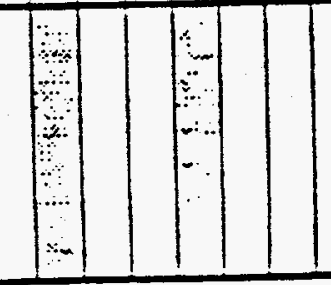

$\left.\right|_{A-53}$

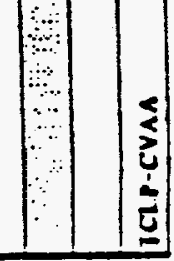


-

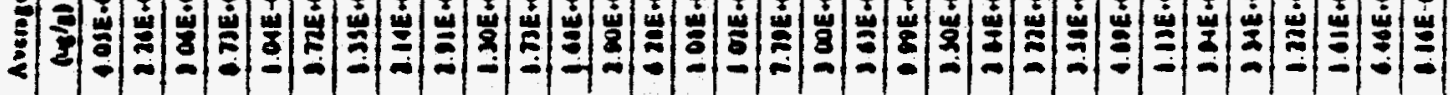

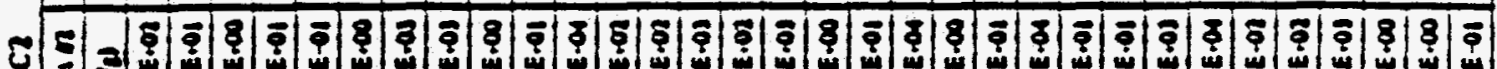

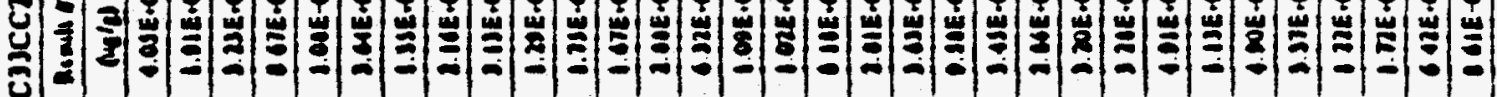
$=12$ (2)

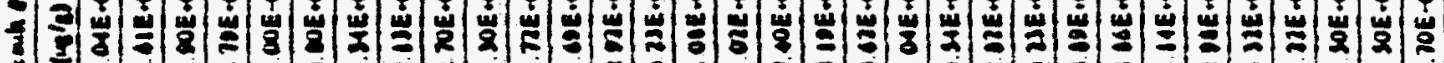

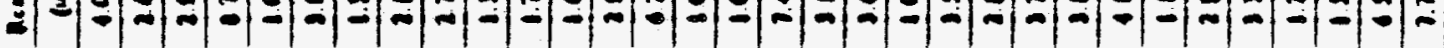

- -

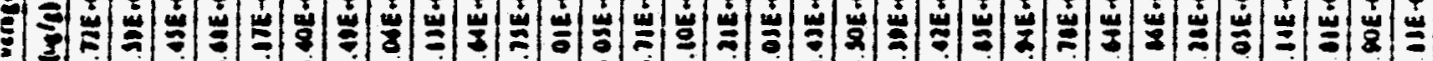

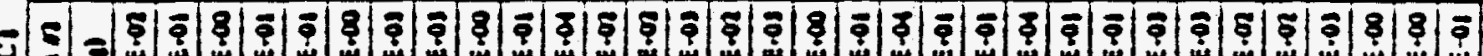

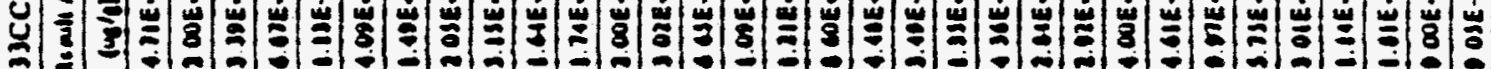
-

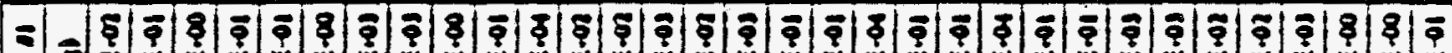

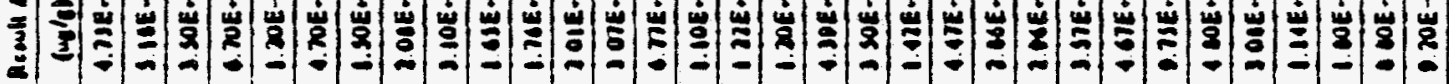
-

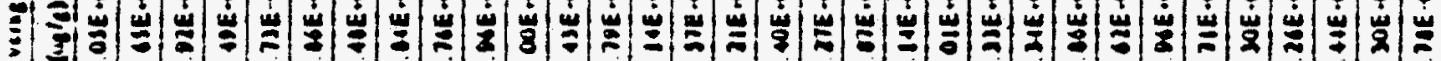

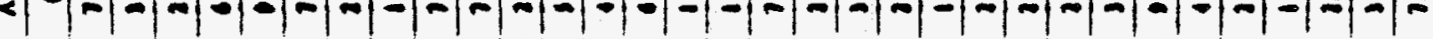
4) 2 -

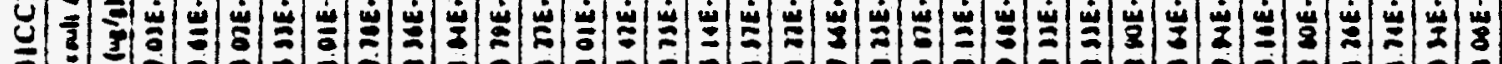

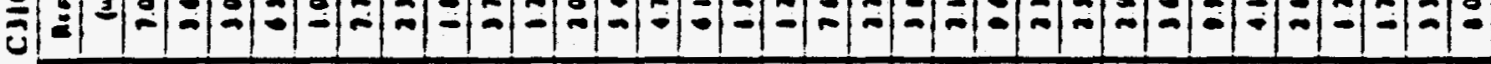

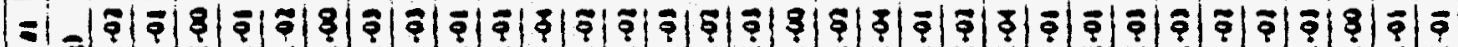

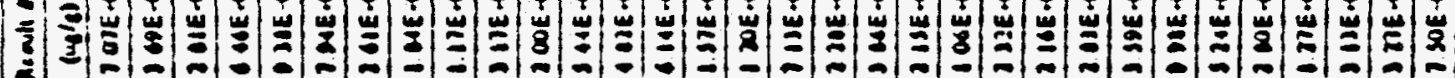

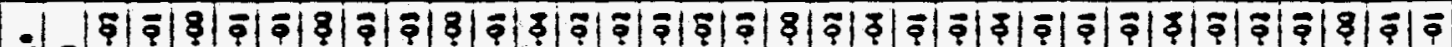

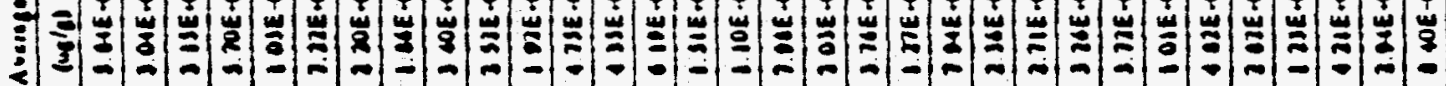

|

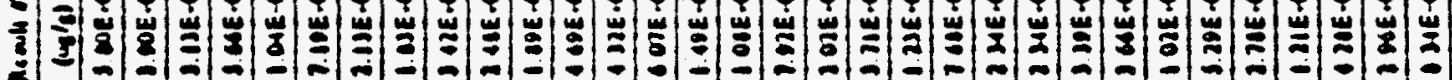
$\overline{4}$

U.

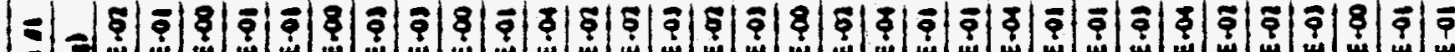

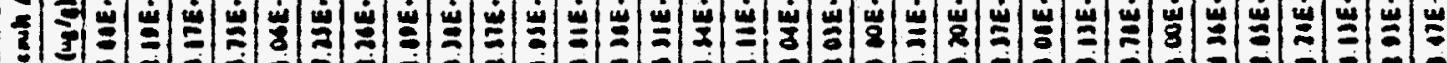

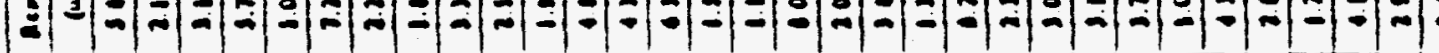

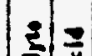
दे

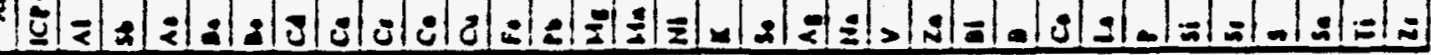




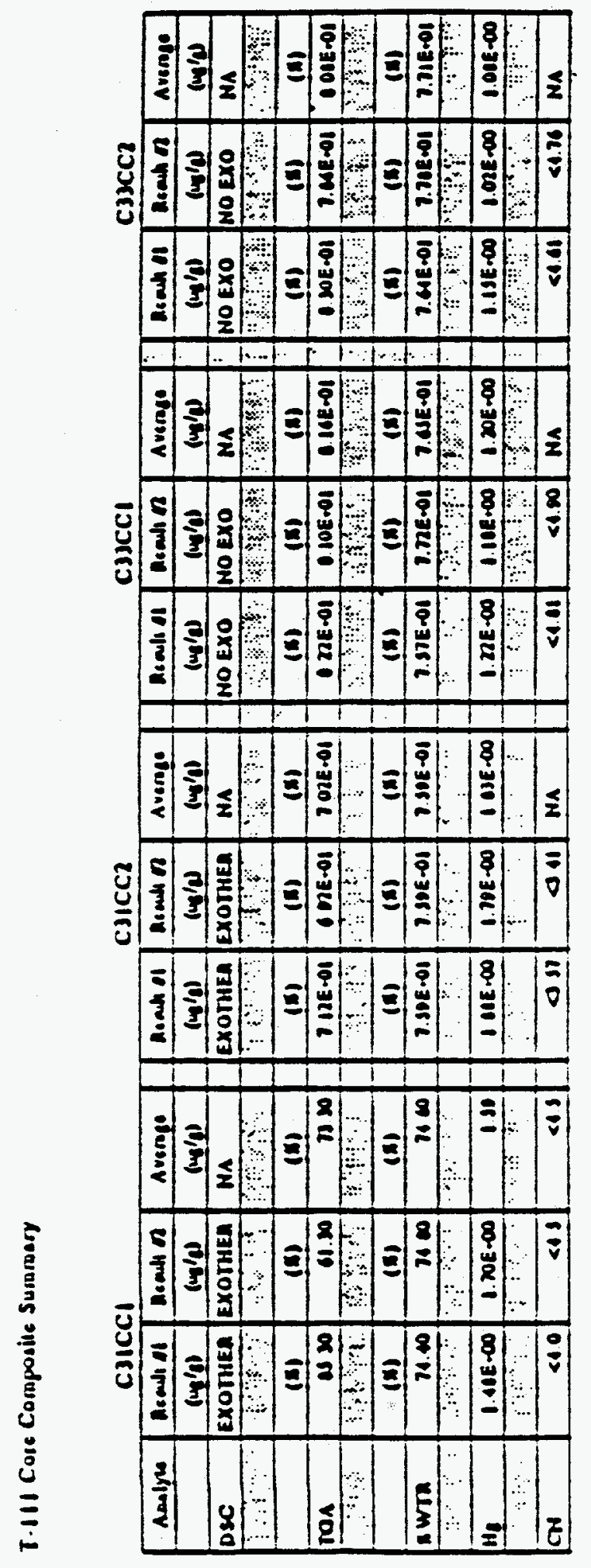




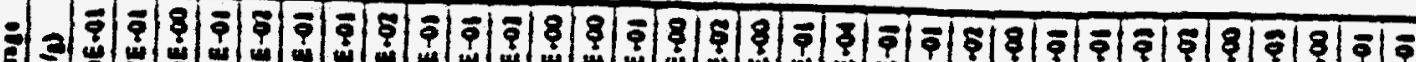

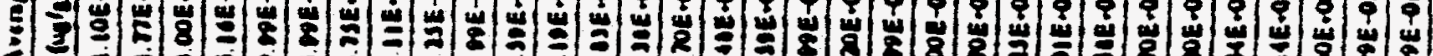

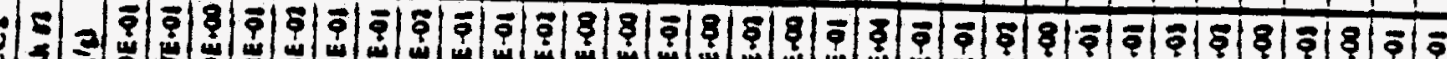

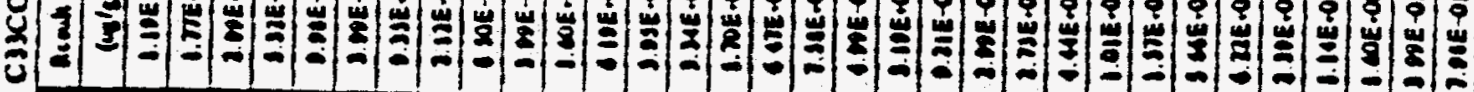

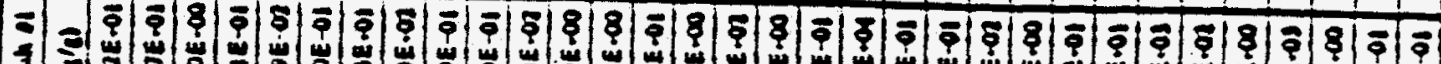
¿

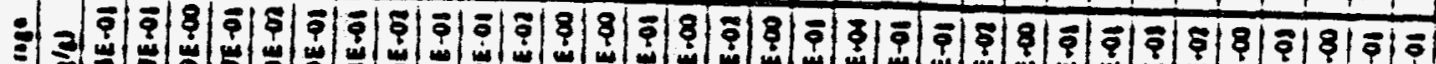

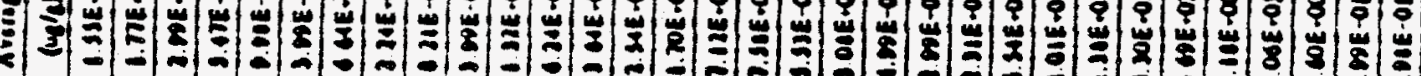

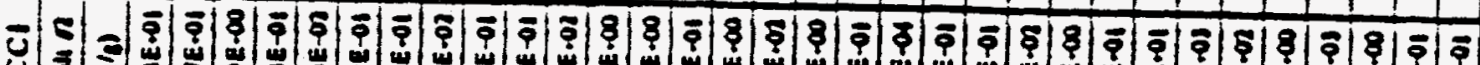

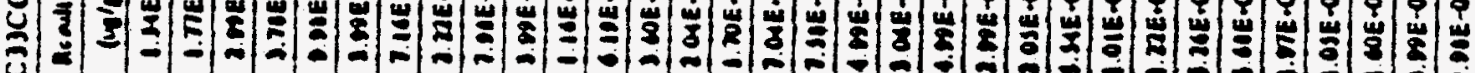

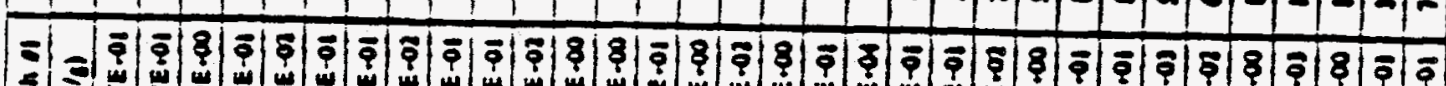

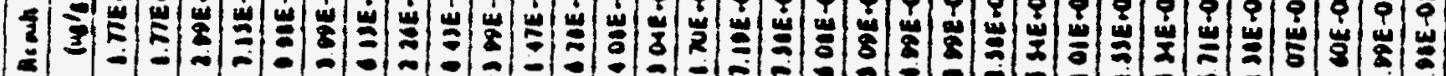

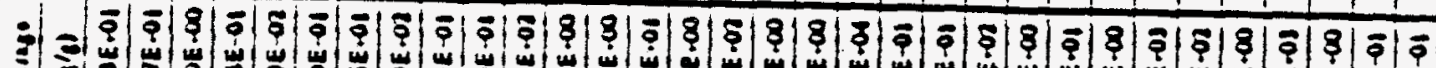

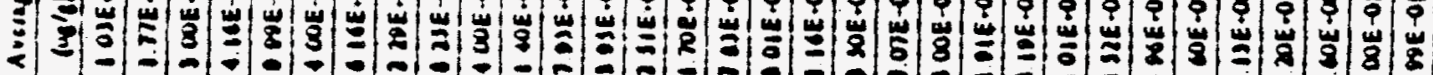
¿

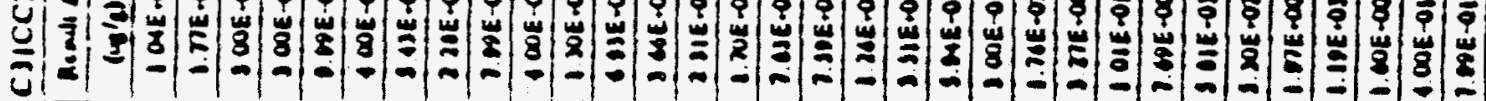

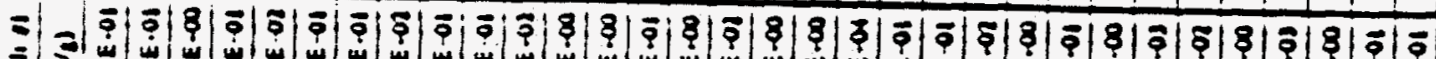

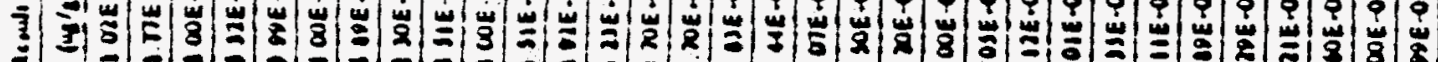

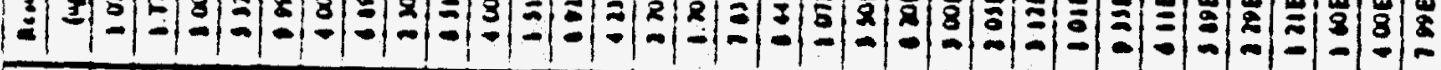

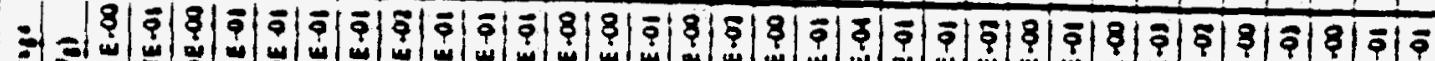

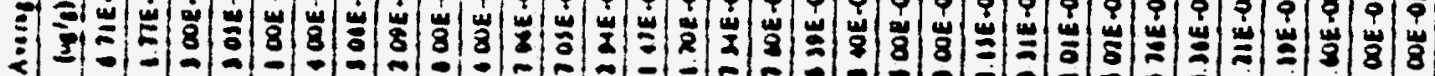

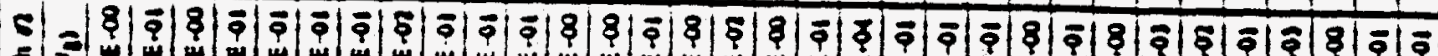

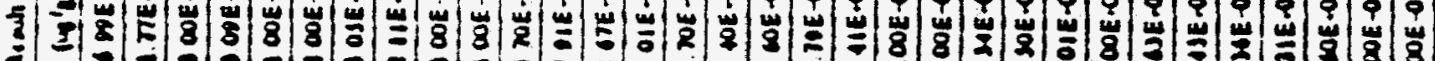
$\overline{\mathrm{u}}$

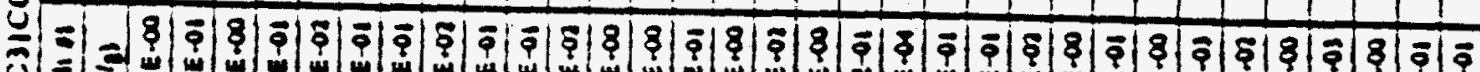

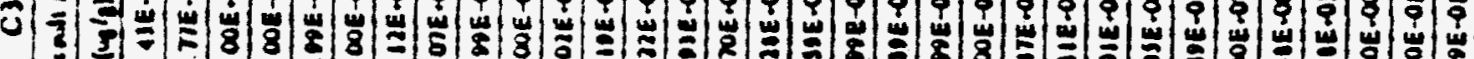

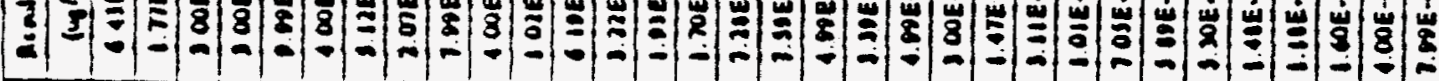

3

aิ

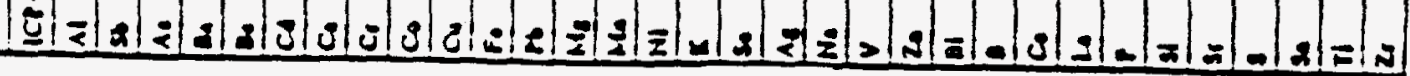
A-56 57 
C)ICCl

cjicc2

csucci

c33cc2

\begin{tabular}{|c|c|c|c|c|c|c|c|c|c|c|c|c|}
\hline \multirow{3}{*}{ Aoslyo } & & \multirow[b]{2}{*}{ - Dank of } & & & \multirow[b]{2}{*}{ Aroun 11} & \\
\hline & and 11 & Dacull n & Arenge: & & Minulin $n$ & Averoge & Aroun ol & Mrous $n$ & Avenge & & Mean n & Avorage \\
\hline & 1410 & $(4 / 1)$ & $\left.(4)^{\prime} d\right)$ & (4e/lo) & $\left(1 x^{\prime} d\right)$ & $($ lus's) & $\left(n y^{\prime}\right)$ & $(4 / 2)$ & $\left.(4)^{\prime}\right)$ & $(n / d)$ & $(40 / 4)$ & $(4) / 4$ \\
\hline F & $10 J E-03$ & $3.14 E-03$ & 3 ODE-OS & DOAE-0I & 1 IGE.03 & 2.13E+03 & $126 E-01$ & 1.47E-03 & 1. . IIE-03 & $1.50 E-01$ & $1.07 E-03$ & -1 \\
\hline a & AE.01 & 02 & NOE.02 & 4.25E-02 & 1.10E-OO & 1.01E.0n & 3026.01 & LEE.01 & 20. & & & \\
\hline Nos & $011 \mathrm{E}-04$ & on & 1.43E.04 & 1. BOE-ON & 1 MEEAT & 4101 & SUIE-OS & $0.206-01$ & 0.005 .01 & 4.03E.04 & a4 & \\
\hline 102 & 1.0008 & $<1.10 E$ & $\mathrm{NA}$ & $\angle 1000[1]$ & ene-0n & MA & $A E-01$ & $E-0$ & -02 & TOSE-On & $7.50 E-00$ & $7.021 \cdot-09$ \\
\hline rat & TE.01 & 1.54E.04 & $162 \mathrm{e}-04$ & nE.04 & 1.11E.04 & 1 & E-04 & E.01 & & & & 04 \\
\hline 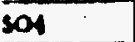 & & 1 & $100-03$ & $1.115 \cdot 03$ & InE-0\} & 01 & E.03 & .03 & & 03 & & \\
\hline @ & Whis & 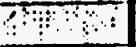 & 3 & $\therefore$ & 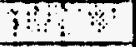 & & $1 \div$ & 796 & $8 \%$ & $\infty$ & 7\%+1:! & 8 \\
\hline 402 & OSSE-OR & +01 & -0 & $2 \pi E \cdot 02$ & $112 E \cdot 02$ & $125 E \cdot 0$ & OAE.M & ent:-02 & $E-9$ & $E-01$ & & $-\infty$ \\
\hline- & $\therefore: \therefore \%$ & & $7:$ & $\because$ & & $\ddot{\because} \quad \therefore$ & & $\because$ & (3:!: & & $3+1$ & $\therefore$ \\
\hline$H$ & $100 E-01$ & 1 ODE & 1.028 .01 & DAE-O & 0.01E-00 & $0.01 E-00$ & $1.00 \varepsilon-01$ & $101 E-01$ & $1.00 E-01$ & OUENOO & 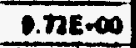 & D.mE- \\
\hline $.7:$ & 1! & 72 & & $\because \because \vdots \vdots$ & $\therefore 9$ & $\because \div$ & $\because$ & $5 x$ & $4:$ & 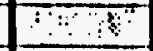 & 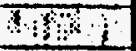 & : \\
\hline MMS & $<1300$ & $<1300$ & MA & $<1800$ & 41500 & $M A$ & $<4500$ & $<1800$ & 84 & 54500 & $\cos 4$ & $\mathrm{MA}$ \\
\hline$\because \because$ & 81 & $\because \because$ & $\because: \vdots$ & $\because$ & $0 \vdots$ & & $8 \div$ & $\because$ & 19 & $8 \div 4$ & Phit:? & $\% \cdot \square$ \\
\hline 10c & $1608-03$ & $30 E+01$ & $140 E-01$ & $0015-01$ & $4.136-01$ & $300 E-01$ & $200 E-01$ & $2.00 E-01$ & $2008+01$ & $100 E-01$ & $1.005 \cdot 03$ & $300 E-01$ \\
\hline & & $\cdot 4$ & & & ?:? & $\because$ & & $\because \div$ & 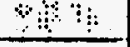 & & : & \\
\hline & $6 \operatorname{soc}-\infty$ & $\triangle D E \cdot 2$ & NA & 1 ME-02 & Q USE.ON & $024 E-02$ & 0 QUE-OS & $1.40 E-02$ & 1 UE 0 & $1.00 E \cdot 0$ & 0.105 .03 & D.SOE-On \\
\hline
\end{tabular}

$>$

ù

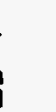


WHC-EP-0806

WHC-SD-WM-DP-024 ADDENDUM 2, REV 0

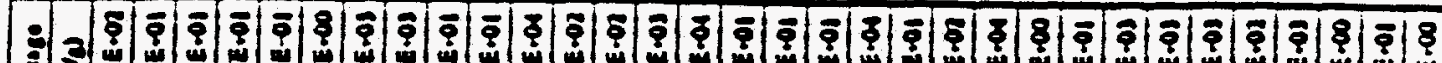

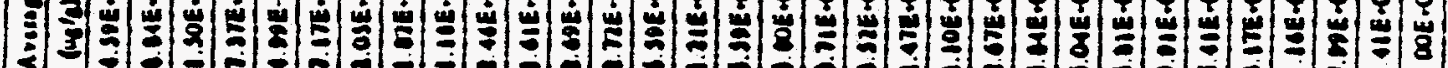

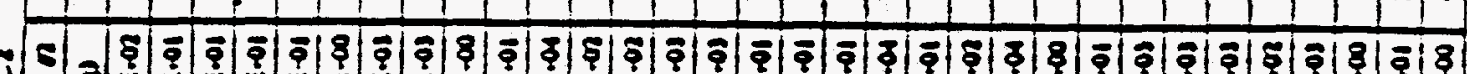

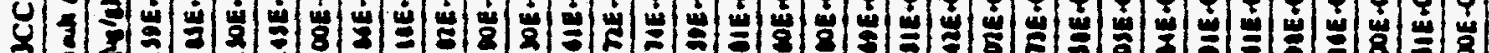
3)

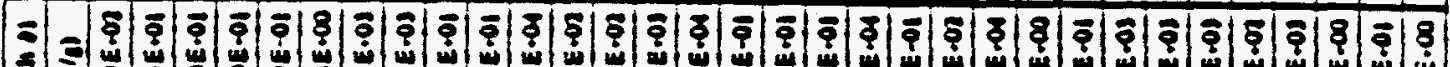

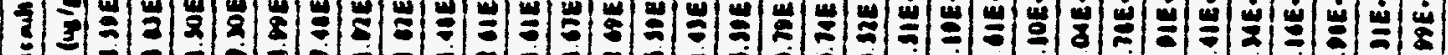

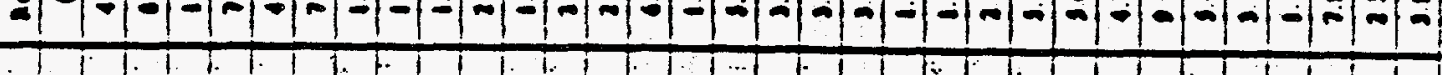

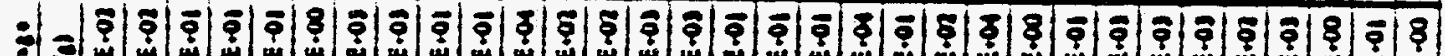
之

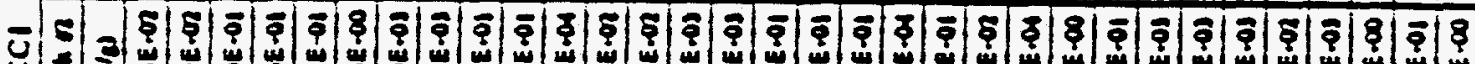

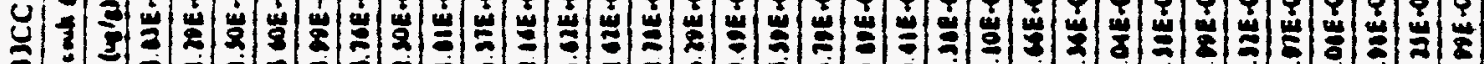

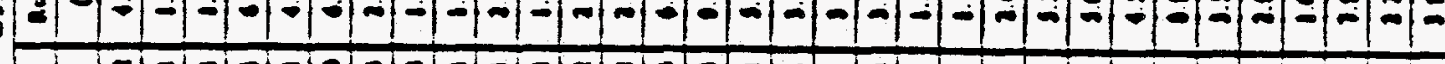

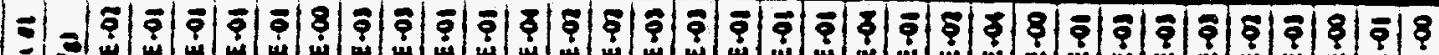

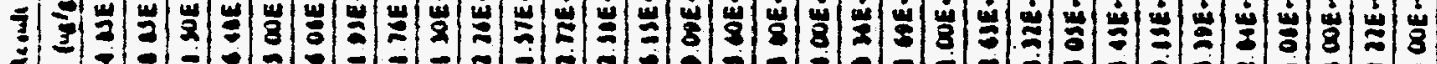

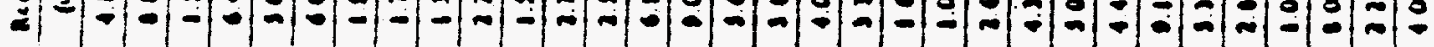

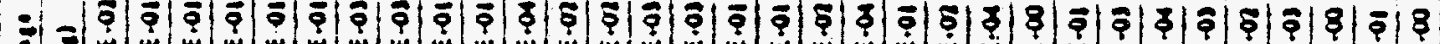
之.

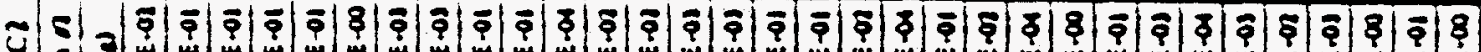

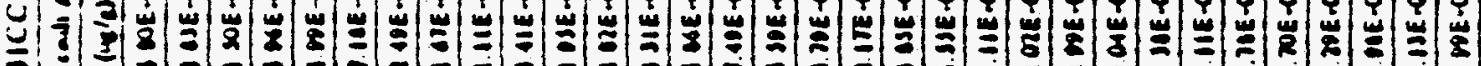

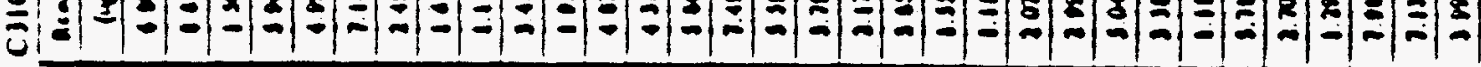

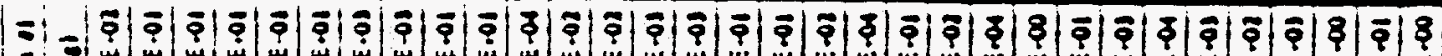

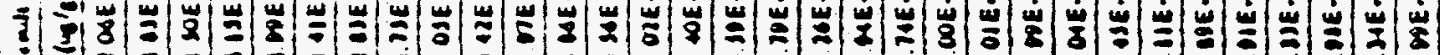

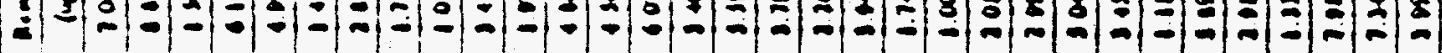

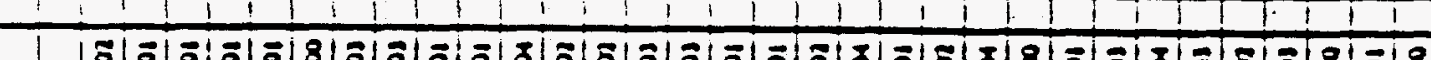

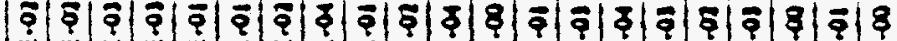

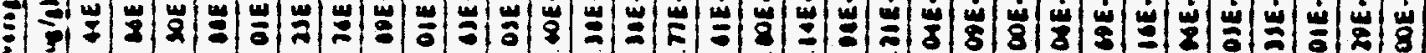

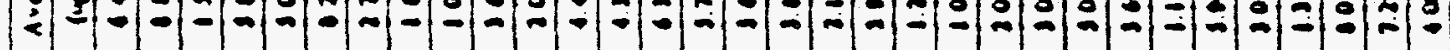

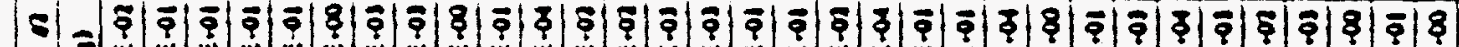

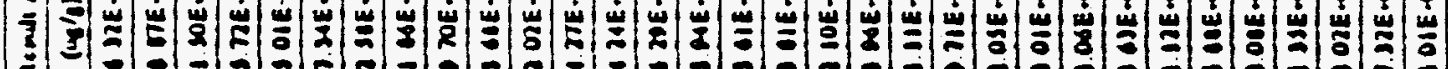

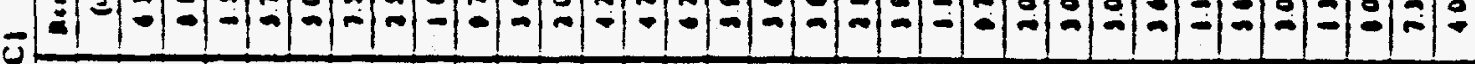

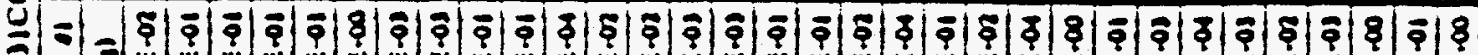

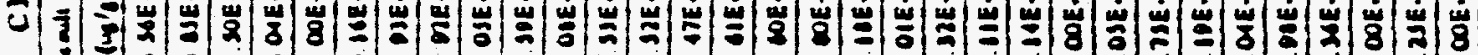

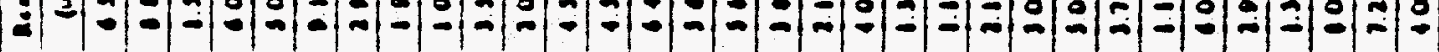
3.8 象

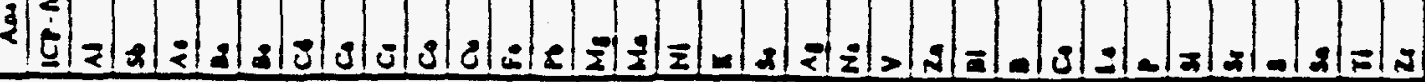


CuICCI

\begin{tabular}{|c|c|c|c|c|c|c|}
\hline & \\
\hline Asolpon & Rouli II & Acalln & Averefe & Acoull II & Homenn & Avoroge \\
\hline & $(\log / 3)$ & $(4019)$ & $\left(y^{\prime} / 6\right)$ & $\mid u^{\prime} \underline{\underline{L}}$ & $(m / a)$ & $\left(4 y^{\prime}\right)$ \\
\hline u & $121 E-03$ & $2(1 \in E, 0)$ & $210 E .03$ & IJE-03 & A $\operatorname{COE}-0$ ) & I BAE-OS \\
\hline$U_{\text {ou wCV }}$ & & & $1.24 E-01$ & & & 129001 \\
\hline 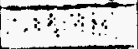 & गैas & की० & 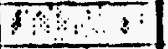 & 1 & 8 & $\because$ \\
\hline Aaslpho & Reoun 0 & Remun $n$ & Ansoroge & Roanh oI & Romun $n$ & Averiogs \\
\hline & $\left(\mu V_{D}\right)$ & (uciva) & $\left(\mu v_{1}\right)$ & $\left(x u_{0}\right)$ & Kivs & $\left(\mu \subset v_{Q}\right)$ \\
\hline$\underline{I A}$ & S SUE-OI & ISPE-01 & B.S1E-O1 & 100 OI & $200-01$ & DSOE-OI \\
\hline InMPUNA & & & $200 E+\infty$ & & & $201 E-\infty$ \\
\hline & $8 \%$ & 3 & & & 15 & 3: \\
\hline 18 & $207 E-01$ & $200 E-01$ & 104E-O1 & 2IIE.01 & I I 16E.01 & 2.1SE-OI \\
\hline Iece.86 & & & DQNE-O1 & & & $1.00 E-00$ \\
\hline$\because$ & 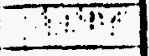 & 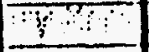 & $\therefore$ & & 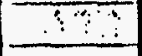 & $\because$ \\
\hline$c 0-137$ & $2.11 E-01$ & $2.12 E-01$ & 211E-O & $2 J 1 E$ OI & $2360-01$ & $30 \mathrm{E}-01$ \\
\hline EN-1S & $1018-01$ & $100 E-03$ & $100 E-03$ & J]16.03 & SIOSE- 1 & $M A$ \\
\hline$E n-131$ & $0000-2$ & Q01E-3 & $\mathrm{MA}$ & Q12E-1 & Q112E-1 & $\mathrm{NA}$ \\
\hline $10-211$ & $100-2$ & $4 m E-02$ & 1.10E-D? & $1106-2$ & $4.018-9$ & $100 E-9$ \\
\hline$c_{0}-\infty$ & Q.10E-1 & $C 12 U E-1$ & $\mathrm{HA}$ & QUSE-4 & Q NSE-A & Mn \\
\hline 8 & $4: 9$ & & $\square^{\circ}$ & & & \\
\hline 10230100 & I.41E-01 & IIIE-OI & $1.30 E-01$ & 1.10E-01 & 1.ME-OI & 1 ME-01 \\
\hline pu-230 & CI GTE-3 & $\leq 1.04 E-2$ & $\mathrm{MA}$ & SOAE-2 & $C 1$ OSE- & NA \\
\hline मा & 10 & 3 & ? & & $19 \%$ & \\
\hline $10-21 !$ & D. LSE-02 & $1015-02$ & 1.14E-02 & 1 ME 02 & 1 ME - OI & $131 E-02$ \\
\hline Aa-2111 & $A / \sqrt{A}=0-2416$ & ptapl & DIIE-W & & & $100 E-01$ \\
\hline$\therefore \because \vdots$ & 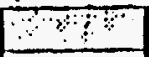 & in & 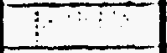 & & $\because$ & $\because$ \\
\hline$\overline{c m-2 H}$ & 0000 dicosk & & & $000 \times 2$ \& 1006 & & \\
\hline & & $5 \%$ & $\because$ & & & \\
\hline HP-23T & Q.14E-2 & Q.2JE-2 & MA & Q11E-? & Q 24E-2 & NA \\
\hline & $\therefore:$ & $\because \because$ & 5 & & & \\
\hline $1 C-n$ & (.116-0) & $4.08[-0]$ & $3.14 E-03$ & 4.SOE-OS & SDEE-OS & $1.73 E-01$ \\
\hline & 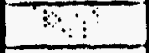 & $\because$ & 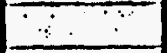 & & & \\
\hline 129 & $\leq 1.7 \mathrm{EE}-2$ & $<1.70 E-2$ & NA & $51 \mathrm{nE}-2$ & Q 00 - 2 & $\mathrm{MA}$ \\
\hline
\end{tabular}

cuscci

\begin{tabular}{|c|c|c|c|c|c|c|}
\hline Rosali al & nioun $n$ & Aversege & & Acaus of & Deach $n$ & Aucriege \\
\hline$(m / 1)$ & $\left(4 x^{\prime}\right)$ & $(1+1)$ & & (Myly) & $(4 / 2)$ & $M^{\prime}$ \\
\hline \multirow[t]{3}{*}{3 HE.0I } & DOIE-0) & (10E-0I) & & 1.02E.03 & $200 \mathrm{E} \cdot 03$ & 1.ME-01 \\
\hline & & 100 & : & & & C.TIE-A \\
\hline & का? & का & & m?!e? & Kम? & की \\
\hline Asoun of & Droun $n$ & Avorase & 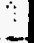 & Beanil of & Lenan $n$ & Averege \\
\hline$\left(u c v_{s}\right)$ & $(u C v)$ & $\left(\mathrm{Cl}_{4}\right)$ & & (uCVs) & $\left(\Delta v_{1}\right)$ & $\left(n c v_{2}\right)$ \\
\hline \multirow[t]{2}{*}{$3706-01$} & 1.70E-01 & S.7EE-01 & & 1.00E-01 & $3.7 \mathrm{Me} \cdot 01$ & I.DE-01 \\
\hline & & $2.196-00$ & $\because$ & & & $1.575=-\infty$ \\
\hline $4 \pi$ & 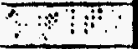 & की & 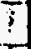 & 3 & \%? & $9: 9$ \\
\hline \multirow[t]{3}{*}{ OUE-O } & $1005-00$ & $0.31 E \cdot 00$ & & Q.JIE-CD & 0.018 .00 & CNEEDOO \\
\hline & & DIIE-OI & & & & DOLE-O1 \\
\hline & 31 & 3.7 & & $\because$ & a! & $\because: 9$ \\
\hline I IUE-OI & $0.15 E-01$ & $1.118-01$ & & $101 E-01$ & $0.035-01$ & $1018-01$ \\
\hline $5101 E .3$ & $\angle 1.01 E-1$ & HA & & SUE-1 & DIE-1 & Md \\
\hline $1105-01$ & 2.mE-01 & $3.07 \varepsilon-41$ & & Ci.41E-1 & S1.40E-3 & $\mathrm{MA}$ \\
\hline $0.70 E-02$ & 1.0se-on & -02 & & 141E-02 & $4.24 E-n$ & 1.4 \\
\hline a.roe-1 & 0.41E-4 & $M A$ & & 4.41E-4 & $0.202+$ & MA \\
\hline 7 & $\because \div$ & 60 & & $4: 13$ & 14 & \\
\hline $121 E-01$ & I.30E.01 & 1.34 & & $1.428-01$ & 1.51E-0I & $1.0 \pi k-01$ \\
\hline CI OOE- 1 & $<1$ OSE-2 & MA & & C1.04E-2 & C1.1SE-2 & 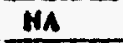 \\
\hline 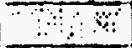 & 7x+4 & ओं। & & 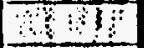 & $3 \%$ & 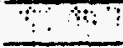 \\
\hline \multirow[t]{2}{*}{ 1.4E-02 } & 1.71E-02 & 1.02E-02 & & S.11E on & L AEE-OR & $1.70 E-02$ \\
\hline & & $1.01 E+\infty 0$ & & & & D.MTE-O1 \\
\hline 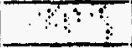 & 93 & 8 & & & 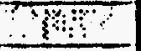 & \\
\hline conse diclecle & & & & evon Aclecte & & \\
\hline$\because \because$ & 9 & $4:$ & & 4 & 3 & $\because$ \\
\hline \multirow[t]{2}{*}{ Q211E-2 } & $0.14 E-2$ & NA & & $0.242-2$ & Q.24E-1 & MA \\
\hline & $\therefore$ & 4 & & & 2 & ? \\
\hline $1.10 E-02$ & L.11E-0 & $\mathrm{MA}$ & & $1.016-02$ & $1018-02$ & $1048-02$ \\
\hline & $: \because 1 \%$ & 41 & & & & \\
\hline ALE-2 & Q.1IE-2 & $\mathrm{HA}$ & & Q.12E-2 & SI.TSE-2 & MA \\
\hline
\end{tabular}




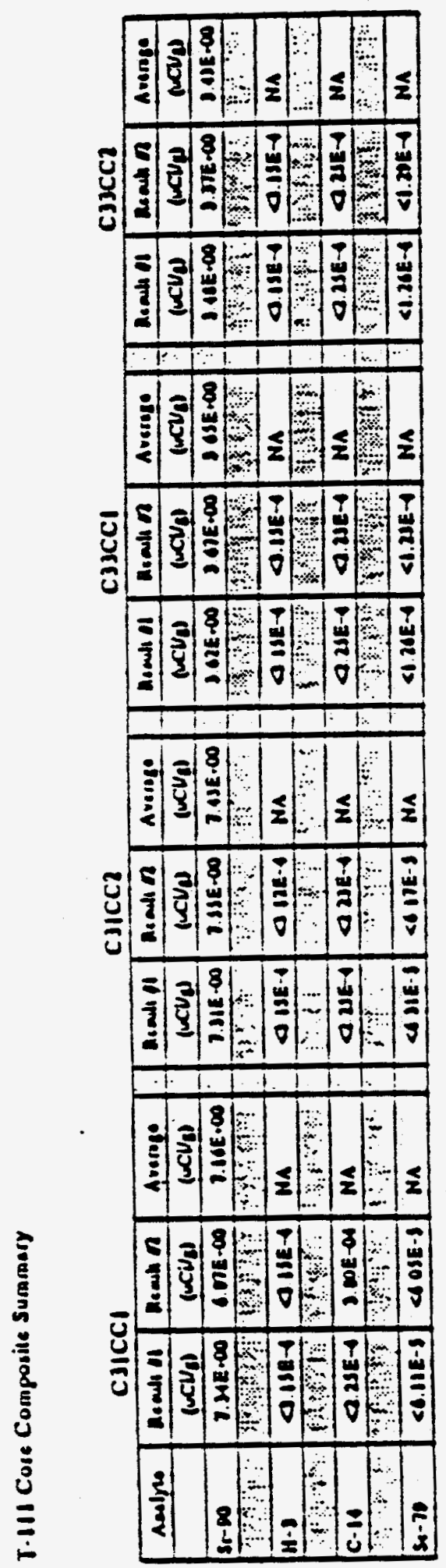


WHC-EP-0806

WHC-SD-WM-DP-024 ADDENDUM-2, REV 0
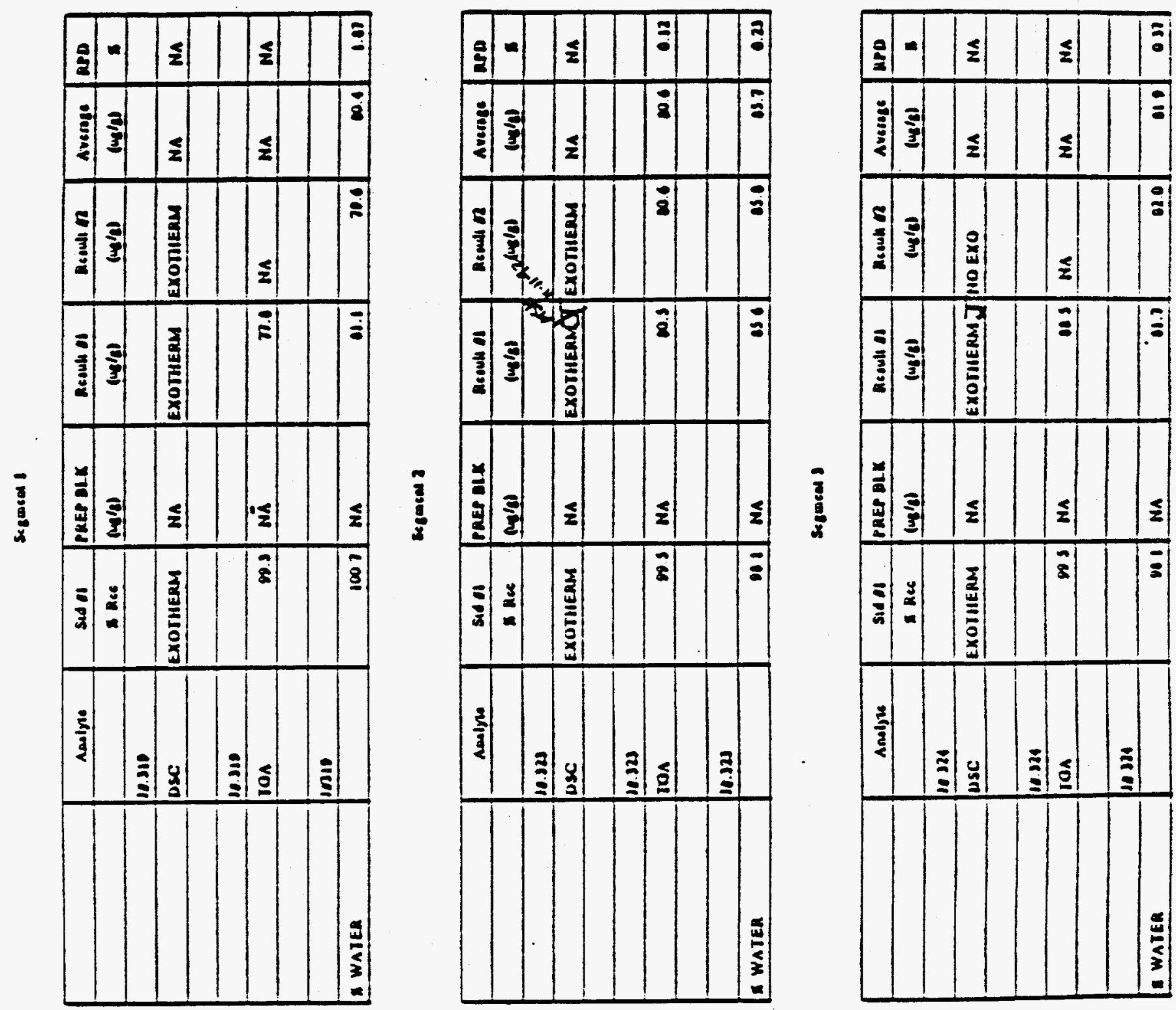

$\frac{5}{3}$

음

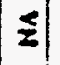

힐

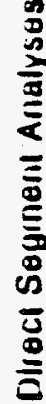

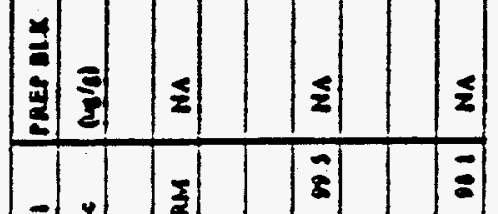

$\frac{5}{3}$

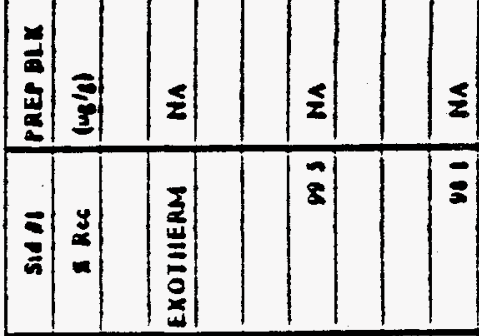

है

है่

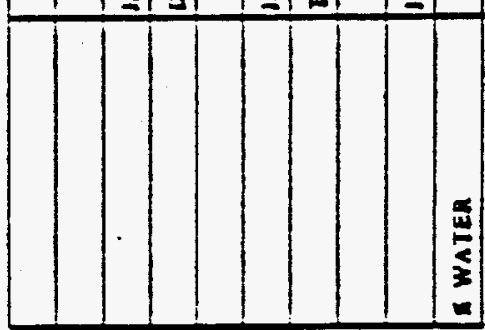

童 


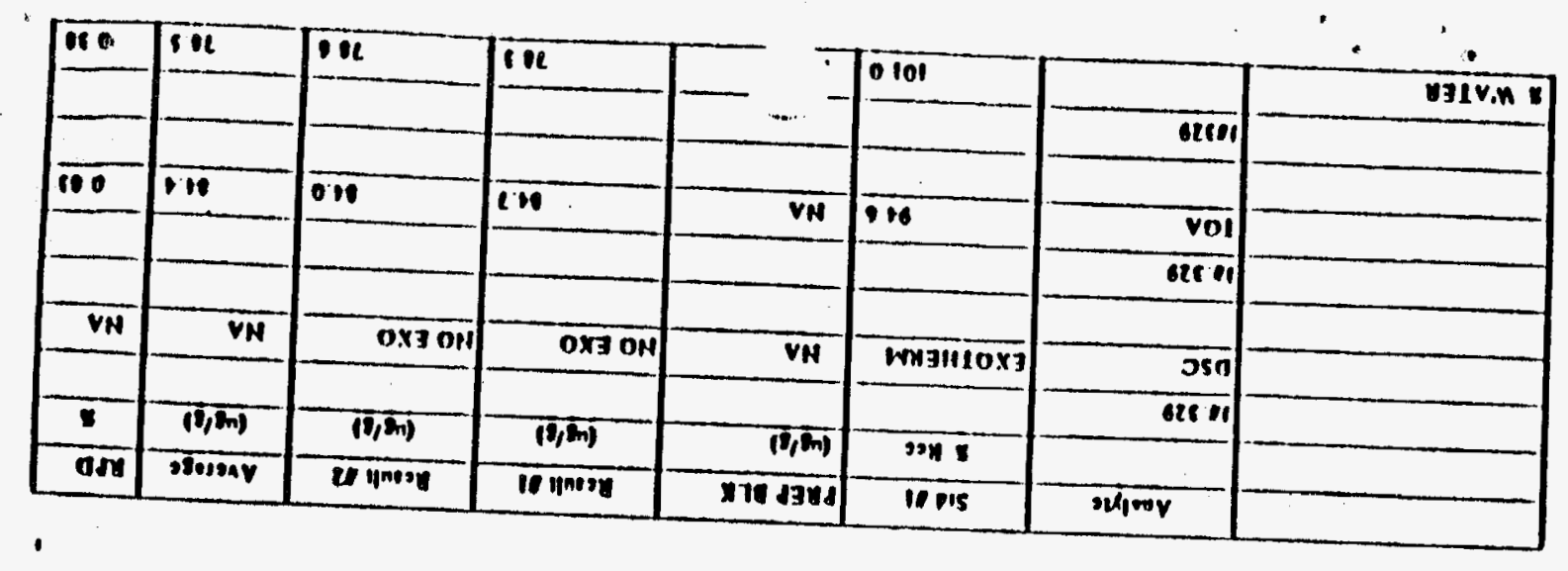

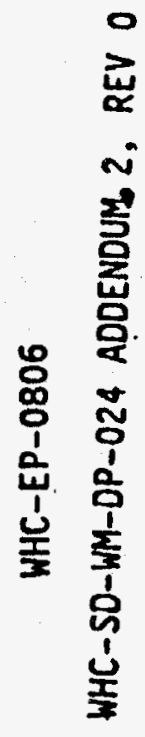

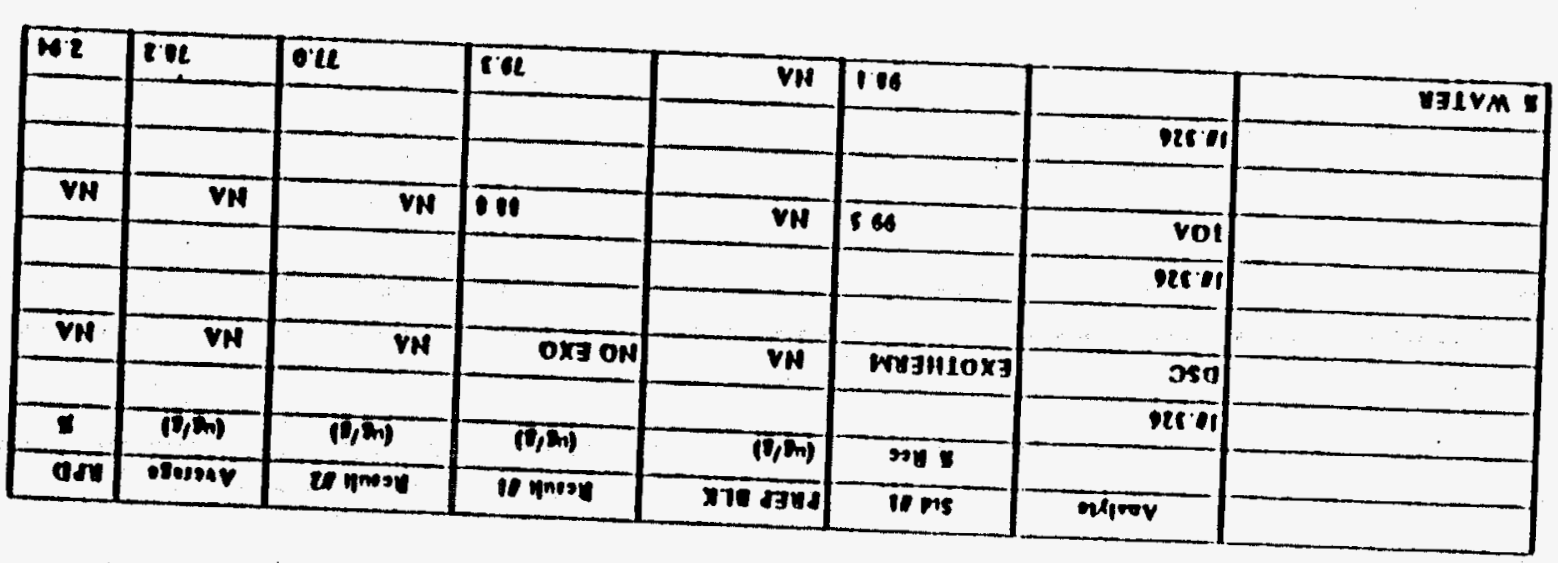

erouts

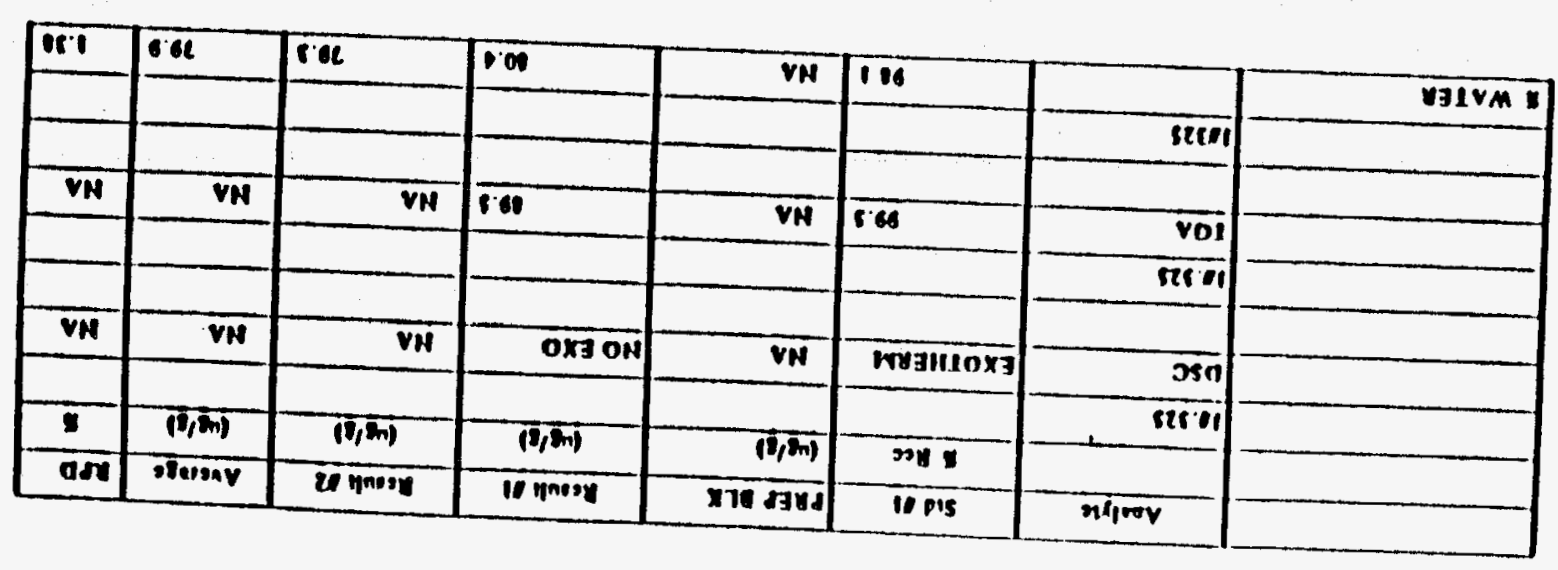

imsonens 
WHC-EP-0806

WHC-SD-WM-DP-024 ADDENDUM,2, REV 0
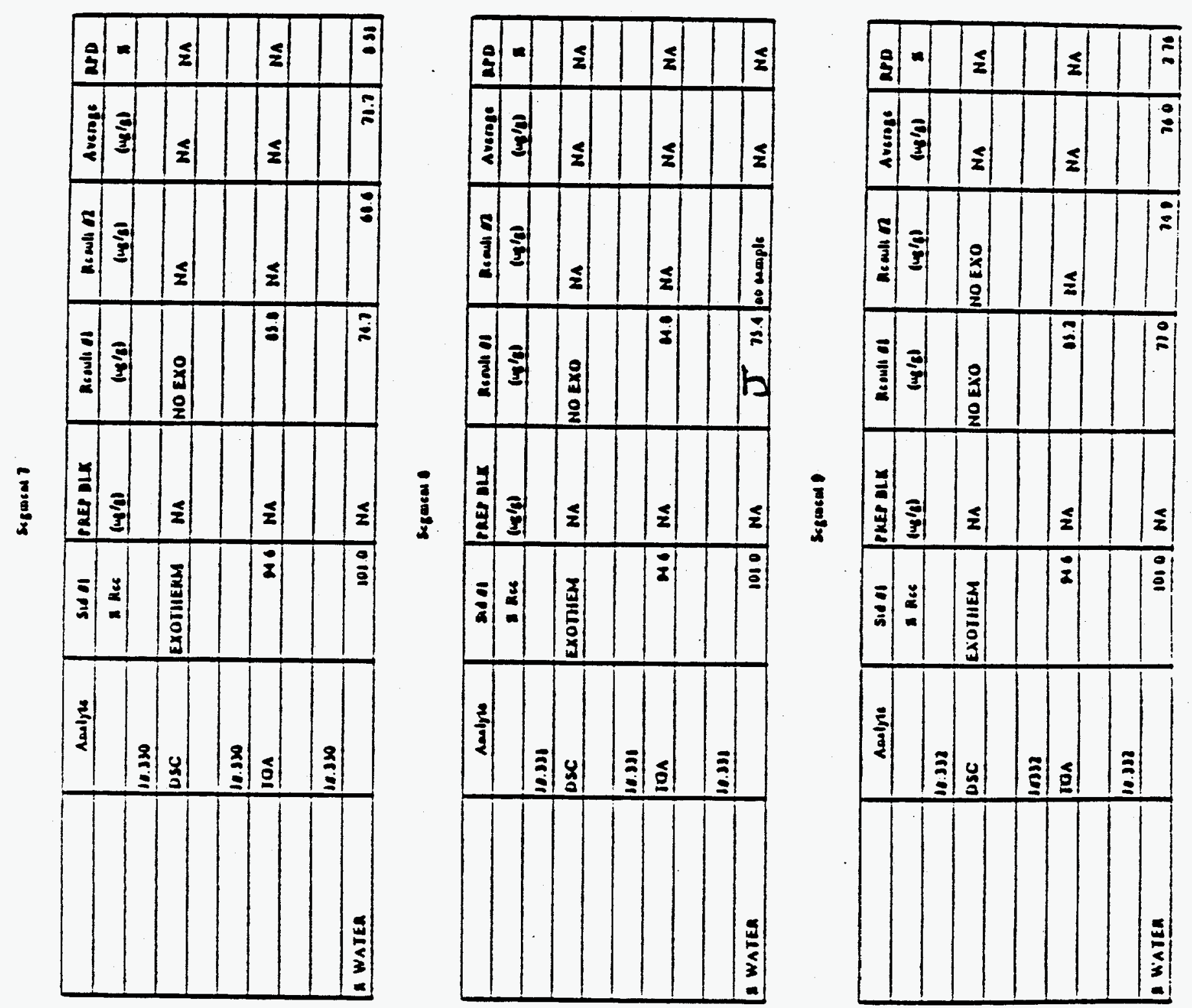

$\frac{3}{3}$

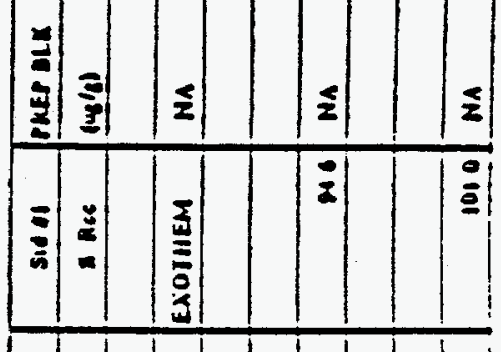

ํํำ

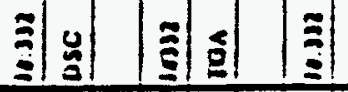


WHC-EP-0806

WHC-SD-WM-DP-024 ADDENOUM_2, REV 0

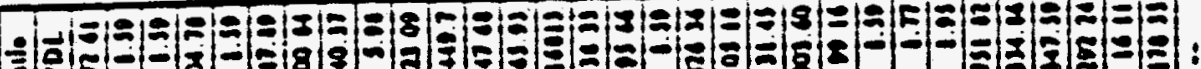

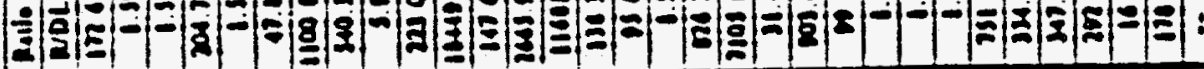

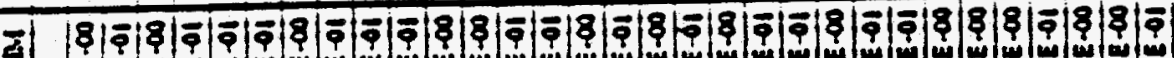

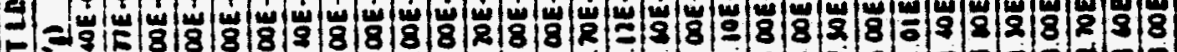

:

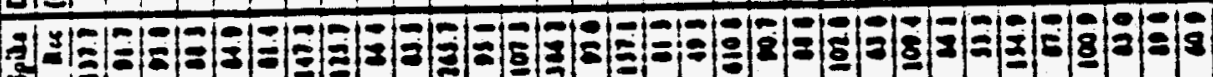

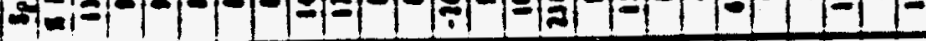

-

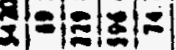

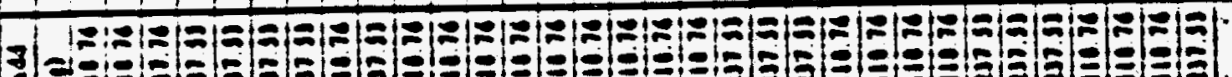

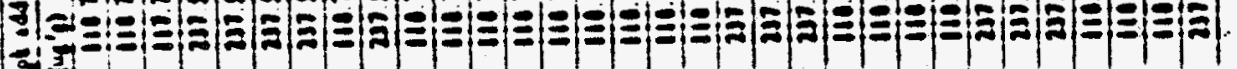

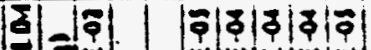

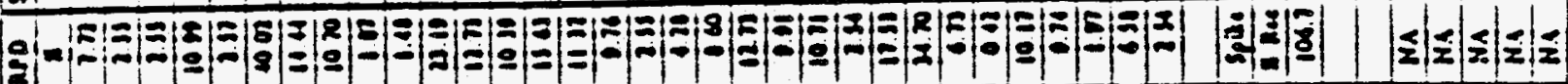

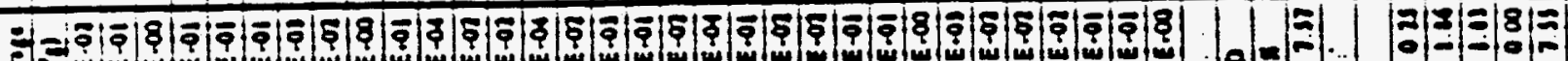

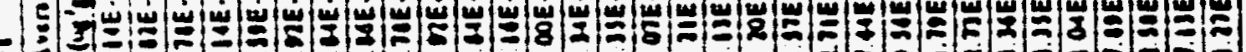

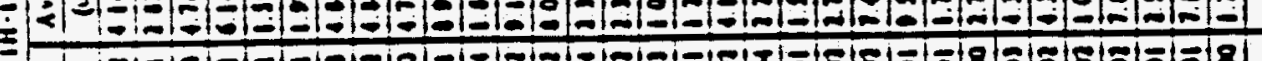

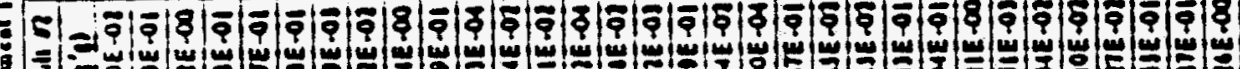

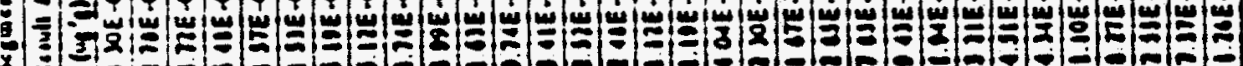

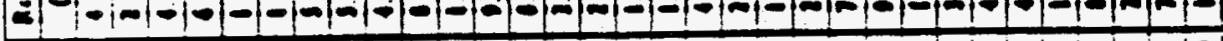

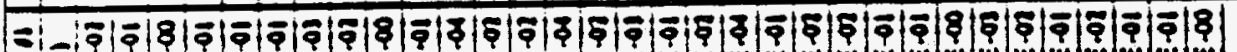

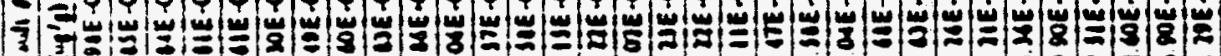

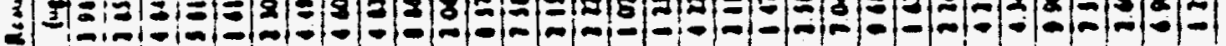

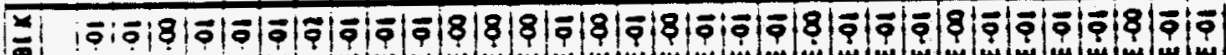

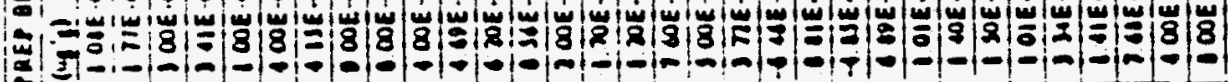

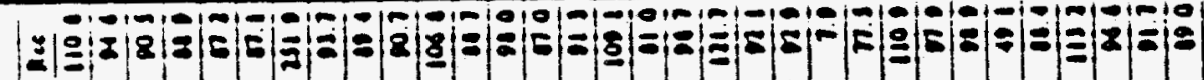
$+1$

三

:

2!

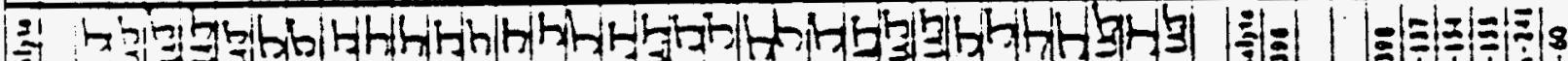

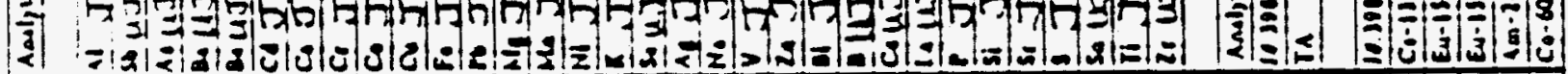

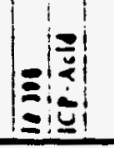

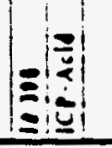

$\mid \begin{gathered}1 \\ 0 \\ 0 \\ 0 \\ 0 \\ 0\end{gathered}$

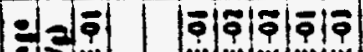

(릴.

बa잉

3ी

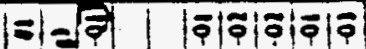

包结

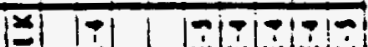

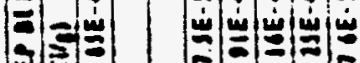

छ)

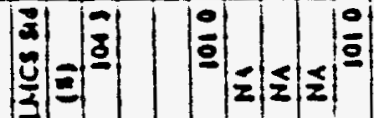

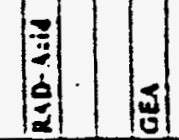


WHC-EP-0806

WHC-SD-WM-DP-024 ADDENDUM,2, REV 0

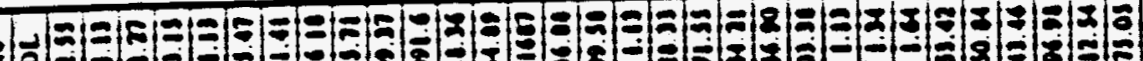

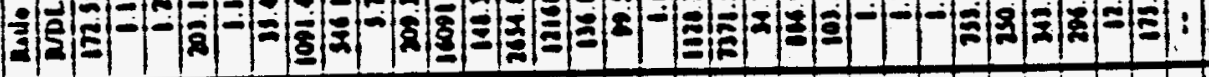

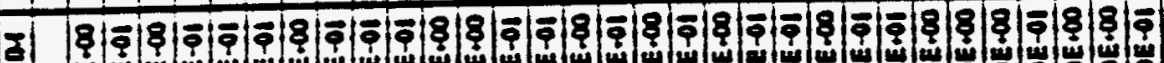

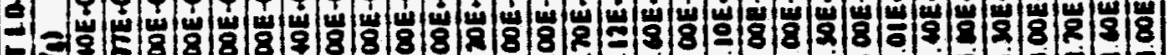

E.

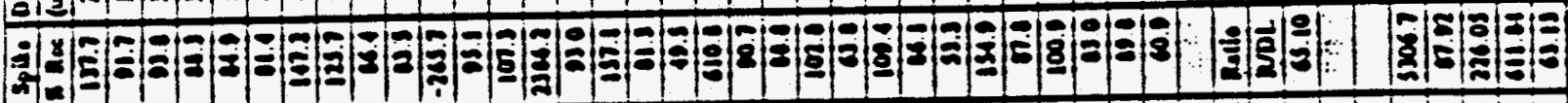

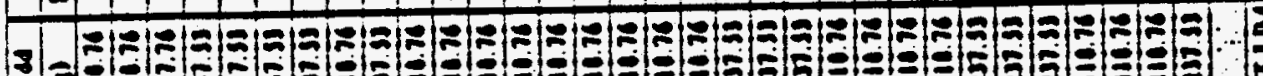

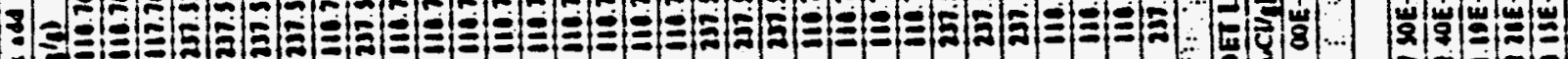

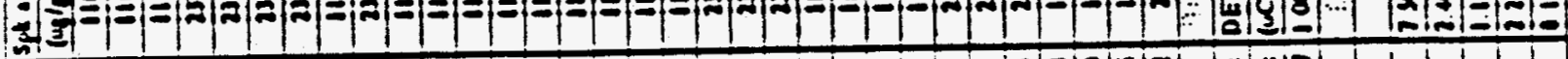

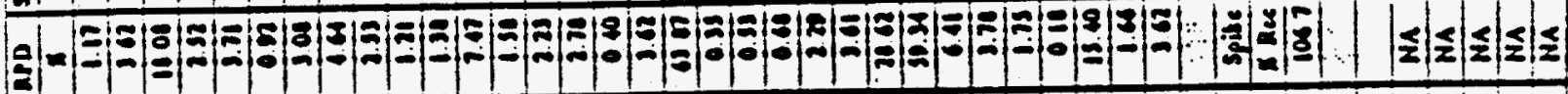

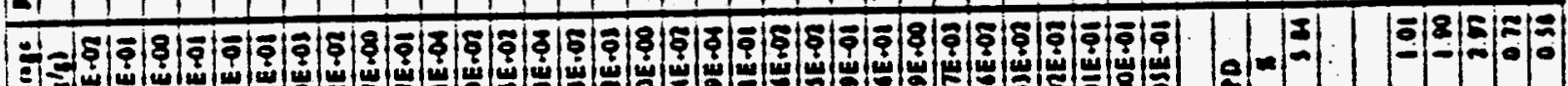
- ₹ 3 글

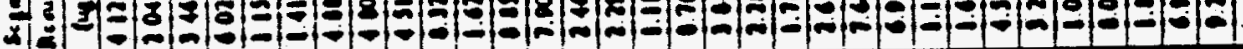

(2)

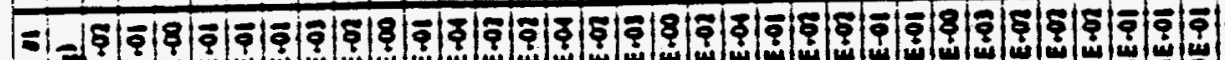

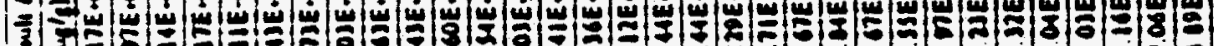

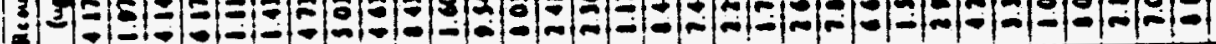

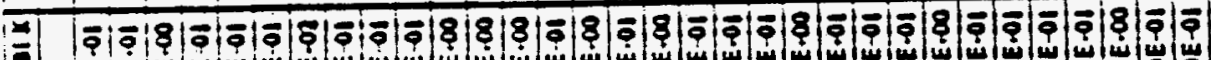
- 2

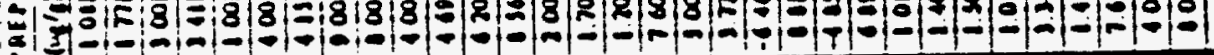

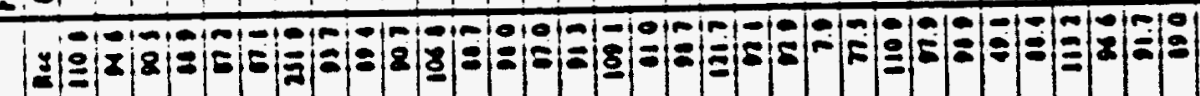
zi:

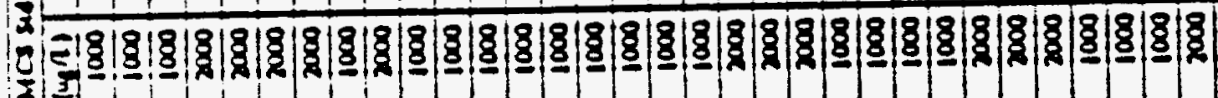
3 畒

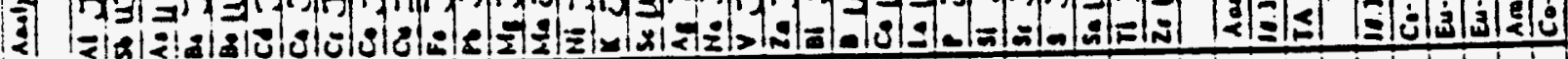

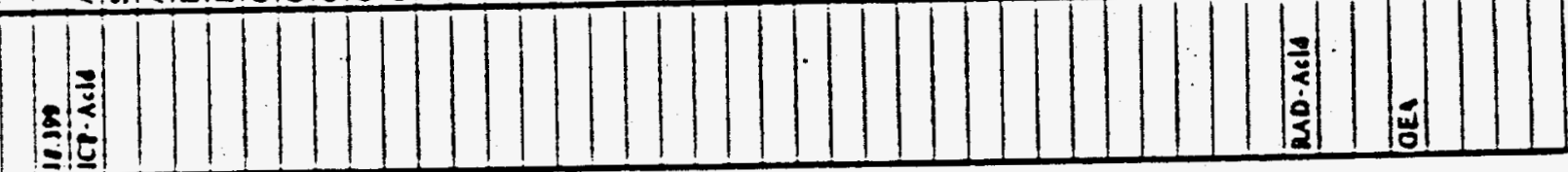


WHC-EP-0806

WHC-SD-WM-DP-024 ADDENDUM 2, REV 0

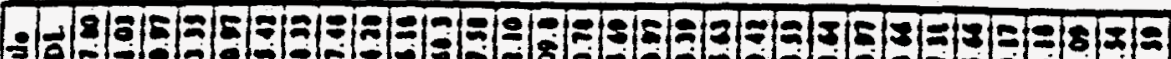

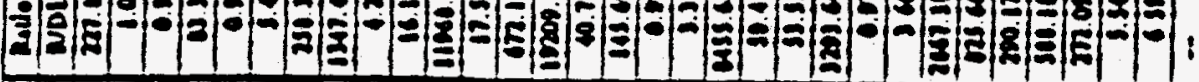

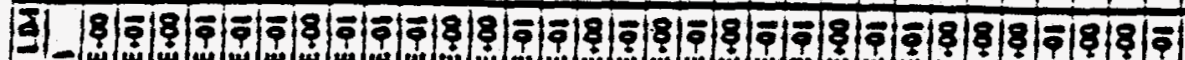

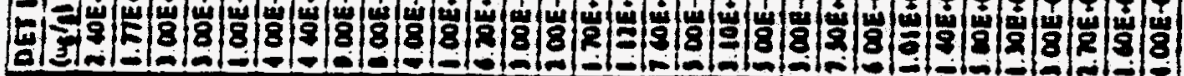

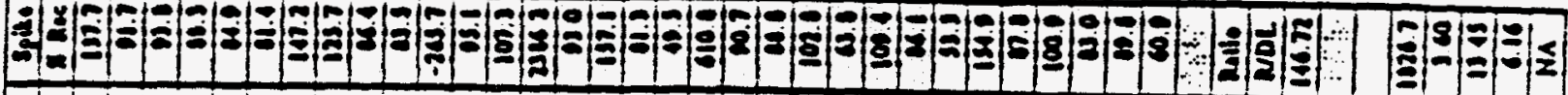

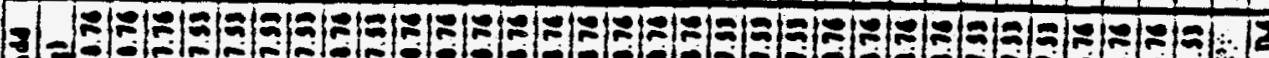

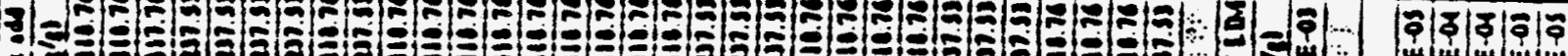

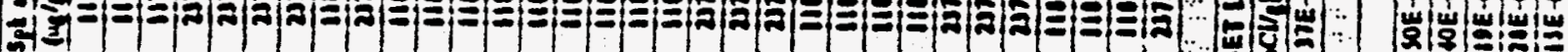

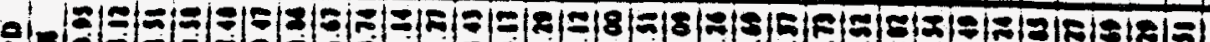

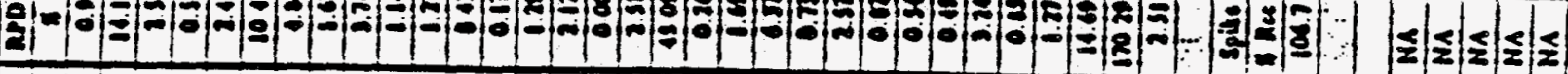

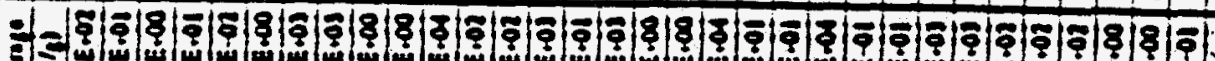

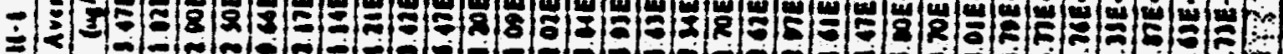

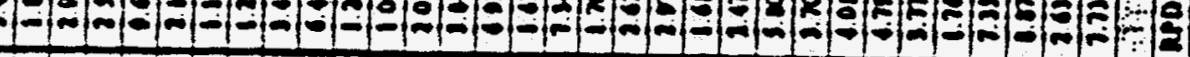

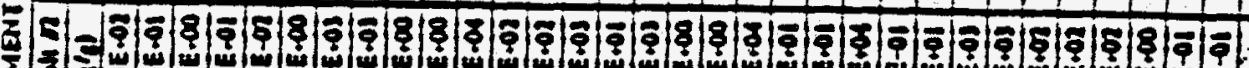

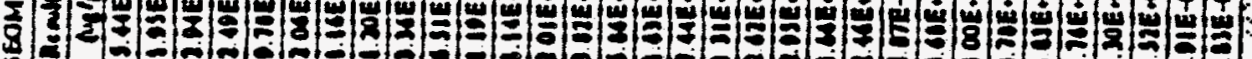

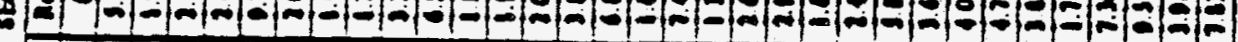

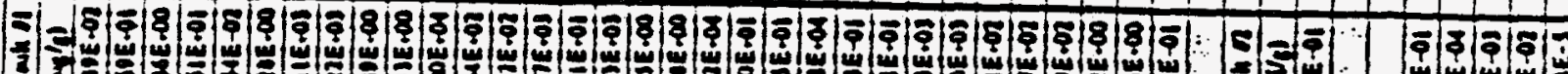

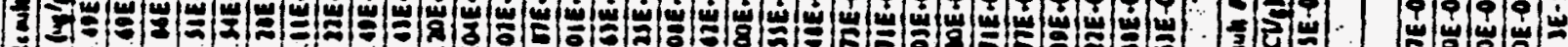

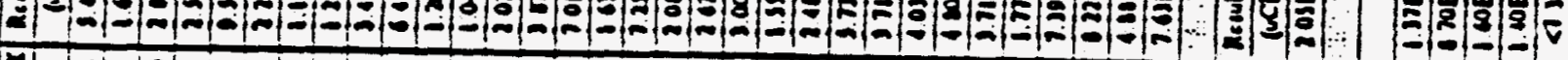

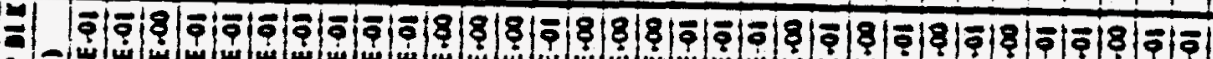

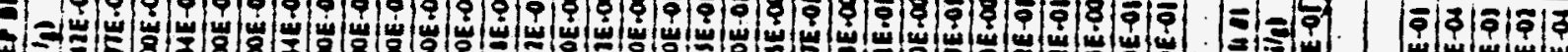

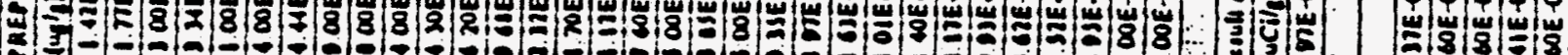

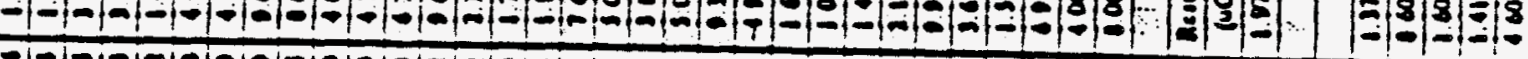

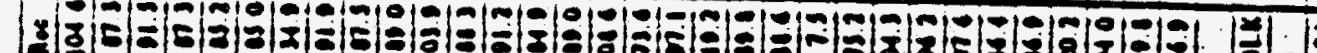
$+1$

c) $3 !$

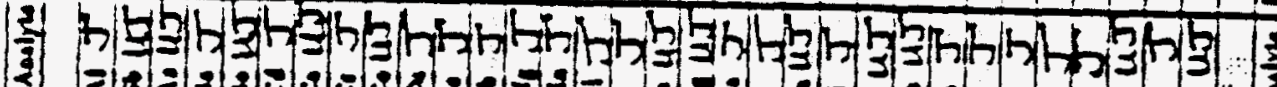

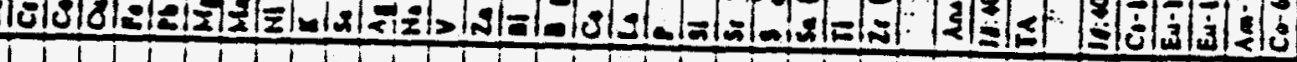




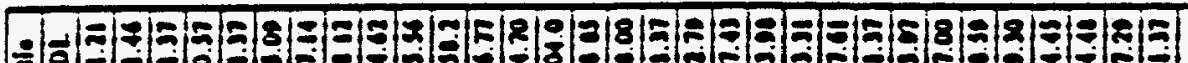
三ิ

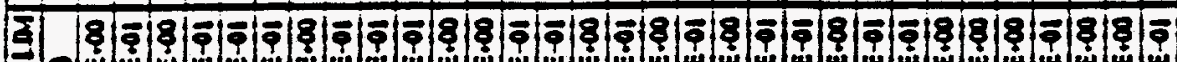
E 술

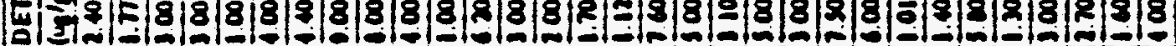

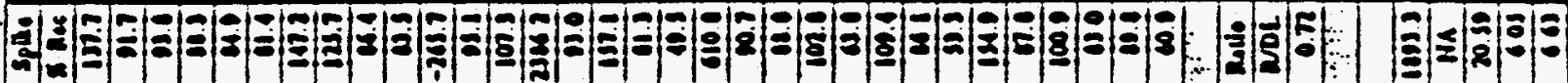

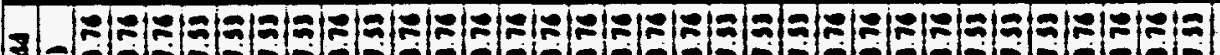

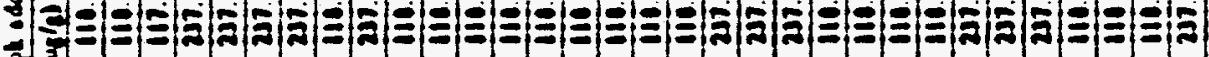

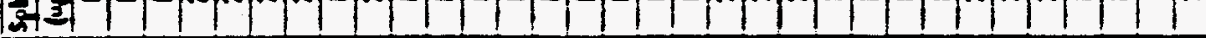

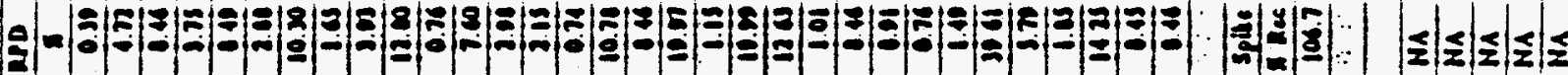

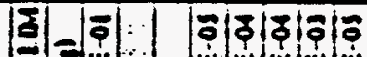

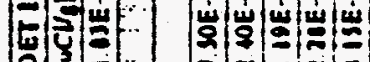

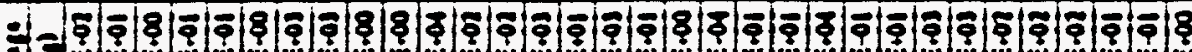

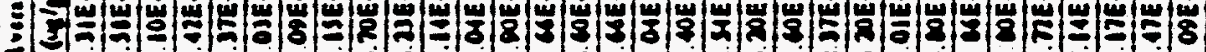
亡

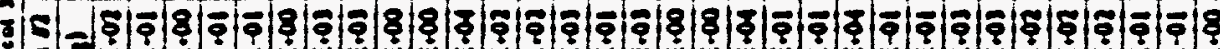

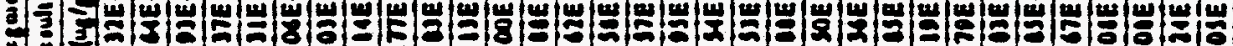

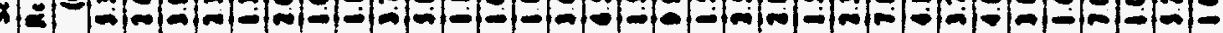

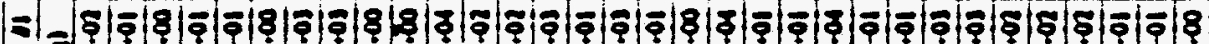

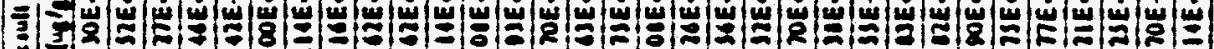

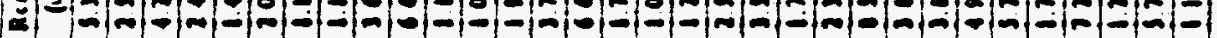

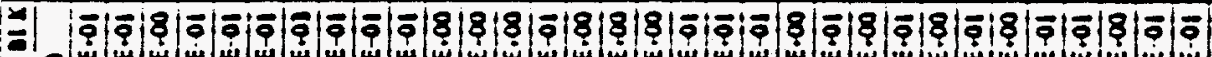

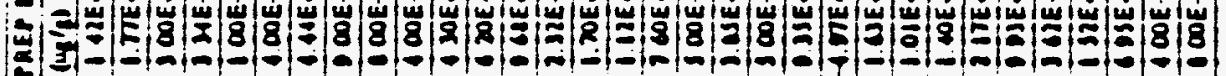

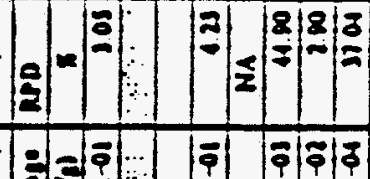

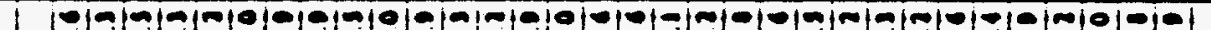

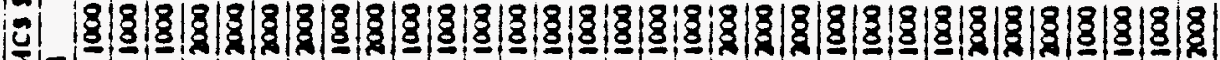
․․․

\begin{tabular}{|c|c|c|c|c|}
\hline$\left|\begin{array}{l|}\mid \begin{array}{l}a \\
0\end{array} \\
\mathbf{3}\end{array}\right|$ & $\left|\begin{array}{l}|c| \\
\frac{4}{8}\end{array}\right|$ & $\mid \begin{array}{l}\dot{m} \\
\mathbf{v}\end{array}$ & 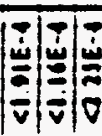 & $\mid \frac{\dot{c}}{\sigma}$ \\
\hline $\mid \begin{array}{l}\bar{n} \\
\bar{n} \\
\overline{2}\end{array}$ & 하: & 이 & $\leq|\leq| \leq$ & 18 \\
\hline
\end{tabular}

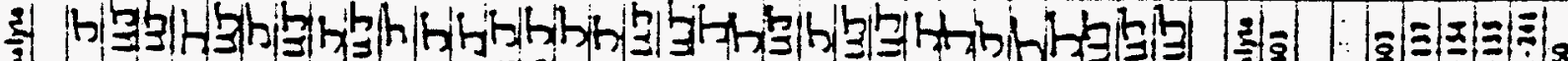

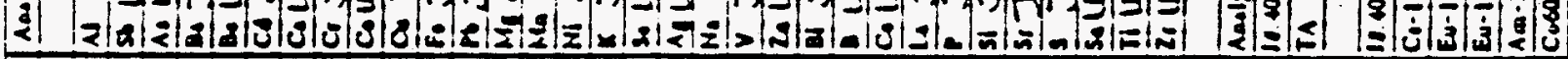


WHC-EP-0806

WHC-SD-WM-DP-024 ADDENDUM 2, REV 0

- TIF

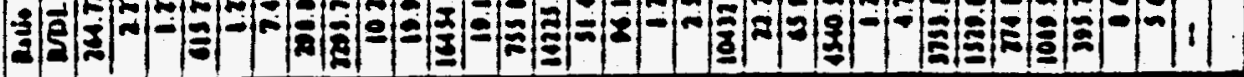

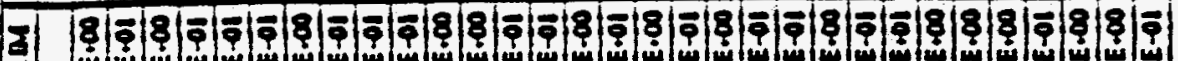

- =

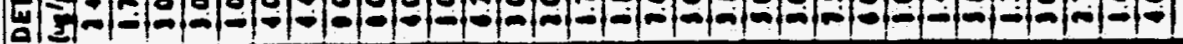

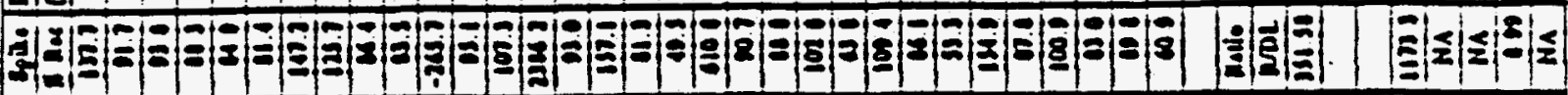

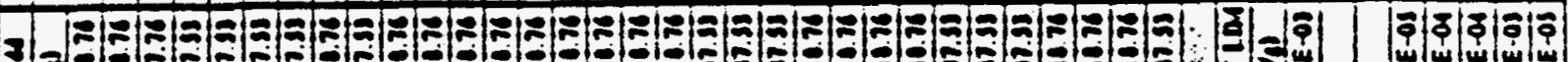

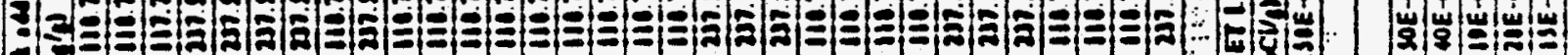

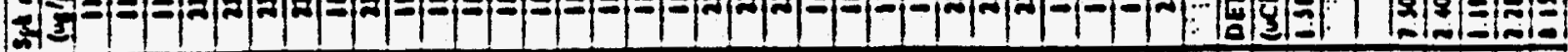

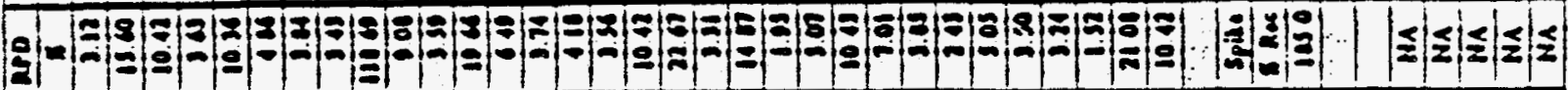

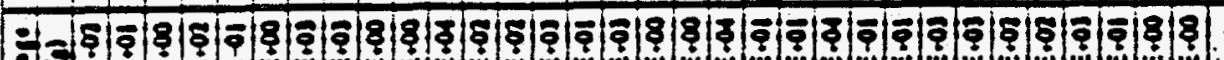

-

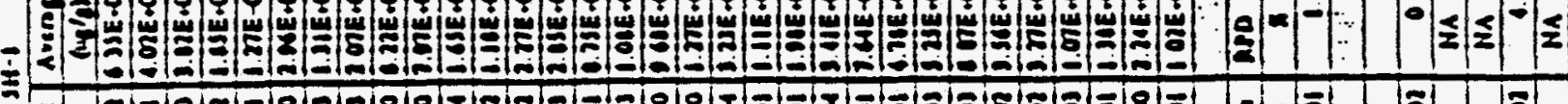

3 5 -

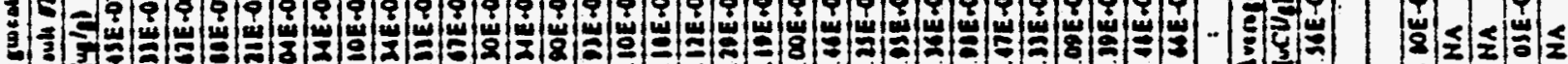

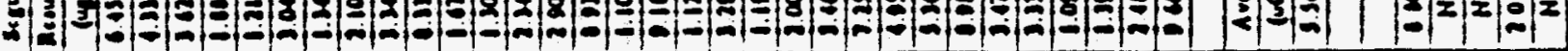

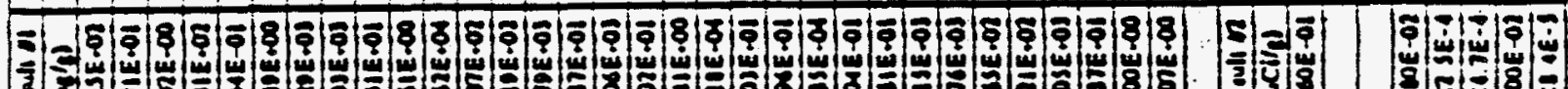

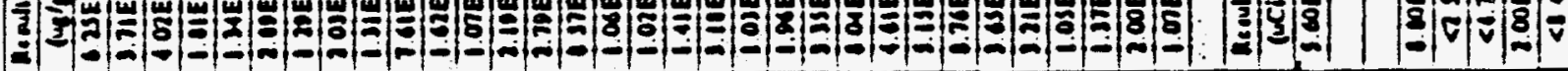

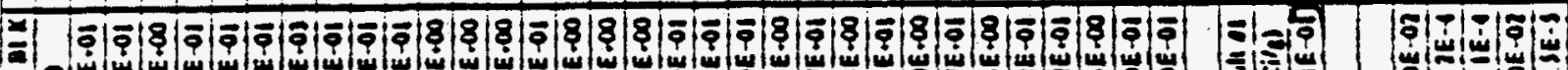

:

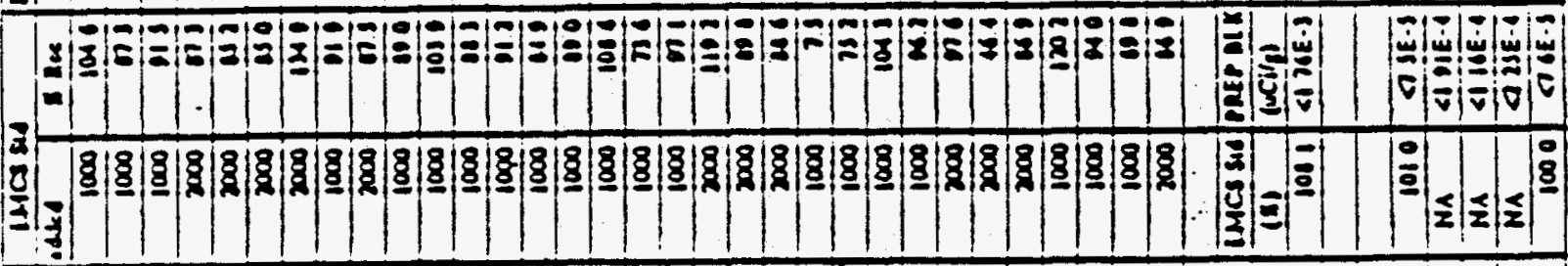

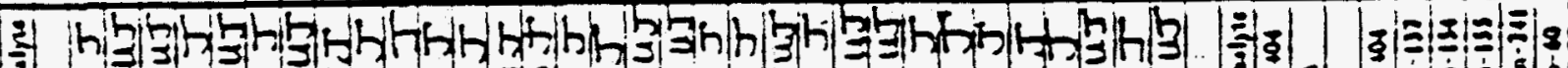

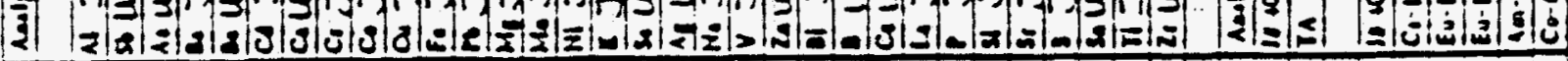

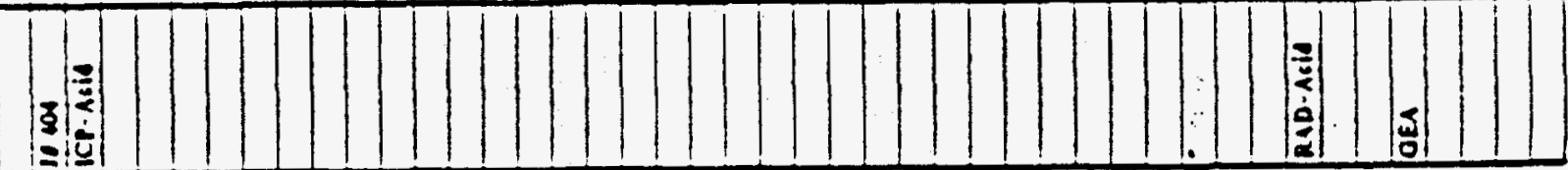


WHC-EP-0806

WHC-SD-WM-DP-024 ADDENDUM 2, REV 0

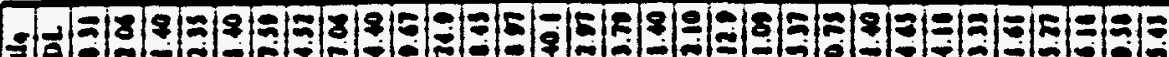

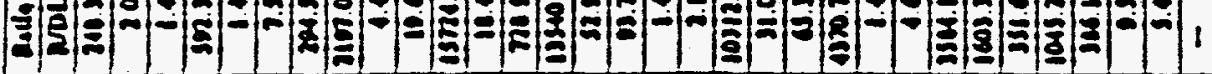

క.

-

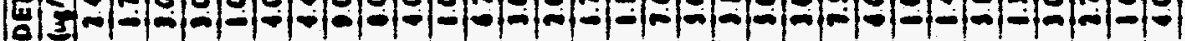

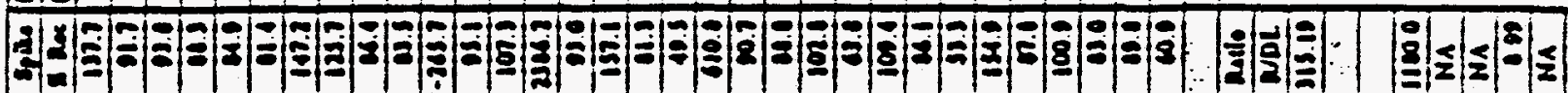

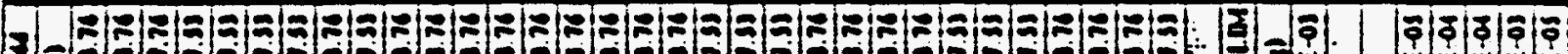

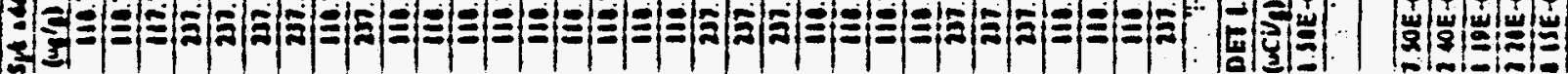

m

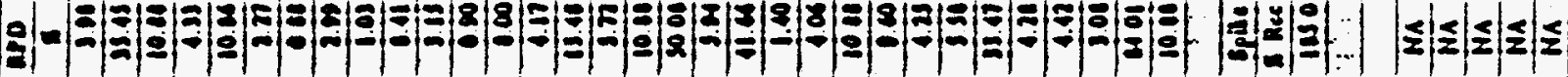

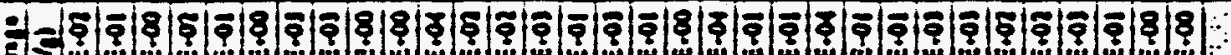

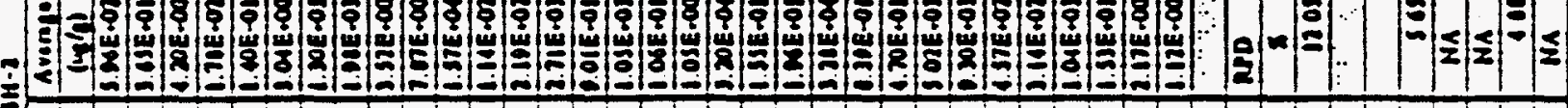

ప/

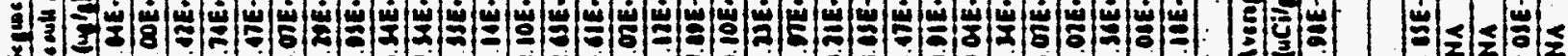

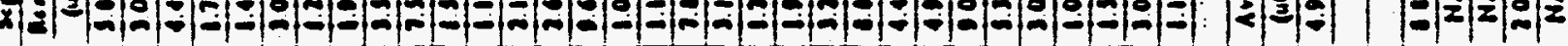

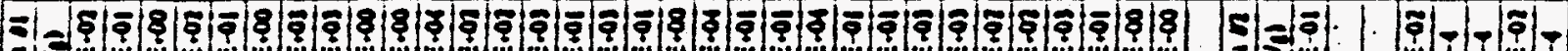

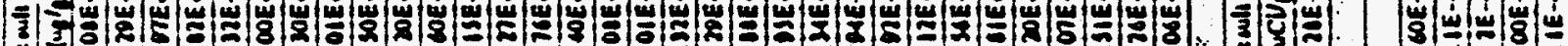

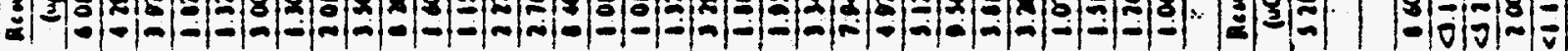

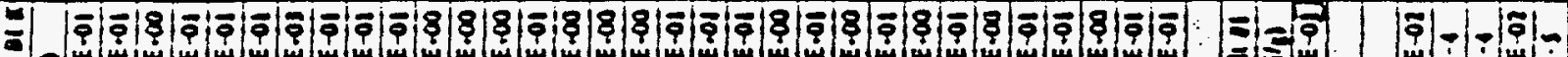

복

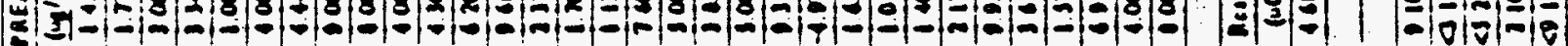

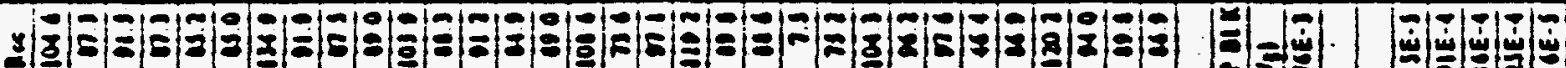

z.

II

굴

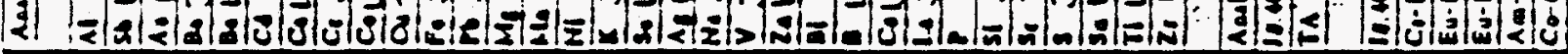

$-\frac{9}{8}$

는

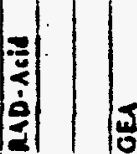




\begin{tabular}{|c|c|c|c|c|c|c|c|c|c|c|c|c|}
\hline & & $\overline{Y M}$ & so-351! & VN & $\mathbf{V N}$ & $\overline{Y N}$ & $8-3(1)$ & $3 i$ & 1.320 & 10201 & & \\
\hline & & 50 & $0-301$ & YH & 000 & $60-3961$ & $00-391$ & $10-3111$ & 1.310 & $\overline{V H}$ & int-ov & \\
\hline & & $\mathrm{VN}$ & $00-3611$ & VN & $\overline{V M}$ & YN & -310 & 0.350 & -3612 & IN & $m 1-m$ & \\
\hline & & $\overline{V N}$ & $00-300 ?$ & VH & $\overline{V H}$ & $\overline{V H}$ & -300 & 1.300 & 1.310 & $\mathrm{VH}$ & i11-n3 & \\
\hline & & It & $30-3002$ & VH & $\underline{\underline{u}}$ & $20-3112$ & $20-3012$ & $10.3 n 2$ & 100.3000 & 0101 & iit. & $\sqrt{30}$ \\
\hline & & & & & & & & & & & $m$ & \\
\hline & & 7.0. & $\min 0$ & & & & & & & & & \\
\hline & & $\frac{1260}{20 \pi}$ & $\frac{10-3 h)}{\left(1 / ! x^{m}\right)}$ & $\frac{\ln 1}{\operatorname{mos} 8}$ & $\frac{u_{L}}{1}$ & $\frac{10-3(1)}{\left.1 / 10^{n}\right)}$ & 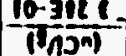 & $\frac{10-3508}{01}$ & $\frac{n-3 n g}{\left(1 n n^{n}\right)}$ & $\frac{1 n}{|n|}$ & & pirg-arn \\
\hline & & onou & 01130 & -175 & adx & Dlueny & rinomo & 11 Ine? & 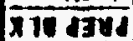 & onsonit & Toov & \\
\hline & $\because$ & $\because 6$ & $i$ & & 96 & 5 & & & & & & \\
\hline - & & 10 & titit & In & 00.3501 & $10-3 n 6$ & $\infty+311 !$ & $10-3001$ & 104 & al & 12 & \\
\hline 20 & $10-3000$ & 10 & iniI & IIt & 03002 & 0003918 & 318 & io-3in! & $i$ & & & \\
\hline Q611 & 00091 & 00 & LIII & 18 & 10.3122 & 10.31101 & R? & 100311 & 6 & a! & $\overline{8}$ & \\
\hline tII & $00.302 ?$ & 001 & EIII & 110 & $10 \cdot 3 \pi 2$ & $10-3221$ & II & $10-3601$ & iI & ii & & \\
\hline pon! & $10-30$ & 100 & in & 1000 & eass & 20.3001 & 0003169 & $10-3000$ & 10 & a & & \\
\hline olis & 000301 & nI & I & III & 60.371 & 20.3100 & 2003121 & 10.301 & 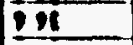 & & & \\
\hline Leno & 00301 & ses & & III & 10.31E: & 10.3001 & 100341 & 1003118 & 16 & $x$ & & \\
\hline soun & $00.301 !$ & 10 & II & 101 & 10.3100 & (o-311) & 100.3301 & $000+300+1$ & & nt & & \\
\hline 1 & 103101 & 1001 & Q.01! & iin & 10.3100 & 10.3108 & $1003 n !$ & oi & 1001 & of & & \\
\hline aI & $10-3009$ & $2 \pi$ & eoii & $\overline{\underline{a}}$ & $10-3110$ & $10.3 \mathrm{~mL}$ & $10-3006$ & 7 & 116 & o! & $\operatorname{sn} 0$ & \\
\hline ICSI & 0.301 & 201 & & BI & 3310 & 1003001 & $10+361$ & 7 & ! & & & \\
\hline u & $10-3001$ & In & $\pi$ & $\mathrm{NO}$ & 10.3112 & $100306 ?$ & 10.3212 & ii & 60 & az & & \\
\hline 6 & $10-3005$ & $6 a$ & & Q & $00+3100$ & $\infty=0111$ & $\infty+3 n !$ & $100-3009$ & 10 & & & \\
\hline exsil & $00.301 ?$ & 1010 & Ifin & II & $10+316 !$ & roo3rs: & no.211: & $10-3118$ & (4)! & $\infty$ & & \\
\hline 011 & $10-3001$ & iof & & 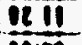 & 00-3ifl & $\infty 0,3 n 1$ & $\infty+3 n !$ & & & & & \\
\hline & $00+3016$ & Ele & & t & 1101 & 0003910 & $I$ & 21 & 10 & 0001 & F) & \\
\hline Efile & 10.3111 & 121 & i & i & $20-3102$ & $10.3 \mathrm{Hi}$ & \pm & & & का & & \\
\hline roll & 00.3001 & 010 & & & 1003160 & 1003111 & $10-3001$ & & 3 & 0001 & & \\
\hline$i \cos \alpha$ & $10-300$ & $2 \mathrm{~min}$ & $\Rightarrow=$ & 느? & $10+3110$ & $10+3901$ & lo-301: & 103008 & 10 & 0001 & & \\
\hline i11 & $10-30$ & r. & & & 0.2 & 20.3350 ? & 1 & 1 & $i$ & 0001 & & \\
\hline Q 11 & $00 \cdot 3002$ & 130 & 2 & $\underline{a}$ & 60.3011 & ion-3111 & 1 & $i$ & 126 & 0001 & & \\
\hline $0 \cos 1$ & $00 \cdot 3001$ & $\cos 2-$ & 1 & II & 1003410 & 1003961 & 1 & 18 & & & & \\
\hline 012 & $10-3001$ & in & 9 & & 3918 & $00-3502$ & I & & & 0001 & & \\
\hline sis & 3008 & in & & & 3928 & $0003<?$ & & & & 000 & 2 & \\
\hline orosu & $10-3000$ & ent & II & I & 60030t & 6003112 & $315 !$ & 3000 & ina & 0001 & 50 & \\
\hline woot & $00 \cdot 30$ & 2.41 & & 11 & 1003801 & $100-3101$ & 1 & $10 \cdot 3$ & IIII & 000 & & \\
\hline & $10-300 !$ & in & I2 & 201 & 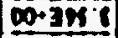 & $00+391]$ & 1 & 01 & 10 & $\overline{000 x}$ & & \\
\hline al & $10-3001$ & 1 & & an & $10-3110$ & II & & 11 & :01 & 0 & $\pi=$ & \\
\hline 000 & 10 & 10 & $\underline{w}$ & 0011 & 100302 & $100.39+2$ & 10.3102 & io a & 108 & oxoe & $\Gamma=$ & \\
\hline HI & 00.3001 & of & IIf & $\underline{\underline{t} \underline{\underline{a}}}$ & $00-3000$ & $\infty+3190$ & 3 air! & $00+3001$ & ine & 0001 & & \\
\hline & $1003 e 1$ & 610 & EIII & $\underline{\underline{4}}$ & 10.3112 & 1003118 & $10 \cdot 3118$ & $10-3 u i$ & 6 & 0001 & $\sin$ & \\
\hline is & 7 & El & & $\omega$ & & & & in & iniii & $\infty$ & $\mid \pi n$ & \\
\hline $\operatorname{Tan}$ & & $\infty$ & & I & & & & $(1,(m)$ & oro & & & \\
\hline opves & nol13a & Lends & Fis & on & sloger & & II moner & $8 \sqrt{384}$ & & olv & $n \sqrt{100 y}$ & \\
\hline
\end{tabular}




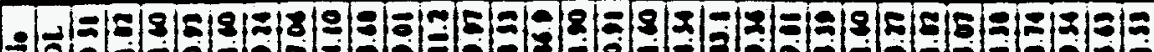
2.

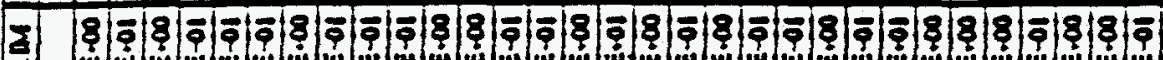
E⿹

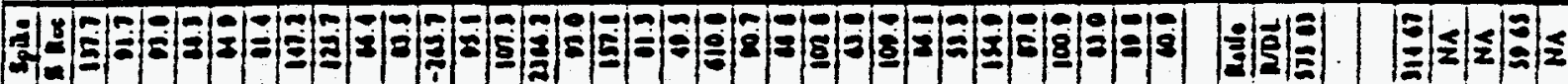

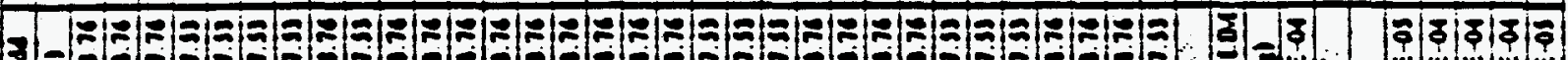

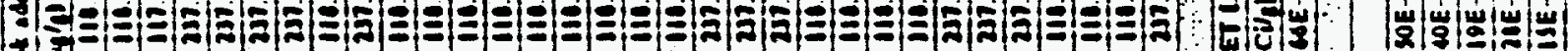

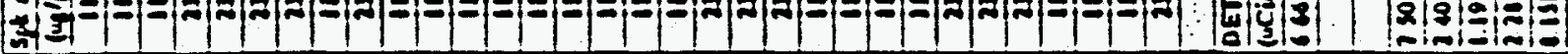

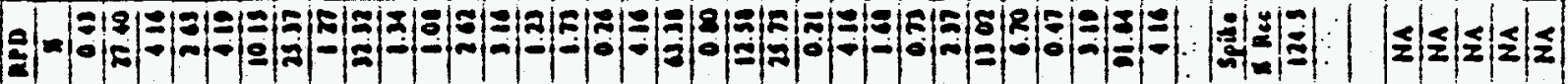

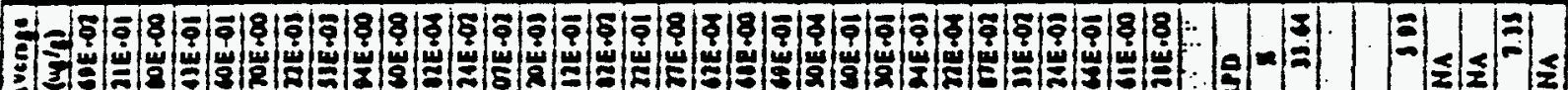
i

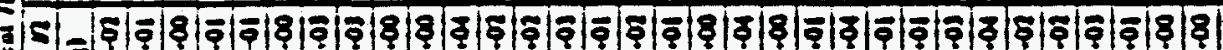

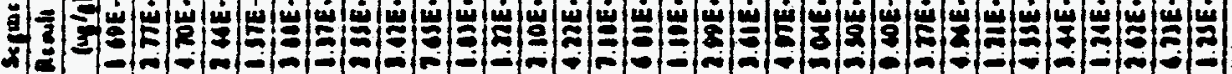

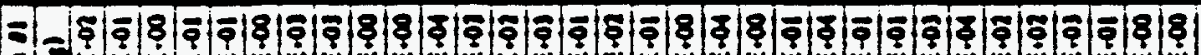

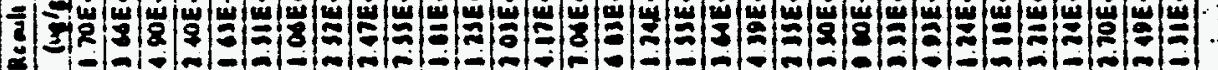

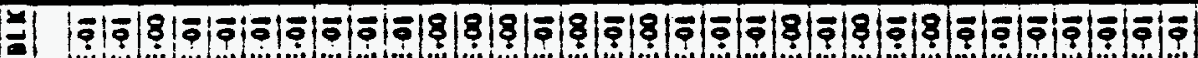
e 긴.

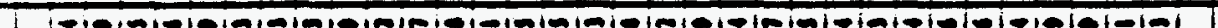

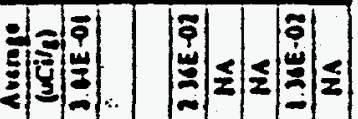
(1)

3.

3.8:

은

$\mathbf{s}=\overline{\bar{q}}$

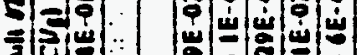

ثิ宀

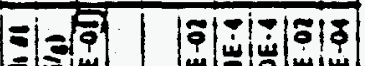

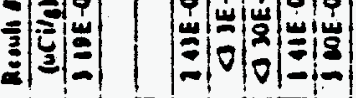

3

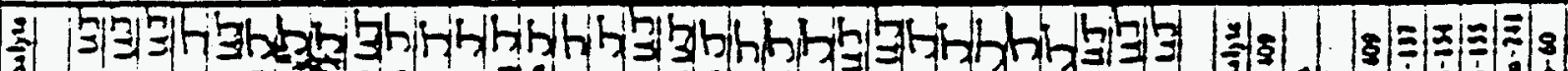

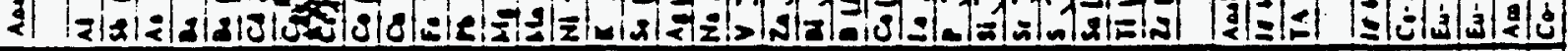
$8 \mid \frac{2}{8}$

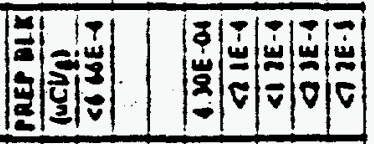

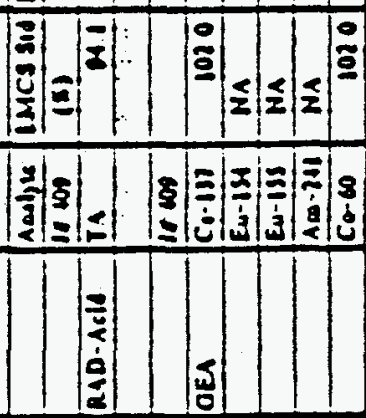




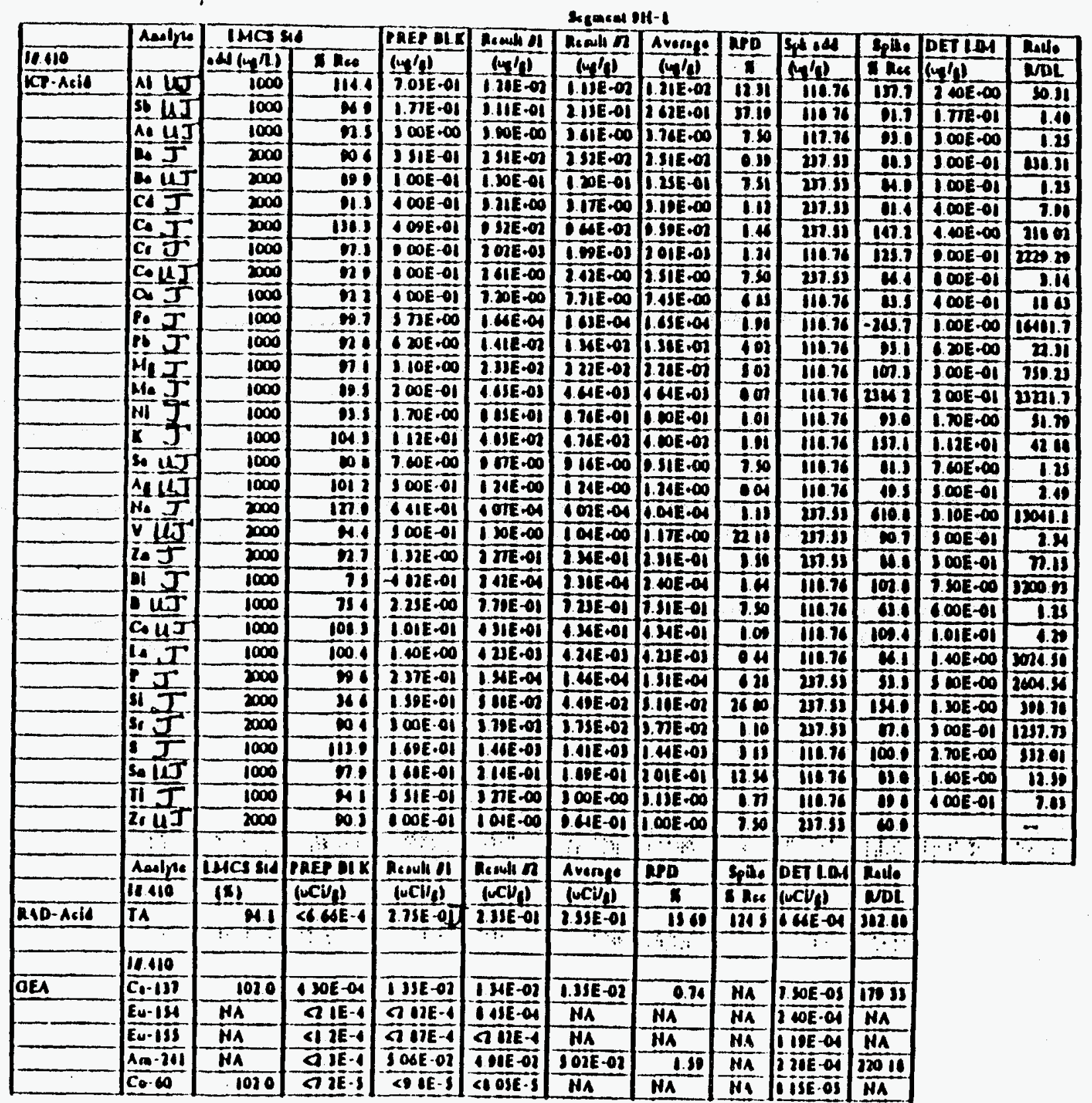


WHC-SD-WM-DP-024 ADDENDUM 2, REV 0

- $\rightarrow$ :

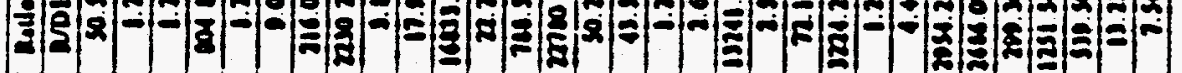

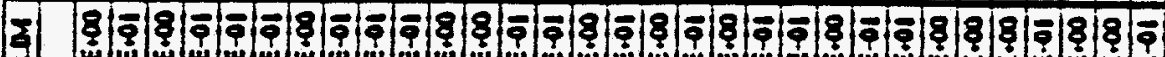

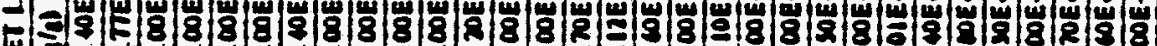

El

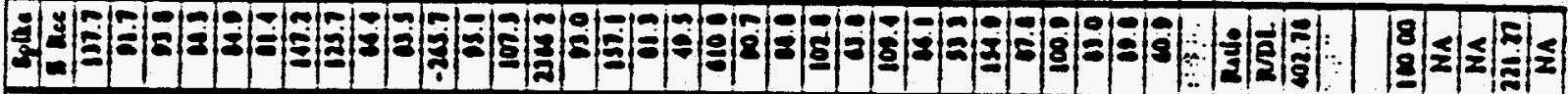

- Fof

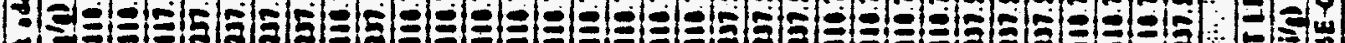

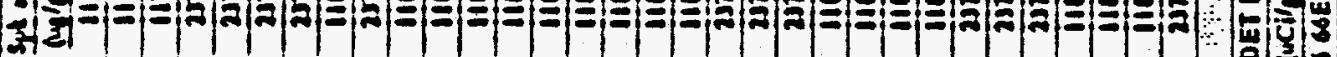

히히항

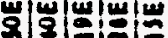

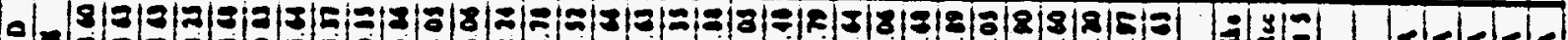

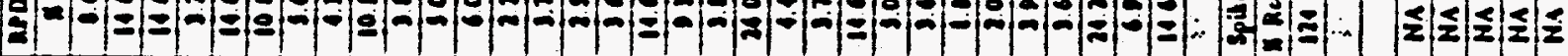

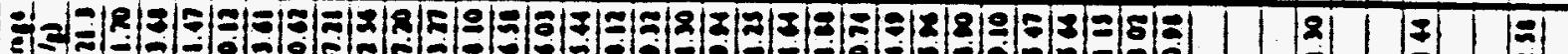

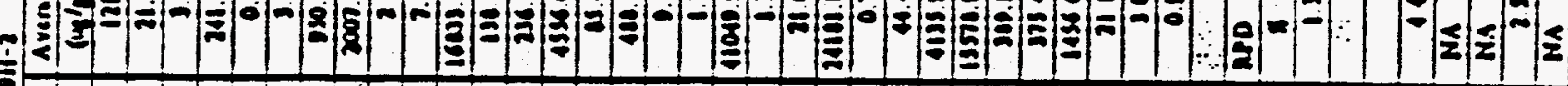
$=$ =

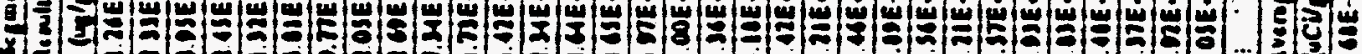

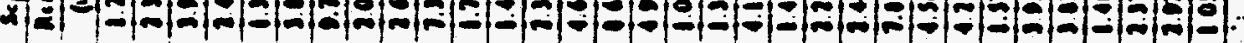

(5)

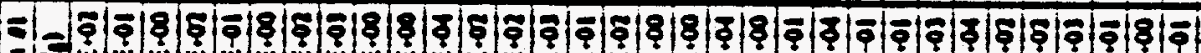

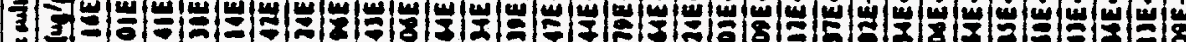

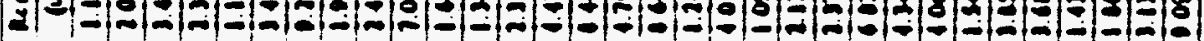

3

$\underline{z} \leq \leq \mid$

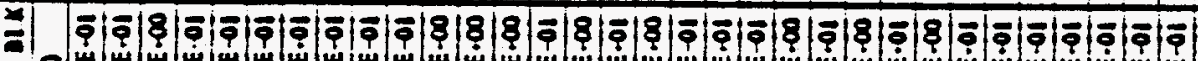

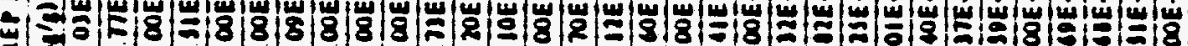

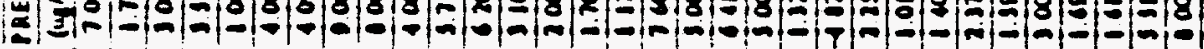

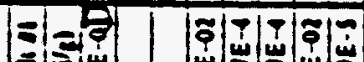

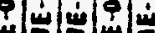

50

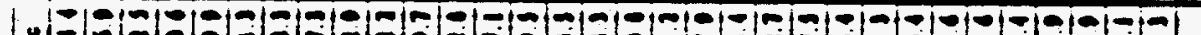

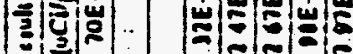

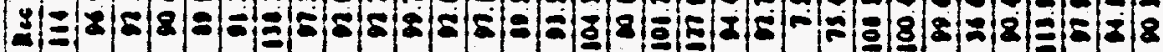

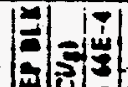

STIT/P

3.

o.

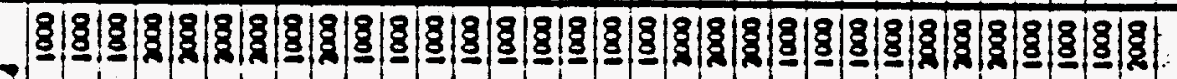

3

E) 3!:

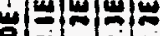

ज1

ath

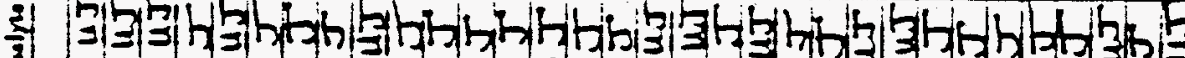

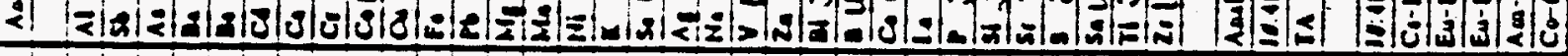




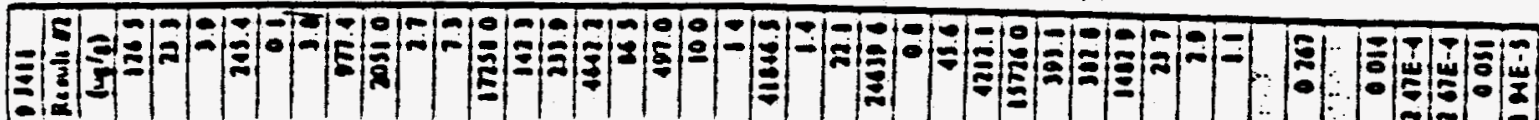

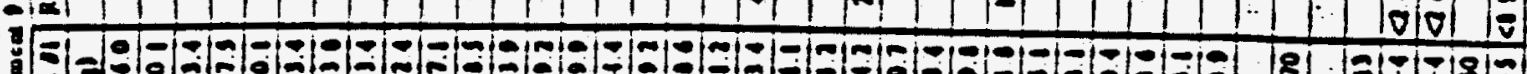
y

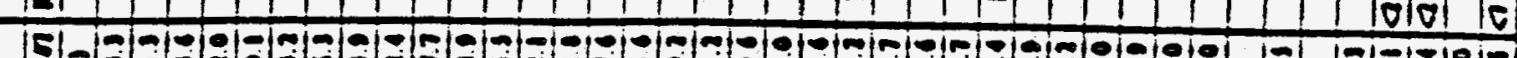

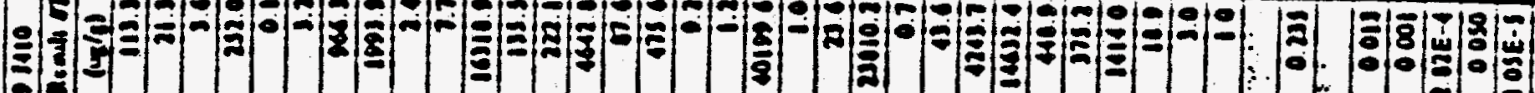
$3=1$ r 7)

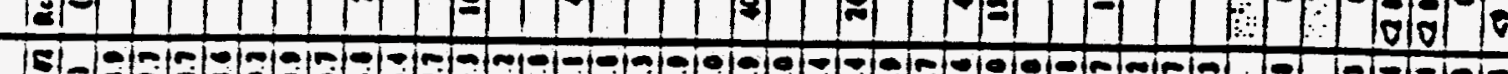
\$三丨

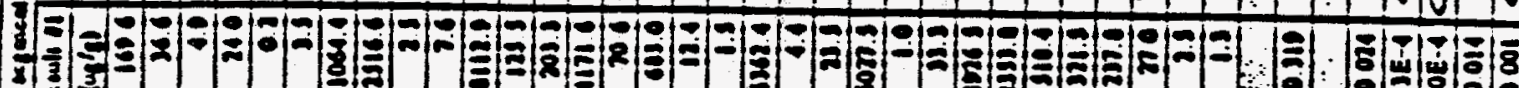

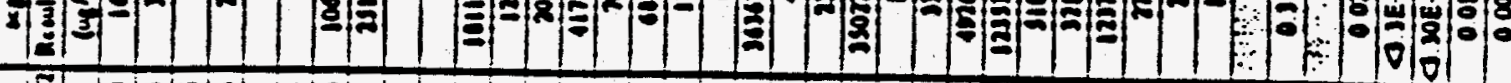

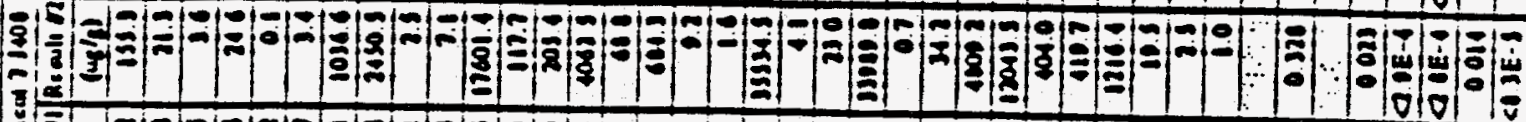

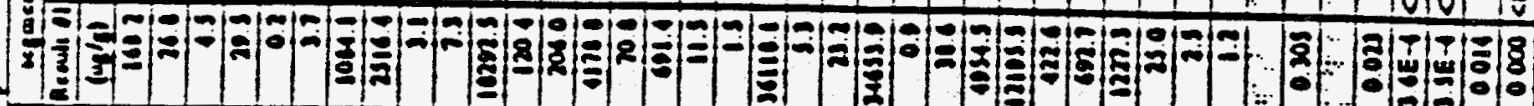

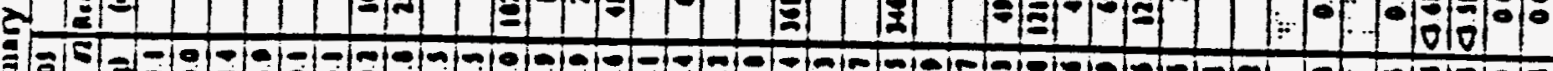

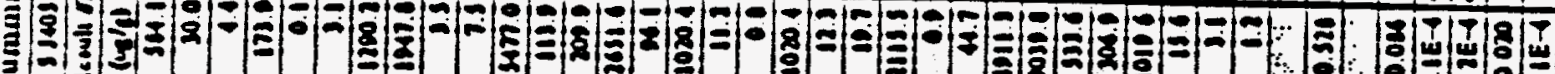

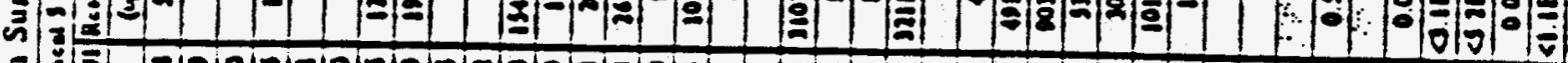

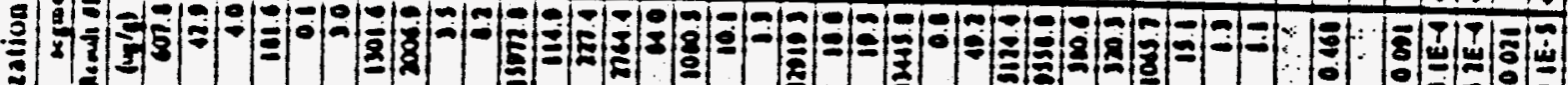
光

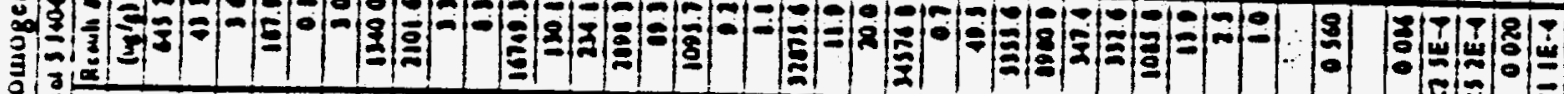
일

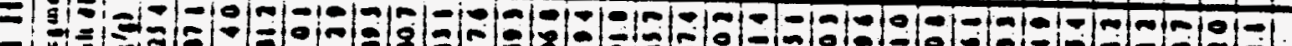

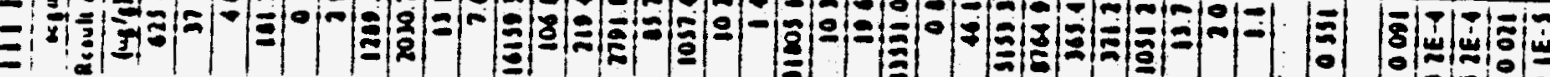

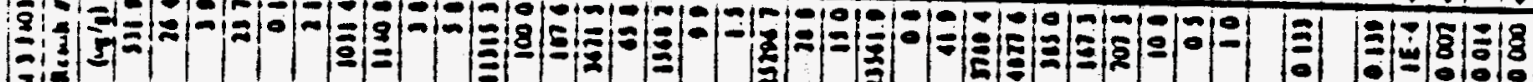

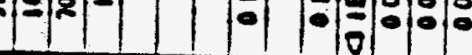

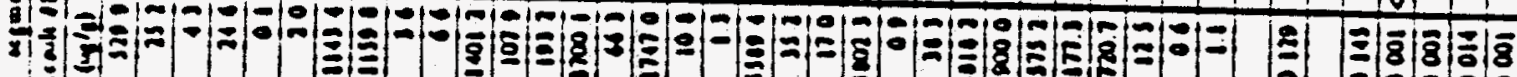
- 0 -

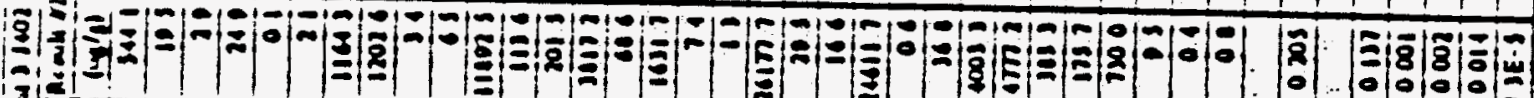

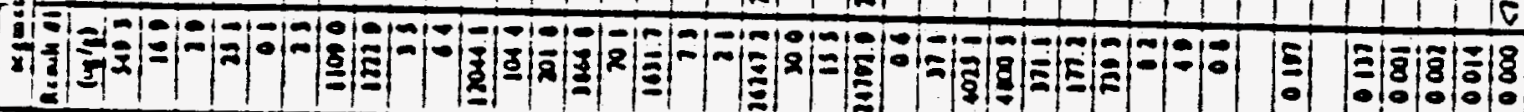

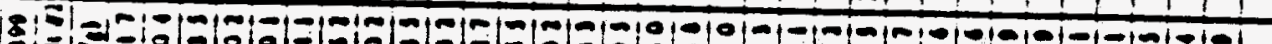

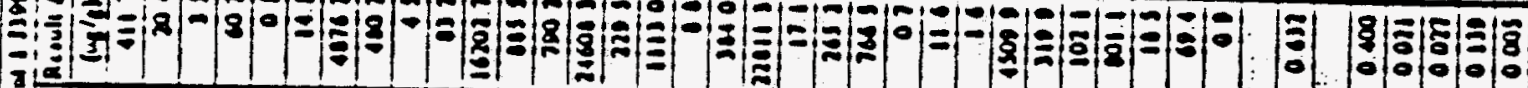

E

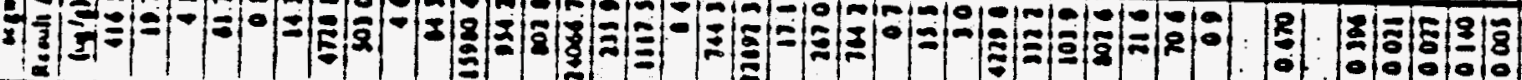

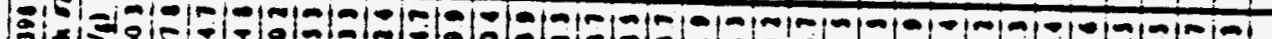

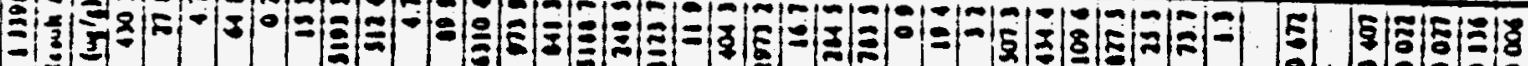
उ-

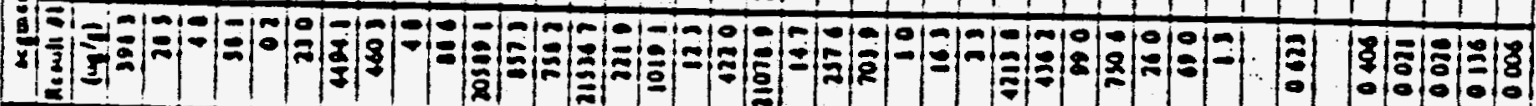

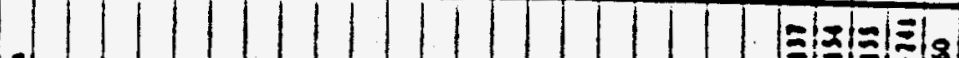

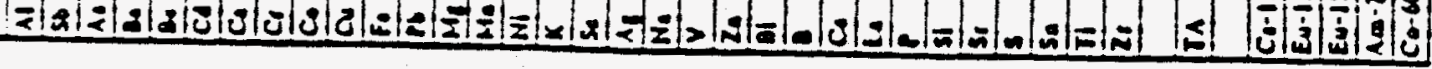




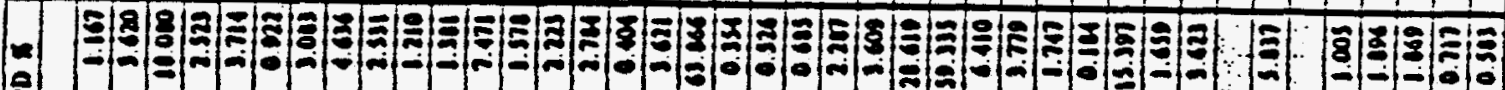

:

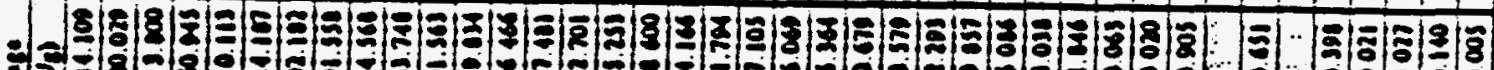

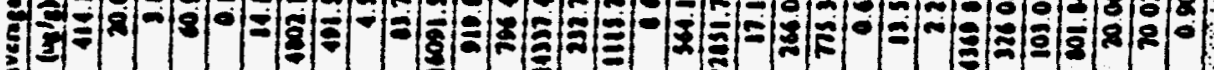

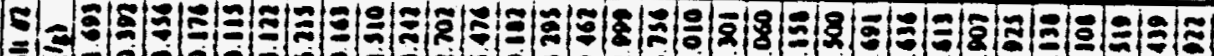

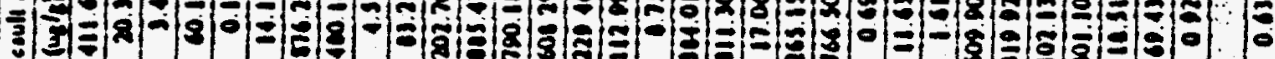

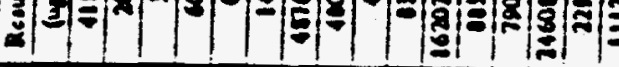

-

-

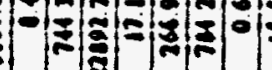

$-$

.

a

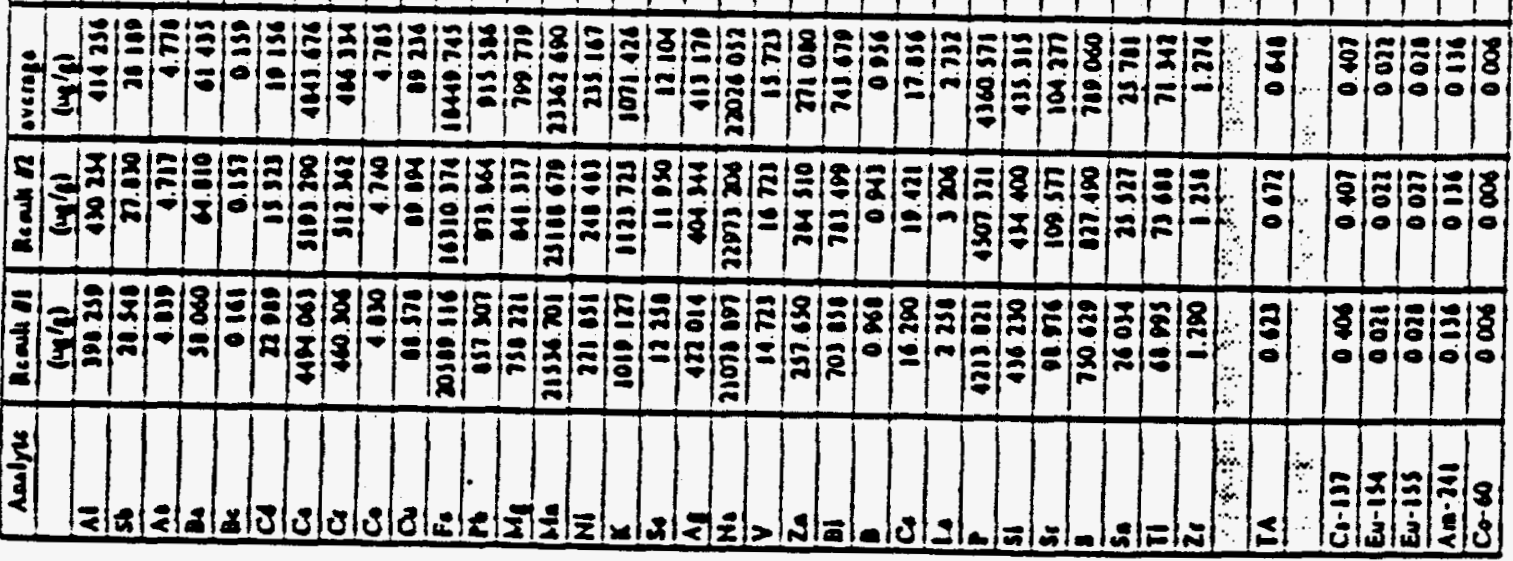

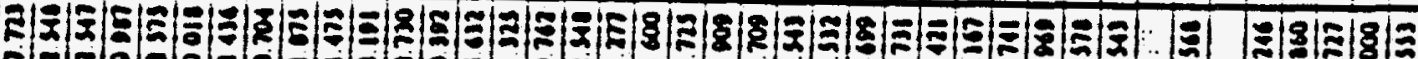

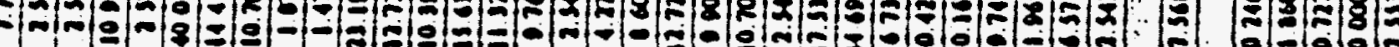


WHC-EP-0806

WHC-SD-WM-DP-024 ADDENDUM,2, REV 0

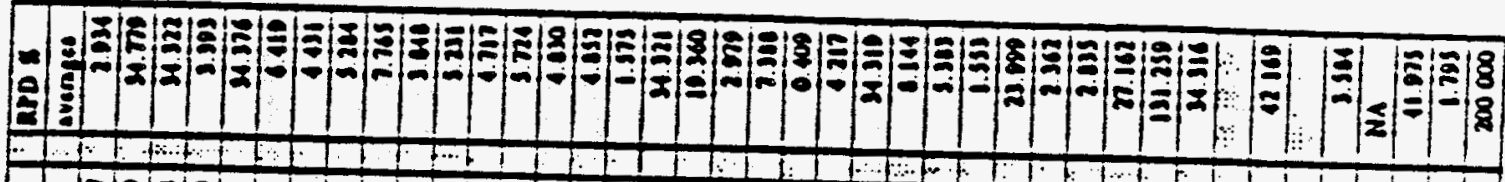
- Eิ

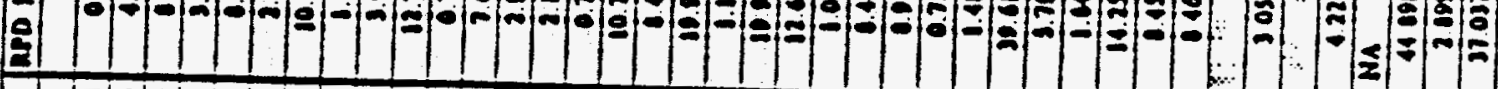

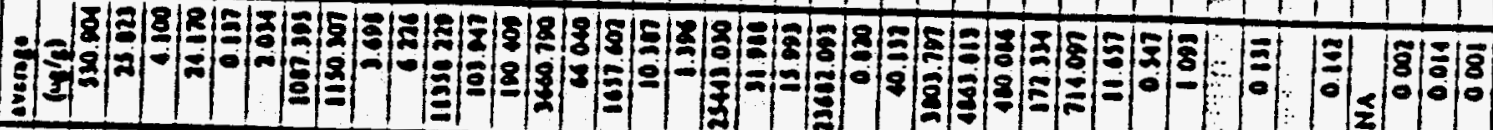

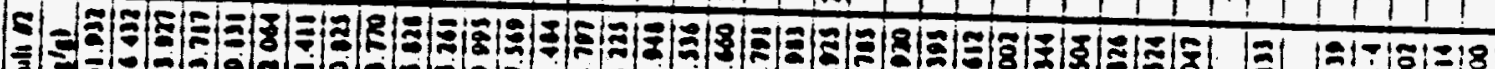

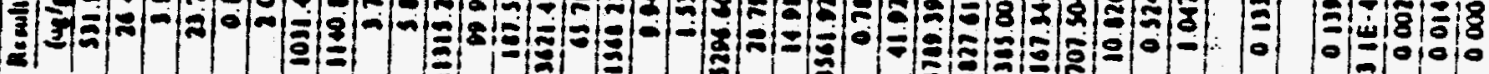

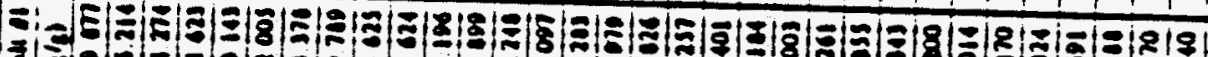

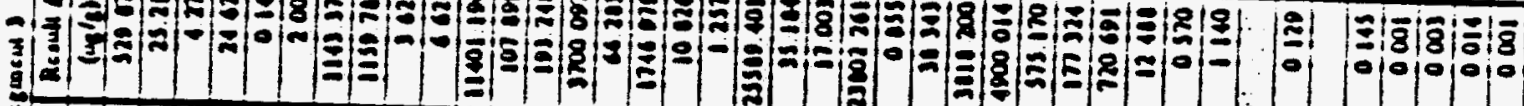

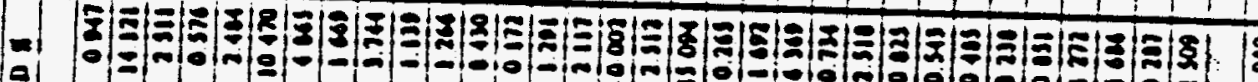

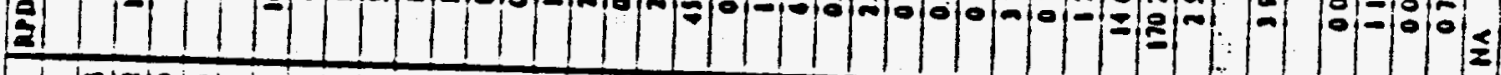
(E)

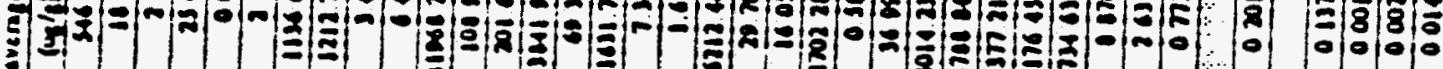

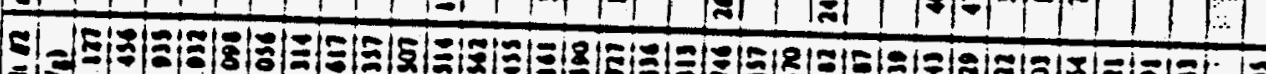

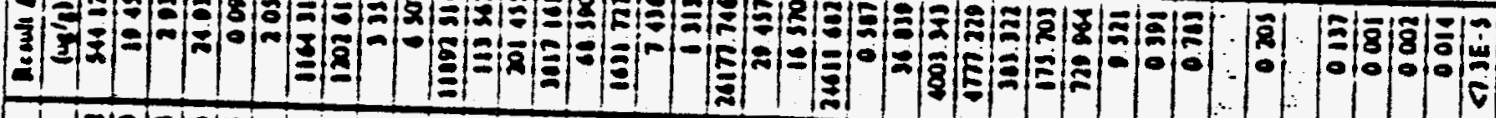

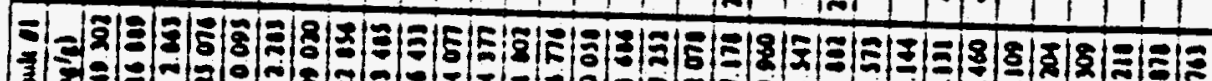

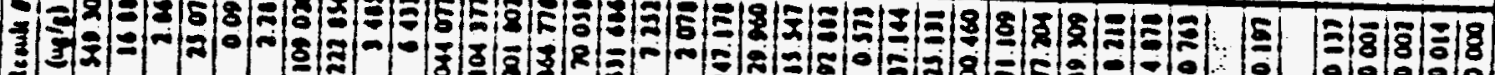
$\frac{3}{3}$ 

a

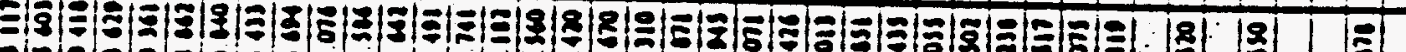

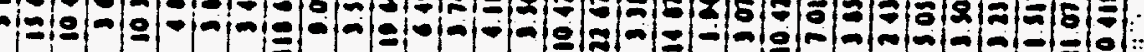




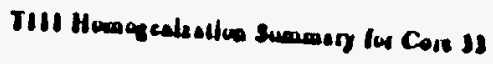

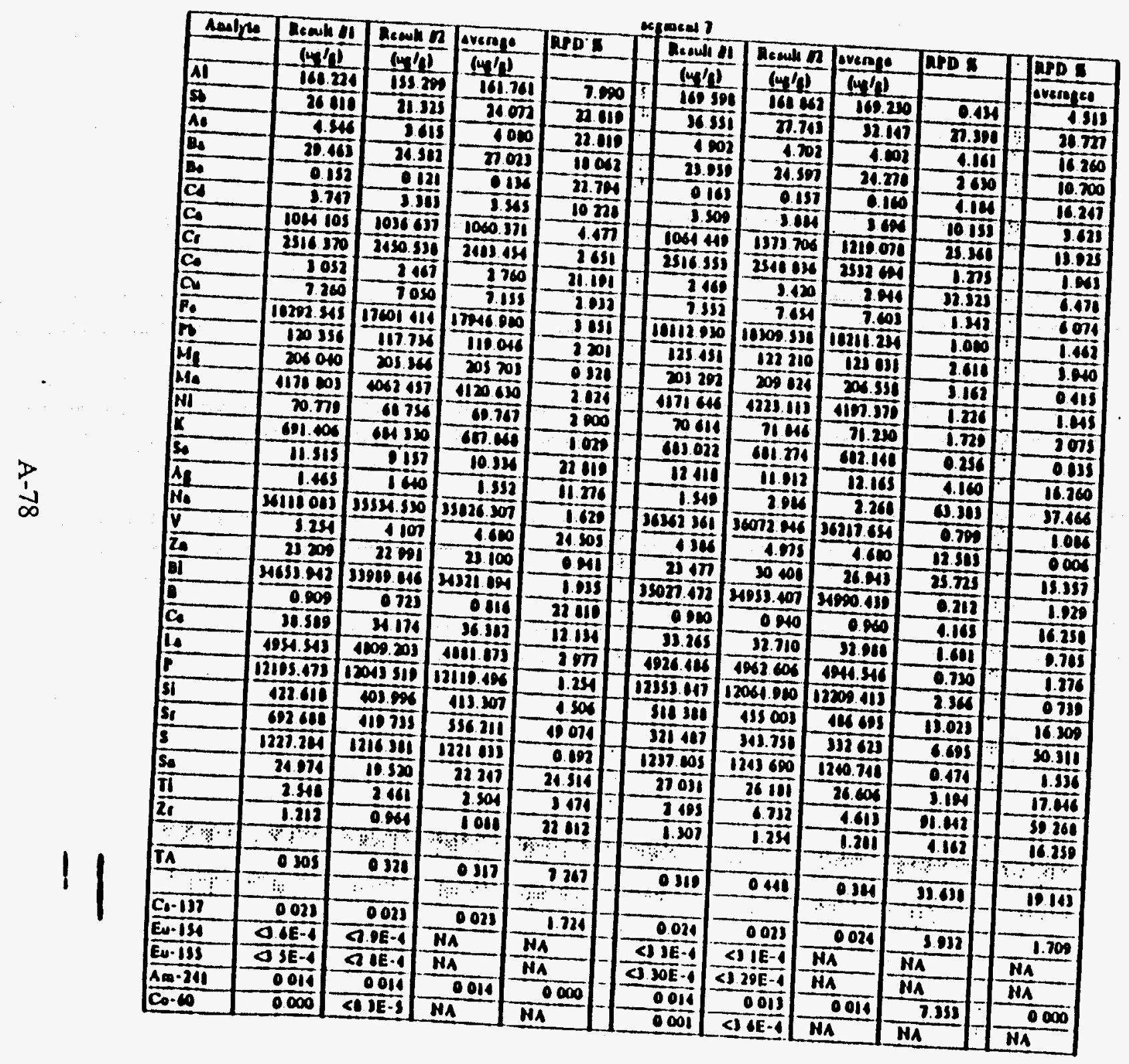


WHC-EP-0806

WHC-SD-WM-DP-024 ADDENDUM 2, REV 0

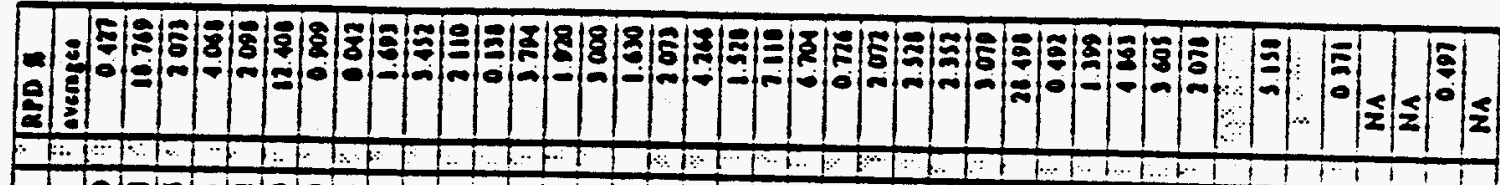

- EE E E

ह E.

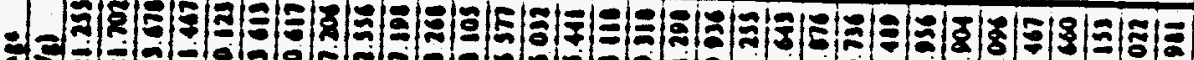

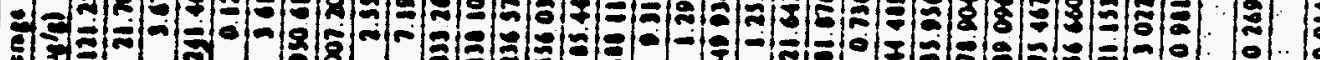

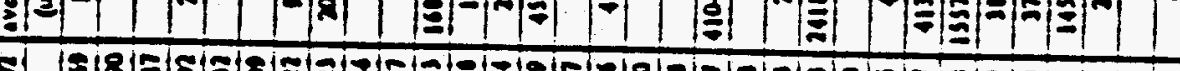

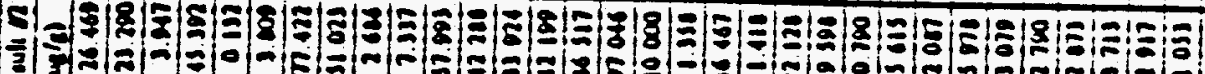

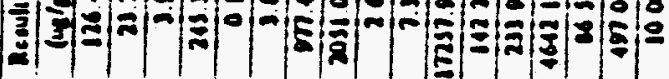

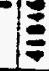

-

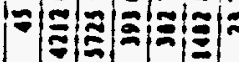

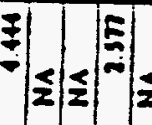

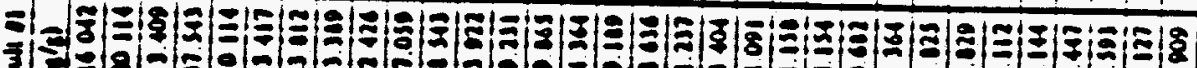

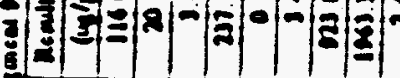

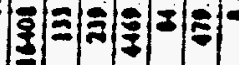

के

$=$

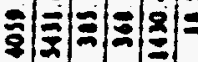

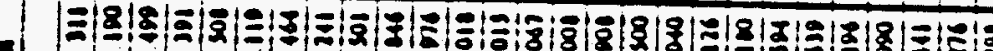

ลิ)

$=$

$|\leq| \leq\left|\begin{array}{l}R \\ 0 \\ 0 \\ 0\end{array}\right| \leq \mid$

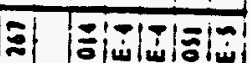
a) $|\sigma| \sigma|| \frac{1}{|c|}$

.

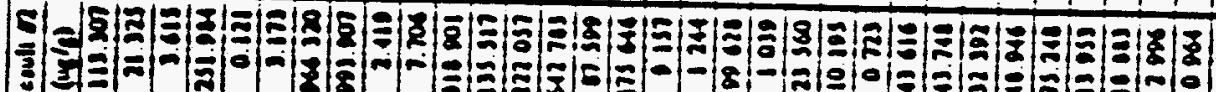

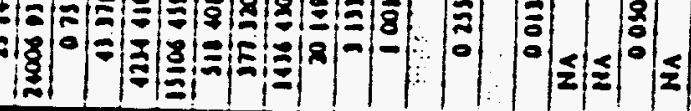




\begin{tabular}{|c|c|c|c|c|c|c|c|c|c|c|c|c|c|c|}
\hline $0, r e$ & Andyna & Iman & & renes sux & Arand II & nowh n & Anomis & Aso & stens & yile & DET LM & Roste & $=1$ & Mol L \\
\hline & & ested & Mno & $m^{\prime} w$ & $x^{\prime} \underline{e}$ & Mutu & $\left(n x^{\prime}\right)$ & 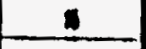 & $(4 / 2)$ & $\ln$ & $(n) / 4)$ & NOL & hen & $\left(w_{1}^{\prime \prime}\right)$ \\
\hline$A r \cdot A G A$ & $\begin{array}{ll}1 \\
0\end{array}$ & $\$ 000$ & $142 \times$ & $1.42 E-01$ & I. ME -.02 & $0.118-02$ & ARE-O & 64 & 32.11 & n.10 & 200.00 & 19061 & & \\
\hline & $D$ & $\infty_{0}$ & 110 & DE- $\mathrm{n}$ & $11 \mathrm{~J} 1.00 \mathrm{E}-01$ & $2.008-01$ & B.SPE-0O & 41 & 8..11 & 25.10 & L.ME-01 & 2.03 & & \\
\hline & An & now & ase & $1000-\infty$ & 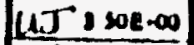 & $0.306-00$ & 1.482 .00 & 1.08 & 21.01 & 0.10 & $1000-\infty$ & 1.01 & & \\
\hline & 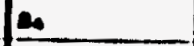 & 10000 & a.. & $0.00 E-91$ & I & COIE-01) & B SOEE-OI & 0.40 & D16.0. & $\infty \infty$ & $200 E-01$ & min & & \\
\hline & le. & 10000 & $n=0$ & $1.006-01$ & LIT I DUE-01 & $0.032-03$ & $1.178-01$ & I.n & 114.11 & 101.20 & $1.00 E-01$ & 1.11 & & \\
\hline & a & 10000 & 01.10 & $1.00 E-01$ & I $1.70 \mathrm{E}-\infty)$ & 1008.00 & $1.00 E-00$ & 110 & B11.u & $n \cdot \infty$ & $0.00 E-01$ & 100 & & \\
\hline & c. & 10000 & $112 \times 0$ & $1138-01$ & I : N0E-01 & (.42E-0) & (.4PE-0) & OM & 114.01 & $110 \times 0$ & 1.0E-DO & 210.82 & - $\bar{x}$ & 00 \\
\hline & c & soo & en w & $0000-01$ & I $1028-01$ & $303(-0)$ & 2008.03 & 1.18 & 01.4 & 130.20 & 0 OOE-O! & 209311 & e.in & 은 \\
\hline & co & ${ }_{10000}$ & $11 \infty$ & $0006-01$ & uT $1.108-\infty$ & D.1SE-D & 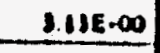 & 16 & 114.11 & D..60 & 1.00E-01 & 0.01 & 도 & \\
\hline & $\alpha$ & 2000 & 1100 & $1000-01$ & I I.NE-OI & LAE-OI & I.ME-OI & 0.01 & s1.41 & 0.00 & $0.00 E-01$ & Q1112 & 축 & \\
\hline & r. & $\infty$ & 1010 & DUSE-OO & I l.ME-or & $2.142-04$ & 1.11E-OA & 1.4 & II.11 & 20100 & $1.00 E . \infty$ & 11462.8 & od & \\
\hline & ro & soxu & n.. & 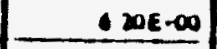 & $I$ I01E.0? & $200 E-02$ & $2.016-02$ & 0.50 & 37.4 & 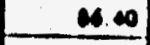 & $0.20 E-\infty$ & 22.11 & 3 & $\frac{1}{\Sigma}$ \\
\hline & Mu & $\$ 000$ & $104 \times$ & $3012-00$ & I SOTE-OI & sore-n & sose-n & 1.82 & 02.11 & on.e. & $100 E-01$ & $1011 \times$ & त् & $\frac{1}{\rho}$ \\
\hline & 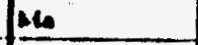 & 2000 & 1110 & $2000-01$ & $J$ A. TE & Cose.0s) & (.ne-0s & $1 . n$ & 31.01 & 101.00 & $200 E-01$ & 114612 & 0.9 & T⿱宀丁 \\
\hline & NII & soo & $\infty$ & 1. $206-\infty$ & I 1.10E-0n & $1.00=\cdot 0 ?$ & $1.10 E-0$. & en & 87.41 & 103.20 & 1.70E-a & A.4. & $\cdot g$ & e \\
\hline & $\underline{E}$ & 3000 & 100.20 & 1.11E-01 & {$[\quad[\quad n \in-0 s$} & $0.218-01$ & 1.21E-03 & 0.0 & $\pi .4$ & 0.0 & $1.12 E \cdot 01$ & 100.4 & 0.02 & $\begin{array}{l}\infty \\
0 \\
0\end{array}$ \\
\hline & so & 2000 & HN & $i \omega \in-\infty$ & 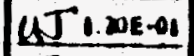 & C COE-D & 1.038 .01 & 31.0 & 30.4 & 09.00 & 1.00E-00 & 1.4 & 9 & \\
\hline & $A_{1}$ & 2000 & 1010 & SOOE-O1 & $I$. J10.01 & 1.41E-01 & $0.43 E-01$ & 1.4 & 8.41 & 10000 & SODE-01 & H. & 4 & \\
\hline & $\mathrm{H}_{2}$ & 10000 & 10100 & $C$ COE-OI & $I$ SOSEA & D.415-04 & 1.002 .04 & 0.21 & 111.01 & 14.6 & $1.100-\infty$ & 11mis & (ii) & 0.02 \\
\hline & $v$ & 10000 & M.10 & $8.00 E-01$ & $I_{1.426-01}$ & 1.18E.01 & e.10e-01 & A.n. & 114.41 & +6.20 & 1.00E-01 & n.10 & & \\
\hline & $x_{0}$ & 10000 & a.no & $-23 \Omega E-\infty$ & I & 1.ME-OI & 4.43E-01 & 2.11 & I16.01 & 101.10 & $3.00 E-01$ & 101.21 & & \\
\hline & $\omega$ & 000 & 10.0 & 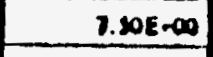 & J 2.ME $-\infty$ & 2uten & 2.09E-04 & Q4 & n..41 & $250 . \pi$ & 1.20E-DO & 100000 & $0+1$ & 001 \\
\hline & e & 2000 & 101.20 & 1.2UE-01 & UI I.NE-01 & 2ne-01 & 2ME-O1 & 1.4 & 31.41 & 31.00 & $\Delta \infty E_{-01}$ & 0.0 & & \\
\hline & c. & $\$ 000$ & n.x & 1016.01 & $1 \mathrm{LT}, 37 \mathrm{E}-01$ & $100 E-01$ & D.ME-01 & 11.8 & si.4 & 1..60 & $1.01 E-01$ & 1.03 & & \\
\hline & 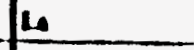 & sow & 13. & 1.0E- $-\infty$ & 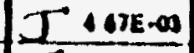 & 0.01E.002 & 0.648 .03 & 1.11 & 37.41 & 100.0 & $1.00 E-\infty$ & 2313.03 & 0.10 & 001 \\
\hline & e & 10000 & $n \omega$ & 1. DEE-OI & T $0.03 \mathrm{E}-\mathrm{as}$ & $0.01=-03$ & D.ese-02 & 111 & 111.01 & 2004 & 1000.00 & 1600.0 & 013 & eor \\
\hline & u & 10000 & 11320 & I.10E-01 & $I+\infty 06-0]$ & S.11E- $n$ & 1.20E-02 & 10.1 & III) & $+\infty$ & $1.00 E-\infty$ & cos.11 & & \\
\hline & 4 & 10000 & on.00 & SOOE-OS & $I$, one-02 & 1018-03 & $1005-02$ & 200 & 110.11 & 4.80 & $3000-01$ & 101300 & & \\
\hline & 2 & 2000 & $111 \times 0$ & $130 E-01$ & I I CAE-01 & (1.04E-0) & 1.14E-OS & 0.13 & s1.41 & $111 . \infty$ & $200-\infty$ & $\operatorname{sn} 0$ & O11 & 000 \\
\hline & 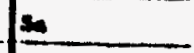 & $\infty$ & 02.20 & $2.00 E-00$ & $|\angle T: \infty,-\infty|$ & 1.116-0 & 1.01E-00 & 0.11 & n.11 & $\infty . \infty$ & 1. $.06-\infty$ & 1.11 & & \\
\hline & $n$ & $\$ 000$ & n.2.0 & 4.00E-01 & 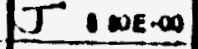 & $100 E-00$ & D.OE-OO & 2.20 & 31.4 & $\% .10$ & 1.00E-01 & n.2. & & \\
\hline & $\mathbf{z}$ & 10000 & $\infty \times 0$ & $000-01$ & $11 \mathrm{~J} \cdot$ DE 01 & $.035-01$ & D.11E-0. & 1.4 & - & man & & & & \\
\hline
\end{tabular}


WHC-SD-WM-DP-024 ADDENDUM \&, REV 0

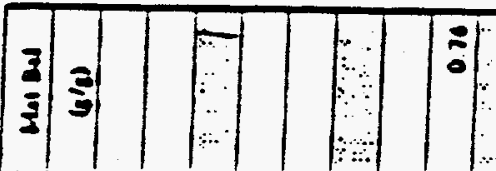

3

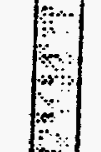

2

1

$11 \%$

है

$\leqslant$

$\leqslant 2$

.

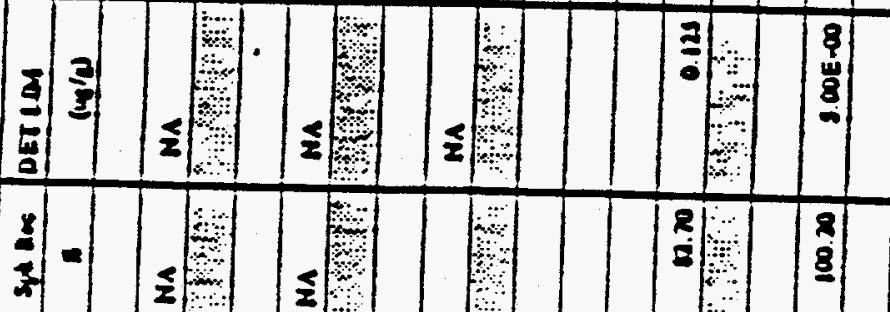

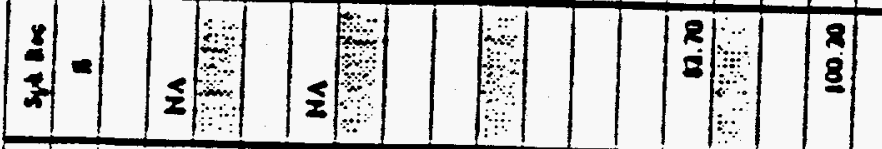

\begin{tabular}{|c|c|c|c|c|c|}
\hline$\underline{\mathbf{z}}$ & $\Sigma$ & 2 & 2 & 2 & 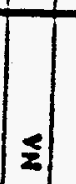 \\
\hline & & & 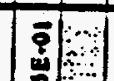 & 8 & \\
\hline
\end{tabular}

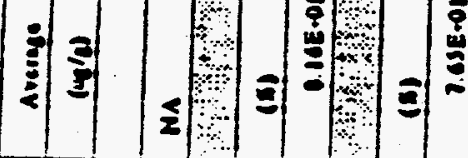

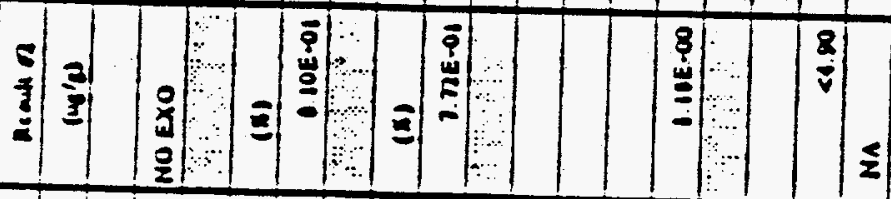

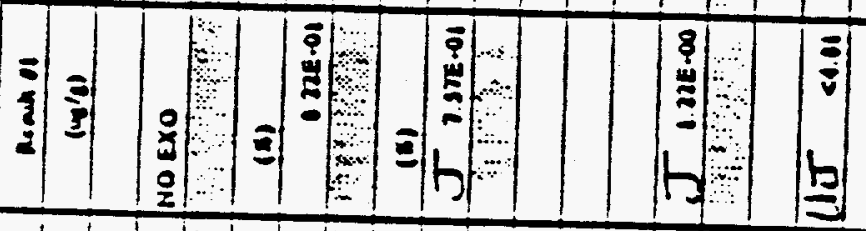

$\leq|\leq| \leq|\leq|$

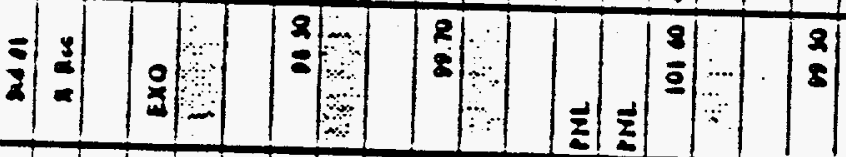

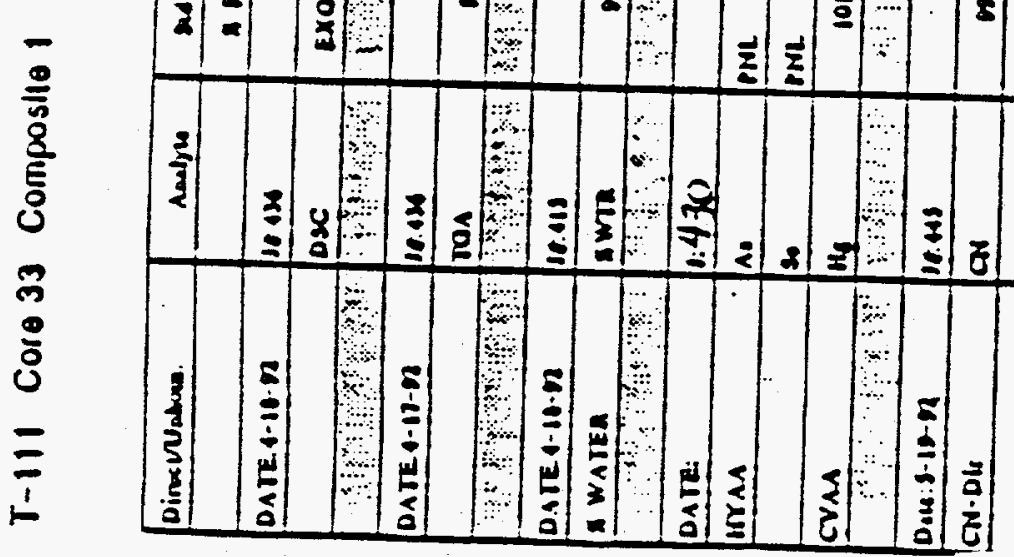




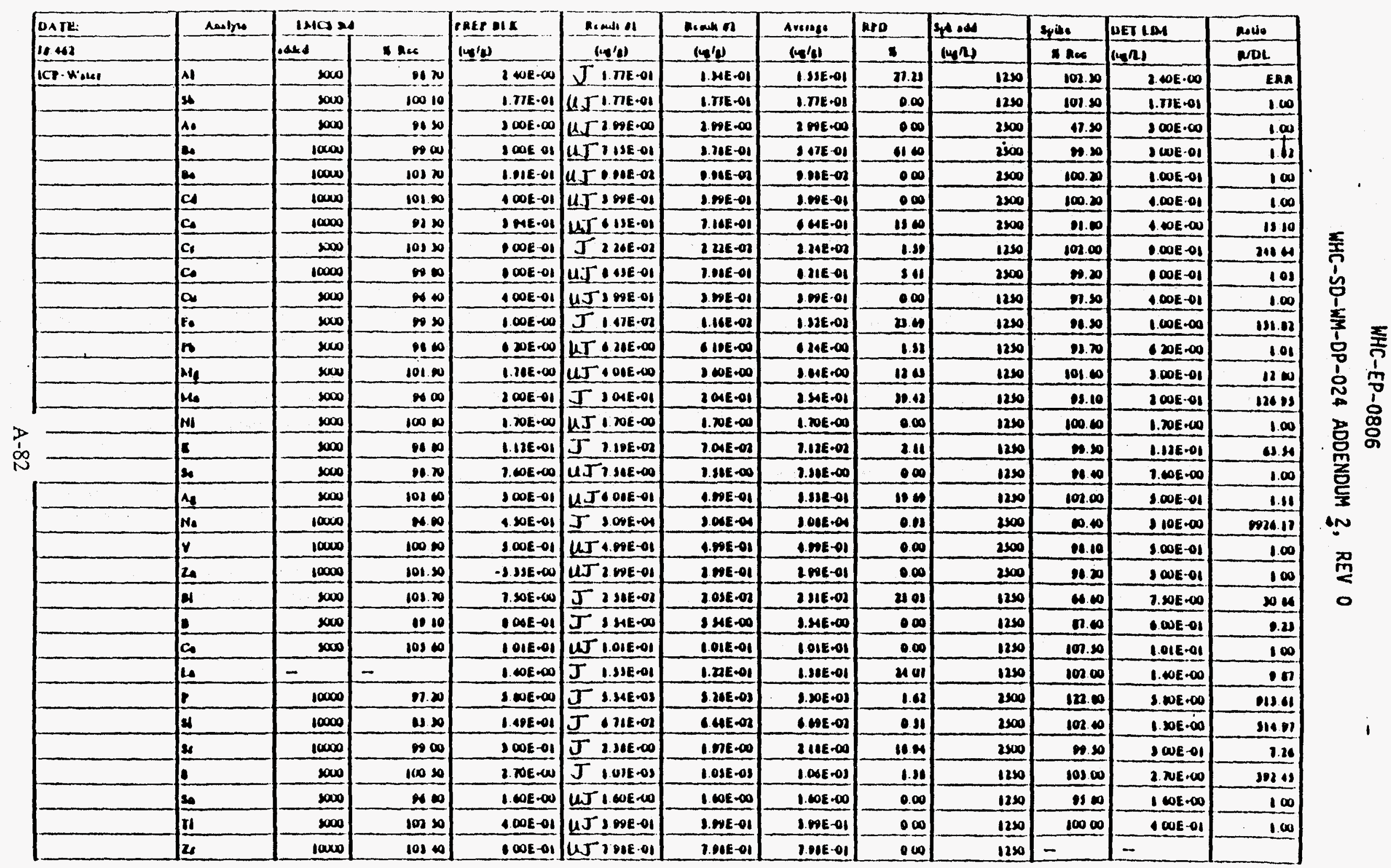


WHC-SD-WM-DP-024 ADDENDUM 2, REV 0

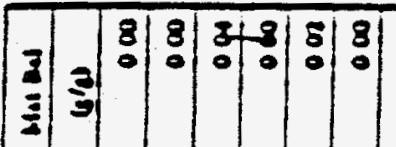

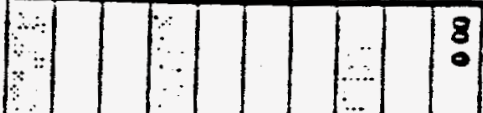

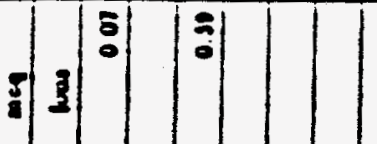

.

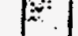

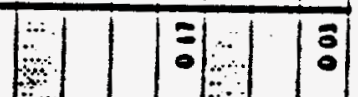

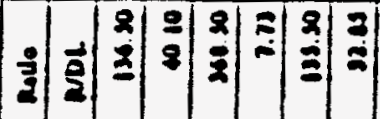

$=$ का

3.

:

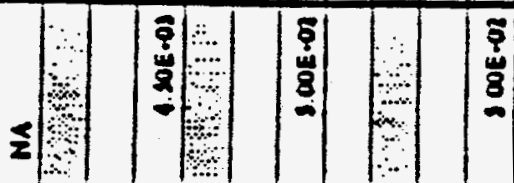

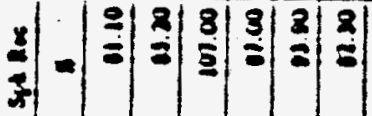

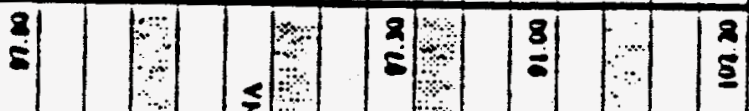

$=0$

\$

4101010 :

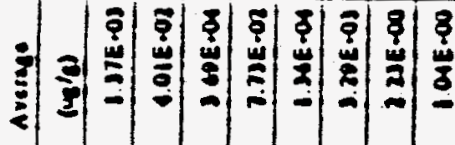

$\%$

ह खिए

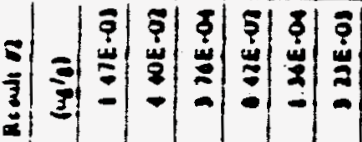

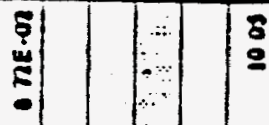

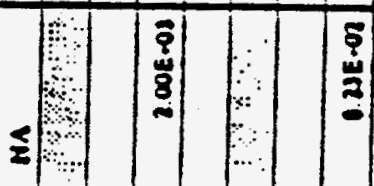

$=0: 0$

$=(3)$

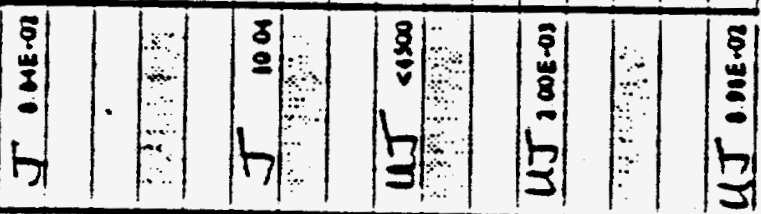

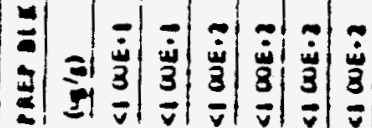

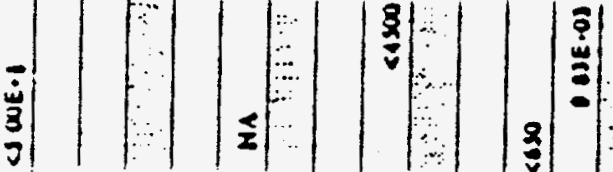

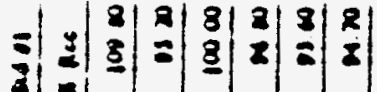

2.111 20

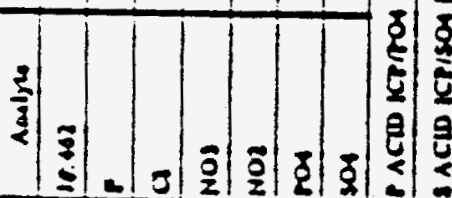

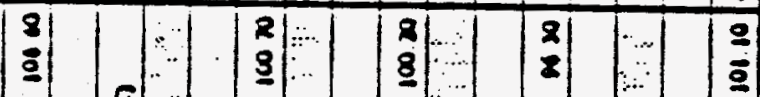

112

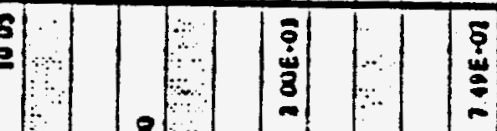

1 
WHC-SD-WM-DP-024 ADDENDUM_2, REV 0

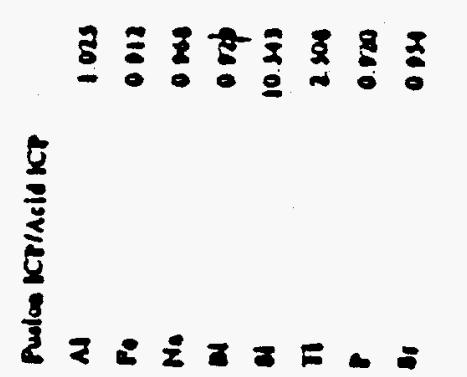

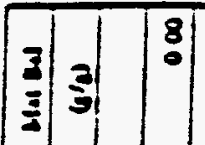

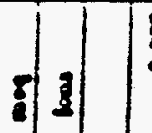

:

.

$-1$

(3)

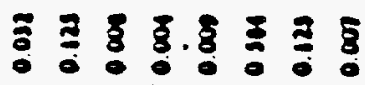

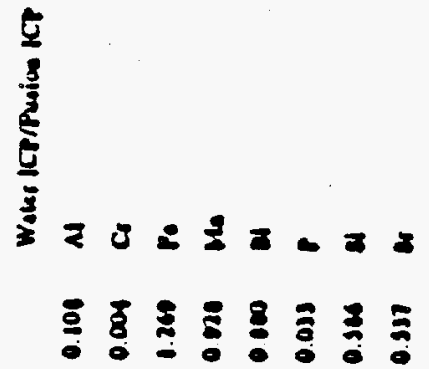

(3)

$=$

3

$4 \sqrt[2]{\div} \div$

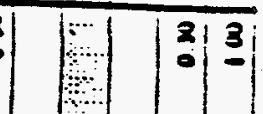

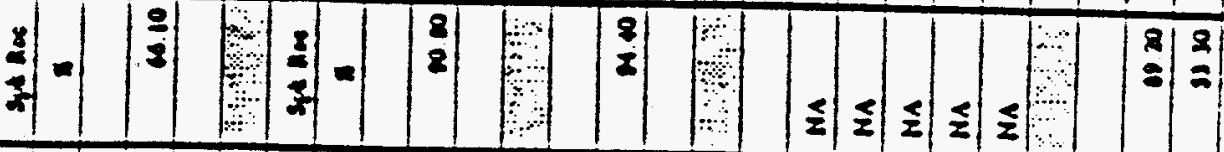

-

-

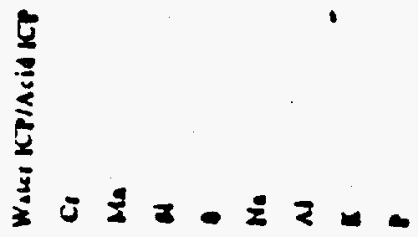

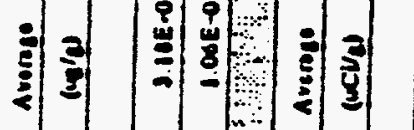

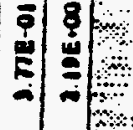

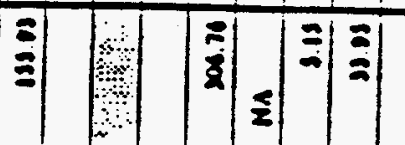

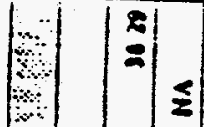

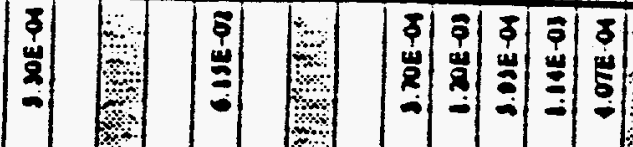

का 5

8

\&

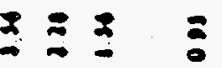

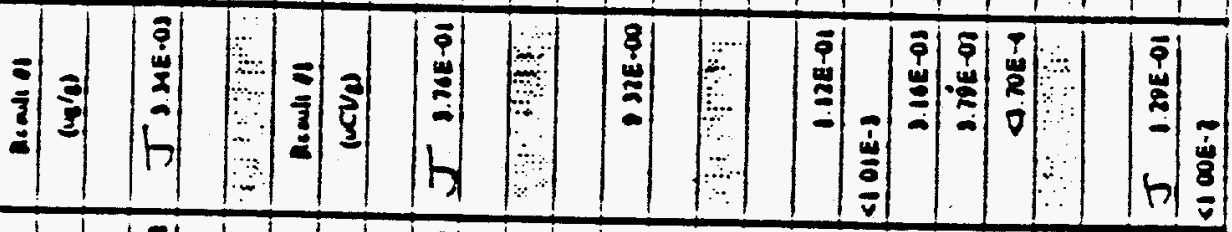

\begin{tabular}{|c|c|c|c|c|c|c|c|c|c|c|c|c|c|}
\hline & 岁 & $\begin{array}{r}\mid \\
0 \\
\end{array}$ & $\overline{\dot{u}}$ & 8 & & $\left|\begin{array}{c}\tilde{y} \\
\dot{u} \\
\dot{v}\end{array}\right|$ & 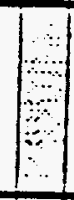 & 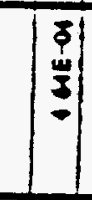 & $\frac{\bar{u}}{\bar{v}}$ & $\mid \begin{array}{l}\bar{s} \\
\bar{v}\end{array}$ & & & $\left|\begin{array}{l}1 \\
0 \\
0\end{array}\right|$ \\
\hline & $\mid \begin{array}{l}\frac{8}{a} \\
a\end{array}$ & $6=$ & & 11 & & 2 & & $\left|\begin{array}{l}8 \\
2\end{array}\right|$ & & & & 8 & \\
\hline
\end{tabular}

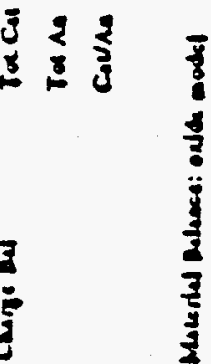

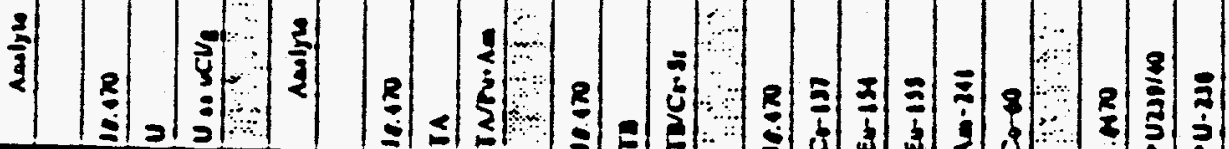

\%
0
0
0
$\overline{0}$

(2)

$\because$. 
WHC-SD-WM-DP-024 ADDENDUM 2, REV 0

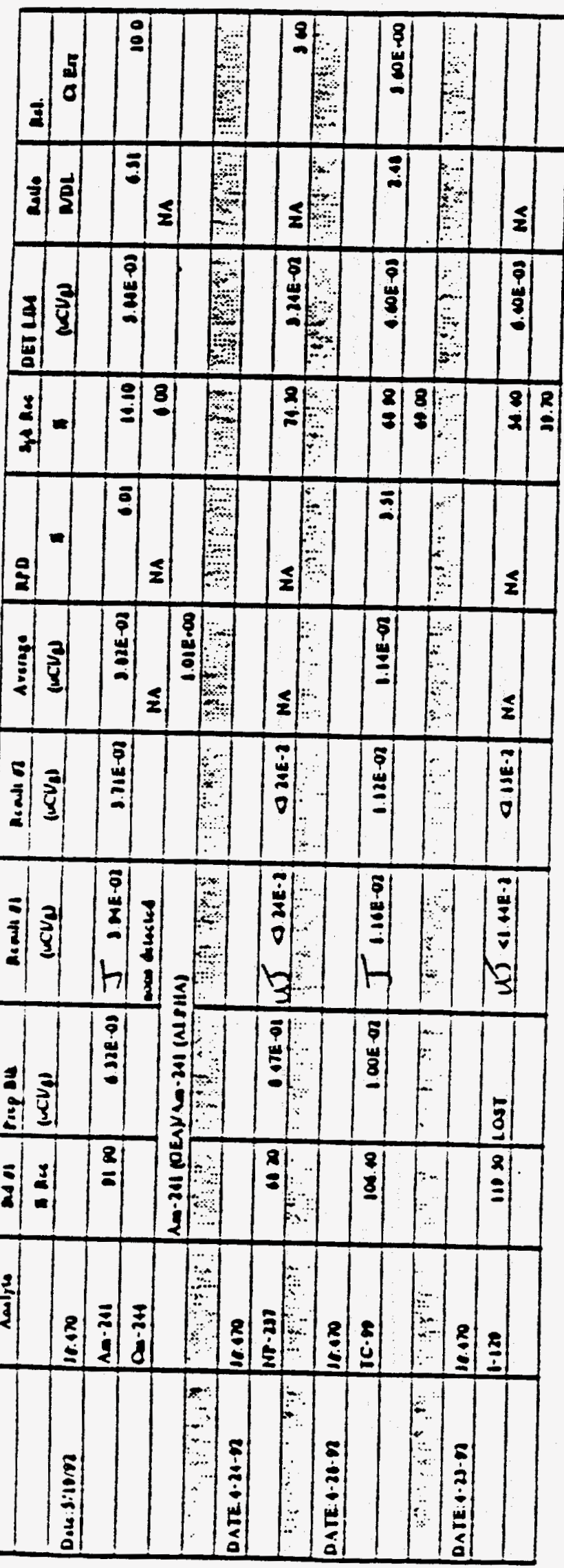




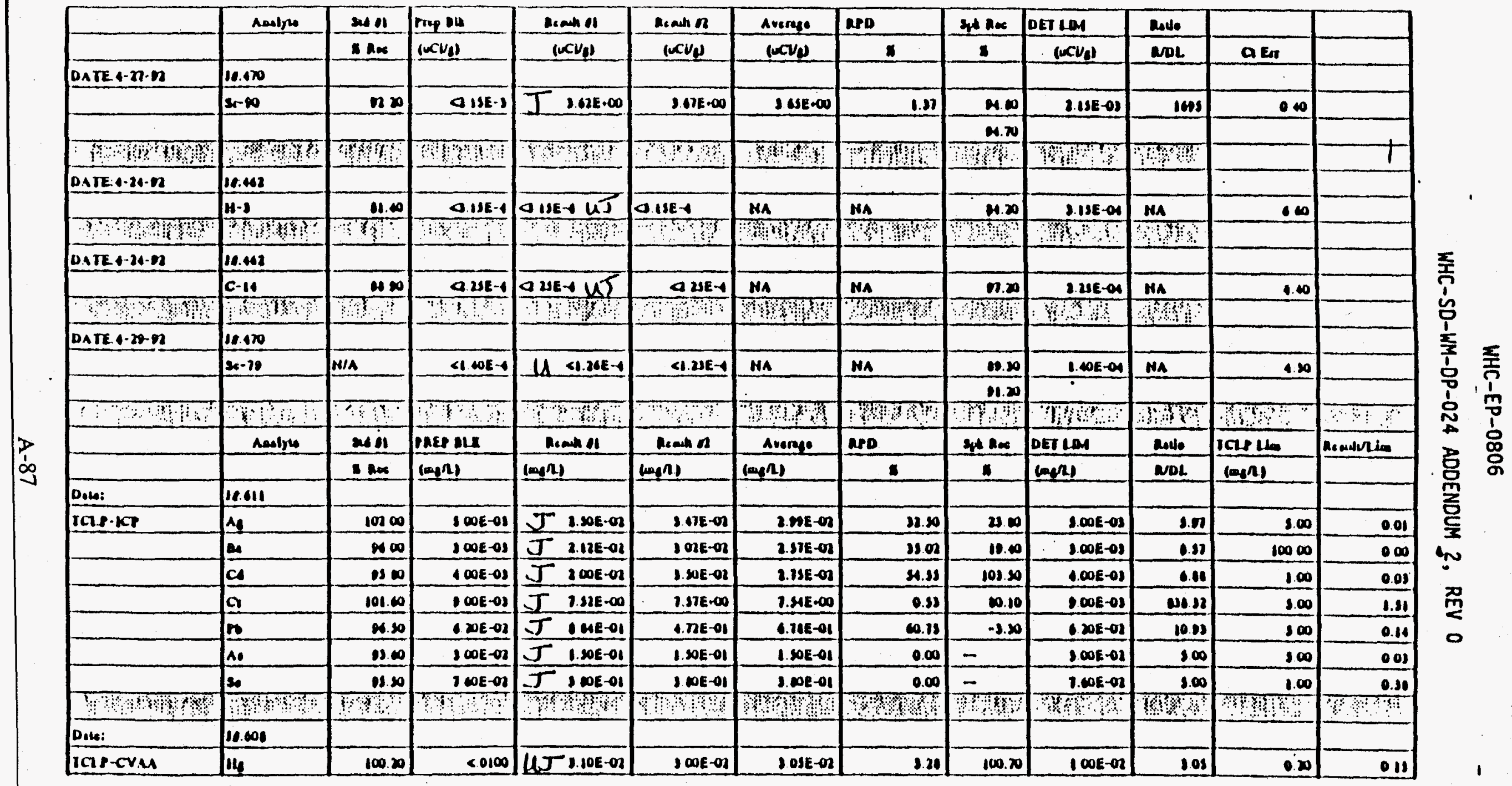




\begin{tabular}{|c|c|c|c|c|c|c|c|c|c|c|c|c|c|c|}
\hline & & - & - & $\infty$ & - & 1111 & $10-2910$ & $10-3110$ & $10-30 \times[T$ & $10-3000$ & or as & 00001 & 2 & \\
\hline & & 1111 & $10-3001$ & 1014 & 110 & 121 & oo. $3 \times 18$ & $\cos 30$ & $00-300$ & $10-3001$ & $0 \mathrm{n}$ & 10006 & ul & \\
\hline & & 101 & coston' & 010 & ines & 011 & con-210' & $\infty x+1$ & $00-3001$ & $00-360^{2}$ & a 10 & noot & - & \\
\hline$\infty$ & 110 & 10180 & $\infty+3 \times 2$ & an 211 & $11 \cdot 26$ & $m 0$ & $10-3 \mathrm{nt}$ & costai & ro-3at I & $10-30 t$ & 0111 & 0006 & 1 & \\
\hline 1 & & $11+111$ & $10-3001$ & $\infty N$ & 11011 & 16.1 & to-3ne & conglet & cosits $E$ & $10.300 \mathrm{~s}$ & 0.16 & 00001 & 2 & \\
\hline & & atot & 00.7001 & $\infty n$ & 10111 & 111 & 10-3h's & $20-3001$ & to-3net & 10-910 & anses & 00001 & n) & \\
\hline 100 & 011 & ritent & oosens & on ont & $10 \cdot 11$ & $n$ & $00-361.6$ & n. 1111 & $10-3011$ & $10-3 \times 1$ & 016 & 000001 & 1 & \\
\hline 100 & 110 & 10016 & 00.3001 & 0101 & Btes & 81.8 & $(0-700)$ & $10-2110$ & $10.3 n 1$ & $00-3001$ & 11 & 0006 & 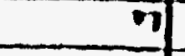 & \\
\hline & & ert & 10.3101 & on'ts & II) & 1011 & $10-2016$ & 10.3911 & $10-3018$ & 1091101 & $a$ & 0006 & $\infty$ & \\
\hline & & 2018 & $10-3001$ & $x \times$ & ints & ate & $10-30.8$ & 103001 & $10-3 n+5 n$ & $10-3(2)$ & 0101 & $\infty$ & 9 & \\
\hline 100 & & of rist & $00-3002$ & and & $11 \cdot 11$ & $n$ & benet & $0.3 n t$ & wates & oo-gore & 000 & 0008 & n) & \\
\hline & $\underline{4}$ & 11011 & $10-7008$ & 01001 & 18111 & one & 100.306. & 10-3int & $10-3 \times 5.5$ & $60.9012-$ & a'n & 00001 & 2 & \\
\hline & $\infty$ & 1011 & 10-7001 & 24 & 1011 & 120 & $00-340$ & oo-3010 & $10-3101 \mathrm{C}$ & $10-2008$ & orn & $\infty 0001$ & A) & \\
\hline 100 & 61 & $\operatorname{son} 11$ & $00-3018$ & 0161 & 11011 & Ao & rosto: & 10.3ros & $00-310 \times I$ & $10-360$ & 0011 & 00001 & OH & \\
\hline & ह & was & $10-1001$ & 0001 & 1126 & a.1 & $10 \cdot 3001$ & 10.3118 & $10-36115$ & $10-1005$ & 0101 & 000 & iv & \\
\hline$=\infty$ & E & 101 & $\cos 2001$ & an & $16 \cdot 18$ & 2001 & $00+342$ & 00.7110 & $00-300 \mathrm{nn}$ & $\cos 3012$ & 6010 & 0006 & E) & \\
\hline$-\stackrel{0}{0}$ & 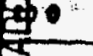 & $10 \mathrm{n}$ & 10.3t1! & oro & $10 \cdot 25$ & 210 & $10-9601$ & co.2101 & $10-3201 \Gamma$ & $10-3 t 11$ & $0<101$ & 0006 & 1 & \\
\hline-1 & & $11 \pi$ & $00.3 \times 1$ & aren & Wit & 060 & 20.7001 & 10.5601 & 10.31001 & mo-30e. & $00 N$ & 1000 & (N) & \\
\hline 11 㟧 & 6 & Dr1118 & $10-3008$ & $0 n$ & 1128 & 11 & $10-7018$ & conste & 10.3120 .1 & $10-300 t$ & 0110 & 0001 & $m$ & \\
\hline - 堊 & 0 & $10 \mathrm{es}$ & $10-3008$ & 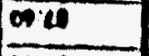 & 116 & of 1 & 10.300 .8 & $20-5118$ & $20-320 \times \Gamma$ & $00-9101$ & or 01 & mor & (111) & \\
\hline-3 & & 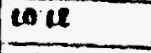 & 00.3010 & 00 & Iines & 81 & $20-2001$ & 10.2191 & $10-34011$ & 00.3021 & 0018 & 000 & 4 & \\
\hline 2 & 30 & o orces & $\infty 0.3001$ & $\infty \mathrm{nit}$ & 1126 & 101 & $10-316$ & no-atit & Do-3et $\Omega$ & on-210! & 0101 & 000 & al & \\
\hline & 官 & 00.21 & $10-3000$ & an & 116 & 100 & 10.30 .1 & $10-764$ & $100.301 \mathrm{~T}$ & 169000 & 010 & 0006 & $\infty$ & \\
\hline & (3) & 10! & $10-5000$ & osen & $18+11$ & un & $00+3108$ & $00-3118$ & mo-30e? 17 & $10-300: 0$ & 00 & 00001 & 5 & \\
\hline$\infty 8$ & \$0 & Hint & $10-3000$ & oriti & 1028 & ort & $10-3+12$ & co-31te & $100118 \Gamma$ & $10-2000$ & 20 & 000 & 10 & \\
\hline$\infty 0$ & 100 & $10 \times 0$ & $00-300.6$ & arin & 1011 & 40 & 10-ast' & $10-718$. & $60-3 n+5$ & 10.3111 & a'm & 00001 & 0 & \\
\hline & & ats & $10-3000$ & 06 & $11 m$ & 11 & Do-3et & oo.7nt & $000001 \Omega$ & $10-2001$ & 0110 & 00001 & 5 & \\
\hline & $\therefore$ & 01 & 10.3001 & Q.101 & $10 \cdot 111$ & eret & $10-3 \times 11$ & $10-210.1$ & $103001 \mathrm{~m}$ & $10-3001$ & 0110 & 00001 & n) & \\
\hline & & 1014 & $10-3001$ & 010 & $10 ! 11$ & BE: & $10-3 x$ & 10.210 & $10-3010 \mathrm{mn}$ & 103001 & 02 & 00001 & $\infty$ & \\
\hline & & 601 & $00-3008$ & 010 & 1028 & 8101 & $00-3908$ & $00-312$ & $00-3008 \mathrm{CI}$ & $00-3001$ & ort & 000 & iv & \\
\hline & & II & 100211 & $01 \pi$ & 112 & a.11 & $10-3128$ & $10-3101$ & 10-3118nn & 10.2111 & oll & 006 & 8 & \\
\hline & & of 811 & $00-3002$ & 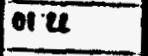 & inte & 00 & $20-3 \times 0$ & $20-3001$ & 10-310: I & $10-3101$ & ort1 & $\infty$ & $\bar{N}$ & $y^{2} y-20$ \\
\hline$\frac{0,5}{n}$ & $m$ & $70 /$ & $(1, m)$ & $\infty 1$ & (t)m & 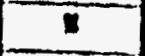 & D, & $n, m$ & $n, w$ & $n, m$ & mex & m170 & & not \\
\hline $.2 \mathrm{mn}$ & he & onis & 101130 & कs & $m \cdot m$ & $0+10$ & ofvent & 210 & $11 x+y$ & $210 \times 114$ & & tolv1 & nlowr & anvo \\
\hline
\end{tabular}




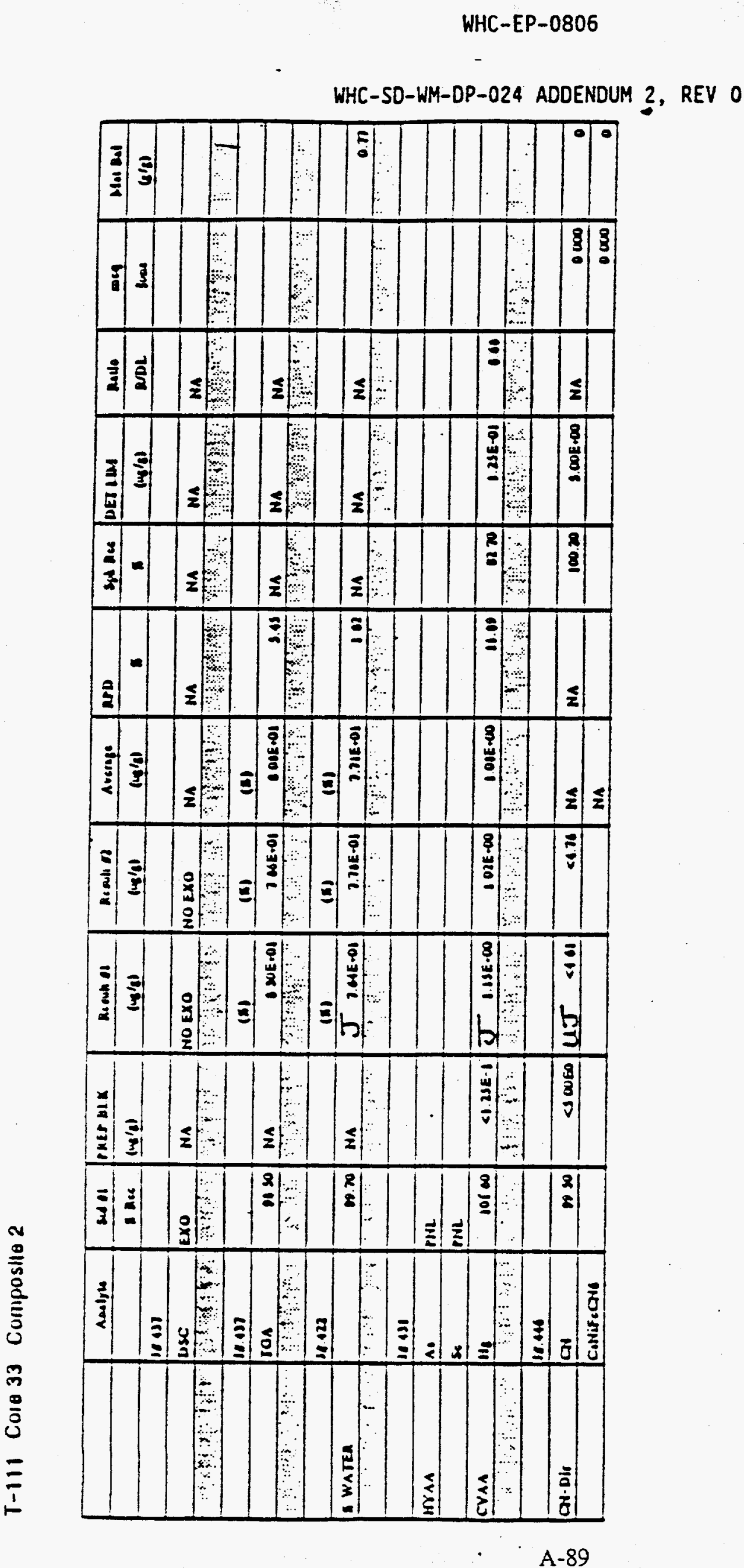




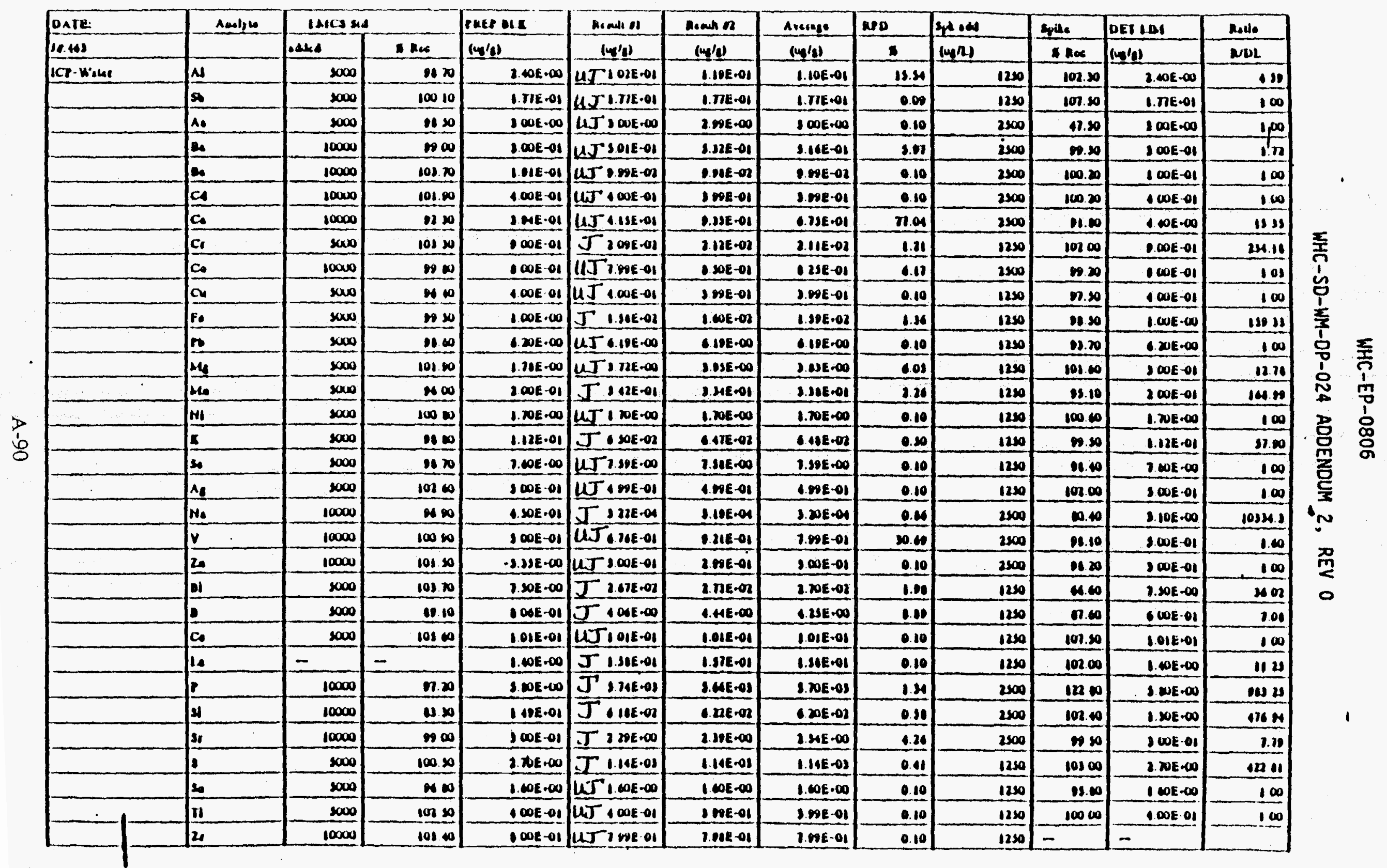


WHC-SD-WM-DP-024 ADOENDUM 2, REV 0

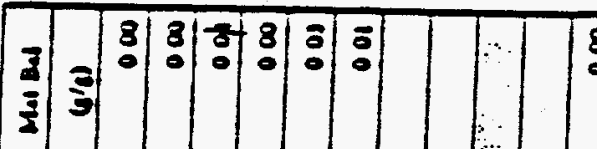

8

. $3: 0$

:!

(t:

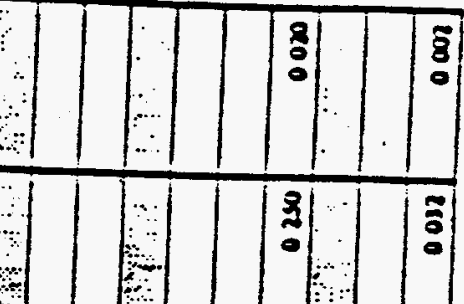

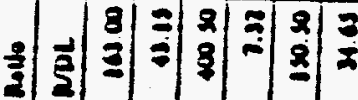

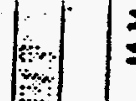

$=12$

$\div-1 \quad:$

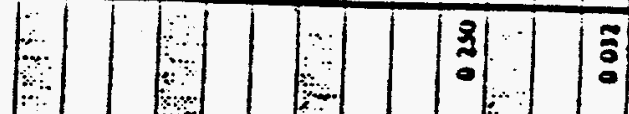

3.

है

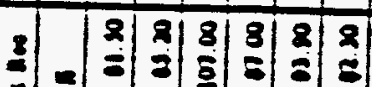

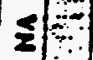

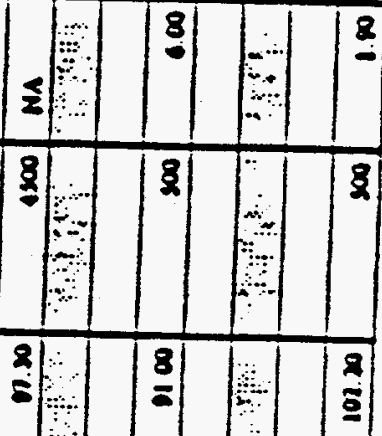

$\div 2: 30$

:

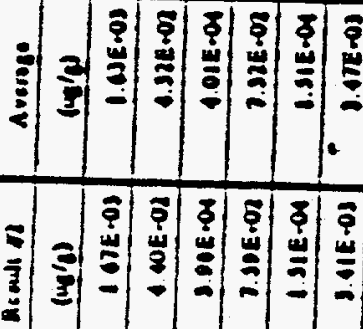

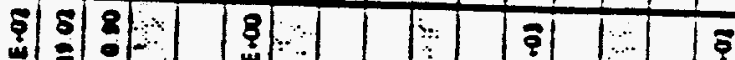

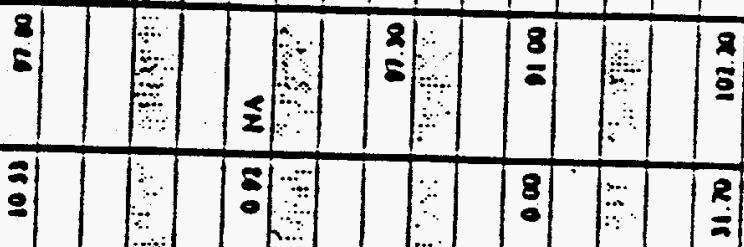

$\%$

$\pm$

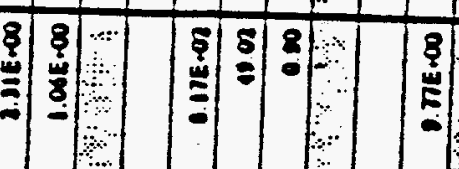

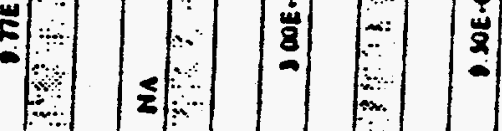

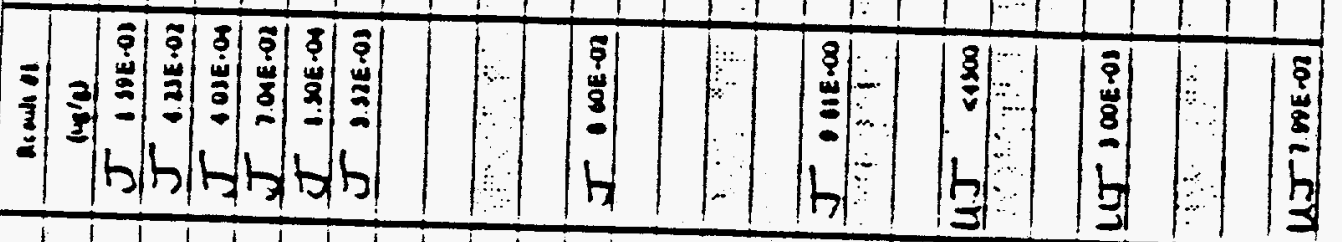

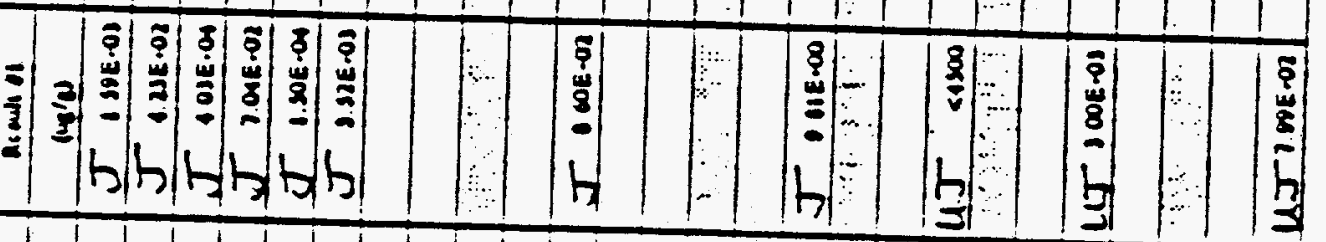

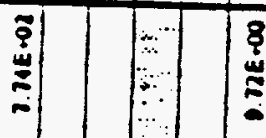

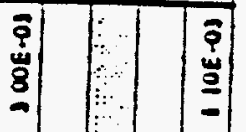

:

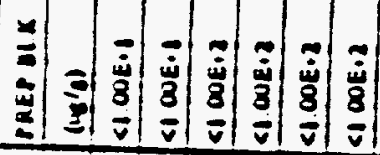

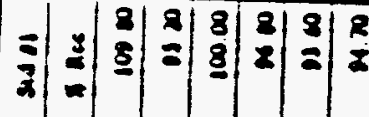

1

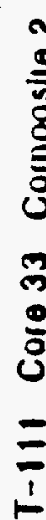

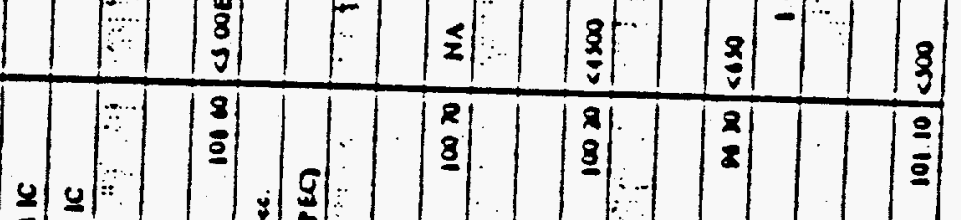

?.

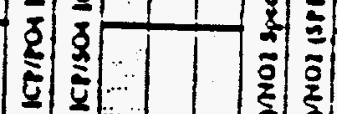

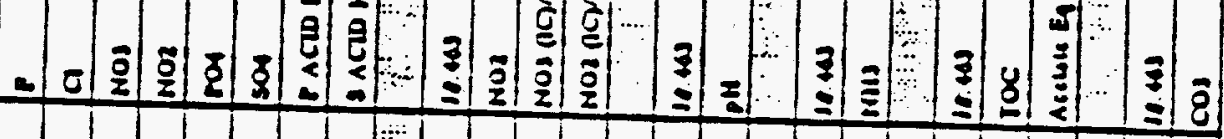

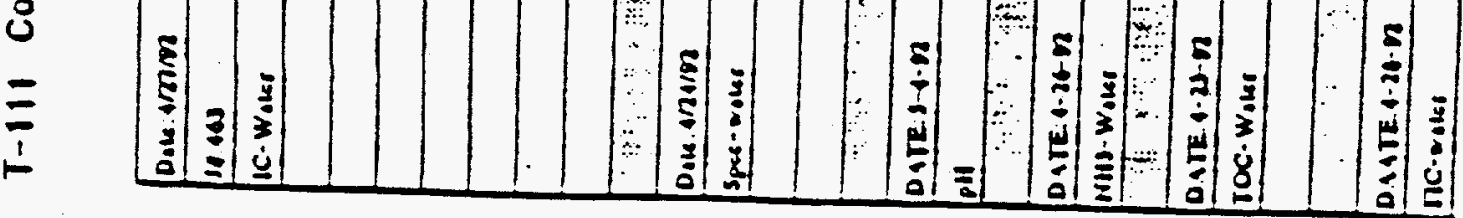




\begin{tabular}{|c|c|c|c|c|c|c|c|c|c|c|c|c|c|c|}
\hline DAIE: & Asolyu & $12109=$ & & peres wax & Acoude II & Meanin $n$ & Averege & ArD & yes & suile & DES IM & Losio & $=n$ & Mns \\
\hline 110171 & & $\underline{w}(\underline{m}) \underline{2}$ & Ine & $\left(x^{\prime}(x)\right.$ & $\left.(4)^{\prime}\right)$ & $(4-1)$ & (48/2) & 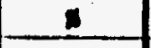 & $(x) \mu$ & Dhe & $\left(\operatorname{sos}^{\prime}\right)$ & NoL & noo & $\underline{4}$ \\
\hline ICP- Fustive & AI & s000 & 1110 & $1208-01$ & I. $20 \mathrm{E}-02$ & $1.99 E-02$ & A.SPE-O2 & 0.00 & 120 & N.00 & $1.20 E-01$ & 2125 & & \\
\hline & 50 & 3000 & $+\infty$ & - CSE-O1 & $\angle J$ IUE-OI & - OSE-OI & AnE-01 & 0.20 & 1250 & $\omega \infty$ & COSE-OI & 1.00 & & \\
\hline & A & 8000 & 1310 & $1.00=01$ & LT $1.00 \mathrm{E} \cdot 01$ & $1.00 \mathrm{E}-0 \mathrm{I}$ & 1. $.00 E-01$ & 0.20 & 2500 & 4360 & 1. $00=01$ & 100 & & \\
\hline & 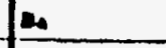 & 10000 & 110 & $130 E-\infty$ & I 1 noE-01 & 0.43E-01 & 0.87E-01 & 202 & $2 \times 00$ & $n+\infty$ & 1. $.0 E-\infty)$ & I.14.14 & & \\
\hline & $\underline{\omega}$ & 10000 & 110 & $100 E-\infty$ & $\mu \mathrm{T}$. $.00 \mathrm{E}-01$ & SOOE-O1 & A.PSE-01 & 0.20 & 3800 & $M 20$ & $100 E \cdot 00$ & 0 (i) & & \\
\hline & a & $100 \times 0$ & os 00 & 2 WE $+\omega$ & $\angle T T_{0.06 E-00}$ & C.COENOO & D.1IE-W0 & $\omega$ & 200 & $\infty \infty$ & $2 \operatorname{COE}-\infty$ & 3.31 & & \\
\hline & c. & 10000 & $\infty$ & $240 E-02$ & \begin{tabular}{|l|l|l|l|l|l|l|l|l|} 
\\
\end{tabular} & 2.MUE-03 & 2035.03 & 12.7 & 200 & 0.20 & 2 SOE.-OZ & 14 & & \\
\hline & ca & $\infty \times 0$ & es $x$ & + XOE $+\infty$ & I $102 \mathrm{E} \cdot 0 \mathrm{0}$ & $102 E-03$ & $1.02 E-08$ & 0.10 & 1250 & 10.20 & $4.00 E-00$ & $+\infty 0110$ & 중 & \\
\hline & c. & 10000 & $11 \infty$ & 1 COE. & 115, UIE-01 & $1 \omega E=\infty$ & $1.100-01$ & 41.8 & 2000 & $\infty .10$ & $100 E-\infty 0$ & 20 & & - \\
\hline & ou & $x \times 0$ & 020 & $223 E-\infty$ & I ${ }_{101 E-01}$ & 2. $.00=01$ & 2.46E-01 & 120 & 1250 & 01.40 & $223 E-\infty 0$ & 100 & $\underline{2}$ & $\underline{E}-$ \\
\hline & $P_{0}$ & 2000 & 020 & 2 SOE-OI & I IOIE-DA & IOIE.OS & 1.0IE-OA & 0.11 & 1250 & 121.00 & $239 E-01$ & 021.74 & $\sum$ & \\
\hline & In & 2000 & 010 & $+10 E-01$ & I 2 (IE:-02 & 2.11E-02 & 2.10E-02 & 1.11 & 1250 & $\infty 20$ & $3.10 E-01$ & 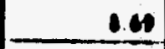 & t. & \\
\hline & Me & 200 & $\because 10$ & $1.03 E-\infty$ & I $2000-02$ & $234 E-02$ & 2.7nE-02 & 1.0 & 1250 & 01.20 & 2.23E.-D & 310 & & D - \\
\hline & $\mu$ & xwo & $\infty 20$ & I ISE-01 & I & $0.18 E-08$ & 6.80E-03 & 0.01 & 1250 & 02.20 & 1.3SE-01 & sus.49 & N & \\
\hline & Ni & 2000 & os $x$ & $1001=02$ & $I$ I 11E-OA & $0.01 E+0\}$ & 1.21E-OS & 31.2 & 1260 & 4.10 & 1.01E-0n & 11241 & & - \\
\hline & $\underline{x}$ & seop & $n \infty$ & 3. $00-01$ & US $1.30 E-01$ & S. COE -01 & $3.00 E+01$ & 0.20 & 1250 & -100 & 1 COE.OI & 1.00 & 8 & \\
\hline & 5 & 2000 & 00 & I COE-01 & $\angle T, 20 E-01$ & 200 -OS & D.OE-01 & 0.20 & 1230 & $\omega \infty$ & 2.0NE.01 & 1.00 & $y^{2}$ & \\
\hline & 슨 & 2000 & 110 & 2OIE-D & I 8.74 E-01 & 2 COE-O1 & D.2UE-OS & 0.41 & 1250 & $n \infty$ & $201 E .00$ & $12 n$ & & - \\
\hline & H. & 10000 & $02 \times 0$ & [MENOS & $\mathcal{I}_{\text {S.S2E-04 }}$ & 1.31E-OS & $0.82 E-01$ & 0.83 & 2000 & 200 & CHE-0? & 38.42 & & \\
\hline & $v$ & 10000 & $02 \infty$ & $2.00 E \cdot 00$ & I I.J1E-01 & $1.02 E-01$ & $1.47 E-01$ & S.M & 2000 & 01.20 & $2.00 E-10$ & 101 & & \\
\hline & 20 & 10000 & M. & $1.11 E-01$ & $J$ I 10E-O? & $1.02 E .02$ & $1.10 E .01$ & 18.4 & 2000 & $n \infty$ & 1.27E-O1 & 004 & 尊 & \\
\hline & 盟 & sowo & n.s. & 3 J3E-01 & I 2 OIE-OH & $2.73 E \cdot 04$ & 2.0IE-OA & 4.52 & 1260 & 21.0 & D.JSE-01 & $211 \%$ & & L \\
\hline & e & 2000 & 11.20 & SUSE- 10 & $\omega \sigma^{\circ} .100-\infty 0$ & 4.81E-00 & AME.DO & 10.8 & 1250 & 30.0 & DOSE.0O & 0.08 & & \\
\hline & a & $\$ 000$ & 1010 & SOSE.01 & LLT I OAE-OI & $203 E-01$ & SOAE.01 & 0.20 & 1250 & 103.20 & DOSE-OL & 1.00 & & \\
\hline & $\underline{11}$ & $x+\infty$ & 10110 & ICOE..$\infty$ & I t.menos & QNE.03 & 1.01E-0) & 1.25 & 1250 & M.so & 1 COEE -00 & en.11 & & \\
\hline & I & 10000 & 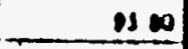 & | ISE-OI & $I 0.016-03$ & Q.P1E-03 & 1.01E-02 & 001 & 2500 & 1520 & IIJE.01 & 111.0 & & $\ldots$ \\
\hline & 31 & 10000 & $10 . \infty$ & 2.J0E.01 & IS 11 E.01 & 1.41E-01 & S.41E.01 & o.94 & $25 \times 0$ & 4650 & T.ME-OI & 3109 & 0130 & \\
\hline & sis & 10000 & 0100 & $1.37 E+\infty$ & J I XOE-02 & 2 Q0E-01 & 2IIE-01 & 11.0 & 2500 & 1100 & $117 \mathrm{UE} .00$ & nes & & \\
\hline & 1 & 2000 & $\infty+0$ & 1. SSE.01 & $I_{110 E-03}$ & 1.1.6E-0) & 1.168 .09 & 0.32 & 1250 & $0 x$ & I JSE.01 & 13.10 & & \\
\hline & so & $x 000$ & 01.80 & CONE:CO & UTine-nos & $000 E \cdot 00$ & $1.00 E-\infty)$ & 020 & 1280 & n.20 & C $\operatorname{COE}-\infty$ & 100 & & \\
\hline & II & 2000 & $n \infty$ & $200 E+\infty 0$ & $I_{1}, 110.01$ & $231 E-01$ & $241 E-01$ & 102 & 1230 & 01.10 & 2 LOE. $-\infty$ & 1208 & & \\
\hline & $\underline{\underline{u}}$ & $=$ & - & CNOE - $\infty$ & 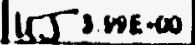 & $100 E-\infty$ & $4 . \omega 0 E-\infty$ & 0.20 & - & - & C OUE. $\infty 0$ & & & \\
\hline
\end{tabular}


WHC-EP-0806

WHC-SD-WM-OP-024 ADDENDUM,2, REV O

$\frac{\frac{3}{3}}{\frac{8}{3}}$

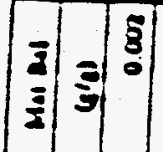

5.

วิำำำำำร
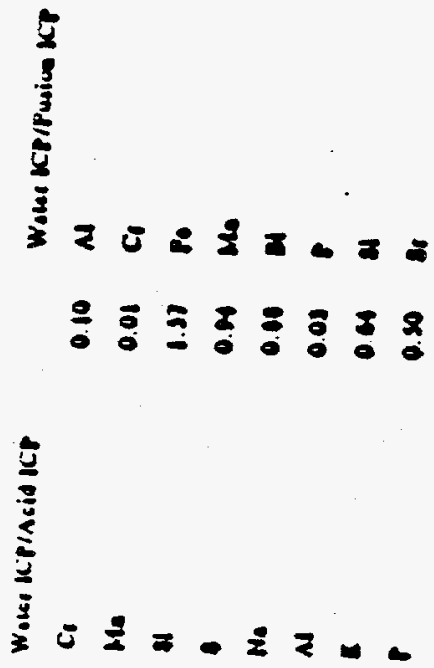

$\Xi \vdots \vdots \vdots$

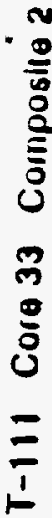

13 0 a

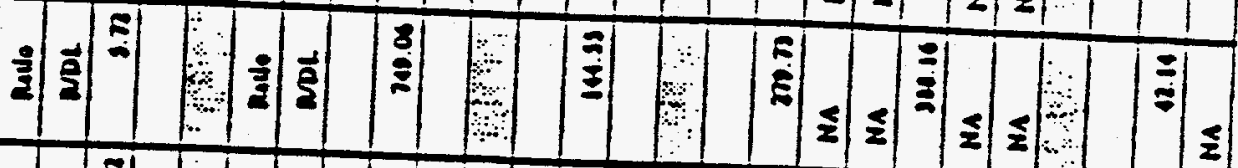

\begin{tabular}{|c|c|c|c|c|c|c|c|c|c|c|c|c|c|c|}
\hline 4 & \begin{tabular}{|c|c|} 
\\
$\vdots$ \\
$\vdots$ \\
0
\end{tabular} & us & 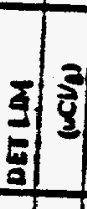 & & & 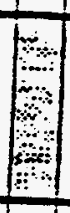 & 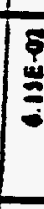 & 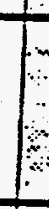 & & $\begin{array}{l}a \\
\text { aे } \\
-1\end{array}$ & $\mid \begin{array}{l}3 \\
\vdots \\
\vdots \\
\vdots\end{array}$ & 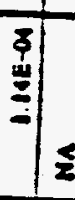 & & \begin{tabular}{|l|l}
$\mathbf{9}$ & \\
$\bar{\alpha}$ & \\
2 &
\end{tabular} \\
\hline 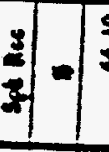 & $\begin{array}{l}9 \\
3\end{array}$ & 3 & if & 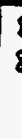 & & 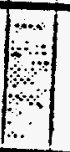 & {$\left[\begin{array}{l}8 \\
2\end{array}\right.$} & 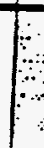 & & & & & 15 & $\left|\begin{array}{l}2 \\
3\end{array}\right|$ \\
\hline
\end{tabular}

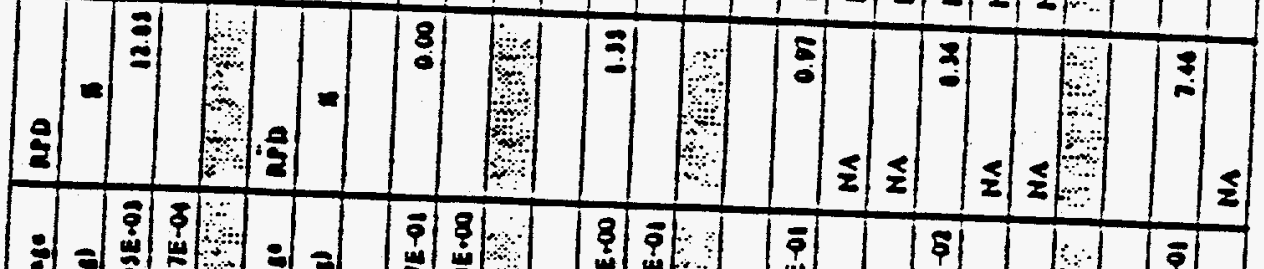

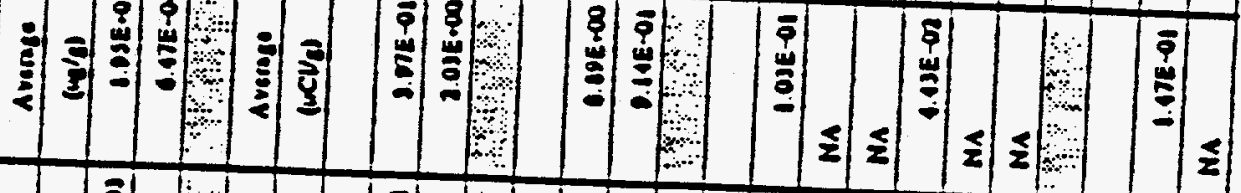

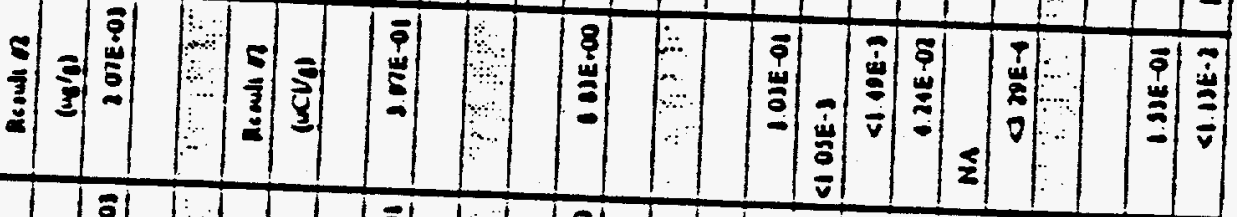

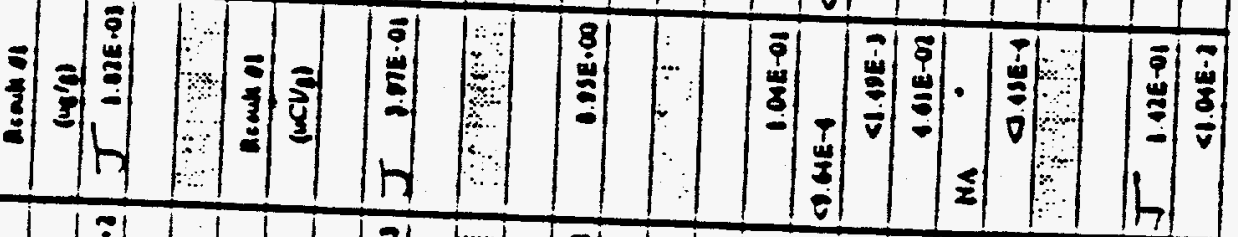

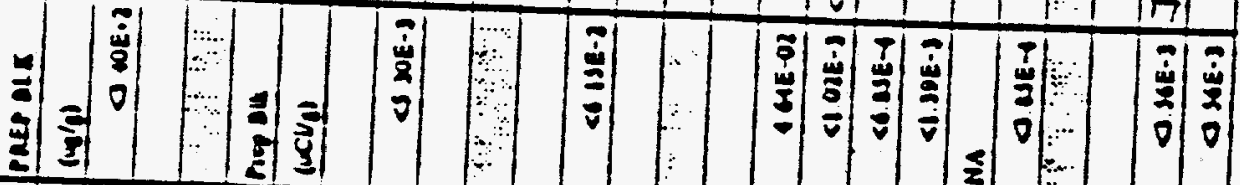

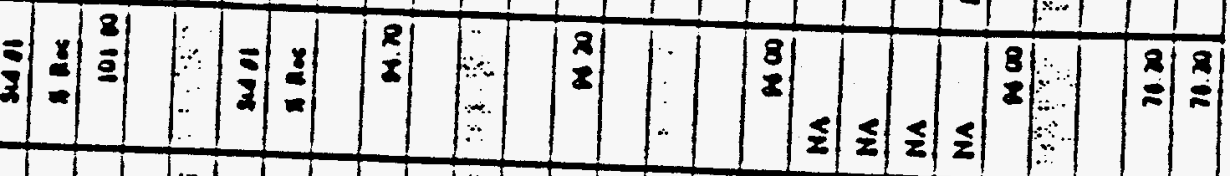

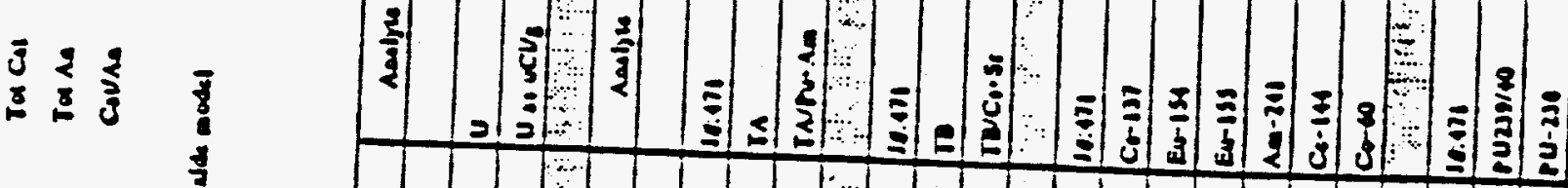

$\grave{d}$

:

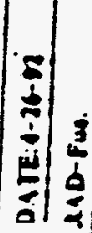

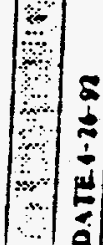

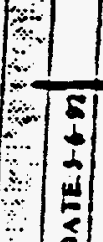


WHC-SD-WM-DP-024 ADDENDUM;2, REV 0

\begin{tabular}{|c|c|c|c|c|c|c|c|c|c|c|c|c|}
\hline 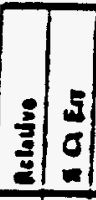 & 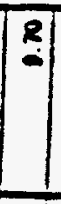 & & 1 & 9 & 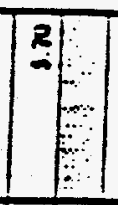 & & 3 & ? & $\approx$ & 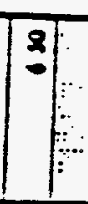 & 10 & $\stackrel{8}{9}$ \\
\hline$\vec{s}$ & $|\mathbf{z}|$ & $\xi$ & 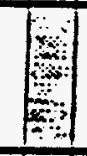 & 2 & 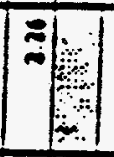 & $1 \leq 1$ & 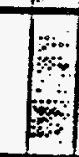 & 道 & 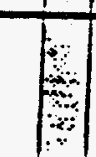 & $\leq$ & $\leqslant$ & $|\leq|$ \\
\hline है। & $\begin{array}{l}\overline{\mathbf{p}} \\
\overline{8} \\
\end{array}$ & & $=$ & \begin{tabular}{|l|l|}
5 & \\
& \\
& \\
\end{tabular} & 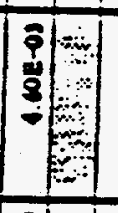 & $|\overline{\mid}|$ & 8 & 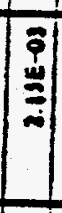 & 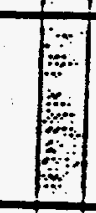 & 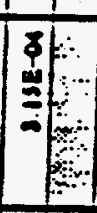 & 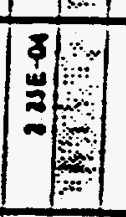 & $\mid \begin{array}{l}\left|\begin{array}{l}1 \\
\vdots \\
8\end{array}\right| \\
\end{array}$ \\
\hline & & & 3 & \begin{tabular}{|l|l|}
8 \\
\end{tabular} & $8:=$ & $\begin{array}{l}\boldsymbol{Z} \\
\vdots\end{array}$ & 1 & & 28 & $2:=$ & $=$ & $\mid \begin{array}{l}2 \\
:\end{array}$ \\
\hline
\end{tabular}

\begin{tabular}{|c|c|c|c|c|c|c|c|c|c|c|c|c|}
\hline 11 & $\vec{b}=$ & $\leq$ & 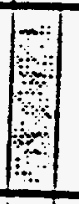 & $\leqslant$ & 8 & $\leqslant$ & 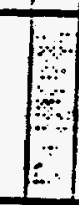 & $\equiv$ & $\$$ & $\mathbf{s}$ & 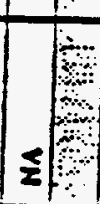 & $\underline{z}$ \\
\hline & ב⿱ & 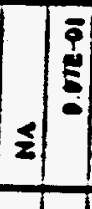 & 8 & $\Sigma$ & \begin{tabular}{|l|l|}
$\mathbf{a}$ & \\
3 & \\
& \\
\end{tabular} & s & 2 & 量 & $\because$ & 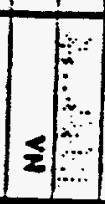 & $\begin{array}{r}2 \\
\end{array}$ & 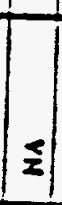 \\
\hline 豫 & & & $\because$ & $\overline{\tilde{u}}$ & \begin{tabular}{l|l}
5 \\
$\vdots$ \\
$\vdots$
\end{tabular} & 家 & i & 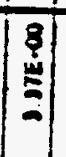 & 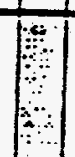 & : & 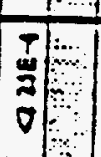 & \\
\hline
\end{tabular}

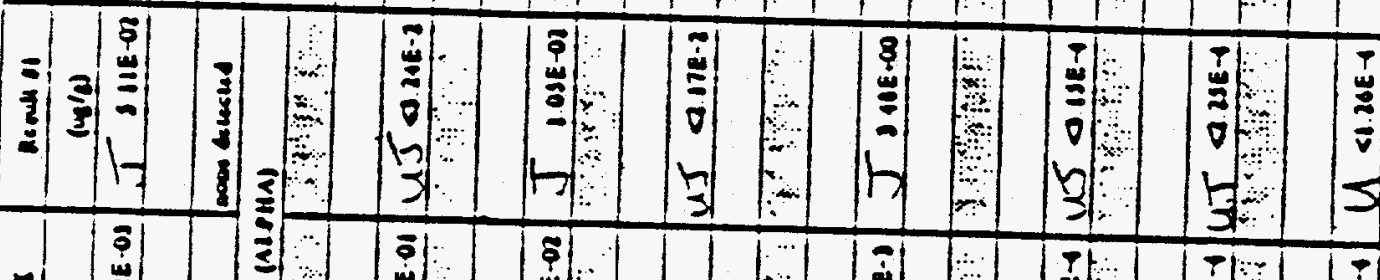

要

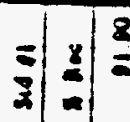

辛 $=$

8

1

$\because \quad$

:

棓

है:

$=0$

$=$

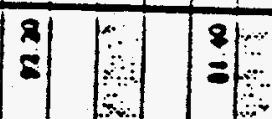

$=$ 


\section{TABLE OF CONTENTS}

Page

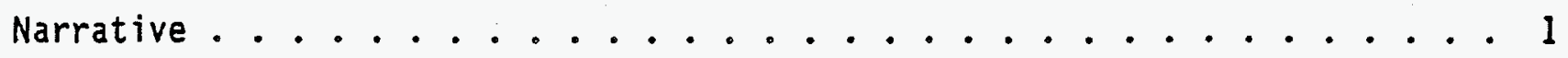

Sample Data Summary . . . . . . . . . . . . . . . . . . . 4 4

Letters of Instruction . . . . . . . . . . . . . . . . . . 6

Request for Special Analysis .................... . . . . . . . . . .

Calibrations . . . . . . . . . . . . . . . . . . . . . . . . . . . . . . . . . .

Sample Analyses Results . . . . . . . . . . . . . . . . . . . 24

Differential Thermal Analysis R-4600 . . . . . . . . . . . . . . 25

Differential Thermal Analysis R-4601 . . . . . . . . . . . . . . . . . . . . . . . . . 31

Thermal Gravimetric Analysis R-4600, R-4601 . . . . . . . . . . . . 37

Cyanide Analysis R-4600, R-4601 . . . . . . . . . . . . . . . 47

Cyanide Analysis R-4600, R-4601 . . . . . . . . . . . . . . . . . 58

Total Organic Carbon Analysis R-4600, R-4601 . . . . . . . . . . . . . 69

Total Organic Carbon Analysis R-4600, R-4601

ADDITIONAL DATA SUBMITTED ON 05/18/94 . . . . . . . . . . . . . . . . . . . 96

Differential Scanning Calorimetry Analysis J-1668-J1672 $\quad$. . . . . . . . . 97

Thermal Gravimetric Analysis J-1668-J1672 $\quad$. . . . . . . . . . . . . . 117

This report consists of pages 1 through 135, plus $3.1-3.3,4.1,5.1,9.1-9.30$, $23.1-23.2$ and 32.1 . 


\section{WHC-EP-0806 \\ WHC-SD-WM-DP-058 REV.OB}

$188.5 \mathrm{~J} / \mathrm{g}$ calculatêd dry (wt. basis) value compared to average May exotherm values of $280.9 \mathrm{~J} / \mathrm{g}$ on a calculated dry (wt. basis) value. The exotherm trace obtained in May is less well resolved than the January scan. The exotherms are very broad and not well separated from the water endotherms, so the baselines have been conservatively estimated.

Comparison of the current 222-S data (May 1994), and the original January 1992 data obtained for Core 33 segments 1 and 2 is quite interesting. The original data (Jan.1992) was obtained on a wet sample under air. The January 1994 and current data are on a dried sample as previously described. The wet sample (Jan. 1992), Core 33 segment 1 yielded an average value of $1151 \mathrm{~J} / \mathrm{g} d r y$ (wt. basis), and $2848.5 \mathrm{~J} / \mathrm{g}$ dry (wt. basis) for segment 2. Both of these values are considerably different from the values obtained on the dried sample either in January or May 1994.

Samples from Core 33 segment 2 were also run by PNL in January 1994, reference 6 . Results for Core 2 samples run under nitrogen purge were $942 \mathrm{~J} / \mathrm{g}$ dry (wt. basis) and $1011 \mathrm{~J} / \mathrm{g}$ dry (wt. basis) for an average value of $976.5 \mathrm{~J} / \mathrm{g}$ dry. Sample preparation for the January 1994 samples run by both labs were similar. The PNL sample was vacuum dried at 60 degrees $C$ for 24 hours. At 222-S the sample was vacuum dried ( 35 torr) at 60 degrees $C$ to a constant weight. The two laboratories used different heating rates for the DSC. The 222-S lab used $10 \mathrm{C}$ per minute, while PNL ran their sample at $5 \mathrm{C}$ per minute. This difference should not effect the magnitude of the exotherm, but may cause a shift in the curve. The instruments used by the laboratories were also different. The instrument used at $222-S$ is a Mettler M3 balance DSC Model 20 TG-50, and at PNL a Perkin Elmer Model 2 was used. 
WHC-EP-0806

WHC-SD-WM-DP-058

$\operatorname{Re} \bar{v} . \bar{O}-B$

Tank 241-T-111 Limited Analys is of Core 33 Segment 2

\section{Introduction}

The analyses in this package were performed by the Westinghouse Hanford Company (WHC), under the guidance provided by the Analytical

Integration Characterization Program (AICP), refer to references 1, 2, and 3 . The analyses presented in this report provides additional information on the energetics previously observed for Tank $241-T-111$, reference 4 . There were no exotherms that exceeded the safety criteria.

Sample preparation and analyses were performed by the Analytical Services of WHC. Core 33 segment 2 was placed in an oven on 1/10/94 at 1500 with an initial weight of 28.64 grams (gms) and removed on $1 / 12 / 94$ at 0735 and was stabilized in a hood for 1 hour, the final weight of the sample was 6.82 gms. The dried sample was stored in archive and was retrieved in May to perform this body of work. The specific analyses requested included Differential Scanning Calorimetry (DSC), which was performed under a nitrogen atmosphere on the sample previously dried under vacuum $(35 \mathrm{~mm}$ of $\mathrm{Hg}$ ) at 60 degrees $\mathrm{C}$. In addition, Thermographic Analysis (TGA) were performed on the dried archive sample. The analyses were performed to the quality assurance protocols reference 7 .

\section{Data Evaluation of Tank 241-T-111}

Thermogravimetric analysis on the dried samples yielded an average value of $11.2 \%$ weight loss interpreted to be water loss. Differential Scanning Calorimetry of $5-10 \mathrm{mg}$. and $10-20 \mathrm{mg}$. sample sizes under nitrogen purge were performed. This analysis (May 1994) of Core 33 segment 2 showed consistent low broad exotherms, with no significant differences caused by sample sizes. These results are consistent with previous work performed on Core 33 segment 2 in January 1994, reference 5. The average CSC exotherm value from January was 


\section{WHC-EP-0806}

\section{References:}

\section{WHC-SD-WM-DP-058}

1. Internal Memo, D. R. Bratzel to J. G. Kristofzski, "Letter of Instruction on Centrifugation of Tank 241-T-111 Samples," dated April 22, 1994. 7E720-94-119 Westinghouse Hanford Company, Richland Wa.

2. Internal Memo, D. R. Bratzel to J. G. Kristofzski, "Letter of Instruction for Tank 241-T-111 Archive Samples, "dated April 29, 1994. 7E720-94-120 Westinghouse Hanford Company, Richland Wa.

3. Internal Memo, D. R. Bratzel to J. G. Kristofzski, "Revised Letter of Instruction for Tank 241-T-111 Archive Samples." dated May 2, 1994. Internal Memo, D. R. Bratzel to J. G. Kristofzski, "Letter of Instruction for Tank 241-T-111 Archive Samples," dated April 29, 1994. 7E720-94-122 Westinghouse Hanford Company, Richland Wa.

4. WHC-SD-WM-DP-024, Rev 0. Tank 241-T-111 Core 31 and Core 33.

5. WHC-SD-WM-DP-058, Rev 0. Tank 241-T-111 Reanalyses of T-111 limited Analysis.

6. Pacific Northwest Laboratories, Tank Waste Characterization Project. Tank 241-T-111 Core 33 Data Report Rev. O. January 10, 1994. Pacific Northwest Laboratories, Richland Wa.

7. WHC-SD-WM-PLN-047, Appendix A, Core Sample Characterization Quality Assurance Project Pian. 
Summary Table for Tank $241-\mathrm{T}-111$ Core 33 Segment 2, dried archive sample.

\begin{tabular}{|c|c|c|c|c|c|c|c|}
\hline Sample Prep. & Analyte & Safety Criteria & Std. \#1 & Result \#1 & Result \#2 & Average & RPD \\
\hline & & $\mathrm{J} / \mathrm{g}$ dry & $\%$ & $\mathrm{~J} / \mathrm{g}$ & $\mathrm{J} / \mathrm{g}$ & $\mathrm{J} / \mathrm{g}$ & $\%$ \\
\hline & & & $J 1667-5511$ & $J 1668-5711$ & $J 1668-5711$ & & \\
\hline \multirow{2}{*}{ Direct } & DSC & $>522 \mathrm{~J} / \mathrm{g}$ dry & 96.0 & 251.2 & 269.0 & 260.1 & 6.84 \\
\hline & & & $J 1667-5511$ & $J 1669-5711$ & $J 1669-5811$ & & \\
\hline \multirow[t]{3}{*}{ Direct } & DSC & $>522 \mathrm{~J} / \mathrm{g} d r y$ & 96.0 & 309.2 & 287.5 & 298.4 & 7.27 \\
\hline & & & & & & & \\
\hline & & & $J 1667-5511$ & $\mathrm{~J} 1670-5711$ & $1670-5811$ & & \\
\hline \multirow[t]{3}{*}{ Direct } & DSC & $>522 \mathrm{~J} / \mathrm{g} d r y$ & 96.0 & 180.2 & 187.1 & 183.7 & 3.76 \\
\hline & & & & & & & \\
\hline & & & $J 1667-5511$ & $J 1671-5711$ & $J 1671-5811$ & & \\
\hline \multirow[t]{3}{*}{ Direct } & DSC & $>522 \mathrm{~J} / \mathrm{g}$ dry & 96.0 & 162.7 & 175.3 & 168.8 & 7.46 \\
\hline & & & & & & & \\
\hline & & & $J 1667-5511$ & $\mathrm{~J} 1672-5711$ & $1672-5811$ & & \\
\hline \multirow[t]{2}{*}{ Direct } & DSC & $>522 \mathrm{~J} / \mathrm{g} \mathrm{dry}$ & 96.0 & 336.2 & 335.9 & 336.0 & 0.09 \\
\hline & & & & & & & \\
\hline 1 & & & $\%$ & $\%$ & $\%$ & Average \% & \\
\hline 1 & & & $J 1667-5512$ & J1668-5712 & $J 1668-5812$ & & \\
\hline \multirow[t]{3}{*}{ Direct } & $\mathrm{TGA}$ & & 99.1 & 11.68 & 10.06 & 10.9 & 14.86 \\
\hline & & & & & & & \\
\hline & & & $\mathrm{J} 1667-5512$ & $J 1669-5712$ & $\mathrm{~J} 1669-5812$ & & \\
\hline \multirow[t]{3}{*}{ Direct } & TGA & & 99.1 & 10.66 & 9.90 & 10.3 & 7.38 \\
\hline & & & & & & & \\
\hline & & & $J 1667-5512$ & $J 1670-5712$ & $1670-5812$ & & \\
\hline \multirow[t]{3}{*}{ Direct } & TGA & & 99.1 & 11.35 & 11.99 & 11.7 & 5.47 \\
\hline & & & & & & & \\
\hline & & & $\mathrm{J} 1667-5512$ & $J 1671-5712$ & $\mathrm{~J} 1671-5812$ & & \\
\hline \multirow[t]{3}{*}{ Direct } & TGA & & 99.1 & 12.07 & 12.08 & 12.075 & 0.08 \\
\hline & & & & & & & \\
\hline & & & $J 1667-5512$ & $\mathrm{J1672-5712}$ & $\mathrm{J} 1672-5812$ & & \\
\hline Direct & TGA & & 99.1 & 11.21 & 11.10 & 11.15 & 0.99 \\
\hline & & & & & & & \\
\hline
\end{tabular}


Westinghouse Hanford Company

From: Analytical Integration

7E720-94-119

Phone: $\quad 373-3579$ R2-18

Date: April 29, 1994

Subject: LETTER OF INSTRUCTION FOR TANK 241-T-111 ARCHIVE SAMPLES

To:

J. G. Kristofzski

$\begin{array}{ll}\text { CC: H. Babad } & R 2-78 \\ \text { G. S. Barney } & T 5-12 \\ \text { D. B. Bechtold } & T 6-09 \\ \text { C. DeFigh-Price } & \text { R2-31 } \\ \text { D. B. Engelman } & R 1-49 \\ \text { J. M. Grigsby } & H 4-62 \\ \text { C. S. Haller } & \text { R2-12 } \\ \text { J. M. Kier } & T 3-01\end{array}$

\section{T6-06}

$\begin{array}{lll}\text { R2-78 } & \text { K. L. Kocher } & \text { T6-06 } \\ \text { T5-12 } & \text { R. P. Marshall } & \text { T6-14 } \\ \text { T6-09 } & \text { L. M. Sasaki } & \text { R2-12 } \\ \text { R2-31 } & \text { P. Segall } & H 4-19 \\ \text { R1-49 } & \text { B. C. Simpson }- & R 2-12 \\ \text { H4-62 } & \text { D. A. Turner } & \text { R2-78 } \\ \text { R2-12 } & \text { fo T. E. WhelanHKA } & \text { SI-57 } \\ \text { T-01 } & \text { LMS File/LB } & \end{array}$

Reference: Internal Memo, D. R. Bratzel to J. G. Kristofzski, "Letter of Instruction on Centrifugation of Tank 241-T-111 Samples," dated April 22, 1994.

This letter of instruction provides direction to the 222-S Laboratory for the performance of differential scanning calorimetry (DSC) and thermal gravimetric analysis (TGA) tests on archived material from single-shell tank 241-T-111. This letter also cancels the centrifugation and moisture ineasurements requested in the previous letter of instruction (Reference). The previously requested tests were determined not to be an effective means of addressing the U.S. Departinent of Energy, Headquarters' concerns regarding the safety of pumping the tank. Alternative testing to estimate the moisture that will remain in the waste after pumping is being considered and may be requested in the future. However, it has been determined that additional information on the waste energetics is necessary to evaluate the safety of pumping the tank.

Purcose: Perform additional OSC analysis and TGA on tank 241-T-I11 archive sample to more accurately measure the exotherm observed in the sample.

Safetv Considerations: Radioactive materials will be used in these tests, therefore all laboratory procedures applicable to radiological control will be adhered to in conjunction with as low as reasonable achievable (ALARA) practices dealing with hazardous materials in the preparation and handling of these samples.

\section{hiork Scope:}

1. The sample to be analyzed in the archived sample from tank 241-T-111, core 33 , segment 2 which had been dried, but never used, for adiabatic calorimetry analysis. Homogenize the semple to ensure that it is well mixed. 
J. G. Kristofzski

WHC-SD-WM-DP-058

7E720-94- 119

Page 2

April 29, 1994

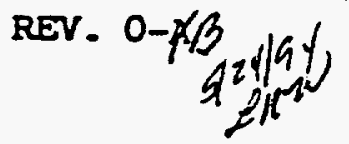

2. Obtain three aliquots from the sample and perform DSC and TGA analyses in duplicate on each aliquot. The sample size for the DSC analysis should be 5 to 10 milligrams. Perform the DSC under a nitrogen atmosphere.

3. Obtain two aliquots from the sample and perform DSC and TGA analyses in duplicate on each aliquot. The sample size for the DSC analys is should be twice the amount used in step 2 above (i.e., 10 to 20 milligrams). Perform the DSC under a nitrogen atmosphere.

Quality Assurance: If the sample and duplicate for a given aliquot do not agree within 25 calories/gram, rerun the DSC using a sample from the same aliquot. Approval designator $Q$ has been established for this work; samples and the indicated number of duplicates shall be run. The DSC shall be performed in accordance with procedure number LA-514-113 and the TGA shall be performed in accordance with procedure number LA-560-112. The requirements of WHC-SD-CP-QAPP (Quality Assurance Project PIan for the Analysis of Highly Radioactive Mixed Waste Samples in Support of Environmental Activities on the Hanford Site) shall be implemented as applicable. The data shall be reviewed to ensure that all quality assurance/quality control requirements were met.

Data Evaluation: The 222-5 Laboratory shall evaluate the results of the analyses against the DSC analyses performed previously on the tank T-111 samples that show exotherms in excess of 200 calories/gram (both cores 31 and 33 ) at both the 222-5 and 325 laboratories. The evaluation should include a best estimate of the sample energetics along with uncertainties and the rationale behind the estimate.

Reoorting Requirements: A letter presenting the results of the measurements will be the final deliverable of this task. The letter shall include a summary table of the results and a narrative. Advance notification of results via cc:mail is requested for representatives from the Characterization Program (D. R. Bratzel), Characterization Support (B. C. Simpson), Waste Tank Safety.(H. Babad), Waste Tank Stabilization (D. B. Engelman), and TWRS Safety Analysis and Engineering (J. M. Grigsby). All analytical results shall be reported by Kay 3, 1994, the data evaluation shall be reported by May 5, 1994, and the letter report shall be issued by May 9, 1994. 
WHC-EP-0806

WHC-SD-WM-DP-058

J. G. Kristofzssi

REV. $0-\not K h$

$7 E 720-94-119$

Page 3

April 29, 1994

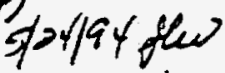

Funding for this task is provided under task package control number N5402. A cost estimate should be provided to the Characterization Program by May 3, 1994.

If there are any questions or comments regarding this letter, please contact

L. M. Sasaki at 373-1027 or 8. C. Simpson at 373-5915.

22Bitil

D. R. Bratzel, Manager Analytical Integration Characterization Program

mjg 
Westinghouse

WHC-SD-WM-DP-058

REV. $0-\not \times B$

Internal

Hanford Company

Memo

From: Analytical Integration

Phone: $\quad 373-3579$ R2-18

Date: May 2, 1994

Subject: REVISED LETTER OF INSTRUCTION FOR TANK 241-T-III ARCHIVE SAMPLES

$7 E 720-94-120$

To:

J. G. Kristofzski

Tó-06

$\begin{array}{ll}\text { CC: H. Babad } & R 2-78 \\ \text { G. S. Barney } & T 5-12 \\ \text { O. B. Bechtold } & T 5-09 \\ \text { C. DeFigh-Prica } & R 2-31 \\ \text { O. B. Engelman } & R 1-49 \\ \text { J. H. Grigsby } & H 4-02 \\ \text { C. S. Halier } & R 2-12 \\ \text { J. H. Kier } & T 3-01\end{array}$

K. L. Kocher

T5-06

R. P. Marshall

To-14

L. M. Sasaki

R2-12

P. Segall

B. C. Simpson

H4- 19

D. A. Turner

R2-12

T. E. Whelan

R2-i8

J. H. Kier LiUS File/LB

$51-57$

Reference: Internal Memo, D. R. Bratzel to J. G. Kristofzski, "Letter of Instruction for Tank 241-T-111 Archive Samples, "dated April 29, 1994.

This letter of instruction (LOI) provides a revision to the referenced LOI. This revision expands the work scope to include additional differential scanning Calorimetry (DSC) and thermal gravimetric analysis (TGA) tests on wet (as received) archive sample from tank 241-T-111, core 33, segment 2 and revises the due dates for the reporting of results. All other requirements of the referenced LOI remain the same.

idditional liork Scooe:

1. The additional semple to be analyzed.is the 20 gram of wet sample from the tank 211-T-111, core 33, segment 2 archived sample. This sample is being shipped from the Pacific iNorthwest Laboratory (PNL) 325 Building to the 222-5 Laboratory for analysis. PNL is not able to analyze the sample at this time due to the stand down at the laboratory. Homogenize the sample to ensure that it is well mixed.

2. Obtain three aliquots from the sample and perform OSC and TGA analyses in duplicate on each aliquot. should be 5 to 10 milligrams. atmosphere.

The sample size for the DSC analysis

Perform the DSC under a nitrogen

3. Obtain two aliquots from the sample and perform OSC and TEA analyses in duplicate on each aliquot. The sample size for the DSC analysis on the wet sample should be five times the amount used in step 2 above (i.e., 25 to 50 milligrams). Perform the OSC under a nitrogen atmosphere.

Chanoe to Reporting Due Dates:

Analytical results and preliminary data evaluation on the dried archived sample shall be reported by May 6. 1994. Final evaluation of both dry and wet sample results, in the for:n of a lettar report, shall be made within four full working days after recaip 
WHC-EP-0806

J. G. Kristofzski

Page 2

May 2, 1994
WHC-SD-WM-DP-058

REV. $O-\not B$

$7 E 720-94-120$

If there are any questions or comments regarding this letter, please contact L. M. Sasaki at 373-1027 or B. C. Simpson at 373-5915.

2.m. Sack;

for O. R. Bratzel, Manager Analytical Integration Characterization Program 
From: Analytical Integration

Phone: $373-3579$ R2-18

Date: . . May 12, 1994

Subject: LETTER OF INSTRUCTION FOR TANK 241-T-111 ARCHIVE SAMPLES REVISION 2

To: -J. G. Kristofzski $\quad$ T6-06

$\begin{array}{llll}\text { CC: H. Babad } & \text { R2-78 } & \text { K. L. Kocher } & \text { TE-06 } \\ \text { G. S. Barney } & \text { T5-12 } & \text { R. P. Marshall } & \text { T6-14 } \\ \text { D. B. Bechtold } & \text { T6-09 } & \text { L. M. Sasaki } & \text { R2-12 } \\ \text { C. DeFigh-Price } & \text { R2-31 } & \text { P. Segall } & \text { H4-19 } \\ \text { D. B. Engelman } & \text { R1-49 } & \text { B. C. Simpson } & \text { R2-12 } \\ \text { J. M. Grigsby } & \text { H4-62 } & \text { D. A. Turner } & \text { R2-78 } \\ \text { C. S. Haller } & \text { R2-12 } & \text { T. E. Whelan } & \text { S1-57 } \\ \text { J. M. Kier } & \text { T3-01 } & \text { LMS File/LB } & \end{array}$

References: (1) Internal Memo, D. R. Bratzel to J. G. Kristofzski, "Revised Letter of Instruction for Tenk 241-T-1ll Archive Semples." deted May 2.1904.

(2) Internal Memo, D. R. Bratzel to J. G. Kristofzski, "Letter of Instruction for Tank 241-T-111 Archive Samples," dated April 29, 1994.

This letter of instruction (LOI) provides a second revision to the referenced LOls. This revision eliminates the additional work scope requested in Reference 1. It has been determined that additional differential scanning calorimetry and thermal gravimetric analysis tests on wet (as received) archive sample from tank 241-T-111, core 33, segment 2 are not needed at this time. The final letter report should be issued by May $19,1994$.

If there are any questions or comments regarding this letter, please contact L. M. Sasaki at 373-1027 or B. C. Simpson at 373-5915.

DRB मेty

D. R. Bratzel, Manager Analytical Integration Characterization Program

pkc 
TO: - JG Kristofzski, JH Frye, KL Kocher

FROM: TL Welsh, RD Cromar, $R$ Jeppson

DATE: May 6, 1994

SUBJECT: Statistical Anaiysis of Core Segments

WHC-SD-WM-DP-058

REV.OB

Performing a one-way analysis of variance (ANOVA) on segment. two (core 33 only), we found that the standard deviation of segment two is $211.631 \mathrm{~J} / \mathrm{g}$ dry wt. The ANOVA also leads us.to conclude that some of the means are different. A multiple range comparison test showed that the means of the $1993 \mathrm{~T}-11 \mathrm{ll}$ data and the present data are not statistically different, with a significance level of 0.05 . These two means differ from the mean of the $1993 \mathrm{PNL}$ data and also from the mean of the original data. The 1993 PNL mean and the mean of the original data also differ from each other.

Performing a one-way analysis of variance on segment one (core 33 only), the standard deviation of segment one is $169.621 \mathrm{~J} / \mathrm{g}$ dry wt. The AlNOVA. leads us to conclude that the mean of the original data and the mean of the 1993 T-111 data are different. Using the error from segment two to test segment one, the means are also statisticaliy difierent, with a significance level of 0.05 .

Sumary Statistics for Coré Samples

(in $\mathrm{J} / \mathrm{a}$ dry wt)

\begin{tabular}{|c|c|c|c|c|c|}
\hline & \multicolumn{2}{|c|}{ Confidence Interval } & \multirow[t]{2}{*}{ Mean } & \multirow{2}{*}{$\begin{array}{l}\text { Standard } \\
\text { Deviation }\end{array}$} & \multirow[t]{2}{*}{ RSD } \\
\hline & L.L. & U.L. & & & \\
\hline $\begin{array}{l}\text { Core } 33, \\
1994\end{array}$ & * & * & 280.9 & 81.29 & 0.2894 \\
\hline Secment 1 & 441.50 & 3088.17 & 1764.83 & 532.67 & 0.3018 \\
\hline Segnent 2 & -164.55 & 2671.11 & 1253.28 & 1142.06 & 0.9113 \\
\hline Secment 3 & -14518.50 & 17932.56 & 1707 & 1805.95 & 1.0580 \\
\hline
\end{tabular}




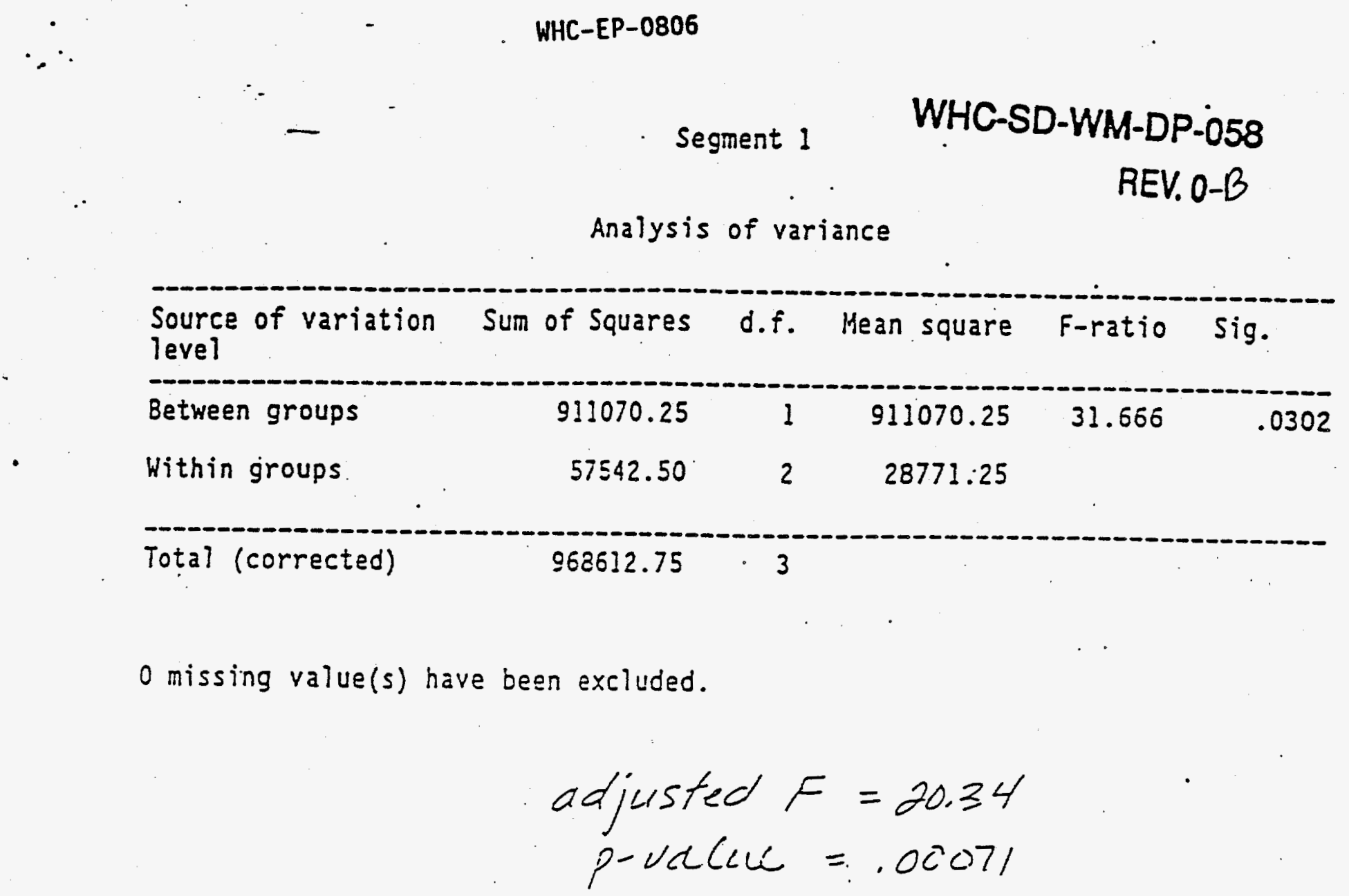


WHC-EP-0806

Segment 2

Analysis of variance

\section{WHC-SD-WM-DP-058}

REV. O-B

Source of variation Sum of Squares
level
Between groups

A-108 


\section{WHC-EP-0806}

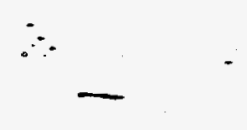

\section{WHC-SD-WM-DP-058 \\ REV. O-B}

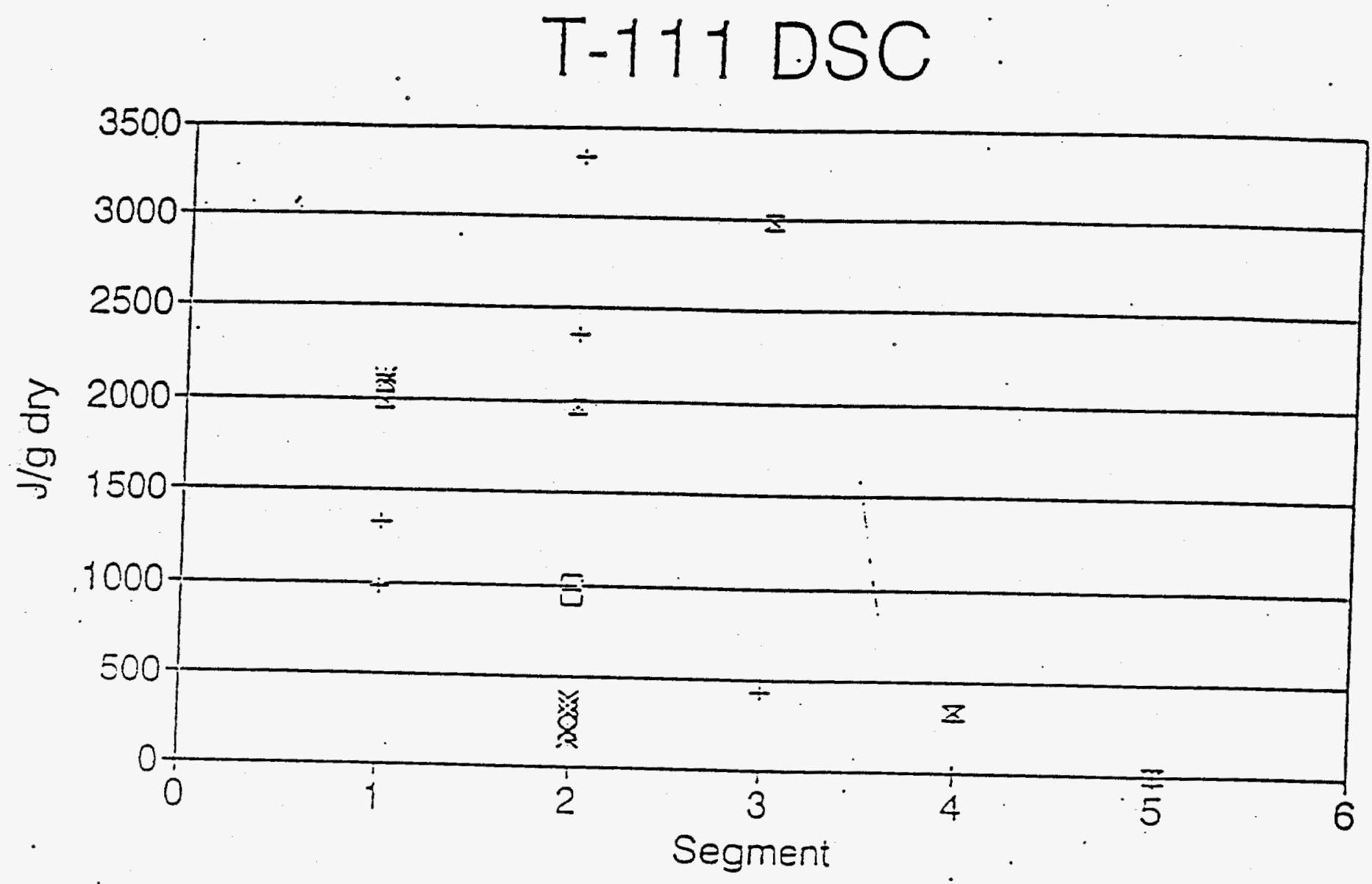

z Core 31 (1991) $\div$ Core 33(1991) $\because$ Core 33,(1993) - Core 33 (1993) P $\times$ Core $33(1994)$ 


\section{WHC-SD-WM-DP-058}

REV. O-B

Preliminary Data for re-analysis on tank T-111 Core 33 Segment 2, May 2, 1994 All data is reported on a archive sample which was vacuum dried 60 degrees $C$. on 12/93. The analyses were performed under a nitrogen purge. This preliminary data fulfills the requirements per the letter or instruction (LOI) 7E720-94-119 and the revised LOI 7E720-94-120. The DSC values are not corrected and do not take into account the water content of the samples.

\begin{tabular}{|c|c|c|c|c|c|}
\hline $\begin{array}{l}\text { Laboratory } \\
\text { Id. number }\end{array}$ & Sample $\frac{\|}{\pi}$ & Analys is & $\begin{array}{l}\text { Sample } \\
\text { Size (mg) }\end{array}$ & $\begin{array}{l}\text { Result I } \\
\mathrm{J} / \mathrm{g}\end{array}$ & $\begin{array}{l}\text { Result } 2 \\
\mathrm{~J} / \mathrm{g}\end{array}$ \\
\hline $\begin{array}{l}J 1668-5711 \\
\mathrm{~J} 1668-5811\end{array}$ & $\begin{array}{l}\text { Sample } 1 \\
\text { Sample } 1 \\
\text { dup }\end{array}$ & DSC & $\begin{array}{l}16.957 \\
13.267\end{array}$ & 251.2 & 269.0 \\
\hline $\begin{array}{l}J 1669-5711 \\
J 1669-5811\end{array}$ & $\begin{array}{l}\text { Sample } 2 \\
\text { Sample } 2 \\
\text { dup } \\
\end{array}$ & DSC & $\begin{array}{l}12.596 \\
18.182\end{array}$ & 309.2 & 287.5 \\
\hline $\begin{array}{l}31670-5711 \\
\text { J1670-5811 }\end{array}$ & $\begin{array}{l}\text { Sample } 3 \\
\text { Sample } 3 \\
\text { dup }\end{array}$ & DSC & $\begin{array}{l}5.897 \\
6.179\end{array}$ & 180.2 & 187.1 \\
\hline $\begin{array}{l}31671-5711 \\
31671-5811\end{array}$ & $\begin{array}{l}\text { Sample } 4 \\
\text { Sample } 4 \\
\text { dup }\end{array}$ & DSC & $\begin{array}{l}6.695 \\
7.023\end{array}$ & 162.7 & 175.3 \\
\hline $\begin{array}{l}31672-5711 \\
01672-5811\end{array}$ & $\begin{array}{l}\text { Sample } 5 \\
\text { Sample } 5 \\
\text { dup } \\
\end{array}$ & OSC & $\begin{array}{l}7.740 \\
6.154\end{array}$ & 336.3 & 335.9 \\
\hline $\begin{array}{l}\text { Laboratory } \\
\text { Id. number }\end{array}$ & Sample $\#$ & Analysis & $\begin{array}{l}\text { Sample } \\
\text { Size (mg) }\end{array}$ & $\begin{array}{l}\text { Result } 1 \\
(\% \text { H2O) }\end{array}$ & $\begin{array}{l}\text { Result }{ }^{2} \\
(\% \mathrm{H} 20) \\
\end{array}$ \\
\hline $\begin{array}{l}J 1668-5712 \\
\text { J1668-5812 }\end{array}$ & $\begin{array}{l}\text { Sample } 1 \\
\text { Sample } 1 \\
\text { dup }\end{array}$ & TEA & $\begin{array}{l}11.928 \\
15.604\end{array}$ & 11.68 & 10.06 \\
\hline $\begin{array}{l}31659-5712 \\
31650-5812\end{array}$ & $\begin{array}{l}\text { Sample } 2 \\
\text { Sample } 2 \\
\text { dup }\end{array}$ & $T G A$ & $\begin{array}{l}17.548 \\
19.760\end{array}$ & 10.66 & $\begin{array}{r}9.90 \\
1\end{array}$ \\
\hline $\begin{array}{l}J 1670-5712 \\
\text { J1670-5812 }\end{array}$ & $\begin{array}{l}\text { Sample } 3 \\
\text { Sample } 3 \\
\text { dup }\end{array}$ & $T G A$ & $\begin{array}{l}6.338 \\
8.043\end{array}$ & 11.35 & 11.99 \\
\hline $\begin{array}{l}31671-5712 \\
31671-5812\end{array}$ & $\begin{array}{l}\text { Sample } 4 \\
\text { Sample } 4 \\
\text { dup } \\
\end{array}$ & $T G A$ & $\begin{array}{l}7.786 \\
5.750\end{array}$ & 12.07 & 12.08 \\
\hline $\begin{array}{l}J 1672-5712 \\
J 1672-5812\end{array}$ & $\begin{array}{l}\text { Sample } 5 \\
\text { Sample } 5 \\
\text { dup }\end{array}$ & TGA & $\begin{array}{r}7.101 \\
9.313 \\
\therefore-\end{array}$ & 11.21 & 11.10 \\
\hline
\end{tabular}


WHC-EP-0806.

WHC-SD-WM-DP-058

REV. O-B

Original T-111 DSC Data $4 / 92$ 


\section{WHC-EP-0806}

Core 31 seg 1, wet sample run under static air 4/92

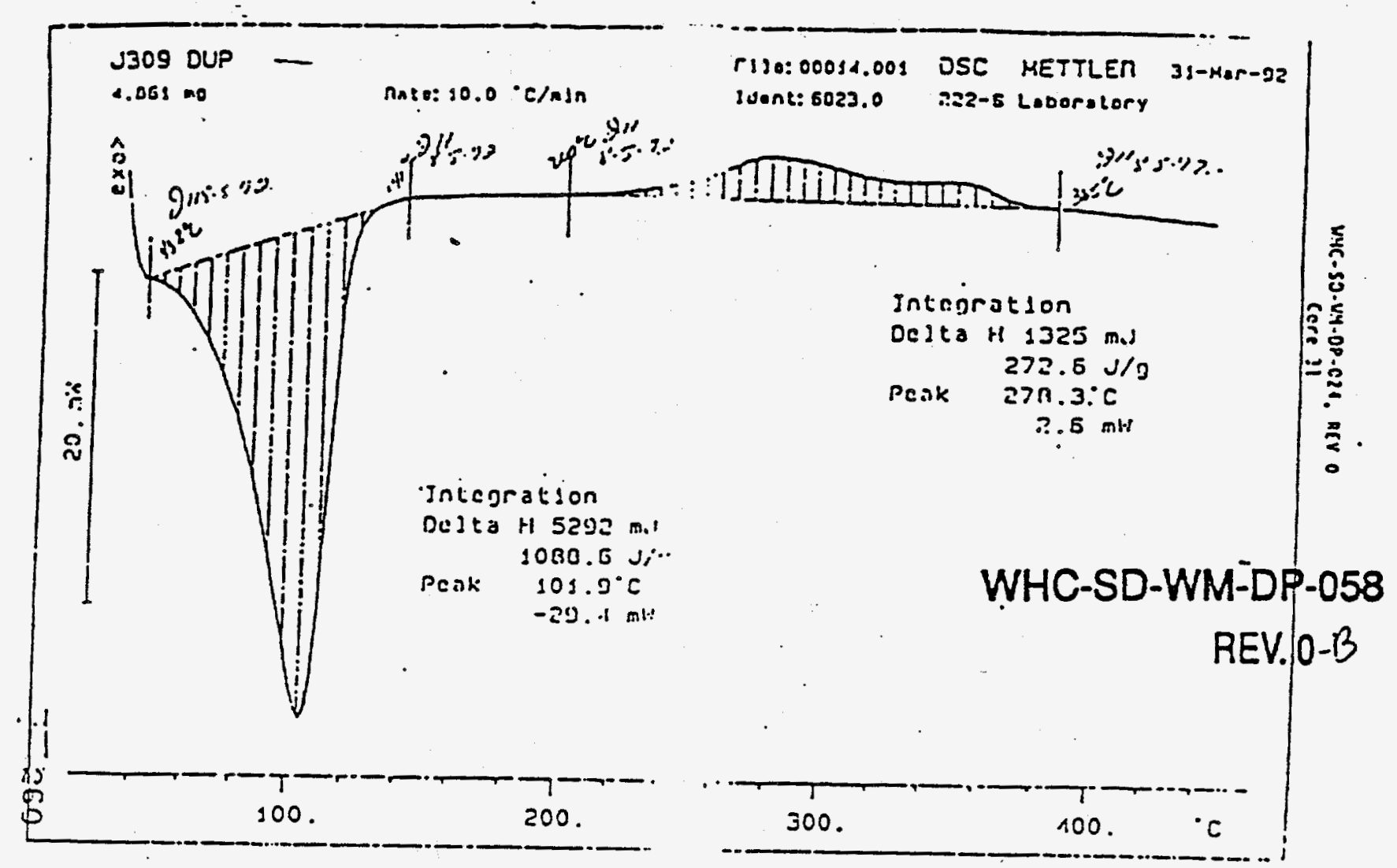

Core 31 seg 2, wet sample run under static air 4/92

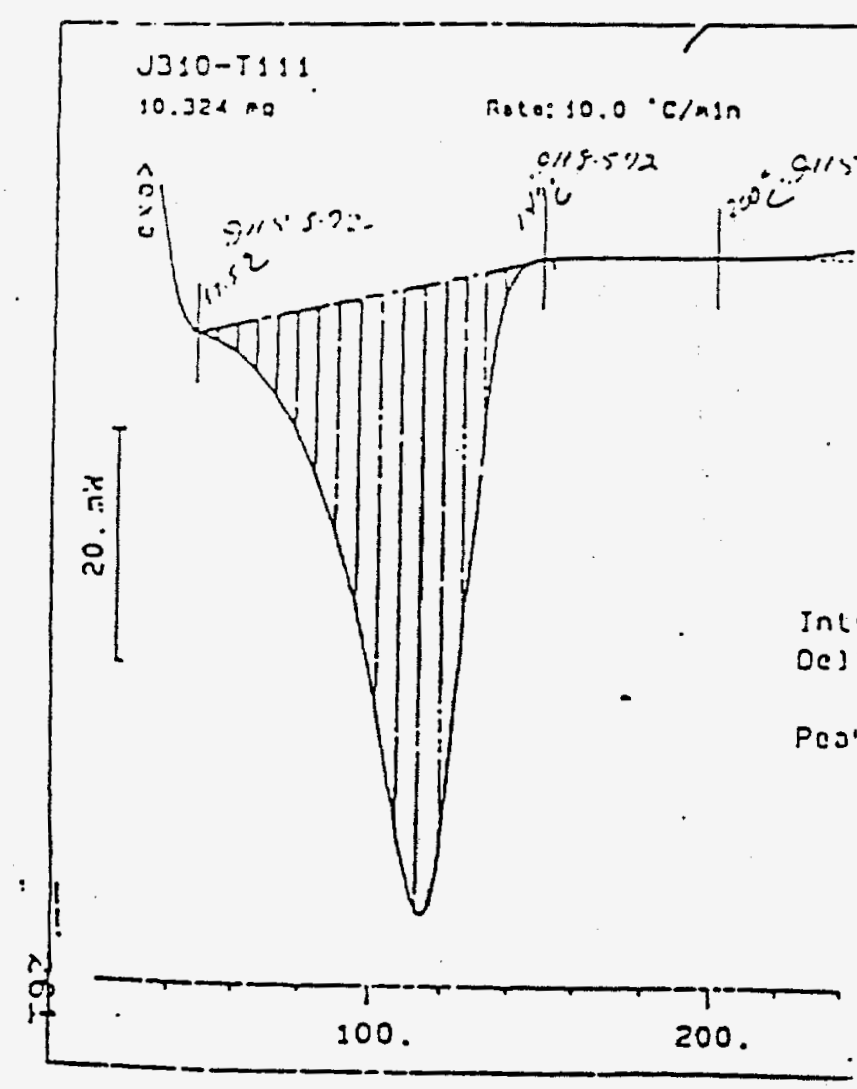

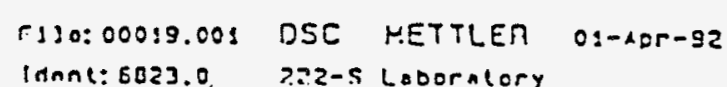

innnt: 6023.0 7.2Z-S Loborntory

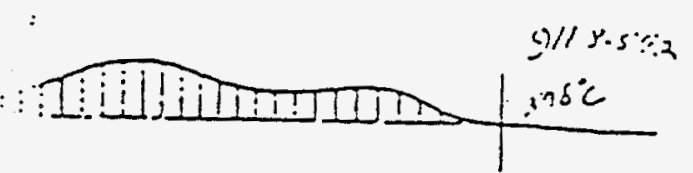

Intceration

Delta $\mathrm{H}$ [दि $\mathrm{mJ}$

bosk 52jo.

PeOK 203.3. $\mathrm{C}$

1.. $\mathrm{nH}$

Int. .'itsion

Dcl. - I1111111 $\mathrm{mJ}$

$1108.5 \mathrm{~J} / 9$

$109.5^{\circ} \mathrm{C}$

$-53.5 \mathrm{mH}$

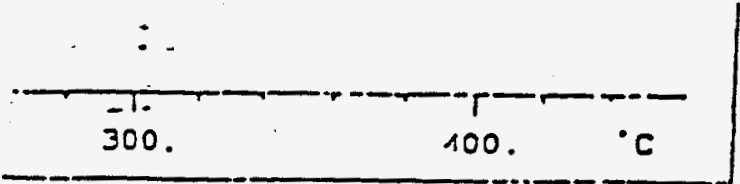




\section{WHC-EP-0806}

$\therefore \quad$ Core $31 \mathrm{seg} 3$, wet sample run under static air $4 / 92$

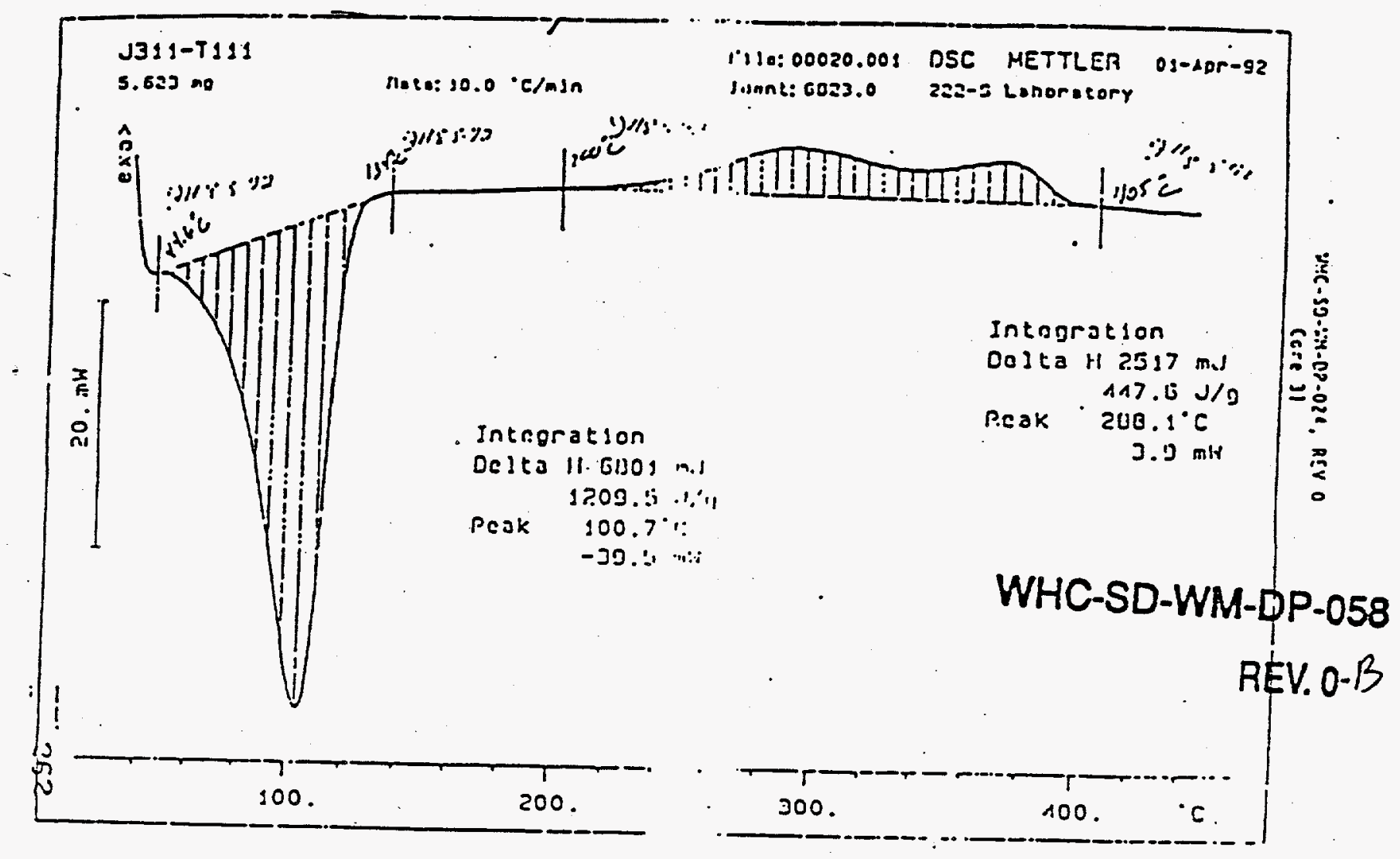

Core 31 seg 4 , wet sample run under static air $4 / 92$

$1312-t 111$

$15.213 \mathrm{mo}$

nnte::0.0 $0.0 / m$

111.00021 .001 14..11: 603.3.0

DSC METTLFE - OI-LPE-93

2.?.?-5 Loooratory

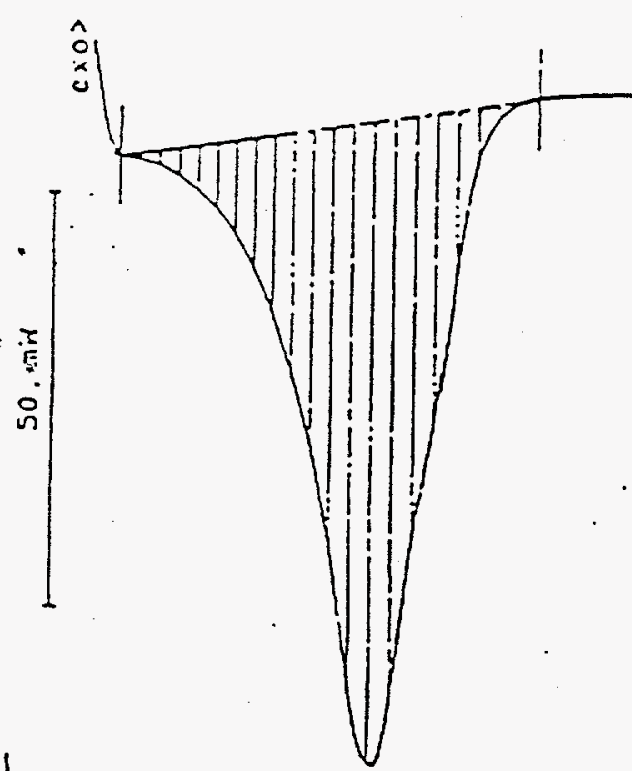

Integr: inn

Dolto lisuilill $\mathrm{mJ}$

$\begin{aligned} & : \therefore: i . .1 \mathrm{~J} / \mathrm{g} \\ \text { Peak } & : 1: 1.10^{*} \mathrm{C}\end{aligned}$

arjon

Dclto $H$ oal mJ

$5.5 .7 \mathrm{~J} / \mathrm{a}$

peak rur. $1^{\circ} \mathrm{C}$

$1.2 \mathrm{mH}$

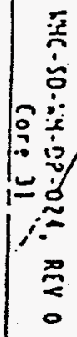

0

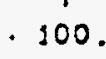

200.

iil. $11 \mathrm{~m} \mathrm{~N}$ 
Core $33 \mathrm{seg} 1$, wet sample run under static air $4 / 92$

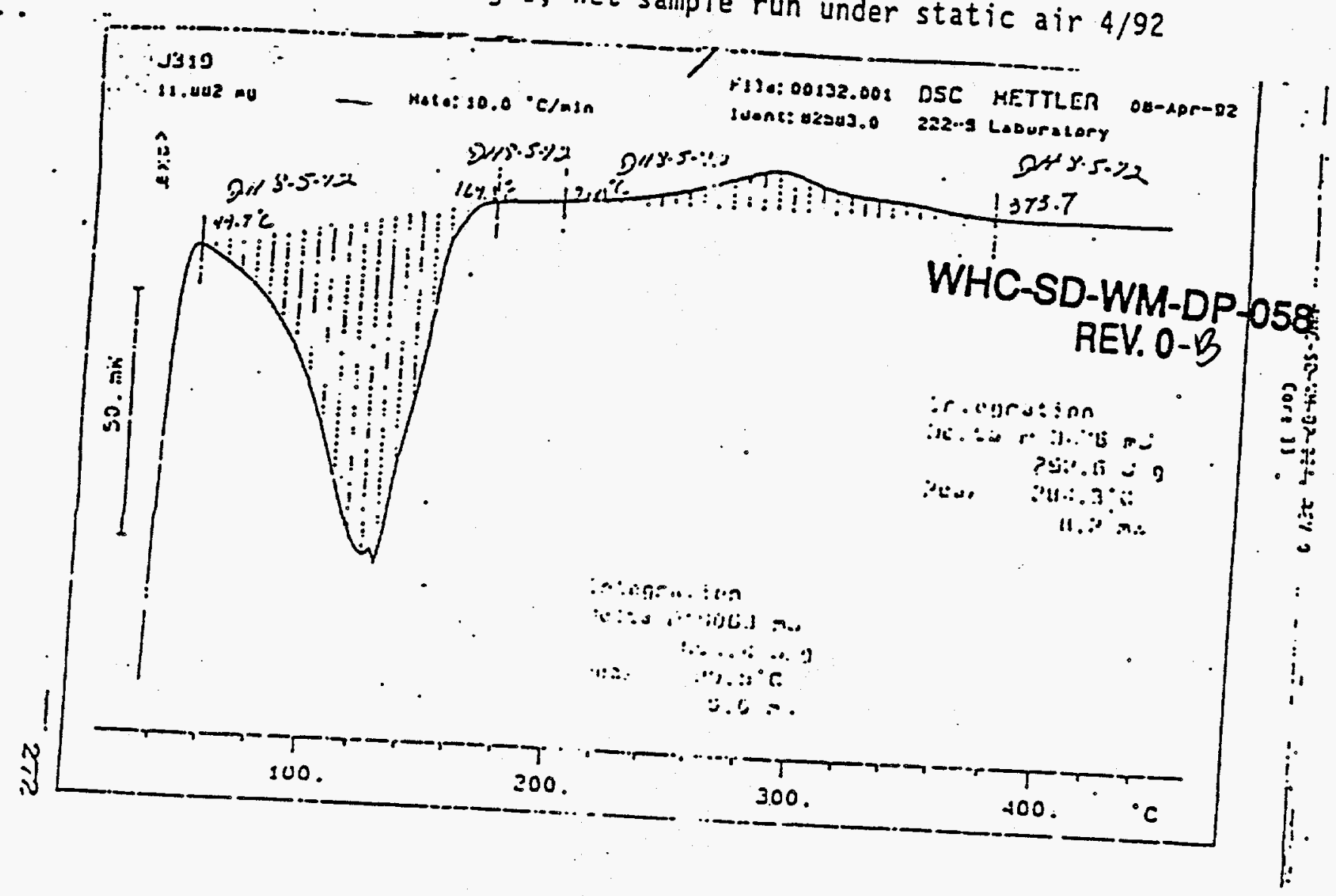

Core $33 \mathrm{seg} 2$, wet sample run under static air $4 / 92$

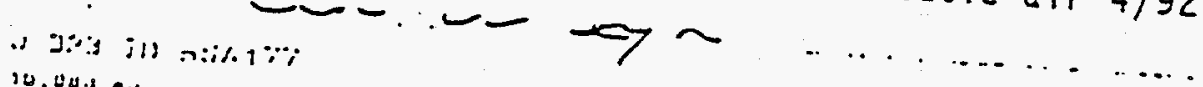

$\because$ 11910: $20.0 \cdot \mathrm{c} / \mathrm{m}$.

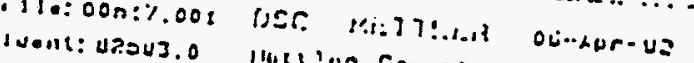

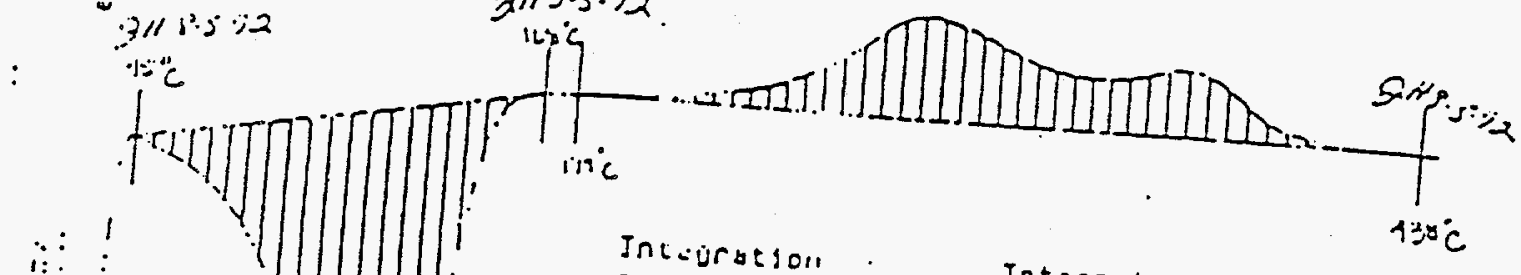

$\vdots \cdots$

Intouratgon

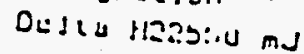

Pu-h div:i.: $\mathrm{d} / \mathrm{O}$

$11 \% .1 \% \mathrm{C}$

- U11. I mk

Inteoratgon

Dol:2 H $0733 \mathrm{~ms}$

pook idi.3 $3 / 0$

$.117^{-1} \mathrm{C}$
$13.7 \mathrm{mH}$

ch
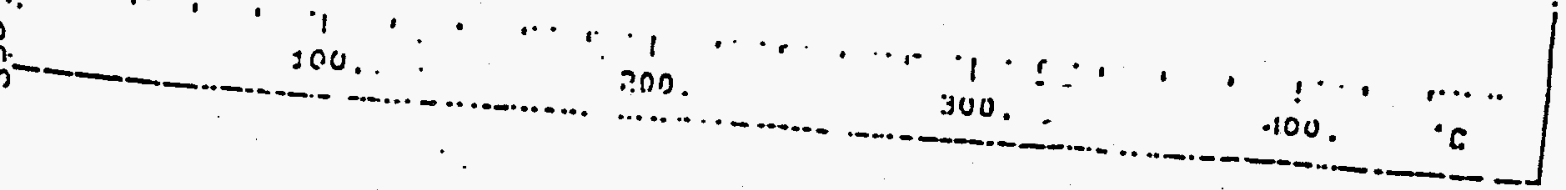


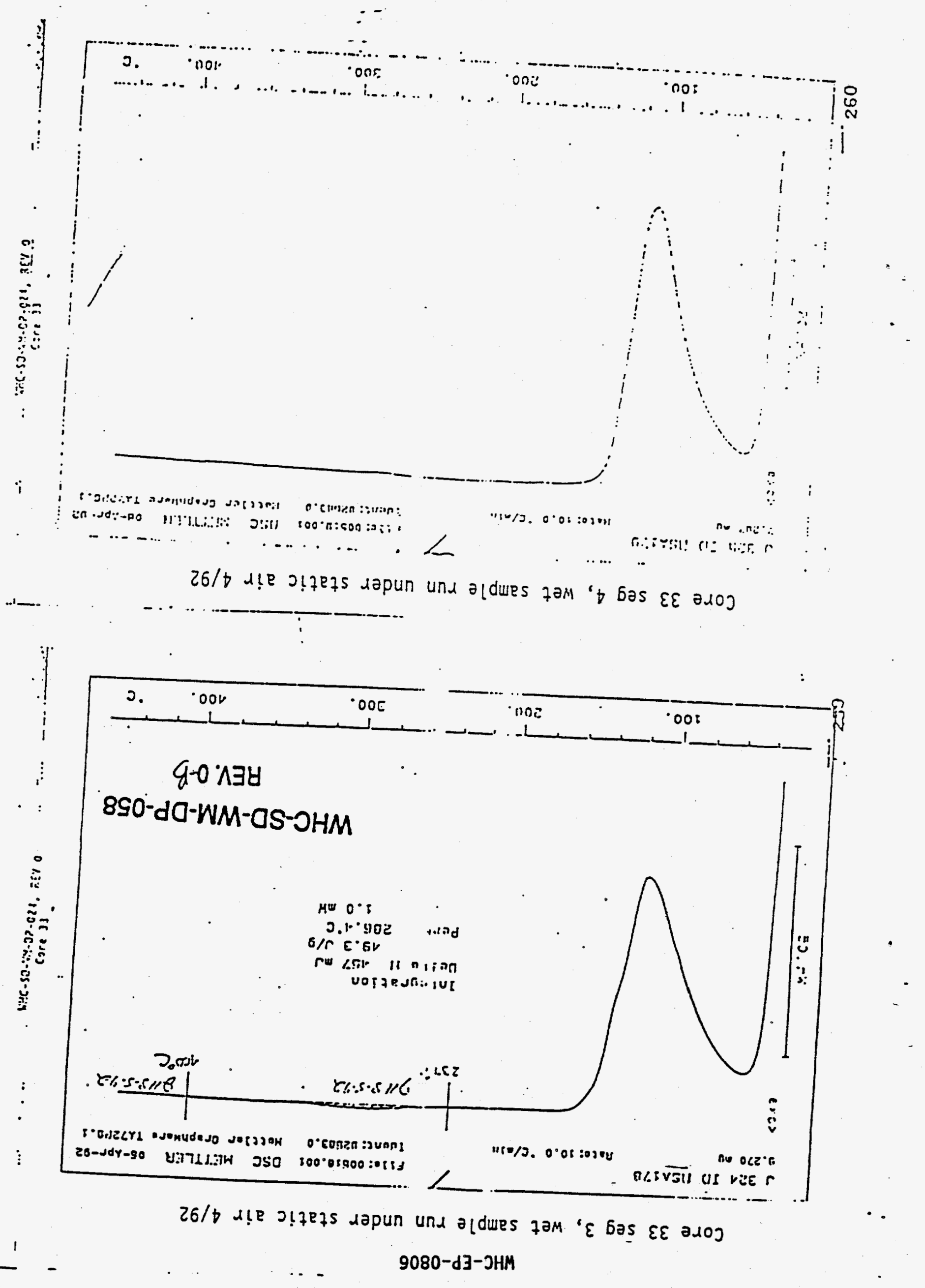


WHC-EP-0806

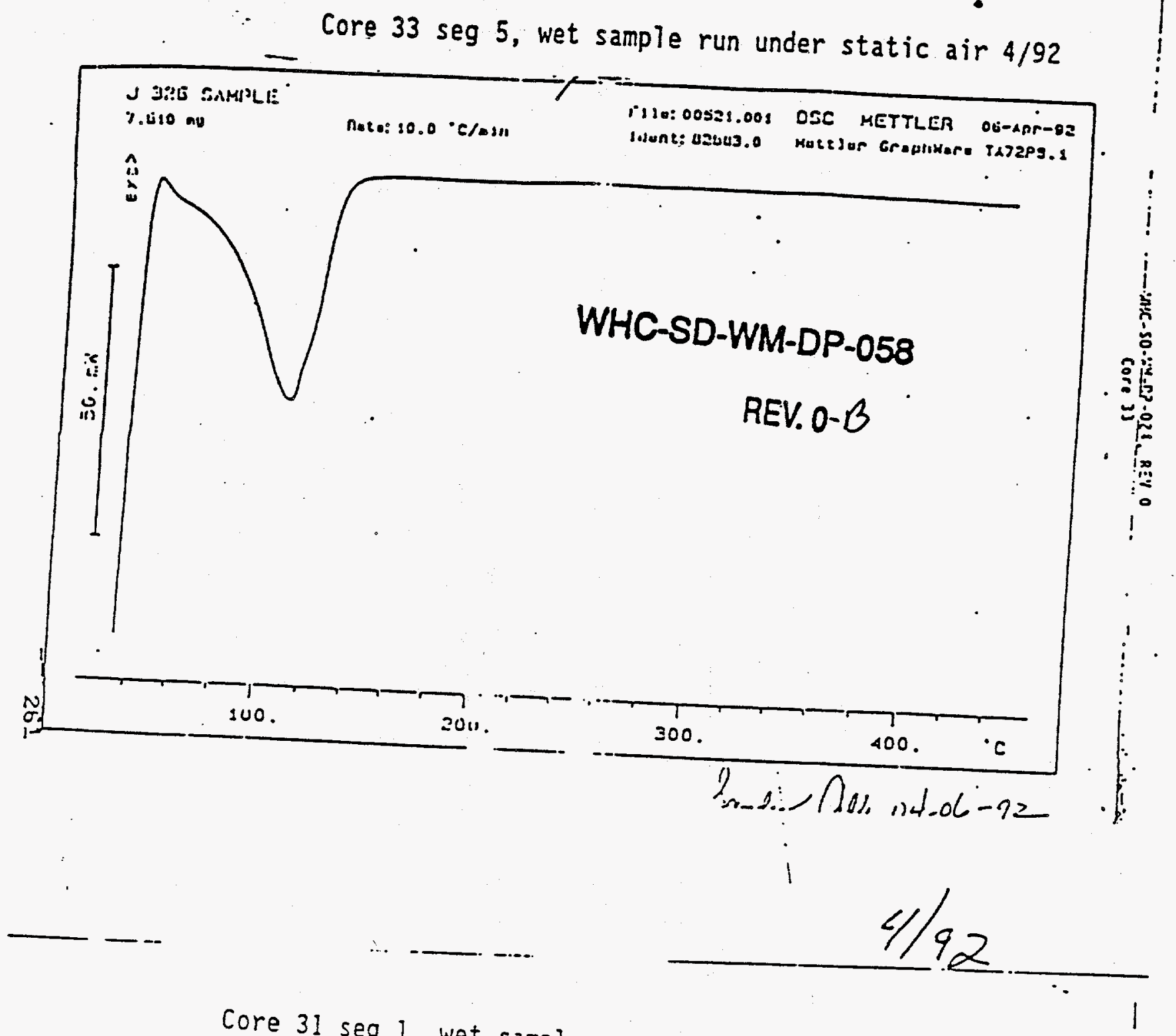

Core $31 \mathrm{seg} 1$, wet sample run under static air $4 / 92$

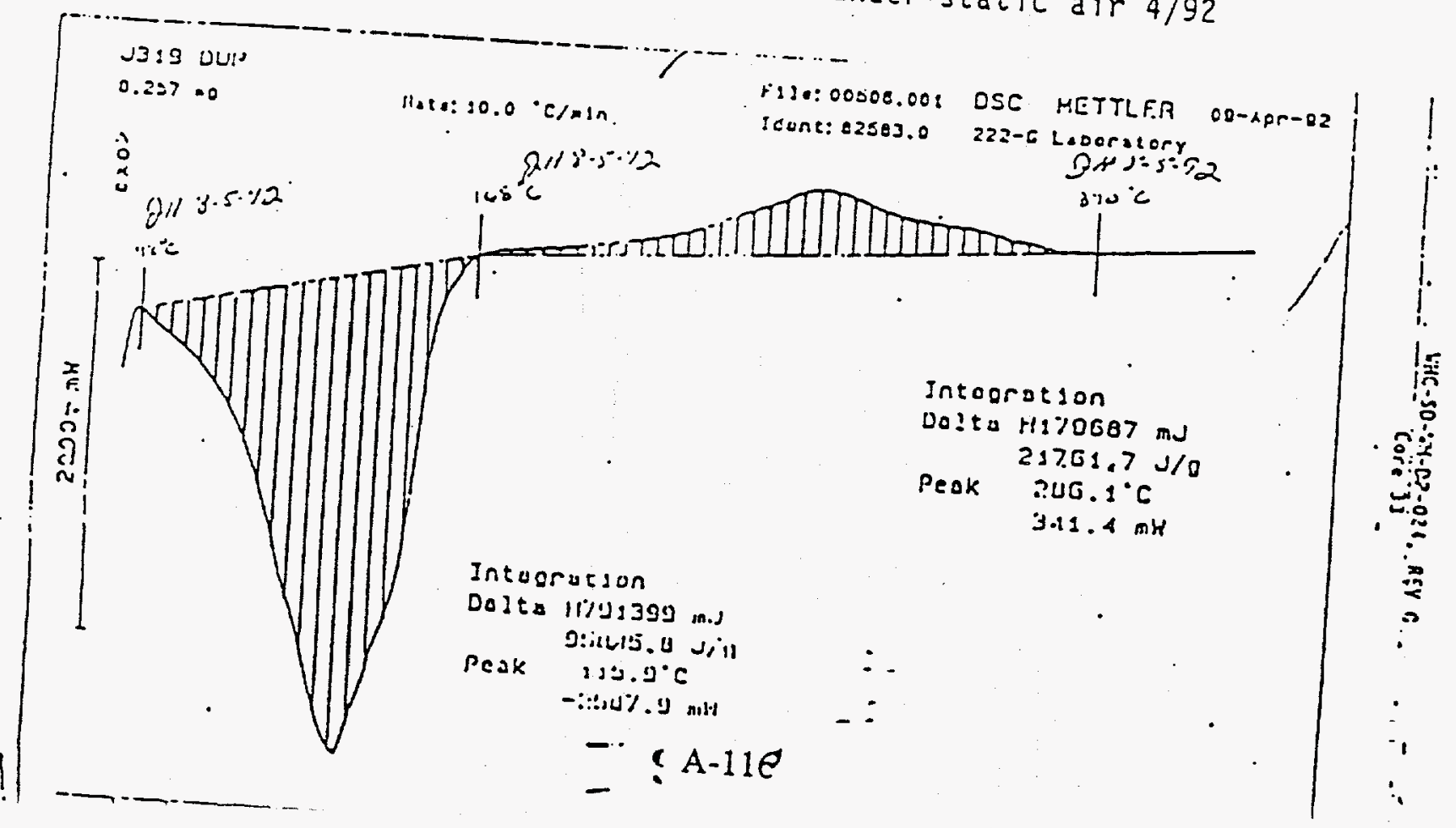


WHC-SD-WM-DP-058

REV.O-B

Re-analysis T-111 DSC Data 1/94 
Core $33 \mathrm{seg} \mathrm{1,} \mathrm{dried} \mathrm{sample} \mathrm{run} \mathrm{under} \mathrm{static} \mathrm{air} \mathrm{1/94}$

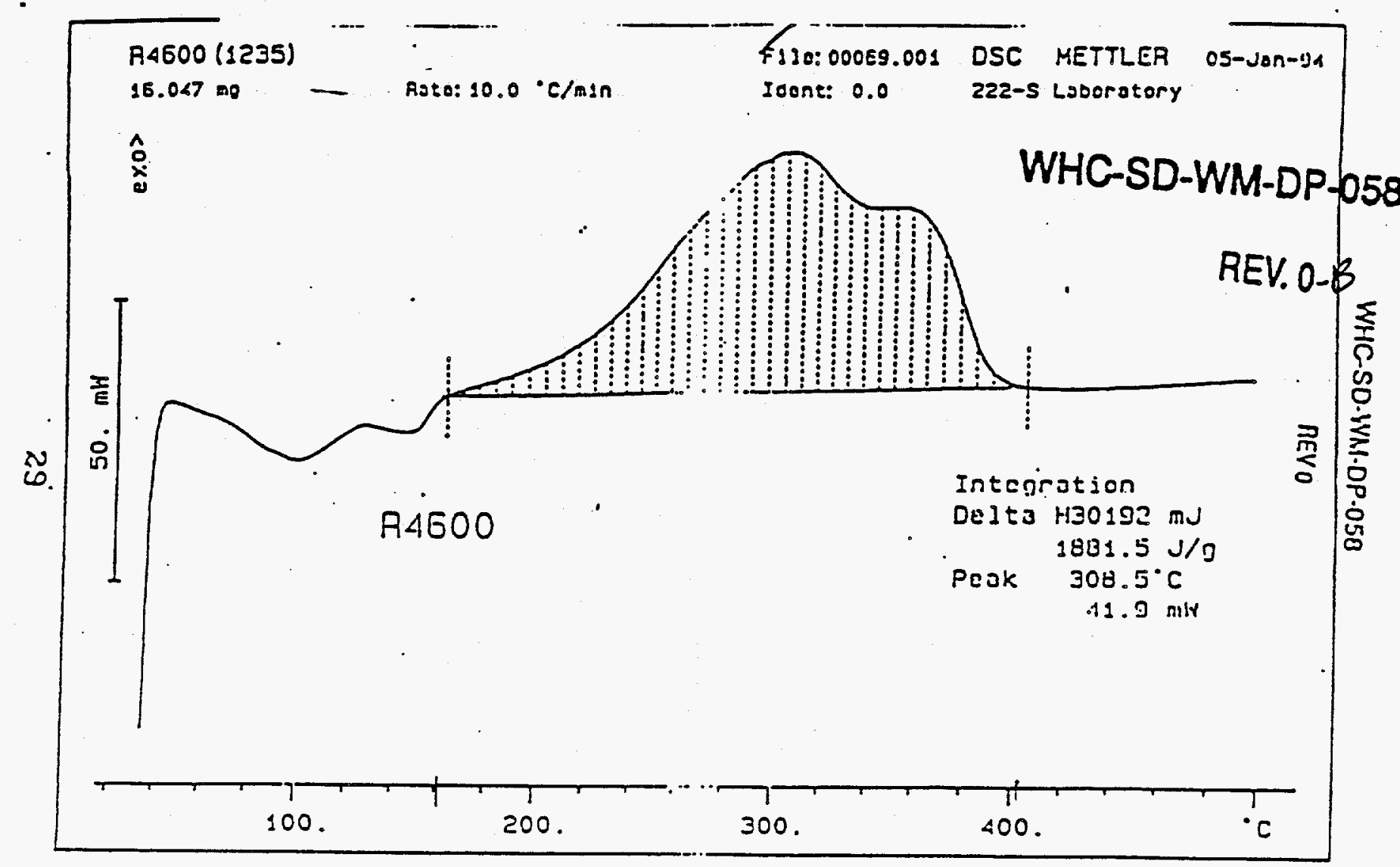

Core $33 \mathrm{seg} 1$, dried sample run under static air $1 / 94$

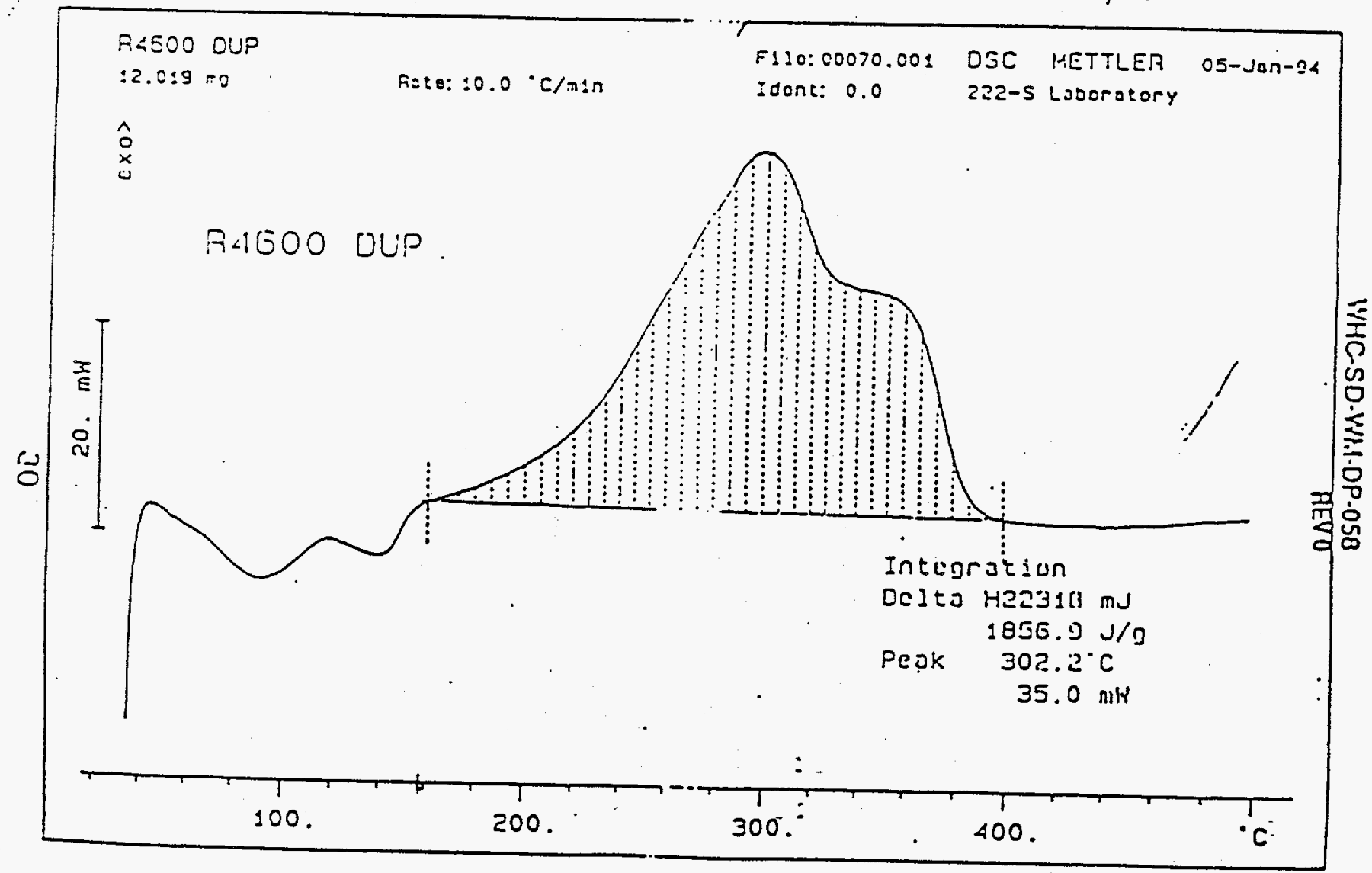


WHC-EP-0806

Core $33 \operatorname{seg} 2$, dried sample run under static air 1/94
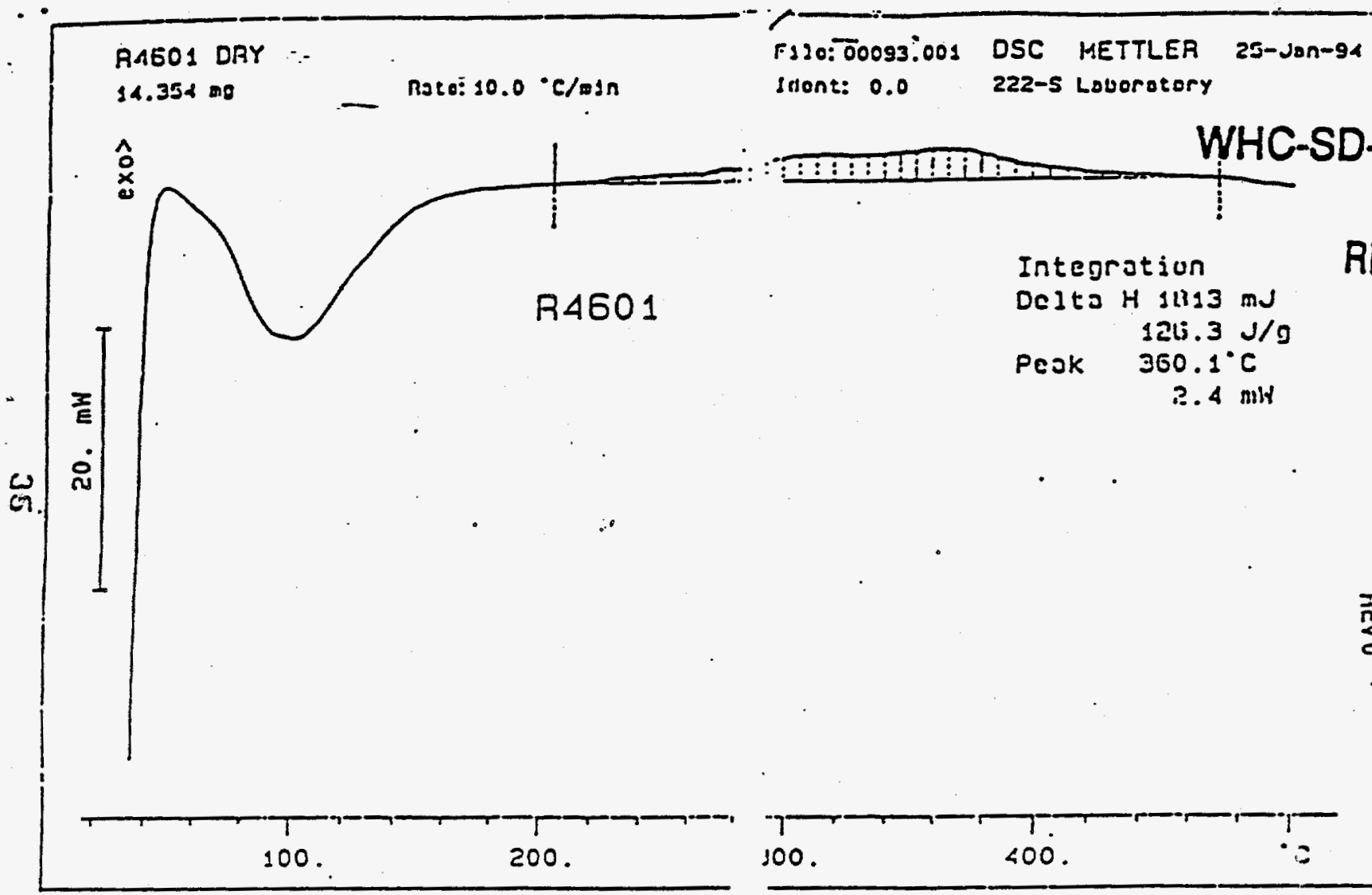

Inont: 0.0 222-S Lovorotory
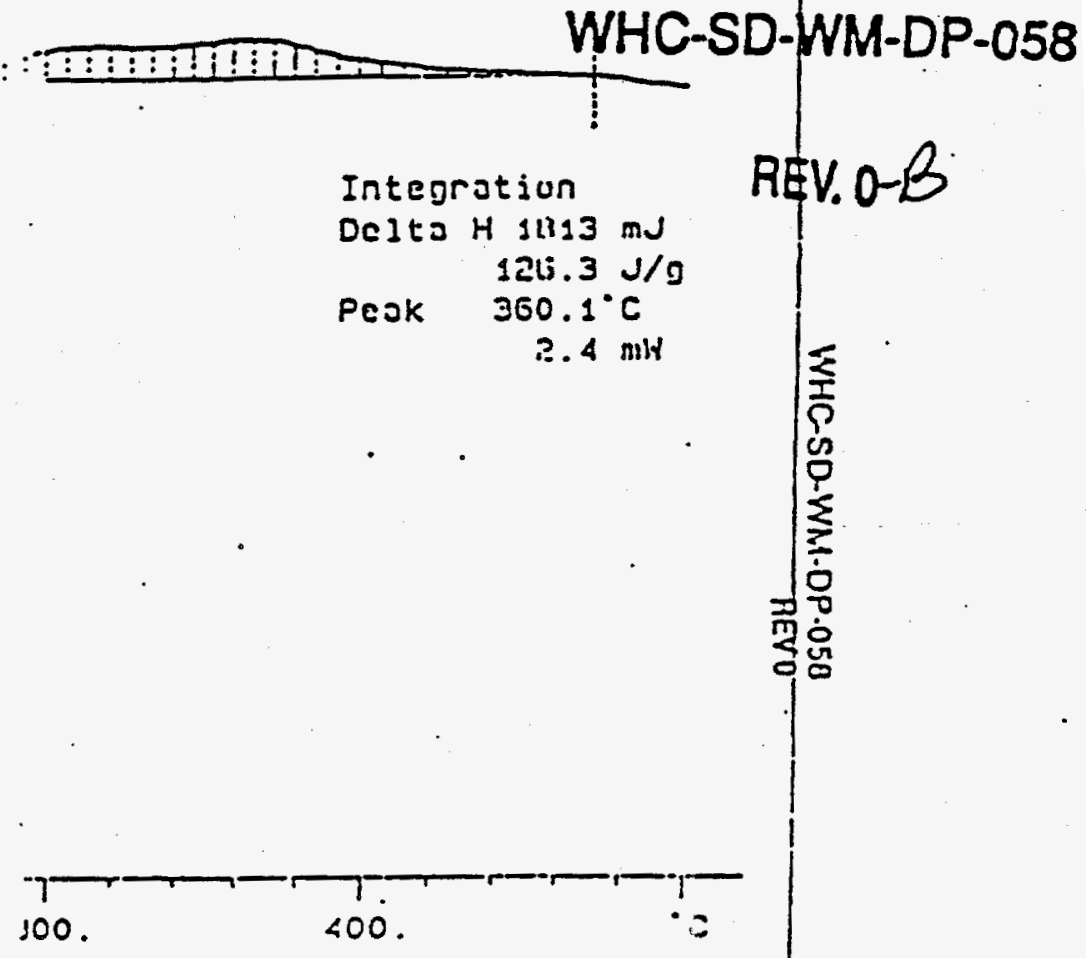

Core 33 seg.2, dried sample run under static air 1/94

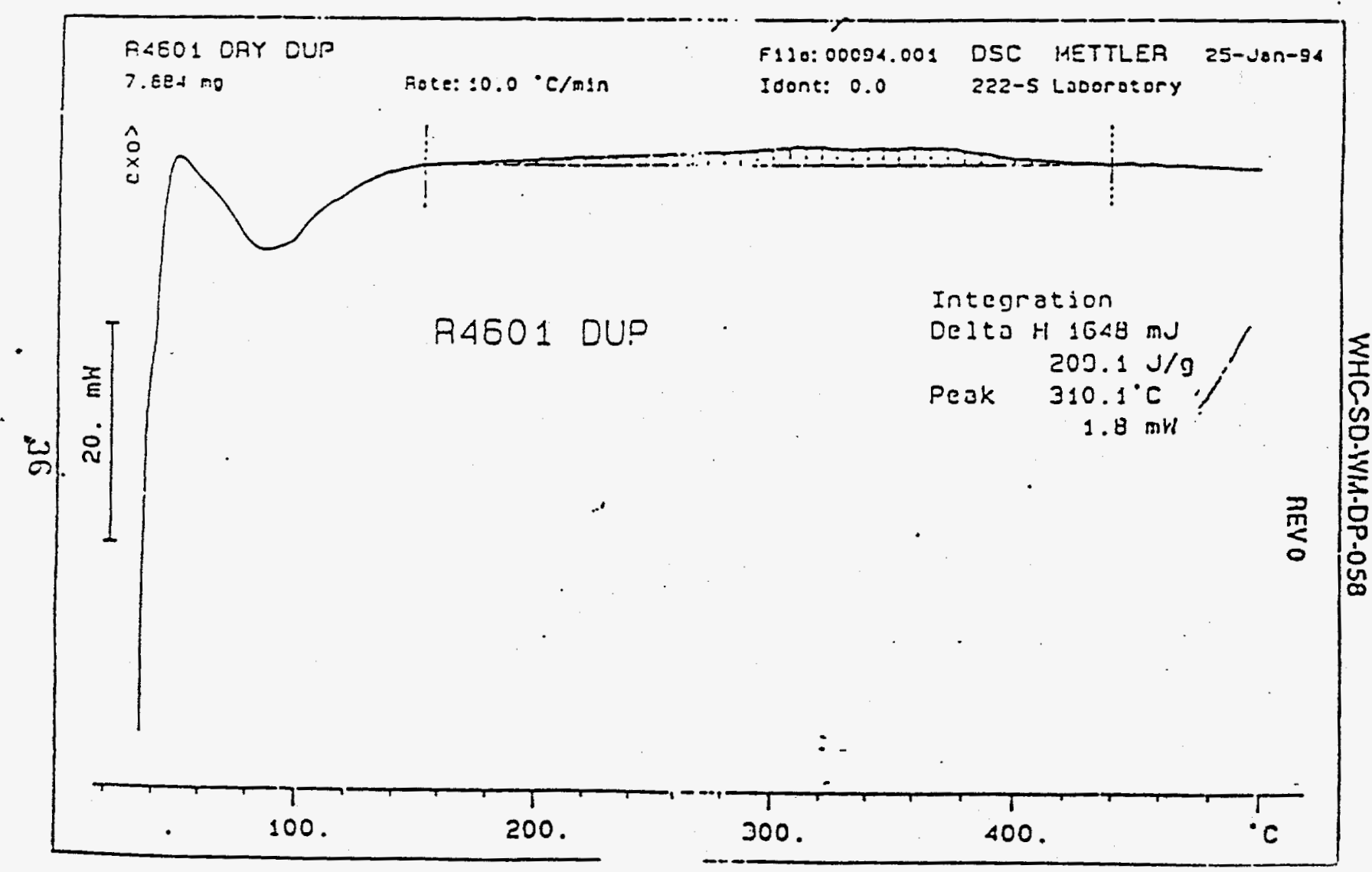


WHC-EP-0806

\section{WHC-SD-WM-DP-058}

\section{REV. O-B}

Re-analysis T-111 DSC Data 5/94 
Core 33 seg 2 , dried sample run under a nitrogen purge 5/94

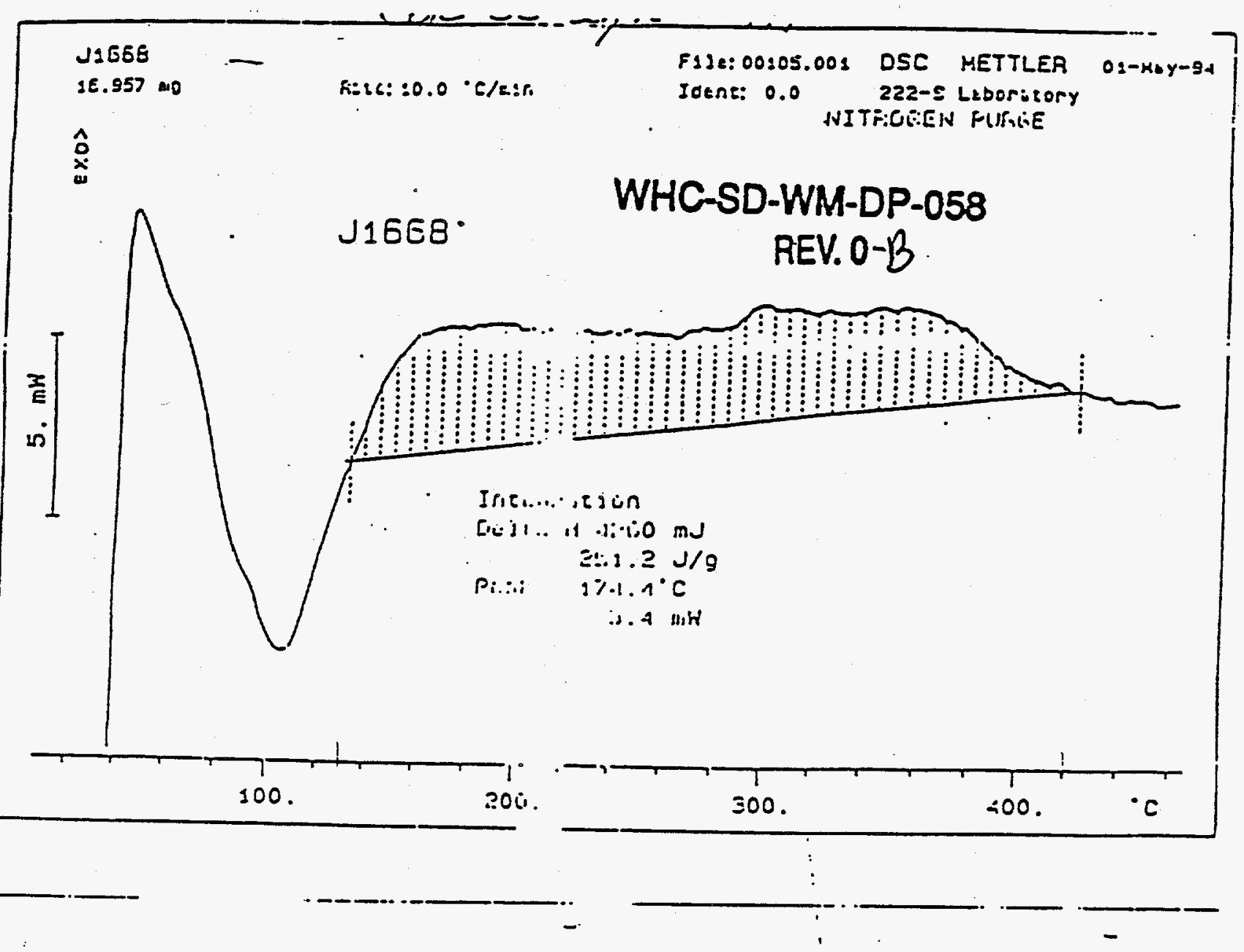

Core 33 seg 2 , dried sample run under a nitrogen purge 5/94

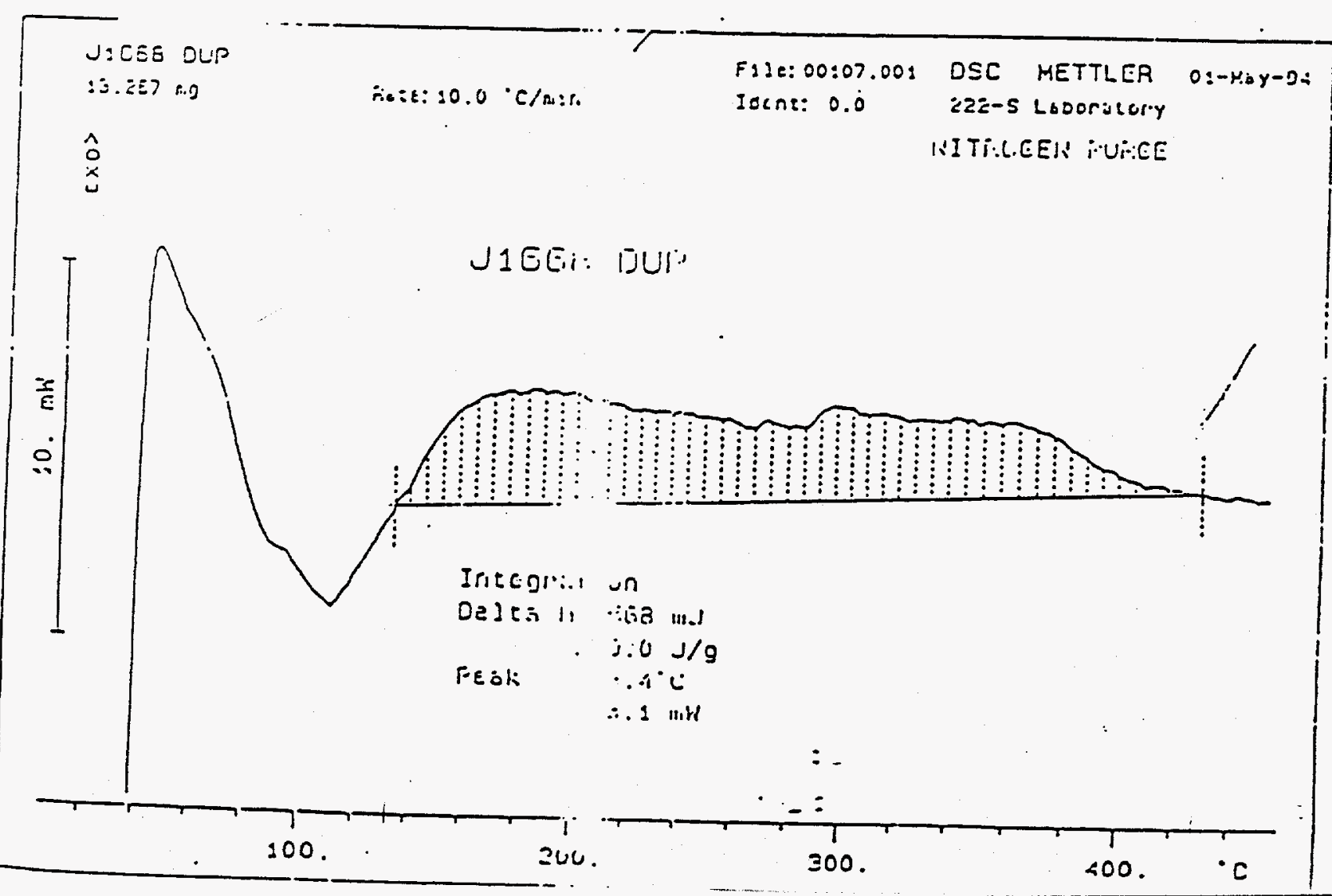




\section{WHC-EP-0806}

$\therefore$ Core 33 seg 2 , dried sample run under a nitrogen purge 5/94

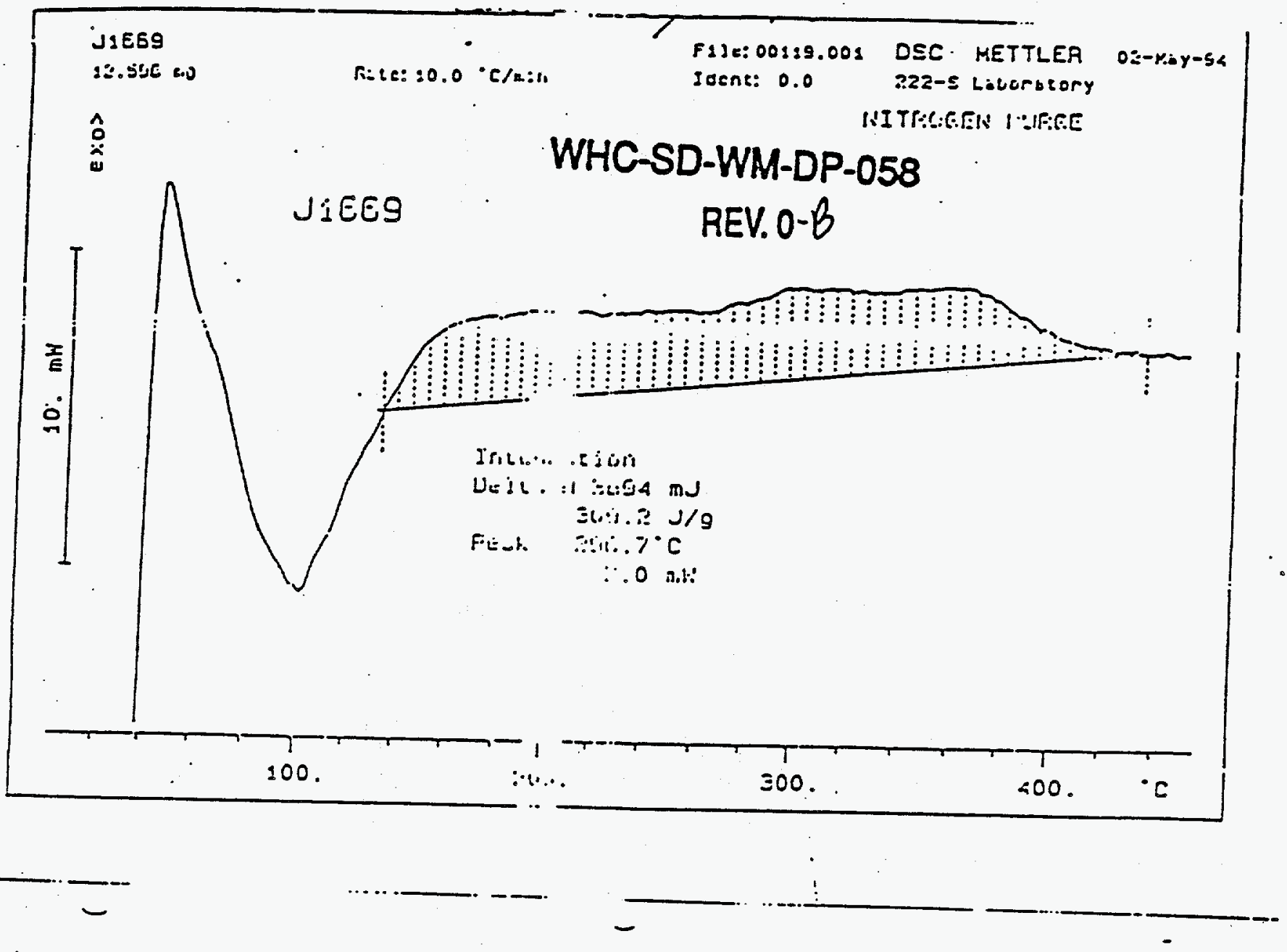

Core 33 seg 2, dried sample run under a nitrogen purge 5/94

JIESO LUF

:9.:U2 A.J

$\hat{o}$
F:2::00:23.c0: DSC 1.1ETTLER 02-rey-24

Icens: 0.0 2z2-5 Ledoratory

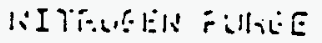

JIEES DUR
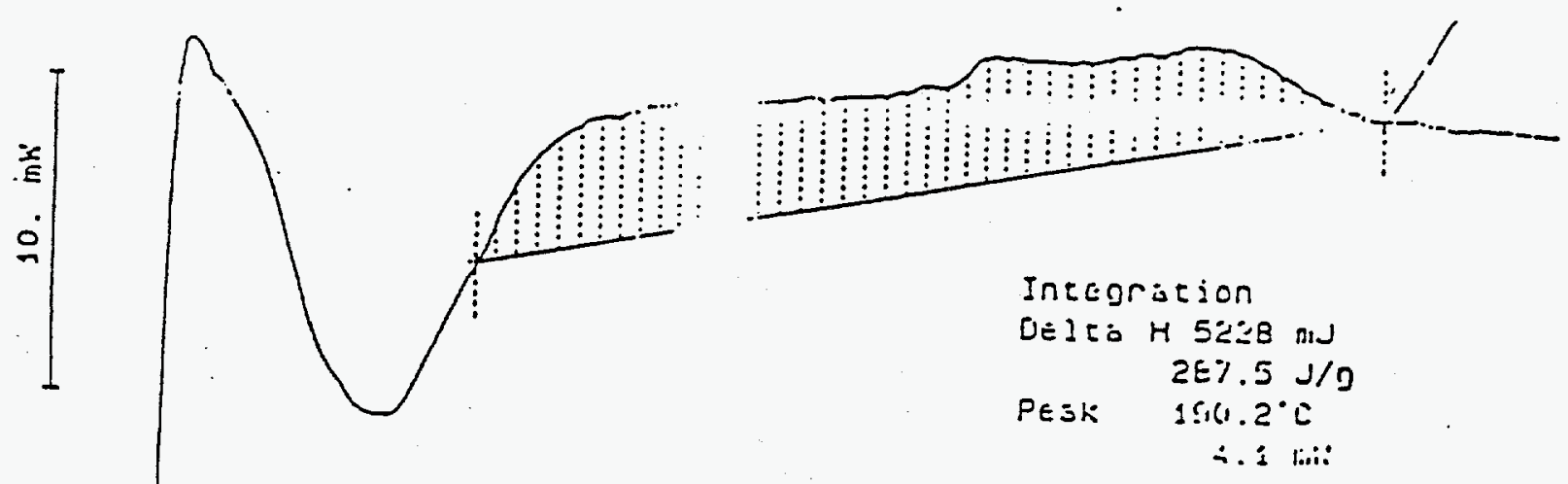

- $\{\mathrm{A}-122, \ldots$ 

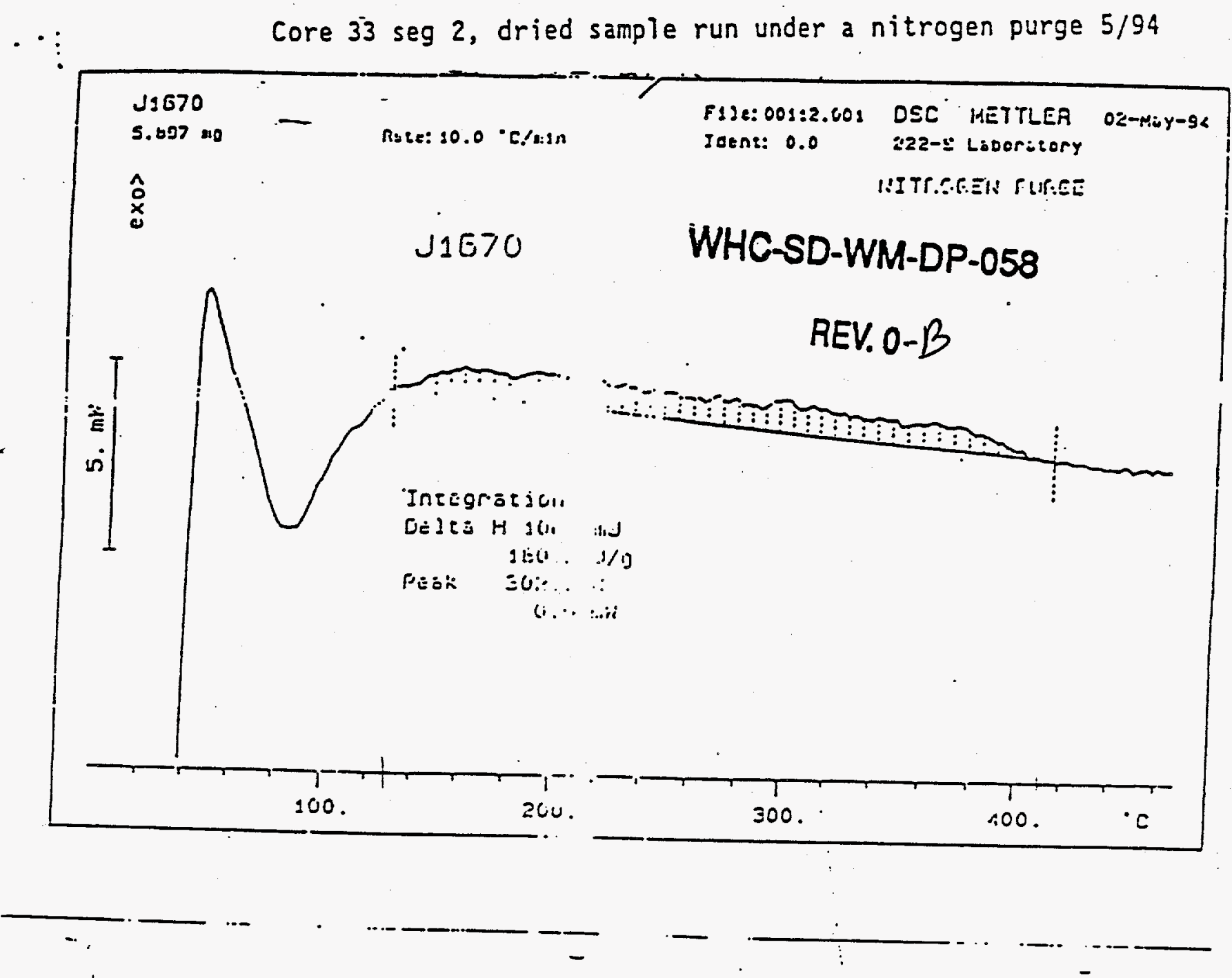

WHC-SD-WM-DP-058

REV. O-B

Core $33 \operatorname{seg} 2$, dried sample run under a nitrogen purge 5/94

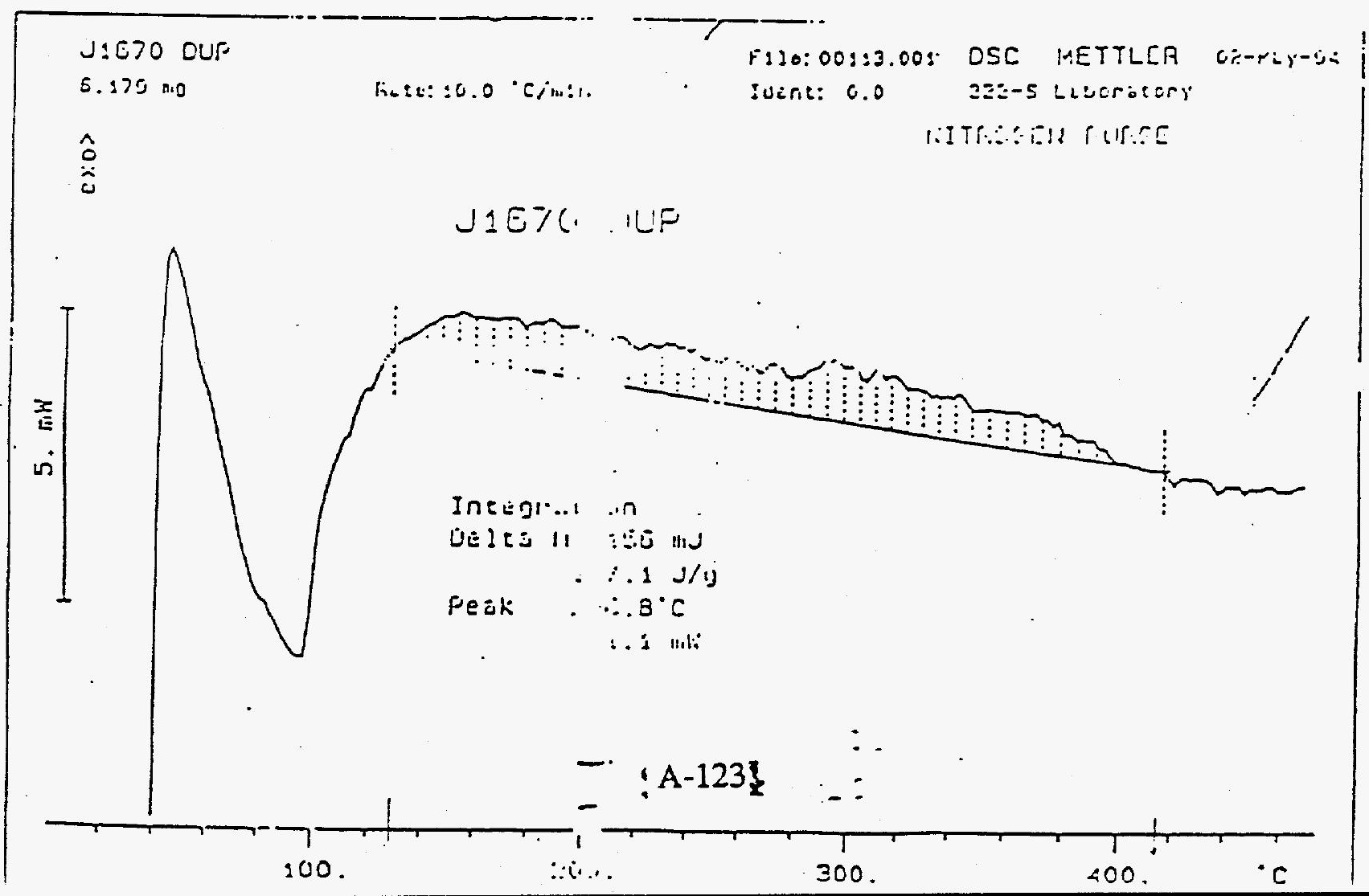


Core 33 seg 2, dried sample run under a nitrogen purge $5 / 94$

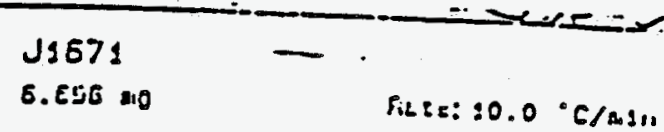

$\hat{0}$
$x$
0

$\hat{x}$
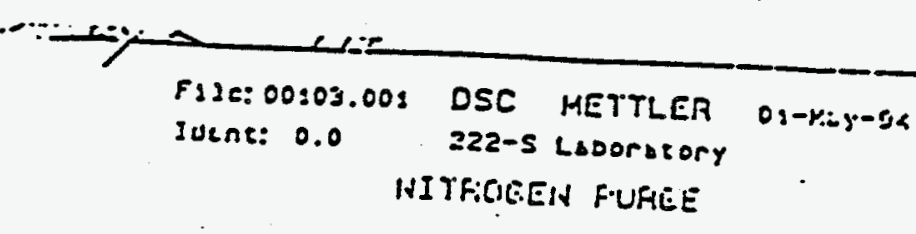

J1E>1

WHC-SD-WM-DP-058

REV. O.B

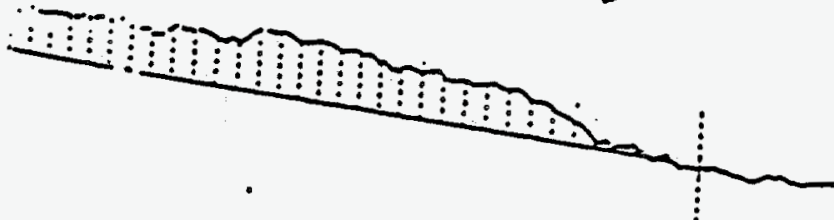

Integrostich

DElis $H$ goso.

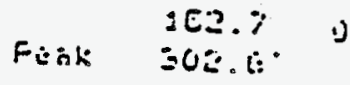

I. i. .

Core 33 seg 2, dried sample run under a nitrogen purge 5/94

U:67: DUF

$2.023 \cdots .0$

$\hat{0}$
$\hat{0}$
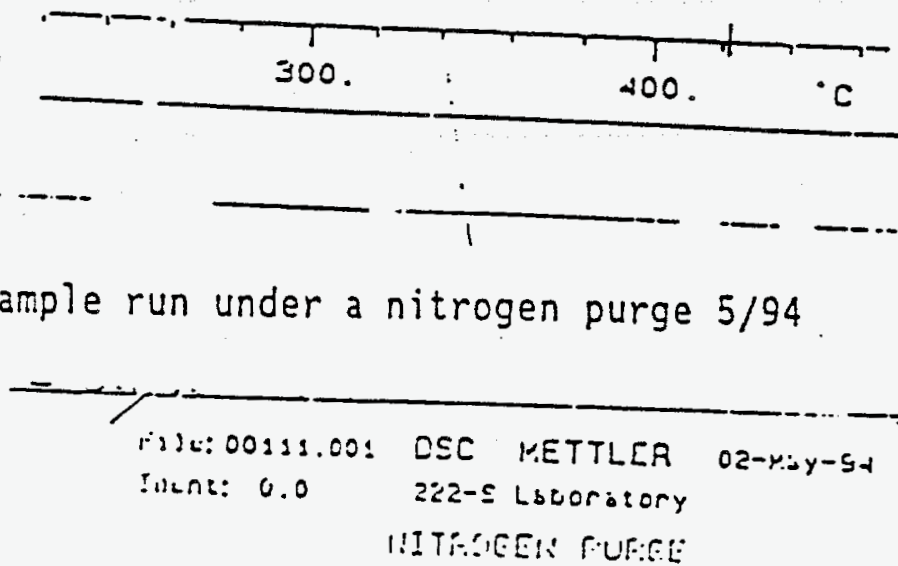

1! IT:PEE: r.UF:CE

J1E7 I IUP

Thina. Ejon

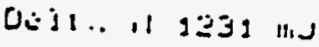

$17 \%$

Fut: 20.5. ${ }^{\circ} \mathrm{C}$

1.0 molt:

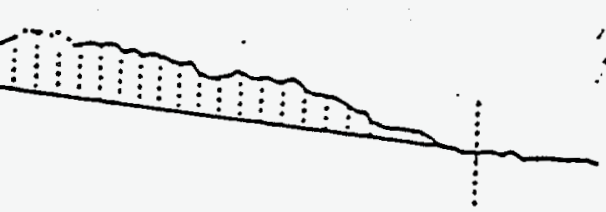

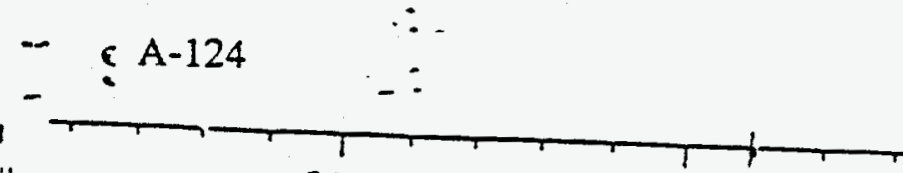




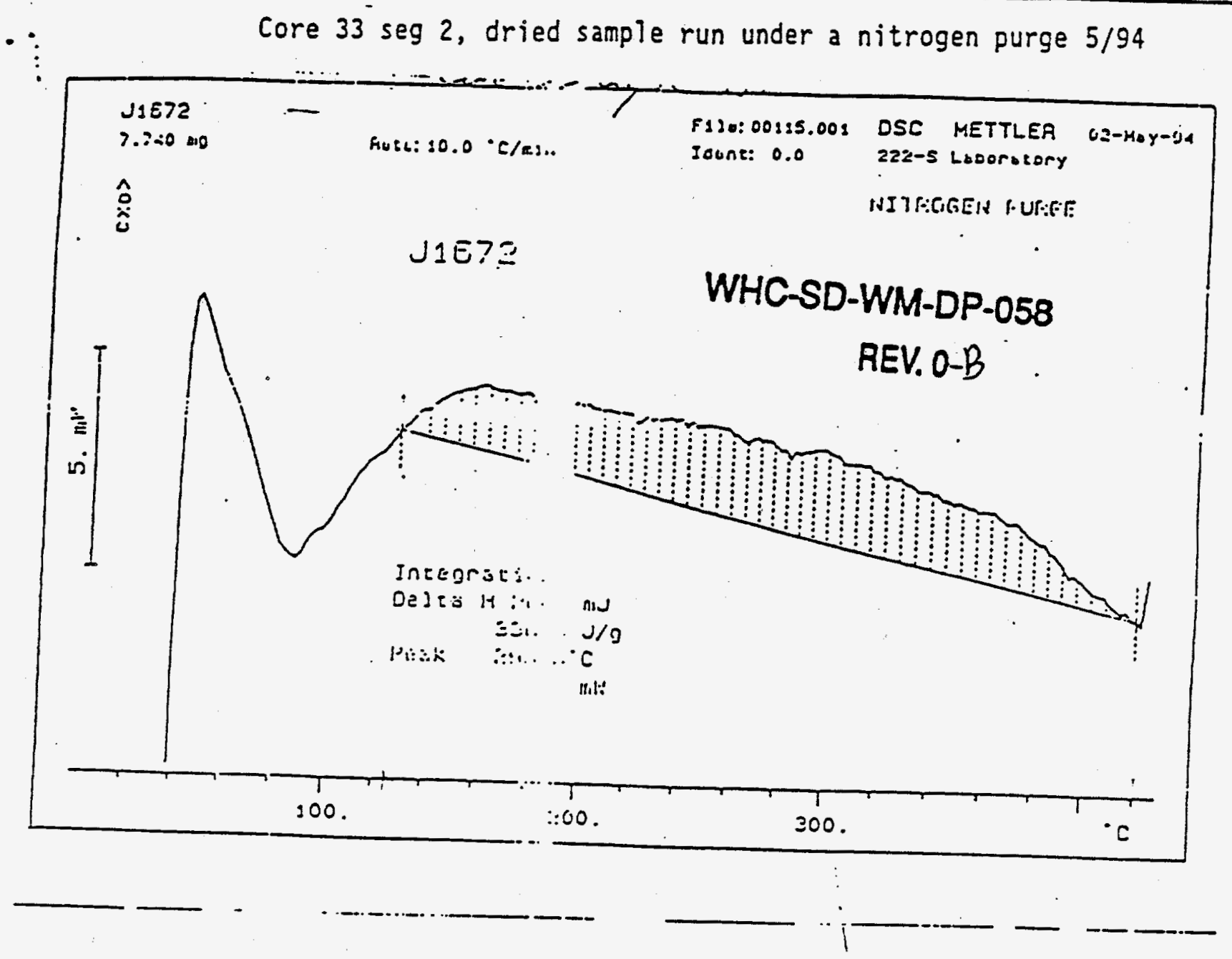

Core 33 seg 2, drjed sample run under a nitrogen purge 5/94

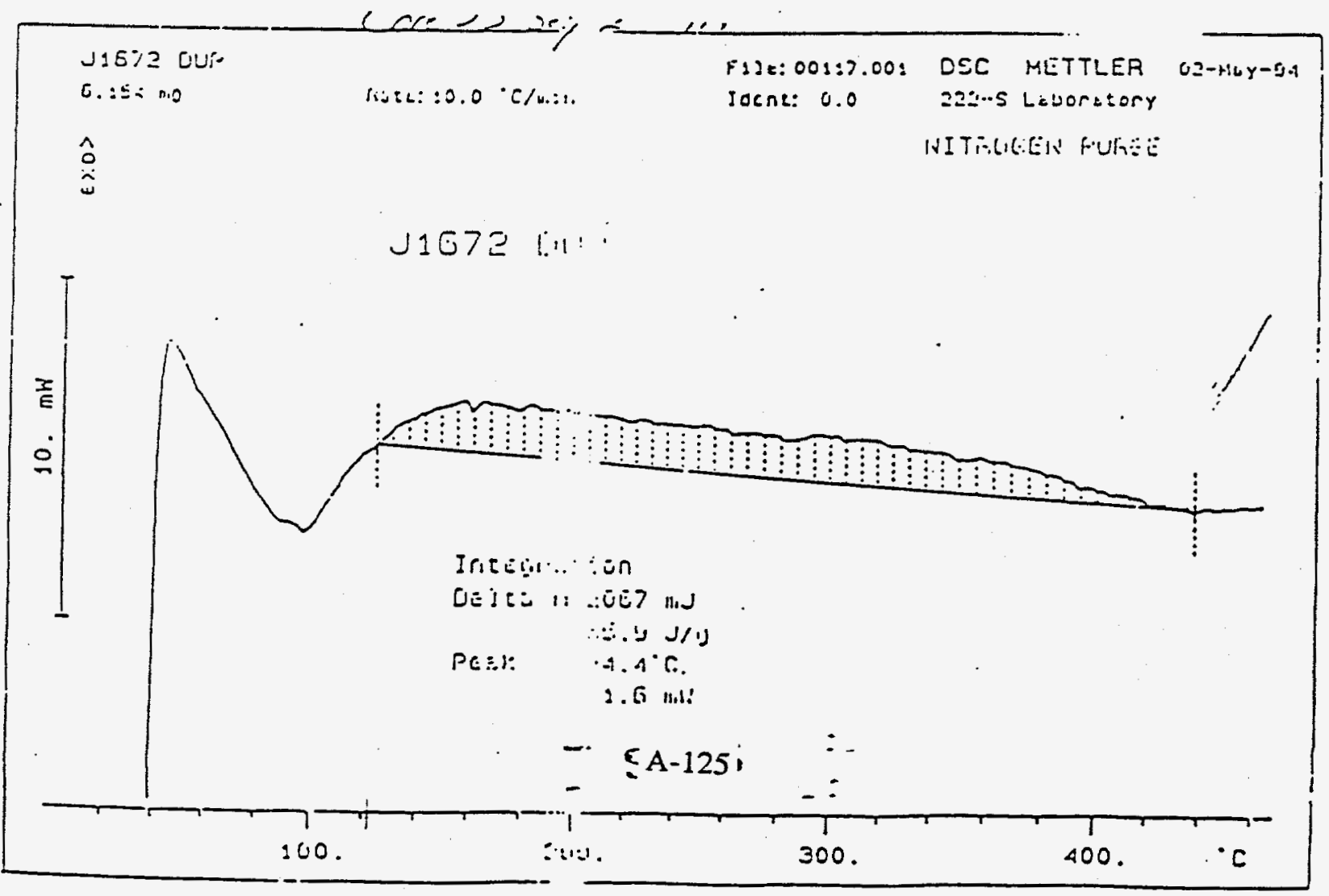


WHC-EP-0806

\title{
WHC-SD-WM-DP-058
}

\author{
REV. O-B \\ PNL Re-Analysis 12/93
}


Thermal analyses of tank waste material from Tank 241-T-111 Core 33, segment 2 were performed in duplicate. The thermal analysis includes both differential scanning calorimetry (DSC) and scanning thermogravimetry (TEA). OSC analyses were performed on dried sample material, but the TEA analyses were performed on the as-received sample. These analyses were performed according to technical procedure PNL-ALO-508, "Laboratory Procedure for Operation of the Differential Scanning Calorimeter (DSC), Thermogravimetric Analyzer (TG), and High Temperature Difierential Thermal Analyzer (OTA) and DSC."

DSC analyses of sample $92-05856-14$ and it's duplicate were pericrmed on a Perkin Eimer Kodel 2 Difierential Scanning Calorimeter. The sample was prepared by transferring $0.48 \subseteq 6$ grams of sample from $92-05856$ (labeled T-111, Core 33, Seginent 2) to a glass vial. This sample was placed in a vacuum oven at $60 \cdot C$ and $28 \mathrm{in.} \mathrm{Hg} \mathrm{(7ll} \mathrm{km} \mathrm{hg}$ ) at 1315 hours on Decenber 9, 1993 . The sample vies removed

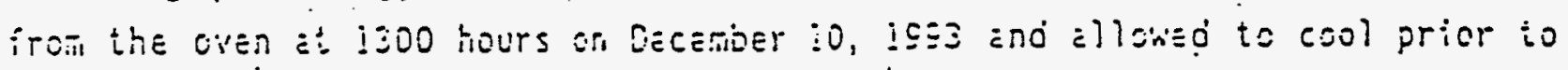
heighing. The sample weight efier this orying period was 0.0721 grams (a loss. of 0.4175 grams or $85.3 \%$ mass loss). The sample kas placed back in the oven at $60 . \mathrm{C}$ and $28 \mathrm{in.}$. $\mathrm{gg}$ at 1310 hours on December 10,1993 and ranoved at 1500 hours cn the same day. The sample was raveighed and a loss of only 0.0005 grams was observed; therefore, the sample was sealed and placed in a desiccator. The sample was analyzed on December 13, iso3 using a nitrogen gas environment. Sampies of 11.19 and 15.72 milligrams here used for Runs 1 and 2 , respectively. A temperature range from 35 to $550 . \mathrm{C}$ was scanned at $5 \cdot \mathrm{c} / \mathrm{min}$. The results of these analyses are given in Tible $1-1$.

Table 1-?: Core 33, Segment 2, Energetics

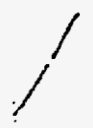

\begin{tabular}{|c|c|c|c|}
\hline RUN & RANGE $(\cdot \mathrm{C})$ & ONSET $(\cdot \mathrm{C})$ & ENTHALPY $(\mathrm{J} / \mathrm{g})$ \\
\hline 1 & $107-381$ & 201 & -898 \\
\hline 2 & $113-394$ & 196 & -836 \\
\hline
\end{tabular}


An indium and a zine standard was run prior to analyzing the sample. The indium standard had an onset temperature of $156.8 \cdot \mathrm{C}$ with an enthaloy of $28.3 \mathrm{~J} / \mathrm{g}$. The Titerature values for indium are $156.6 . \mathrm{C}$ and $28.45 \mathrm{~J} / \mathrm{g}$. The zine standaro had an onset temperature of $417.1 \cdot C$ with an enthalpy of $98.7 \mathrm{~J} / \mathrm{g}$. The literature values for zine are $419.47^{\circ} \mathrm{C}$ and $108.37 \mathrm{~J} / \mathrm{g}$.

Thermogravimetric analysis was performed in triplicate on an aliquot of asrecaived sample material using a Perkin Elmer Model 2 Thermogravimetric Analyzer. A nitrogen gas environiment wis used to analyze thase samples. Semples of 11.32, 17.11, and 19.40 milligrems kere used for Runs 1, 2, and 3, respectiveiy. Run 1 was performed on Decenber 28, Run 2 on December 29, 1993, and 8 un 3 on Jenuary 3,1994 . A temperature range from 35 to $550 \cdot \mathrm{C}$ was scanned at $5 \cdot \mathrm{C} /$ min for Runs 1 and 2. The temperature range for Run 3 was from 35 to $200 \cdot \mathrm{C}$ at a scan rate of $5 \cdot c / m i n$. This shorter scan range was chosen, because no significant weight loss was cbserved above $150^{\circ} \mathrm{C}$. The results of these analyses are given in Table $1-2$.

Table 1-2: Core 33, Segment 2, Mass Losis as a Function of Temperature

\begin{tabular}{|c|c|c|}
\hline RUN & RAHGE (.C) & HEIERT LOSS (Wt\%) \\
\hline 1 & $31-103$ & 67.3 \\
\hline 2 & $31-116$ & 80.3 \\
\hline 3 & $30-130$ & 79.7 \\
\hline
\end{tabular}

Run 1 appeared to be on a sample that was significantiy drier than the other samples. Runs 2 and 3 compare well with the gravimetric/determinations weight percent solids measurements. It. was also noted in Runs' 1 and 2 that no significant weight loss was observed in the temperature range of the exothermic reaction.

Alumel and perkalloy eurie point standards were run prior to analyzing the sample. The alumel standard had an onset temperature of $162.35^{\circ} \mathrm{C}$, and the perkalloy standard had an onset temperature of $595.73 \cdot \mathrm{C}$. The literature values for alumel and perkalloy are $163{ }^{\circ} \mathrm{C}^{\circ}$ and $596^{\circ} \mathrm{C}$, respectively. 
Core $33 \mathrm{seg} 2$, dried sample run under a nitrogen purge 12/93

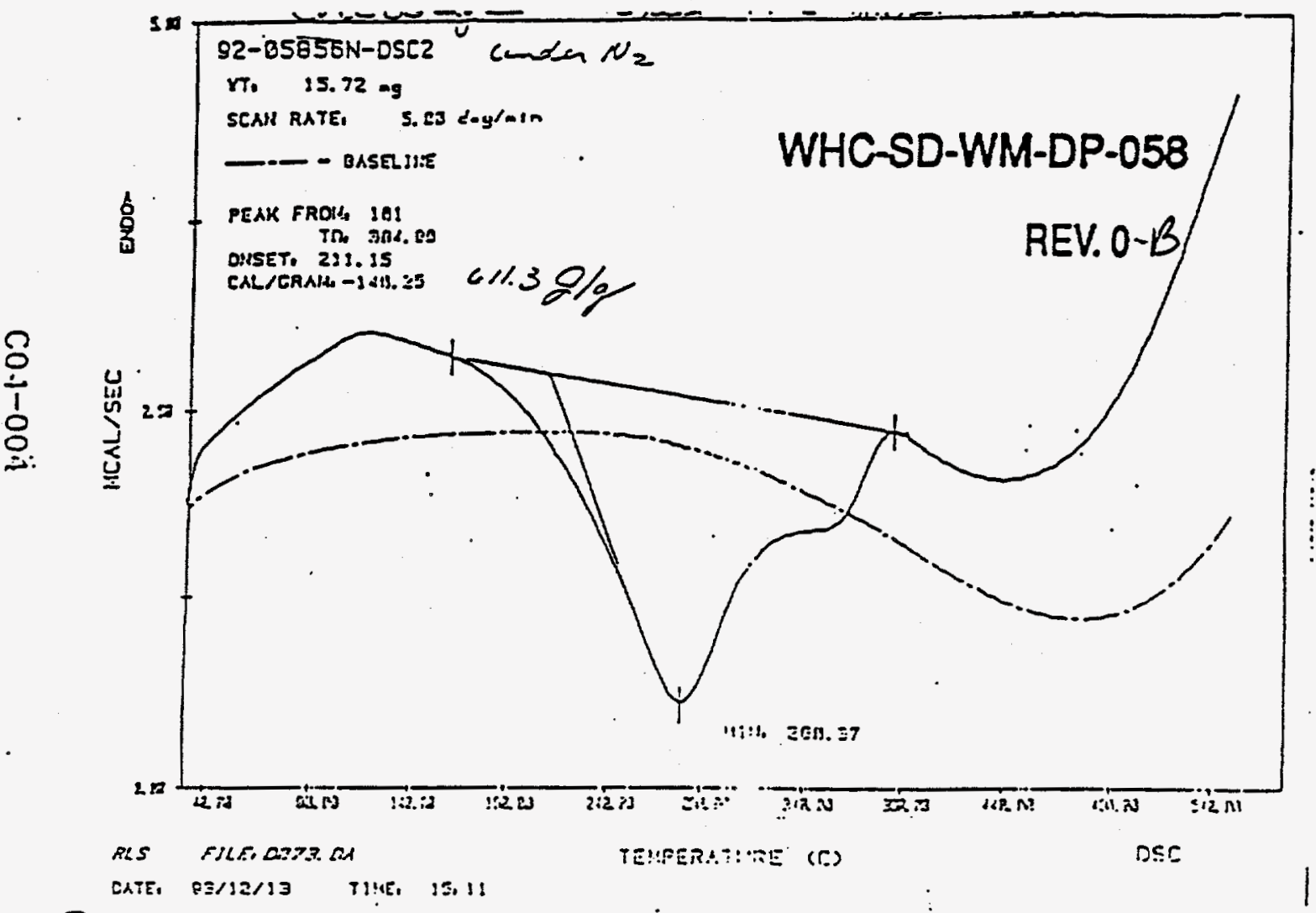

:

Core 33 seg 2, dried sample run under a nitrogen purge 12/93

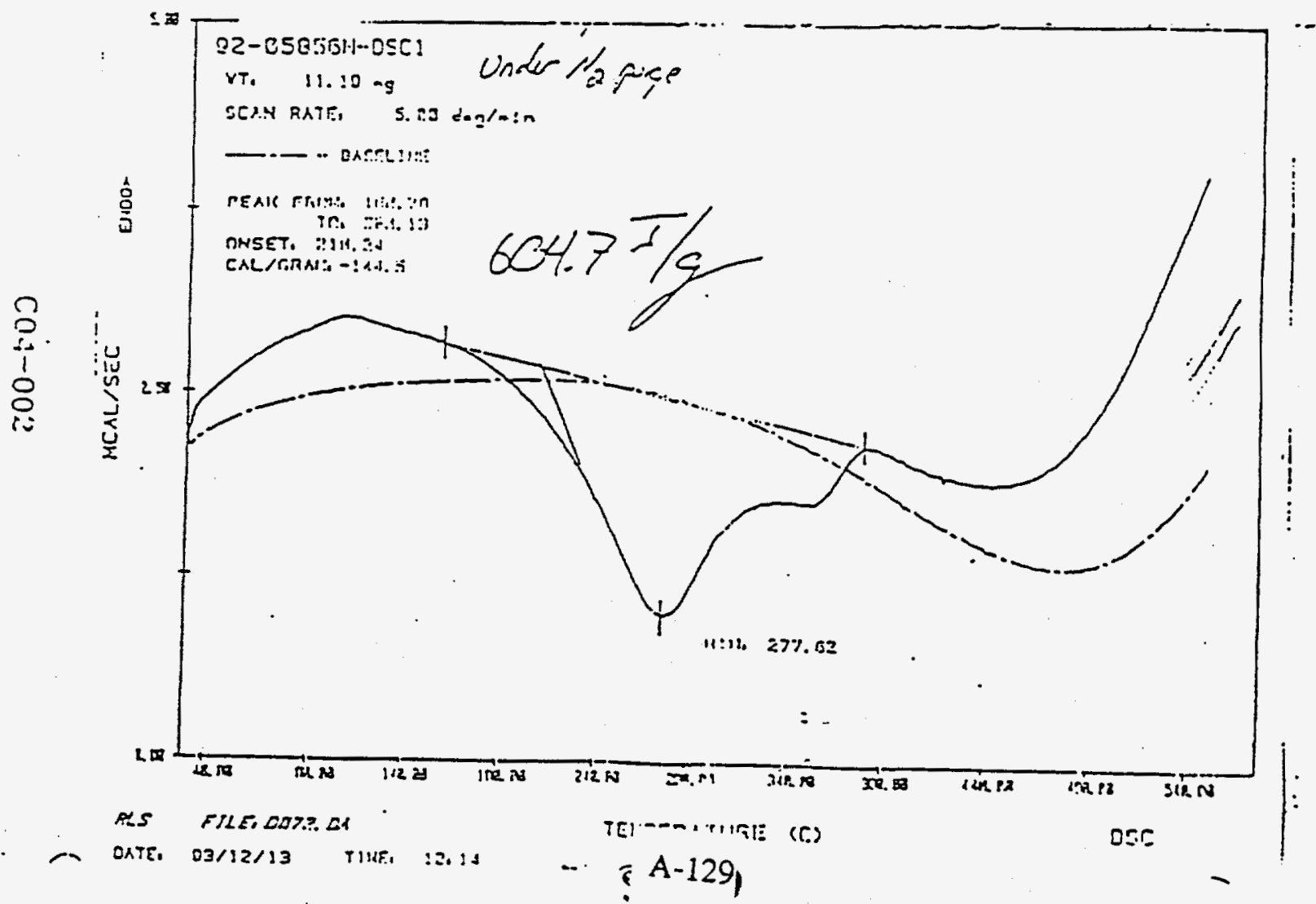


WHC-EP-0806

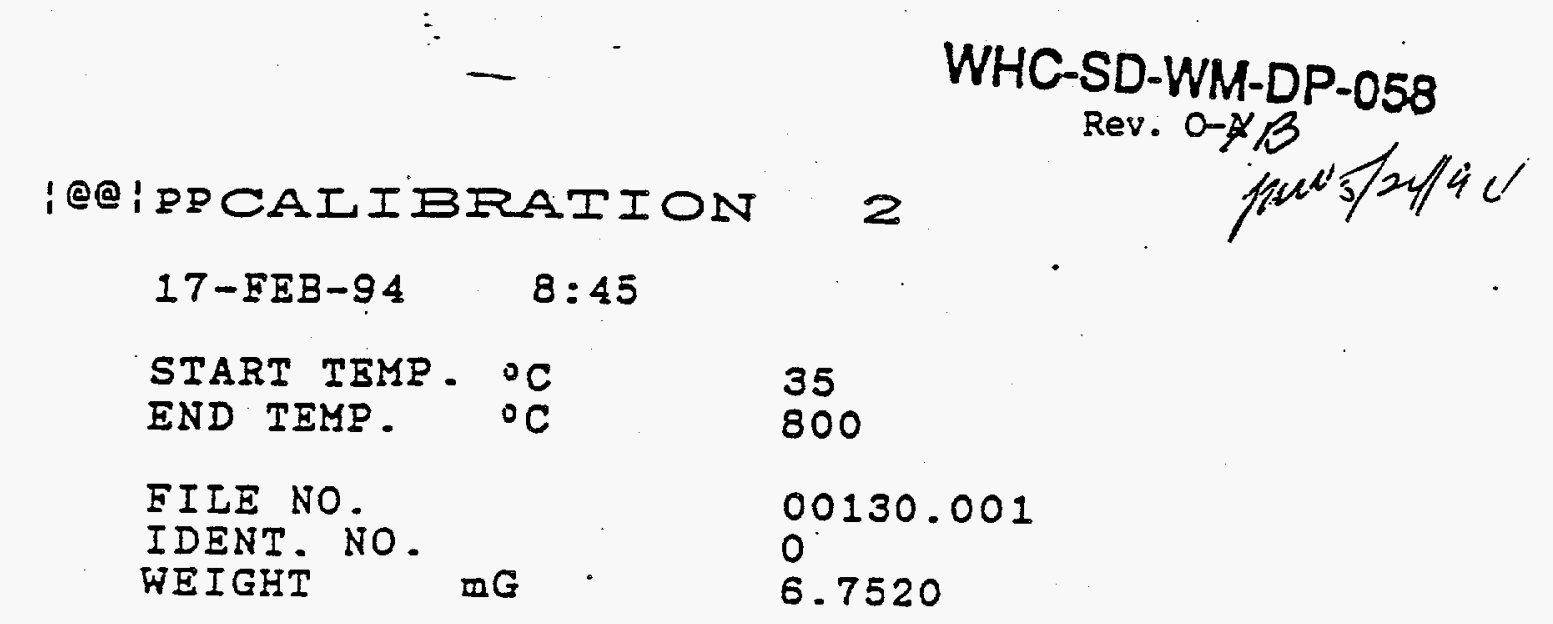

TEMPERATURE ${ }^{\circ} \mathrm{C}$

WEIGHT

GAIN---- >
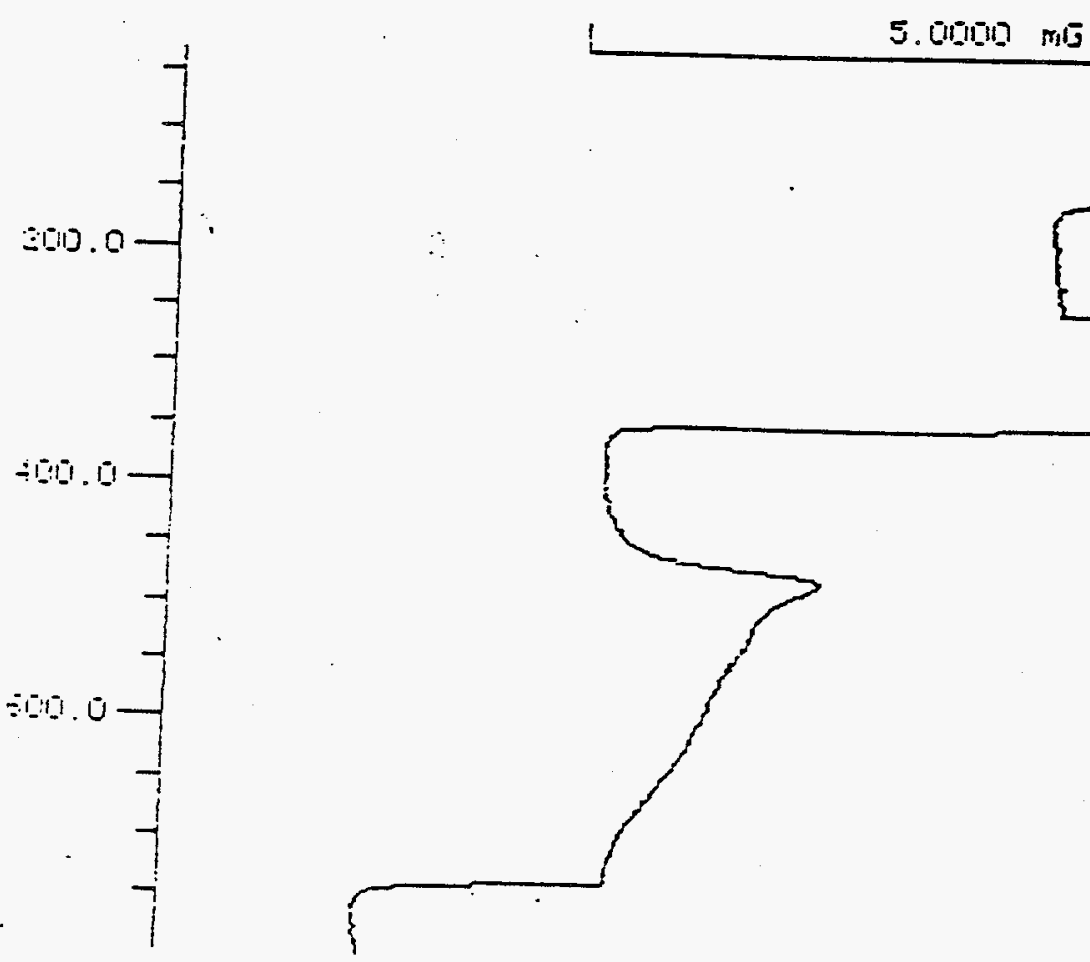

TEMP.

TEMP.

143.67

349.67

739.00

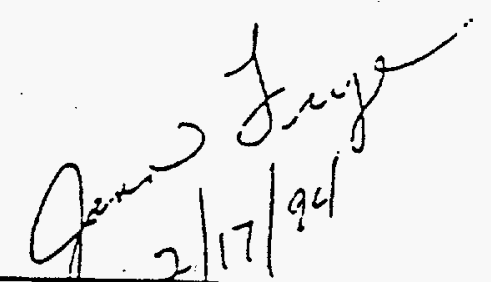

A. PT100

B PT100

${ }^{\circ} \mathrm{C}$

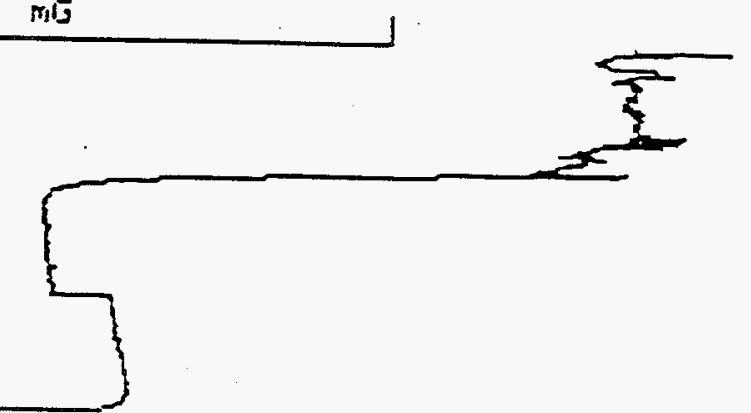

C :PTI00

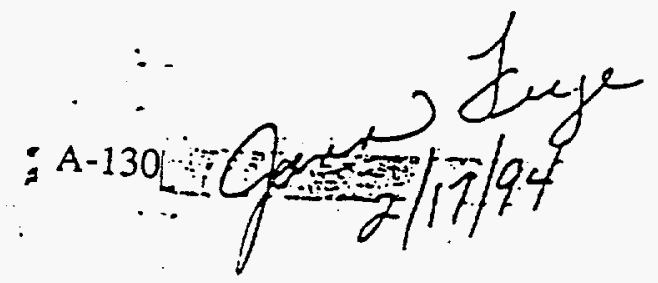


WHC-EP-0806

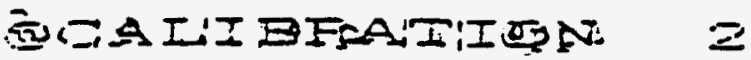

$$
\text { 31-JAN-94 10:16 }
$$

START TEMP. ${ }^{\circ} \mathrm{C}$

END TEMP. $\triangle \mathrm{C}$

EILE NO.

IDENT. NO. WEIGHT $\mathbf{m G}$
35

750 .

00120.001

0

7.57
1

WHC-SD-WM-DP-058 Rev. $0-\not B$ fpov $5 / 24 / 44$

TEMPERATURE :C

HEAT ELOW

EXOTHERHAL $->$

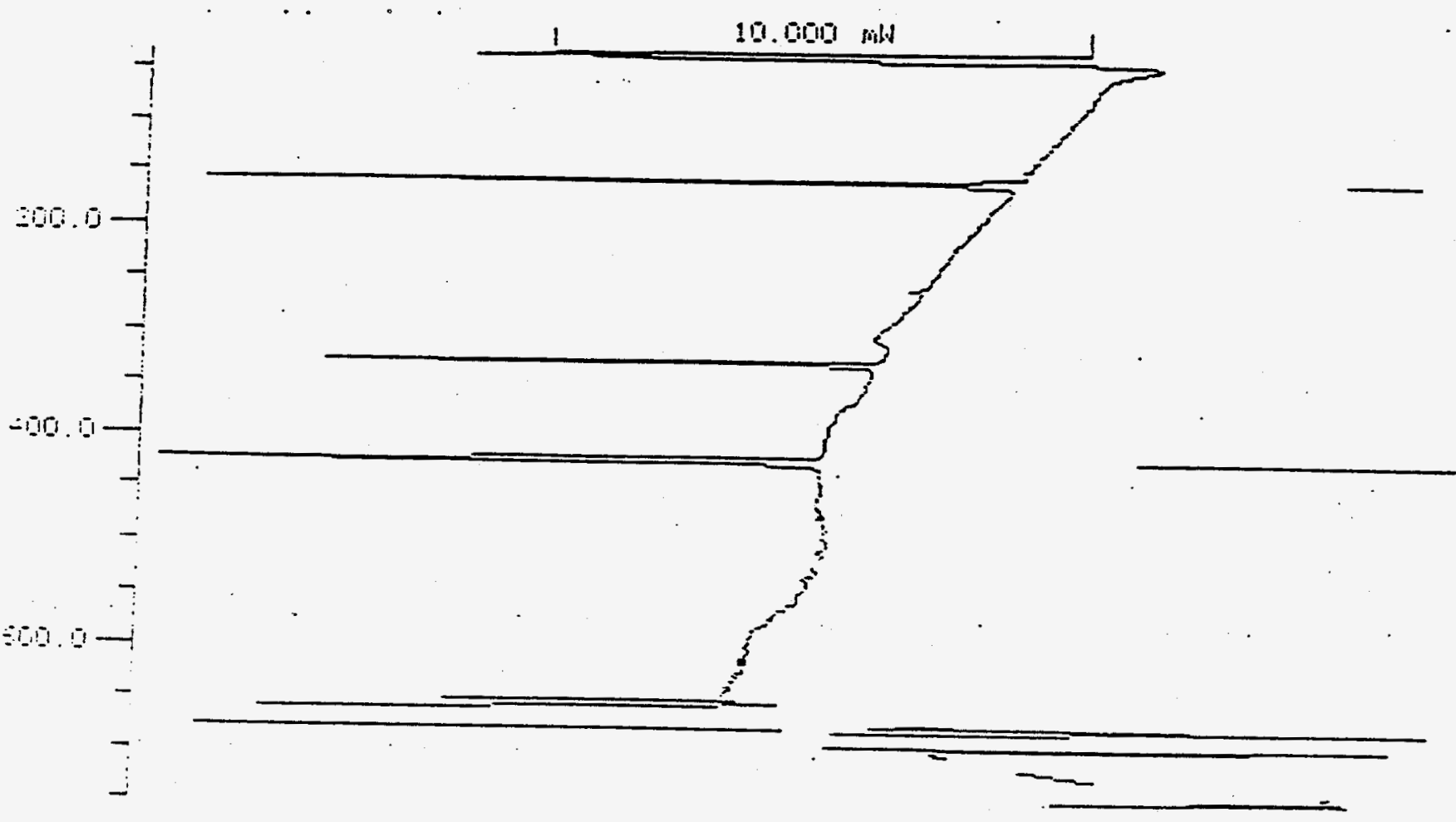
A. PTI00
B PT100
C PTIOO
E INDIUM
.21401
.75726
$-.12421$
310.23

\section{******** METTLER TA 4000}

SYSTEM *********

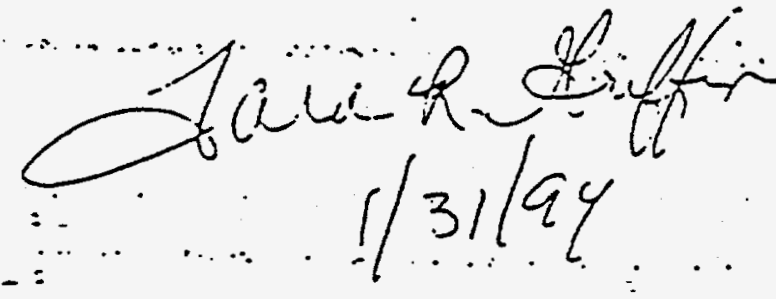


WHC-EP-0806

WHC-SD-WM-DP-058

REY. O-B

ADDITIONAL DATA SUBMITTED ON 05/18/94 


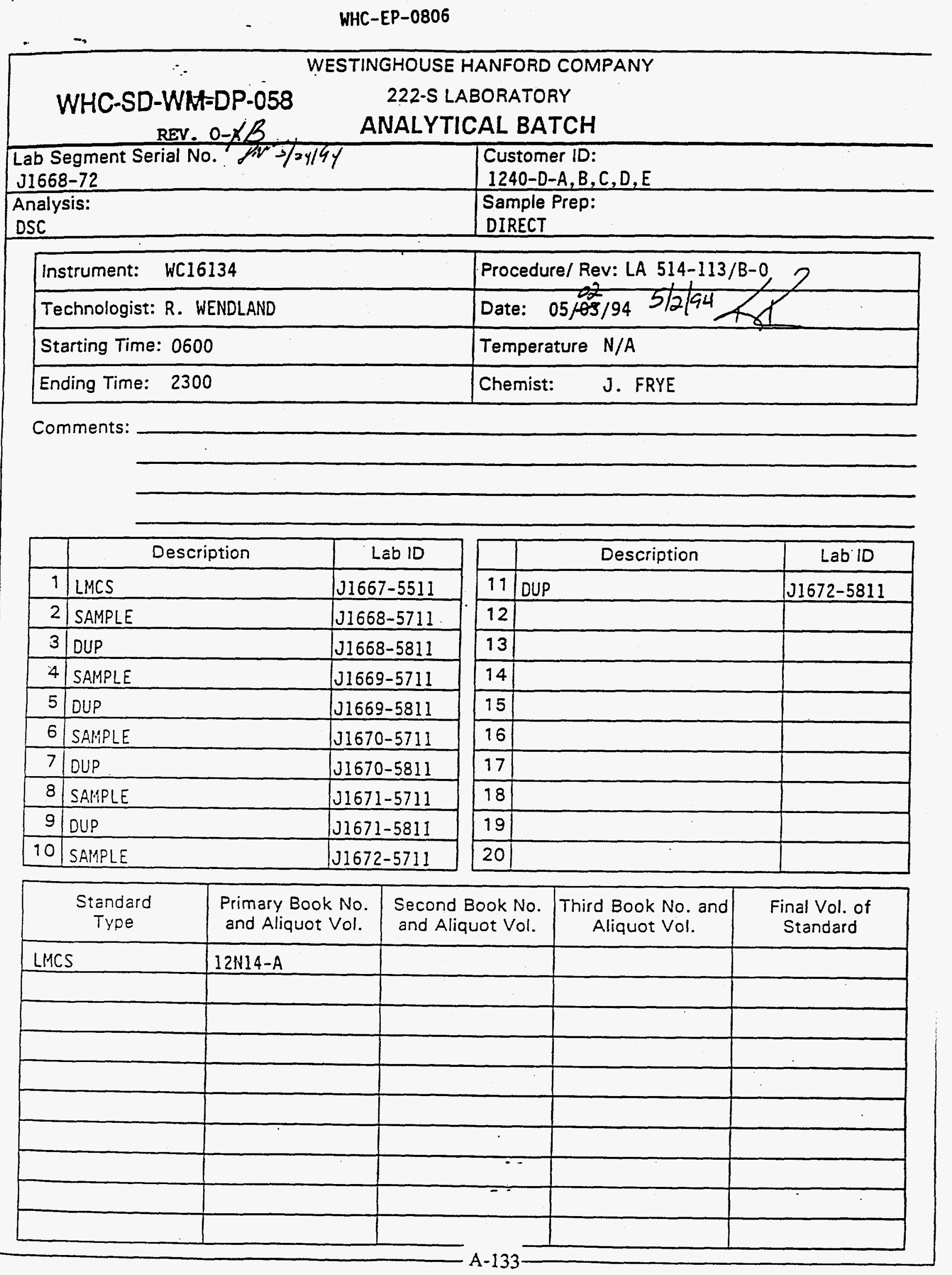


WHC-EP-0806

$\therefore \quad$ WHC-SD-WM-DP-058

REV: $0-\not B B$

Her. 524154

DON'T SAY IT ... Write It!

To Data Paddling

Better 3364

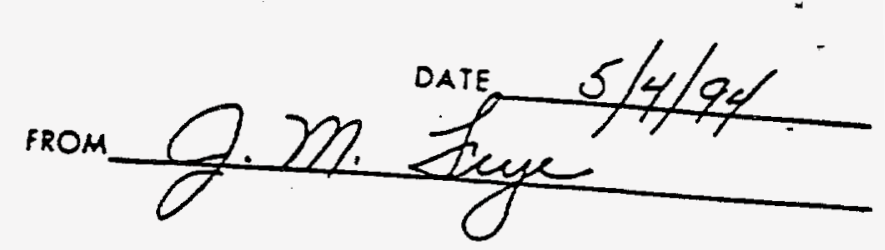

the $28 C$ exothermic in these $T=11$ compleat were very brad the sight end of the exothen was ensilysen, but the left end merged into the water endatienn. The plots provided ane optimized pelota the suns wee all done to $500^{\circ} \mathrm{C}$

Pan n Mu Tue

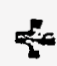

"TO HAKE LIFE LAST, PUT SAFETY FIRST"

A-134. 
WHC-EP-0806

WHC-SD-WM-DP-058

REV. $O-\not \beta$

DIFFERENTIAL SCANNING CALORIMETRY ANALYSIS - UNDIGESTED SAMPLE

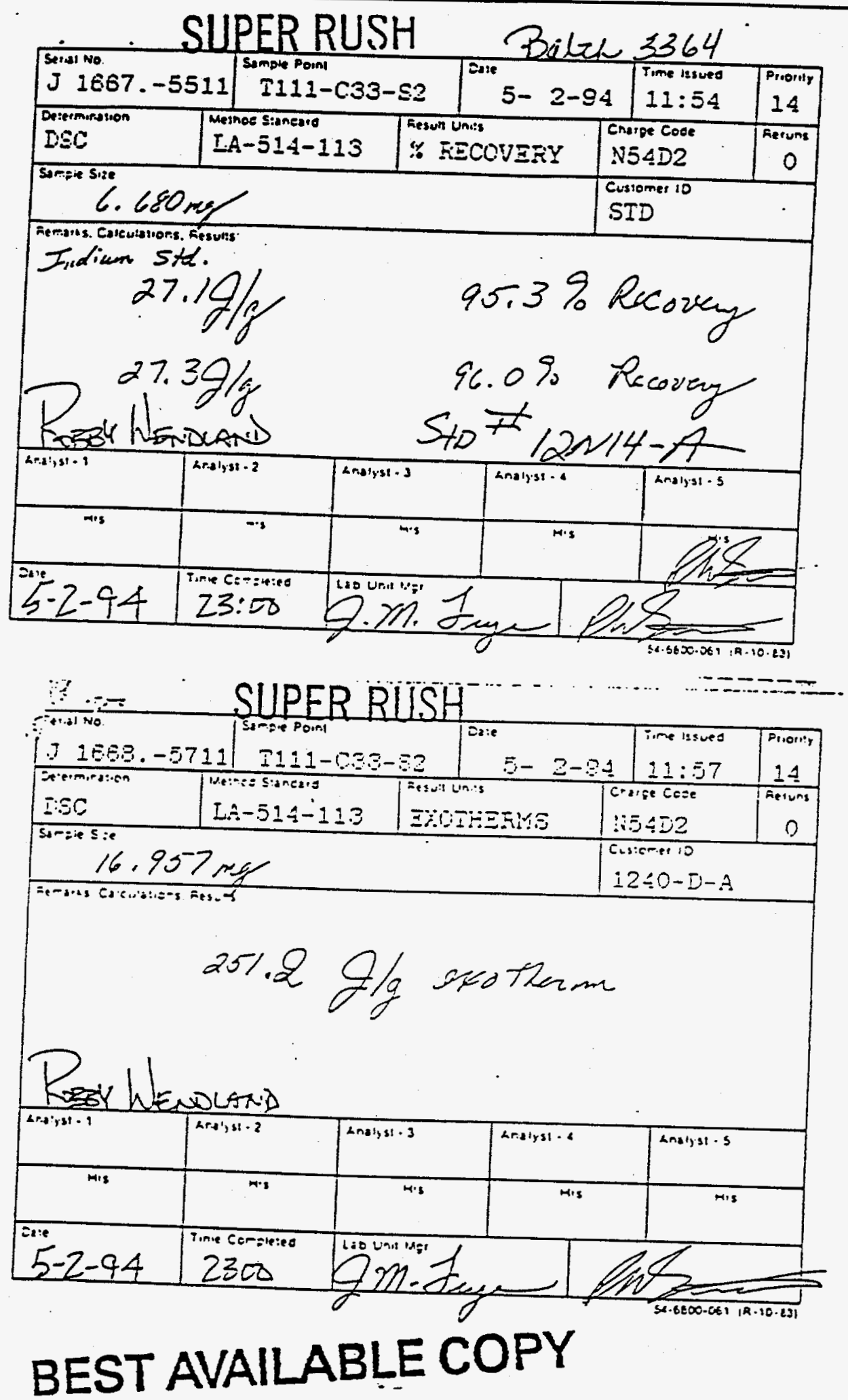


WHC-EP-0806

WHC-SD-WM-DP-058

REV. OX HOW STYYFAP

DIFFERENTIAL SCANTING CALORIMETRY ANALYSIS - UNDIGESTED SAMPLE

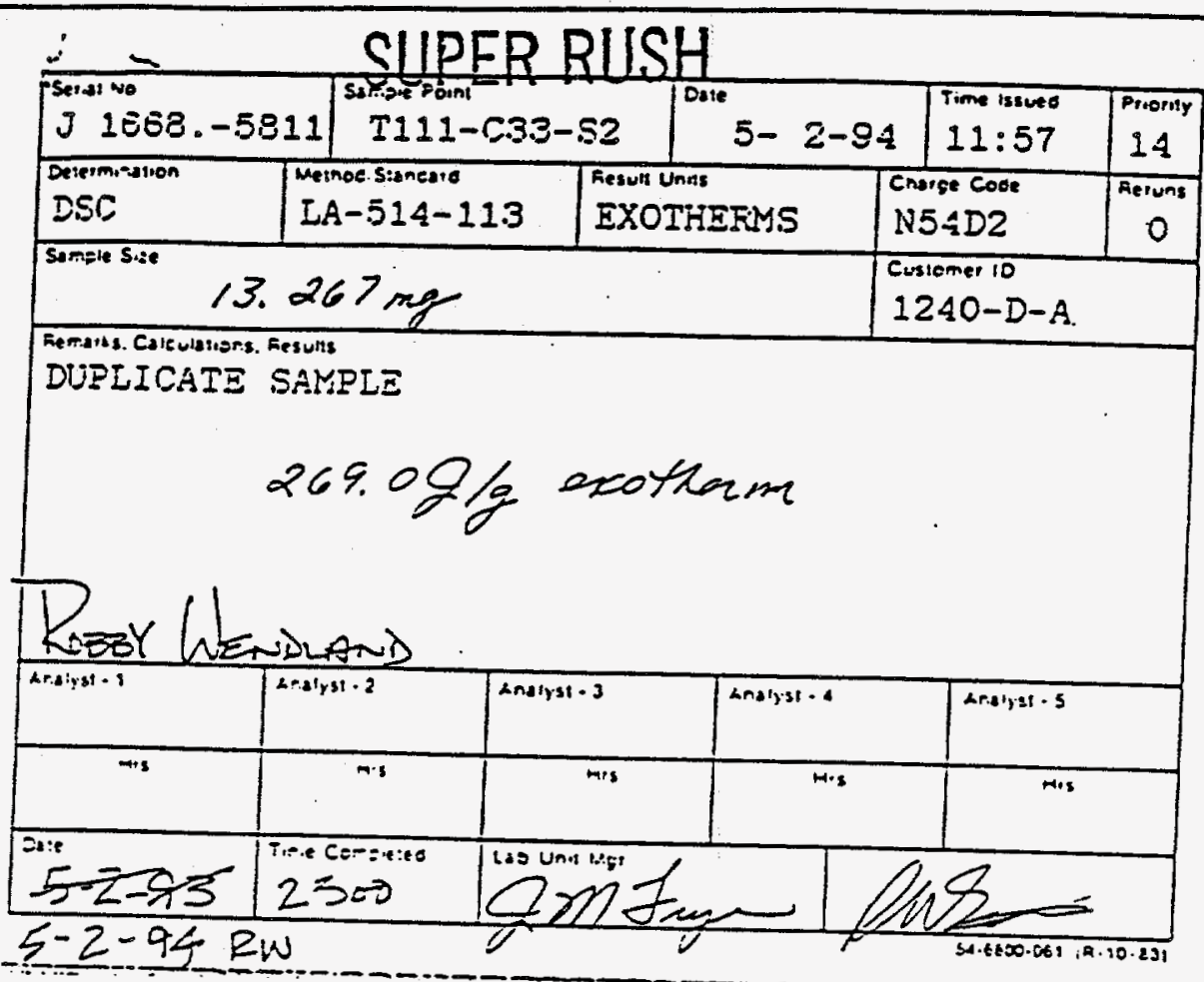

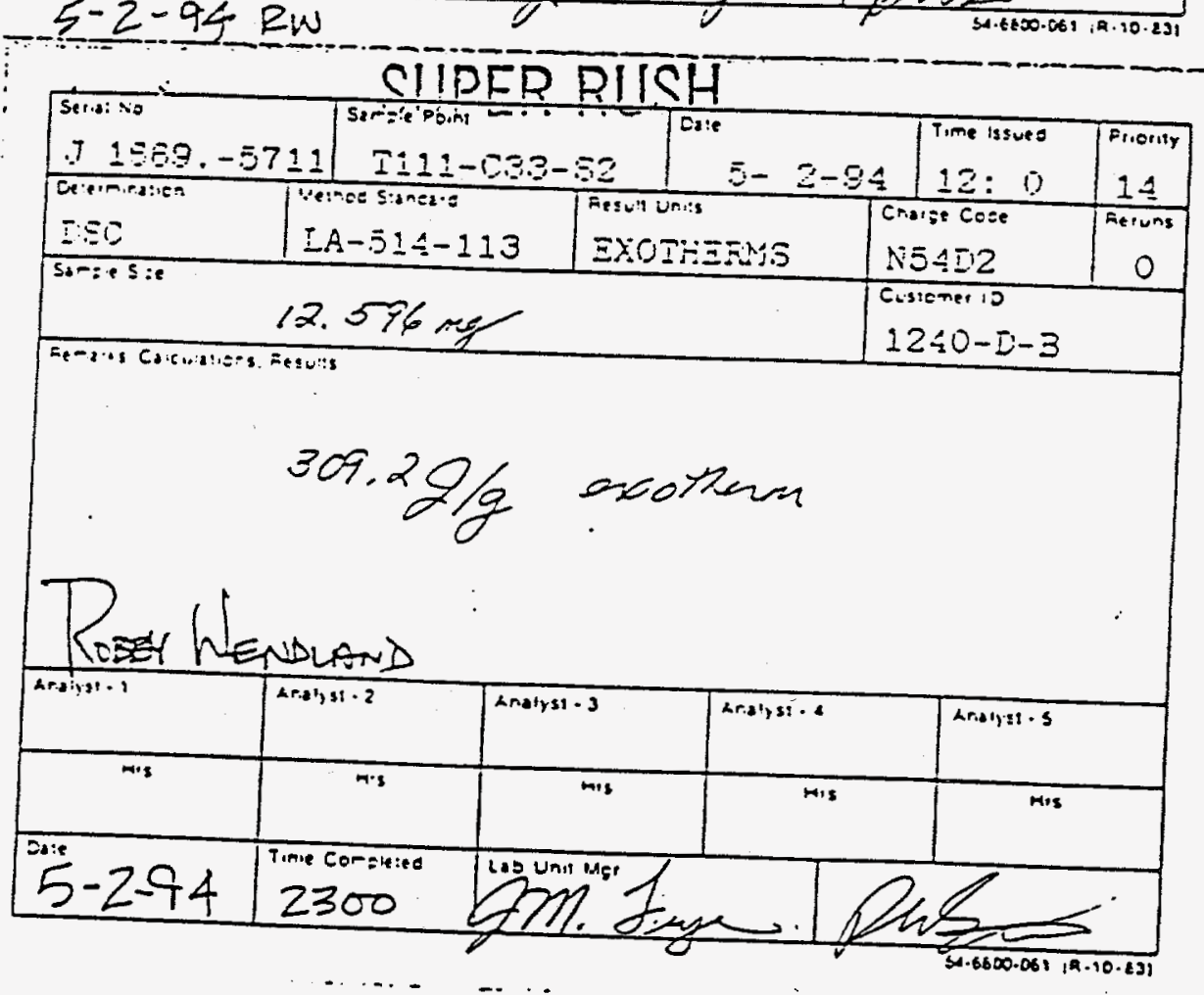

BEST AVAILABLE COPY

A-136 
WHC-EP-0806

WHC-SD-WM-DP-058

REV. O-XB HUC

DIFFERENTIAL SCANNING CALORIMETRY ANALYSIS - UNDIGESTED SAKPLE

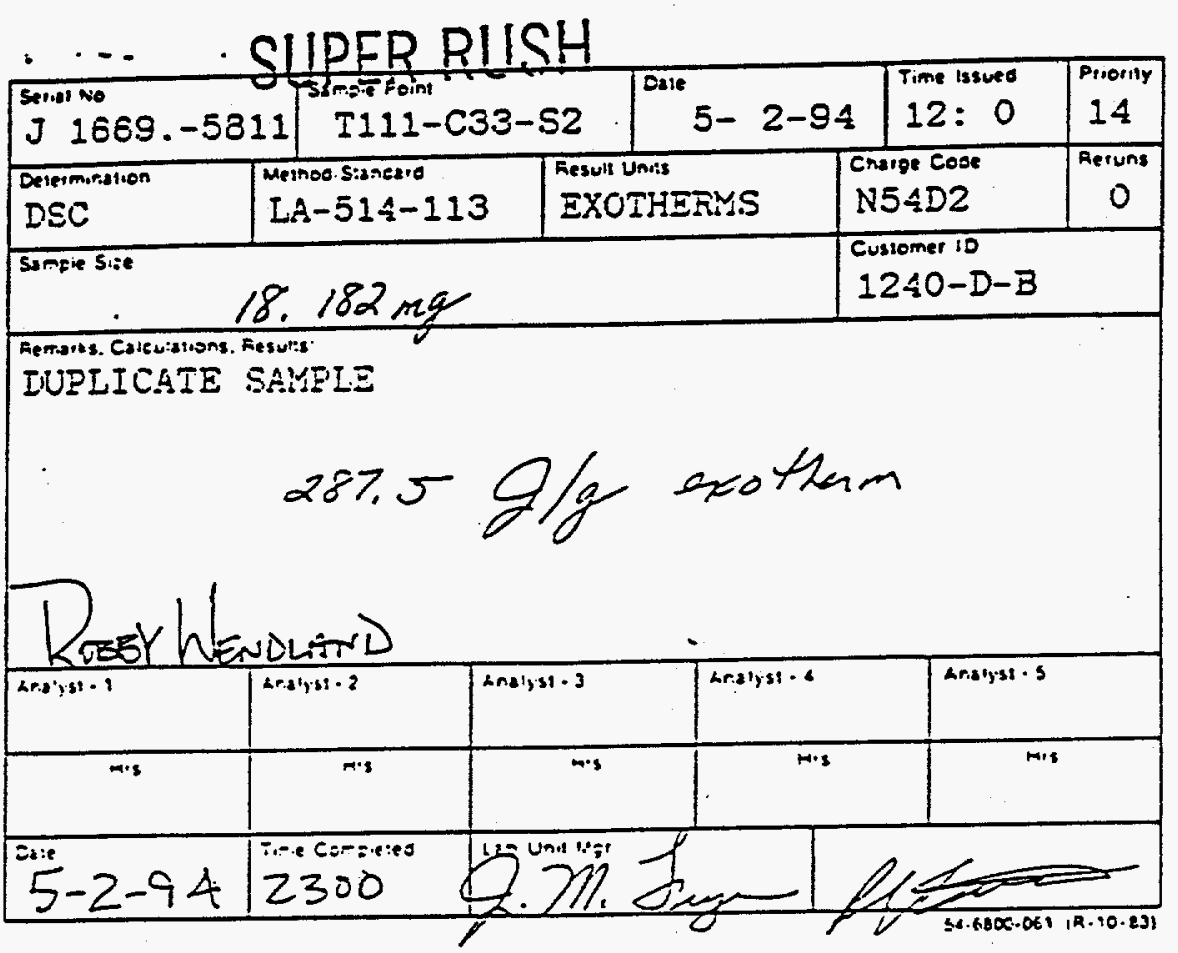

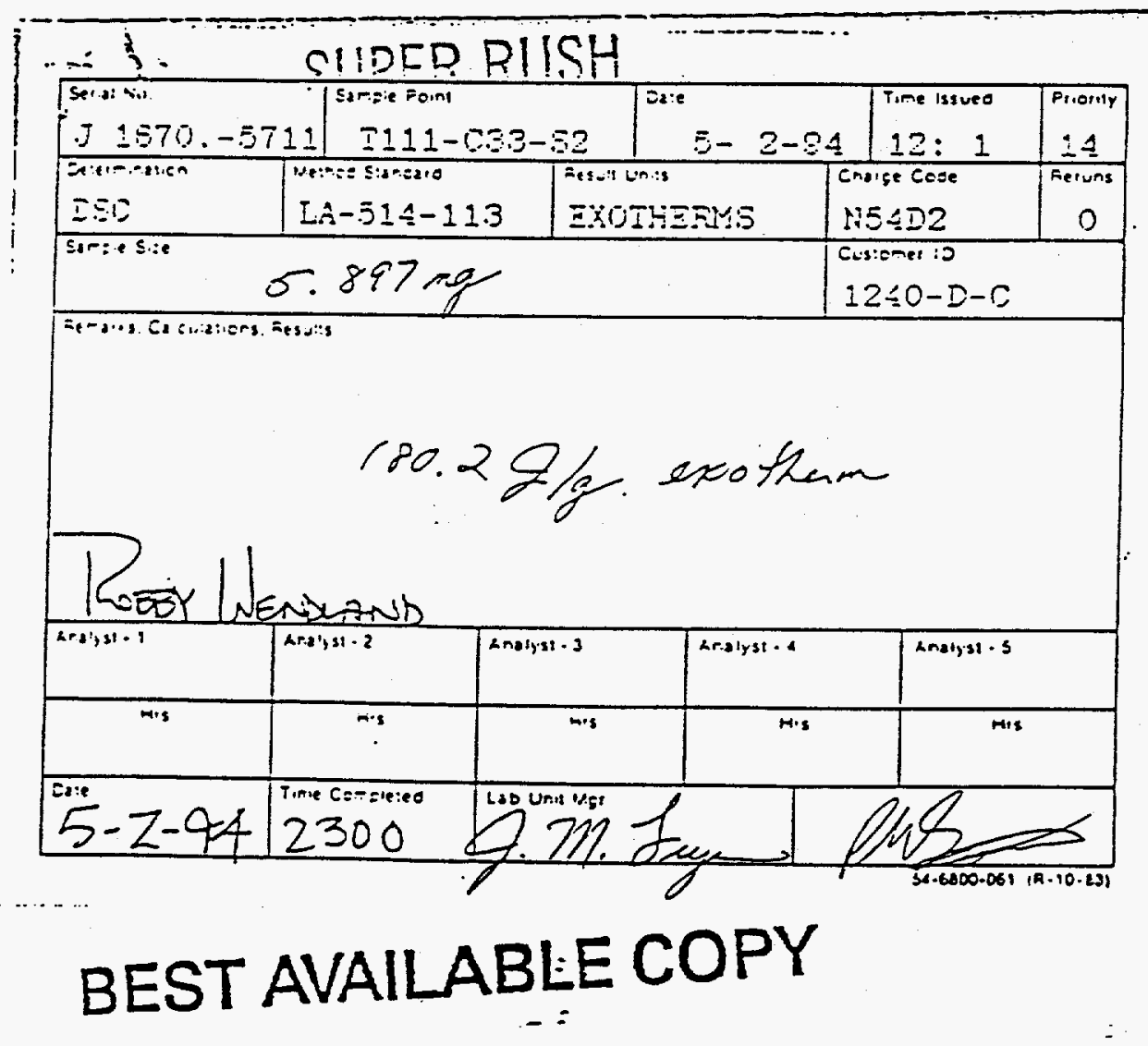



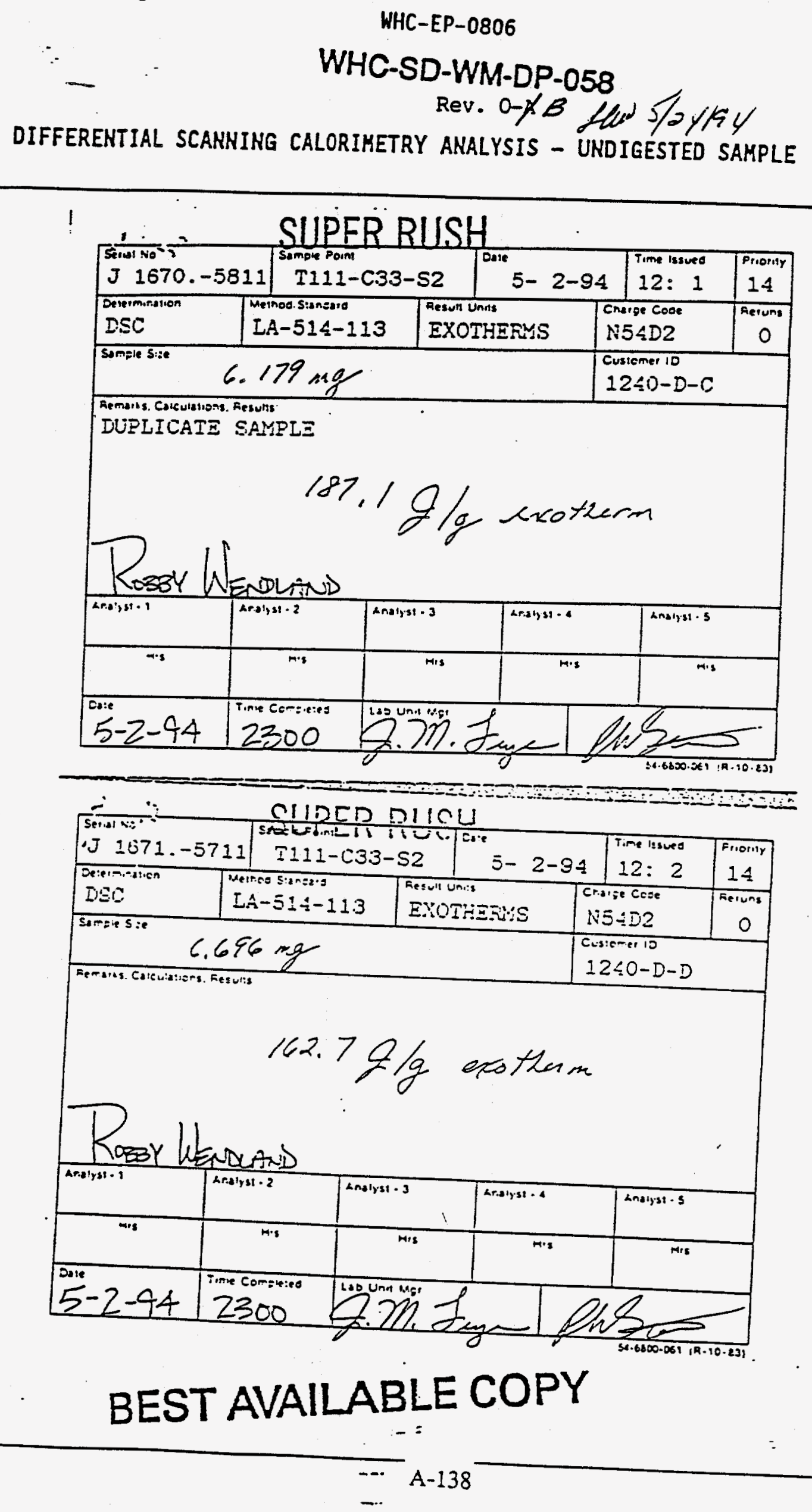
WHC-EP-0806

WHC-SD-WM-DP-058

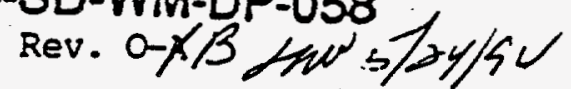

DIFFERENTIAL SCANNING CALORIMETRY ANALYSIS - UNDIGESTED SAMPLE

$1 \cdot$

$\because \quad$ SUPFR RIICU

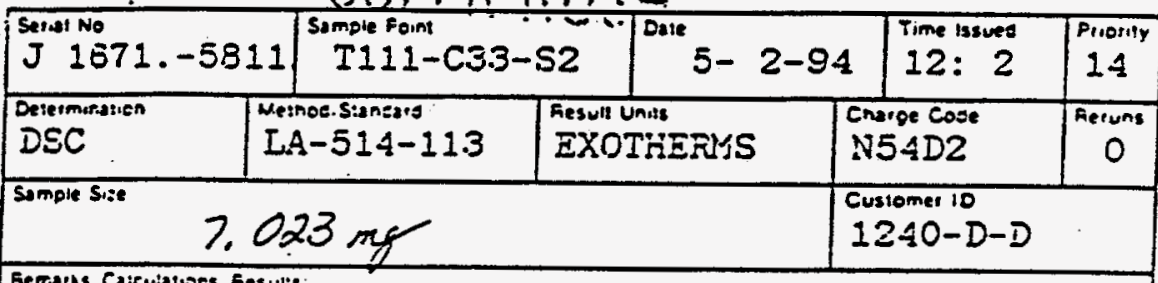

DUFIICATE SAMPIE

$175.3 \mathrm{~g} / \mathrm{g}$ exotham

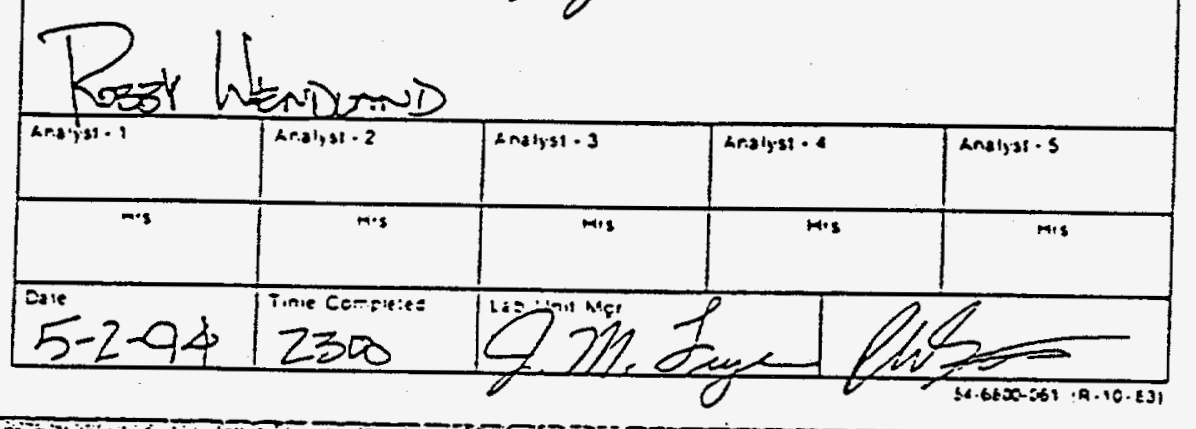

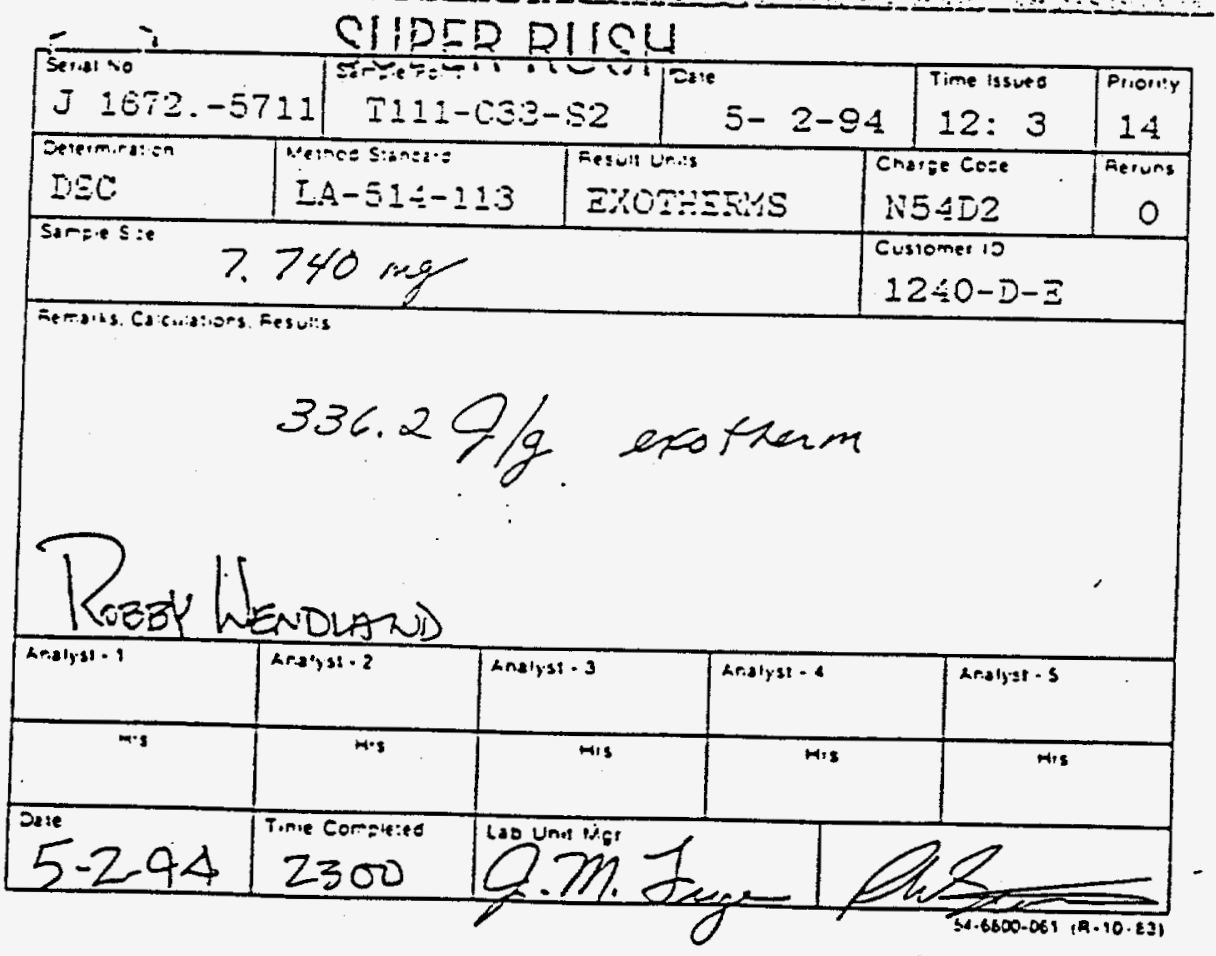

BEST AVAILABLE COPY

A-139 
WHC-EP-0806

WHC-SD-WM-DP-058

REV. 0-X/S HWW S/LfFY

DIFFERENTIAL SCANNING CALORIMETRY ANALYSIS - UNDIGESTED SAMPLE

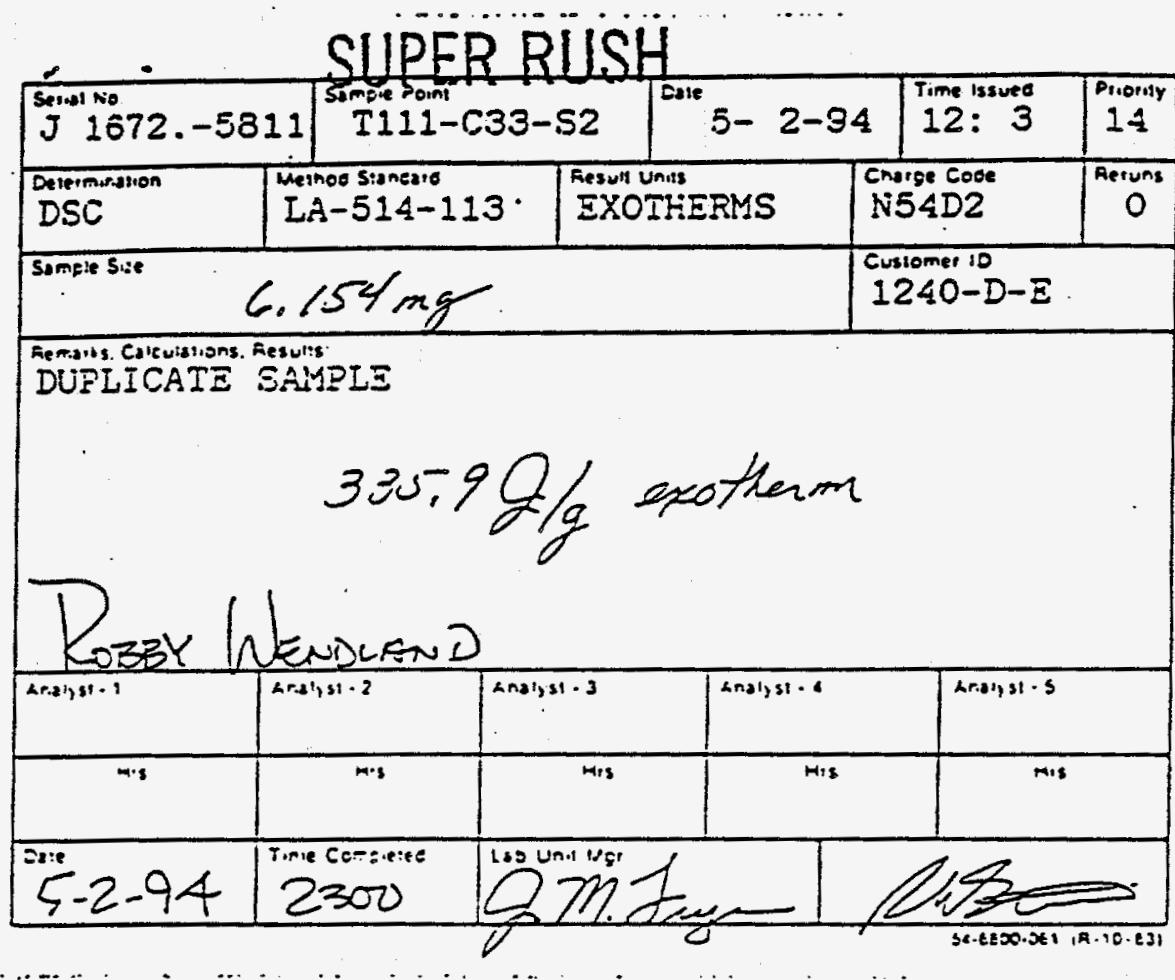

BEST AVAILABLE COPY 


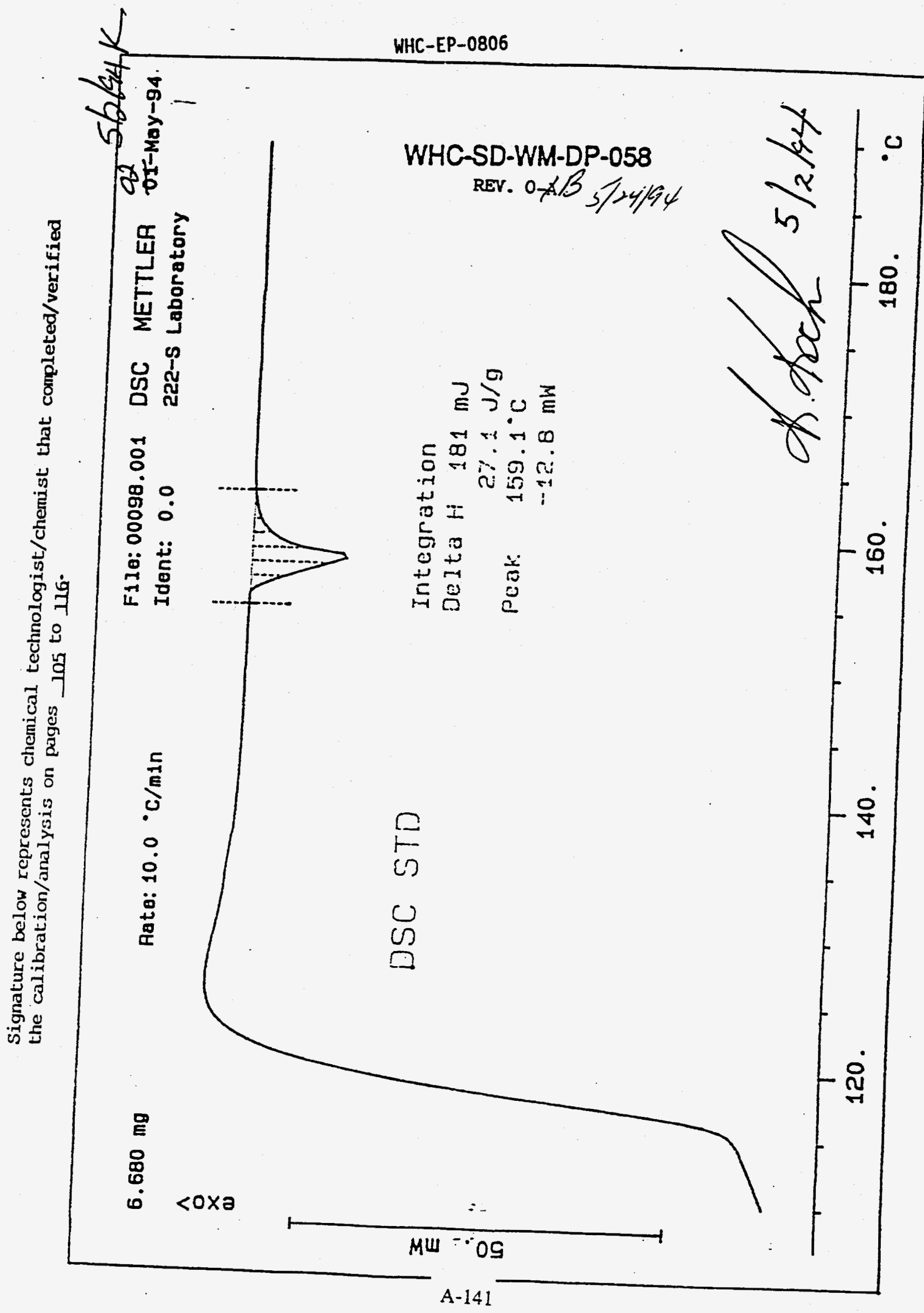




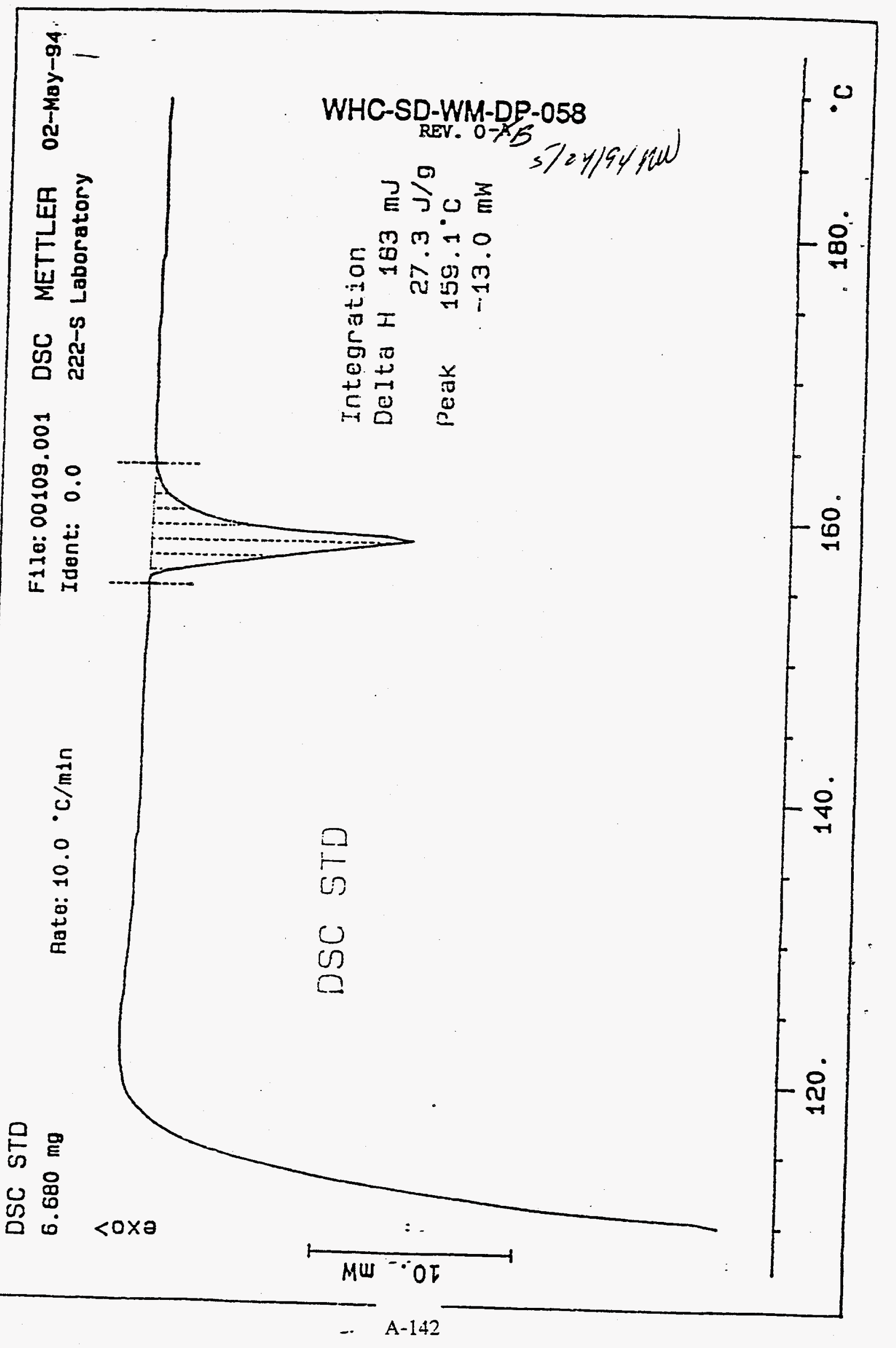




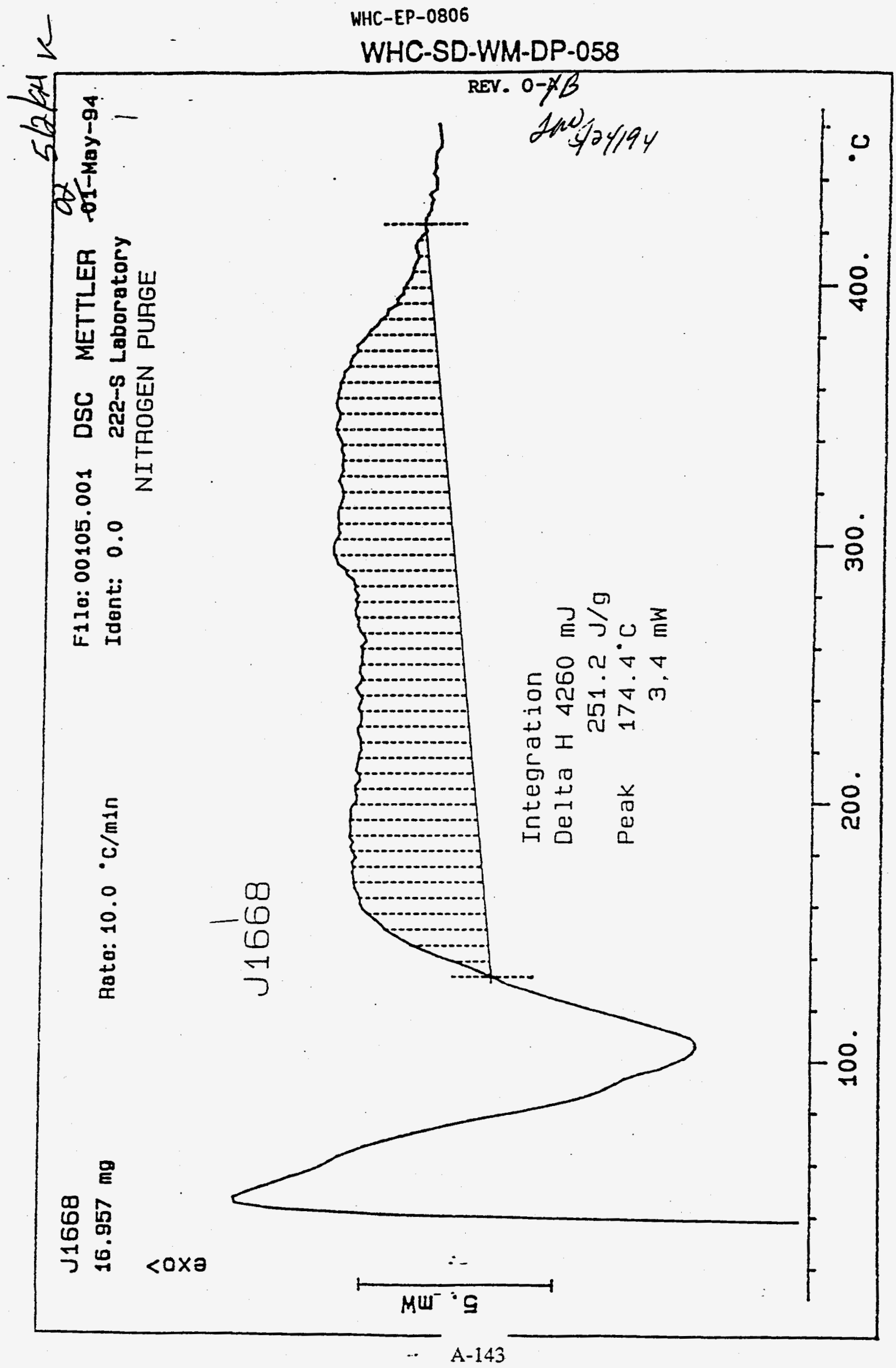




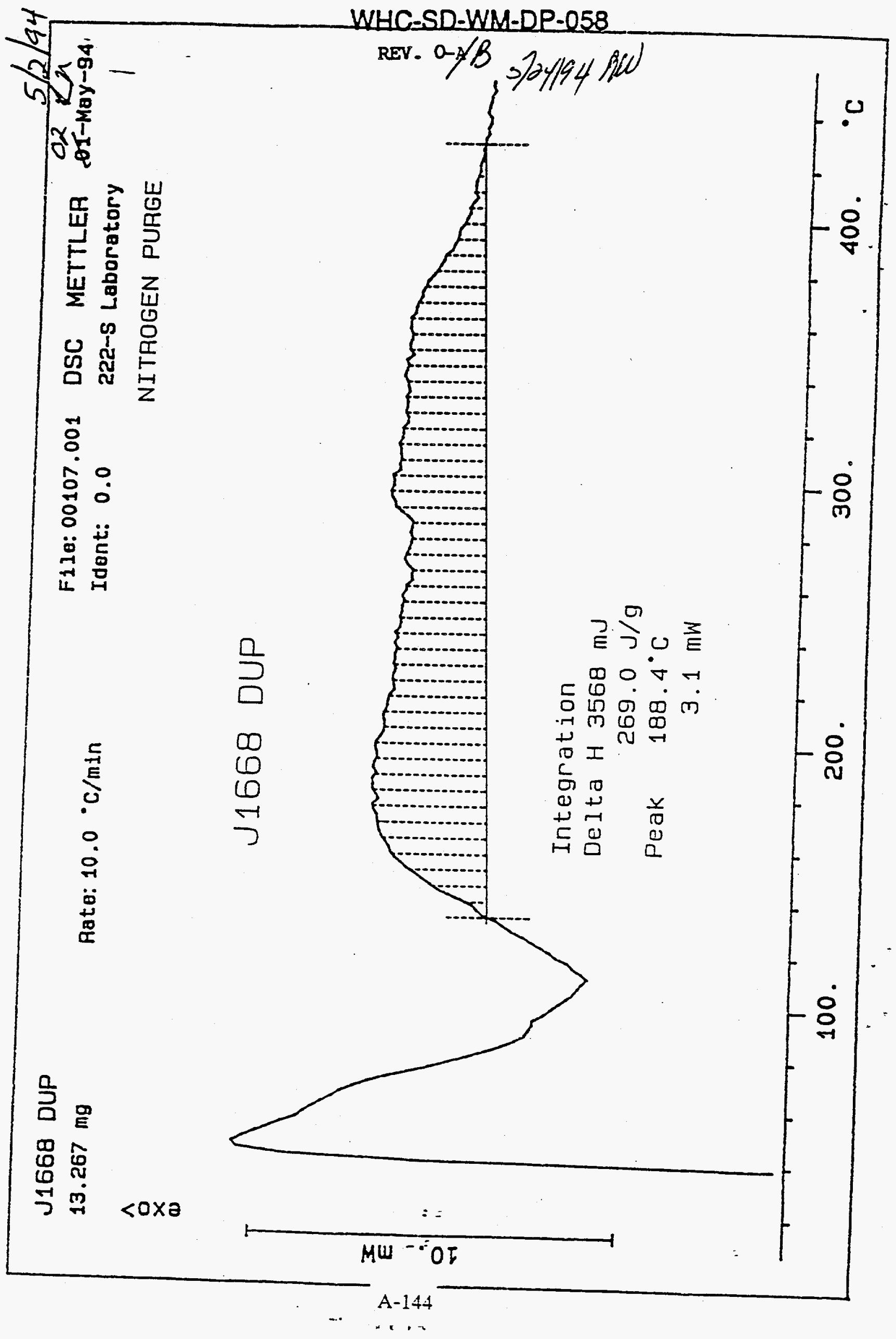


WHC-EP-0806

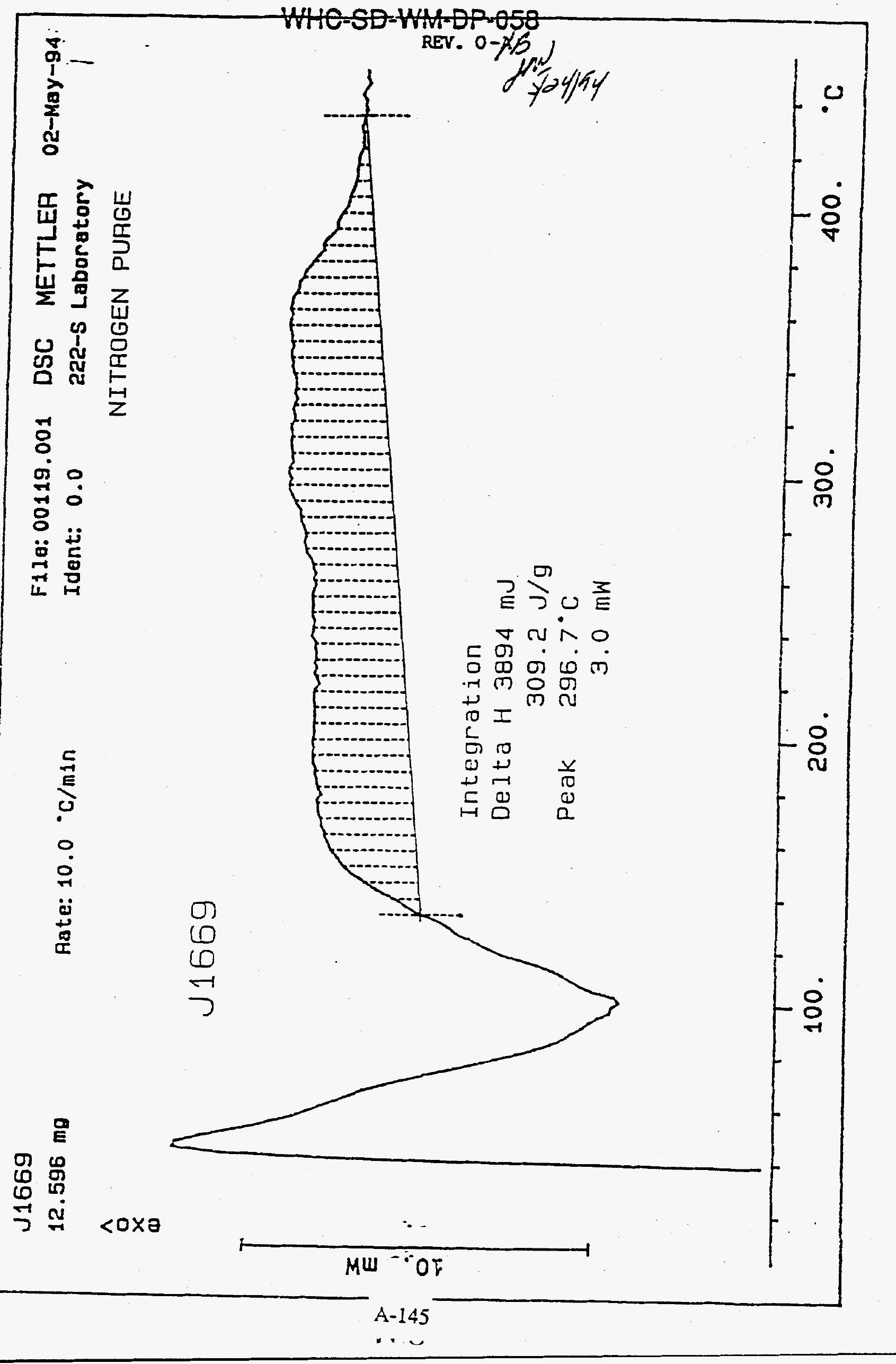




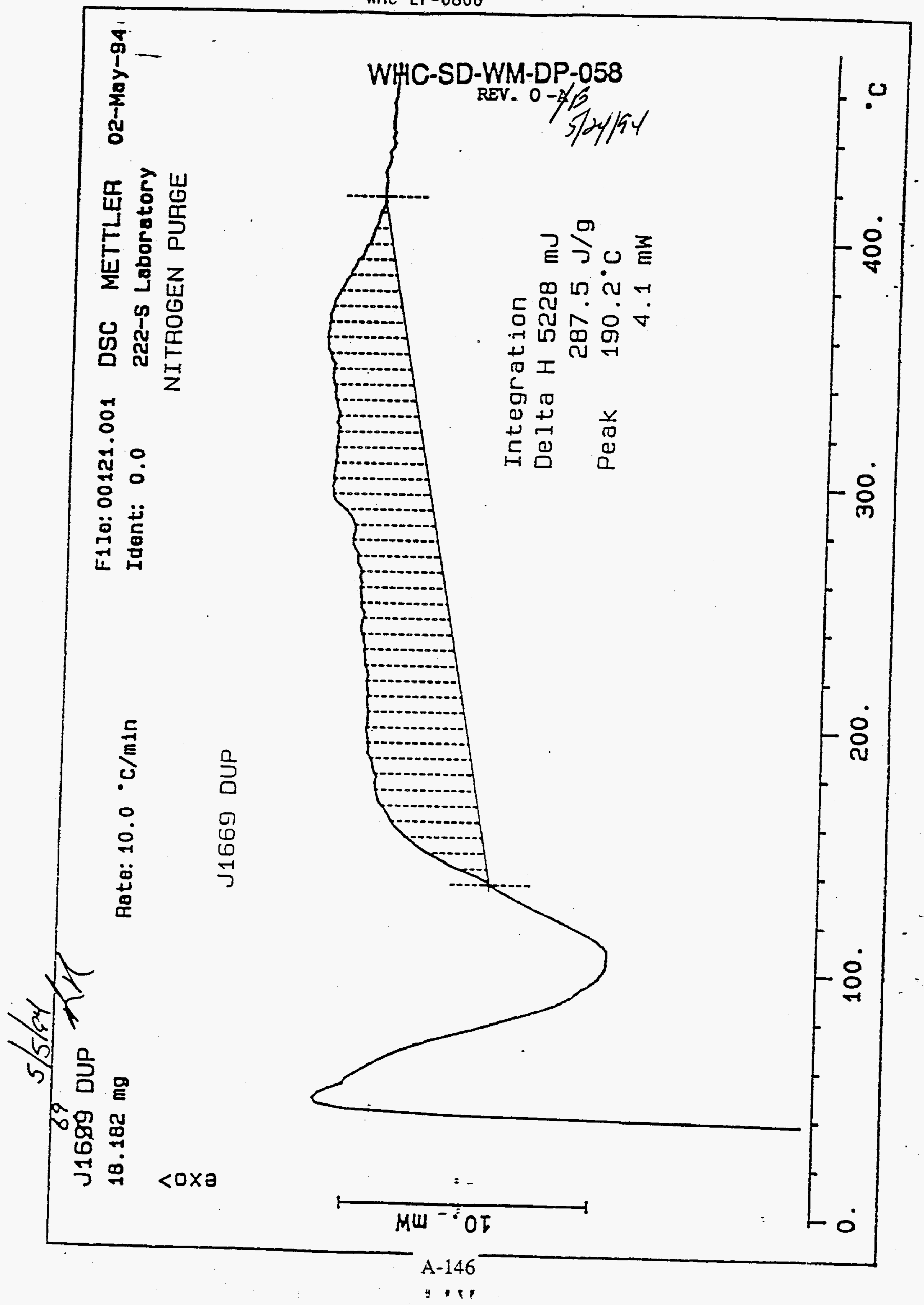




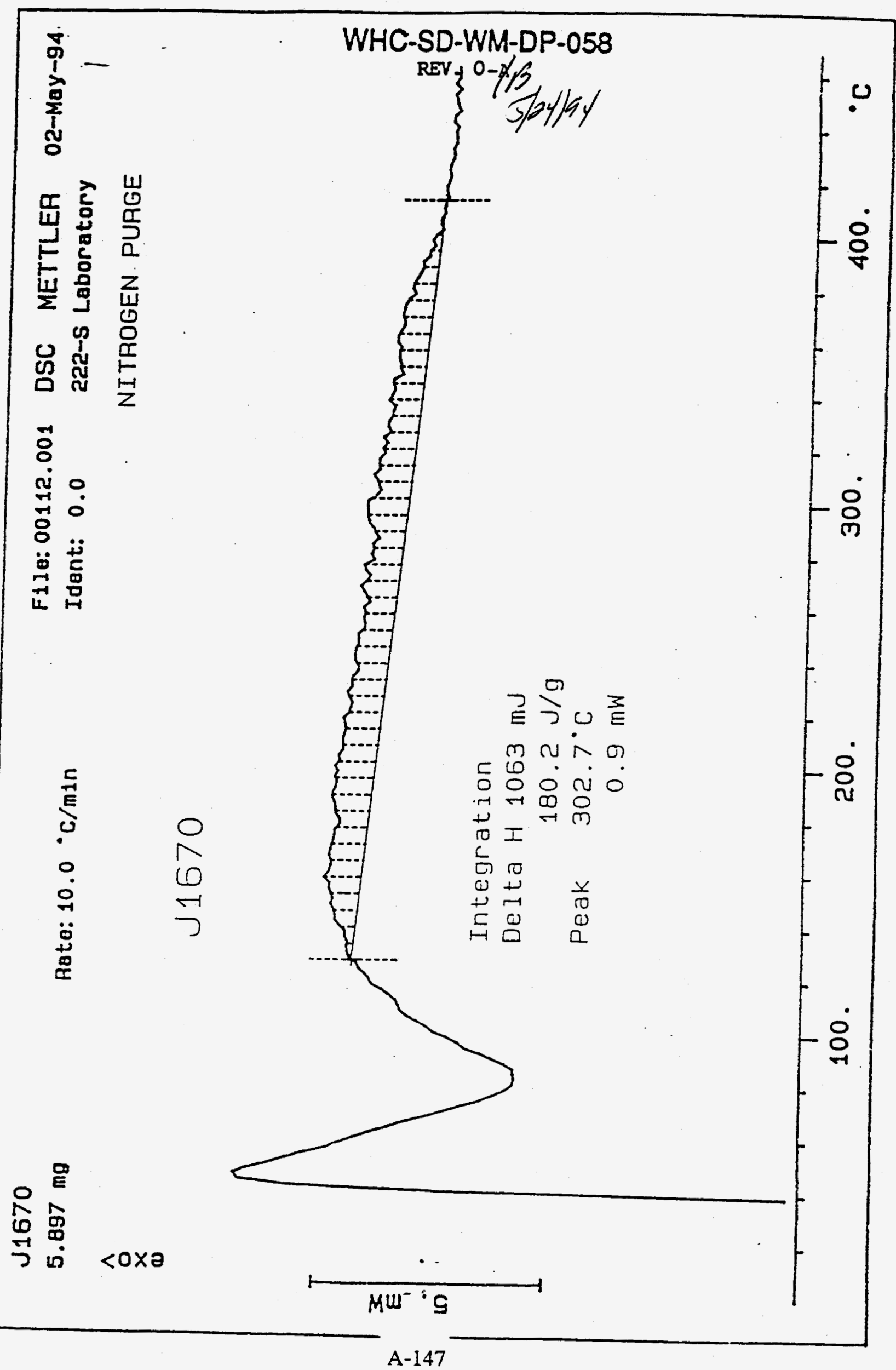




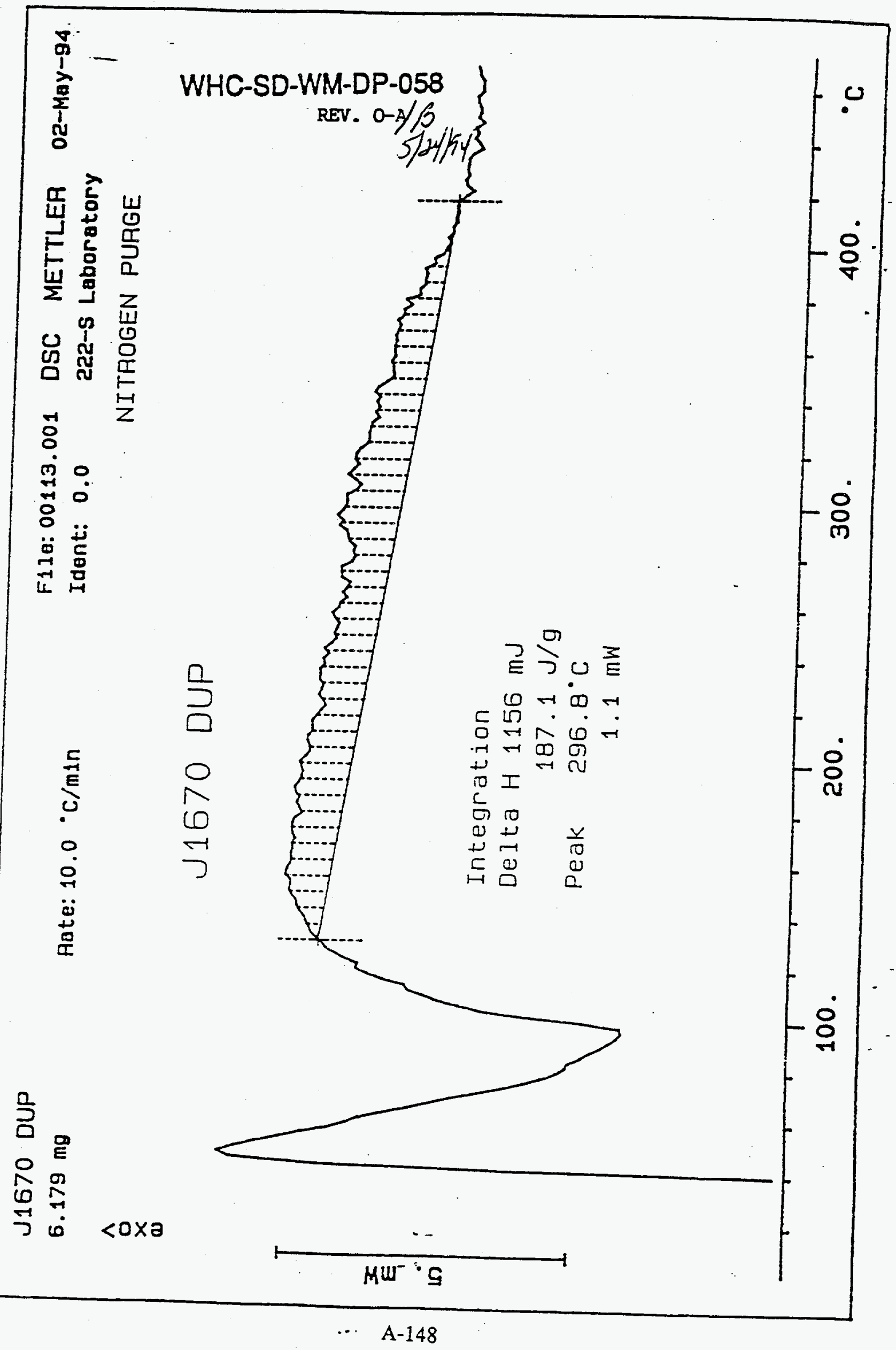




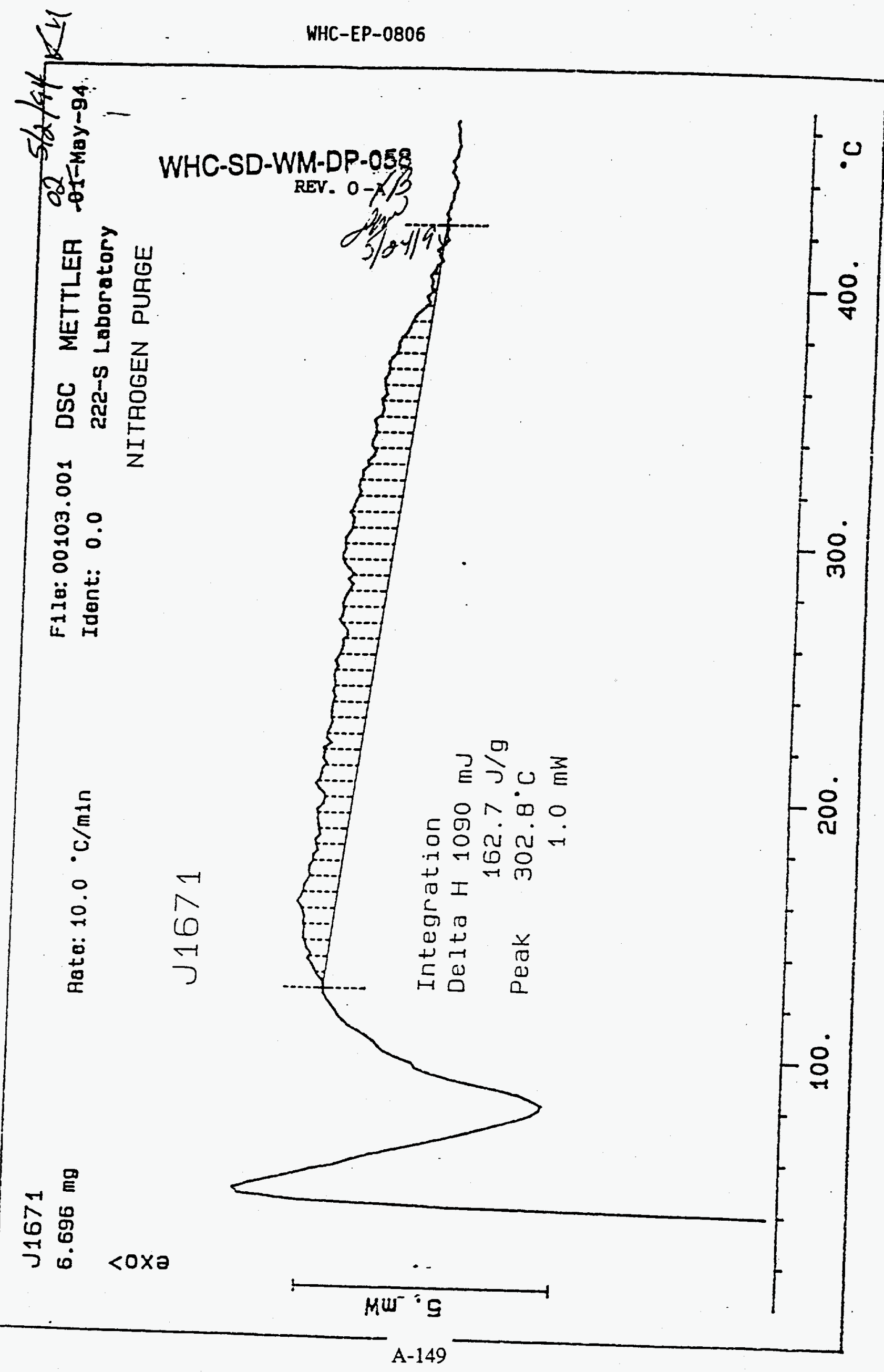




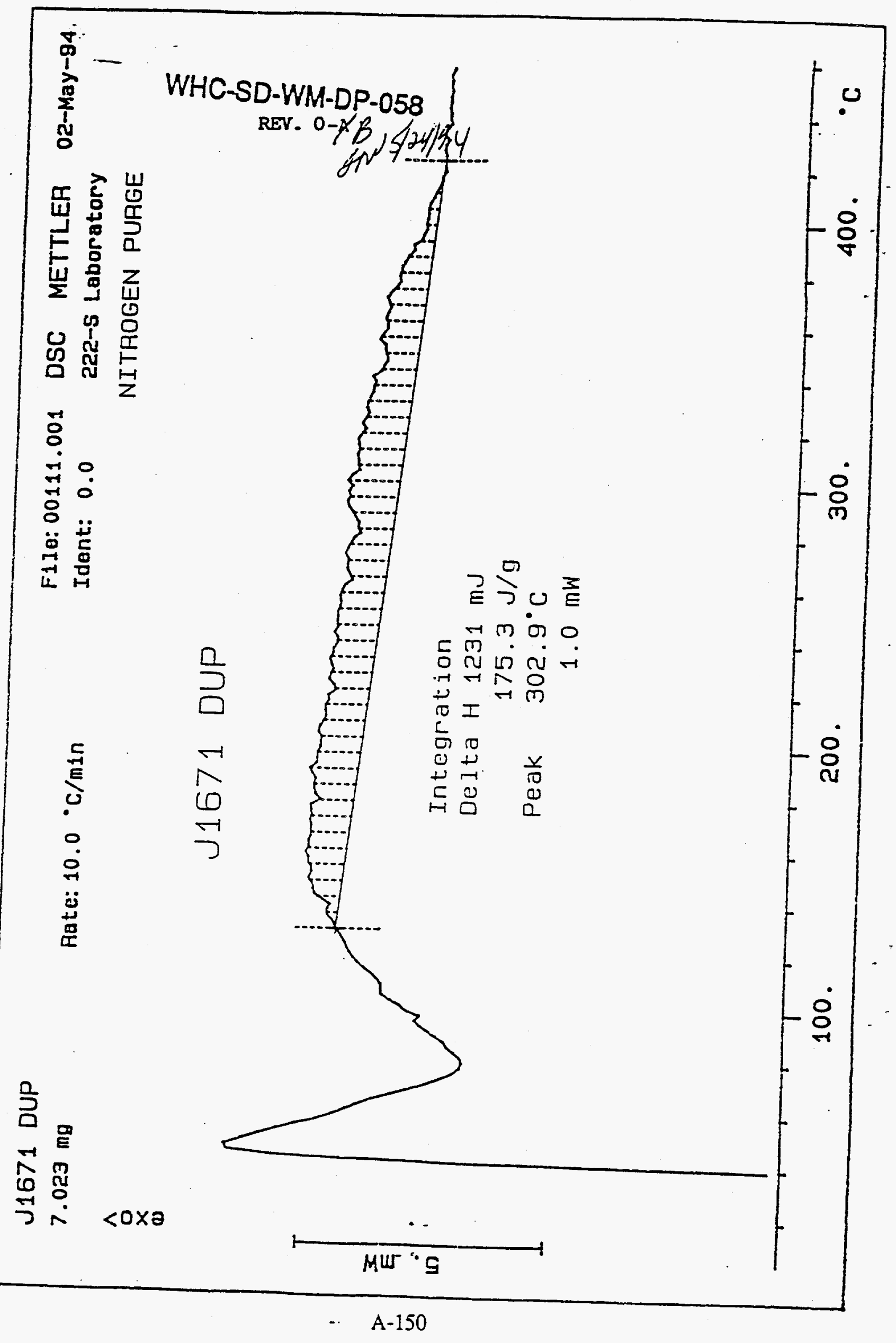




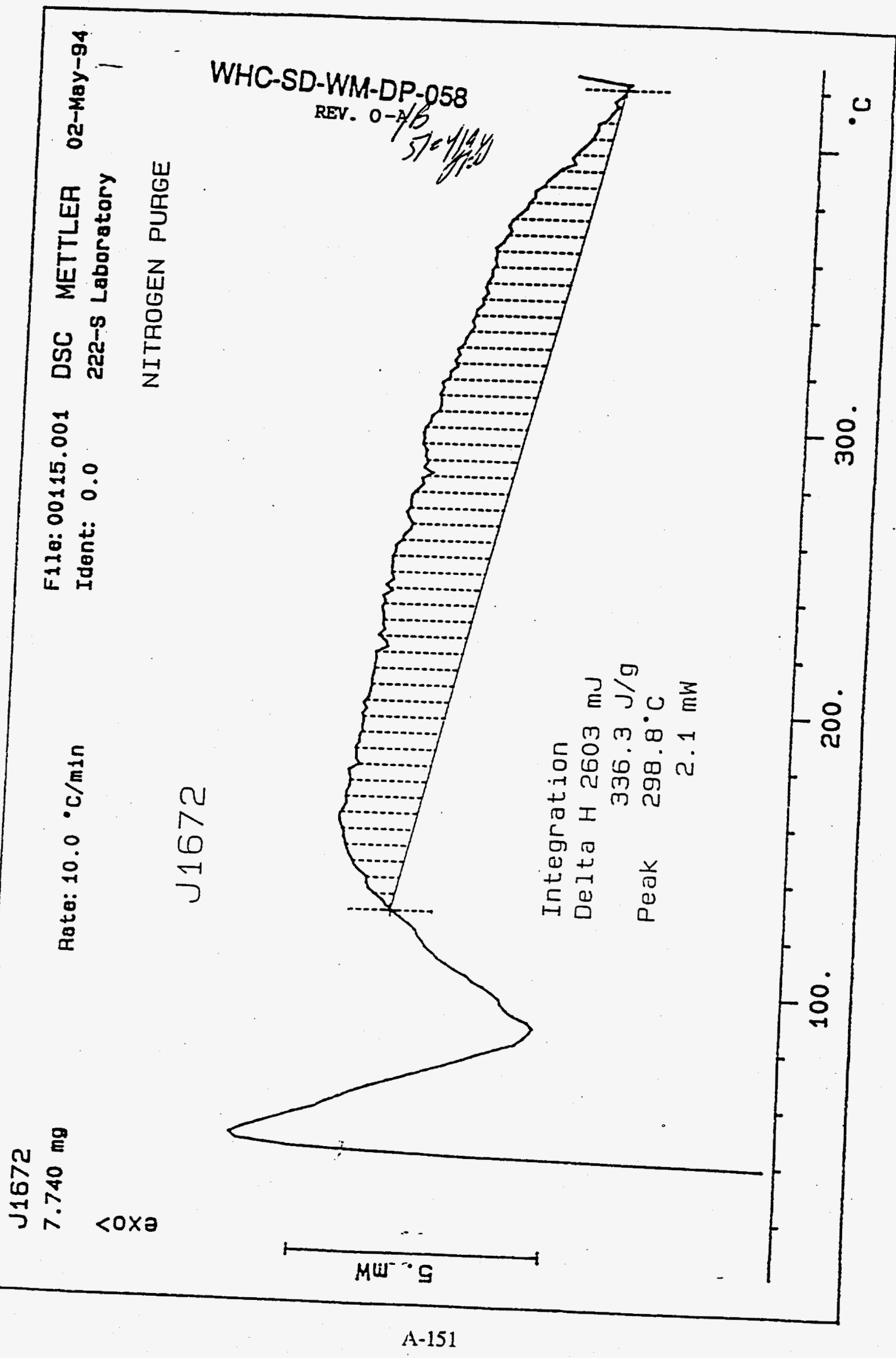




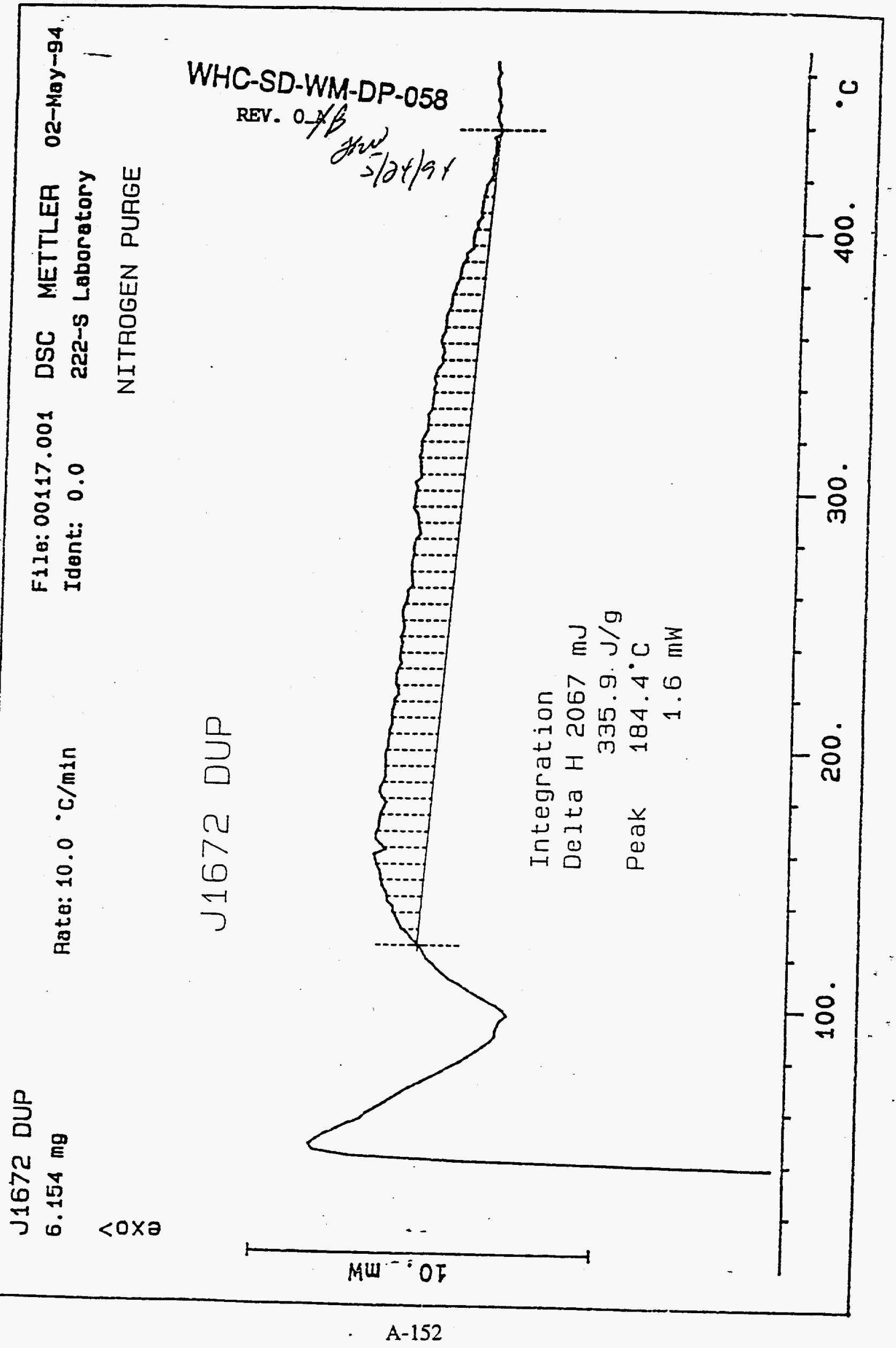




\section{WHC-EP-0806}

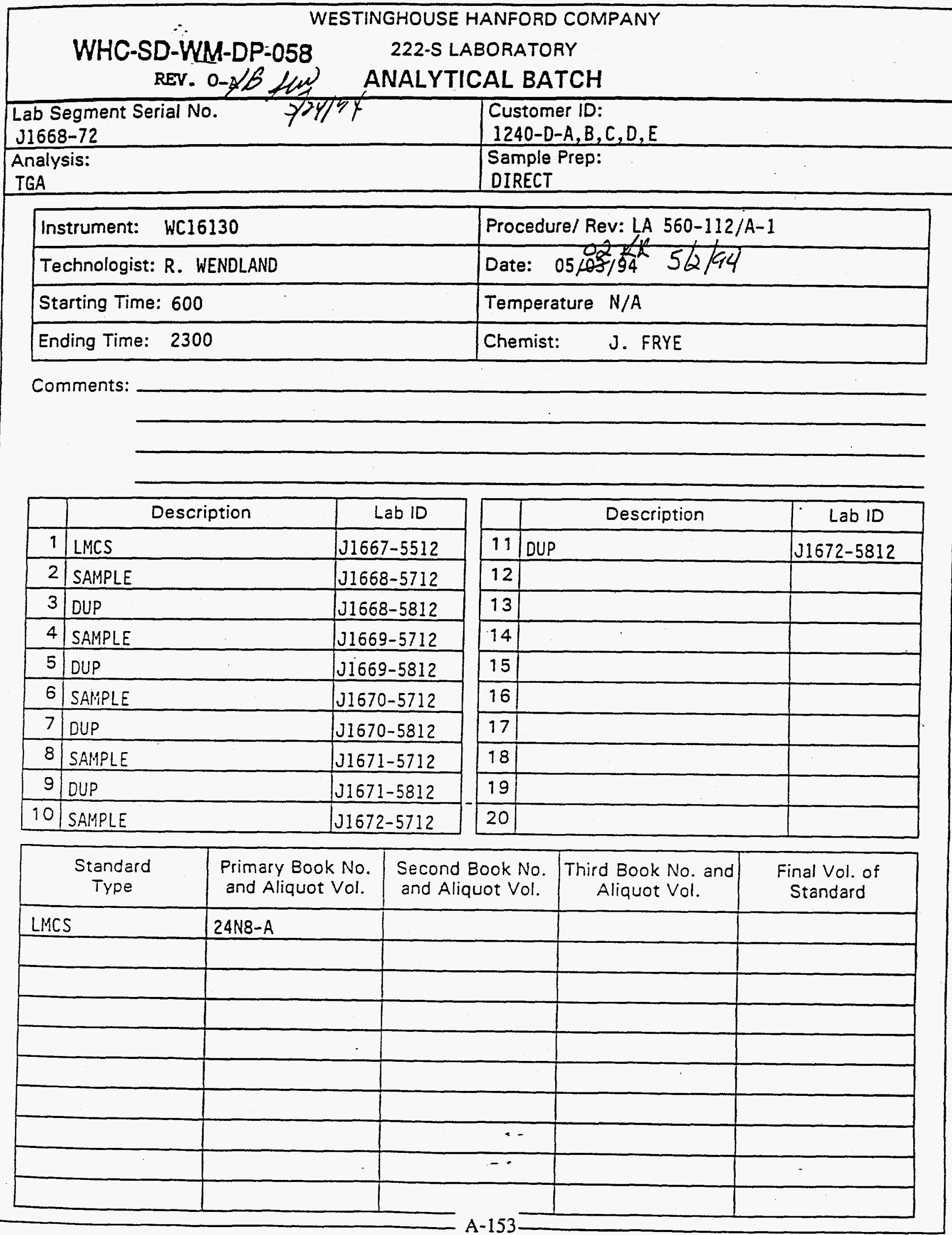




$$
\begin{aligned}
& \text { WHC-EP-0806 } \\
& \text { WHC-SD-WM-DP-058 } \\
& \text { REV. 0- } / 3 \text { /24/44 }
\end{aligned}
$$

- THERMAL GRAVIMETRIC ANALYSIS - UNDIGESTED SAMPLE

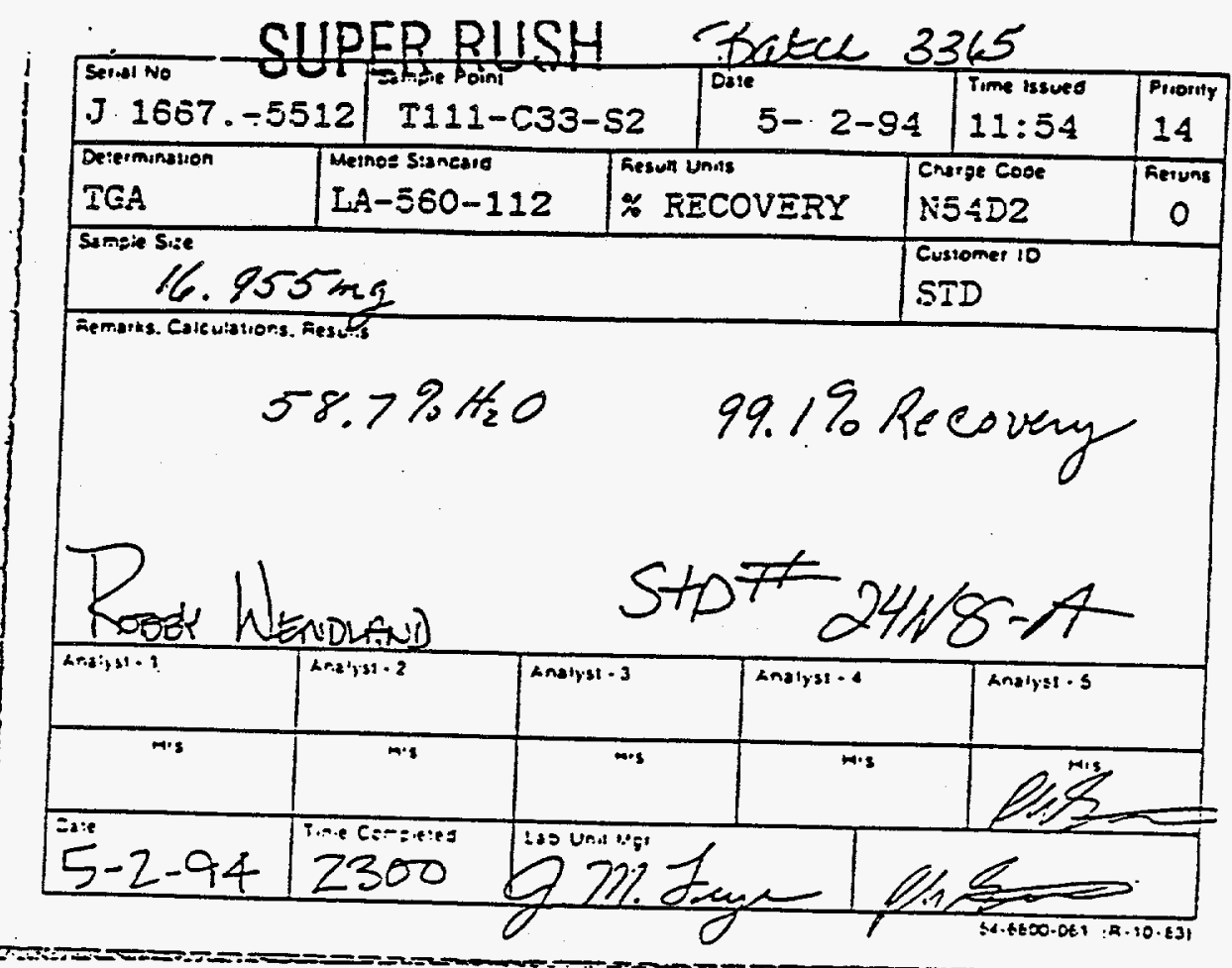

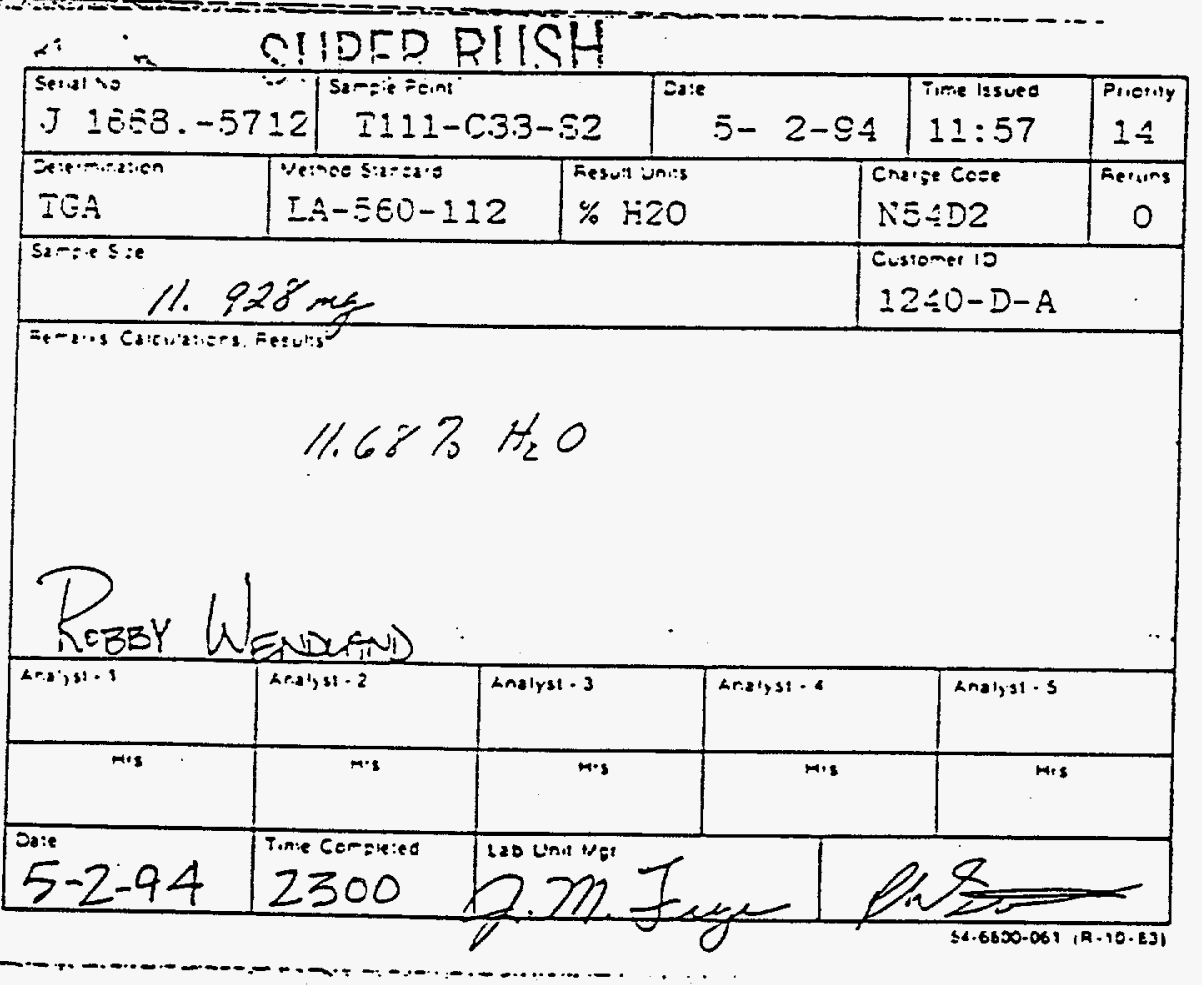

BEST AVAILABLE COPY

$$
A-154
$$


WHC-EP-0806

WHC-SD-WM-DP-058

THERMAL GRAYIMETRIC ANALYSIS - UKDIGESTED SAMPLE

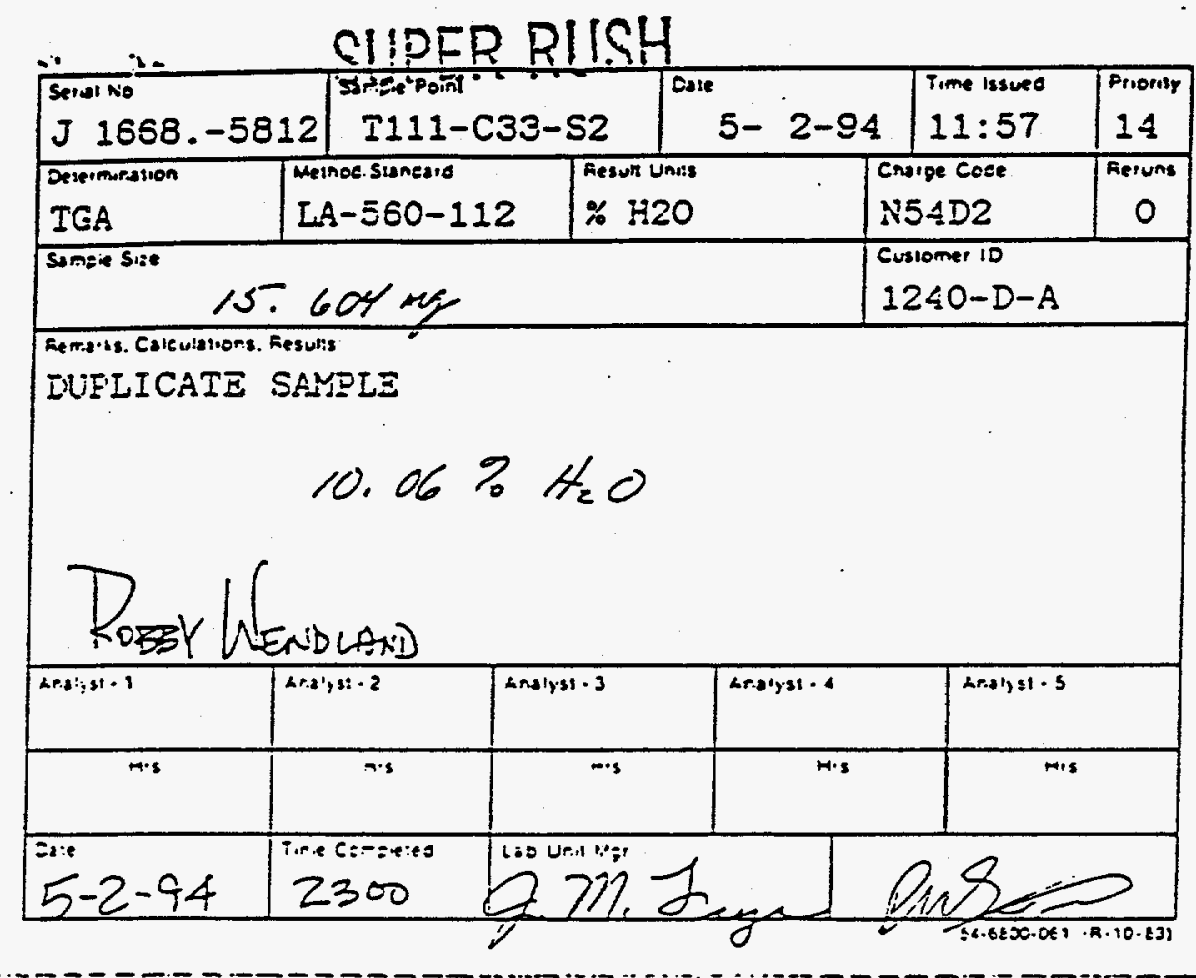

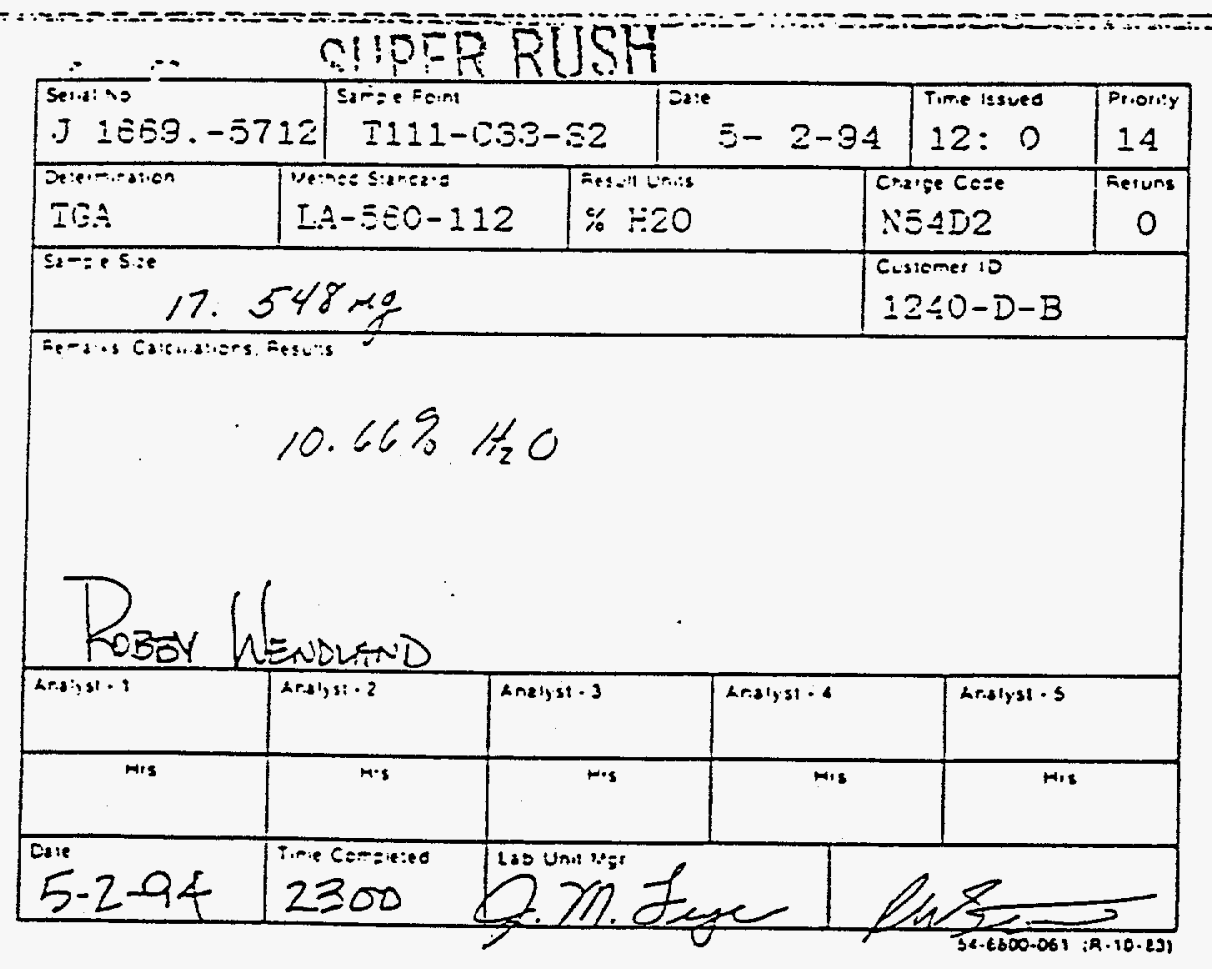

BEST AVAILABLE COPY

A-155 


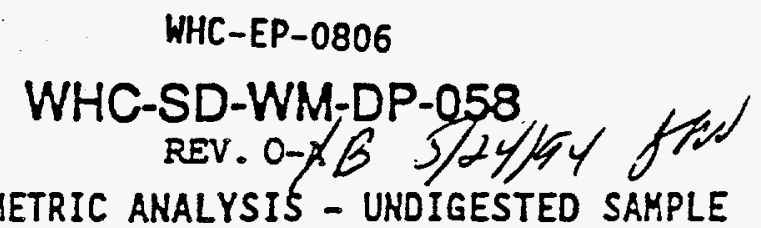

THERMAL GRAVIMETRIC ANALYSIS - UNDIGESTED SAMPLE

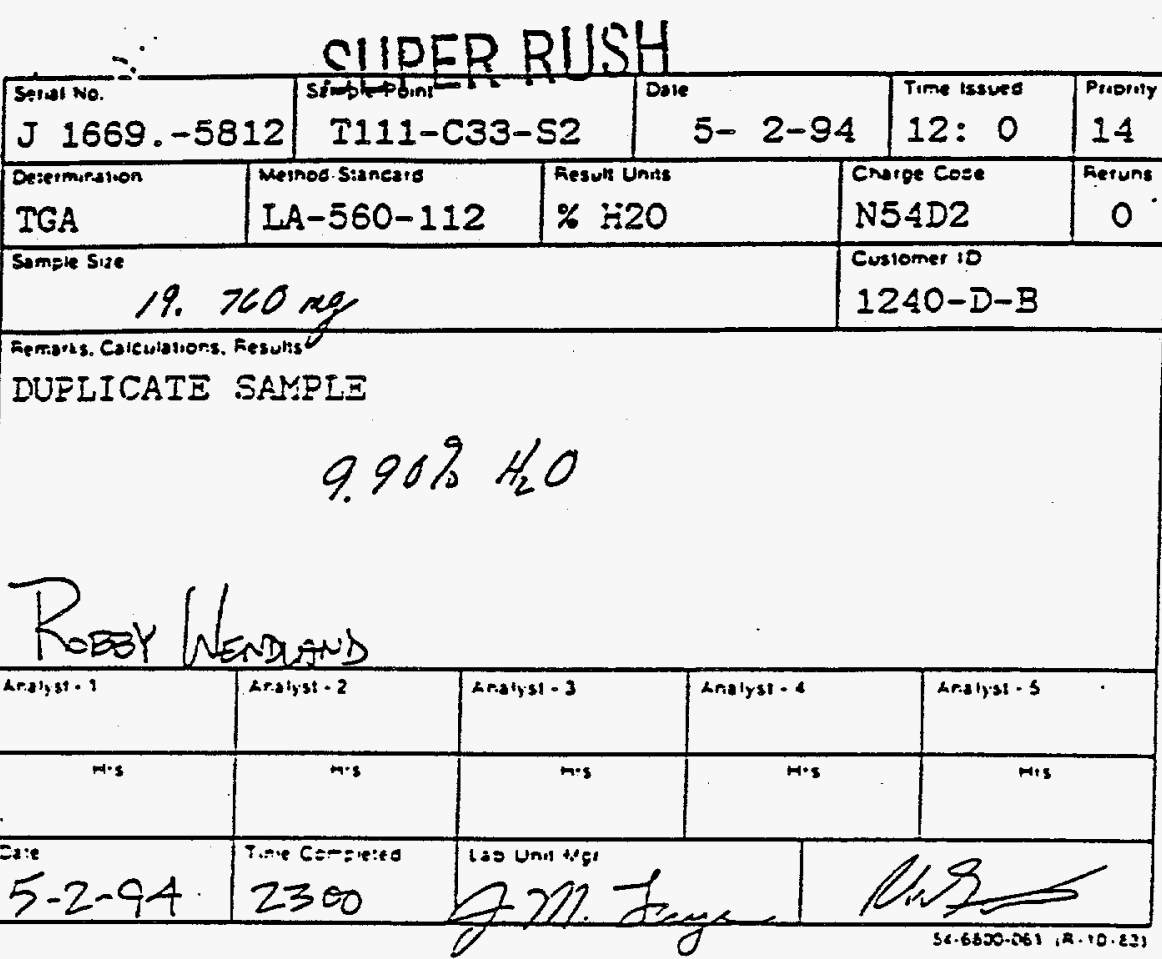

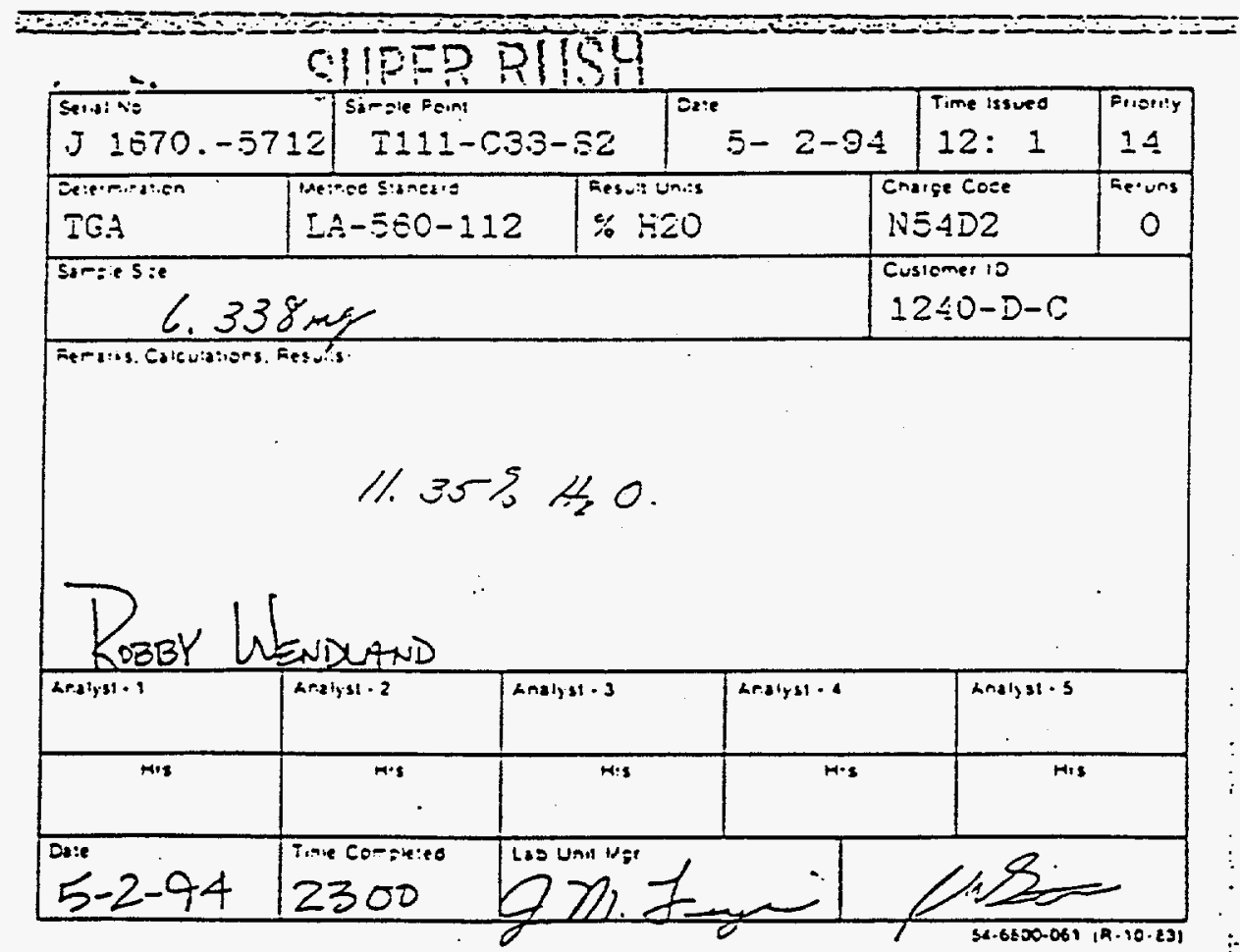

BEST AVAILABLE COPY 
WHC-EP-0806

WHC-SD-WM-DP-058

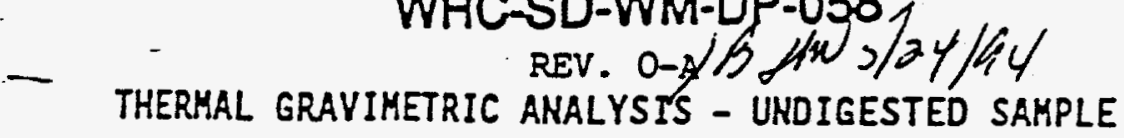
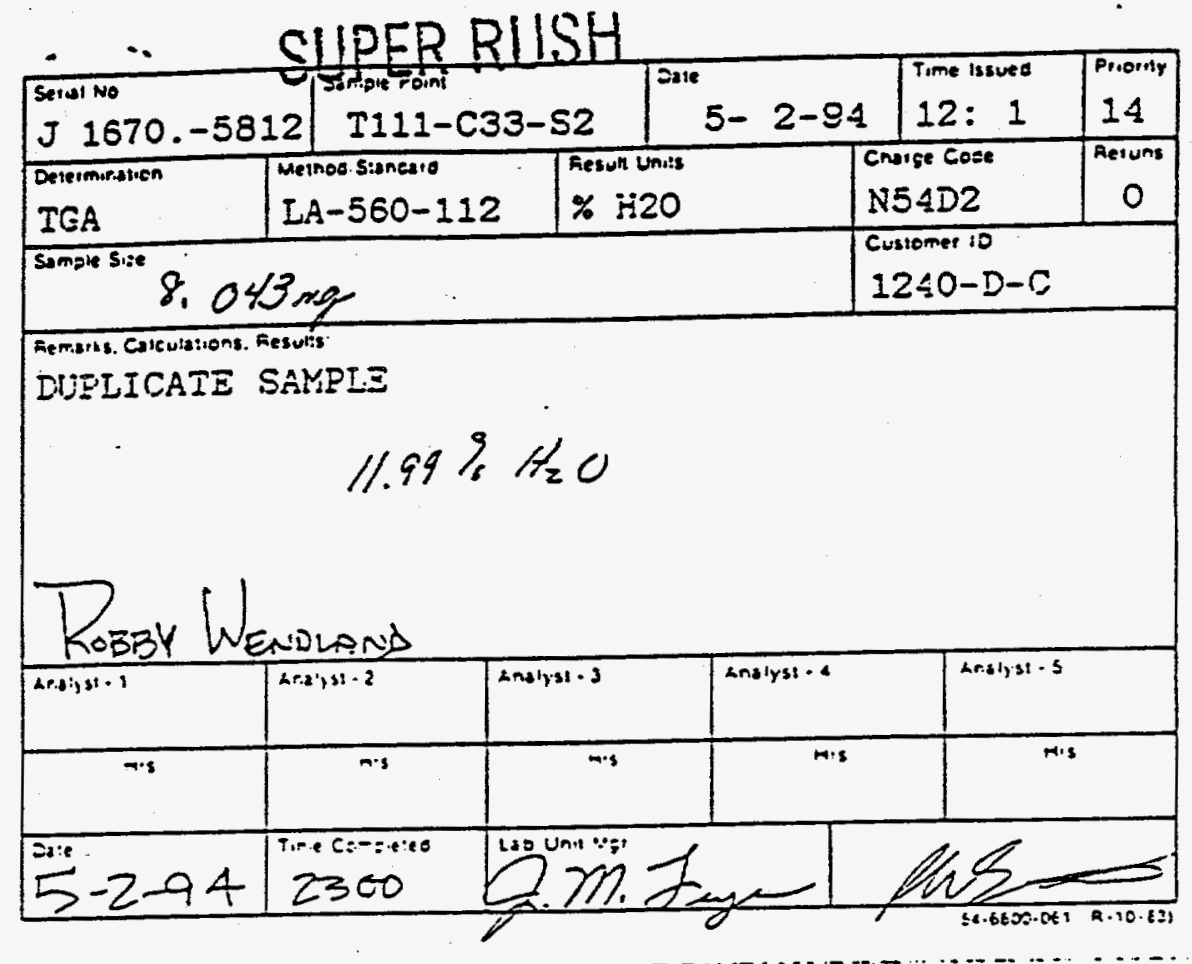

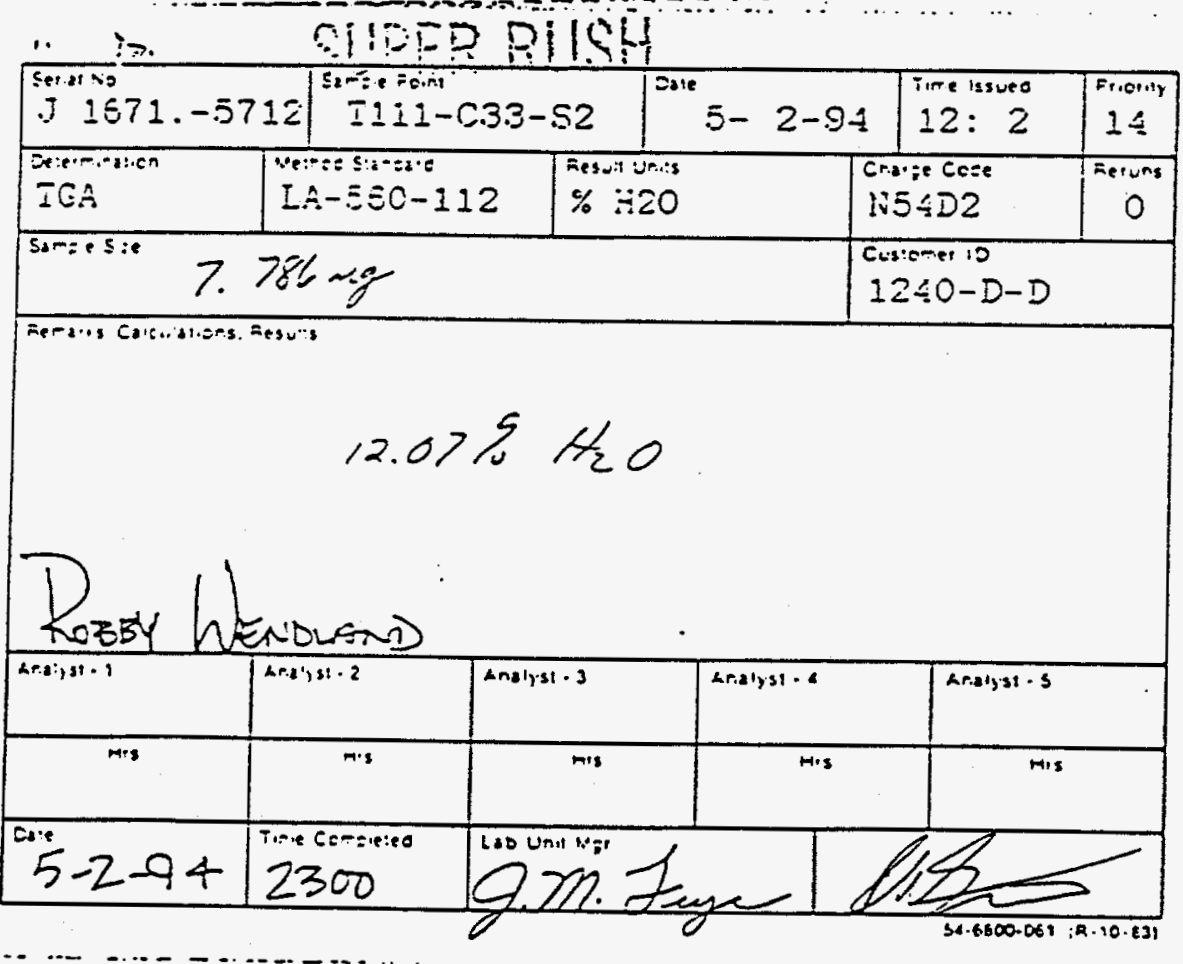

BEST AVAILABLE COPY

A-157. 
- therMal GRAVIMETRIC ANALYSIS 6 UNDIGESTEU SAMPLE

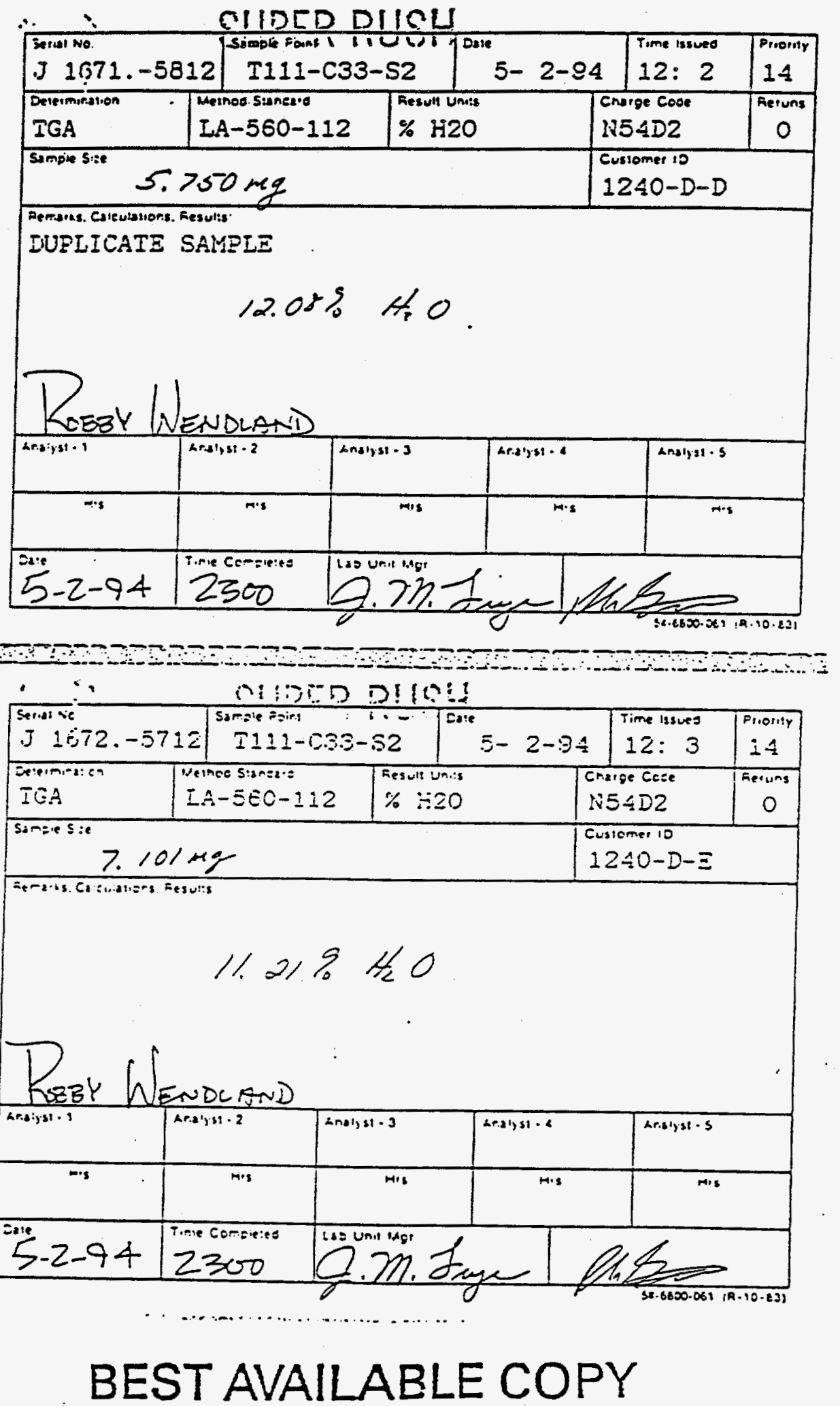


WHC-EP-0806

WHC-SD-WM-DP-058

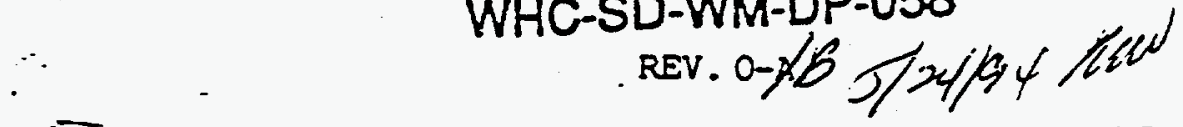

THERMAL GRAVIMETRIC ANALYSIS - UNDIGESTED SAMPLE

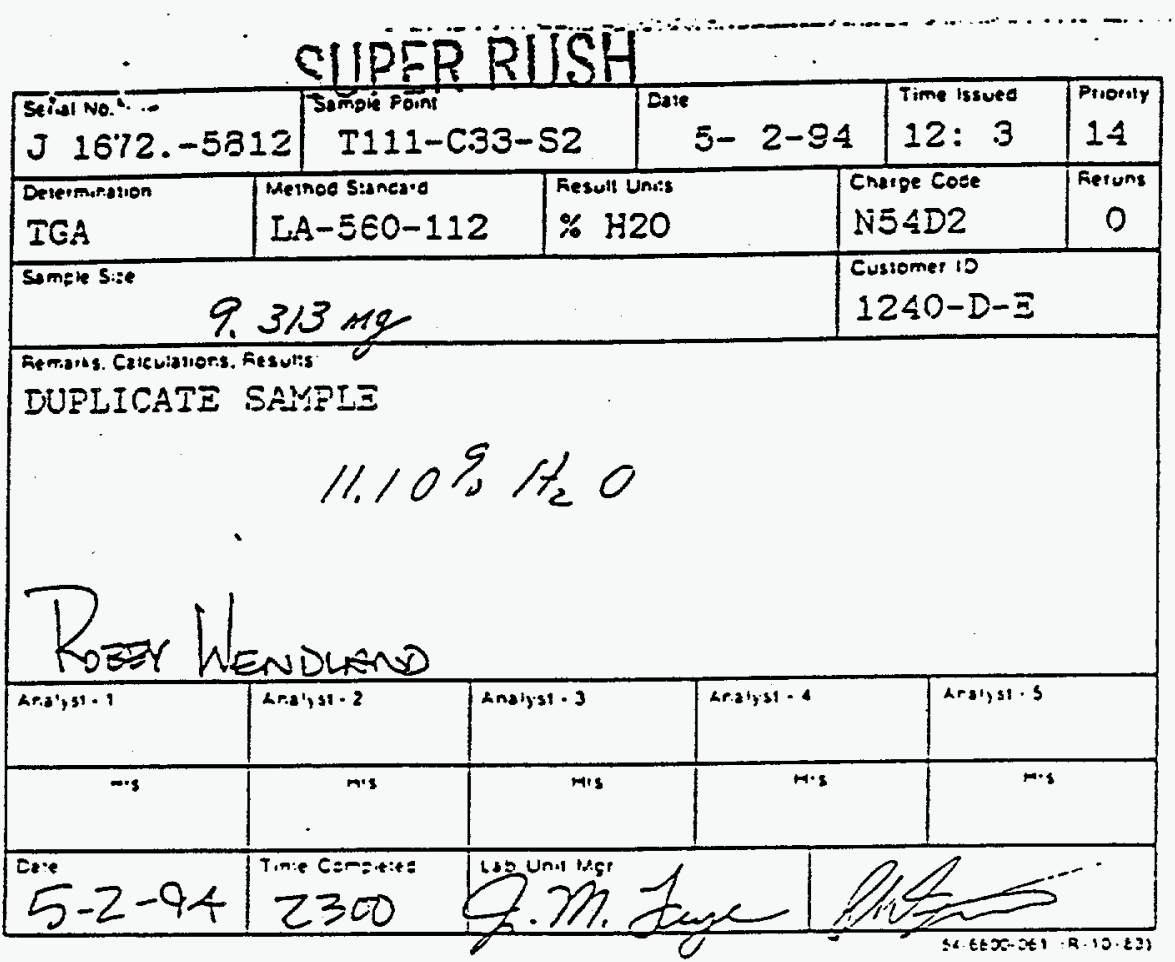


Signature below represents chemical 'l'echnologist/chemist that completed/verified the calibration/analysis on page 124 to 135

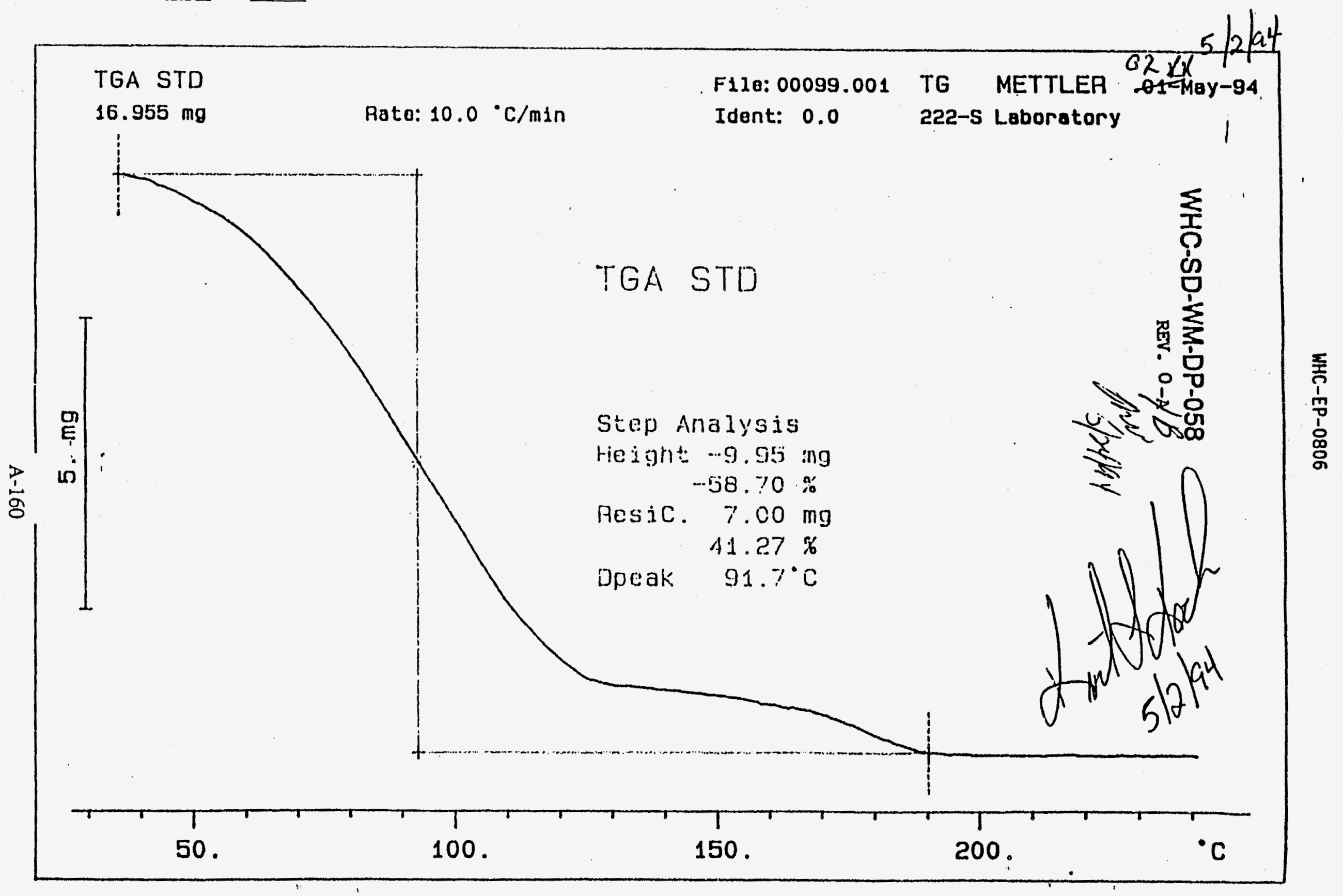




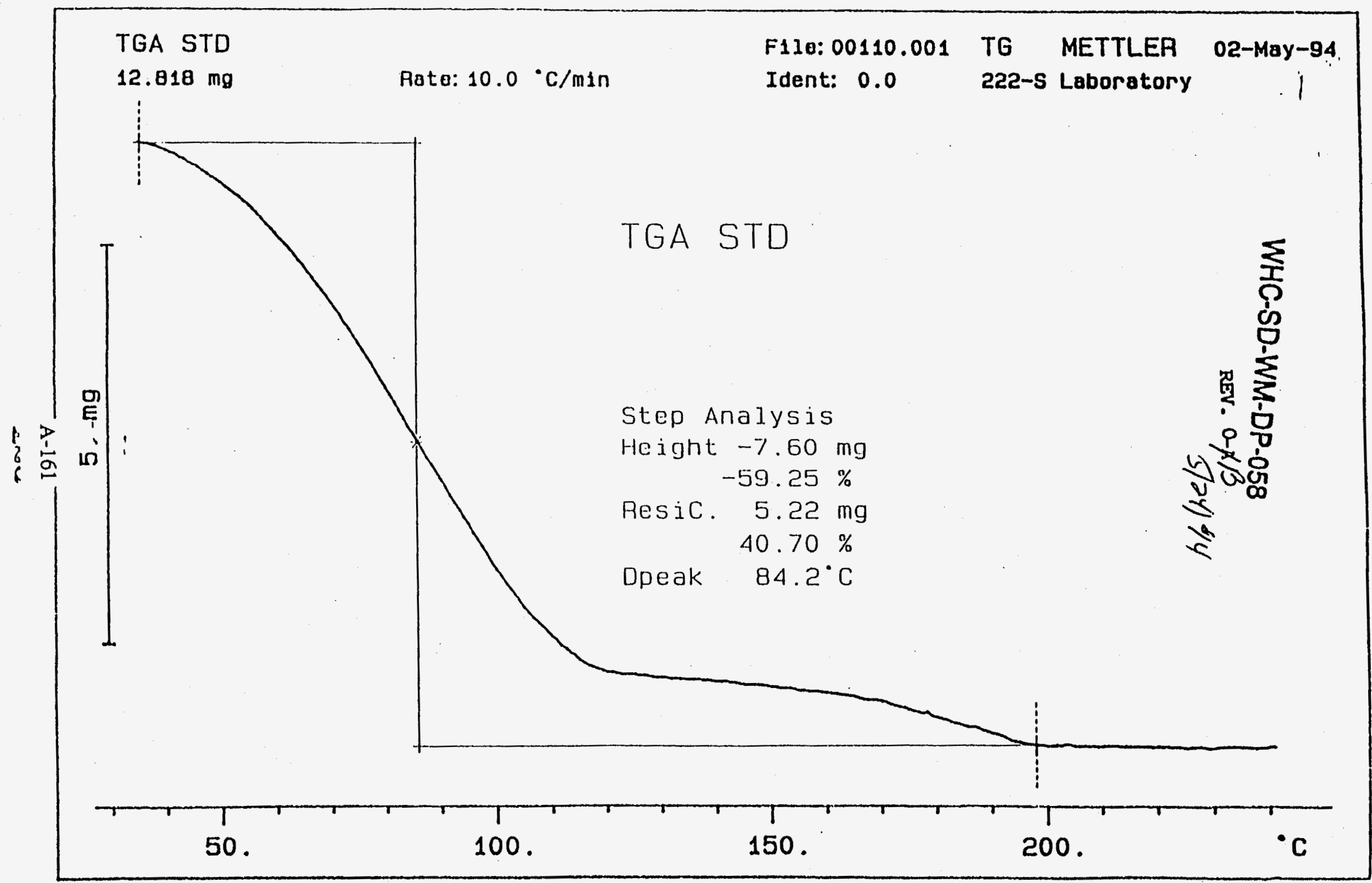




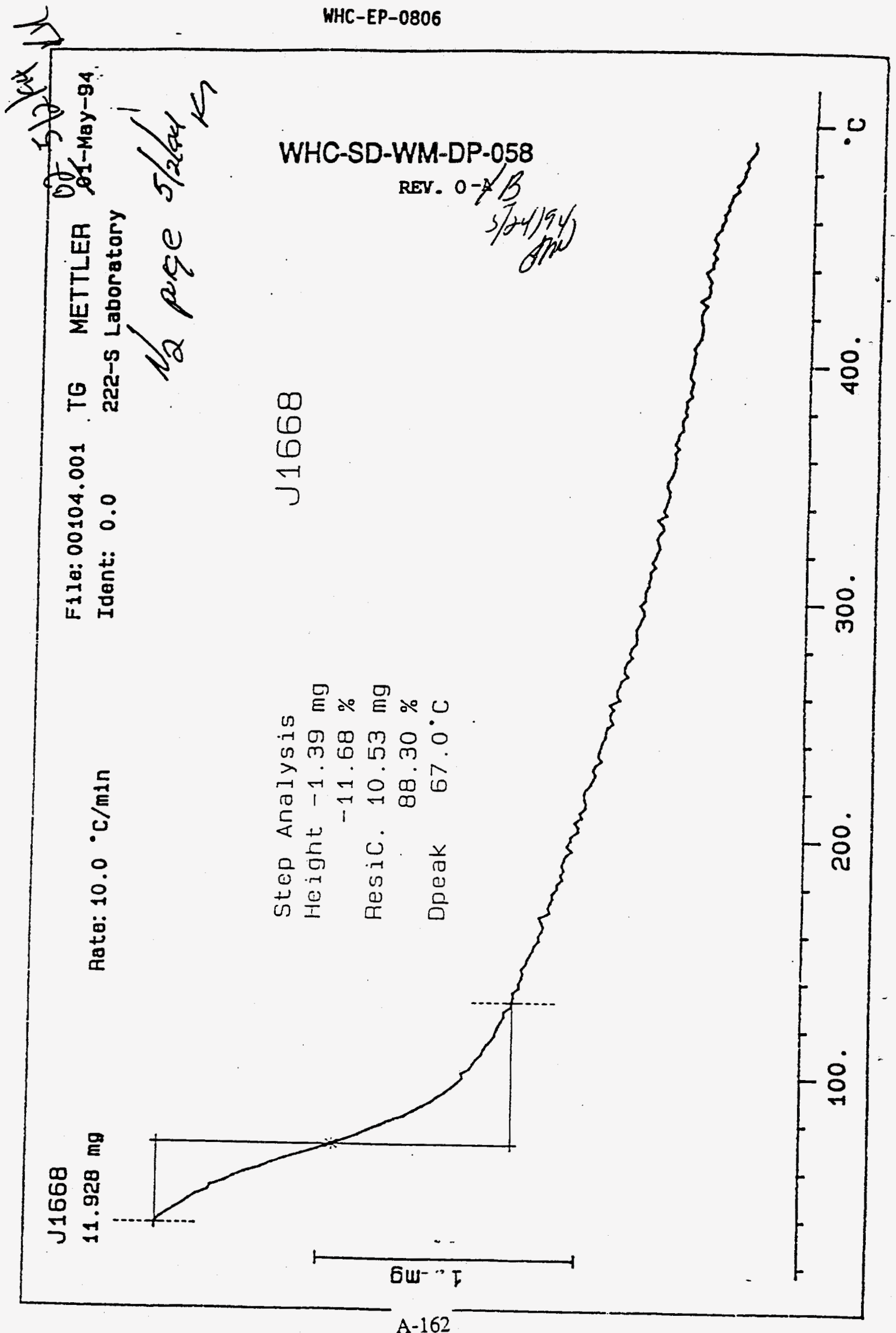




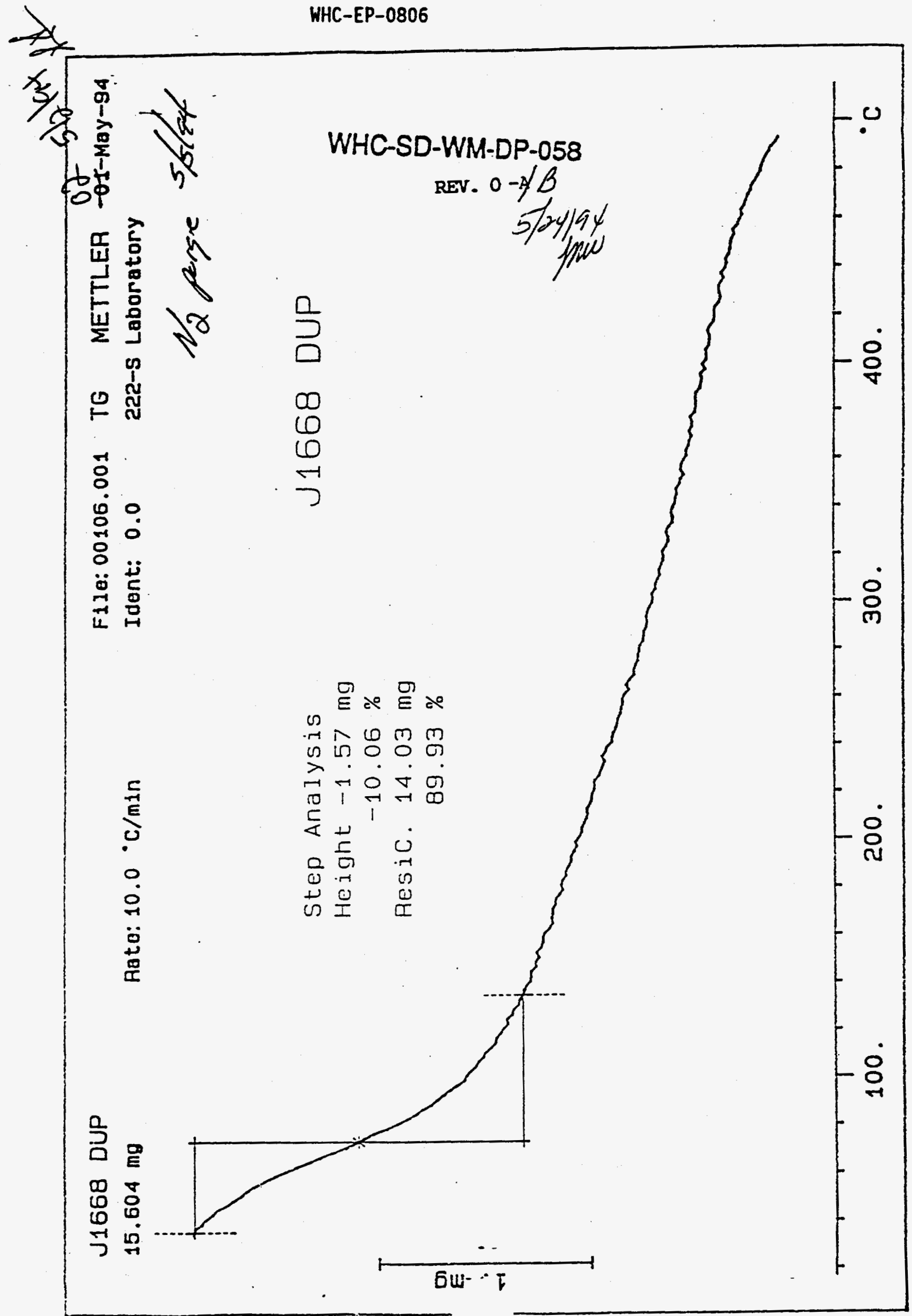




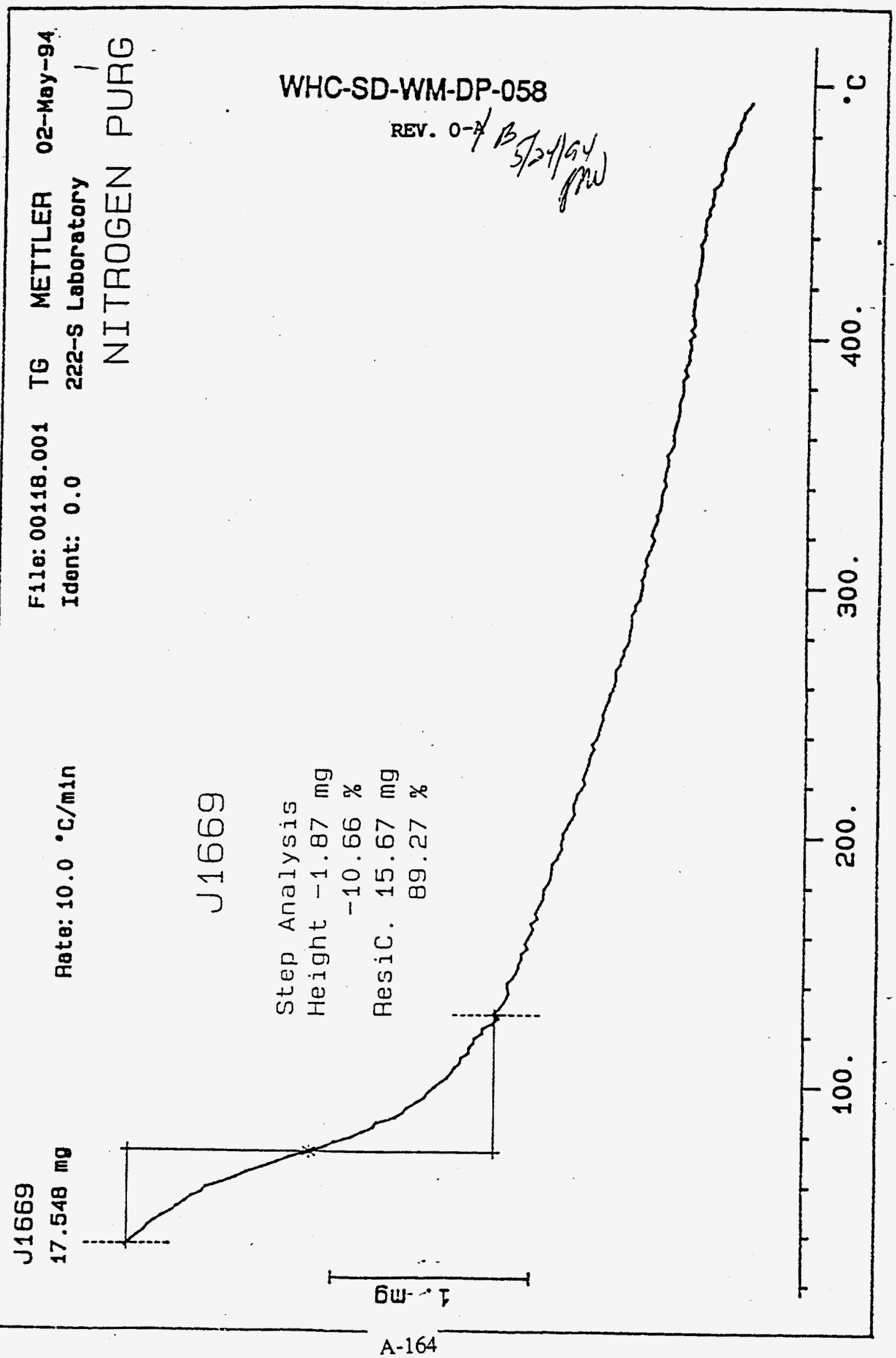


WHC-EP-0806

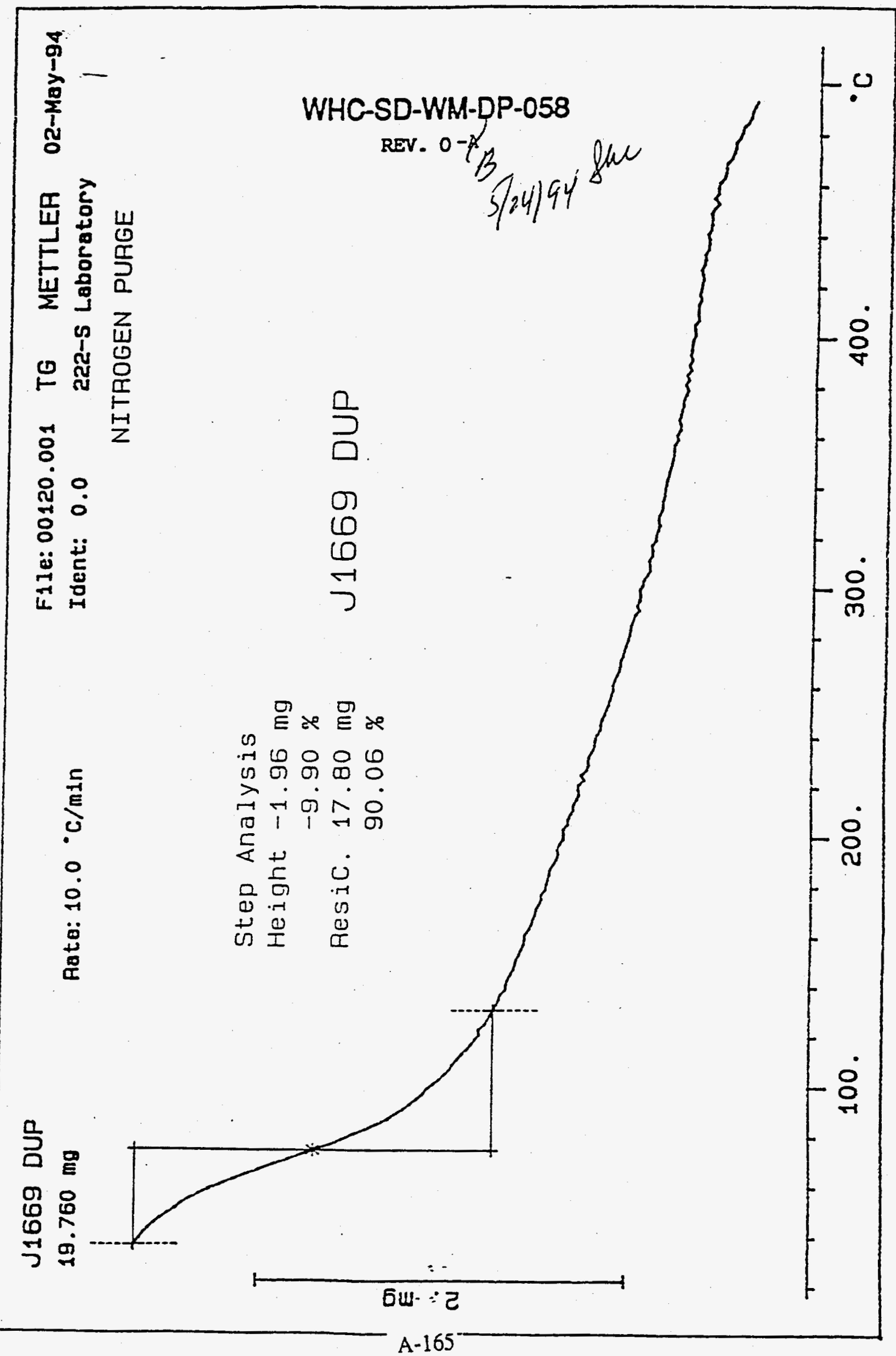




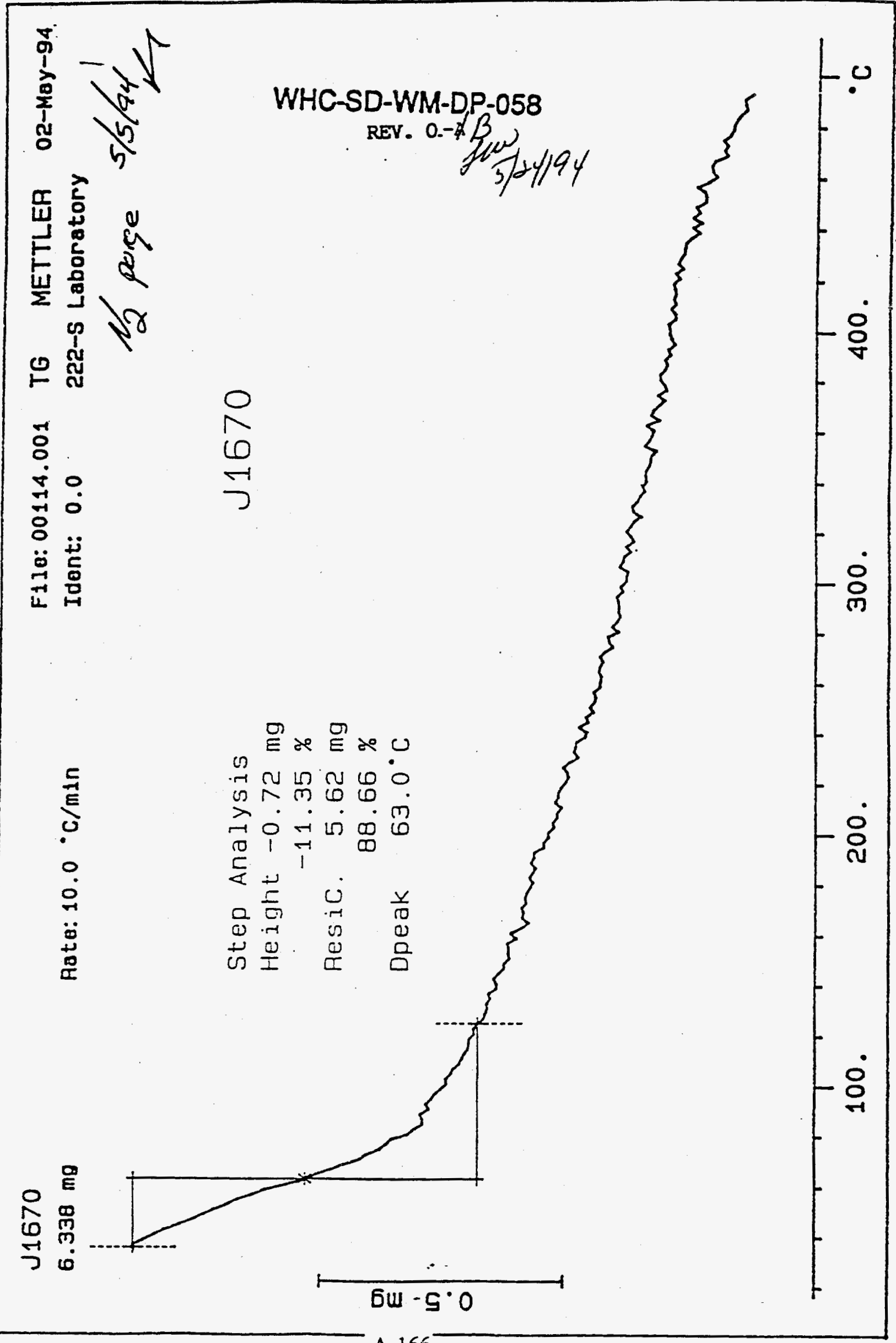


WHC-EP-0806

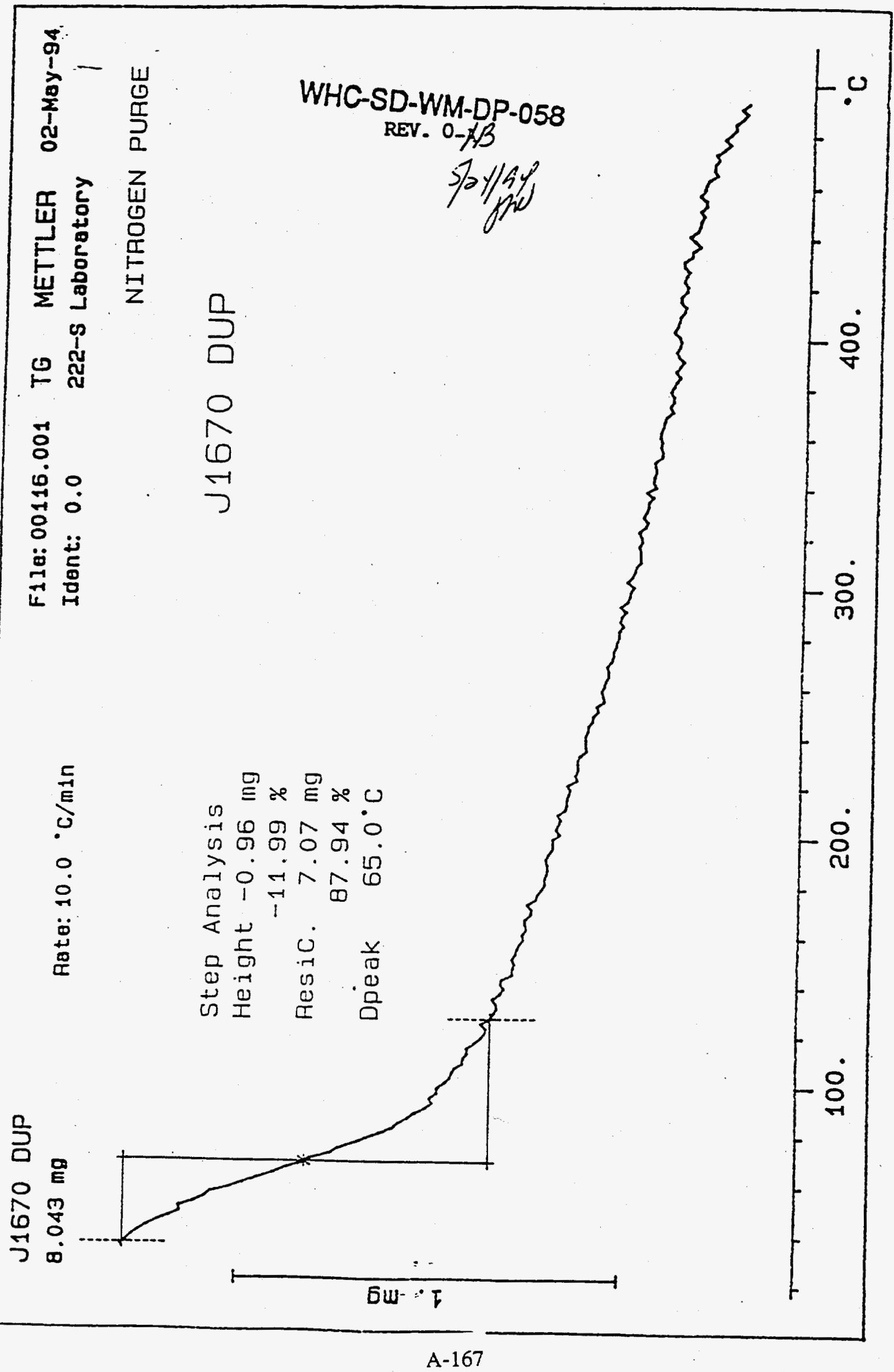




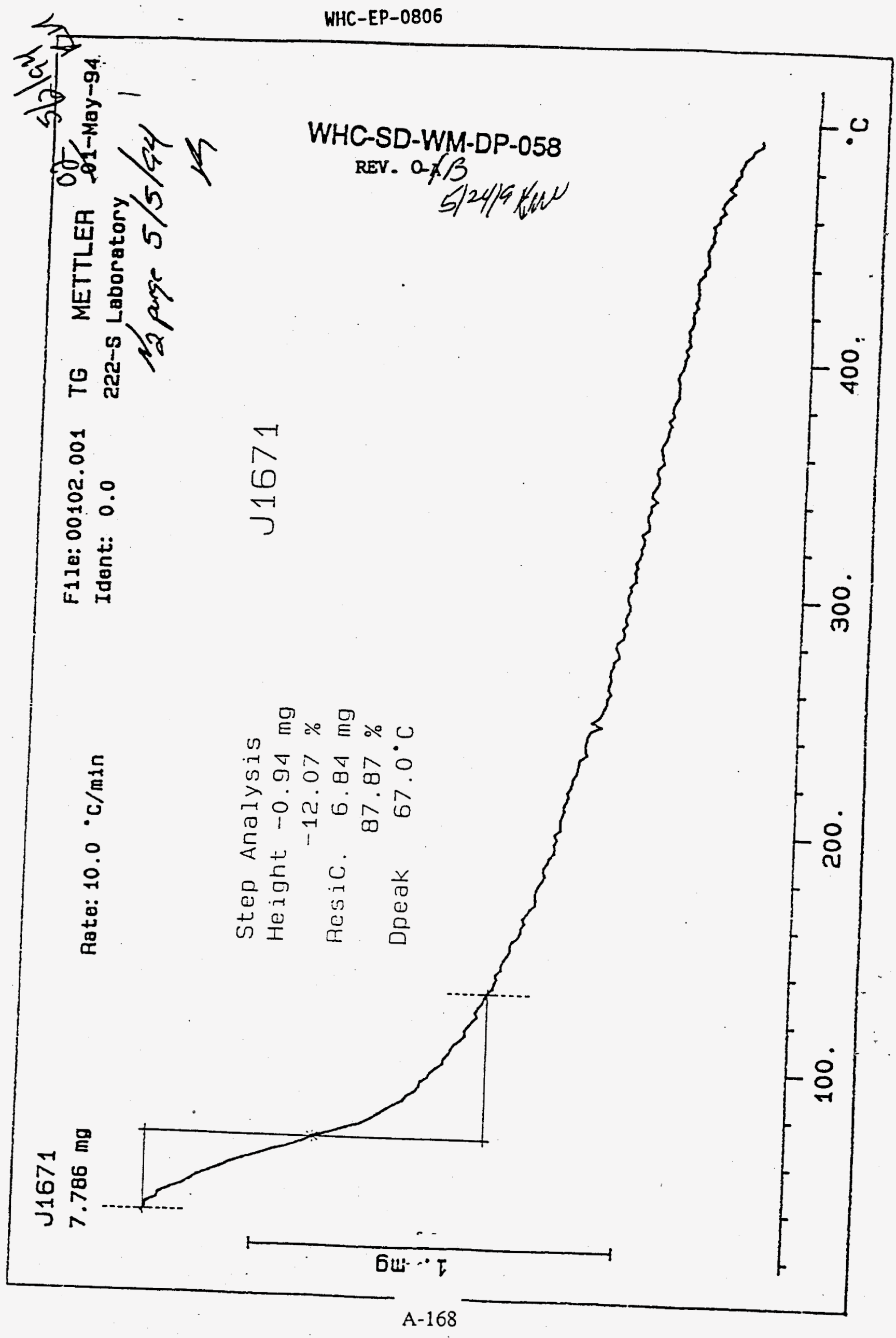


WHC-EP-0806

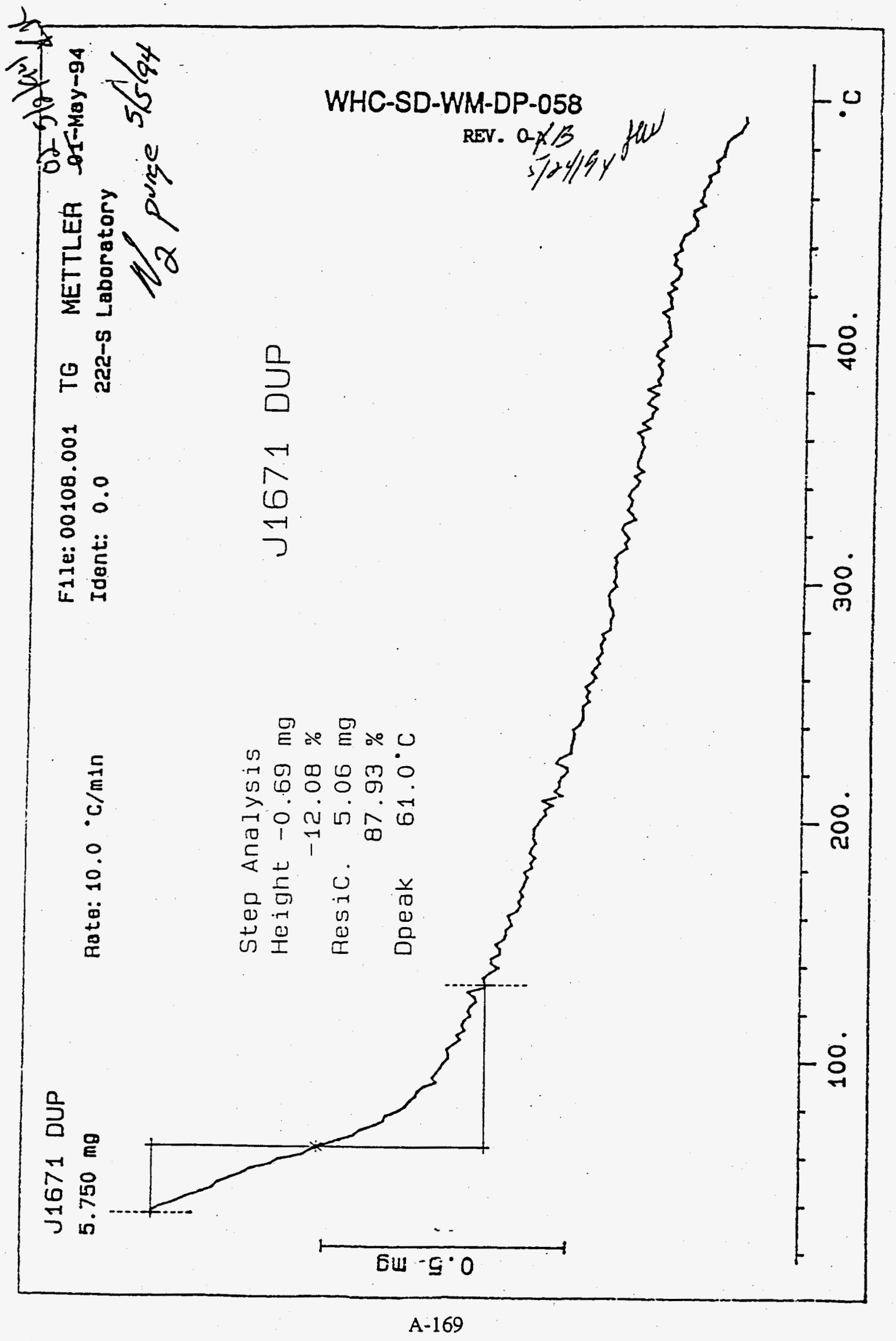




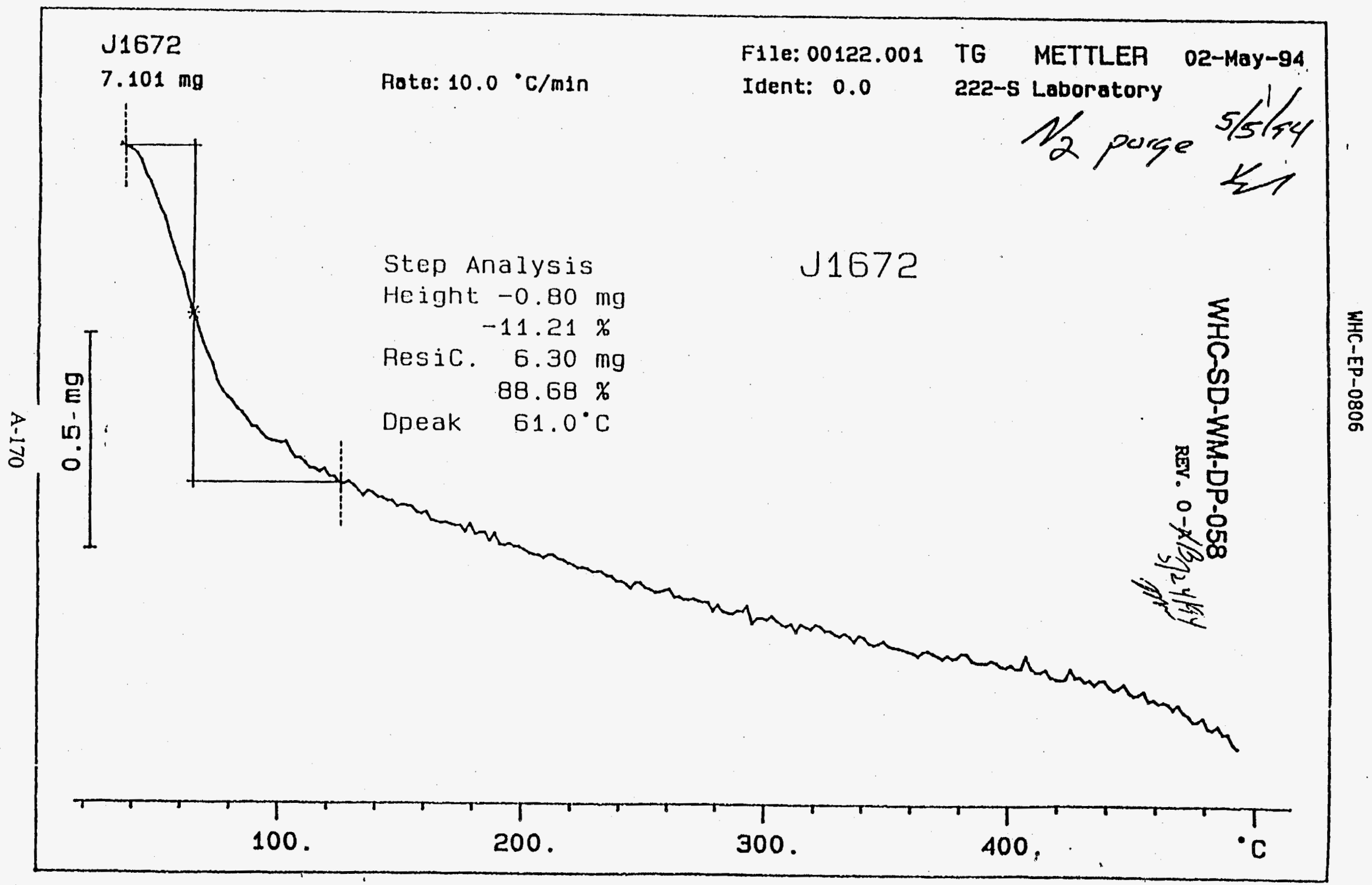




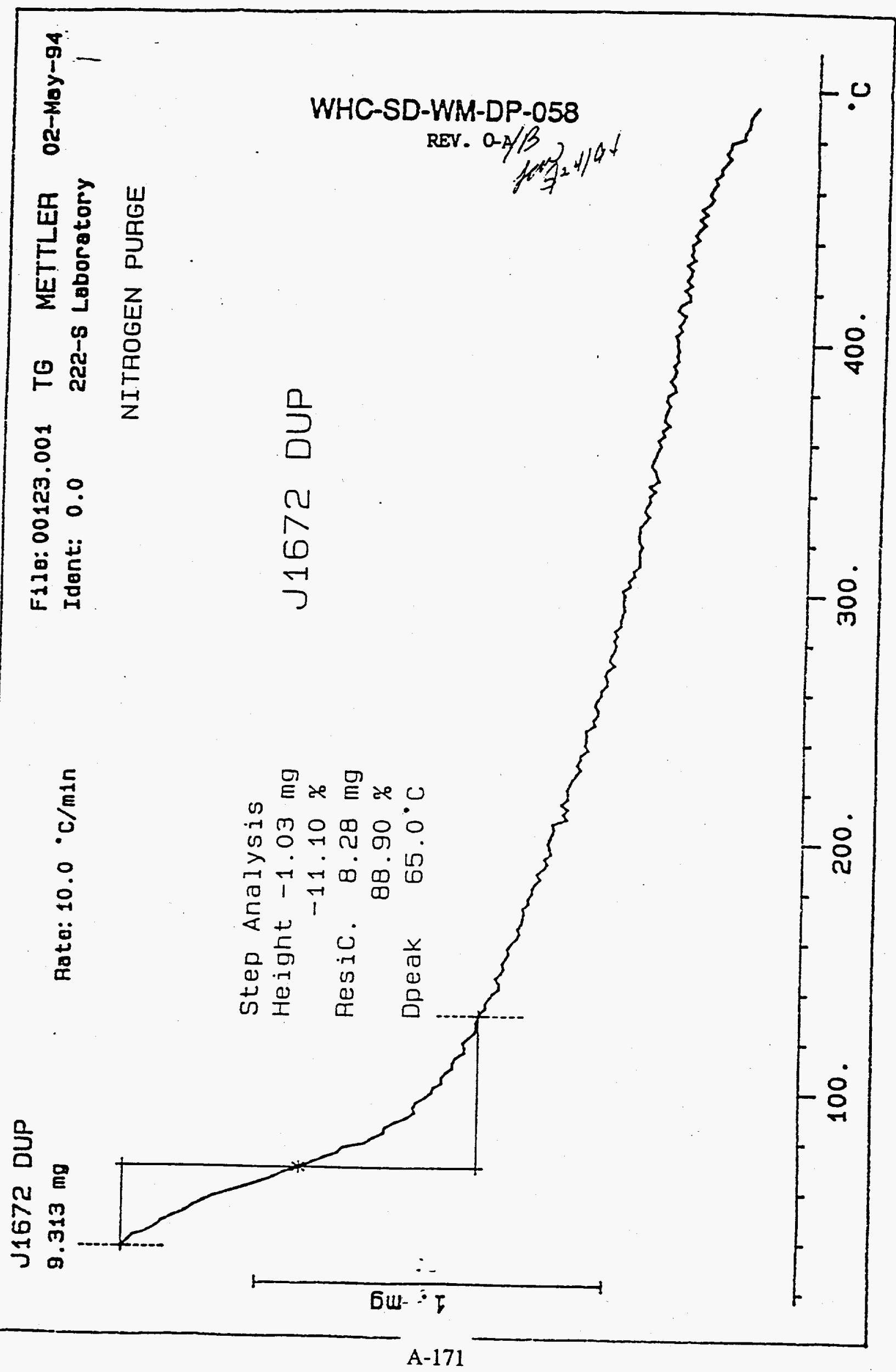


WHC-EP-0806

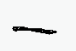

A-172 
This page intentionally left blank. 
2. Title

Statistical Characterization Report for Single-She11 Tank 241-T-111

5. Key words

Single-Shell Tank, Waste, Characterization, Sampling, Sample Homogenization, Core Composite Samples

3. Number

WHC-SD-WM-TI-650
4. Rev No.

0

6. Author

Name: R. D. Cromar/S.R. Wilmarth

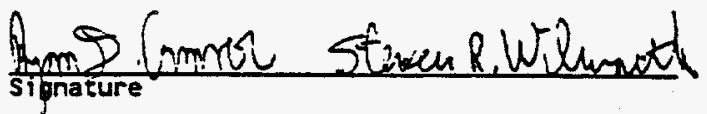
Name: Louis Jensen

\section{APPROVED FOR}

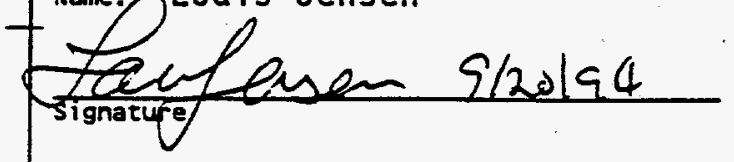

\section{$\%$ T/20/at PUBLIC RELEASE}

Organization/Charge Code $8 E 100 / N 4026$

7. Abstract

This report documents the statistical analyses performed on core data from Single-She11 Tank 241-T-111

8. PORROSE AND USE OF DOCUMENT - This document was prepared for use with in the U.S. Department of Energy and its contractors It is to be used ontx to perform, direct, or integrate work under U.S. Department of Energy contracts. This docyment is not approved for public release unt reviewed.

PATENT STATUS - This document donk since it is transmitted in advance of patent clearance ts made avojable in confidence solely for use in performance of work under contracts with the U.S. Department of energy. This document is not to be published nor its contents otherwise disseminated or used for purposes-ather than specifia above before patent approval for such release or Doe has been secured, upon request, from the Patent Counsel, U.S. Department 10. RELEASE STAMP

DISCLAIMER - This report was prepared as an account of work sponsored by an agency of the United States Goverment. Neither the United States Goverment nor any agency thereof, nor any of their emoloyees, nor any of their contractors, subcontractors or their employees, makes any warranty, express or implied, or assumes any legal liability or responsibility for the accuracy, completeness, or any third party's use or the results of such use of any information, apparatus, product, or process disclosed, or represents that its use would not infringe privately owned rights. Reference herein to any specific commercial product, process, or service by trade name, trademark, manufacturer, or otherwise, does not necessarily constitute or imply its endorsement, recommendation, or favoring by the United States Government or any agency thereof or its contractors or subcontractors. The views and opinions of authors expressed herein do not necessarily state or reflect those of the United States Goverment or any agency thereof.

9. Impact Level NA 


\begin{tabular}{|c|c|c|}
\hline $\begin{array}{l}\text { 2. To: (Receiving organization) } \\
\text { Distribution }\end{array}$ & $\begin{array}{l}\text { 3. From: (originating Organization) } \\
\text { Process Laboratories \& } \\
\text { Technology }\end{array}$ & $\begin{array}{l}\text { 6. Related EDT No.: } \\
\qquad 600490\end{array}$ \\
\hline $\begin{array}{l}\text { 5. Proj./Prog./Dept./Div.: } \\
\text { WM }\end{array}$ & $\begin{array}{l}\text { 6. Cog. Engr.: } \\
\text { L. Jensen }\end{array}$ & $\begin{array}{r}\text { 7. Purchase order No.: } \\
\text { NA }\end{array}$ \\
\hline \multirow{2}{*}{\multicolumn{2}{|c|}{$\begin{array}{l}\text { 8. Originator Remarks: } \\
\text { Release of document "Statistical Characterization Report for } \\
\text { Single-Shel1 Tank 241-T-111" }\end{array}$}} & $\begin{array}{c}\text { 9. Equip./Component No.: } \\
\text { NA }\end{array}$ \\
\hline & & $\begin{array}{c}\text { 10. System/Bldg./facility: } \\
\text { NA }\end{array}$ \\
\hline \multirow{3}{*}{\multicolumn{2}{|c|}{ 11. Receiver Remarks: }} & $\begin{array}{c}\text { 12. Major Assm. Dwg. No.: } \\
\text { NA }\end{array}$ \\
\hline & & $\begin{array}{l}\text { 13. Permit/Permit Apolication No.: } \\
\text { NA }\end{array}$ \\
\hline & & $\begin{array}{l}\text { 14. Required Response Date: } \\
\text { 9-30-94 }\end{array}$ \\
\hline
\end{tabular}

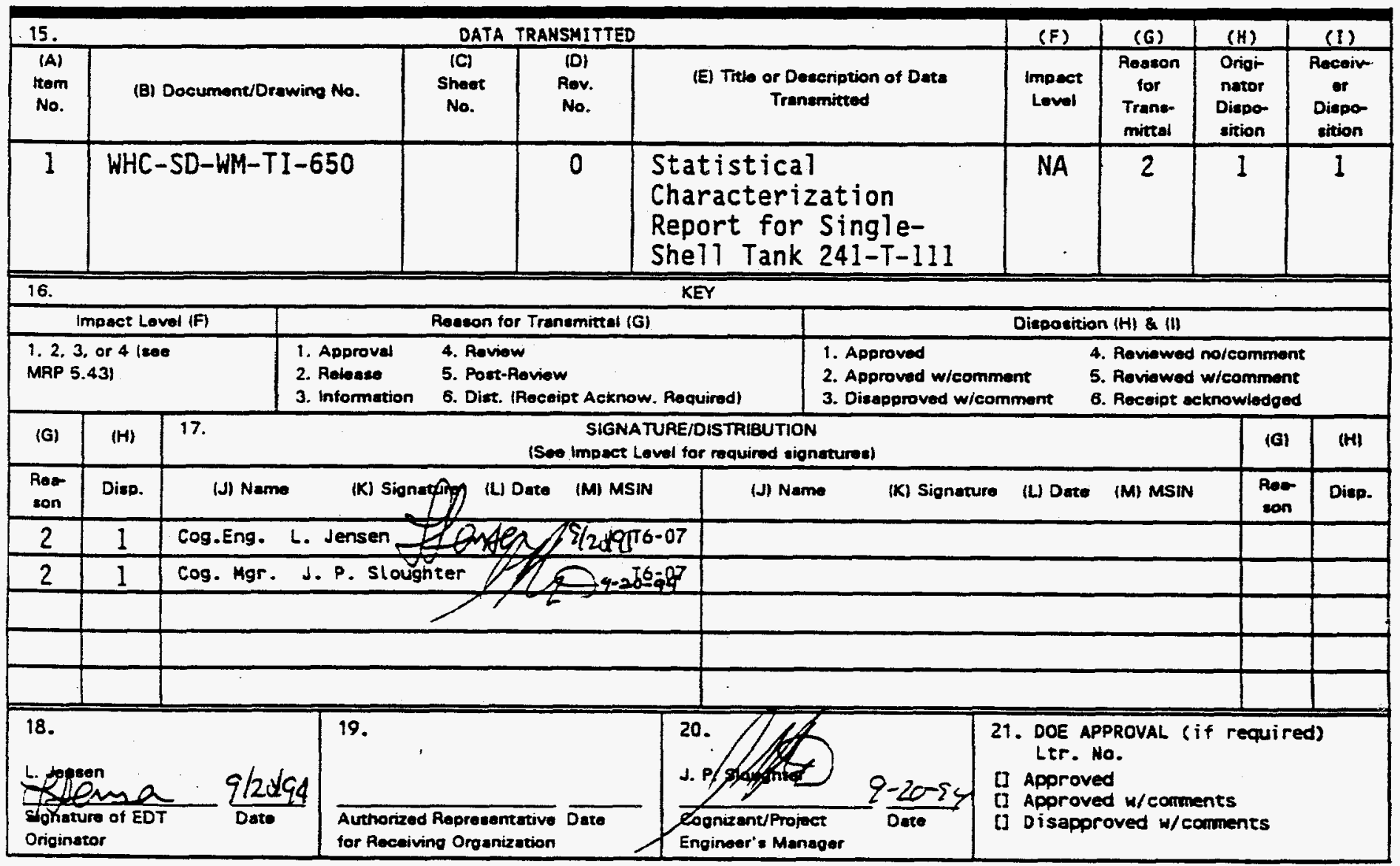

$60-7400-172-2(07 / 91)$ GEF097 


\section{CONTENTS}

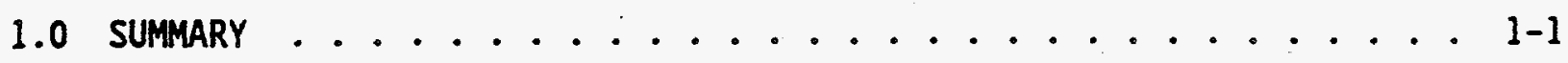

2.0 INTRODUCTION . . . . . . . . . . . . . . . . . . . 2-1

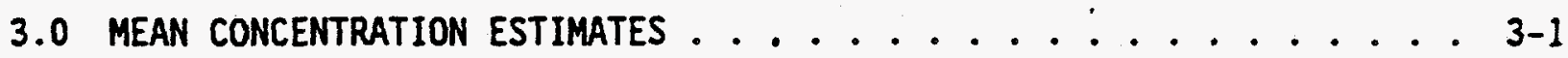

3.1 STATISTICAL METHODS ................. 3-1

3.2 STATISTICAL RESULTS ................... 3- . . . .

4.0 COMPARISON OF THE VARIANCE COMPONENT ESTIMATES . . . . . . . . . . 4-1

4.1 STATISTICAL METHODS .................... 4-1

4.2 STATISTICAL RESULTS ................. 4-1

5.0 REFERENCES .......................... 5-1

\section{LIST OF APPENDICES}

A CORE COMPOSITE DATA . . . . . . . . . . . . . . . . . . . A-1

B CORE COMPOSITE DATA PLOTS . . . . . . . . . . . . . . . . B-1

C MEAN CONCENTRATION CALCULATION METHODS . . . . . . . . . . . . . . c-

\section{LIST OF TABLES}

2-1 T-111 Core Recoveries ...................... 2-1

2-2 Special Analyte List. . . . . . . . . . . . . . . . . . 2-3

3-1 Concentration Estimate Statistics . . . . . . . . . . . . 3-2

4-1 Variance Component Estimates . . . . . . . . . . . . . 4-2

A-1 Core Composite Data . . . . . . . . . . . . . . . . A-3

\section{LIST OF FIGURES}

2-1. Riser location .......................... 2-2 


\section{LIST OF TERHS}

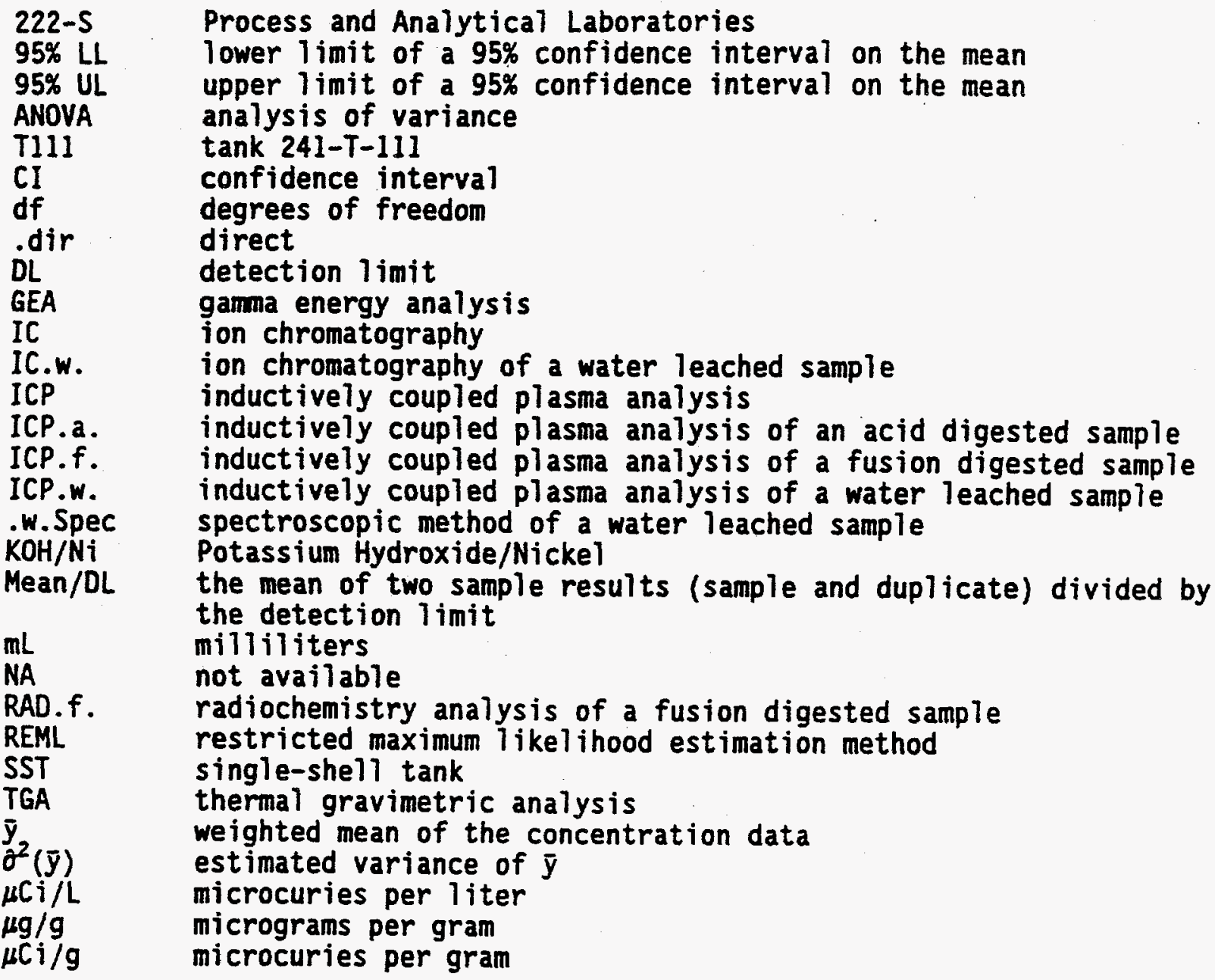


WHC-SD-WIT-TI-650, ReV. 0

\author{
STATISTICAL CHARACTERIZATION REPORT \\ FOR \\ SINGLE-SHELL TANK 241-T-111
}

\title{
1.0 SUMARY
}

This report contains the results of the statistical analysis of data from two core samples obtained from Single-She11 Tank 241-T-111 (T111).

Section 2 contains a description of the core samples and the chemical analyses done on the core samples.

Section 3 contains mean concentration estimates and associated 95\% confidence intervals (CI) on the mean for each of the analytes in TIII.

Section 4 contains estimates of the spatial variability (variability between cores) and estimates of the "analytical error" from the core composite data.

Two types of analytical error were estimated from the core composite data: (1) compositing variability (variability between composite samples within the same core) and (2) analytical measurement error (variability between the primary and duplicate analyses within each core composite sample). Estimates of the analytical measurement error were used as the reference value to test the significance of the spatial and compositing variability. Spatial variability was significantly different than zero for 39 out of 85 analytes in T111. The compositing variance was significantly different than zero for 39 out of the 85 analytes. 


\section{WHC-EP-0806}

WHC-SD-MH-TI-650, Rev. O

This page was intentionally left blank. 


\subsection{INTRODUCTION}

Two core samples (cores 31 and 33) were taken from T111. Cores 31 and 33 were obtained form risers 6 and 3, respectively. Figure 2-1 (p. 2-2) gives the locations of the risers. The segment recoveries for each core are given in Table 2-1. Core 31 had nearly $100 \%$ segment recovery for all segments except segments 1 and 6 . There was nearly $100 \%$ segment recovery for all of the segments in Core 33 .

Table 2-1. T-111 Core Recoveries.

\begin{tabular}{|c|c|c|c|c|c|c|c|c|c|}
\hline \multirow{2}{*}{ Core } & \multicolumn{10}{|c|}{ Segment Number } \\
\cline { 2 - 9 } & 1 & 2 & 3 & 4 & 5 & 6 & 7 & 8 & 9 \\
\hline 31 & $27 \%$ & $\begin{array}{c}80- \\
100 \%\end{array}$ & $\begin{array}{c}95- \\
100 \%\end{array}$ & $\begin{array}{c}80- \\
100 \%\end{array}$ & $100 \%$ & $0 \%$ & $\begin{array}{c}90- \\
100 \%\end{array}$ & $100 \%$ & $100 \%$ \\
\hline 33 & $100 \%$ & $100 \%$ & $\begin{array}{r}87- \\
100 \%\end{array}$ & $\begin{array}{c}75- \\
85 \%\end{array}$ & $88 \%$ & $100 \%$ & $100 \%$ & $100 \%$ & $100 \%$ \\
\hline
\end{tabular}

Due to the incomplete core sample recovery, the concentration estimates given in this report are biased. The magnitude of the bias is unknown.

Two core composite samples were made for each core sample from the homogenized solid segment waste. Primary and duplicate results were obtained from each core composite sample.

The chemical analysis of the primary and duplicate samples consisted of the following analytical methods and sample preparations (the notation for the method and preparation is also listed):

- inductively coupled plasma analysis (ICP) of an acid digested sample (ICP.a),

- ICP of a potassium hydroxide/nickel (KOH/Ni) fused sample, (ICP.f)

- ICP analysis of a water leached sample (ICP.W),

- ion chromatography (IC) of a water leached sample (IC.W),

- radio chemistry, and

- gamna energy analysis (GEA).

Occasionally, special analytical methods are used on prepared and unprepared waste samples. The notation for the results from such methods is given in the tables of Appendix $A$ and the tables in Sections 3 and 4 .

Whenever possible, the results and data given here are identified by the analysis method, the type of dissolution and analyte. For example, the notation ICP.a.AI refers to the Al concentration from an ICP analysis of an acid digested sample. 
WHC-EP-0806

WHC-SD-WH-TI-650, Rev. 0

Figure 2-1. Riser location.

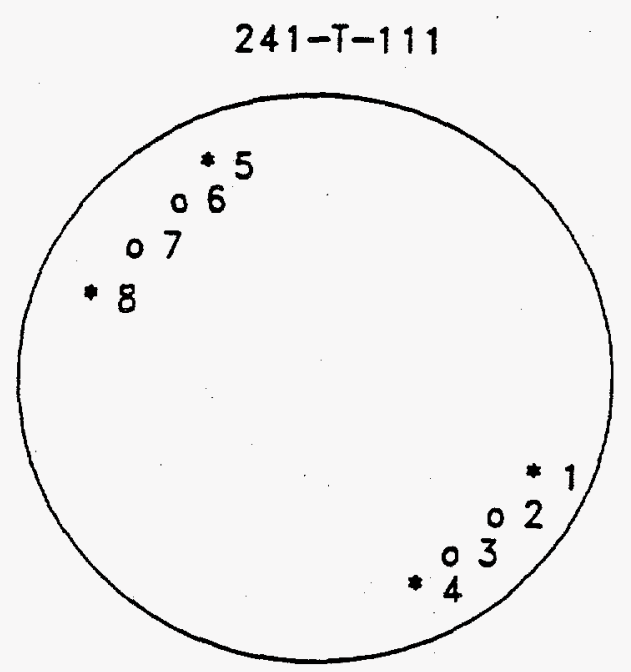

$$
\text { - 12" Riser }
$$

" 4" Riser 
The core composite sample results are contained in Table A-1 (Appendix A). Ratios of the mean of each primary and duplicate result divided by the detection limit for that pair are also included. The ratios (Mean/OL) are provided to show how large the analyte concentrations are relative to the DL. The data packages for tank T111 (Kocher, 1993 and McKinney, 1993) contain a complete report of the sample results along with the laboratory quality control data. The core composite data for each analyte are illustrated in the figures provided in Appendix B.

Analysis of variance (ANOVA) models were fit to the data for all analytes that did not have any "less than values". All of the data available for statistical analysis, including the analytes with at least one "less than value," are reported in Table A-1. The ratios (Mean/DL) of all of the data are also reported in Table $A-1$.

From a quality of data perspective, it is desirable that the ANOVA models be applied to analyte concentrations greater than 10 times the detection limit. However, Analytical Evaluation and Reporting personnel, with in the TWRS Information Management Systems, identified a list of "special analytes," given in Table 2-2. For this list, they requested that the ANOVA models be fit to the data provided the concentration values were greater than 3 times the detection limit or less than 10 times the detection limit.

Whenever possible the ANOVA models were fit using all of the data, regardless of the value of the detection limit. To warn the reader of potential detection 1 imit problems the analytes in Tables 3-1, 4-1 and A-1 are denoted by a "." or a " $\star$ " whenever a concentration is less than 3 times or 10 times the detection limit respectively. The results for such analytes are to be used with caution.

In Table A-1, some analytes are marked with a "*." Due to the dilution factors, the analytical result values are so close to the detection limit (DL), that the concentration values are questionable. For these analytes, ANOVA models were not fit to the data.

Table 2-2. Special Analyte List.

\begin{tabular}{|ll|}
\hline Aluminum & Nitrate \\
Bismuth & Nitrite \\
Calcium & Phosphate \\
Chromium & Carbonate \\
Iron & Fluoride \\
Silicon & Chloride \\
Sodium & Total Organic Carbon \\
Zirconium & Cyanide \\
\hline
\end{tabular}

A close examination of the figures in Appendix B reveals several "outlier data points" in the core composite data:

- ICP.a.Co The primary result for core 31 , composite 2 of $11.7 \mu \mathrm{g} / \mathrm{g}$ is over three times as large as the duplicate result. The other results for ICP.a.Co all fall in the range 2.7 to 3.8 $\mu \mathrm{g} / \mathrm{g}$. The detection imit for ICP.a.Co is $0.8 \mu \mathrm{g} / \mathrm{g}$. 
- ICP.a.Cu The duplicate result for core 31, composite 2 of $127 \mu \mathrm{g} / \mathrm{g}$ is about four times as large as the primary result of 31.7 $\mu \mathrm{g} / \mathrm{g}$. The detection limit for ICP.a.Cu is $0.4 \mu \mathrm{g} / \mathrm{g}$.

- $\mathrm{NO}_{2}$ Both the primary and duplicate results from core 31 , composite 2 are about one half the results for core 31 , composite 1. The average of the results for core 31 , composite 1 , is $952 \mu \mathrm{g} / 9$, the average for composite two is $525 \mu \mathrm{g} / \mathrm{g}$. The detection limit for $\mathrm{NO}_{2}$ (by water digestion spectrophometric analysis) is $50 \mu \mathrm{g} / \mathrm{g}$.

There is no direct evidence that the results noted above are due to analytical measurement errors. Consequently, the statistical analysis was performed on the data as it is reported in Table A-1. The potential anomalies in the data noted above can be clearly seen in the figures in Appendix $B$. 
WHC-EP-0806

MHC-SD-MH-TI-650, ReV. 0

\subsection{MEAN CONCENTRATION ESTIMATES}

One of the tasks outlined in the Tank Waste Characterization Plan, Section 5.1.1.2 (Be11, 1993), is to estimate the constituent inventories in the waste. The inventories are estimated by computing mean concentrations and 95\% confidence intervals (CIS) on the mean concentrations for each constituent. The estimate of the inventory and CI on the inventory of an analyte in the tank are equal to the corresponding mean concentration estimates and CI multiplied by the volume of waste in the tank. Therefore, estimates of tank inventory are not given in this document.

Table A-1 (Appendix A) contains the core composite data used to compute the mean concentration estimates and associated $\mathrm{CIs}$.

\subsection{STATISTICAL METHODS}

The concentration estimates are given in the form of $95 \% \mathrm{CIs}$ on the mean concentration. It is assumed that each primary sample and its duplicate are analyzed independentiy of one another. The two analytical results are used to estimate the analytical measurement error. Due to the hierarchical structure of the data, the analytical measurement error alone is not the appropriate error term to use in computing the CIs. A linear combination of the analytical measurement variance and the spatial variance is the appropriate variance of the mean for the CIs (Snedecor and Cochran, 1980). Appendix C contains a description of the statistical model and formulas used to calculate estimates of the mean, variance of the mean and the CI on the mean.

\subsection{STATISTICAL RESULTS}

Table 3-1 contains the summary statistics, by analyte, for ICP acid digestion, ICP water leach, ICP $\mathrm{KOH} / \mathrm{Ni}$ fusion dissolution, radio chemistry and IC analyses. The summary statistics are defined as follows:

$\bar{y}$

$\hat{\sigma}^{2}(\bar{y})$

mean of the concentration data,

df estimated variance of $\bar{y}$,

degrees of freedom,

95\% LL lower limit to the $95 \% \mathrm{CI}$ on the mean and

95\% UL upper limit to the $95 \%$ CI on the mean.

For some analytes the lower confidence limit (95\% LL) was negative. Since concentrations are greater than or equal to zero, any negative $95 \% \mathrm{LL}$ values were set equal to zero.

The confidence intervals in Table 3-1 are wide relative to the range of the data because only two cores were used to estimate the spatial variability. Two core samples is the minimum number of core samples needed to estimate a tank's spatial variability. 
Table 3-1. Concentration Estimate Statistics (Units $\mu \mathrm{g} / \mathrm{g}$ Except Radionuclides $\mu \mathrm{Ci} / \mathrm{g}$ ). (sheet 1 of 3 )

\begin{tabular}{|c|c|c|c|c|c|}
\hline Analyte & $\bar{y}$ & $\partial^{2}(\bar{y})$ & df & $95 \times 4$ & $95 \times$ UL \\
\hline ICP.A.Ag & $1.26 E+02$ & $7.86 E+03$ & 1 & 0.00 & $1.25 E+03$ \\
\hline ICP.a.Al & $5.41 E+02$ & $1.06 E+04$ & 1 & 0.00 & $1.85 E+03$ \\
\hline ICP.A.B & $2.80 E+01$ & $7.56 E+00$ & 1 & 0.00 & $6.30 E+01$ \\
\hline ICP.A.Bo & $6.90 E+01$ & $6.46 E+01$ & 1 & 0.00 & $1.71 E+02$ \\
\hline ICP.A.Bi & $2.59 E+04$ & $6.38 E+06$ & 1 & 0.00 & $5.80 E+04$ \\
\hline ICP.e.Co & $1.88 E+03$ & $2.12 E+05$ & 1 & 0.00 & $7.72 E+03$ \\
\hline ICP.A.Cdt & $5.80 E+00$ & $3.03 E+00$ & 1 & 0.00 & 2. $79 E+01$ \\
\hline ICP.A.Ces & $3.37 E+01$ & $9.69 E+00$ & 1 & 0.00 & $7.33 E+01$ \\
\hline ICP.e.COt & $4.30 E+00$ & $1.63 E+00$ & 1 & 0.00 & $2.05 E+01$ \\
\hline ICP.e.Cr & $1.98 E+03$ & $1.63 E+04$ & 1 & $3.5 \pi \mathrm{k}+02$ & $3.60 E+03$ \\
\hline ICP.A.Cu & $3.35 \mathrm{E}+01$ & $3.53 E+02$ & 1 & 0.00 & $2.72 E+02$ \\
\hline ICP.a.Fe & $1.85 E+04$ & $1.21 E+06$ & 1 & $4.55 E+03$ & $3.25 E+06$ \\
\hline ICP.B.K & $1.14 E+03$ & $2.24 E+03$ & 1 & $5.34 E+02$ & $1.74 E+03$ \\
\hline ICP.A.LO & 4.22E+03 & $3.00 E+05$ & 1 & 0.00 & $1.12 E+04$ \\
\hline ICP.A.Mg & 3. $7 \pi E+02$ & $6.36 E+03$ & 1 & 0.00 & $1.39 E+03$ \\
\hline ICP.a.mn & 6.33E+03 & $2.68 E+04$ & 1 & $4.25 \mathrm{E}+03$ & $8.41 E+03$ \\
\hline ICP.a.Mg & $3.69 \varepsilon+04$ & $1.56 E+06$ & 1 & $2.10 \mathrm{E}+04$ & $5.27 E+04$ \\
\hline ICP.e.Mi & $1.32 E+02$ & $5.12 E+02$ & 1 & 0.00 & $4.19 E+02$ \\
\hline ICP.A.P & $1.03 E+04$ & $1.21 E+05$ & 1 & $5.90 \mathrm{E}+03$ & $1.47 E+04$ \\
\hline$I C P \cdot A \cdot P b$ & $3.47 E+02$ & $2.64 E+04$ & 1 & 0.00 & $2.41 E+03$ \\
\hline ICP.a.s & $1.21 E+03$ & $1.06 E+03$ & 1 & 8.00E+02 & $1.63 E+03$ \\
\hline ICP.a.sbo & $3.14 E+01$ & $1.65 E+01$ & 1 & 0.00 & $8.30 E+01$ \\
\hline ICP.a.si & $4.69 E+02$ & $9.17 E+02$ & 1 & $8.40 E+01$ & $8.54 E+02$ \\
\hline ICP.a.sr & $3.00 E+02$ & $3.75 E+02$ & 1 & $5.39 E+01$ & $5.46 E+02$ \\
\hline ICP.8.Ti & $1.95 E+01$ & $1.39 E+02$ & 1 & 0.00 & $1.69 E+02$ \\
\hline ICP.B.V & $1.45 E+01$ & $6.58 E+00$ & 1 & 0.00 & $4.71 E+01$ \\
\hline $1 C P-a \cdot 2 n$ & $6.50 E+01$ & $6.46 \mathrm{E}+02$ & 1 & 0.00 & $3.88 E+02$ \\
\hline ICP. P.Ag & $1.28 E+02$ & $8.05 E+03$ & 1 & 0.00 & $1.27 \mathrm{E}+03$ \\
\hline$|C P . f . A|$ & $5.70 E+02$ & $9.70 E+03$ & 1 & 0.00 & $1.82 E+03$ \\
\hline ICP. $f .8 \mathrm{~B}$ & $6.46 E+01$ & $2.45 E+01$ & 1 & $1.73 E+00$ & $1.28 E+02$ \\
\hline ICP.f.Bi & $2.36 E+04$ & $9.08 E+06$ & 1 & 0.00 & $6.18 E+04$ \\
\hline ICP.f.Cat & $2.42 E+03$ & $8.2 \pi E+04$ & 1 & 0.00 & $6.07 E+03$ \\
\hline ICP.f.Cd+ & $8.12 E+00$ & $1.76 E+00$ & 1 & 0.00 & $2.50 E+01$ \\
\hline ICP.f.Co: & $1.15 E+01$ & $1.16 E+00$ & 1 & 0.00 & $2.52 E+01$ \\
\hline ICP.f.Cr & $1.80 E+03$ & $1.56 E+03$ & 1 & $1.30 E+03$ & $2.30 E+03$ \\
\hline
\end{tabular}


WHC-SD-WH-TI-650, Rev. 0

Table 3-1. Concentration Estimate Statistics (Units $\mu \mathrm{g} / \mathrm{g}$ Except Radionuclides $\mu \mathrm{Ci} / \mathrm{g}$ ). (sheet 2 of 3 )

\begin{tabular}{|c|c|c|c|c|c|}
\hline Analyte & $\bar{y}$ & $g^{2}(\bar{y})$ & $d f$ & $95 \times 4$ & $95 \%$ UL \\
\hline ICP.f.Cut & $2.3 \%+01$ & $3.56 E+01$ & 1 & 0.00 & $1.05 E+02$ \\
\hline ICP.f.Fe & $1.80 E+06$ & $4.05 E+06$ & 1 & 0.00 & $4.36 E+04$ \\
\hline ICP,f.Le & $4.11 E+03$ & $3.08 E+05$ & 1 & 0.00 & $1.12 E+04$ \\
\hline ICP.f.Mr & $3.55 E+02$ & $7.31 E+03$ & 1 & 0.00 & $1.44 E+03$ \\
\hline ICP.f. in & $6.28 E+03$ & $1.88 E+04$ & 1 & 4.54E+03 & $8.02 E+03$ \\
\hline ICP.f.Me & $3.70 E+04$ & $6.00 E+06$ & 1 & $5.82 E+03$ & $6.81 E+04$ \\
\hline ICP.f.Mi & 8.14E+03 & $6.41 E+06$ & 1 & 0.00 & $4.03 E+04$ \\
\hline ICP.f.P & $1.04 E+04$ & $8.42 E+05$ & 1 & 0.00 & $2.21 E+04$ \\
\hline ICP.f.Pbt & $3.65 E+02$ & $9.38 E+03$ & 1 & 0.00 & $1.60 E+03$ \\
\hline ICP.f.S & $1.23 E+03$ & $1.13 E+04$ & 1 & 0.00 & $2.58 E+03$ \\
\hline ICP.f.Si & $5.67 E+03$ & $5.41 E+04$ & 1 & $2.71 E+03$ & $8.62 E+03$ \\
\hline ICP.f.Sr & $2.98 E+02$ & $6.24 E+01$ & 1 & $1.97 \mathrm{E}+02$ & $3.98 E+02$ \\
\hline ICP.f.Ti & $4.795+01$ & $6.09 E+02$ & 1 & 0.00 & $3.62 E+02$ \\
\hline ICP.t.Vt & $1.4 \pi E+01$ & 8.32E-01 & 1 & $3.06 E+00$ & $2.62 E+01$ \\
\hline $1 C P .+.2 \mathrm{nt}$ & $1.06 E+02$ & $7.17 E+00$ & 1 & $7.22 E+09$ & $1.40 E+02$ \\
\hline ICP.W.Alo & $1.09 E+01$ & $5.75 E+00$ & 1 & 0.00 & 4.14E+01 \\
\hline$I C P \cdot W . B t$ & $4.07 \mathrm{E}+00$ & $6.7 \pi-01$ & 1 & 0.00 & $1.45 E+01$ \\
\hline ICP.H.Bi & $2.02 E+02$ & $2.40 E+03$ & 1 & 0.00 & $8.24 E+02$ \\
\hline ICP.W.Cat & $6.16 E+01$ & $3.32 E+01$ & 1 & 0.00 & $1.35 E+02$ \\
\hline ICP.W.Cr & $2.18 E+02$ & $2.45 E+01$ & 1 & $1.55 E+02$ & $2.81 E+02$ \\
\hline ICP.W.Fe & $1.28 E+02$ & $3.11 E+02$ & 1 & 0.00 & $3.52 E+02$ \\
\hline ICP.W.K & $7.19 \mathrm{E}+02$ & $1.56 E+03$ & 1 & $2.21 E+02$ & $1.22 E+03$ \\
\hline ICP.H.LEt & 1. 10E+01 & $1.42 E+01$ & 1 & 0.00 & $5.89 E+01$ \\
\hline ICP.H.Mgt & $3.64 E+00$ & $5.45 E-02$ & 1 & 6.75E-01 & $6.61 E+00$ \\
\hline ICP.M.Mn & $2.47 E+01$ & $2.36 E+01$ & 1 & 0.00 & $8.65 E+01$ \\
\hline ICP.H.Ma & $3.30 E+04$ & $2.44 E+06$ & 1 & $1.31 E+04$ & $5.28 E+04$ \\
\hline ICP.M.P & $5.68 E+03$ & $3.26 E+04$ & 1 & $3.39 E+03$ & $7.97 \mathrm{E}+03$ \\
\hline ICP.W.S & $1.15 E+03$ & $2.38 E+03$ & 1 & $5.29 E+02$ & $1.7 \pi E+03$ \\
\hline ICP.H.Si & $5.72 E+02$ & $5.35 E+03$ & 1 & 0.00 & $1.50 E+03$ \\
\hline ICP.w.Srt & 1.96E+00 & 8.65E-02 & 1 & 0.00 & $5.70 E+00$ \\
\hline 1C.w.Cl & $4.50 E+02$ & $1.11 E+03$ & 1 & $2.56 E+01$ & $8.74 E+02$ \\
\hline IC.W.F & $2.30 E+03$ & $6.46 E+05$ & 1 & 0.00 & $1.25 E+04$ \\
\hline IC.M.NO3 & $4.12 E+04$ & $7.77 E+06$ & 1 & $5.82 E+03$ & $7.67 E+04$ \\
\hline IC.W.PO4 & $1.55 E+04$ & $1.53 E+06$ & 1 & 0.00 & $3.13 E+04$ \\
\hline IC.W.SO4 & $3.54 E+03$ & $2.85 E+04$ & 1 & $1.60 E+03$ & $5.69 E+03$ \\
\hline
\end{tabular}


WHC-EP-0806

WHC-SD-MMI-TI-650, Rev. 0

Table 3-1. Concentration Estimate Statistics (Units $\mu \mathrm{g} / \mathrm{g}$ Except Radionucl ides $\mu \mathrm{Ci} / \mathrm{g}$ ). (sheet 3 of 3 )

\begin{tabular}{|c|c|c|c|c|c|}
\hline Analyte & $y$ & $\partial^{2}(\bar{y})$ & $d f$ & $95 \times \mathrm{LL}$ & $95 \%$ UL \\
\hline GEA.Am-241 & 4.24E-02 & $2.61 E-06$ & 1 & $2.19 E-02$ & 6.29E-02 \\
\hline CEA.Cs-137 & $1.66 E-01$ & $3.35 E-03$ & 1 & 0.00 & $9.02 E-01$ \\
\hline Gross.elphe & $3.73 E-01$ & $1.96 E-04$ & 1 & 1.95E-01 & 5.51E-01 \\
\hline Gross.bets & $1.51 E+01$ & $3.48 E+01$ & 1 & 0.00 & $9.00 E+01$ \\
\hline TGA.X.h2O & $7.65 E+01$ & $2.23 E+01$ & 1 & $1.64 E+01$ & $1.37 E+02$ \\
\hline NIII-261* & $4.26 E-02$ & $6.65 E-25$ & 1 & 4.26E-02 & $4.26 E-02$ \\
\hline Hgt & $1.43 E+00$ & $1.53 E-01$ & 1 & 0.00 & $6.40 E+00$ \\
\hline MO2.H.Spec & $7.93 E+02$ & $8.76 E+03$ & 1 & 0.00 & $1.98 E+03$ \\
\hline Percent.H2O & $7.60 \mathrm{E}+01$ & 5.81E-01 & 1 & $6.63 E+01$ & $8.57 E+01$ \\
\hline Pu-239/40 & $1.39 E-01$ & $9.19 \varepsilon-06$ & 1 & $1.00 E-01$ & $1.77 \mathrm{E}-01$ \\
\hline$s r-90$ & 5.49E+00 & $3.53 E+00$ & 1 & 0.00 & $2.93 E+01$ \\
\hline TOC $t$ & $3.12 E+03$ & $3.83 E+05$ & 1 & 0.00 & $1.10 E+04$ \\
\hline Te- 99. & $7.92 E-03$ & $8.90 E-06$ & 1 & 0.00 & $4.58 E-02$ \\
\hline$u_{*}$ & $2.79 E+03$ & $2.01 E+05$ & 1 & 0.00 & $8.50 E+03$ \\
\hline PH & $9.98 E+00$ & $7.79 E-03$ & 1 & $8.86 E+00$ & $1.11 E+01$ \\
\hline
\end{tabular}

t: Analytes with a portion of the data betow 10 times the DL. 


\subsection{COMPARISON OF THE VARIANCE COMPONENT ESTIMATES}

Using the hierarchical structure of the core composite data, estimates of the between core spatial variability $\left(\sigma^{2}(S)\right)$, the compositing variability $\left(\sigma^{2}(C)\right)$ and the analytical measurement variability $\left(\sigma^{2}(A)\right)$ can be obtained. The spatial variance is a measure of the variability between cores. The compositing variance measures the variability between composite samples within the same core. The analytical measurement variance includes, among other things, the sample handling error and the chemical analysis error. This variance is a measure of the difference between the analytical results from the primary and duplicate samples.

The estimate of the variance of the mean is a linear function of the spatial, compositing and analytical measurement variances. To help evaluate the magnitude of these three variance components, estimates of each variance component are given in Table 4-1.

\subsection{STATISTICAL METHODS}

Estimates of the spatial variance $\left(\hat{\sigma}^{2}(S)\right)$, compositing variance $\left(\hat{\sigma}^{2}(C)\right)$ and analytical measurement variance $\left(\hat{\sigma}^{2}(A)\right)$, were obtained for each analyte using Restricted Maximum Likelihood Estimation (REML) methods. Restricted maximum likel ihood estimation is discussed by Harville (1977).

To test the significance of the variance components, an analysis of variance (ANOVA) was calculated using the hierarchical statistical model described in Appendix $C$. The mean square error terms in the ANOVA tables were used to perform F-tests on the spatial variability and F-tests on the composite variability. These tests determine whether or not $\sigma^{2}(S)$ and $\sigma^{2}(C)$ are significantly different than zero. The $p$-values given in Table 4-1 were derived from the resuits of these tests.

\subsection{STATISTICAL RESULTS}

The REML estimates of each component of variability along with the p-values (significance level) from the F-tests are given in Table 4-1. A p-value less than 0.05 indicates that $\sigma^{2}(S)$ or $\sigma^{2}(C)$ is significantiy different than zero at the 0.05 level.

The p-values from the tests on $\sigma^{2}(S)$ were less than 0.05 for 39 out of the 85 analytes in T111. This indicates that the differences between the two cores were statistically significant for these 39 cases.

The p-values from the tests on $\sigma^{2}(c)$ were less than 0.05 for 39 out of the 85 analytes in Till. This indicates that, relative to the analytical error, differences between composite samples were significantly different than zero in 39 cases. This means, for these 39 analytes, the two composite samples were statistically different from each other. Conversely, for 46 out of 85 cases, differences between composite samples were not statistically significant. 
Table 4-1. Variance Component Estimates. (sheet 1 of 3)

\begin{tabular}{|c|c|c|c|c|c|}
\hline Analye & $g^{2}(s)$ & $\begin{array}{l}\text { Test: } \\
\sigma^{2}(s)=0 \\
\text { p-value }\end{array}$ & $\partial^{2}(c)$ & $\begin{array}{l}\text { Test: } \\
\sigma^{2}(c)=0 \\
\text { p-value }\end{array}$ & $g^{2}(A)$ \\
\hline ICP.A.Ag & $1.56 E+06$ & 0.001 & $1.94 E+02$ & 0.000 & $3.16 E+00$ \\
\hline ICP_A.AI & $1.89 E+04$ & 0.055 & $4.79 E+03$ & 0.000 & $1.06 E+01$ \\
\hline ICP.A.8 & $1.25 E+01$ & 0.093 & $9.28 E-01$ & 0.387 & $8.59 E+00$ \\
\hline ICP.A.Be & $6.91 E+01$ & 0.263 & $1.20 E+02$ & 0.000 & $3.54 E-01$ \\
\hline ICP.B.Bi & $1.2 \pi E+07$ & 0.000 & $6.25 E+03$ & 0.360 & $3.75 E+04$ \\
\hline ICP.A.Ca & 4. 10E+05 & 0.010 & $2.17 E+06$ & 0.074 & $9.95 \mathrm{E}+03$ \\
\hline ICP.A.CAt & $5.96 E+00$ & 0.004 & $1.90 \mathrm{E}-01$ & 0.039 & 5.34E-02 \\
\hline ICP.a.Cee & $1.69 \mathrm{E}+01$ & 0.064 & $9.66 \mathrm{E}-01$ & 0.380 & $7.87 E+00$ \\
\hline$I C P \cdot A \cdot C O t$ & $8.92 E-01$ & 0.376 & 8.08E-01 & 0.389 & $7.84 E+00$ \\
\hline ICP.e.Cr & $3.17 E+04$ & 0.007 & $1.36 E+03$ & 0.081 & $0.75 E+02$ \\
\hline ICP.A.Cu & $3.39 E+02$ & 0.290 & $1.6 \pi E+02$ & 0.369 & $1.14 E+03$ \\
\hline ICP.e.Fe & $2.33 E+06$ & 0.013 & $1.55 E+05$ & 0.063 & $6.25 E+04$ \\
\hline ICP.e.K & $2.45 E-24$ & 0.911 & $8.86 E+03$ & 0.000 & $1.75 E+02$ \\
\hline ICP_e.La & $5.91 E+05$ & 0.003 & $1.63 E+04$ & 0.019 & $2.88 E+03$ \\
\hline ICP.A.Mg & $1.25 E+04$ & 0.005 & $5.18 E+02$ & 0.001 & $1.58 E+01$ \\
\hline ICP.e.Mn & $2.97 \mathrm{E}+04$ & 0.254 & $4.29 E+04$ & 0.030 & $1.00 E+04$ \\
\hline ICP.A.Ma & $2.76 E+06$ & 0.057 & $6.73 E+05$ & 0.016 & $1.05 E+05$ \\
\hline ICP.A.Mi & $1.02 E+03$ & 0.000 & $0.13 E+00$ & 0.091 & $3.38 E+00$ \\
\hline ICP.A.P & $2.37 E-22$ & 0.608 & 4.7TE+05 & 0.000 & $1.25 E+04$ \\
\hline ICP.A.Pb & $5.20 E+04$ & 0.003 & $1.41 E+03$ & 0.000 & $1.91 E+01$ \\
\hline ICP.A.S & $1.11 E+03$ & 0.268 & $1.94 E+03$ & 0.003 & $1.25 E+02$ \\
\hline ICP. O.Sbo & $1.11 E-20$ & 0.739 & $1.44 E-14$ & 0.578 & $1.32 E+02$ \\
\hline ICP.a.si & $2.57 \mathrm{E}-31$ & 0.946 & $7.61 E-14$ & 0.418 & $7.34 \mathrm{E}+03$ \\
\hline ICP.a.Sr & $6.38 E+02$ & 0.079 & $2.18 E+02$ & 0.004 & $1.54 E+01$ \\
\hline ICP.A.Ti & $2.75 E+02$ & 0.001 & $4.69 E+00$ & 0.000 & 7. $83 E-02$ \\
\hline ICP.A.V & $1.83 E+00$ & 0.423 & $2.25 E+01$ & 0.000 & $2.30 E-01$ \\
\hline ICP.E. $2 n$ & $1.22 E+03$ & 0.021 & $1.35 E+02$ & 0.008 & $1.42 E+01$ \\
\hline ICP.f.Ag & $1.61 E+04$ & 0.000 & $6.23 E+00$ & 0.295 & $1.83 E+01$ \\
\hline ICP.f.AI & $1.90 E+04$ & 0.005 & $6.78 E+02$ & 0.030 & $1.57 E+02$ \\
\hline ICP.f.8a & $3.99 E+01$ & 0.102 & $1.71 E+01$ & 0.012 & $2.19 E+\infty 00$ \\
\hline ICP.f.Bi & $1.81 E+07$ & 0.001 & $2.88 E+04$ & 0.392 & $2.94 E+05$ \\
\hline ICP.f.Cat & $1.51 E+05$ & 0.008 & $2.0 \pi-19$ & 0.804 & $5.86 E+04$ \\
\hline$I C P \cdot f \cdot C d_{t}$ & $2.17 \pi+00$ & 0.126 & $1.21 E-20$ & 0.649 & $5.38 E+00$ \\
\hline ICP.f.COP & $1.44 E+00$ & 0.078 & $1.01 E-29$ & 0.755 & $3.48 E+00$ \\
\hline ICP.f.Cr & $3.72 E-15$ & 0.994 & $5.63 \mathrm{E}+03$ & 0.013 & $1.21 E+03$ \\
\hline
\end{tabular}

-: Analytes with portion of the date below 3 times the DL.

*: Analytes with a portion of the data belou 10 times the DL. 
Table 4-1. Variance Component Estimates. (sheet 2 of 3)

\begin{tabular}{|c|c|c|c|c|c|}
\hline Analyte & $g^{2}(s)$ & $\begin{array}{l}\text { Test: } \\
\sigma^{2}(s)=0 \\
p \text {-value }\end{array}$ & $a^{2}(c)$ & $\begin{array}{l}\text { Test: } \\
\sigma^{2}(c)=0 \\
p \text {-value }\end{array}$ & $g^{2}(A)$ \\
\hline ICP.f.Cut & $6.97 E+01$ & 0.005 & $2.00 E+00$ & 0.119 & $1.43 E+00$ \\
\hline ICP.f.Fe & $8.00 E+06$ & 0.003 & $1.68 E+05$ & 0.079 & 8. $13 E+04$ \\
\hline ICP.f.LO & 5.96E+05 & 0.010 & $3.82 E+04$ & 0.012 & $4.98 E+03$ \\
\hline ICP.t.Mg & $1.46 E+04$ & 0.000 & $5.15 E-44$ & 0.913 & $1.60 E+02$ \\
\hline 1CP.f.Mn & $1.66 \mathrm{E}-11$ & 0.553 & $7.02 E+04$ & 0.019 & $9.70 E+03$ \\
\hline ICP.f.Ne & $1.17 E+07$ & 0.007 & $5.43 E+05$ & 0.044 & $1.65 E+05$ \\
\hline ICP.f.Mi & $1.17 E+07$ & 0.033 & $4.18 E-12$ & 0.498 & $4.39 E+06$ \\
\hline ICP.f.P & $1.57 E+06$ & 0.028 & $1.95 E+05$ & 0.069 & $6.45 E+04$ \\
\hline ICP.f.PbE & $1.85 E+04$ & 0.003 & $4.35 E+02$ & 0.030 & $1.02 E+02$ \\
\hline ICP.f.S & $2.15 E+04$ & 0.017 & $2.00 E+03$ & 0.008 & 2. $13 E+02$ \\
\hline ICP.f.Si & $1.06 E+05$ & 0.005 & $1.00 E+03$ & 0.369 & $6.83 E+03$ \\
\hline ICP.t.Sr & $6.12 E-16$ & 0.661 & $1.15 E+02$ & 0.222 & $2.69 E+02$ \\
\hline ICP.f.Ti & $1.22 E+03$ & 0.000 & $2.66 \mathrm{E}-01$ & 0.331 & $1.12 E+00$ \\
\hline ICP.f.Vt & $5.86 E-19$ & 0.905 & $2.17 E+00$ & 0.107 & $2.31 E+00$ \\
\hline ICP.f. $\mathrm{nt}$ & $5.69 E-23$ & 0.440 & $1.10 \mathrm{E}-22$ & 0.839 & $5.74 E+01$ \\
\hline ICP.W.Ale & $7.35 E+00$ & 0.208 & $6.93 E+00$ & 0.061 & $2.72 E+00$ \\
\hline ICP.H.Bt & $1.14 E+00$ & 0.082 & $3.99 E-01$ & 0.008 & $3.99 \mathrm{E}-02$ \\
\hline ICP.M.Bi & $3.90 E+03$ & 0.102 & $1.30 E+03$ & 0.123 & $9.66 E+02$ \\
\hline ICP.H.Cak & $1.86 E-11$ & 0.164 & $1.69 E-22$ & 0.862 & $2.66 E+02$ \\
\hline ICP.W.Cr & $5.66 E-20$ & 0.979 & 9.52E+01 & 0.001 & $5.62 E+00$ \\
\hline ICP.W.Fe & $6.16 E+01$ & 0.436 & $9.05 E+02$ & 0.077 & $4.29 E+02$ \\
\hline ICP.W.K & $2.28 E+03$ & 0.148 & $1.57 \mathrm{E}+03$ & 0.001 & 4.73E+01 \\
\hline ICP.H.LOE & $2.71 E+01$ & 0.015 & $1.34 \mathrm{E}+00$ & 0.226 & $2.23 E+00$ \\
\hline ICP.H.Mgt & $3.04 E-21$ & 0.597 & 1.61E-01 & 0.098 & $1.14 E-01$ \\
\hline ICP.W.Mn & $2.51 E+01$ & 0.266 & $3.19 E+01$ & 0.130 & $2.51 E+01$ \\
\hline ICP.W.Na & $4.53 E+06$ & 0.030 & $6.84 E+05$ & 0.002 & $2.88 E+04$ \\
\hline ICP.H.P & $3.98 E+04$ & 0.222 & $3.94 E+04$ & 0.089 & $2.13 E+04$ \\
\hline ICP.H.S & $3.95 E+03$ & 0.099 & $1.50 E+03$ & 0.014 & 2.13E+02 \\
\hline ICP.W.Si & $8.53 E+03$ & 0.113 & $1.98 E+03$ & 0.272 & $4.72 E+03$ \\
\hline ICP.W.SrA & $6.35 E-02$ & 0.340 & $1.83 E-01$ & 0.061 & $7.19 E-02$ \\
\hline IC.W.Cl & $1.99 E+03$ & 0.043 & $1.15 E-10$ & 0.509 & $9.66 \mathrm{E}+02$ \\
\hline IC.W.F & $1.28 E+06$ & 0.001 & $1.37 E+04$ & 0.102 & $8.44 E+03$ \\
\hline IC.M.NOZ & $1.42 E+07$ & 0.038 & $2.46 E+06$ & 0.013 & $3.44 E+05$ \\
\hline IC.W.PO4 & $2.59 E+06$ & 0.082 & $8.54 E+05$ & 0.030 & $1.99 E+05$ \\
\hline
\end{tabular}

-: Analytes with o portion of the data below 3 times the DL.

*: Analytes with a portion of the data below 10 times the oL. 
WHC-SD-WM-TI-650, ReV. O

Table 4-1. Variance Component Estimates. (sheet 3 of 3)

\begin{tabular}{|c|c|c|c|c|c|}
\hline Analyte & $\alpha^{2}(s)$ & $\begin{array}{l}\text { Test: } \\
\sigma^{2}(s)=0 \\
p \text {-value }\end{array}$ & $\partial^{2}(c)$ & $\begin{array}{l}\text { Pest: } \\
\sigma^{2}(c)=0 \\
\text { p-velue }\end{array}$ & $\partial^{2}(A)$ \\
\hline IC.W.SOH & $5.27 E+04$ & 0.032 & $7.04 E+03$ & 0.071 & $3.14 E+03$ \\
\hline GEA.Am-249 & $2.99 E-32$ & 0.786 & 8.13E-06 & 0.062 & 4.59E-06 \\
\hline GEA_Cs-137 & $6.61 E-03$ & 0.003 & $1.87 E-04$ & 0.000 & $1.88 E-06$ \\
\hline Grossialpho & $3.42 E-0.4$ & 0.065 & $7.74 E-05$ & 0.098 & 4.58E-05 \\
\hline Gross.beta & $6.93 E+01$ & 0.000 & $3.14 E-01$ & 0.026 & $6.62 E-02$ \\
\hline TGA.X.H2O & $3.17 \varepsilon+01$ & 0.008 & $3.78 E-33$ & 0.935 & $5.18 \varepsilon+01$ \\
\hline$A n-241 t$ & $6.65 E-25$ & 0.976 & $7.41 E-06$ & 0.173 & $1.66 E-05$ \\
\hline Hot & $1.53 E-01$ & 0.022 & $1.36 E-02$ & 0.115 & $9.38 E-03$ \\
\hline NOZ.W.Spee & $1.92 E-16$ & 0.789 & $3.46 E+04$ & 0.000 & $9.50 E+02$ \\
\hline Percent.H2O & 8.99E-01 & 0.128 & $2.55 E-01$ & 0.259 & $5.46 E-01$ \\
\hline Pu-239/40 & $2.49 E-28$ & 0.736 & 2.01E-05 & 0.179 & $3.33 E-05$ \\
\hline$s r-90$ & $7.04 E+00$ & 0.000 & $1.79 E-02$ & 0.209 & 2.61E-02 \\
\hline TOC. & $6.10 E+05$ & 0.113 & $2.98 E+05$ & 0.006 & $2.72 E+04$ \\
\hline IC- 99. & $1.76 E-05$ & 0.001 & $2.63 E-07$ & 0.027 & $5.75 E-08$ \\
\hline$u_{ \pm}$ & $6.24 E-06$ & 0.839 & $7.91 E+05$ & 0.001 & $2.99 E+04$ \\
\hline gH & $7.11 E-28$ & 0.601 & $3.06 E-02$ & 0.001 & $1.19 E-03$ \\
\hline
\end{tabular}

*: Analytes with a portion of the data below 10 times the OL. 
WHC-EP-0805

WHC-SD-WH-TI-650, Rev. 0

\subsection{REFERENCES}

Bel7, K. E., 1993, Tank Waste Remediation Systen Tank Waste Characterization Plan, WHC-SD-WM-PLN-047, Rev. 1, Westinghouse Hanford Company, Richland, Washington.

Harville, D. A., 1977, Maximum Likelihood Approaches to Variance Component Estimation and to Related Problems," Journal of the American Statistical Association, pp. 320-340.

Kocher, K. L., Single Shell Tank Waste Characterization, 241-T-111, Cores 31 and 33, WHC-SD-WM-DP-058, Rev. 0, Westinghouse Hanford Company, Richl and, Washington.

McKinney, S. M., Single Shell Tank Waste Characterization, 241-T-111, Cores 31 and 33, WHC-SD-WM-DP-024, Rev. 0, Westinghouse Hanford Company, Richland, Washington.

Snedecor, G. W. and W. G. Cochran, 1980, Statistical Methods, Seventh Edition, Iowa State University Press, Ames, Iowa. 
WHC-EP-0806

WHC-SD-WH-TI-650, Rev. 0

This page was intentionally left blank. 
WHC-SD-WM-TI-650, ReV. 0

APPENDIX A

CORE COMPOSITE DATA

A-1

B-17 
WHC-EP-0806

WHC-SD-WM-TI-650, Rev. O

This page was intentionally left blank. 
Table A-1. Core Composite Data (Units $\mu \mathrm{g} / \mathrm{g}$ except Radionuclides $\mu \mathrm{Cl} / \mathrm{g})$. (sheet 1 of 9 )

\begin{tabular}{|c|c|c|c|c|c|c|c|c|c|}
\hline \multirow{16}{*}{$\stackrel{p}{b}$} & Analyte & $\begin{array}{l}\text { Core } 31 \\
\text { Comp. } 1 \\
\end{array}$ & Mean/DL & $\begin{array}{l}\text { Core } 31 \\
\text { Comp. } 2 \\
\end{array}$ & Rean/DL & $\begin{array}{l}\text { Core } 33 \\
\text { Comp. } 1 \\
\end{array}$ & Mean/DL & $\begin{array}{l}\text { Core } 33 \\
\text { Comp. } 2 \\
\end{array}$ & Mean/DL \\
\hline & ICP.A.Ag & $\begin{array}{l}2.02 E+02 \\
2.03 E+02 \\
\end{array}$ & $4.05 E+02$ & $\begin{array}{r}2.25 E+02 \\
2.28 E+02 \\
\end{array}$ & $4.53 E+02$ & $\begin{array}{r}4.48 E+01 \\
4.39 E+01 \\
\end{array}$ & 8.87E+01 & $\begin{array}{r}2.81 E+01 \\
3.19 E+01 \\
\end{array}$ & $6.00 E+01$ \\
\hline & ICP.A.AI & $\begin{array}{r}5.80 E+02 \\
5.88 E+02 \\
\end{array}$ & $2.43 E+02$ & $\begin{array}{r}7.03 E+02 \\
7.07 E+02 \\
\end{array}$ & $2.94 E+02$ & $\begin{array}{r}4.71 \mathrm{E}+02 \\
4.73 \mathrm{E}+02 \\
\end{array}$ & $1.97 E+02$ & $\begin{array}{r}4.05 E+02 \\
4.04 E+02 \\
\end{array}$ & $1.69 E+02$ \\
\hline & ICP.O.As & $\begin{array}{r}3.13 E+00 \\
3.17 E+00 \\
\end{array}$ & Ma & 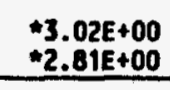 & Ma & $\begin{array}{r}3.39 E+00 \\
3.50 E+00 \\
\end{array}$ & $1.15 E+00$ & $\begin{array}{r}3.23 E+00 \\
+2.90 E+00 \\
\end{array}$ & MA \\
\hline & ICP.A.B & $\begin{array}{r}2.34 E+01 \\
3.0 B E+01 \\
\end{array}$ & $4.52 E+01$ & $\begin{array}{l}2.53 E+01 \\
2.16 E+01 \\
\end{array}$ & $3.91 E+01$ & $\begin{array}{l}2.92 E+01 \\
2.96 E+01 \\
\end{array}$ & $4.90 E+01$ & $\begin{array}{r}3.20 E+01 \\
3.23 E+01 \\
\end{array}$ & 5.36E+01 \\
\hline & ICP.A.84 & $\begin{array}{r}5.66 E+01 \\
5.75 E+01 \\
\end{array}$ & $1.90 E+02$ & $\begin{array}{l}6.53 E+01 \\
6.46 E+01 \\
\end{array}$ & $2.17 E+02$ & $\begin{array}{l}6.67 \mathrm{E}+01 \\
6.70 \mathrm{0}+01 \\
\end{array}$ & $2.23 E+02$ & $\begin{array}{l}8.67 E+01 \\
8.79 E+01 \\
\end{array}$ & $2.91 E+02$ \\
\hline & ICP.A.BE & $\begin{array}{r}* 1.04 E-01 \\
1.06 E-01 \\
\end{array}$ & MA & $\begin{array}{r}1.01 E-01 \\
* 9.30 E-02 \\
\end{array}$ & MA & $\begin{array}{r}1.13 E-01 \\
1.20 E-01 \\
\end{array}$ & $1.17 E+00$ & $\begin{array}{r}1.08 E-01 \\
+1.00 E-01 \\
\end{array}$ & MA \\
\hline & ICP.A.BI & $\begin{array}{l}2.34 E+04 \\
2.37 E+04 \\
\end{array}$ & $3.14 E+03$ & $\begin{array}{r}2.33 E+04 \\
2.32 E+04 \\
\end{array}$ & $3.10 E+03$ & $\begin{array}{l}2.84 E+04 \\
2.86 E+04 \\
\end{array}$ & 3.80E+03 & $\begin{array}{l}2.86 E+04 \\
2.02 E+04 \\
\end{array}$ & $3.79 E+03$ \\
\hline & ICP.A.CA & $\begin{array}{l}2.13 E+03 \\
2.26 E+03 \\
\end{array}$ & 4.99E+02 & $\begin{array}{r}2.36 E+03 \\
2.61 E+03 \\
\end{array}$ & $5.65 E+02$ & $\begin{array}{r}1.49 E+03 \\
1.50 E+03 \\
\end{array}$ & $3.40 E+02$ & $\begin{array}{l}1.35 E+03 \\
1.34 E+03 \\
\end{array}$ & $3.06 E+02$ \\
\hline & ICP.A.Cdk & $\begin{array}{r}7.19 E+00 \\
7.25 E+00 \\
\end{array}$ & $1.81 E+01$ & $\begin{array}{r}7.78 E+00 \\
7.94 E+00 \\
\end{array}$ & $1.97 E+01$ & $\begin{array}{r}4.09 E+00 \\
4.70 E+00 \\
\end{array}$ & $1.10 E+01$ & $\begin{array}{r}3.64 E+00 \\
3.80 E+00 \\
\end{array}$ & $9.30 E+00$ \\
\hline & ICP.A.Ceo & $\begin{array}{r}3.39 E+01 \\
3.13 E+01 \\
\end{array}$ & $3.23 E+00$ & $\begin{array}{r}2.90 E+01 \\
2.03 E+01 \\
\end{array}$ & $2.84 E+00$ & $\begin{array}{l}4.00 E+01 \\
3.57 E+01 \\
\end{array}$ & $3.75 E+00$ & $\begin{array}{l}3.28 E+01 \\
3.89 E+01 \\
\end{array}$ & $3.55 E+00$ \\
\hline & ICP.A.COH & $\begin{array}{r}3.42 E+00 \\
3.38 E+00 \\
\end{array}$ & $4.25 E+00$ & $\begin{array}{l}3.79 E+00 \\
1.17 E+01 \\
\end{array}$ & $9.68 E+00$ & $\begin{array}{l}3.15 E+00 \\
3.10 E+00 \\
\end{array}$ & $3.91 E+00$ & $\begin{array}{l}3.13 E+00 \\
2.70 E+00 \\
\end{array}$ & $3.64 E+00$ \\
\hline & ICP.A.Cr & $\begin{array}{r}1.83 E+03 \\
1.89 E+03 \\
\end{array}$ & $2.07 E+03$ & $\begin{array}{l}1.84 E+03 \\
1.84 E+03 \\
\end{array}$ & $2.04 E+03$ & $\begin{array}{r}2.05 E+03 \\
2.08 E+03 \\
\end{array}$ & $2.29 E+03$ & $\begin{array}{l}2.16 E+03 \\
2.13 E+03 \\
\end{array}$ & $2.38 E+03$ \\
\hline & ICP.A.Cu & $\begin{array}{l}2.48 E+01 \\
2.57 E+01 \\
\end{array}$ & $6.31 E+01$ & $\begin{array}{r}1.27 E+02 \\
3.17 E+01 \\
\end{array}$ & $1.98 E+02$ & $\begin{array}{l}1.64 E+01 \\
1.65 E+01 \\
\end{array}$ & $4.11 E+01$ & $\begin{array}{r}1.29 E+01 \\
1.30 E+01 \\
\end{array}$ & $3.24 E+01$ \\
\hline & ICP.A.Fe & $\begin{array}{l}1.89 E+04 \\
1.95 E+04 \\
\end{array}$ & $1.92 E+04$ & $\begin{array}{r}2.01 E+04 \\
2.00 E+04 \\
\end{array}$ & $2.01 E+04$ & $\begin{array}{l}1.74 E+04 \\
1.76 E+04 \\
\end{array}$ & $1.75 E+04$ & $\begin{array}{l}1.75 E+04 \\
1.72 E+04 \\
\end{array}$ & $1.74 E+04$ \\
\hline & ICP.A.K & $\begin{array}{l}1.08 E+03 \\
1.11 E+03 \\
\end{array}$ & $9.78 E+01$ & $\begin{array}{r}1.22 E+03 \\
1.20 E+03 \\
\end{array}$ & $1.08 E+02$ & $\begin{array}{r}1.21 E+03 \\
1.22 E+03 \\
\end{array}$ & $1.08 E+02$ & $\begin{array}{r}1.02 E+03 \\
1.02 E+03 \\
\end{array}$ & $9.11 E+01$ \\
\hline
\end{tabular}

Analytes vilth $\mathrm{DL}$ or less than 5 percent above the $\mathrm{DL}$.

- Analytes with a portion of the data below 10 times the Di. 
Table A-1. Core Composite Data (Units $\mu \mathrm{g} / \mathrm{g}$ except Radionuclides $\mu \mathrm{Cl} / \mathrm{g}$ ). (sheet 2 of 9 )

\begin{tabular}{|c|c|c|c|c|c|c|c|c|}
\hline Analyte & $\begin{array}{l}\text { Core } 31 \\
\text { Comp. } 1 \\
\end{array}$ & Mean/DL & $\begin{array}{l}\text { Core } 31 \\
\text { Comp. } 2 \\
\end{array}$ & Mean/DL & $\begin{array}{l}\text { Core } 33 \\
\text { comp. } 1 \\
\end{array}$ & Mean/DL & $\begin{array}{l}\text { Core } 33 \\
\text { Comp. } 2 \\
\end{array}$ & Mean/DL \\
\hline ICP.S.LA & $\begin{array}{r}3.66 E+03 \\
3.78 E+03 \\
\end{array}$ & $2.66 E+03$ & $\begin{array}{r}3.64 E+03 \\
3.59 E+03 \\
\end{array}$ & $2.58 E+03$ & $\begin{array}{r}4.61 E+03 \\
4.67 E+03 \\
\end{array}$ & $3.31 E+03$ & $\begin{array}{r}4.91 E+03 \\
4.86 E+03 \\
\end{array}$ & $3.49 E+03$ \\
\hline ICP.A.Mg & $\begin{array}{r}4.32 E+02 \\
4.38 E+02 \\
\end{array}$ & $1.45 E+03$ & $\begin{array}{r}4.75 E+02 \\
4.82 E+02 \\
\end{array}$ & $1.60 E+03$ & $\begin{array}{r}3.02 E+02 \\
3.07 E+02 \\
\end{array}$ & $1.02 E+03$ & $\begin{array}{r}2.88 E+02 \\
2.92 E+02 \\
\end{array}$ & $9.67 E+02$ \\
\hline ICP.A.Mn & $\begin{array}{l}6.07 E+03 \\
6.31 E+03 \\
\end{array}$ & $3.10 E+04$ & $\begin{array}{l}6.14 E+03 \\
6.14 E+03 \\
\end{array}$ & $3.07 E+04$ & $\begin{array}{l}6.65 E+03 \\
6.77 z+03 \\
\end{array}$ & $3.36 E+04$ & $\begin{array}{l}6.32 E+03 \\
6.23 E+03 \\
\end{array}$ & $3.14 E+04$ \\
\hline ICP.A.Ma & $\begin{array}{r}3.71 E+04 \\
3.80 E+04 \\
\end{array}$ & $1.21 E+04$ & $\begin{array}{r}3.87 E+04 \\
3.86 E+04 \\
\end{array}$ & $1.25 E+04$ & $\begin{array}{r}3.49 E+04 \\
3.50 E+04 \\
\end{array}$ & $1.13 E+04$ & $\begin{array}{r}3.63 E+04 \\
3.62 E+04 \\
\end{array}$ & $1.17 E+04$ \\
\hline ICP.A.NI & $\begin{array}{r}1.49 E+02 \\
1.54 E+02 \\
\end{array}$ & 8.91E+01 & $\begin{array}{l}1.57 E+02 \\
1.57 E+02 \\
\end{array}$ & $9.24 E+01$ & $\begin{array}{l}1.09 E+02 \\
1.10 E+02 \\
\end{array}$ & $6.44 E+01$ & $\begin{array}{r}1.09 E+02 \\
1.08 E+02 \\
\end{array}$ & $6.38 E+01$ \\
\hline ICP.A.P & $\begin{array}{r}1.02 E+04 \\
1.00 E+04 \\
\end{array}$ & $1.74 E+03$ & $\begin{array}{l}9.94 E+03 \\
9.98 E+03 \\
\end{array}$ & $1.72 E+03$ & $\begin{array}{l}9.97 E+03 \\
9.75 E+03 \\
\end{array}$ & 1. $70 E+03$ & $\begin{array}{r}1.13 E+04 \\
1.14 E+04 \\
\end{array}$ & $1.96 E+03$ \\
\hline ICP.A.Pb & $\begin{array}{r}4.69 E+02 \\
4.81 E+02 \\
\end{array}$ & $7.66 E+01$ & $\begin{array}{r}5.42 E+02 \\
5.44 E+02 \\
\end{array}$ & $8.76 E+01$ & $\begin{array}{l}2.00 E+02 \\
2.01 E+02 \\
\end{array}$ & $3.23 E+01$ & $\begin{array}{r}1.67 E+02 \\
1.69 E+02 \\
\end{array}$ & $2.71 E+01$ \\
\hline ICP.A.S & $\begin{array}{r}1.21 E+03 \\
1.24 E+03 \\
\end{array}$ & $4.54 E+02$ & $\begin{array}{r}1.26 E+03 \\
1.2 \pi E+03 \\
\end{array}$ & $4.69 E+02$ & $\begin{array}{l}1.14 E+03 \\
1.14 E+03 \\
\end{array}$ & $4.22 E+02$ & $\begin{array}{l}1.22 E+03 \\
1.22 E+03 \\
\end{array}$ & $4.52 E+02$ \\
\hline ICP.A.Sb• & $\begin{array}{r}3.90 E+01 \\
2.19 E+01 \\
\end{array}$ & $1.72 E+00$ & $\begin{array}{r}3.61 E+01 \\
3.69 E+01 \\
\end{array}$ & $2.06 E+00$ & $\begin{array}{l}2.00 E+01 \\
5.18 E+01 \\
\end{array}$ & $2.03 E+00$ & $\begin{array}{r}1.91 E+01 \\
2.61 E+01 \\
\end{array}$ & $1.28 E+00$ \\
\hline ICP.A.Se & $\begin{array}{r}7.92 E+00 \\
8.04 E+00 \\
\end{array}$ & $M A$ & $\begin{array}{r}7.66 E+00 \\
7.13 E+00 \\
\end{array}$ & $\mathrm{MA}$ & $\begin{array}{l}8.60 E+00 \\
1.20 E+01 \\
\end{array}$ & $1.36 E+00$ & $\begin{array}{r}8.18 E+00 \\
-7.40 E+00 \\
\end{array}$ & mi \\
\hline ICP.s.sI & $\begin{array}{r}5.29 E+02 \\
4.36 E+02 \\
\end{array}$ & $3.71 E+02$ & $\begin{array}{r}4.18 E+02 \\
5.24 E+02 \\
\end{array}$ & $3.62 E+02$ & $\begin{array}{r}5.75 E+02 \\
4.80 E+02 \\
\end{array}$ & $4.06 E+02$ & $\begin{array}{r}4.90 E+02 \\
2.98 E+02 \\
\end{array}$ & $3.03 E+02$ \\
\hline ICP.A.Sn & $\begin{array}{r}4.28 E+00 \\
4.13 E+00 \\
\end{array}$ & $2.63 E+00$ & $\begin{array}{r}1.74 E+00 \\
3.13 E+00 \\
\end{array}$ & $1.52 E+00$ & $\begin{array}{r}1.81 E+00 \\
1.80 E+00 \\
\end{array}$ & $1.13 E+00$ & $\begin{array}{r}1.72 E+00 \\
+1.50 E+00 \\
\end{array}$ & MA \\
\hline ICP.A.sr & $\begin{array}{r}2.78 E+02 \\
2.85 E+02 \\
\end{array}$ & $9.38 E+02$ & $\begin{array}{l}2.80 E+02 \\
2.80 E+02 \\
\end{array}$ & $9.33 E+02$ & $\begin{array}{r}3.01 E+02 \\
3.08 E+02 \\
\end{array}$ & $1.02 E+03$ & $\begin{array}{r}3.37 E+02 \\
3.32 E+02 \\
\end{array}$ & $1.12 E+03$ \\
\hline ICP.A.TI & $\begin{array}{r}2.96 E+01 \\
2.93 E+01 \\
\end{array}$ & $7.36 E+01$ & $\begin{array}{r}3.34 E+01 \\
3.27 E+01 \\
\end{array}$ & $8.26 E+01$ & $\begin{array}{r}9.00 E+00 \\
8.80 E+00 \\
\end{array}$ & $2.23 E+01$ & $\begin{array}{r}6.42 E+00 \\
6.50 E+00 \\
\end{array}$ & $1.62 E+01$ \\
\hline ICP.Q.V & $\begin{array}{r}1.23 E+01 \\
1.31 E+01 \\
\end{array}$ & $2.54 E+01$ & $\begin{array}{l}2.13 E+01 \\
2.15 E+01 \\
\end{array}$ & $4.28 E+01$ & $\begin{array}{r}1.35 E+01 \\
1.42 E+01 \\
\end{array}$ & $2.77 E+01$ & $\begin{array}{l}9.58 E+00 \\
1.04 E+01 \\
\end{array}$ & 2.00E+01 \\
\hline
\end{tabular}

औ: : Not nvoiloble.

- Analytes with portion of the dat bercent above the DL.

- : Analytes with a portion of the dats below 10 times the oL. 
Table A-1. Core Composite Data (Units $\mu \mathrm{g} / \mathrm{g}$ except Radionuclides $\mu \mathrm{Cl} / \mathrm{g}$ ). (sheet 3 of 9)

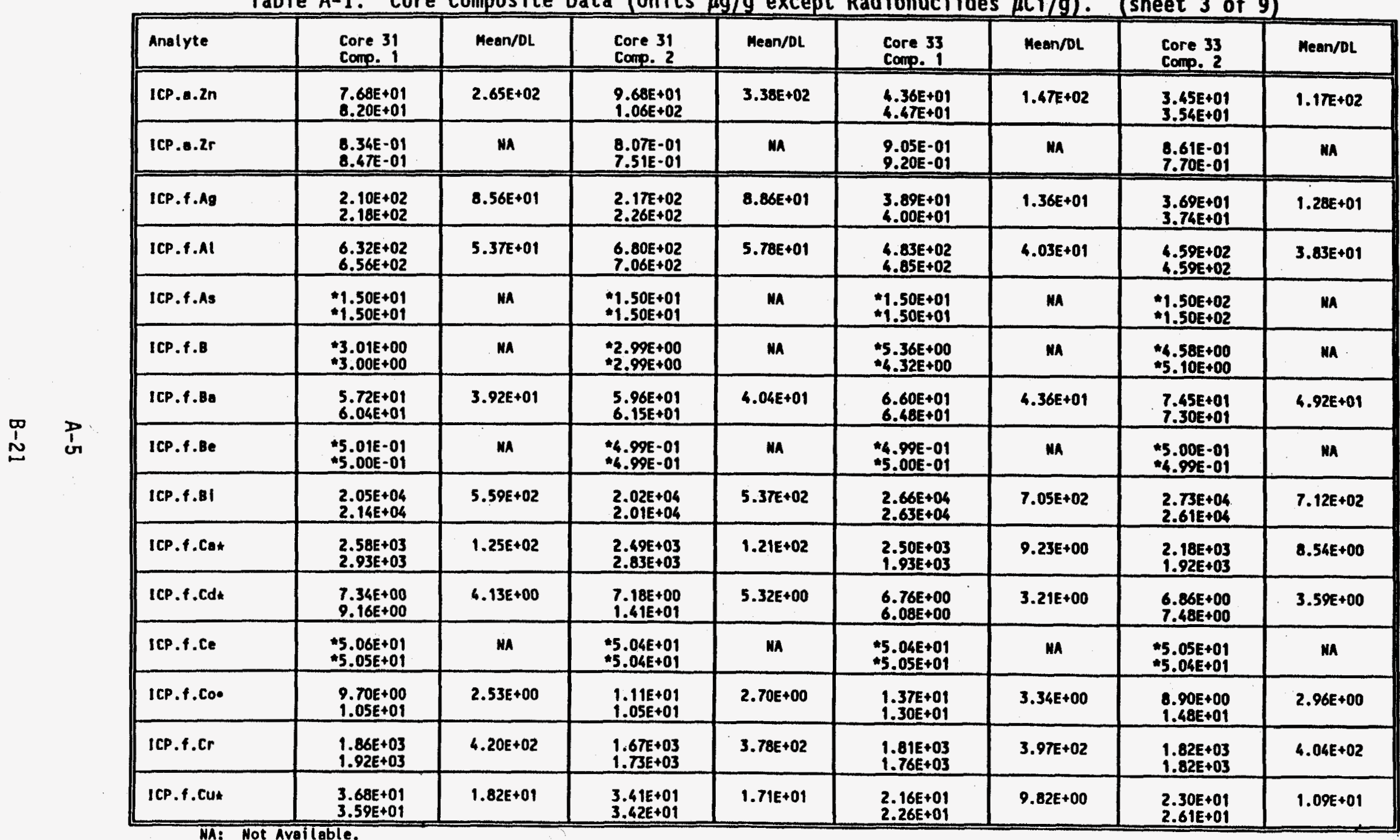

NA: Not Avoilable.

: Value less than DL or less than 5 percent obove the DL.

*: Analytes with a portion of the data below 10 times the oL. 
Table A-1. Core Composite Data (Units $\mu \mathrm{g} / \mathrm{g}$ except Radionuclides $\mu \mathrm{Cl} / \mathrm{g}$ ). (sheet 4 of 9)

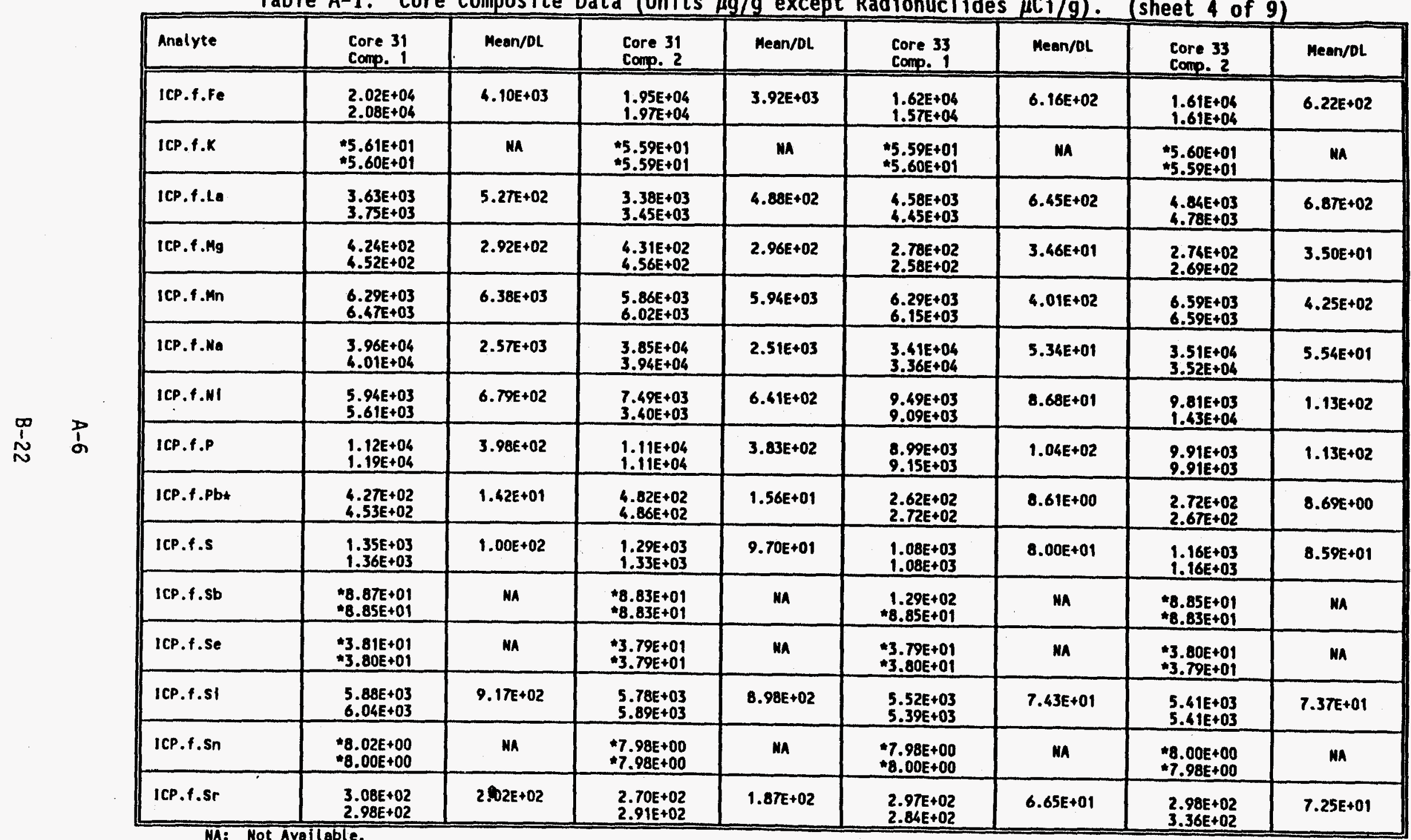

NA: Not Avoilable.

DL or less than 5 percent above the $\mathrm{DL}$.

- Analytes with portion of the date below 3 times the DL. 
Table A-1. Core Composite Data (Units $\mu \mathrm{g} / \mathrm{g}$ except Radionuclides $\mu \mathrm{Cl} / \mathrm{g}$ ). (sheet 5 of 9 )

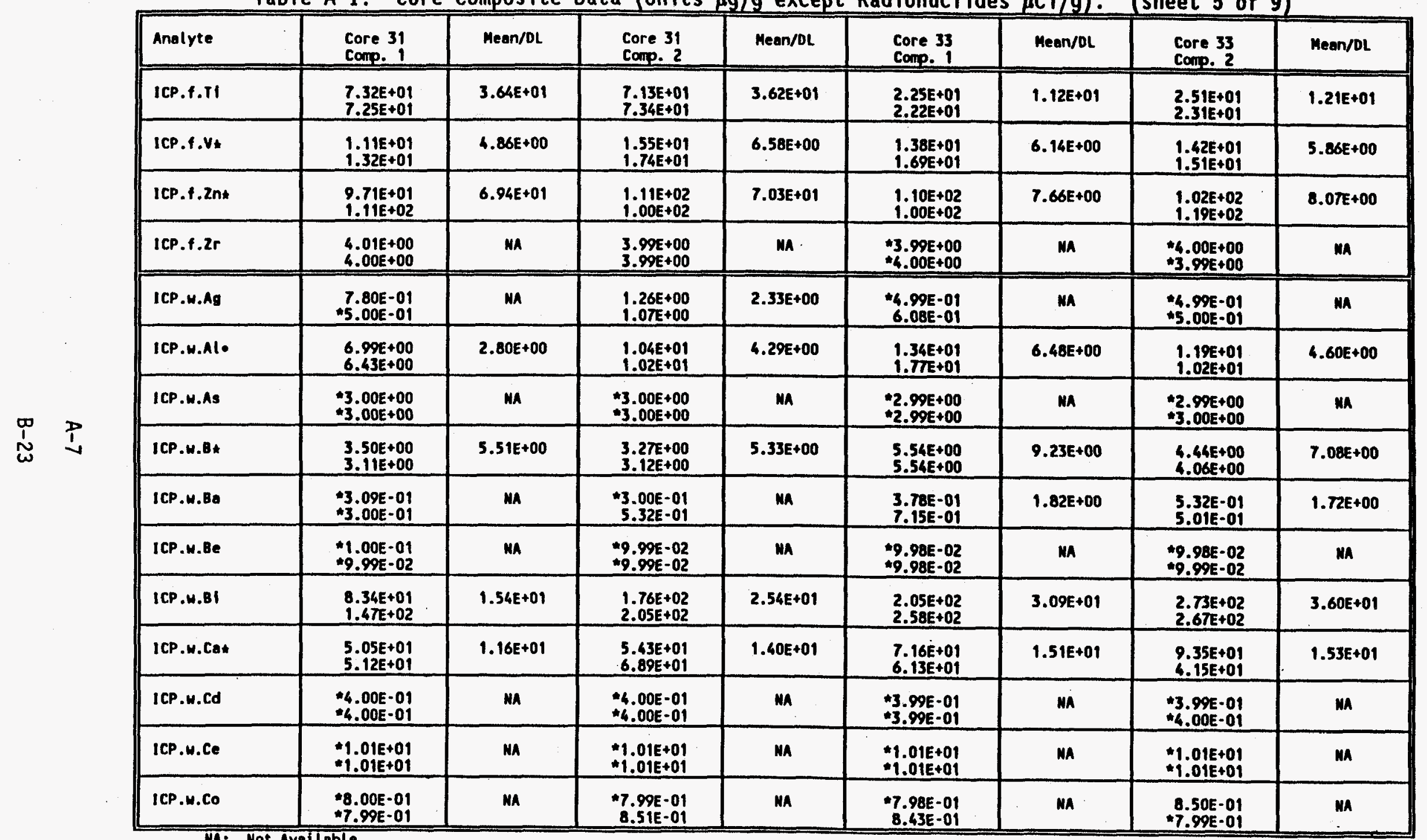

NA: Not Available.

- : Value less than $\mathrm{DL}$ or less than 5 percent above the $\mathrm{DL}$.

a: Analytes with a portion of the data below 10 times the DL. 
Table A-1. Core Composite Data (Units $\mu \mathrm{g} / \mathrm{g}$ except Radionuclides $\mu \mathrm{Cl} / \mathrm{g}$ ). (sheet 6 of 9)

\begin{tabular}{|c|c|c|c|c|c|c|c|c|c|}
\hline \multirow{16}{*}{ 齐 } & Analyte & $\begin{array}{l}\text { Core } 31 \\
\text { Comp. } 1 \\
\end{array}$ & Mean/DL & $\begin{array}{l}\text { Core } 31 \\
\text { Comp. } 2 \\
\end{array}$ & Mean/DL & $\begin{array}{l}\text { Core } 33 \\
\text { Comp. } 1 \\
\end{array}$ & Mean/DL & $\begin{array}{l}\text { Core } 33 \\
\text { Comp. } 2 \\
\end{array}$ & Meon/DL \\
\hline & ICP.W.Cr & $\begin{array}{l}2.11 E+02 \\
2.07 E+02 \\
\end{array}$ & $2.32 E+02$ & $\begin{array}{l}2.28 E+02 \\
2.30 E+02 \\
\end{array}$ & $2.54 E+02$ & $\begin{array}{l}2.22 E+02 \\
2.26 E+02 \\
\end{array}$ & $2.49 e+02$ & $\begin{array}{l}2.12 E+02 \\
2.09 E+02\end{array}$ & $2.34 E+02$ \\
\hline & ICP.W.CU & $\begin{array}{r}* 4.00 E-01 \\
* 4.00 E-01 \\
\end{array}$ & NA & $\begin{array}{r}4.00 E-01 \\
* 4.00 E-01 \\
\end{array}$ & MA & $\begin{array}{r}3.99 E-01 \\
* 3.99 E-01 \\
\end{array}$ & MA & 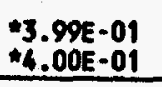 & Ma \\
\hline & ICP.W.Fe & $\begin{array}{l}5.70 E+01 \\
1.02 E+02 \\
\end{array}$ & $7.95 E+01$ & $\begin{array}{l}1.30 E+02 \\
1.51 E+02 \\
\end{array}$ & $1.41 E+02$ & $\begin{array}{l}1.16 E+02 \\
1.47 E+02 \\
\end{array}$ & $1.32 E+02$ & $\begin{array}{l}1.60 E+02 \\
1.58 E+02 \\
\end{array}$ & $1.59 E+02$ \\
\hline & ICP.W.K & $\begin{array}{l}7.40 E+02 \\
7.28 E+02 \\
\end{array}$ & $6.55 E+01$ & $\begin{array}{l}7.83 E+02 \\
7.83 E+02 \\
\end{array}$ & $6.99 E+01$ & $\begin{array}{l}7.04 E+02 \\
7.19 E+02 \\
\end{array}$ & $6.35 E+01$ & $\begin{array}{l}6.47 E+02 \\
6.50 E+02 \\
\end{array}$ & $5.79 E+01$ \\
\hline & ICP.M.Lak & $\begin{array}{l}5.00 E+00 \\
7.05 E+00 \\
\end{array}$ & $4.30 E+00$ & $\begin{array}{l}7.69 E+00 \\
9.35 E+00 \\
\end{array}$ & $6.09 E+00$ & $\begin{array}{l}1.22 E+01 \\
1.55 E+01 \\
\end{array}$ & $9.89 E+00$ & $\begin{array}{l}1.5 \pi E+01 \\
1.58 E+01 \\
\end{array}$ & $1.13 E+01$ \\
\hline & ICP.H.Mg* & $\begin{array}{l}2.67 E+00 \\
3.22 E+00 \\
\end{array}$ & $9.82 E+00$ & $\begin{array}{r}3.66 E+00 \\
4.23 E+00 \\
\end{array}$ & $1.32 E+01$ & $\begin{array}{r}3.60 E+00 \\
4.08 E+00 \\
\end{array}$ & $1.28 E+01$ & $\begin{array}{l}\text { 3.95E }+00 \\
\text { 3. } 72 E+00 \\
\end{array}$ & $1.28 E+01$ \\
\hline & ICP.M.Mn & $\begin{array}{l}1.01 E+01 \\
1.93 E+01 \\
\end{array}$ & $7.35 E+01$ & $\begin{array}{l}2.31 E+01 \\
2.70 E+01 \\
\end{array}$ & $1.25 E+02$ & $\begin{array}{l}2.04 E+01 \\
3.04 E+01\end{array}$ & $1.2 \pi E+02$ & $\begin{array}{l}3.34 E+01 \\
3.42 E+01\end{array}$ & $1.69 E+02$ \\
\hline & ICP.W.Ma & $\begin{array}{l}3.41 E+04 \\
3.39 E+04 \\
\end{array}$ & $1.10 E+04$ & $\begin{array}{l}3.51 E+04 \\
3.50 E+04 \\
\end{array}$ & $1.13 E+04$ & $\begin{array}{l}3.06 E+04 \\
3.09 E+04 \\
\end{array}$ & $9.92 E+03$ & $\begin{array}{l}3.19 E+04 \\
3.22 E+04 \\
\end{array}$ & $1.03 E+04$ \\
\hline & ICP.W.NI & $\begin{array}{r}1.70 E+00 \\
11.70 E+00 \\
\end{array}$ & Ma & $\begin{array}{r}1.70 E+00 \\
-1.70 E+00 \\
\end{array}$ & $M A$ & $\begin{array}{r}11.70 E+00 \\
+1.70 E+00 \\
\end{array}$ & MA & $\begin{array}{r}1.70 E+00 \\
-1.70 E+00 \\
\end{array}$ & $m a$ \\
\hline & ICP.W.P & $\begin{array}{l}5.63 E+03 \\
5.89 E+03 \\
\end{array}$ & $9.93 E+02$ & $\begin{array}{l}5.81 E+03 \\
6.11 E+03 \\
\end{array}$ & $1.03 E+03$ & $\begin{array}{l}5.26 E+03 \\
5.34 E+03 \\
\end{array}$ & $9.14 E+02$ & $\begin{array}{l}5.66 E+03 \\
5.74 E+03 \\
\end{array}$ & $9.83 E+02$ \\
\hline & ICP.H.Pb & $\begin{array}{r}7.91 E+00 \\
+6.19 E+00 \\
\end{array}$ & MA & $\begin{array}{r}6.93 E+00 \\
8.92 E+00 \\
\end{array}$ & $1.28 E+00$ & 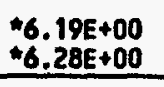 & Ma & $\begin{array}{r}6.19 E+00 \\
-6.19 E+00 \\
\end{array}$ & Ma \\
\hline & ICP.W.S & $\begin{array}{l}1.21 E+03 \\
1.18 E+03 \\
\end{array}$ & $4.43 E+02$ & $\begin{array}{r}1.19 E+03 \\
1.21 E+03 \\
\end{array}$ & $4.44 E+02$ & $\begin{array}{l}1.05 E+03 \\
1.07 E+03\end{array}$ & $3.93 E+02$ & $\begin{array}{l}1.14 E+03 \\
1.14 E+03 \\
\end{array}$ & $4.22 E+02$ \\
\hline & $I C P \cdot H . S b$ & $\begin{array}{r}1.77 \mathrm{E}+01 \\
\star 1.77 \mathrm{E}+01 \\
\end{array}$ & HA & $\begin{array}{r}1.77 E+01 \\
-1.77 \mathrm{E}+01 \\
\end{array}$ & NA & $\begin{array}{r}-1.77 E+01 \\
* 1.77 E+01 \\
\end{array}$ & wa & $\begin{array}{l}1.77 E+01 \\
1.77 E+01 \\
\end{array}$ & MA \\
\hline & ICP.W.Se & $\begin{array}{r}7.60 E+00 \\
7.59 E+00 \\
\end{array}$ & MA & $\begin{array}{r}7.59 E+00 \\
8.44 E+00 \\
\end{array}$ & MA & $\begin{array}{r}7.58 E+00 \\
+7.58 E+00 \\
\end{array}$ & ma & $\begin{array}{r}7.58 E+00 \\
7.59 E+00 \\
\end{array}$ & $M A$ \\
\hline & ICP.W.SI & $\begin{array}{l}3.45 E+02 \\
5.30 E+02 \\
\end{array}$ & $3.3 T E+02$ & $\begin{array}{r}5.30 E+02 \\
5.89 E+02 \\
\end{array}$ & $4.30 E+02$ & $\begin{array}{l}6.68 E+02 \\
6.71 E+02 \\
\end{array}$ & $5.15 E+02$ & $\begin{array}{l}6.22 E+02 \\
6.18 E+02 \\
\end{array}$ & 4. $m E+02$ \\
\hline
\end{tabular}

MA: Not Availoble.

- Value less than DL or less than 5 percent above the DL.

*: Analytes with portion of the data below 3 times the DL. 
Table A-1. Core Composite Data (Units $\mu \mathrm{g} / \mathrm{g}$ except Radionuclides $\mu \mathrm{Cl} / \mathrm{g}$ ). (sheet 7 of 9)

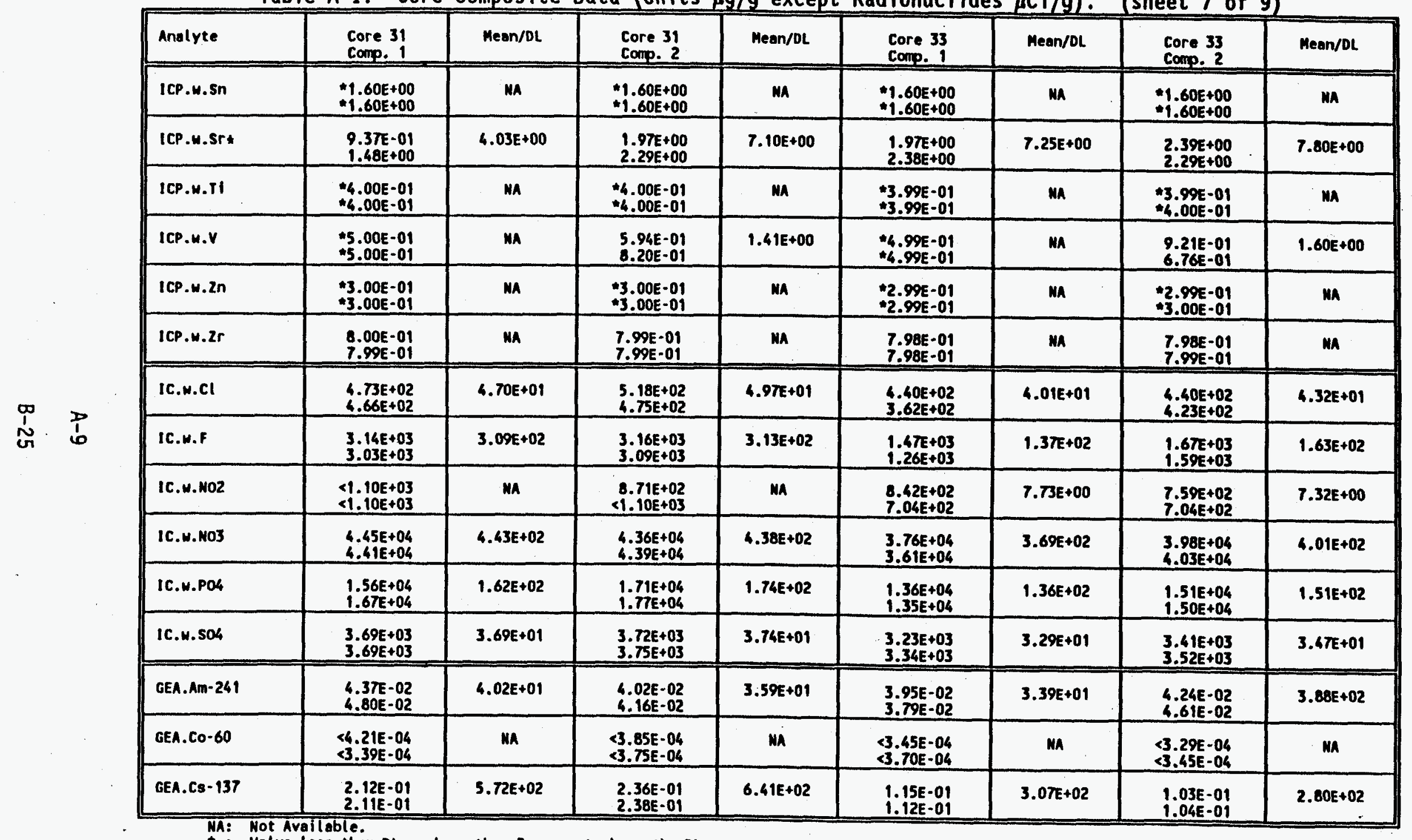

: Value less than $\mathrm{DL}$ or less than 5 percent above the $\mathrm{DL}$.

- : Analytes with a portion of the date below 3 times the DL. 
Table A-1. Core Composite Data (Units $\mu \mathrm{g} / \mathrm{g}$ except Radionuclides $\mu \mathrm{Cl} / \mathrm{g}$ ). (sheet 8 of 9)

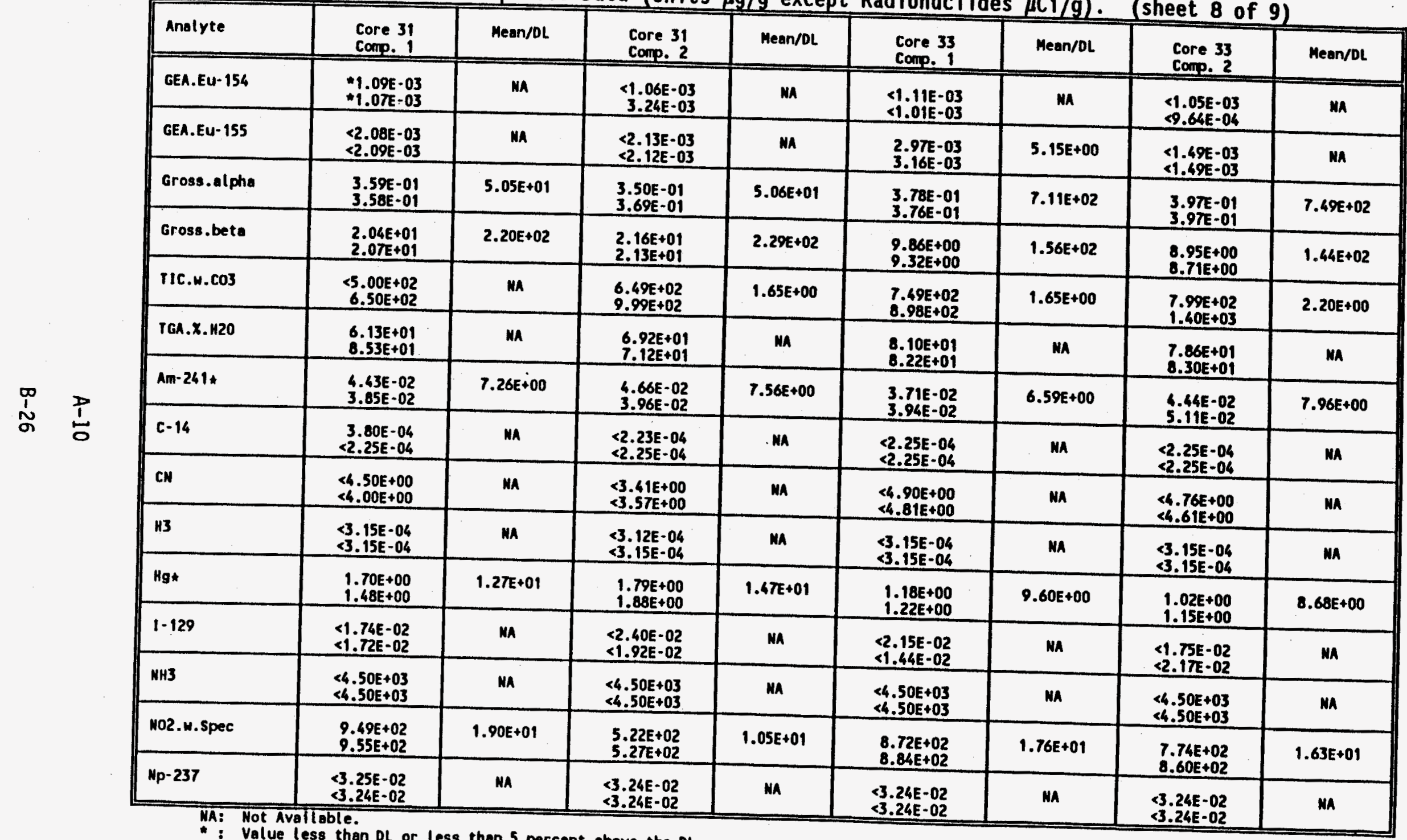

- Value less than DL or less than 5 percent above the DL.

- : Analytes with a portion of the data below 3 times the DL. 
Table A-1. Core Composite Data (Units $\mu \mathrm{g} / \mathrm{g}$ except Radionuclides $\mu \mathrm{Ci} / \mathrm{g}$ ). (sheet 9 of 9 )

\begin{tabular}{|c|c|c|c|c|c|c|c|c|c|}
\hline & Analyte & $\begin{array}{l}\text { Core } 31 \\
\text { Comp. } 1 \\
\end{array}$ & Mean/DL & $\begin{array}{l}\text { Core } 31 \\
\text { Comp. } 2 \\
\end{array}$ & Mean/DL & $\begin{array}{l}\text { Core } 33 \\
\text { Comp. } 1 \\
\end{array}$ & Mean/oL & $\begin{array}{l}\text { Core } 33 \\
\text { comp. } 2 \\
\end{array}$ & Meen/DL \\
\hline & Percent .HZO & $\begin{array}{r}7.48 E+01 \\
7.44 E+01 \\
\end{array}$ & MA & $\begin{array}{r}7.59 E+01 \\
7.59 E+01 \\
\end{array}$ & MA & $\begin{array}{l}7.72 E+01 \\
7.57 \mathrm{E}+01 \\
\end{array}$ & ma & $\begin{array}{r}7.78 E+01 \\
7.64 E+01 \\
\end{array}$ & Ma \\
\hline & Pu-238 & $\begin{array}{r}<1.04 E-02 \\
\leq 1.07 E-02 \\
\end{array}$ & MA & $\begin{array}{l}<1.03 E-02 \\
<1.04 E-02 \\
\end{array}$ & MA & $\begin{array}{r}<1.05 E-02 \\
\leq 1.00 E-02 \\
\end{array}$ & MA & $\begin{array}{r}<1.13 E-02 \\
\leq 1.04 E-02 \\
\end{array}$ & MA \\
\hline & Pu-239/40 & $\begin{array}{r}1.35 E-01 \\
1.41 E-01 \\
\end{array}$ & $3.83 E+01$ & $\begin{array}{r}1.34 \mathrm{E}-01 \\
1.37 \mathrm{E}-01 \\
\end{array}$ & $3.76 E+01$ & $\begin{array}{r}1.39 E-01 \\
1.29 E-01 \\
\end{array}$ & $3.83 E+01$ & $\begin{array}{r}1.53 E-01 \\
1.62 E-01 \\
\end{array}$ & $4.21 E+01$ \\
\hline & se & $\begin{array}{r}<6.05 E-05 \\
<6.111-05 \\
\end{array}$ & MA & $\begin{array}{r}6.17 \pi-05 \\
6.31 E-05 \\
\end{array}$ & $1.11 E+00$ & $\begin{array}{r}\$ 1.23 E-04 \\
\leq 1.26 E-04 \\
\end{array}$ & Ma & $\begin{array}{r}\$ 1.29 E-04 \\
\leq 1.26 \mathrm{E}-04 \\
\end{array}$ & MA \\
\hline & $5 r-90$ & $\begin{array}{r}6.97 \mathrm{E}+00 \\
7.34 \mathrm{E}+00 \\
\end{array}$ & $1.01 E+03$ & $\begin{array}{r}7.55 E+00 \\
7.31 E+00 \\
\end{array}$ & $1.62 E+03$ & $\begin{array}{r}3.67 E+00 \\
3.62 E+00 \\
\end{array}$ & $1.70 E+03$ & $\begin{array}{r}3.37 E+00 \\
3.48 E+00 \\
\end{array}$ & $1.59 E+03$ \\
\hline & TOC* & $\begin{array}{r}3.30 E+03 \\
3.60 E+03 \\
\end{array}$ & $6.98 E+00$ & $\begin{array}{r}6.12 E+03 \\
3.05 E+03 \\
\end{array}$ & $7.97 E+00$ & $\begin{array}{r}2.00 E+03 \\
2.00 E+03 \\
\end{array}$ & $4.00 E+00$ & $\begin{array}{r}3.00 E+03 \\
3.00 E+03 \\
\end{array}$ & $6.00 E+00$ \\
\hline \multirow{3}{*}{$\stackrel{P}{2}$} & TC-990 & $\begin{array}{r}4.95 E-03 \\
5.33 E-03 \\
\end{array}$ & $6.05 E+00$ & $\begin{array}{r}4.90 E-03 \\
4.56 E-03 \\
\end{array}$ & $5.56 E+00$ & $\begin{array}{r}1.12 E-02 \\
1.16 E-02 \\
\end{array}$ & $2.48 E+00$ & $\begin{array}{l}1.03 E-02 \\
1.05 E-02 \\
\end{array}$ & $2.26 E+00$ \\
\hline & $u_{*}$ & $\begin{array}{r}2.14 E+03 \\
2.21 E+03 \\
\end{array}$ & 8. $70 E+00$ & $\begin{array}{r}4.00 E+03 \\
3.75 E+03 \\
\end{array}$ & $1.55 E+01$ & $\begin{array}{r}\text { 3. } 01 E+03 \\
\text { 3. } 34 E+03 \\
\end{array}$ & $9.34 E+00$ & $\begin{array}{l}2.07 E+03 \\
1.82 E+03 \\
\end{array}$ & $5.72 E+00$ \\
\hline & pH & $\begin{array}{r}1.02 E+01 \\
1.02 E+01 \\
\end{array}$ & MA & $\begin{array}{l}9.91 E+00 \\
9.94 E+00 \\
\end{array}$ & $M A$ & $\begin{array}{r}1.01 E+01 \\
1.00 E+01 \\
\end{array}$ & $m n$ & $\begin{array}{r}9.72 E+00 \\
9.81 E+00 \\
\end{array}$ & MA \\
\hline
\end{tabular}

Ma: Hot Avalloble.

- Value less than DL or less than 5 percent above the DL.

: : Analytes with portion of the data below 3 times the DL. 
WHC-EP-0806

WHC-SD-WH-TI-650, Rev. 0

This page was intentionally left blank.

A-12

B-28 
WHC-EP-0806

WHC-SD-WH-TI-650, Rev. 0

APPENDIX B

CORE COMPOSITE DATA PLOTS

B-1

B-29 
WHC-EP-0806

HHC-SO-WMT-TI-650, Rev. 0

This page was intentionally left blank. 
WHC-EP-0806

WHC-SD-WM-TI-650, Rev. 0
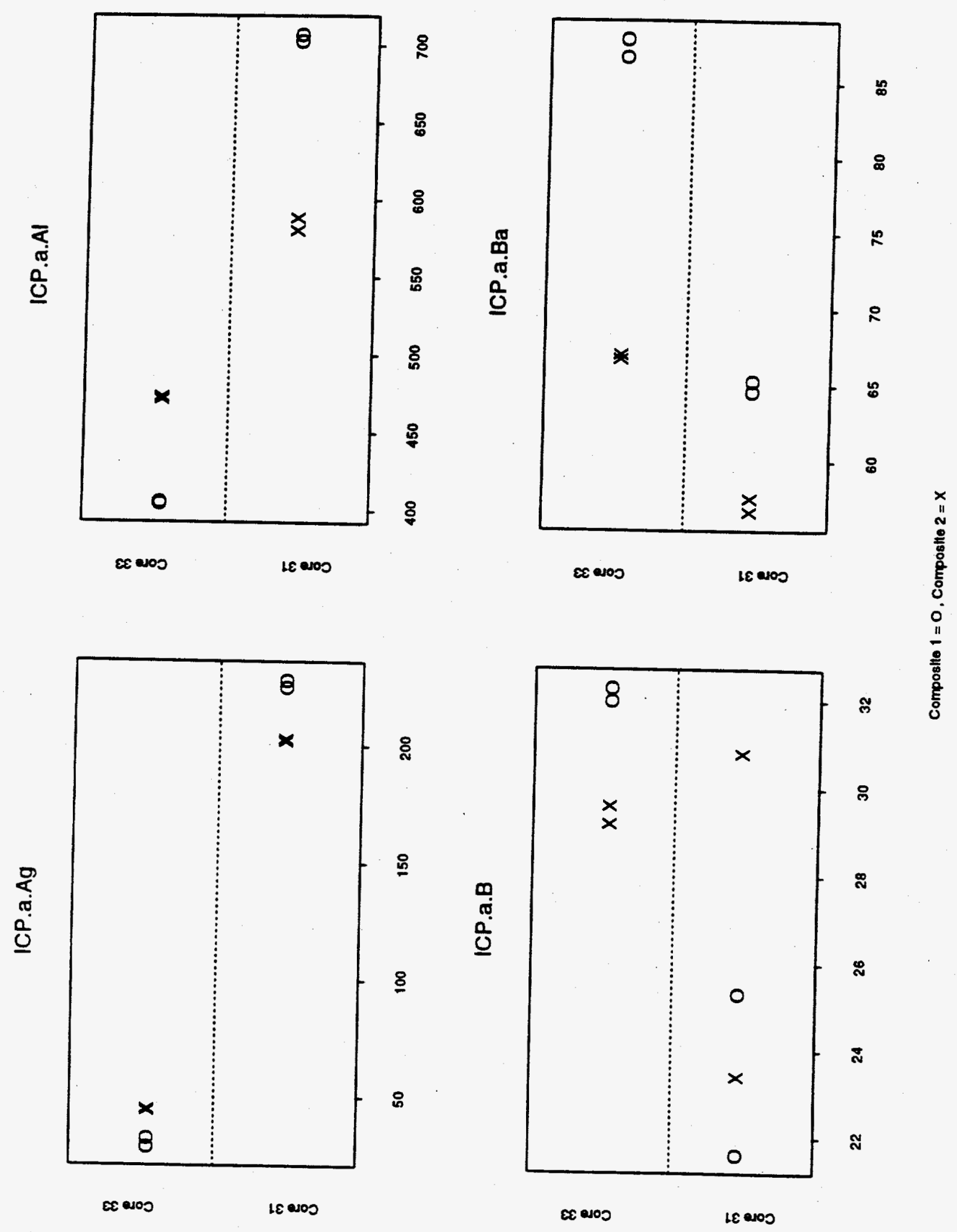

B-3 
WHC-SD-WM-TI-650, Rev. 0
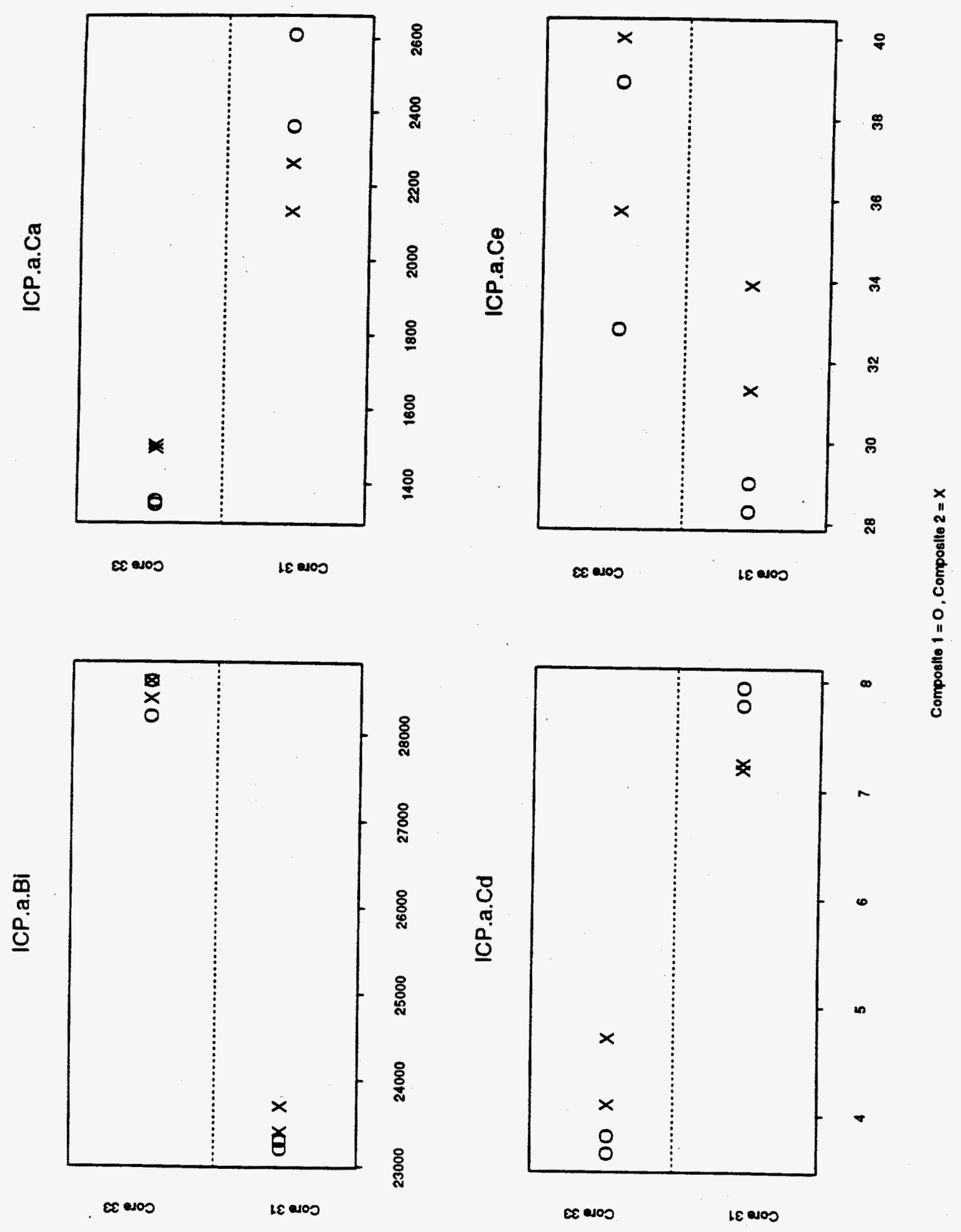
NHC-SD-WIH-TI-650, Rev. O
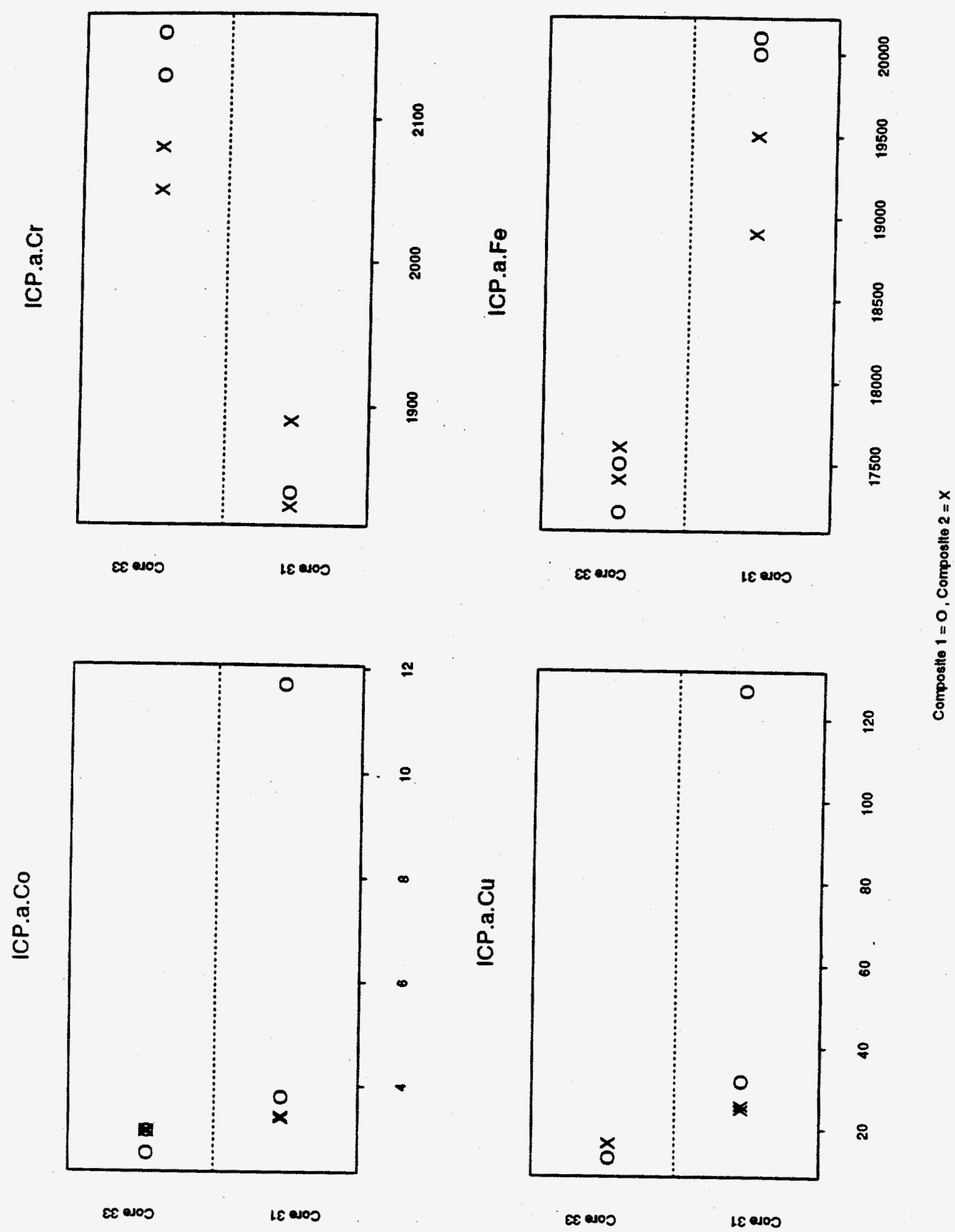

B-5 
HHC-SD-HM-TI-650, Rev. . 0
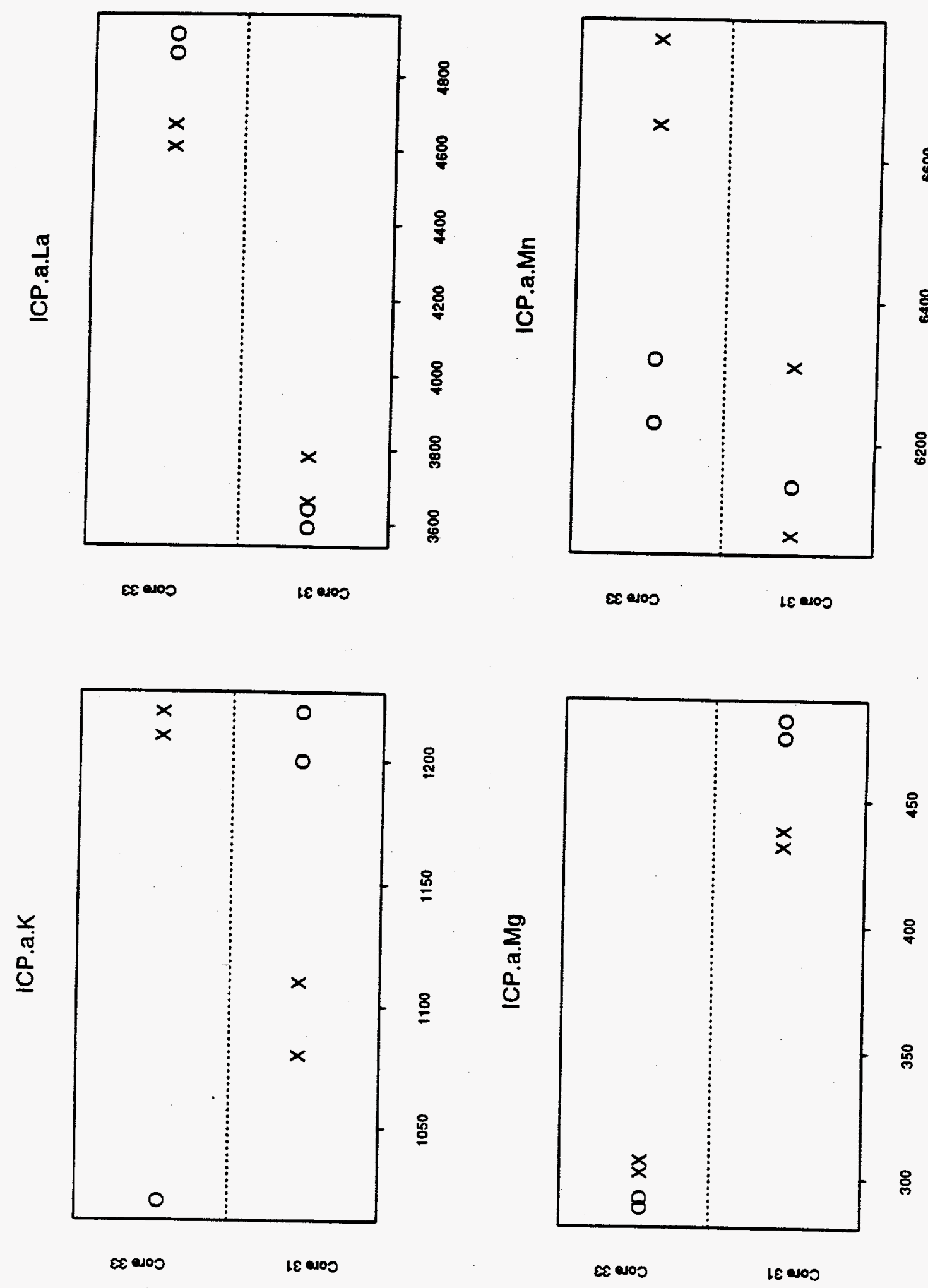
WHC-SD-WM-TI-650, Rev. 0
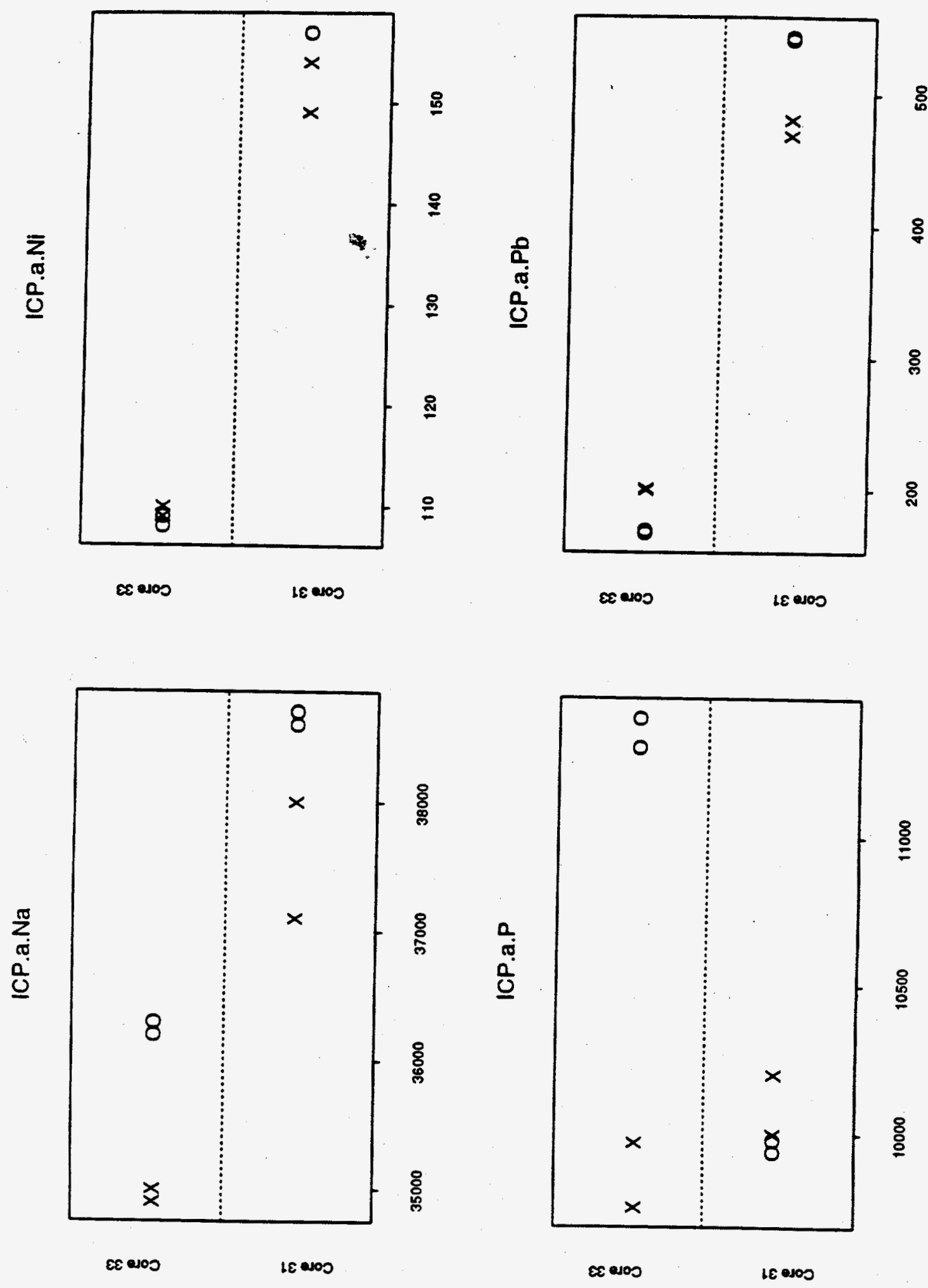
WHC-SD-WM-TI-650, Rev. 0
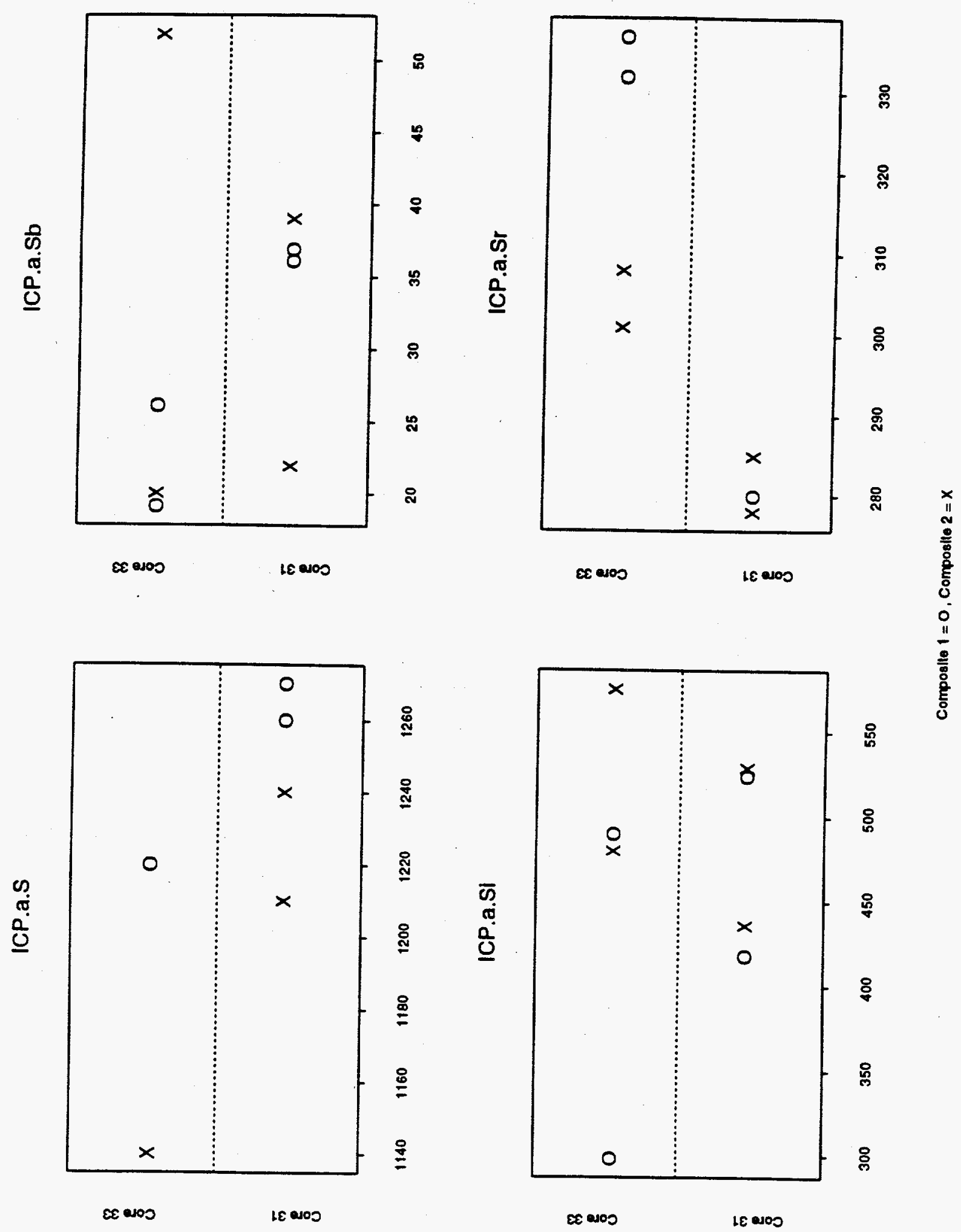

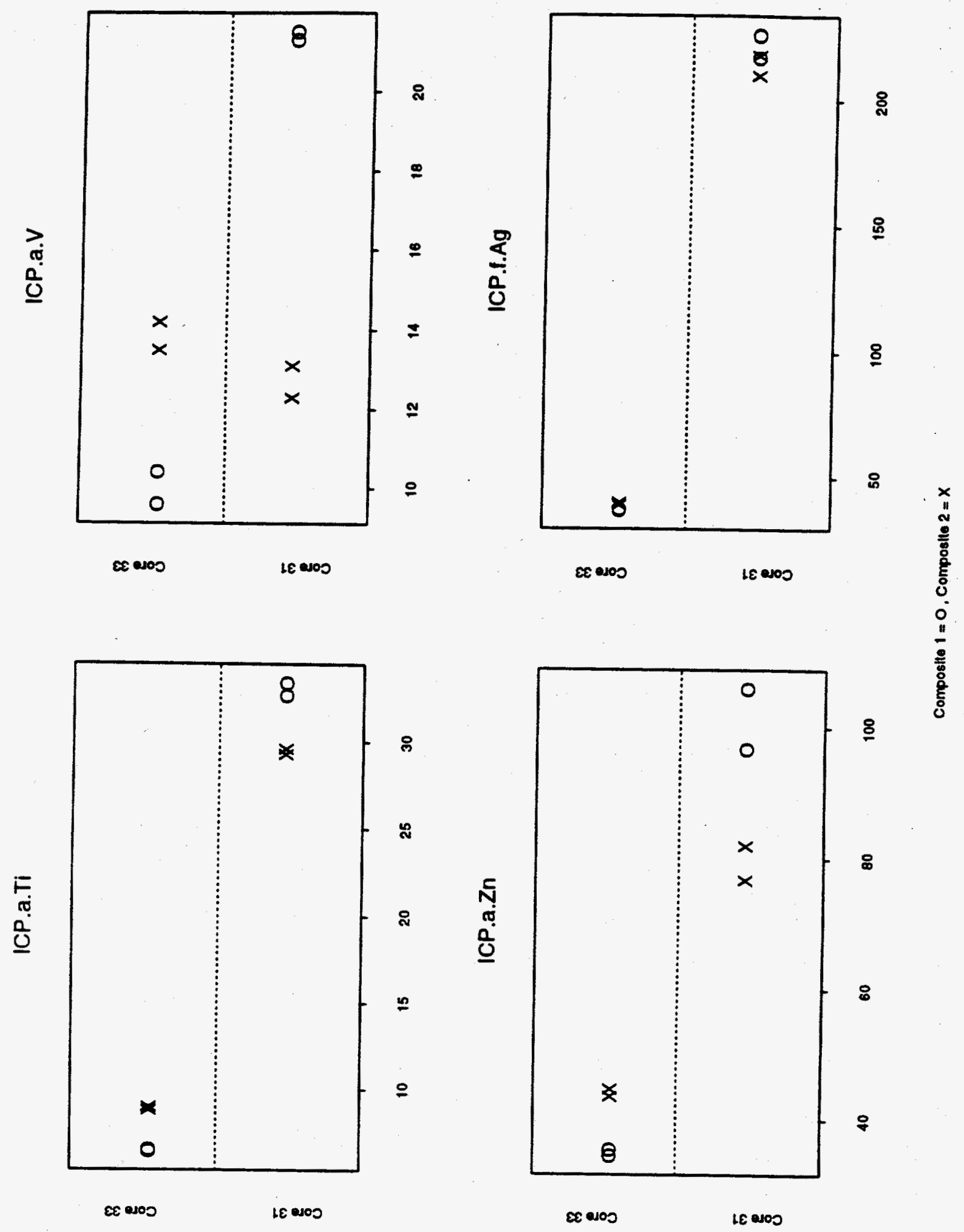

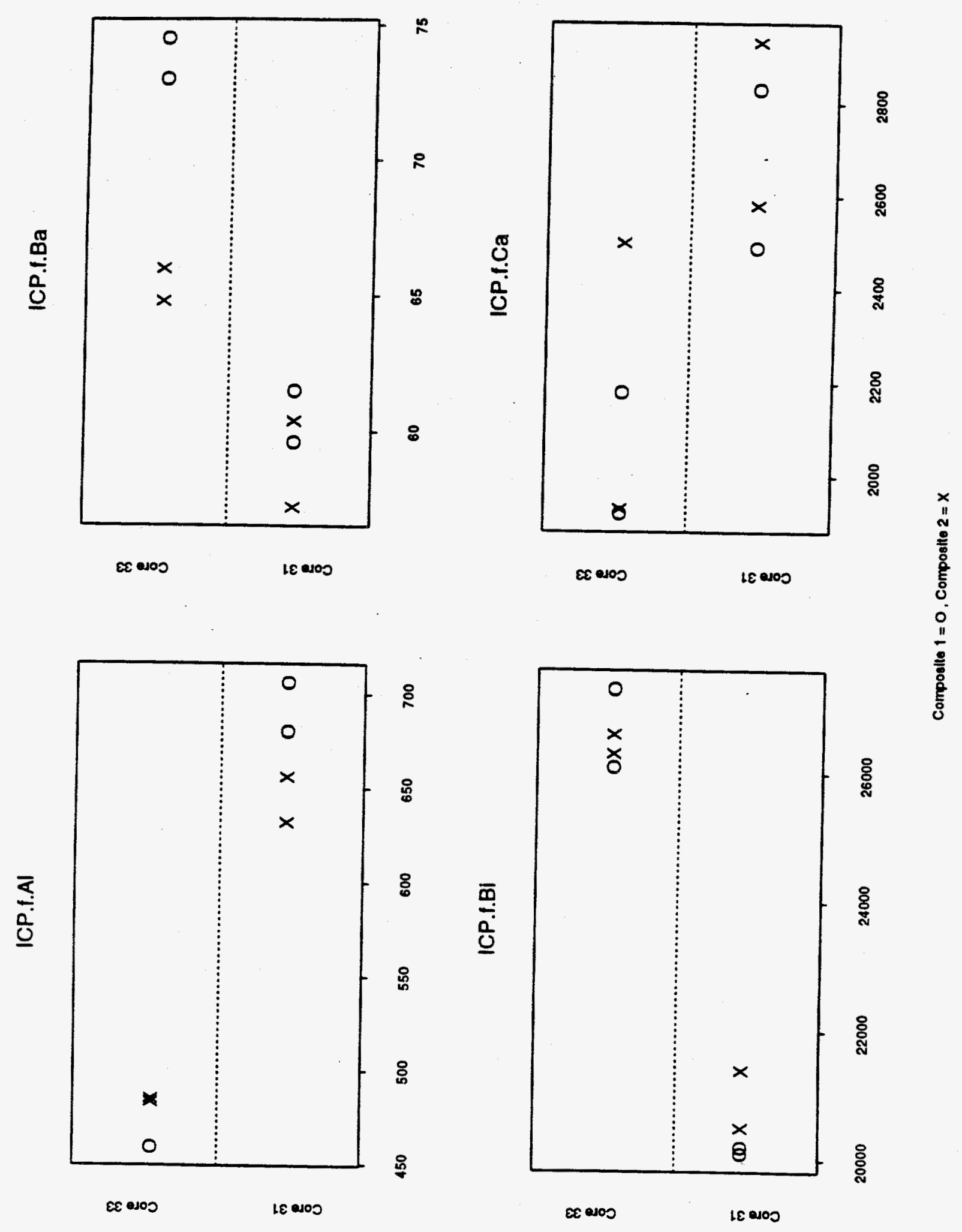
WHC-EP-0806

WHC-SD-WM-TI-650, Rev. 0
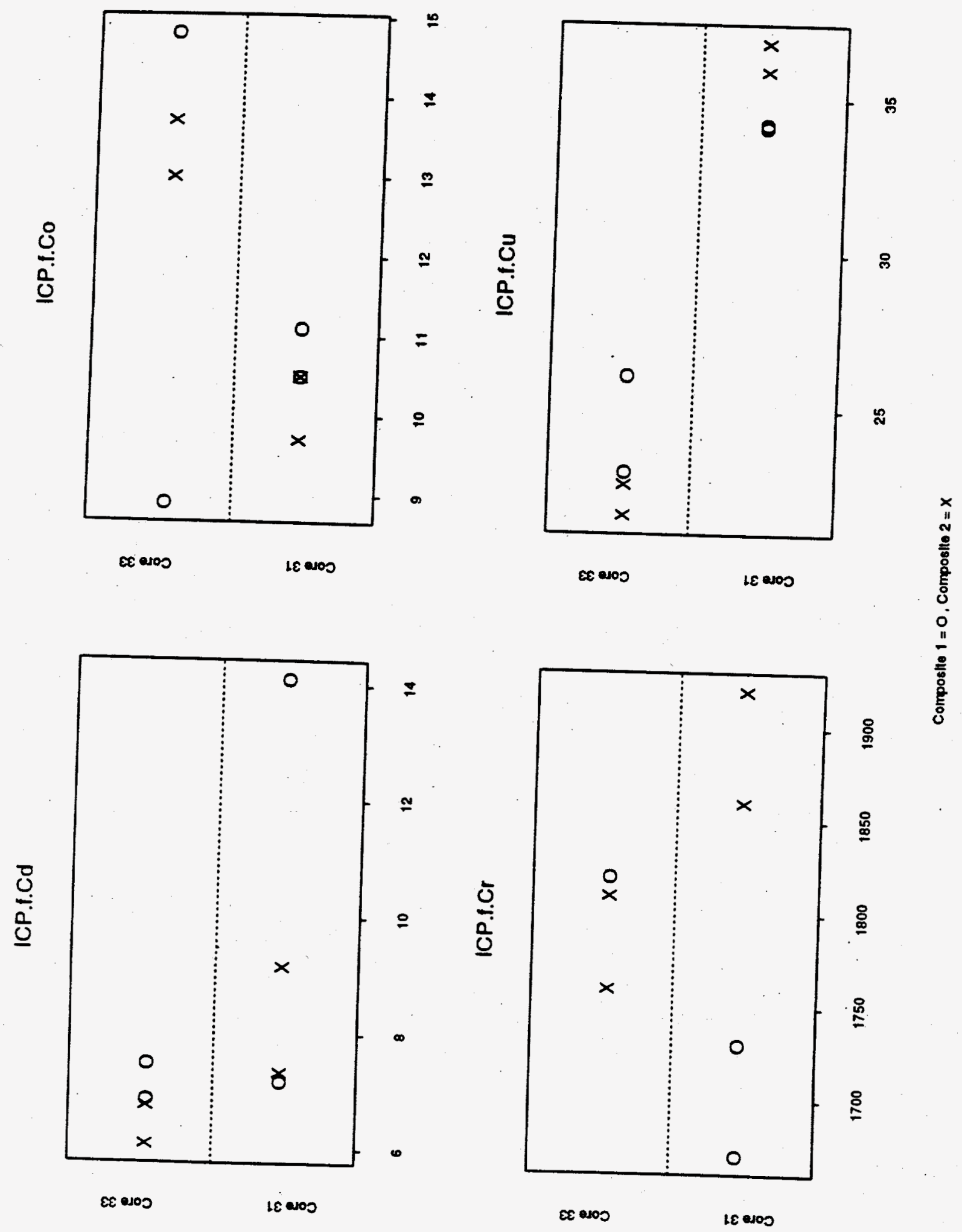

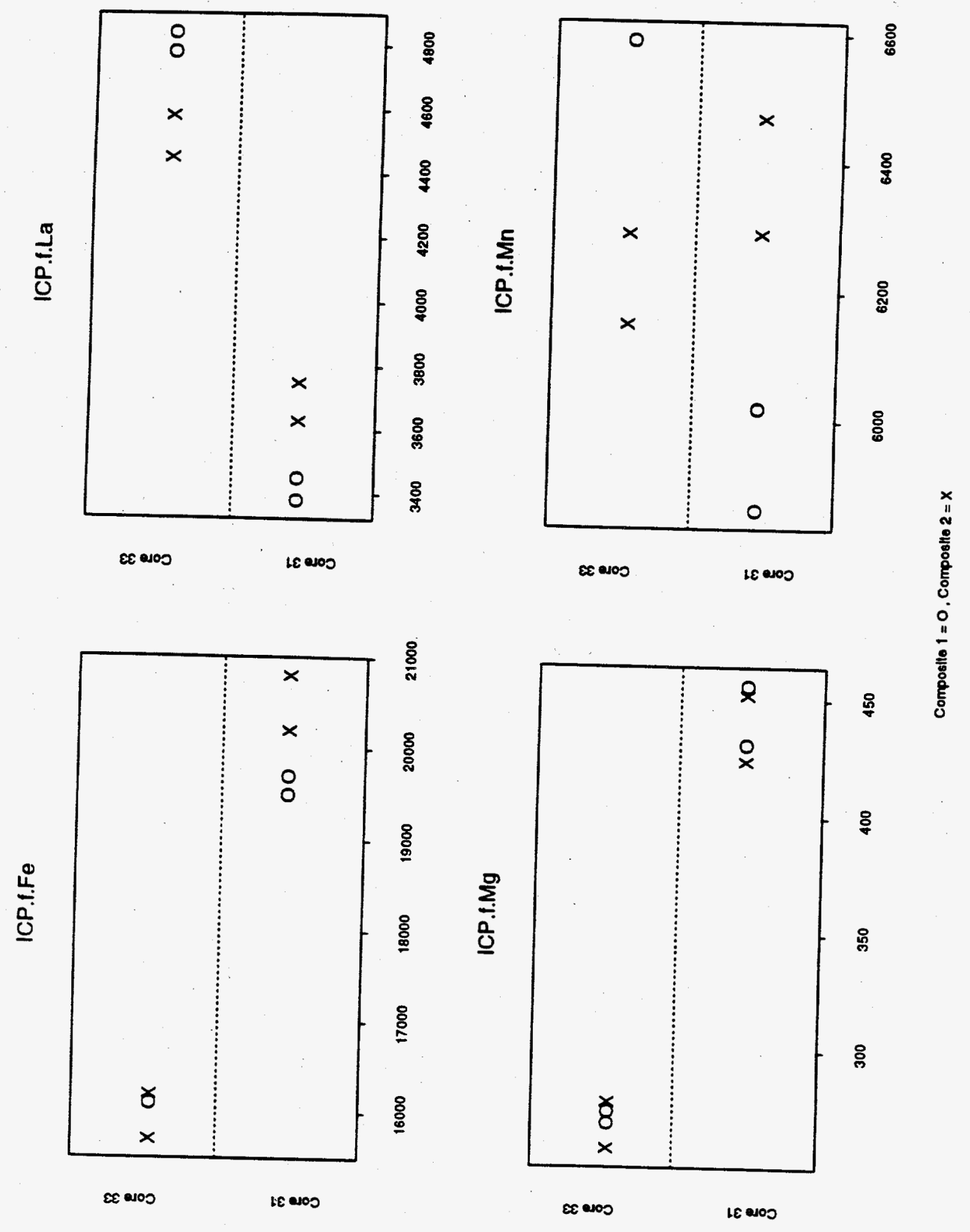
WHC-SD-WM-TI-650, Rev. O
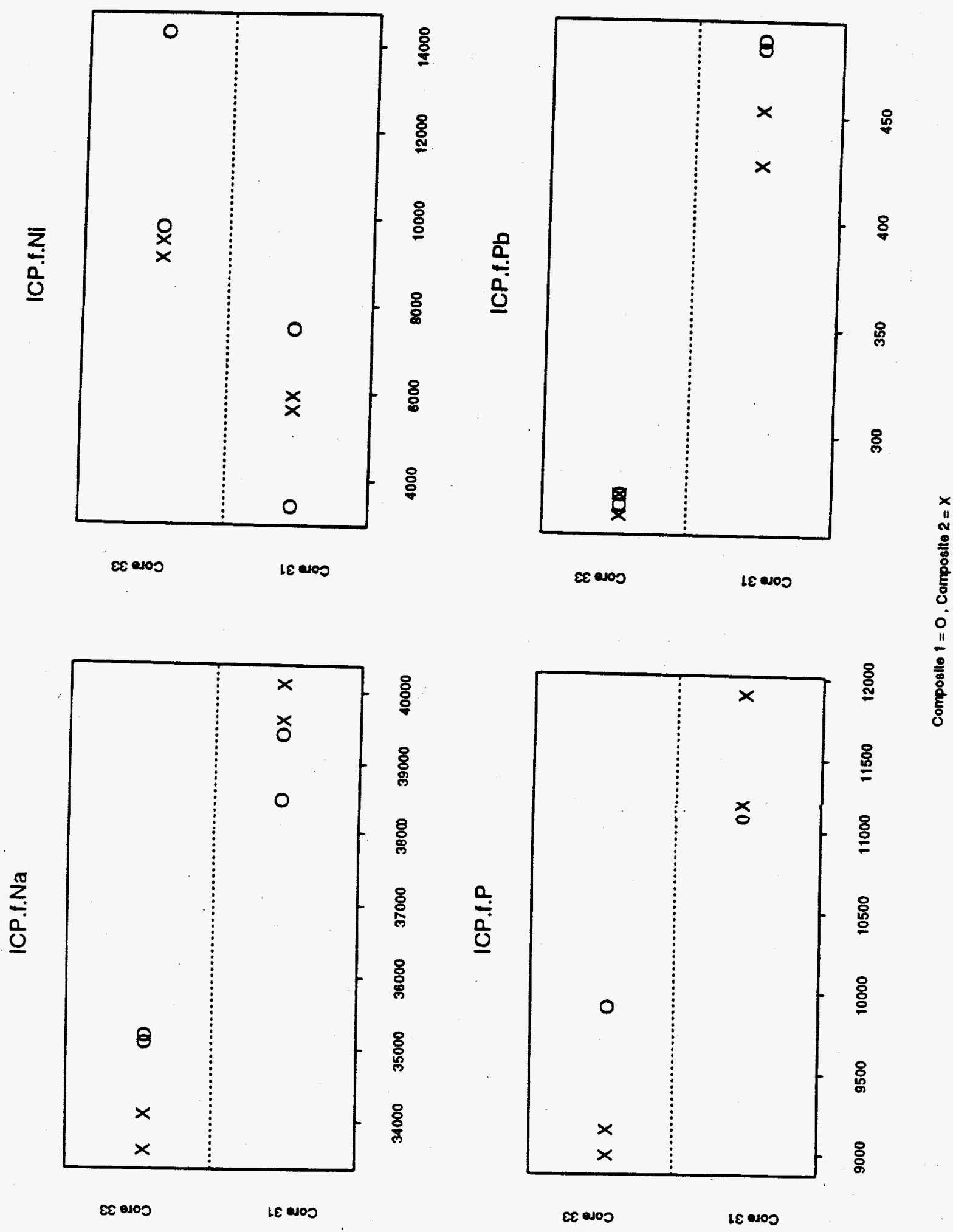

B-13 

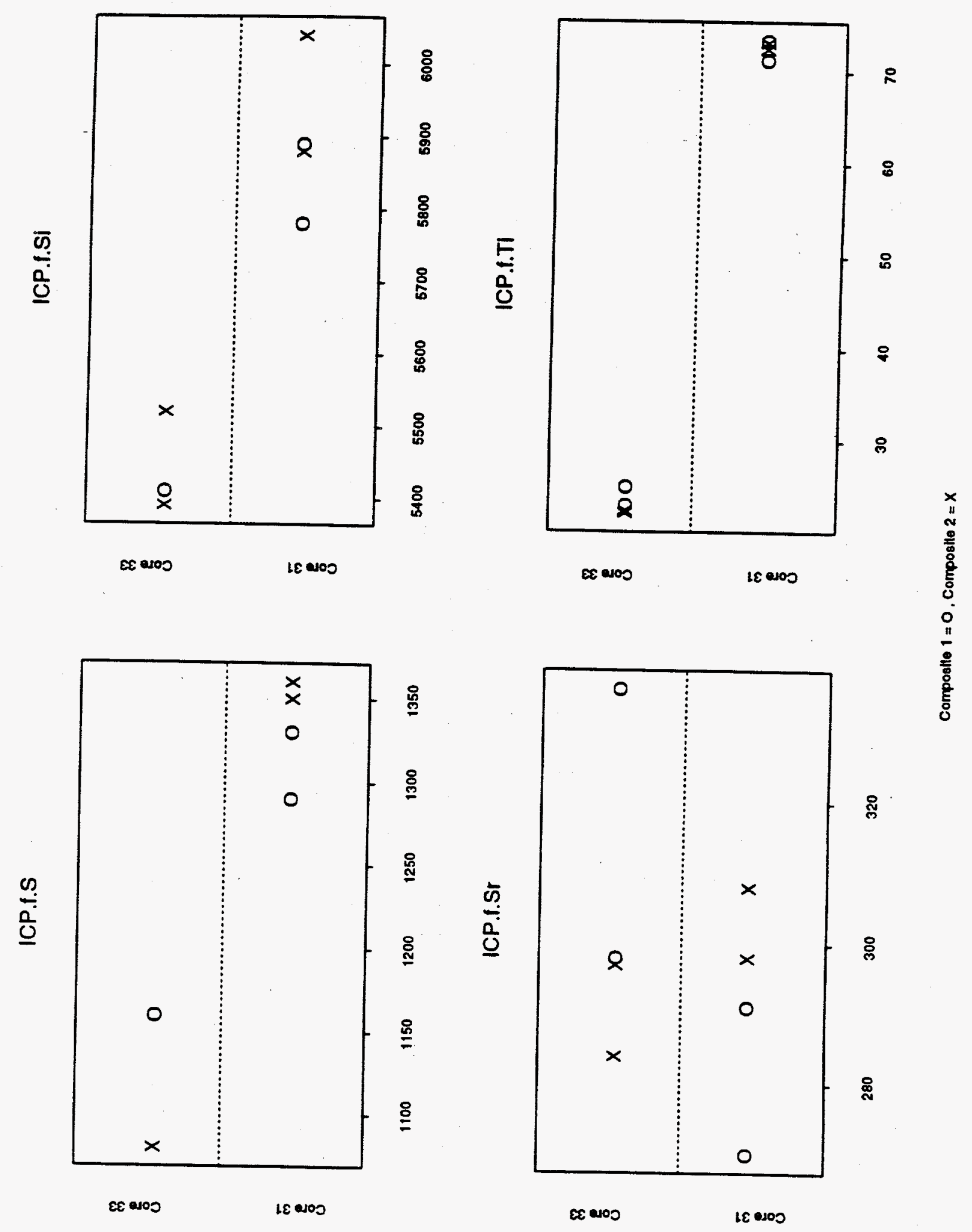
WHC-SD-WM-TI-650, Rev. O
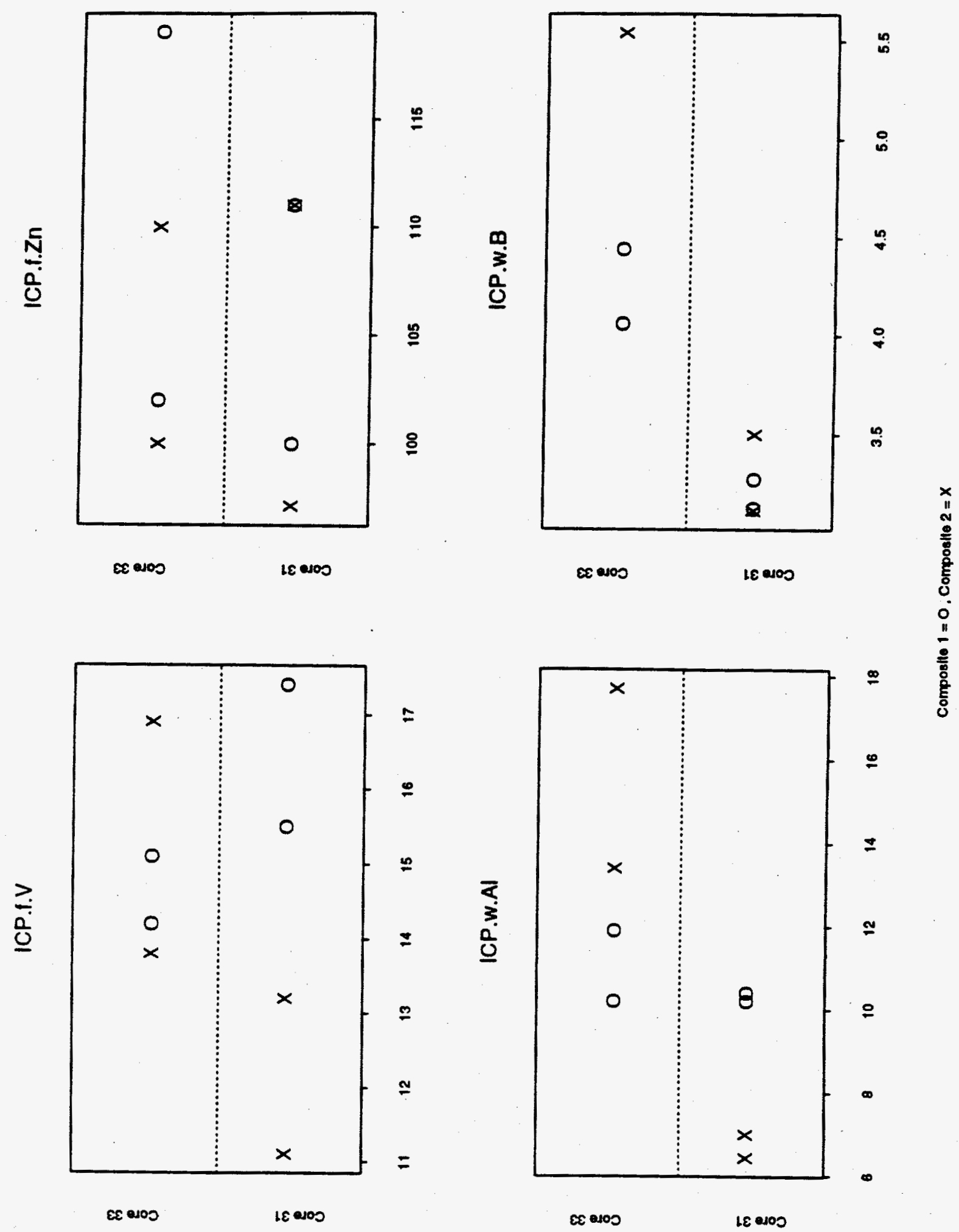
WHC-EP-0806

WHC-SD-HM-TI-650, Rev. 0
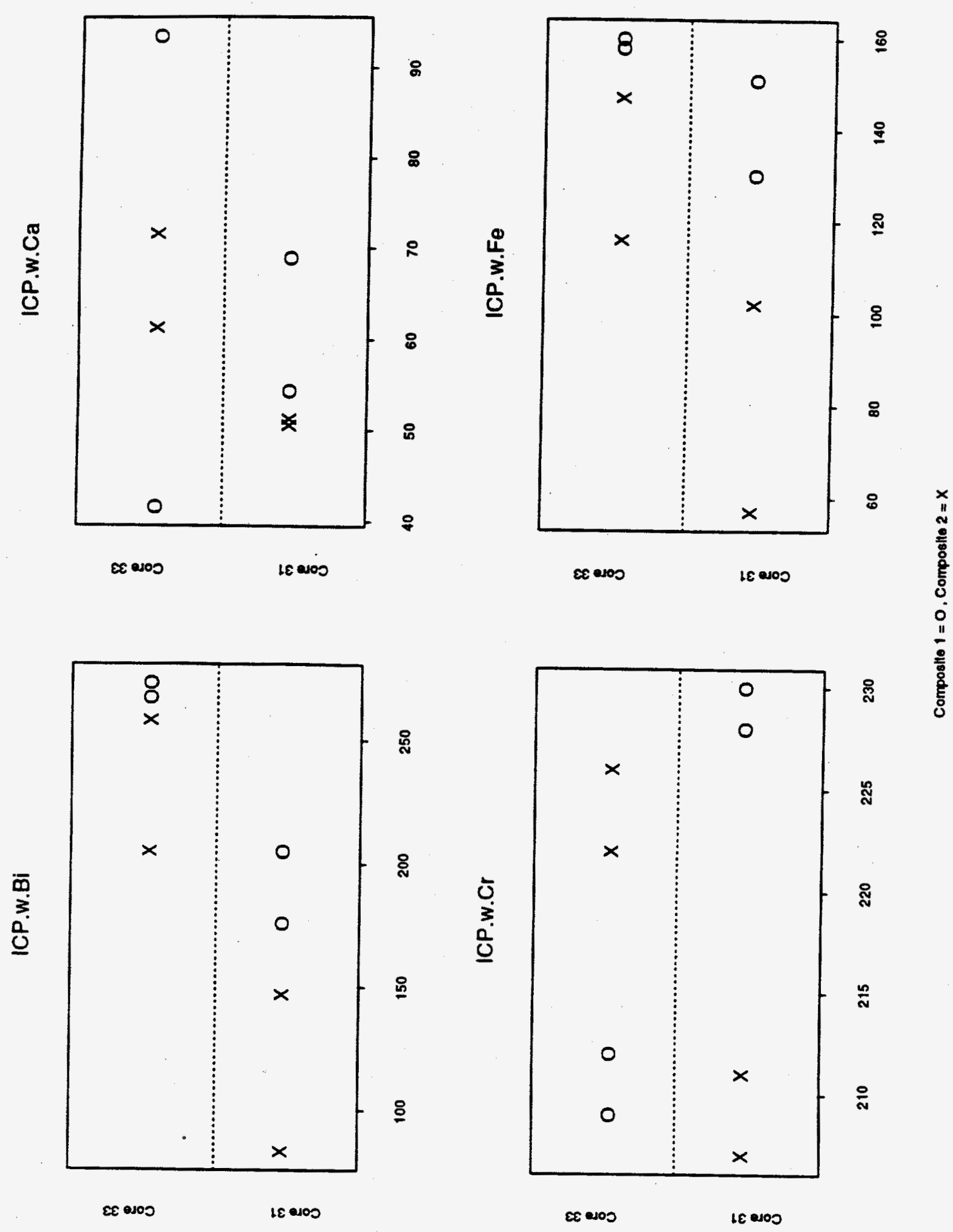

B-16 
WHC-EP-0806

WHC-SD-WH-TI-650, ReV. 0
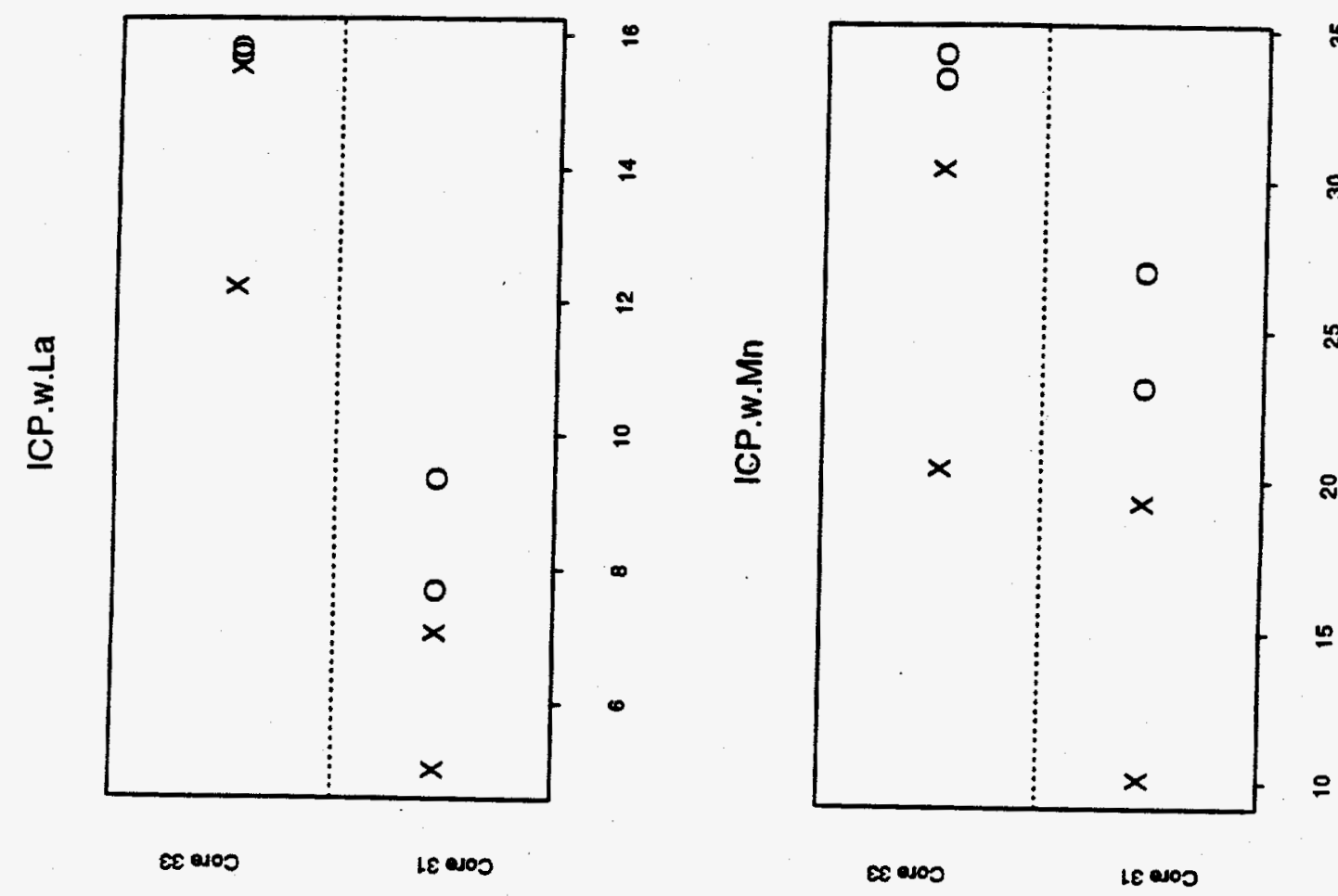

\%

8

$\stackrel{\sim}{*}$

สิ

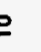

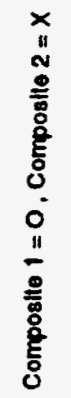
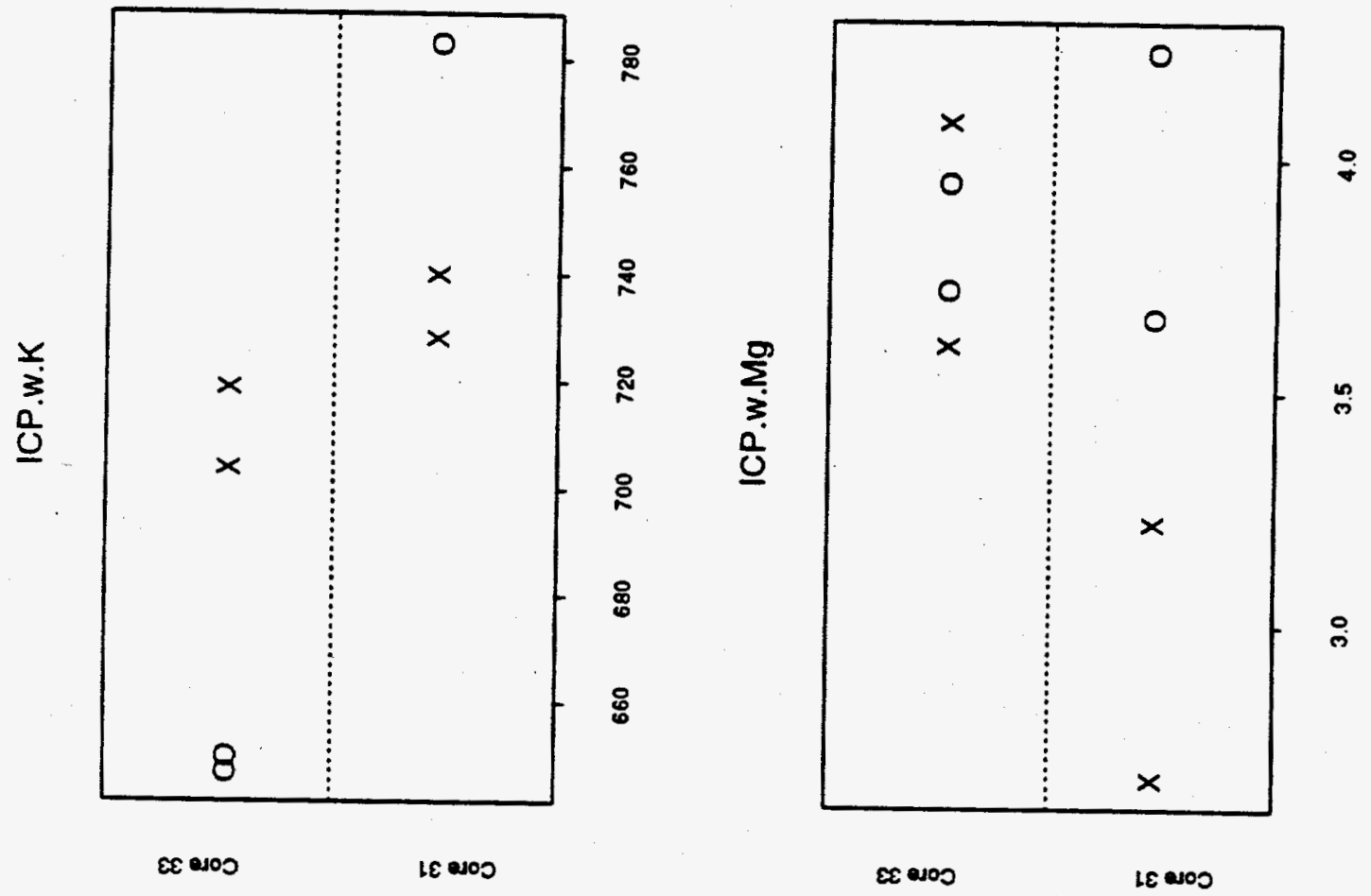

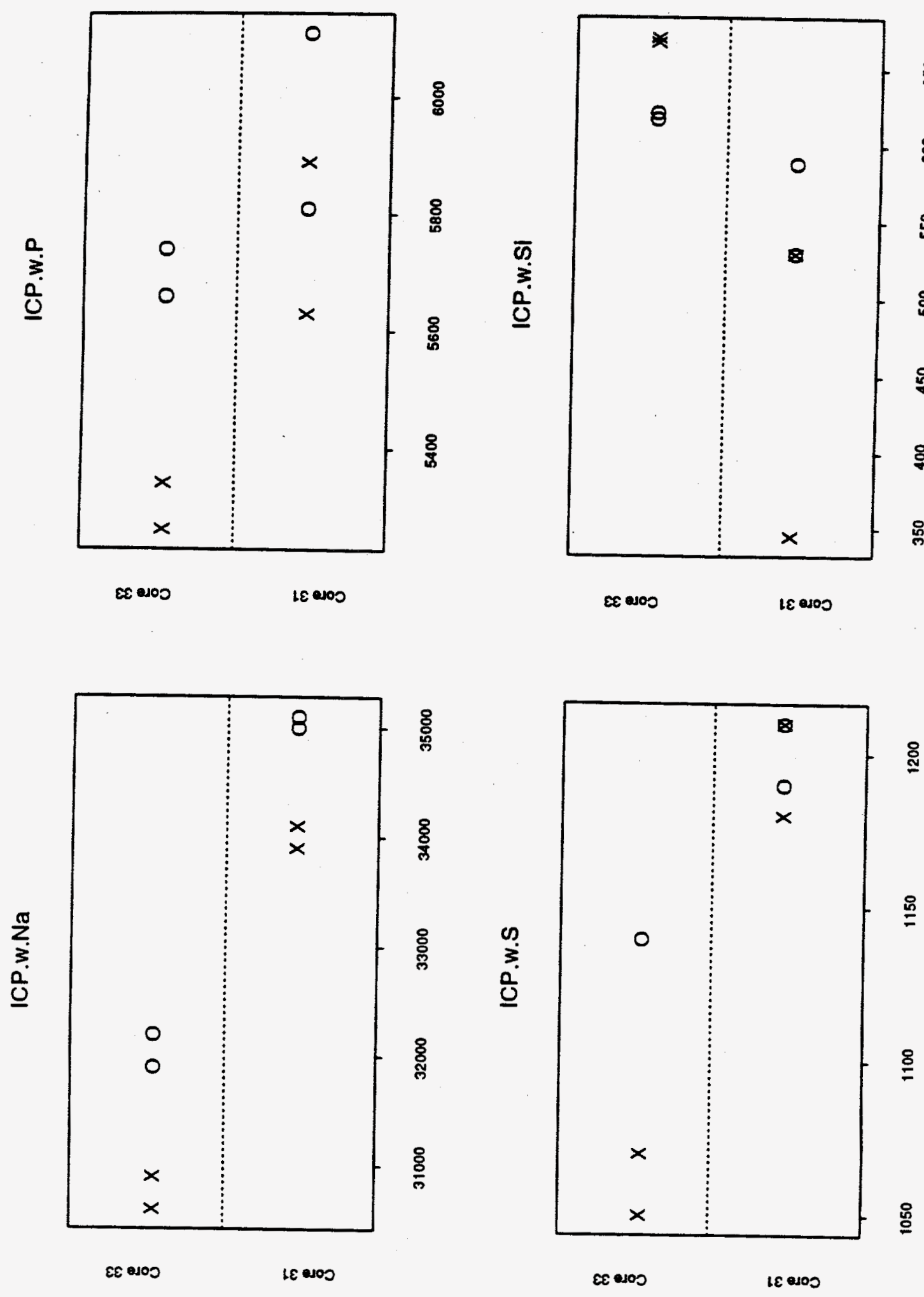
WHC-EP-0806

WHC-SD-WM-TI-650, Rev. 0
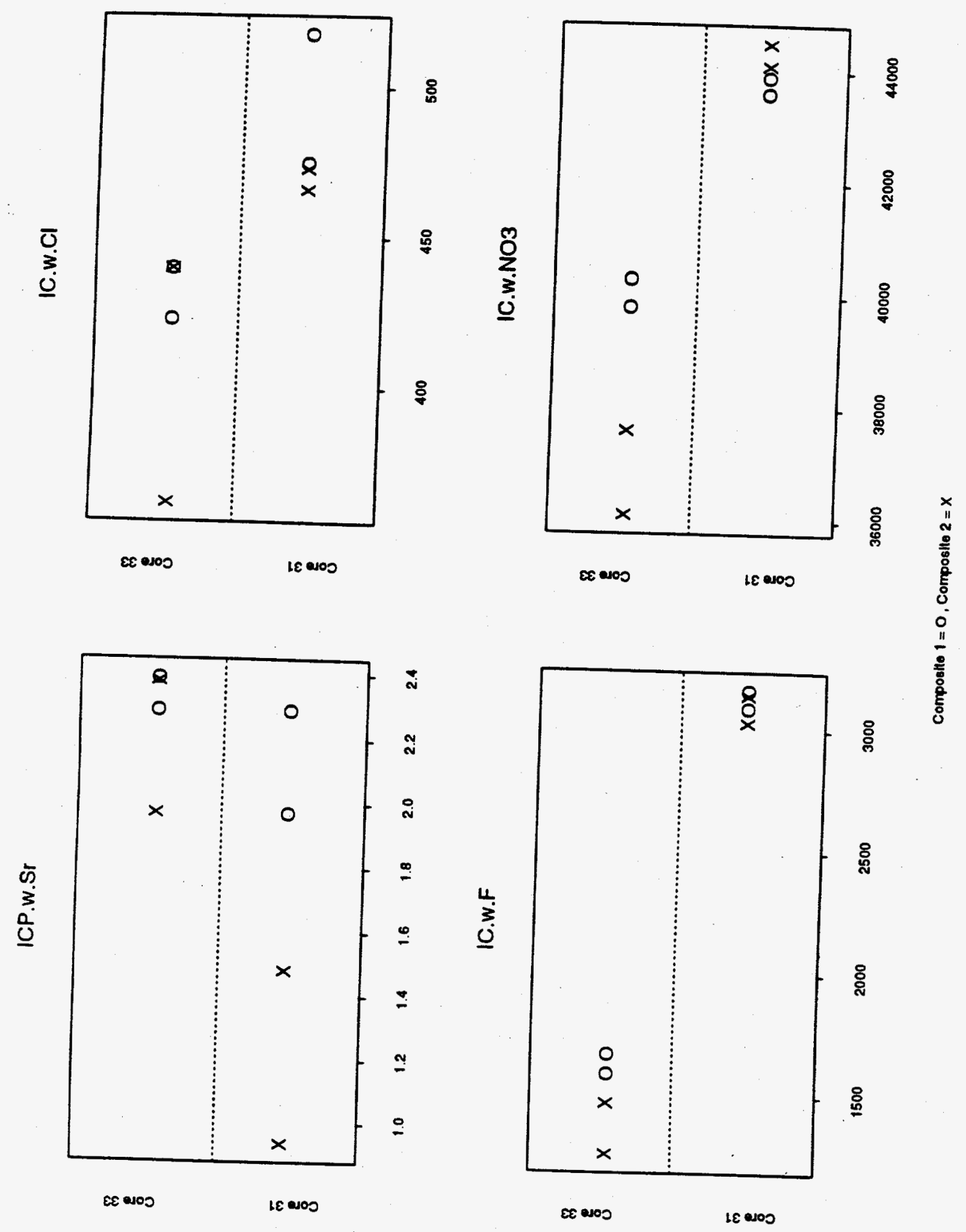

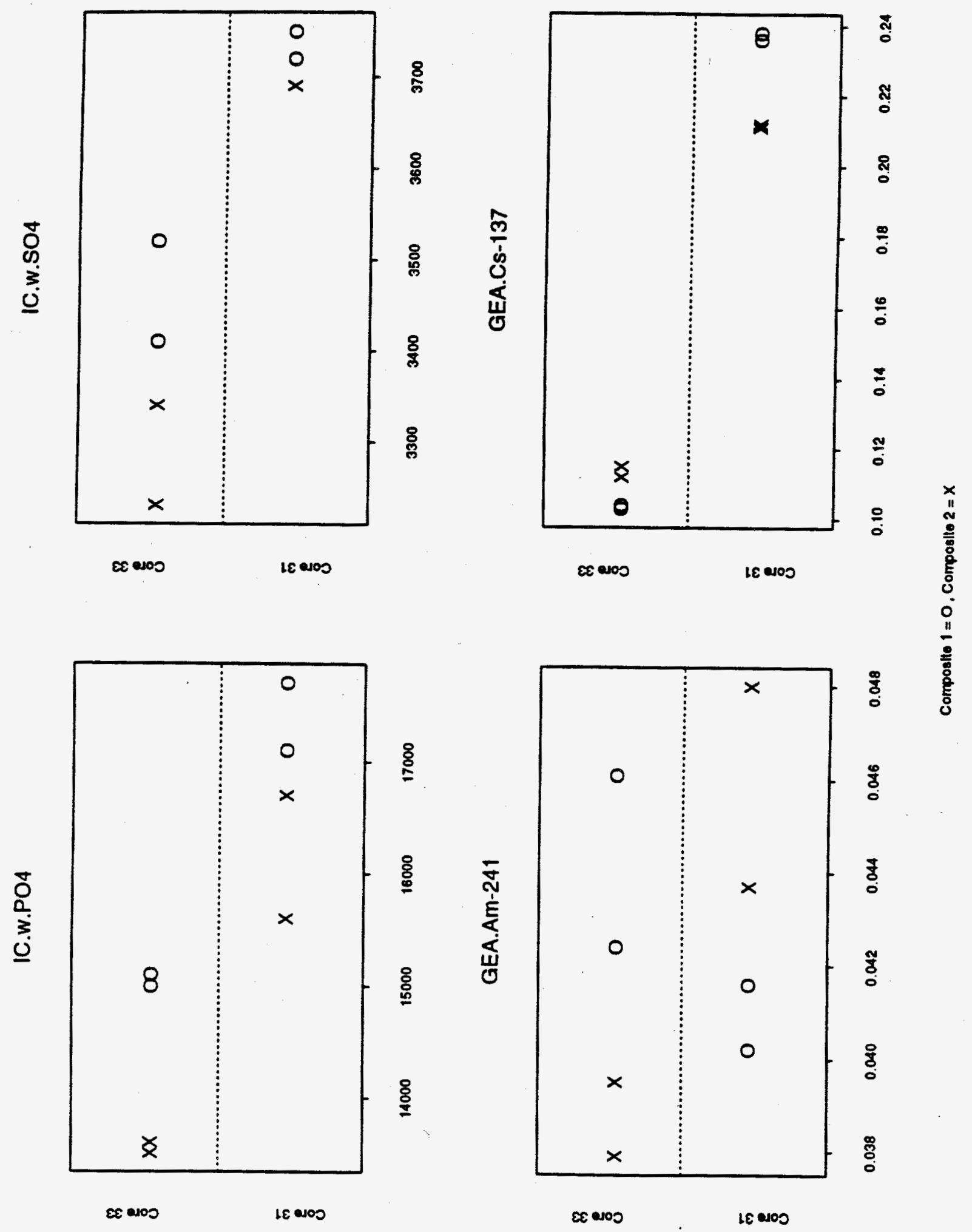
WHC-SD-WM-TI-650, Rev. 0

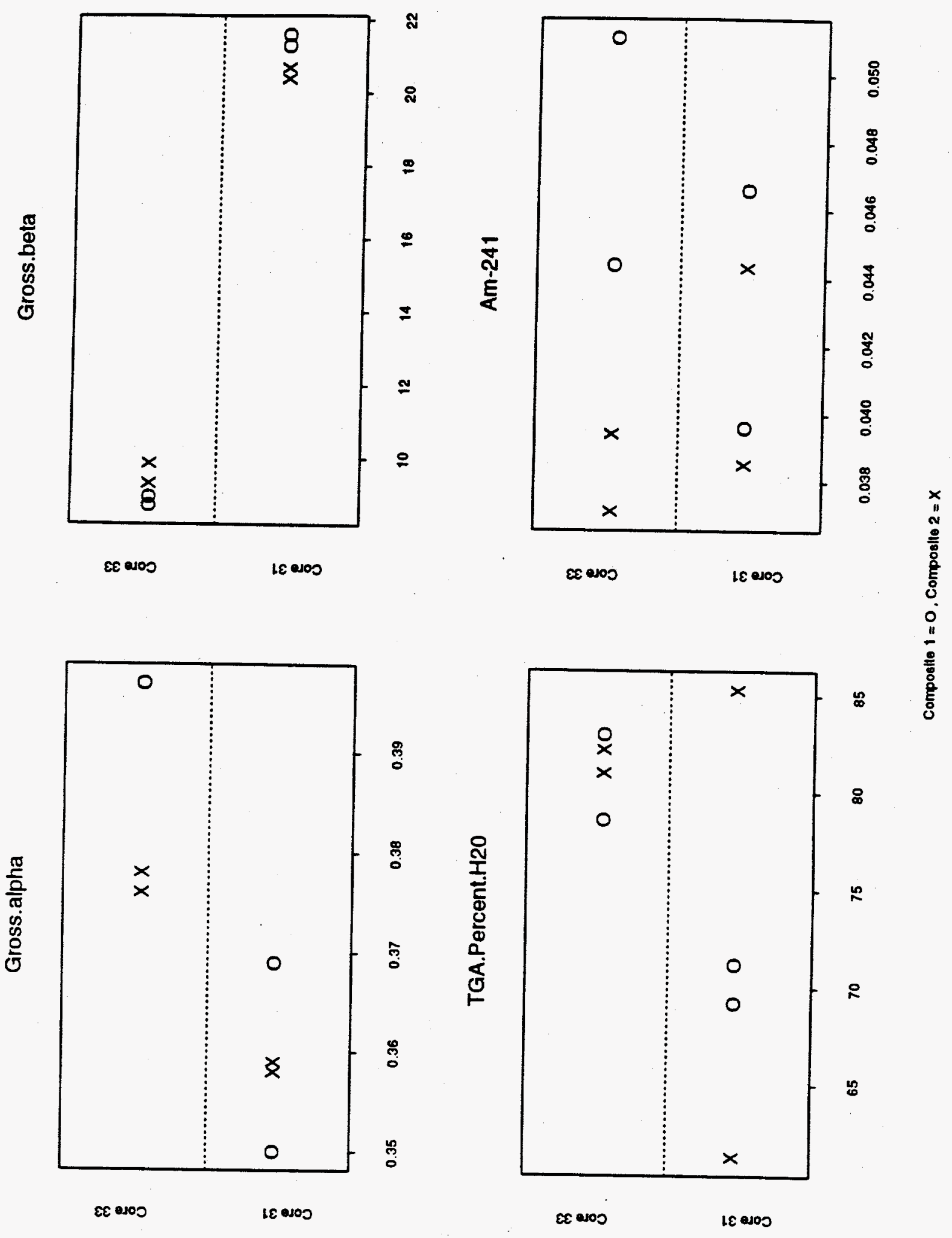


WHC-EP-0806

WHC-SD-WM-TI-650, Rev. O
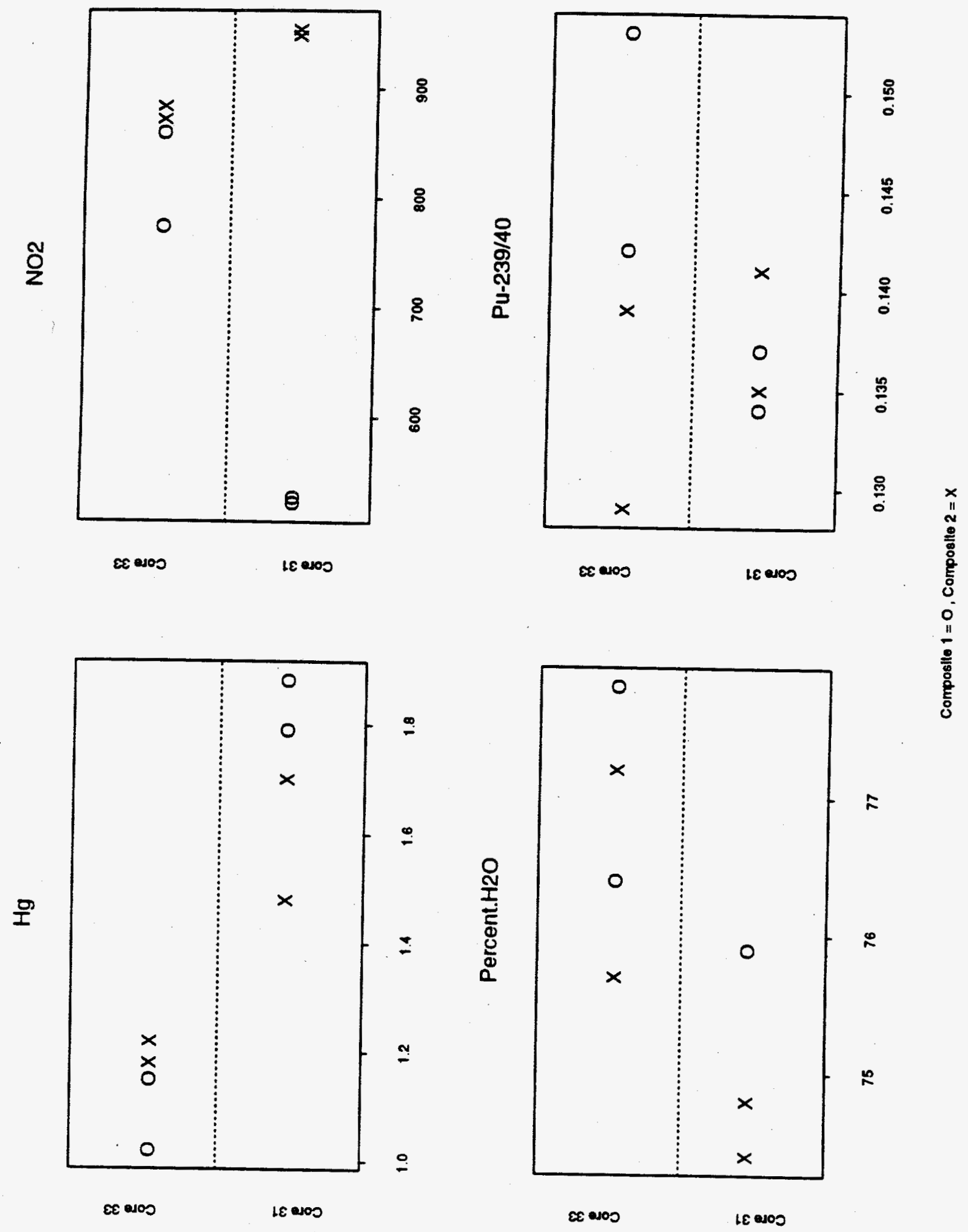
WHC-SD-WM-TI-650, ReV. 0
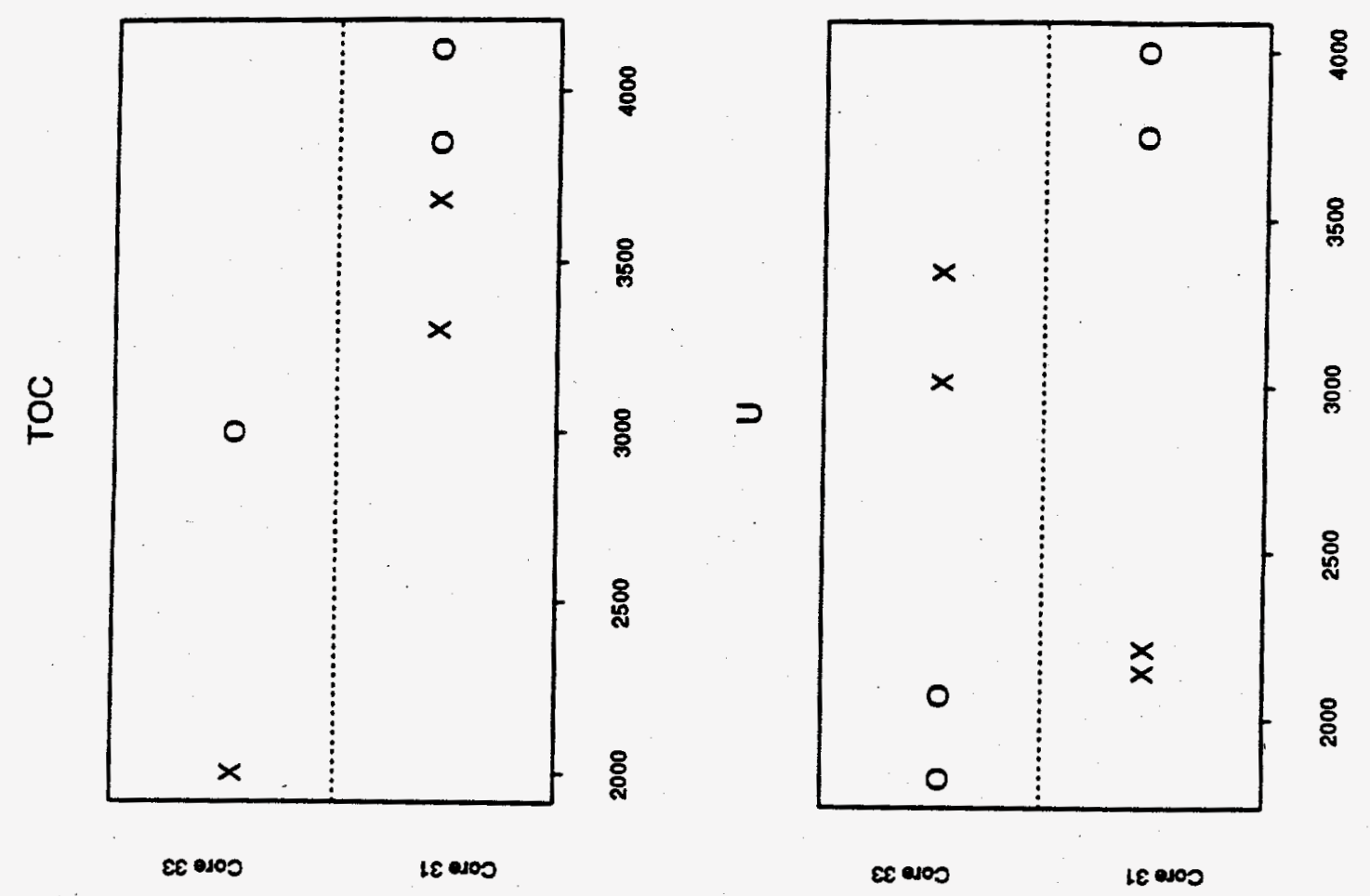

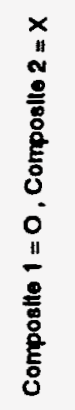
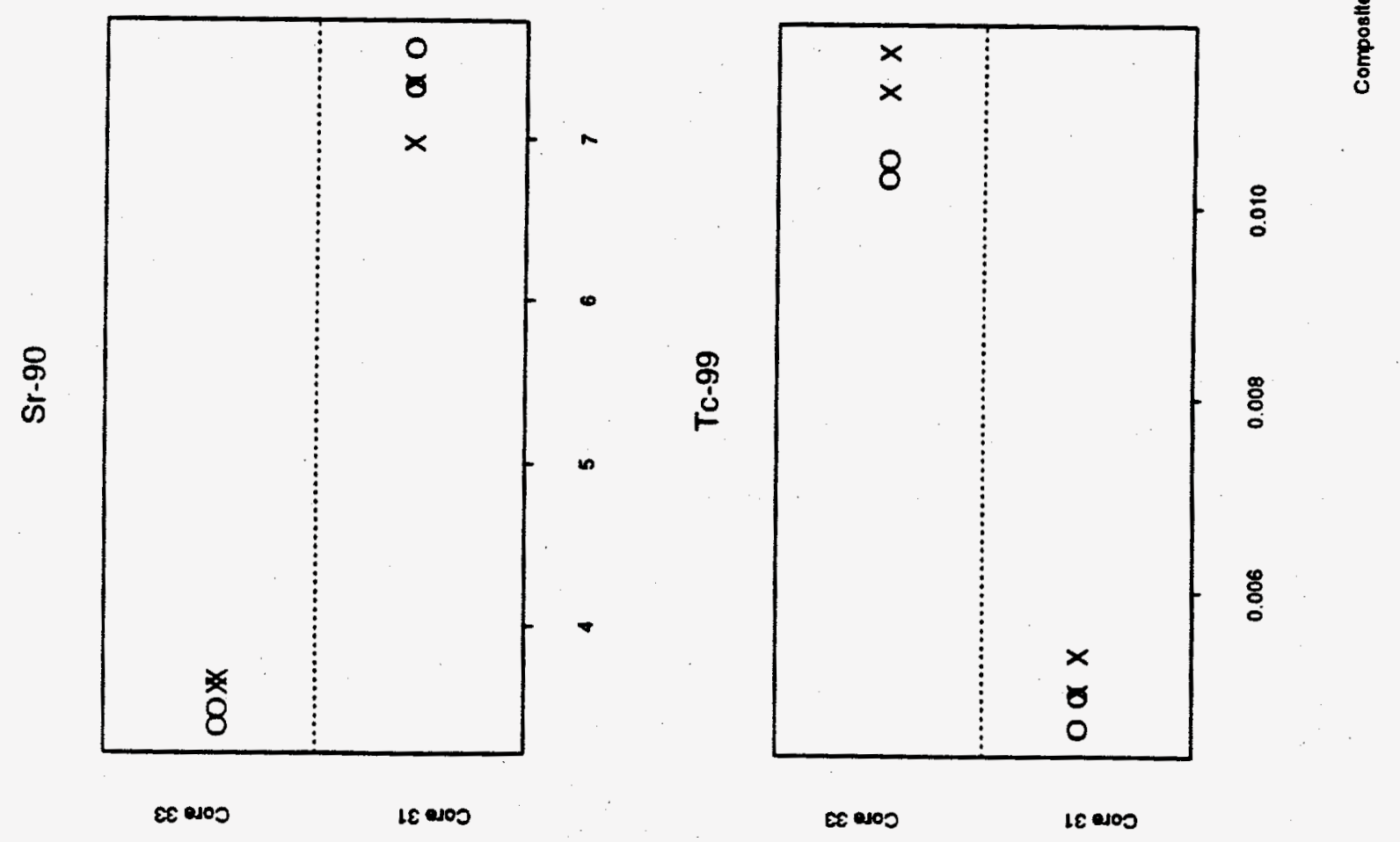


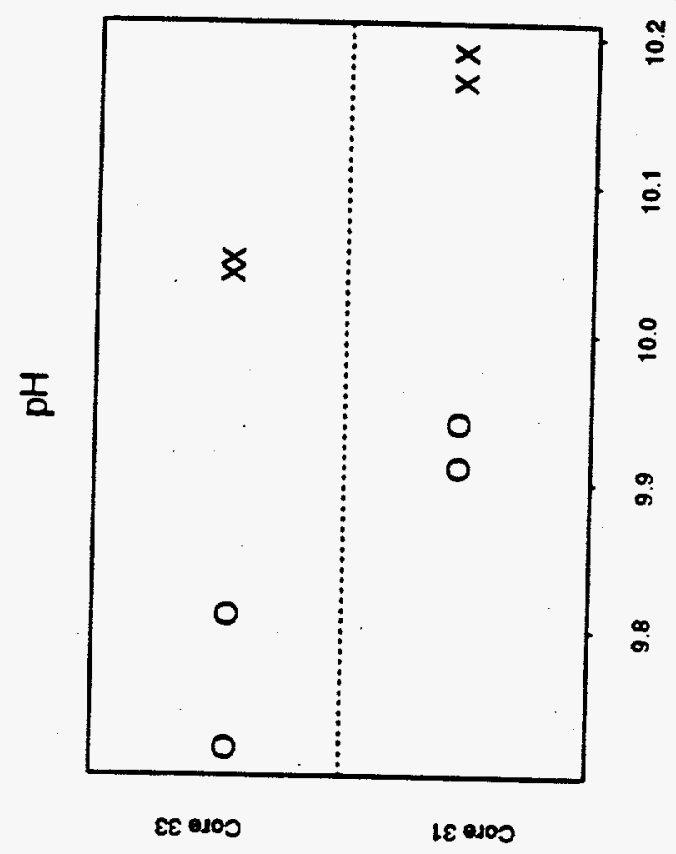


WHC-EP-0806

MHC-SD-WH-TI-650, Rev. 0

APPENDIX C

MEAN CONCENTRATION CALCULATION METHODS

[-] 
WHC-EP-0806

WHC-SD-WH-TI-650, Rev. 0

This page was intentionally left blank.

\section{C-2}

B-54 
This appendix includes a description of the statistical model that describes the structure of the data from core samples taken from Tank 241-T-111. Equations are also presented for estimates of the mean concentration, the variance for the mean concentration, and the $C I$ on the mean concentration. data is

The statistical model that describes the structure of the core composite

$$
y_{i j k}=\mu+S_{i}+C_{i j}+A_{i j k}, i=1, \ldots a, j=1, \ldots b_{i}, k=1, \ldots n_{i j} \text {, }
$$

where

$$
\begin{aligned}
& y_{i j k}=\text { laboratory results from the } k^{\text {th }} \text { duplicate of the } j^{\text {th }} \\
& \text { composite of the } i^{\text {th }} \text { core from the tank, } \\
& \mu=\text { the grand mean, } \\
& S_{i}=\text { the effect of the } i^{\text {th }} \text { core (spatial effect), } \\
& C_{i j}=\text { the effect of the } j^{\text {th }} \text { composite sample from the } i^{\text {th }} \text { core, } \\
& A_{i j k}=\text { the analytical error associated with the } k^{\text {th }} \text { duplicate in } \\
& \text { the } j^{\text {th }} \text { composite from the } i^{\text {th }} \text { core, } \\
& \text { a }=\text { the number of cores, } \\
& b_{i}=\text { the number of composite samples in the } i^{\text {th }} \text { core and } \\
& n_{i j}=\text { the number of analytical results from the } j^{\text {th }} \text { composite }
\end{aligned}
$$

For cores 31 and 33 there are two core composite samples (i.e., $\left.b_{i}=2\right)$.

The variables $S_{i}$ and $C_{i j}$ are treated as random effects. It is assumed that $S_{i}, C_{i j}$ and $A_{i j k}$ are each distributed normally with mean zero and variances $\sigma^{2}(S), \sigma^{2}(C)$ and $\sigma^{2}(A)$, respectively. Estimates of $\sigma^{2}(S), \sigma^{2}(C)$ and $\sigma^{2}(A)$ were obtained using Restricted Maximum Likelihood Estimation (REML). This method applied to variance component estimation is described by Harville (1977). 
The mean concentration of each analyte of interest in the tank was calculated using the following equation:

$$
\bar{y}=\frac{1}{a} \sum_{i=1}^{a} \bar{y}_{i+\infty}=\frac{1}{a} \sum_{i=1}^{a} \frac{\sum_{j=1}^{b_{i}} \sum_{k=1}^{n_{i j}} y_{i j k}}{n_{i+}}=\frac{1}{a} \sum_{i=1}^{a} \frac{\sum_{j=1}^{b_{i}} \sum_{k=1}^{n_{i j}}\left(\mu+S_{i}+C_{i j}+A_{i j k}\right)}{n_{i+}} .
$$

where

$$
\bar{y}_{i++}=\frac{\sum_{j=1}^{b_{i}} \sum_{k=1}^{n_{i j}} y_{i j k}}{n_{i+}} \text { and } n_{i+}=\sum_{j=1}^{b_{i}} n_{i j} \text {. }
$$

This mean gives the results from each core the same weight regardless of the unbalance that may exist for a particular analyte.

The variance of $\bar{y}$ is

$$
V(\bar{y})=C_{1} \sigma^{2}(S)+C_{2} \sigma^{2}(C)+C_{3} \sigma^{2}(A)
$$

where

$$
c_{1}=\frac{1}{a}, \quad c_{2}=\frac{1}{a^{2}} \sum_{i=1}^{a}\left[\frac{1}{n_{i+}}\right]^{2}\left[\sum_{j=1}^{b_{i}} n_{i j}^{2}\right], \quad c_{3}=\frac{1}{a^{2}} \sum_{i=1}^{a}\left[\frac{1}{n_{i+}}\right] .
$$

Using $\hat{\sigma}^{2}(S), \hat{\sigma}^{2}(C)$, and $\hat{\sigma}^{2}(A)$ (REML variance component estimates), an estimated variance of $\bar{y}$ is

$$
\hat{\sigma}^{2}(\bar{y})=C_{1} \hat{\sigma}^{2}(S)+C_{2} \hat{\sigma}^{2}(C)+C_{3} \hat{\sigma}^{2}(A)
$$

The approximate degrees of freedom used for $\hat{\sigma}^{2}(\bar{y})$ is the number of cores with data minus one.

The lower and upper 95\% CI limits (95\% LL and 95\% UL respectively) on the mean concentration are

$$
95 \% L L=\bar{y}-t_{.975} \sqrt{\hat{\sigma}^{2}(\bar{y})} \text { and } 95 \% U L=\bar{y}+t_{.975} \sqrt{\hat{\sigma}^{2}(\bar{y})}
$$

where $t .97$ is the 0.975 quantile from a Student's t-distribution with the approximate degrees of freedom associated with $\hat{\sigma}^{2}(\bar{y})$. 
Appendix C: Calculation and Miscellaneous Data 
This page intentionally left blank. 
ESTIMAIED WASIE IANK INVENIORIES -- TOIAL 1 ST QUARIER, 1081

\begin{tabular}{|c|c|c|c|c|c|c|c|c|c|c|c|c|c|c|}
\hline COMPONENI & $\begin{array}{l}\text { TANK I } \\
\text { MOLES }\end{array}$ & $\begin{array}{l}-108 \\
\text { CURIES }\end{array}$ & $\begin{array}{l}\text { TAHK T } \\
\text { MOLES }\end{array}$ & $\begin{array}{l}-100 \\
\text { CUR IES }\end{array}$ & $\begin{array}{l}\text { TAHK T- } \\
\text { MULES }\end{array}$ & $\begin{array}{l}-110 \\
\text { CURIES }\end{array}$ & $\begin{array}{l}\text { JANK I- } \\
\text { MOLES }\end{array}$ & CURJES & $\begin{array}{l}\text { TANK T- } \\
\text { MOLES }\end{array}$ & ${ }^{112}$ CURIES & $\begin{array}{l}\text { TANK T-201 } \\
\text { MOLES CURIES. }\end{array}$ & $\begin{array}{l}\text { YANK } T- \\
\text { MOLES }\end{array}$ & $\begin{array}{l}202 \\
\text { CURIES }\end{array}$ & \\
\hline 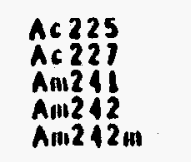 & 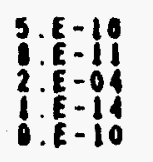 & $\begin{array}{l}\text { E. E-08 } \\
1.08 \\
2.0-01 \\
2.08 \\
2 . E-08\end{array}$ & $\begin{array}{r}5 . E-18 \\
5.10 \\
3.5-05 \\
1.15-15 \\
1 . E-10\end{array}$ & $\begin{array}{r}8 \cdot E-00 \\
\cdot E-08 \\
2 \cdot E-02 \\
3 \cdot E-07 \\
3 . E-01\end{array}$ & 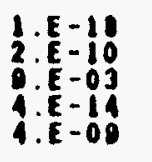 & 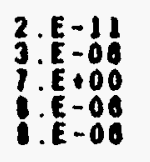 & 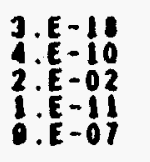 & $\begin{array}{l}4 . E-11 \\
0.5-08 \\
2 . E+01 \\
2 . E-03 \\
2 . E-03\end{array}$ & $\begin{array}{l}\text { A.E-18 } \\
1 \cdot E-08 \\
\text { T.E }-02 \\
2 \cdot E-12 \\
1 . E-07\end{array}$ & 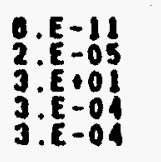 & $\begin{array}{l}0 . \\
0: \\
0: \\
0 .\end{array}$ & $\begin{array}{l}T \cdot E-22 \\
: \cdot E-17 \\
: E-05 \\
0: \\
0 .\end{array}$ & $\begin{array}{l}Q . E-15 \\
0.13 \\
5: E-02 \\
0 . \\
0 .\end{array}$ & • \\
\hline 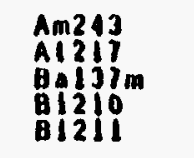 & $\begin{array}{l}1 \cdot E-07 \\
2 \cdot E-23 \\
2 \cdot E-08 \\
2 \cdot E-18 \\
2 \cdot E-17\end{array}$ & 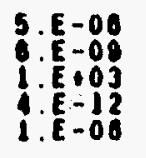 & 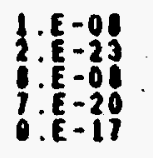 & 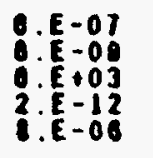 & $\begin{array}{l}\text { S.E-07 } \\
\text { S.E-28 } \\
\text { A.E-1: } \\
\text { A.E-18 } \\
\text { J.E-11 }\end{array}$ & $\begin{array}{l}\text { 2.E-05 } \\
2 \cdot E-1 \\
3 \cdot E-07 \\
1 \cdot E-1 \\
3 . E-06\end{array}$ & $\begin{array}{l}3 \cdot E-00 \\
1: E-25 \\
0 \cdot E-10 \\
9 \cdot E-17\end{array}$ & 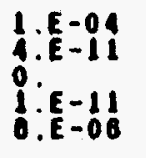 & $\begin{array}{l}1 \cdot E-05 \\
2 \cdot E-25 \\
0 . E-15 \\
4 \cdot E-16\end{array}$ & $\begin{array}{l}5 \cdot E-04 \\
: \cdot E-11 \\
0 \cdot E-11 \\
8 \cdot E-105 \\
2 \cdot E-05\end{array}$ & $\begin{array}{ll}0 . & 0 . \\
0: & 0 \\
0: & 0 \\
0: & 8: \\
0:: & 0 .\end{array}$ & $\begin{array}{l}0 . E-20 \\
2 . E-20 \\
0 . E-22 \\
7 . E-24\end{array}$ & $\begin{array}{l}9 . E-15 \\
0: E-14 \\
: E=-13\end{array}$ & \\
\hline $\begin{array}{l}\text { a } 1213 \\
91214 \\
\text { cit } \\
\text { Cm2 } \\
\text { Cin2 } 12\end{array}$ & $\begin{array}{l}2 \cdot E-18 \\
2 \cdot E-21 \\
2 \cdot E-03 \\
2 \cdot E-12 \\
7 . E-08\end{array}$ & $\begin{array}{l}\text { B.E-OQ } \\
2 . E-11 \\
1 . E-01 \\
2 . E-08 \\
1 . E-04\end{array}$ & $\begin{array}{l}\text { 1.E-12 } \\
\text { D.E }-22 \\
2 \cdot E-03 \\
3 \cdot E-13 \\
1 . E-00\end{array}$ & $\begin{array}{l}P . E-00 \\
0 . E-12 \\
1 \cdot E-01 \\
2 \cdot E-01 \\
2 . E-05\end{array}$ & $\begin{array}{l}4 \cdot E-21 \\
3 \cdot E-21 \\
3 \cdot 5-11 \\
4 \cdot 5-12 \\
4 \cdot E-20\end{array}$ & 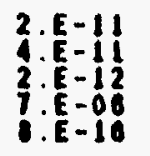 & $\begin{array}{l}1 . E-20 \\
\cdot E-21 \\
0 . E-00 \\
2 \cdot E-00\end{array}$ & $\begin{array}{l}\text { T.E-11 } \\
0 . E-11 \\
2 \cdot E-03 \\
0 .\end{array}$ & $\begin{array}{r}1 . E-20 \\
5 \cdot E-20 \\
\cdot E=30 \\
1 \cdot E-10 \\
T \cdot E-30\end{array}$ & 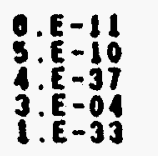 & $\begin{array}{r}0 \\
0 \\
0 \\
0 \\
0\end{array}$ & $\begin{array}{l}2 . E-24 \\
1 . E-23 \\
0 . \\
0 . \\
0 .\end{array}$ & $\begin{array}{l}0 . E-15 \\
1 . E-13 \\
0: \\
0:\end{array}$ & $\frac{7}{y}$ \\
\hline 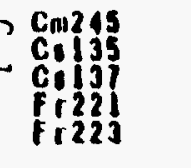 & $\begin{array}{r}5 . E-11 \\
1.6-02 \\
1.0-01 \\
2.8-10 \\
2.6-18\end{array}$ & $\begin{array}{r}2 \cdot E-00 \\
7 \cdot E-03 \\
2.5+03 \\
8.5-08 \\
2 . E-03\end{array}$ & $\begin{array}{l}\text { T.E- }-12 \\
0.01 \\
0-0 \\
0-01 \\
2: E-10 \\
1 . E-17\end{array}$ & 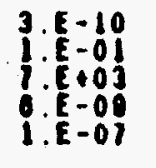 & 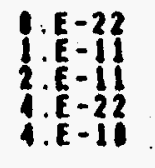 & $\begin{array}{r}1.5-20 \\
2.5-12 \\
3.5-01 \\
2.5-11 \\
4 . E-01\end{array}$ & $\begin{array}{l}0 . \\
0: \\
0: \\
\text { I.E-2! } \\
I . E-11\end{array}$ & & 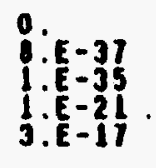 & $\begin{array}{l}\text { P. } \\
\text { I.E-37 } \\
\text { f.E-3 } \\
\text { Q.E- } 11 \\
3 . E-07\end{array}$ & $\begin{array}{l}0 . \\
0: \therefore \\
0:-1 \\
0 . .\end{array}$ & $\begin{array}{l}0 . \\
0 . \\
0: \\
2 . E-25 \\
I . E-24\end{array}$ & $\begin{array}{l}0 . \\
0: \\
: 5-15 \\
0-15\end{array}$ & $\begin{array}{l}0 \\
0 \\
0 \\
0 \\
0\end{array}$ \\
\hline $\begin{array}{l}1120 \\
\text { No } 03 \mathrm{~m} \\
\text { Nisj } \\
\text { Np231 } \\
\text { Np230 }\end{array}$ & 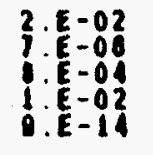 & $\begin{array}{l}\text { S.E }-04 \\
2 . E-0 \\
3 . E \\
3.00 \\
2 . E-03 \\
\text { 5.E-OB }\end{array}$ & 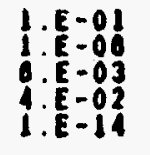 & $\begin{array}{r}3 \cdot E-03 \\
\cdot \cdot E-02 \\
2 \cdot E \cdot 01 \\
y \cdot E-03 \\
6 . E-03\end{array}$ & $\begin{array}{l}\text { A.E-12 } \\
\text { P.E-08 } \\
1 \cdot E-11 \\
3 \cdot E-01 \\
4 \cdot E-13\end{array}$ & $\begin{array}{l}\text { C.E- } 14 \\
2 \cdot E-01 \\
5 \cdot E-1 \\
5.5-05 \\
2 . E-05\end{array}$ & $\begin{array}{l}0 . E-06 \\
8 \cdot E-06 \\
2 \cdot E-04 \\
5 \cdot E-04 \\
2 . E-12\end{array}$ & $\begin{array}{l}0 . E-01 \\
2 \cdot E-01 \\
B \cdot E-01 \\
0 \cdot E-05 \\
1 . E-04\end{array}$ & 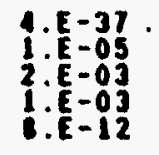 & 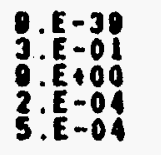 & $\begin{array}{l}0 .: \\
0: \cdots \\
0: \cdots\end{array}$ & $\begin{array}{l}0 . \\
0 . \\
0: \\
2 . E-00 \\
0 .\end{array}$ & $\begin{array}{l}0 . \\
0: \\
3: E-01 \\
0 .\end{array}$ & 9 \\
\hline 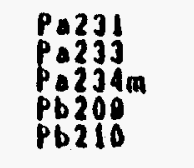 & $\begin{array}{r}3 \cdot E-07 \\
1 \cdot E-10 \\
\dot{E}-13 \\
0.18 \\
2 . E-18\end{array}$ & $\begin{array}{r}1.5-00 \\
2.5-03 \\
1.5-81 \\
6-00 \\
4.12\end{array}$ & $\begin{array}{l}\text { 1.E-98 } \\
\text { 1.E-98 } \\
2.5-13 \\
\text { 1.E-18 }\end{array}$ & 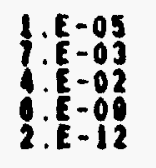 & $\begin{array}{l}\mathrm{E}-01 \\
\mathbf{E}-11 \\
\mathrm{E}-12 \\
2 \cdot E-20 \\
\mathrm{E}-10\end{array}$ & $\begin{array}{r}\text { T.E-08 } \\
5-05 \\
2 \cdot E-01 \\
2 . E-11 \\
\text { E- }-12\end{array}$ & $\begin{array}{r}2 . E-00 \\
2 \cdot E-11 \\
1 \cdot E-12 \\
5 \cdot E-20 \\
0 . E-10\end{array}$ & $\begin{array}{r}2.6-05 \\
0.05 \\
0.0-01 \\
6-11 \\
1 . E-11\end{array}$ & $\begin{array}{l}\text { S.E-08 } \\
3 \cdot E-11 \\
1 \cdot E-11 \\
\cdot E-20 \\
5 . E-15\end{array}$ & 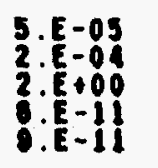 & 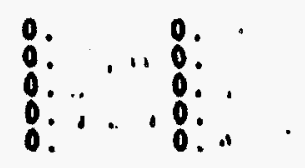 & $\begin{array}{l}2 . E-13 \\
5 \cdot E-14 \\
0 \cdot .5-24 \\
\text { I.E-11 }\end{array}$ & $\begin{array}{l}2 \cdot E-12 \\
3 \cdot E-07 \\
0 \cdot E-15 \\
2 \cdot E-11\end{array}$ & \\
\hline 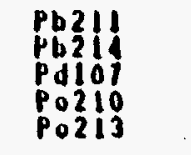 & $\begin{array}{l}3 \cdot E-10 \\
2 \cdot E-21 \\
1 \cdot E-02 \\
1 \cdot E-11 \\
2 \cdot E-21\end{array}$ & 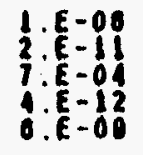 & $\begin{array}{l}2 \cdot E-15 \\
0 \cdot E-22 \\
5 \cdot E-02 \\
2 \cdot E-15 \\
2 \cdot E-21\end{array}$ & 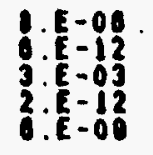 & $\begin{array}{l}S \cdot E-18 \\
0 \cdot E-21 \\
2 \cdot E-12 \\
0.1-18 \\
\cdot E-30\end{array}$ & $\begin{array}{l}3 \cdot E-00 \\
5 \cdot 11 \\
1 \cdot E-13 \\
0.12 \\
2 . E-11\end{array}$ & $\begin{array}{l}\text { LE } E-15 \\
\text { LE }-20 \\
0 \cdot E-17 \\
2 \cdot E-20\end{array}$ & $\begin{array}{l}\text { Q.E-00 } \\
0 . E-11 \\
: E-11 \\
\text { :E-11 }\end{array}$ & $\begin{array}{l}A \cdot E-15 \\
7 \cdot E-20 \\
2 \cdot E-37 \\
9 \cdot E-17 \\
2 \cdot E-20\end{array}$ & 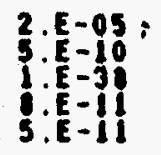 & 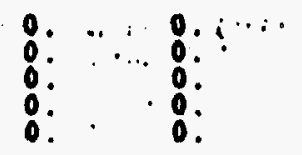 & $\begin{array}{l}1 \cdot E-22 \\
2 \cdot E-23 \\
0 \cdot E-20 \\
2 \cdot E-30 \\
3 \cdot E-33\end{array}$ & $\begin{array}{l}0.5-13 \\
1: 5-13 \\
0: E-14 \\
: E-15\end{array}$ & \\
\hline
\end{tabular}


ESTIMATED WASTE TANK INVENTORIES - - TOTAL 1 ST QUARTER, 1981 - CONTINUEO

\begin{tabular}{|c|c|c|c|c|c|c|c|c|c|c|c|c|c|c|}
\hline COMPONENI & $\begin{array}{l}\text { TANK } \\
\text { MOL.ES }\end{array}$ & $\begin{array}{l}\text { - } 108 \\
\text { CURIES }\end{array}$ & $\begin{array}{l}\text { TANK T } \\
\text { MOLES }\end{array}$ & $\begin{array}{l}-109 \\
\text { CURIES }\end{array}$ & $\begin{array}{l}\text { IANK } \\
\text { MOLES }\end{array}$ & $\begin{array}{l}-110 \\
\text { CURIES }\end{array}$ & $\begin{array}{l}\text { TANK } \\
\text { MOLES }\end{array}$ & CURIES & $\begin{array}{l}\text { TANK T } \\
\text { MOLES }\end{array}$ & 12 URIES & $\begin{array}{l}\text { IANK T- } \\
\text { MOLES }\end{array}$ & $\begin{array}{l}-201 \\
\text { CURIES }\end{array}$ & $\begin{array}{l}\text { TANK } \\
\text { MOLES }\end{array}$ & $\begin{array}{l}202 \\
\text { CURIES }\end{array}$ \\
\hline $\begin{array}{l}\text { Po2 } 14 \\
\text { Po2 } 15 \\
\text { Po218 } \\
\text { Pu238 } \\
\text { Pu239 }\end{array}$ & $\begin{array}{l}3 \cdot E-28 \\
2 \cdot E-22 \\
2 \cdot E-22 \\
2 \cdot E-06 \\
3 \cdot E-01\end{array}$ & $\begin{array}{l}\text { 2. E- } 11 \\
1 . E-06 \\
2 . E-11 \\
8 . E-03 \\
5 . E+00\end{array}$ & $\begin{array}{l}1 . E-28 \\
1 . E-21 \\
1 . E-22 \\
4 . E-07 \\
\text { 3.E-02 }\end{array}$ & $\begin{array}{l}8 \cdot E-12 \\
8 \cdot E-06 \\
6 \cdot E-12 \\
2 . E-03 \\
5 . E-01\end{array}$ & $\begin{array}{l}8 \cdot E-28 \\
4 \cdot E-22 \\
7 \cdot E-22 \\
1 . E-04 \\
1 . E+01\end{array}$ & $\begin{array}{l}6 \cdot E-11 \\
3 \cdot E-06 \\
5 \cdot E-11 \\
4 \cdot E-01 \\
2 . E+02\end{array}$ & $\begin{array}{l}1 . E-27 \\
1 \cdot E-2 \\
1 \cdot E-21 \\
2 \cdot E-04 \\
8 . E+00\end{array}$ & $\begin{array}{l}\text { 9.E }-11 \\
6 \cdot E-06 \\
7 \cdot E-11 \\
7 \cdot E-01 \\
1 . E+02\end{array}$ & $\begin{array}{l}\text { 9.E-27 } \\
\text { 3.E-2 } \\
8 \cdot E-21 \\
\text { 3.E-03 } \\
\text { 1.E+01 }\end{array}$ & $\begin{array}{l}6 \cdot E-10 \\
2 \cdot E-05 \\
5 \cdot E-10 \\
1 \cdot E+01 \\
2 . E+02\end{array}$ & $\begin{array}{l}0 . \\
0 . \\
0 . \\
0 . \\
0 .\end{array}$ & $\begin{array}{l}0 . \\
0 . \\
0 . \\
0 . \\
0 .\end{array}$ & $\begin{array}{l}\text { 2.E }-30 \\
1 \cdot E-28 \\
2 \cdot E-24 \\
5 \cdot E-07 \\
2 \cdot E-02\end{array}$ & $\begin{array}{l}1 \cdot E-13 \\
6 \cdot E-13 \\
1 \cdot E-13 \\
2 \cdot E-03 \\
3 \cdot E-01\end{array}$ \\
\hline $\begin{array}{l}P u 240 \\
P u 241 \\
R a 223 \\
R a 225 \\
R a 226\end{array}$ & $\begin{array}{l}6 \cdot E-03 \\
3 \cdot E-05 \\
1 \cdot E-13 \\
7 \cdot E-16 \\
7 . E-14\end{array}$ & $\begin{array}{l}4 . E-01 \\
8 \cdot E-01 \\
1 . E-06 \\
6 . E-09 \\
2 . E-11\end{array}$ & $\begin{array}{l}7 \cdot E-04 \\
3 \cdot E-06 \\
7 \cdot E-13 \\
7 \cdot E-16 \\
3 \cdot E-14\end{array}$ & $\begin{array}{l}\text { 4.E-02 } \\
9 \cdot E-02 \\
8 \cdot E-06 \\
6 \cdot E-09 \\
6 . E-12\end{array}$ & $\begin{array}{l}\text { 3.E }-01 \\
3 \cdot E-03 \\
2 . E-13 \\
2 . E-18 \\
2 . E-13\end{array}$ & $\begin{array}{l}2 . E+01 \\
6 . E+01 \\
3 . E-06 \\
2 . E-11 \\
5 . E-11\end{array}$ & $\begin{array}{l}4 . E-01 \\
6 \cdot E-03 \\
6 \cdot E-13 \\
5 \cdot E-18 \\
3 . E-13\end{array}$ & $\begin{array}{l}2 . E+01 \\
2 . E+02 \\
6 . E-06 \\
4 . E-11 \\
7 . E-11\end{array}$ & $\begin{array}{l}7 \cdot E-01 \\
1 \cdot E-02 \\
2 \cdot E-12 \\
6 \cdot E-18 \\
2 . E-12\end{array}$ & $\begin{array}{l}4 . E+01 \\
4 \cdot E+02 \\
2 \cdot E-05 \\
6 \cdot E-11 \\
5 \cdot E-10\end{array}$ & $\begin{array}{l}0 . \\
0 . \\
0 . \\
0 . \\
0 .\end{array}$ & $\begin{array}{l}0 \\
0 . \\
0 \\
0 . \\
0 .\end{array}$ & $\begin{array}{l}1 \cdot E-03 \\
2 \cdot E-05 \\
5 \cdot E-20 \\
1 \cdot E-21 \\
5 \cdot E-16\end{array}$ & $\begin{array}{l}6 \cdot E-02 \\
5 \cdot E-01 \\
6 \cdot E-13 \\
9 \cdot E-15 \\
1 . E-13\end{array}$ \\
\hline $\begin{array}{l}\text { Ru1 } 106 \\
\text { Sb } 126 \\
\text { Sb } 126 \mathrm{~m} \\
\text { Se } 79 \\
\text { Sm151 }\end{array}$ & $\begin{array}{l}5 \cdot E-10 \\
3 \cdot E-09 \\
3 \cdot E-12 \\
2 \cdot E-03 \\
2 . E-02\end{array}$ & $\begin{array}{l}2 \cdot E-04 \\
3 \cdot E-02 \\
3 \cdot E-02 \\
9 \cdot E-03 \\
1 . E+02\end{array}$ & $\begin{array}{l}5 . E-11 \\
3 \cdot E-10 \\
4 \cdot E-13 \\
1 . E-02 \\
3 . E-03\end{array}$ & $\begin{array}{l}2 \cdot E-05 \\
3 \cdot E-03 \\
3 \cdot E-03 \\
5 \cdot E-02 \\
1 . E+01\end{array}$ & $\begin{array}{l}3 \cdot E-11 \\
4 \cdot E-09 \\
4 \cdot E-12 \\
5 \cdot E-13 \\
3 \cdot E-02\end{array}$ & $\begin{array}{l}1 . E-05 \\
4 . E-02 \\
4 . E-02 \\
3 . E-12 \\
1 . E+02\end{array}$ & $\begin{array}{l}1 . E-10 \\
4 \cdot E-09 \\
4 \cdot E-12 \\
0 . E-02 \\
2 . E-02\end{array}$ & $\begin{array}{l}\text { 4.E-05 } \\
4 \cdot E-02 \\
4 \cdot E-02 \\
0 . E+01 \\
6 \cdot E+01\end{array}$ & $\begin{array}{l}9 \cdot E-10 \\
5 \cdot E-09 \\
6 \cdot E-12 \\
5 \cdot E-38 \\
2 \cdot E-02\end{array}$ & $\begin{array}{l}\text { 3.E-04 } \\
6 \cdot E-02 \\
6 \cdot E-02 \\
3 \cdot E-37 \\
8 \cdot E+01\end{array}$ & $\begin{array}{l}0 . \\
0 \\
0 \\
0 \\
0 .\end{array}$ & $\begin{array}{l}\mathbf{0} . \\
\mathbf{0} \\
0 \\
0 . \\
0 .\end{array}$ & $\begin{array}{l}0 . \\
0 . \\
0 \\
0 . \\
0 .\end{array}$ & $\begin{array}{l}0 . \\
0 . \\
0 \\
0 . \\
0 .\end{array}$ \\
\hline $\begin{array}{l}\text { Sn126 } \\
\text { Sr90 } \\
\text { Ic99 } \\
\text { Ih227 } \\
\text { Th229 }\end{array}$ & $\begin{array}{l}9 . E-03 \\
4 . E-01 \\
2 . E-01 \\
2 . E-13 \\
1 . E-10\end{array}$ & $\begin{array}{l}\text { 3. E - 02 } \\
4 \cdot E+03 \\
\text { J.E }-01 \\
1 . E-06 \\
6 . E-09\end{array}$ & $\begin{array}{l}1 . E-03 \\
7 . E-03 \\
1 . E+00 \\
1 . E-12 \\
1 . E-10\end{array}$ & $\begin{array}{l}3 \cdot E-03 \\
9 \cdot E+01 \\
2 \cdot E+00 \\
8 \cdot E-06 \\
6 \cdot E-09\end{array}$ & $\begin{array}{l}1 \cdot E-02 \\
4 \cdot E-01 \\
6 \cdot E-11 \\
4 \cdot E-13 \\
3 \cdot E-13\end{array}$ & $\begin{array}{l}4 \cdot E-02 \\
4 \cdot E+03 \\
1 \cdot E-10 \\
3 \cdot E-06 \\
2 . E-11\end{array}$ & $\begin{array}{l}1 . E-02 \\
3 \cdot E-01 \\
0 . E-13 \\
9 \cdot E-13 \\
9 . E-13\end{array}$ & $\begin{array}{l}4 \cdot E-02 \\
4 \cdot E+03 \\
0 \cdot E-06 \\
6 \cdot E-06 \\
4 \cdot E-11\end{array}$ & $\begin{array}{l}2 . E-02 \\
5 \cdot E-01 \\
3 \cdot E-36 \\
3 . E-12 \\
1 . E-12\end{array}$ & $\begin{array}{l}6 \cdot E-02 \\
6 \cdot E+03 \\
5 \cdot E-36 \\
2 \cdot E-05 \\
6 \cdot E-11\end{array}$ & $\begin{array}{l}0 . \\
0 \\
0 \\
0 \\
0 .\end{array}$ & $\begin{array}{l}0 . \\
0 . \\
0 . \\
0 . \\
0 .\end{array}$ & $\begin{array}{l}0 . \\
0 . \\
0 . \\
8 \cdot E-20 \\
2 \cdot E-16\end{array}$ & $\begin{array}{l}0 . \\
0 . \\
0 . \\
6 . E-13 \\
9 . E-15\end{array}$ \\
\hline $\begin{array}{l}\operatorname{Th} 230 \\
\operatorname{Th} 231 \\
\operatorname{Th} 234 \\
\operatorname{l} 1207 \\
\mathrm{U} 233\end{array}$ & $\begin{array}{l}5 \cdot E-10 \\
5 \cdot E-11 \\
2 \cdot E-08 \\
3 \cdot E-17 \\
2 \cdot E-06\end{array}$ & $\begin{array}{l}\text { 2.E }-09 \\
6 \cdot E-03 \\
1 . E-01 \\
1 . E-06 \\
\text { 4.E-06 }\end{array}$ & $\begin{array}{l}2 . E-10 \\
1 \cdot E-11 \\
7 \cdot E-09 \\
2 \cdot E-16 \\
2 . E-06\end{array}$ & $\begin{array}{l}8 . E-10 \\
2 . E-03 \\
4 . E-02 \\
8 . E-06 \\
4 . E-06\end{array}$ & $\begin{array}{l}2 \cdot E-09 \\
8 \cdot E-11 \\
4 \cdot E-08 \\
7 \cdot E-17 \\
3 \cdot E-09\end{array}$ & $\begin{array}{l}1 \cdot E-08 \\
1 \cdot E-02 \\
2 \cdot E-01 \\
3 \cdot E-06 \\
7 . E-09\end{array}$ & $\begin{array}{l}\text { 4.E-09 } \\
2 . E-10 \\
1 . E-07 \\
2 . E-16 \\
8 . E-09\end{array}$ & $\begin{array}{l}\text { 2.E-08 } \\
3 \cdot E-02 \\
6 \cdot E-01 \\
6 \cdot E-06 \\
2 \cdot E-08\end{array}$ & $\begin{array}{l}\text { 3.E }-08 \\
7 \cdot E-10 \\
4 \cdot E-07 \\
5 \cdot E-16 \\
1 . E-08\end{array}$ & $\begin{array}{l}1 \cdot E-07 \\
9 \cdot E-02 \\
2 \cdot E+00 \\
2 \cdot E-05 \\
3 \cdot E-08\end{array}$ & $\begin{array}{l}0 . \\
0 . \\
0 \\
0 . \\
0 .\end{array}$ & $\begin{array}{l}0 . \\
0 . \\
0 \\
0 . \\
0 .\end{array}$ & $\begin{array}{l}6 \cdot E-12 \\
6 . E-17 \\
0.5-23 \\
2 . E-23 \\
5 . E-12\end{array}$ & $\begin{array}{l}\text { 3. } E-11 \\
8 . E-09 \\
0 . \\
6 . E-13 \\
1 . E-11\end{array}$ \\
\hline $\begin{array}{l}U 234 \\
12235 \\
U 238 \\
\text { Y90 } \\
2 \text { r } 93\end{array}$ & $\begin{array}{l}\text { S.E }-06 \\
1 \cdot E+01 \\
2 \cdot E+03 \\
9 \cdot E-05 \\
9 . E-01\end{array}$ & $\begin{array}{l}1 . E-05 \\
6 . E-03 \\
1 . E-01 \\
4 . E+03 \\
2 . E-01\end{array}$ & $\begin{array}{l}\text { 3. E }-06 \\
3 \cdot E+00 \\
5 \cdot E+02 \\
2 . E-06 \\
1 . E-01\end{array}$ & $\begin{array}{l}4 \cdot E-06 \\
2 \cdot E-03 \\
4 \cdot E-02 \\
9 \cdot E+01 \\
2 \cdot E-02\end{array}$ & $\begin{array}{l}5 \cdot E-05 \\
2 \cdot E+01 \\
3 \cdot E+03 \\
9 \cdot E-05 \\
1 . E+00\end{array}$ & $\begin{array}{l}7 \cdot E-05 \\
1 \cdot E-02 \\
2 \cdot E-01 \\
5 \cdot E+03 \\
3 \cdot E-01\end{array}$ & $\begin{array}{l}\text { 8. E-05 } \\
5 . E+01 \\
8 . E+03 \\
8 . E-05 \\
1 . E+00\end{array}$ & $\begin{array}{l}1 \cdot E-04 \\
3 \cdot E-02 \\
6 \cdot E-01 \\
4 \cdot E+03 \\
3 \cdot E-01\end{array}$ & $\begin{array}{l}\text { 7. } \mathrm{E}-04 \\
2 . \mathrm{E}+02 \\
3 . \mathrm{E}+04 \\
1 . \mathrm{E}-04 \\
1 . \mathrm{E}+00\end{array}$ & $\begin{array}{l}1 \cdot E-03 \\
9 \cdot E-02 \\
2 \cdot E+00 \\
6 \cdot E+03 \\
3 \cdot E-01\end{array}$ & $\begin{array}{l}0 . \\
0 . \\
0 \\
0 . \\
0 .\end{array}$ & $\begin{array}{l}0 . \\
0 . \\
0 . \\
0 . \\
0 .\end{array}$ & $\begin{array}{l}1 . E-07 \\
2 . E-05 \\
0 . \\
0 \\
0 .\end{array}$ & $\begin{array}{l}2 . E-07 \\
8 . E-09 \\
0 . \\
0 \\
0 .\end{array}$ \\
\hline $\begin{array}{l}\mathrm{Ag} \\
\mathrm{Al} \\
\mathrm{Ba} \\
\mathrm{Bi} \\
\mathrm{C} 2 \mathrm{H} 303\end{array}$ & $\begin{array}{l}2 . E-08 \\
1 . E+03 \\
3 . E+00 \\
7 . E+03 \\
0 .\end{array}$ & $\begin{array}{l}0 . \\
0 . \\
0 . \\
0 . \\
0 .\end{array}$ & $\begin{array}{l}2 . E-07 \\
2 . E+04 \\
2 . E+00 \\
8 . E+02 \\
0 .\end{array}$ & $\begin{array}{l}0 \\
0 \\
0 \\
0 \\
0\end{array}$. & $\begin{array}{l}2 . E-17 \\
0 . E-03 \\
2 . E-03 \\
1 . E+07 \\
0 .\end{array}$ & $\begin{array}{l}0 \\
0 \\
0 \\
0 \\
0\end{array}$ & $\begin{array}{l}0 . \\
0 . \\
0 \\
1 \\
0 \\
1 .\end{array}$ & $\begin{array}{l}0 . \\
0 . \\
0 . \\
0 . \\
0 .\end{array}$ & $\begin{array}{l}0 . \\
0 . \\
6 . E-03 \\
1 . E+07 \\
0 .\end{array}$ & $\begin{array}{l}0 . \\
0 . \\
0 . \\
0 . \\
0 .\end{array}$ & $\begin{array}{l}0 . \\
0 . \\
0 . \\
0 . \\
0 .\end{array}$ & $\begin{array}{l}\mathbf{0} . \\
\mathbf{0} \\
\mathbf{0} \\
\mathbf{0} \\
0 .\end{array}$ & $\begin{array}{l}0 . \\
0 . \\
0 \\
3 \\
0 .\end{array}$ & $\begin{array}{l}0 \\
0 . \\
0 . \\
0 . \\
0 .\end{array}$ \\
\hline
\end{tabular}


ESTIMATED WASTE TANK INVENTORIES -- TOTAL 1 ST QUARTER, $1981 \cdots$

\begin{tabular}{|c|c|c|c|c|c|c|c|c|c|c|c|c|c|c|}
\hline COMPONENT & $\begin{array}{l}\text { IANK } \\
\text { MOLES }\end{array}$ & $\begin{array}{l}-108 \\
\text { CURIES }\end{array}$ & $\begin{array}{l}\text { TANK ' } \\
\text { MOLES }\end{array}$ & $\begin{array}{l}-109 \\
\text { CURIES }\end{array}$ & $\begin{array}{l}\text { TANK T } \\
\text { MOLES }\end{array}$ & $\begin{array}{l}-110 \\
\text { CURIES }\end{array}$ & $\begin{array}{l}\text { TANK ' } \\
\text { MOLES }\end{array}$ & $\begin{array}{l}-111 \\
\text { CURIES }\end{array}$ & $\begin{array}{l}\text { TANK T } \\
\text { MOLES }\end{array}$ & $\begin{array}{l}-112 \\
\text { CURIES }\end{array}$ & $\begin{array}{l}\text { TANK T } \\
\text { MOLES }\end{array}$ & $\begin{array}{l}-201 \\
\text { CURIES }\end{array}$ & $\begin{array}{l}\text { TANK T } \\
\text { MOLES }\end{array}$ & $\begin{array}{l}-202 \\
\text { CURIES }\end{array}$ \\
\hline $\begin{array}{l}\mathrm{C} 6 \mathrm{H}_{507} \\
\mathrm{CO} \\
\mathrm{Ca} \\
\mathrm{Ce} \\
\mathrm{Cl}\end{array}$ & $\begin{array}{l}0 . \\
1 . E+04 \\
6 . E-33 \\
5 . E-01 \\
4 . E-06\end{array}$ & $\begin{array}{l}\mathbf{0} \\
\mathbf{0} \\
\mathbf{0} \\
\mathbf{0} \\
0 .\end{array}$ & $\begin{array}{l}0 . \\
3 \cdot E+05 \\
6 \cdot E-34 \\
2 \cdot E+01 \\
1 . E-04\end{array}$ & $\begin{array}{l}\mathbf{0} . \\
\mathbf{0} \\
\mathbf{0} \\
\mathbf{0} \\
0\end{array}$ & $\begin{array}{l}0 . \\
0 . \\
0 \\
0 \\
0 .\end{array}$ & $\begin{array}{l}0 . \\
0 . \\
0 \\
0 \\
0 .\end{array}$ & $\begin{array}{l}0 . \\
0 . \\
0 . \\
0 . \\
0 .\end{array}$ & $\begin{array}{l}0 . \\
0 . \\
0 . \\
0 . \\
0 .\end{array}$ & $\begin{array}{l}0 . \\
0 . \\
0 . \\
0 . \\
0 .\end{array}$ & $\begin{array}{l}0 . \\
0 . \\
0 . \\
0 . \\
0 .\end{array}$ & $\begin{array}{l}0 . \\
0 . \\
0 . \\
0 . \\
0 .\end{array}$ & $\begin{array}{l}0 . \\
0 . \\
0 . \\
0 . \\
0 .\end{array}$ & $\begin{array}{l}0 \\
0 \\
0 \\
0 \\
0 \\
0 .\end{array}$ & $\begin{array}{l}0 . \\
0 . \\
0 . \\
0 . \\
0 .\end{array}$ \\
\hline $\begin{array}{l}\text { Cr } \\
\text { EDIA } \\
F \\
\text { Fe } \\
\text { Fe(CN) } 6\end{array}$ & $\begin{array}{l}1 . E+03 \\
0 . E+04 \\
3 . E+04 \\
2 . E+04 \\
3 . E+01\end{array}$ & $\begin{array}{l}0 . \\
0 . \\
0 \\
0 . \\
0 .\end{array}$ & $\begin{array}{l}1 . E+02 \\
0 . E+04 \\
1 . E+04 \\
2 \cdot E+03 \\
3 . E+00\end{array}$ & $\begin{array}{l}0 . \\
0 . \\
0 \\
0 \\
0 .\end{array}$ & $\begin{array}{l}2 . E+04 \\
0 . E+03 \\
8 . E+03 \\
4 . E+05 \\
0 .\end{array}$ & $\begin{array}{l}\mathbf{0} . \\
0 . \\
0 . \\
0 . \\
0 .\end{array}$ & $\begin{array}{l}3 . E+04 \\
0 . E+03 \\
3 . E+03 \\
4 . E+05 \\
0 .\end{array}$ & $\begin{array}{l}\mathbf{0} . \\
0 . \\
0 . \\
0 . \\
0 .\end{array}$ & $\begin{array}{l}3 \cdot E+04 \\
0 \cdot E+03 \\
3 \cdot E+03 \\
5 \cdot E+05 \\
0 .\end{array}$ & $\begin{array}{l}0 . \\
0 . \\
0 \\
0 \\
0 .\end{array}$ & $\begin{array}{l}0 . \\
0 . \\
0 \\
0 \\
0 .\end{array}$ & $\begin{array}{l}0 . \\
0 . \\
0 . \\
0 .\end{array}$ & $\begin{array}{l}2 . E+02 \\
0 . E+04 \\
2 . E+04 \\
0 . \\
0 .\end{array}$ & $\begin{array}{l}0 . \\
0 . \\
0 . \\
0 . \\
0 .\end{array}$ \\
\hline $\begin{array}{l}\text { HEDTA } \\
K \\
L_{a} \\
\text { Mn } \\
\text { NO2 }\end{array}$ & $\begin{array}{l}0 \\
3 \\
0 \\
0 \\
3 . E+02\end{array}$ & $\begin{array}{l}\mathbf{0} \\
\mathbf{0} \\
0 \\
0 \\
0 \\
0 .\end{array}$ & $\begin{array}{l}0 \\
3 \\
0 \\
0 \\
2 . E+01\end{array}$ & $\begin{array}{l}\mathbf{0} \\
\mathbf{0} \\
0 \\
0 \\
0 \\
0 .\end{array}$ & $\begin{array}{l}0 \\
0 \\
0 \\
0 \\
0\end{array}$ & $\begin{array}{l}0 . \\
0 \\
0 \\
0 \\
0 . \\
0 .\end{array}$ & $\begin{array}{l}0 . \\
0 . \\
8 . E+03 \\
2 . E+04 \\
0 .\end{array}$ & $\begin{array}{l}\mathbf{0} . \\
0 . \\
0 \\
0 . \\
0 .\end{array}$ & $\begin{array}{l}0 . \\
0 . \\
8 . E+02 \\
2 . E+03 \\
0 .\end{array}$ & $\begin{array}{l}0 . \\
0 . \\
0 . \\
0 . \\
0 .\end{array}$ & $\begin{array}{l}0 . \\
0 . \\
0 . \\
0 . \\
0 .\end{array}$ & $\begin{array}{l}0 . \\
0 . \\
0 . \\
0 . \\
0 .\end{array}$ & $\begin{array}{l}0 . \\
2 \cdot E+04 \\
1 \cdot E+02 \\
3 \cdot E+02 \\
0 .\end{array}$ & $\begin{array}{l}0 . \\
0 . \\
0 . \\
0 . \\
0 .\end{array}$ \\
\hline $\begin{array}{l}\mathrm{NOJ} \\
\mathrm{Na} \\
\mathrm{Ni} \\
\mathrm{OH} \\
\mathrm{PO} 4\end{array}$ & $\begin{array}{l}2 . E+04 \\
4 \cdot E+05 \\
6 \cdot E-03 \\
6 \cdot E+04 \\
1 . E+05\end{array}$ & $\begin{array}{l}0 \\
0 \\
0 \\
0 \\
0\end{array}$. & $\begin{array}{l}3 . E+05 \\
1 . E+06 \\
6 . E-04 \\
8 . E+03 \\
5 . E+04\end{array}$ & $\begin{array}{l}\mathbf{0} . \\
\mathbf{0} \\
\mathbf{0} \\
0 \\
0 \\
0 .\end{array}$ & $\begin{array}{l}3 \cdot E+04 \\
8 \cdot E+04 \\
0 \cdot \\
1 \cdot E+06 \\
1 \cdot E+07\end{array}$ & $\begin{array}{l}0 . \\
0 . \\
0 \\
0 . \\
0 .\end{array}$ & $\begin{array}{l}0 . \\
0 . \\
0 . \\
2 . E+06 \\
1 . E+07\end{array}$ & $\begin{array}{l}0 . \\
0 . \\
0 . \\
0 . \\
0 .\end{array}$ & $\begin{array}{l}4 \cdot E-28 \\
5 \cdot E-07 \\
0 \cdot E+06 \\
2 \cdot E+06 \\
1 \cdot E+07\end{array}$ & $\begin{array}{l}0 . \\
0 . \\
0 . \\
0 . \\
0 .\end{array}$ & $\begin{array}{l}0 . E+01 \\
0 . E+01 \\
1 . E+01 \\
0 .\end{array}$ & $\begin{array}{l}0 . \\
0 . \\
0 . \\
0 . \\
0 .\end{array}$ & $\begin{array}{l}1 \cdot E+05 \\
2 \cdot E+05 \\
0 \cdot . \\
5 \cdot E+04 \\
3 \cdot E+03\end{array}$ & $\begin{array}{l}0 . \\
0 . \\
0 . \\
0 . \\
0 .\end{array}$ \\
\hline $\begin{array}{l}\mathrm{Pb} \\
\mathrm{SiO} 03 \\
\mathrm{SO} 4 \\
\mathrm{Sr} \\
\mathrm{ZrO}\end{array}$ & $\begin{array}{l}4 . E-11 \\
7 . E+01 \\
3 \cdot E+03 \\
0 . \\
2 . E+03\end{array}$ & $\begin{array}{l}0 . \\
0 \\
0 \\
0 \\
0 .\end{array}$ & $\begin{array}{l}3 \cdot E-10 \\
4 \cdot E+03 \\
8 \cdot E+04 \\
0 . \\
3 \cdot E+02\end{array}$ & $\begin{array}{l}0 . \\
0 . \\
0 . \\
0 . \\
0 .\end{array}$ & $\begin{array}{l}6 \cdot E-11 \\
2 \cdot E-05 \\
2 \cdot E-03 \\
0 . \\
4 \cdot E-01\end{array}$ & $\begin{array}{l}0 . \\
0 . \\
0 . \\
0 . \\
0 .\end{array}$ & $\begin{array}{l}1 . E-10 \\
0 . \\
0 . \\
0 . \\
3 . E-01\end{array}$ & $\begin{array}{l}0 . \\
0 . \\
0 . \\
0 . \\
0 .\end{array}$ & $\begin{array}{l}4 \cdot E-10 \\
6 \cdot E-30 \\
6 \cdot E-03 \\
0 \cdot . \\
4 \cdot E-01\end{array}$ & $\begin{array}{l}0 . \\
0 . \\
0 . \\
0 . \\
0 .\end{array}$ & $\begin{array}{l}0 . \\
0 . \\
0 . \\
0 . \\
0 .\end{array}$ & $\begin{array}{l}0 . \\
0 . \\
0 . \\
0 \\
0 .\end{array}$ & $\begin{array}{l}9 . E-18 \\
0 . j \\
3 . E+02 \\
0 . \\
0 .\end{array}$ & $\begin{array}{l}0 . \\
0 . \\
0 \\
0 . \\
0 .\end{array}$ \\
\hline
\end{tabular}




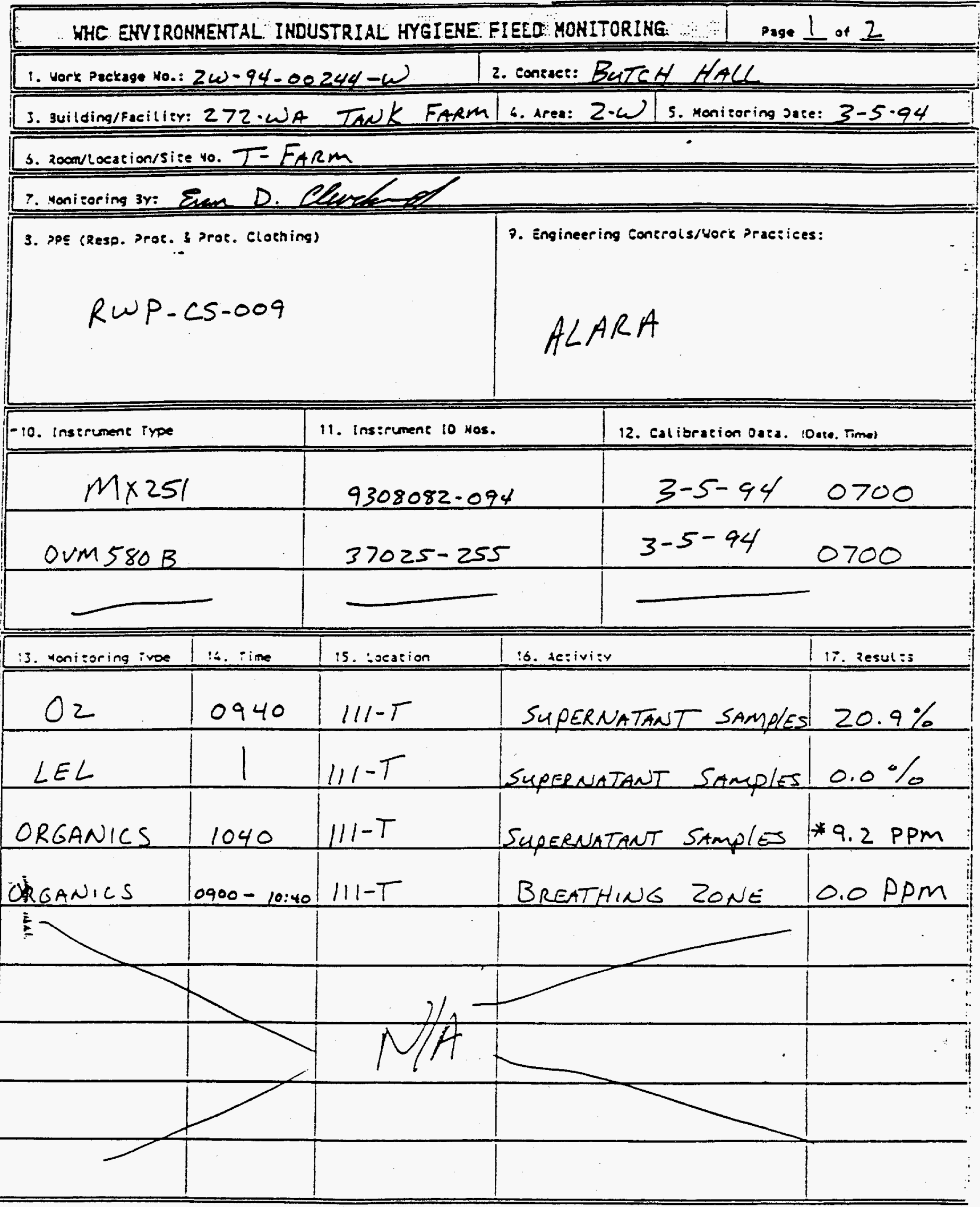




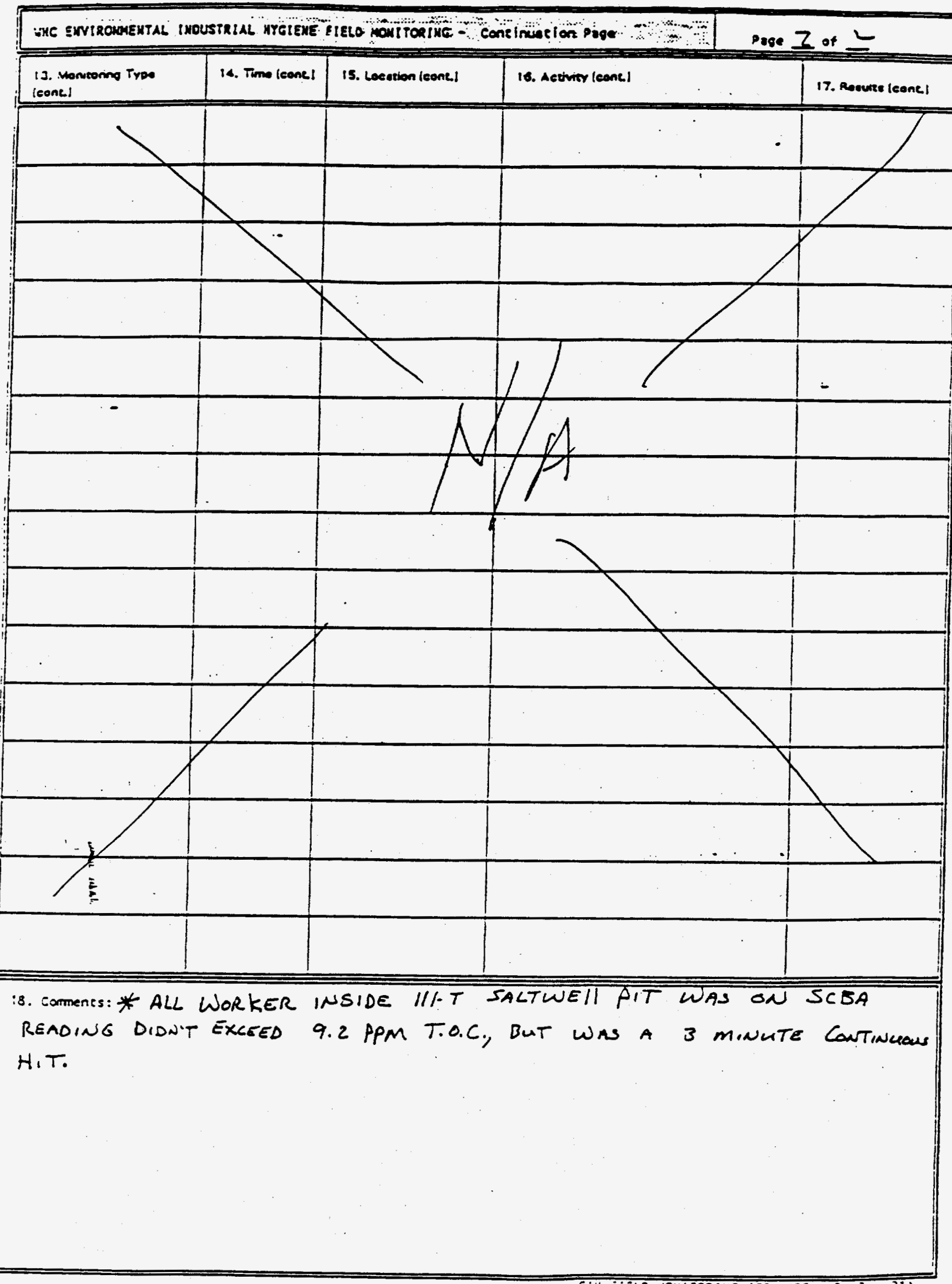


From: West Tank Farms Operations

Phone: $\quad 372-3919$ T4-08

Date: March 3, 1994

Subject: TANK T-111

\begin{tabular}{|c|c|c|c|c|}
\hline To: & D. A. Turner & $R 2-78$ & & \\
\hline $\begin{array}{l}\text { MAR } \\
\text { N. W. KWHO }\end{array}$ & $\begin{array}{l}\text { H. Babad } \\
\text { D. C. Board } \\
\text { V. C. Boyles } \\
\text { D. A. Bragg } \\
\text { IR. G. Brown } \\
\text { R. J. Cash } \\
\text { G. M. Christensen } \\
\text { C. DeFigh-Price } \\
\text { A. J. Duckett } \\
\text { G. T. Dukelow } \\
\text { J. C. Fulton } \\
\text { J. M. Grigsby } \\
\text { G.A. Hanson } \\
\text { J. O. Honeyman } \\
\text { M. N. Islam } \\
\text { G. D. Johnson } \\
\text { R. D. Hojtasek } \\
\text { JHW File/LB }\end{array}$ & $\begin{array}{l}R 2-78 \\
S I-57 \\
R 1-49 \\
R I-49 \\
R 2-11 \\
R 2-78 \\
H 4-21 \\
R 2-31 \\
H O-39 \\
R 2-78 \\
R 2-31 \\
H 2-62 \\
R 2-08 \\
R 2-52 \\
R 2-08 \\
R 2-178 \\
R 2-36\end{array}$ & $\begin{array}{l}\text { J. W. Lentsch } \\
\text { D. M. Lucoff } \\
\text { G. J. Miskho } \\
\text { D. J. Newland } \\
\text { R. Ni } \\
\text { J. W. Osborne } \\
\text { M. A. Payne } \\
\text { M. Plys } \\
\text { A. Postma } \\
\text { T. E. Rainey } \\
\text { R. E. Rayond } \\
\text { J. P. Sederburg } \\
\text { M. H. Shannon } \\
\text { M. J. Sutey } \\
\text { O. S. Wang } \\
\text { N. H. Kirch } \\
\text { J. L. Lee }\end{array}$ & 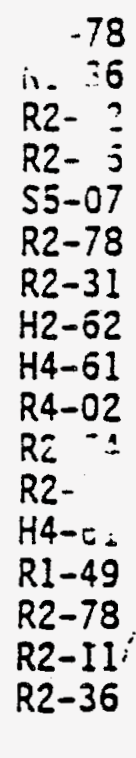 \\
\hline
\end{tabular}

References: (1) Internal Memo, Organic Tank Safety to J. H. Wicks, et al., "Tank T-111" dated February 28, 1994

In accordance with your recommendation in reference 1, Tank T-111 has been placed on the organics tanks Watch List. Operational Specifications for Watch List Tanks (OSD-T-151-00030) has been changed to add tank T-111 to the Organic Salt List in Appendix A. Notification of this change was included in the Daily Operating Report (DOR) on $3 / 3 / 94$.

If you have any questions, please call David P. Reber (373-5385).

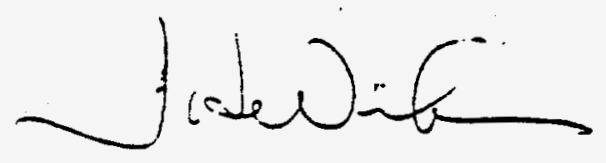

J. H. Wicks, Manager West Tank Farm Operations 
From: Organic Tank Safety

Phone: 373-2238 R2-78

7A700-94.004

Date: February 28, 1394

Subject: TANK T-111

To:

J. H. Wicks

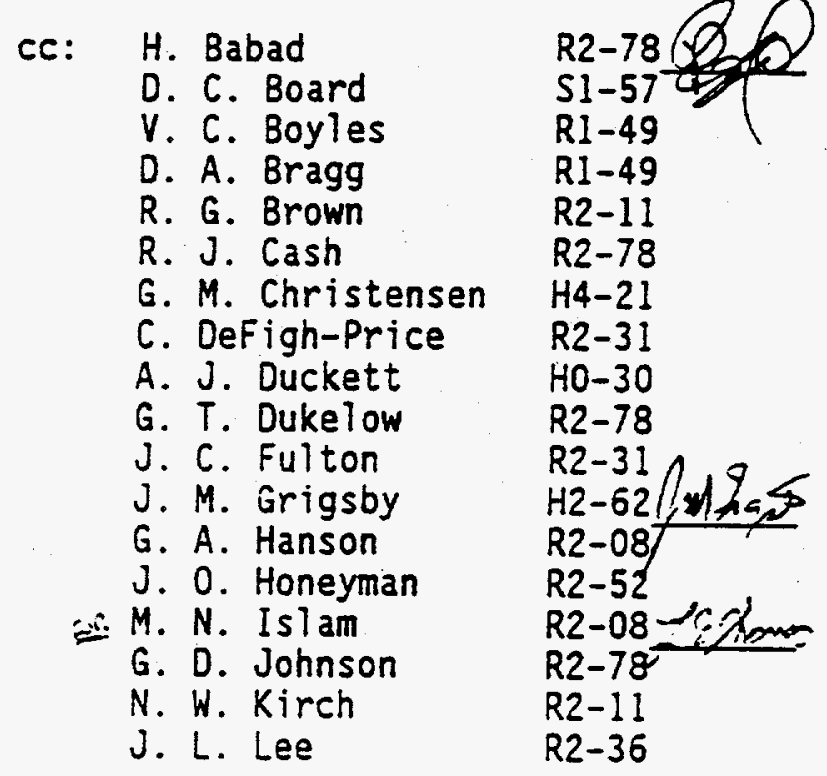

J. W. Lentsch R2-78

D. M. Lucoff N1-36

G. J. Miskho R2-12

D. J. Newl and - R2-36

R. $\mathrm{Ni}$

S5-07

J. W. Osborne R2-78

M. A. Payne

M. Plys

$\mathrm{R} 2-31$

A. Postma

$\mathrm{H} 2-62$

T. E. Rainey R4-02

R. E. Raymond R2-54

IJP Sederburg $R 2-11$

M. H. Shannon H4-6!

M. J. Sutey R1-49

0 . S. Wang R2-78

J. H. Wicks T4-07

R. D. Wojtasek R2-36

DAT FiTe/LB

References: (1) Internal Memo, D. A. Turner to H. Babad, et al., "Reactive Component in Tank 241-T-111," dated January 17, 1994.

(2) PNL Memo, D. L. Baldwin to R. M. Bean, et al., "T-111 Ory/Wet Preliminary TOC Results from Two Methods," dated January 11, 1994.

(3) Letter, S. G. McKinley, PNL, to C. DeFigh-Price, WHC, "Tank T-111, Core 33, Segment 2 Preliminary Data," dated December 20, 1993.

(4) Internal Memo, A. J. Duckett to D. B. Bechtold, et al., "Tank Farms PRC Meeting Minutes for December 1, 1993 Potential Reactive Component in Tank 241-T-111," dated December 2, 1993.

(5) WHC-EP-0681, UC-600, "Interim Criteria for Organic Watch List Tanks at the Hanford Site," dated September 1993. 
Page 2

February. 28, 1994

Waste Tank Safety Program recomends that tank T-111 be placed on the organic tanks Watch List, effective immediately.

The Tank Farms Plan Review Committee (PRC) made a decision on December 1, 1993, that tank T-111 was to be treated as an organics Watch List tank (Reference 4). This decision was prompted by the fact that portions of tank T-111 core material retrieved in 1991 and analyzed in 1992 exhibited significant exothermic activity in Differential Scanning Calorimetry (DSC) tests. The PRC also recomnended that additional analyses be performed on existing samples (Reference 4 ).

PNL has rerun a number of key analyses on tank T-111 Core 33, Segment 2 samples (References 2 and 3 ). Reference 1 was issued after review of the PNL analytical results to put the tank $T-111$ issue into perspective, based on what we know at this time. Two conclusions were reached in Reference I:

- No imminent safety hazard exists relative to the reactive component identified in tank T-111 waste because of the high ( 80 wt.\%) moisture content of the waste.

- Additional information on the active component in tank T-111 waste is required. The observed exothermic activity can not be fully accounted for based on reported total organic carbon (TOC) levels.

The recommendation to place tank T-111 on the organics tank watch list at this time is based on the following rationale:

- Tank T-111 Core 33, Segment 2 sample analyses performed by PNL were conducted on material dried at $60^{\circ} \mathrm{C}$ under vacuum in an effort to reduce the scatter previously encountered in analytical data.

- PNL analytical results indicate exothermic activity in the dried sample of $215 \mathrm{cal} / \mathrm{g}$ (dry basis) from DSC tests (Reference 3). TOC content was determined to be $4.1 \mathrm{wt} . \%$ (dry basis) using the Furnace Total Combustion Method on dried sample material (Reference 2). Waste moisture content was confirmed to be approximately $80 \mathrm{wt. \%}$ (Reference 3 ).

- The attachment derives the energy equivalent of a 5 wt.\% TOC (dry basis) orgánic-nitrate/nitrite mixture based on sodium acetate as the organic waste surrogate. $5 \mathrm{wt. \%}$ TOC (dry basis) is shown to be equivalent to exothermic activity of $151 \mathrm{cal} / \mathrm{g}$.

- Reference 5 establishes interim criteria for organic Watch List tanks at the Hanford Site. Single-shell tank (SST) waste is to be classified as "conditionally safe" if its organic content exceeds 5 wt.\% TOC (dry basis) and its moisture content is $\geq 17 \mathrm{wt}$. \%. 
J. H. Wicks, et al.

7A700-94.004

Page 3

February 28, 1994

- If, as shown above, $151 \mathrm{cal} / \mathrm{g}$ represents the energy equivalent of a 5 wt.\% TOC (dry basis) organic-nitrate/nitrite mixture, then the waste in tank T-111 would be classified as "conditionally safe" in view of its $215 \mathrm{cal} / \mathrm{g}$ exotherm and $80 \mathrm{wt} . \%$ moisture content.

- SSTs with waste classified as "conditionally safe" are to be placed on the organic tanks Watch List (Reference 5).

- Tank T-111 should, therefore, be placed on the organic tanks Watch List.

- It should be noted that. PNL's analytical results indicate a TOC content of only $4.1 \mathrm{wt. \%}$ (dry basis) (Reference 2). This TOC content, by itself, would not qualify tank T-111 for the Watch List. However, what matters from the standpoint of continued safe interim storage (e.g. safety) is waste energy content (cal/g). Tank T-111 clearly qualifies for the Watch List on this basis.

It appears that tank B-202 exhibits similar characteristics to those of tank T-111. However, it is not the recommendation of the Waste Tank Safety Program to place tank B-202 on the organic tanks Watch List at this time. The preliminary and incomplete analytical data have yet to be confirmed and further evaluation is necessary before making a final decision about tank B-202.

Please call (373-2238) if additional information or discussion would be beneficial.

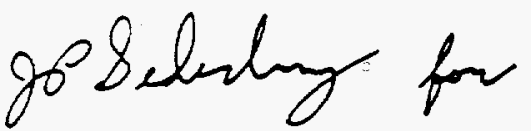

D. A. Turner, Manager

Organic Tank Safety

$\mathrm{mjs}$

Attachment 
Modeling T-111

A simple model of $T-111$ was made on the ESP simulation program to attempt to shed some light on the vapor concentration issue. This simple model would mix about 1 liter of aqueous solution similar to T-111 and 1 liter of air. Some NPH type organics were also mixed. The vapor phase leaving the mixture was estimated.

Aqueous solution

The aqueous solution used for this simulation was:

H2O $1000 \mathrm{~g}$

$\mathrm{NaNO} 2 \quad 0.54 \mathrm{~g}$

$\mathrm{NaNO} 3 \quad 30.7 \mathrm{~g}$

$\mathrm{Na} 2 \mathrm{CO} 3 \quad 0.5 \mathrm{~g}$

The model calculated this to be 1.017 liters with a density of 1.026 compared with T-111 liquid density of 1.07 .

AIR

One liter of air was introduce assuming only 02 and $\mathrm{N} 2$.

The model calculated that there was 1.08 liters of air

Organic

The organic chosen was of the NPH type.

$\mathrm{C} 10 \mathrm{H} 22$

C11H24

$\mathrm{C} 12 \mathrm{H} 26$

$0.3 \mathrm{~g}$

$0.15 \mathrm{~g}$

$0.05 . \mathrm{g}$

This mixture is just an estimation.

Mixture Conditions

The mixture conditions were $72^{\circ} \mathrm{F}$ and 14.7 psia.

Case \#1

A total of 0.5 grams of the organic mixture was added to the mixture.

This resulted in the following vapor composition:

$\begin{array}{ll}\text { Component } & \text { Vol \% } \\ \text { H2O } & 2.62 \% \\ \text { O2 } & 18.81 \% \\ \text { N2 } & 71.68 \% \\ \text { C1OH22 } & 4.32 \% \\ \text { C11 H24 } & 1.97 \% \\ \text { C12H26 } & 0.60 \%\end{array}$


The remainder of the organic was soluble in the liter of aqueous solution. There was no organic phase.

Note that the vapor phase contained large amounts of the hydrocarbons. This is well above what was measured. Several orders of magnitude.

Conclusions:

T-111 does not need a separable phase organic layer to explain the observed vapor pressure of $9 \mathrm{ppm}$. Dissolved organics in an aqueous phase can explain this.

Had T-111 had a small amount of NPH floating on it, it probably would have evaporated by now. Notice that the $\mathrm{C} 10 \mathrm{H} 22$ is very much greater in concentration. This means that over time, the $\mathrm{C} 12 \mathrm{H} 26$ would tend to be left behind. This has a smaller vapor pressure and is safer. 
WHC-EP-0806

\section{Distribution}

IR Pederson

MG Plys

$\mathrm{K} 2-44$

LL Burger

RD Scheele

GL Borsheim

DM Camaioni

MH Campbell

BC Simpson

WD Samueis

JA Campbell

JP Sederberg

H Babad

H4-62

P7-25

P7-25

R2-11

$\mathrm{K} 2-38$

R3- 77

R2-12

- $\mathrm{K} 2-44$

P8-08

R2-11

R2-78 


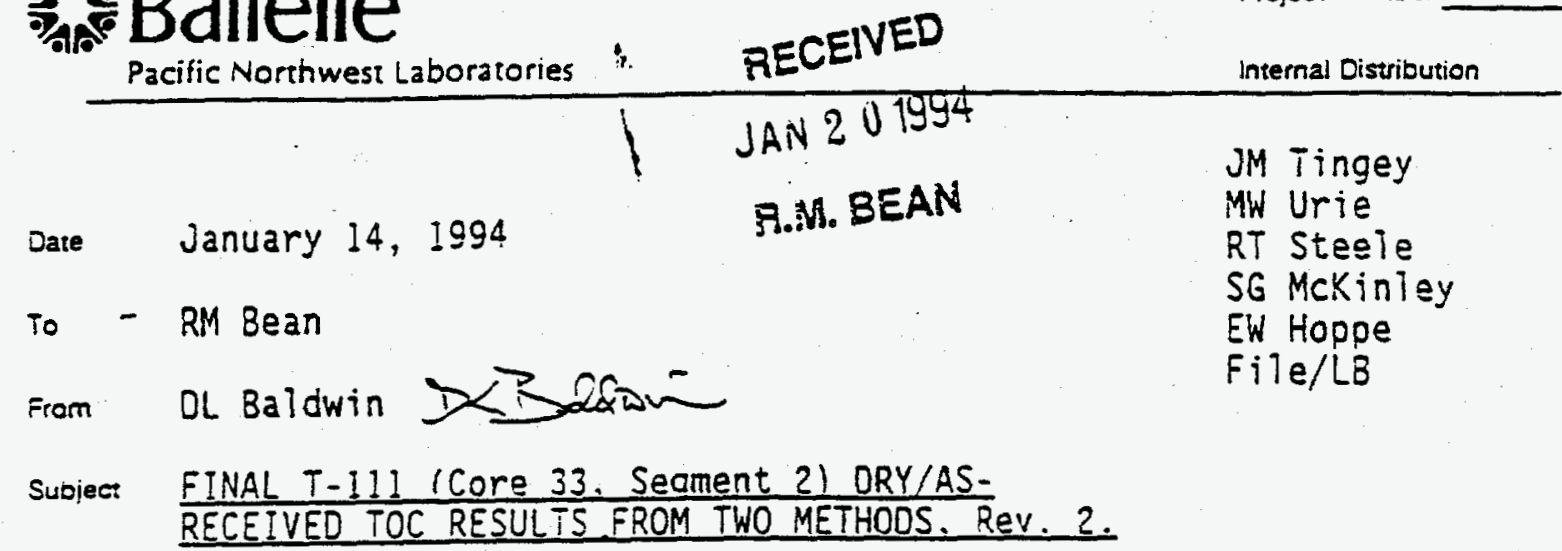

This is the Final report of results from TOC/TIC/TC measurements of the analyzed "dried" and "as-received" T-111 sample, ALO No. 94-2631, analyzed by two methods, as follows:

1) Hot Persulfate method, in normal TIC/TOC mode, and TC mode,

2) Furnace Total Combustion method, in both TOC mode and TC mode.

The data on the drying of the sample, as performed by JM Tingey, shows the samole to contain $18.4 \%$ solids. In this report, no corrections are made for the "dried" samples results.

Description of Methods: Part 1 of this work is done by the hot persulfate oxidation rethod, Test Procedure PNL-ALO-381, rev. 0, "Determination of TC, TOC, and TIC in Radioactive Liquids, Soils and Sludges by Hot Persulfate Method". The M\&TE No. for the carbon measurements is WCO1713, the balance M\&TENo. is 360-06-01-016. The data is located on the accompanying data shests, review reports or on file in the ALO Records Office. TOC standard used is aipha-d-glucose, Kodak lot $31 F$, and the TIC standard is reagent-grade iva. 60 . Both materials are used in liquid form, dissolved in water, for sys :em siandards as well as matrix spikes. Normal operation is with a TIC steo iirst. using acid oniy, followed by the TOC step on the same samole, acding the persulfate. $T C$ is calculated by addition. A modified mode was used in which TC was determined, eliminating the TIC step. This shouid minimize possible loss of any unmeasured volatile organics. The estimated precision is $=10 \%$ and the estimated accuracy is $\pm 15 \%$.

Par: 2 of this work is done by the furnace total combustion method, Test Procedure PNL-ALO-380, rev. O, "Determination of Carbon in Solids Using the Couiometrics Carbon Dioxide Coulometer". The M\&TE No. for the carbon measurements is WD04981, the balance M\&TE No. is 360-06-01-023. The data is locatad on the accompanying data sheets, review reports or on file in the AlO Recoras ofitice. TOC standard used is alpha-d-glucose and the TIC standard is $\mathrm{CaCO}_{2}$. Both materials are used in solid form for system standards as well as matrix spikes. As per normal procedure, TOC is determined at $600^{\circ} \mathrm{C}$ on a sample. Then $T C$ is determined at $1000^{\circ} \mathrm{C}$ on a different sample. TIC is calculated by difference. The estimated precision is $=10 \%$ and the estimated accuracy is $\doteq 15 \%$.

QC Narrative: This sample was analyzed on 1-10-94. The $Q C$ for both methods all came within required MCS-033 limits, with no apparent outliers. For the 
RM Bean

January 14, 1994

Page 2

persulfate method, the TIC and TOC system standard recoveries ranged from $91.9 \%$ to $101.5 \%$. The system blanks were consistent. The RPD's (Relative Percent Difference) for the dried sample, analyzed in duplicata, ranged from $3 \%$ to $10 \%$. The matrix spike recoveries were $95 \%$ and $11 \%$, respectiveiy, for TIC and TOC, and 119\% for the "crushed" sample TC spike.

For the furnace total combustion method, the TIC and TOC systam standard recoveries ranged from $03.9 \%$ to $99.3 \%$. The system blanks were consistant. The RPO's for the dried and as-received samples, analyzed in duplicate, ranged from $3 \%$ to $16 \%$. The matrix spike recoveries, at $600 \cdot \mathrm{C}$, were $102 \%$ and $83 \%$, respectively, for the dried and as-received samples.

Tabie 1: Hot Persulfate Method Results

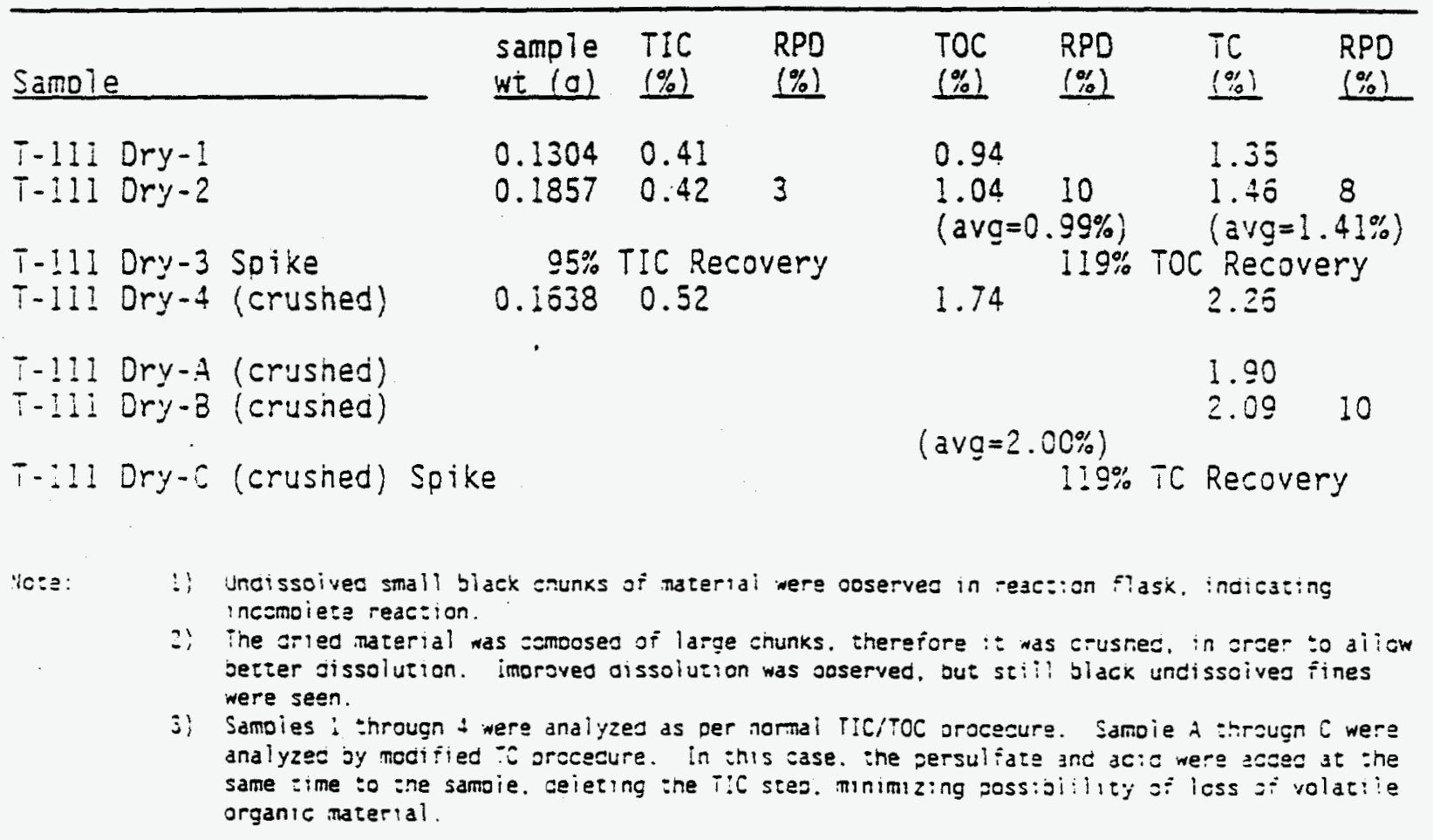


RM Bean

January 14,1994

Page 3

Table 2: Furnace Method Results

\begin{tabular}{|c|c|c|c|c|c|c|c|}
\hline Samole & $\begin{array}{l}\text { sample } \\
\text { wt (a) }\end{array}$ & $\begin{array}{l}\text { TIC } \\
(\%) \\
\end{array}$ & $\begin{array}{l}R P D \\
(\%) \\
\end{array}$ & $\begin{array}{l}\text { TOC } \\
(\%) \\
\end{array}$ & $\begin{array}{l}\text { RPD } \\
(\%)\end{array}$ & $\begin{array}{l}T C \\
(\%) \\
\end{array}$ & $\begin{array}{l}R P D \\
(\%) \\
(\%)\end{array}$ \\
\hline $\begin{array}{l}T-111 \text { Dry-1 }(600 \cdot C) \\
T-111 \text { Dry-2 } \\
T-111 \text { Dry-3, spike }\end{array}$ & $\begin{array}{l}0.01495 \\
0.01864 \\
0.02345\end{array}$ & $102 \%$ & Recovery & $\begin{array}{l}3.76 \\
4.41 \\
\text { lavg }=\end{array}$ & $\begin{array}{l}16 \\
.09 \%)\end{array}$ & & \\
\hline $\begin{array}{lll}T-111 & \text { Ory-1 } & (1000 \cdot C) \\
T-111 & \text { Dry-2 }\end{array}$ & $\begin{array}{l}0.03158 \\
0.02333\end{array}$ & & & & & \multirow{2}{*}{\multicolumn{2}{|c|}{$\begin{array}{l}4.69 \\
4.99 \quad 6.2 \\
(a \vee g=4.84 \%)\end{array}$}} \\
\hline $\begin{array}{l}T-111 \text { As-Recd-1 }\left(600^{\circ} \mathrm{C}\right) \\
T-111 \text { As-Recd-2 } \\
T-111 \text { As-Recd-3, Spike }\end{array}$ & $\begin{array}{l}0.04890 \\
0.10883 \\
0.09272\end{array}$ & $83 \%$ & Recovery & $\begin{array}{l}0.90 \\
0.87 \\
\text { avg }=0\end{array}$ & $\begin{array}{l}3.4 \\
.89 \%)\end{array}$ & & \\
\hline$T-111$ As-Recd-1 $\left(1000^{\circ} \mathrm{C}\right)$ & 0.04227 & & & & & \multicolumn{2}{|l|}{0.98} \\
\hline $\begin{array}{l}:) \text { in the furnace me } \\
\text { constcered to be } \\
\text { oifitarent tembera }\end{array}$ & $\begin{array}{l}\text { ice sni } \\
\text { ses. No } \\
\text {. }\end{array}$ & & $\begin{array}{l}\text { jered } \\
\text { jieren }\end{array}$ & 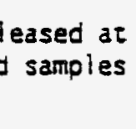 & are & $\begin{array}{l}\text { C. } \\
\text { siwe }\end{array}$ & Eis \\
\hline
\end{tabular}

CONCLUSIONS:

1) The Hot Persulfate method alone provides one conclusion, that there is no loss of volatile organic material in the TIC step. The results appear to agree well with the earlier reported "as-received" sample resulits, after accounting for the water weight loss.

2) The Furnace method results, in comparison, indicate that there is additional organic material present in these samples. This additional organic material was, for some reason, not fully oxidized by hot persulfate, but required oxidizing with some stronger oxidant, (e.i., oxygen) at elevated temperatures.

3 In the dry material, from the Furnace method, the total TOC found was $4.09 \%$, the total TC found was $4.84 \%$. This compares, from the hot persulfate method, with total TOC found of $0.99 \%$ and total TC found 
RH Bean

January 14, $i 994$

Page 4

of 2.0\%. Both method results show good agreement between "dried" and "As-Recieved" results, after accounting for water weight. loss.

4). The missing, additional organic material, in the dried $s$ : 2 , amounts to:

$$
\text { TC comparison: }(4.84 \%-2.00 \%)=2.8 \%
$$

TOC comparison $(4.09 \%-0.99 \%)=3.1 \%$

Concur by:

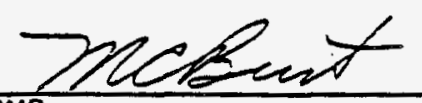

File: $T-111 . \overline{\text { RMB }}$

Date: $1 / 1 / 4 / 94$

System File: Toc 11094 
DON'T SAY IT -.- Write It!

TO: Distribution
DATE: June 9, 1994

FROM: C. H. Delegard Telephone: $373-4658$

SUBJECT: CENTIFUGATION AND ANALYSES OF SLUDGE FROM TANK 241-T-111

Attached please find Internal Memo 8E110-PCL94-046, "Centrifugation and Analyses of Siudge From Tank 241-T-111." The attached IM provides recent thermal analyses of the centrifuged sludge and completes the reporting of the tank 111-T centrifugation tests. The attached IM replaces IM 8E110-PCL94-043, same subject. Please discard the IM 8E110-PCL94-043. 
From: Process Chemistry Lavoratories

8E110-PCL94-046

Phone: $\quad 373-4658$ T6-09

Date: June 9, 1994

Subject: CENTRIFUGATION AND ANALYSIS OF SLUDGE FROM TANK 241-T-111

To:

D. B. Engelman

$c c:$
H. Babad
R2 -78
G. S. Barney
$T 5-12$
D. R. Bratzel
$R 2-12$
J. M. Frye
T6-30
J. R. Jewett/P T6-09
J. G. Kristófzki T6-06
L. M. Sasaki
R2- 12
C. S. Simmons
$\mathrm{K} 6-77$
B. C. Simpson
$\mathrm{R} 2-12$
J. P. Sloughter
T6-07
C. S. Sutter
T5- 12
D. T. Vladimiroff R2-12
CHD File/LB

References:

(1) Internal Memo, G. S. Barney and C. H. Delegard to D. B. Engelman, "Test Plan for Centrifuge Drainage Tests of Tank 241-T-111 Sludge Samples," dated May 3, 1994.

(2) Internal Memo, G. S. Barney to D. W: Jeppson, "Results of Centrifuge Drainage Tests for Simulated Infarm-2 Ferrocyanide Sludge," dated March 28, 1994.

\section{INTRODUCTION AND SUMMARY OF RESULTS}

In Reference 1, a laboratory test procedure was described to determine the liquid retention capacity of sludge from tank 241-T-111 (111-T). The test procedure was basec on a study, described in Reference 2 , conducted to measure sludge drainage rates. In the present studies, tests were designed to simulate the drainage of interstitial liquid from the existing 14-foot ( 4.3 meter) overburden of sluc $=2$ in $111-T$ should salt well pumping at the tank bottom take place.

Pressure-enhanced drainage was imposed in the laboratory by removing interstitial solution from samples of genuine sludge by filtration through coarse-frit glass in a centrifugal field of 500 times gravity $(500 \mathrm{G})$. This field simulates the 4.3 -meter sludge hydrostatic pressure at the tank bottom. The weights of liquids extracted and sludge retained were measured intermittentiy over a period of about five days. By knowing the water concentration of the original sludge and the expressed liquid, the amount of liquid remaining in the sludge cake could be determined and compared with 
water contents of the sludge cake measured directly at the end of centrifugation.

Four sludge samples from 111-T were tested in duplicate by this procedure. Results showed the water content of the initial sludges ranged from about 69 to 80 weight percent (wt\%). Centrifugation filtering produced compressed, but still damp, sludge materials and quantities of expressed liquid. The rate of liquid removal from the sludge cake was rapid in the initial hours of centrifugation and slowed considerably after two days' centrifugation. The water content of the siudges after two days' centrifuging ranged from 58 to $66 \mathrm{wt} \%$; after five days, the water content decreased a further $1.6 \mathrm{wt} \%$ for each sludge on average.

The experiments and measurements performed to determine the solution retention of the centrifuged sludge samples are described in this report. Ancillary chemical and thermal analyses of the intact and separated sludge and solution fractions also are reported.

\section{EXPERIMENTAL MATERIALS AND METHODS}

Archive sludge samples taken in 1991 were used in these tests. The sample materials were derived from segments 3 and 7 of core 31 and from segments 1 and 7 from core 33 . The segment numbering proceeds, in order, from top (segment 1) to bottom (segment 9) in 19-inch $(0.5-\mathrm{m})$ increments corresponding to the length of the segments.

The experimental approach used in the centrifugation tests generally followed the methods described in reference 1 . The experimental observations were recorded in notebook WHC $N$ fish 1

Coarse-frit giass rllters (40 to $60 \mu \mathrm{m}$ pore size) fused into 1-cm diameter glass tubes (about $8 \mathrm{~cm}$ long) were used as the filtration medium. Samples of well-mixed sludge were introduced to the top of frit filter surface by plunger-type polyethylene thief samplers. Tare and gross weight measurements ( \pm 0.00005 grams using a five-place balance) of the tubes before and after introduction of sample were obtained. The glass tubes were placed in screw-top polypropylene $50-\mathrm{mL}$ capacity centrifuge tubes and reweighed. Sample weights ranged from about 1.8 to 3.4 grams. Most sample weights were about 2.3 grams.

The tubes with samples were spun in a centrifuge located in an open-face hood in the 222-S Laboratory at a target velocity of 1680 revolutions per minute (RPM). This velocity corresponded, at the $15.8 \mathrm{~cm}$ distance of the sludge from the axis of rotation, to a field of $500 \mathrm{G}$ at the filter frit disc. Measurements of the rotational velocity of the centrifuge were obtained during the course of the experimentation using an optical tachometer. The nine velocity measurements ranged from 1617 to $1720 \mathrm{RPM}$ (i.e., 464 to $524 \mathrm{G}$ ) and averaged $1684 \mathrm{RPM}(501 \mathrm{G})$. The temperature within the centrifuge was about $1^{\circ} \mathrm{C}$ above ambient lab temperature. The $1 \mathrm{ab}$ temperature ranged from about 19 to $24^{\circ} \mathrm{C}$ during the experiments. 
The centrifuge was stopped periodically, the glass tubes and centrifuge cones were weighed and the weights of centrifuged liquid and sludge were determined by difference. The liquid was sampled for analyses of water content, density, thermal behavior and concentration of total organic carbon (TOC). After 113 hours, the centrifugation was stopped and the sludge analyzed for water content and thermal behavior. Samples of the original sludge also were analyzed for water content and thermal behavior. siudge water content was determined by weight loss on oven heating to constant weight at $116^{\circ} \mathrm{C}$. For the water content determinations, original sludge material sample sizes were 1 to $2 \mathrm{~g}$; about 0.2 to $0.5 \mathrm{~g}$ samples were used for the centrifuged sludge materials.

Densities of the original and centrifuged sludge were determined. The densities of original sludge were determined by weighing sludge samples into volume-calibrated graduated centrifuge tubes and noting the total siudge solution plus settled solids volume after centrifugation.

The compressed centrifuged siudges from the solution retention tests were not sufficiently plastic to slump in the volumetric centrifuge tubes used for density measurement. Therefore, the densities of the compressed sludge were determined via a displacement technique using an immiscible liquid of known density ( $n$-hexane). Samples of the compressed sludge were added to a tare-weighed $5-\mathrm{mL}$ volumetric flask, the flask reweighed, the flask filled to the mark with $n$-hexane, and the flask again reweighed. The volume of added $n$-hexane could be determined by weight and density. The volume and weight of compressed sludge then was calculated by difference and the sludge density calculated.

All chemical, physical and thermal analyses (except the water concentrations of the centrifuged sludges and the densities of the original and centrifuged sludges) were determined by 222-S Analytical Operations. The densities of the expressed liquids were determined by weighing known volumes of solution held in volume-calibrated pipets. The TOC concentrations were found by acidified sample pyrolysis followed by coulometric titration of the product carbon dioxide collected in a scrubber trap. Water content in the expressed solution was determined by weight loss of sample due to heating in an oven.

The thermal analyses inciuded differential scanning calorimetry (DSC) and thermogravimetric analyses (TGA). All sludge and expressed solutions were analyzed by DSC/TGA. The DSC determined if a heat-producing (exothermic) event occurred. An example of an exothermic reaction would be the oxidation of organic carbon by nitrate. The TGA showed fractional weight changes (e.g., weight loss by water evaporation) as a function of increasing temperature. Thus water concentration values were obtained via TGA for all samples.

\section{RESULTS AND DISCUSSION}

All the original sludge samples were dark brown in color with a pasty but slightly gritty consistency. Sludge samples from the segment 1 and 3 archives showed no natural segregation whereas the segment 7 samples had about $10 \%$ supernatant solution. The entire contents of each archive sample 
were mixed prior to drawing subsamples for testing. Subsampling from the same archive vials two days later showed separation of supernatant solution had recurred in the segment 7 samples but again no supernatant solution was found for the segment 1 and 3 samples. Centrifugation resulted in the drainage (through the glass frit filters) of yellow liquids from all sludge samples and the production of a sludge cake that was smaller both in height and diameter than the original sludge (i.e., the sludge compressed as well as shrunk away from the glass tube wall).

The water content of the centrifuged sludge was calculated by weight loss of the sludge as centrifugation proceeded, the water content of the original sludge, and the water content of the expressed liquid. The water content of the centrifuged sludge, after 113 hours' centrifugation at $500 \mathrm{G}$, was also determined directly via oven weight loss. The water content data, presented in the Figure, show the original sludge was about $80 \mathrm{wt} \%$ water for the segment 1 and 3 samples and about 74 wt\% for the segment 7 samples taken near the tank bottom. Though the archive segment 7 samples had supernatant liquid while the segment 1 and 3 samples did not, the segment 7 samples had lower water content than the segment 1 and 3 samples.

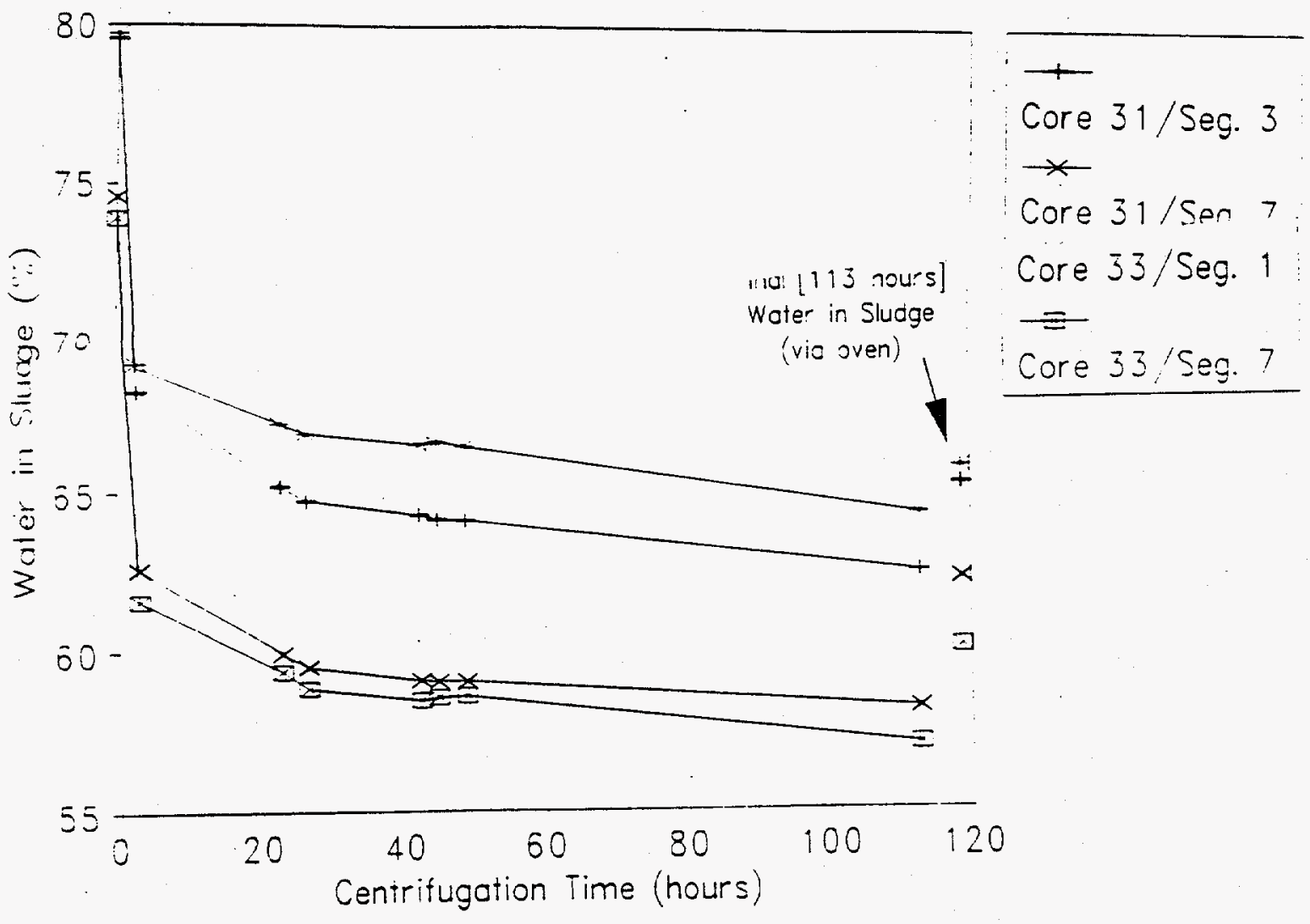

Figure. Water Concentration in Centrifuged 111-T Sludge. 
The sludge samples lost solution (and water content) quickly in the initial three hours of centrifugation. The rate of weight loss decreased with time of centrifugation. After 113 hours, the water contents of the segment 1 and 3 samples were about $63 \mathrm{wt} \%$; the segment 7 samples were about $58 \mathrm{wt} \%$. The water contents of the centrifuged siudges determined by direct measurement of oven weight loss were about $65 \mathrm{wt} \%$ and 61 wt\%, respectively.

The water content data of the individual replicate sludge samples are given in Table 1. The data show precision in the replicate measurements of about $0.5 \%$ relative or $0.8 \%$ absolute in the oven measurements and about $1.3 \%$ relative or $1.9 \%$ absolute for the calculated values based on the sludge weight losses. The oven values are about $2.8 \pm 1.0 \%$ higher, on average, than the calculated values. The bias probably is due to the cumulative effects of water vapor loss from the centrifuged solution during each weighing operation. For this reason, the oven wt\% water values are judged to be more reliable than the calculated values.

Table 1. Water Content of Sludge During Centrifugation.

\begin{tabular}{|c|c|c|c|c|c|c|c|c|c|}
\hline \multirow{2}{*}{$\begin{array}{c}\text { Core/ } \\
\text { Seg/ } \\
\text { Dup }\end{array}$} & \multicolumn{9}{|c|}{ Centrifugation Time (hours) } \\
\hline & 0 & 3 & 23 & 26.5 & 42.5 & 45 & 49 & 113 & $\begin{array}{c}113 \\
\text { (Oven) }\end{array}$ \\
\hline $31 / 3 / 1$ & \multirow[t]{2}{*}{79.54} & 68.6 & 65.8 & 65.4 & 64.7 & 64.5 & 64.6 & 63.0 & 65.14 \\
\hline $31 / 3 / 2$ & & 67.7 & 64.4 & 63.9 & 63.6 & 63.5 & 63.4 & 61.5 & 64.78 \\
\hline $31 / 7 / 1$ & \multirow[t]{2}{*}{74.52} & 63.1 & 60.6 & 50.2 & 59.7 & 59.8 & 59.8 & 59.1 & 62.28 \\
\hline $31 / 7 / 2$ & & 62.0 & 59.2 & 58.7 & 58.3 & 58.2 & 58.2 & 57.1 & 61.83 \\
\hline $33 / 1 / 1$ & \multirow[t]{2}{*}{79.71} & 68.7 & 67.1 & 66.8 & 66.4 & 66.5 & 66.3 & 64.4 & 65.74 \\
\hline $33 / 1 / 2$ & & 69.3 & 67.0 & 66.7 & 66.3 & 66.4 & 66.2 & 63.8 & 65.23 \\
\hline $33 / 7 / 1$ & \multirow[t]{2}{*}{73.87} & 61.8 & 59.9 & 59.4 & 59.1 & 59.2 & 59.3 & 57.3 & 59.66 \\
\hline $33 / 7 / 2$ & & 61.3 & 58.8 & 58.2 & 57.7 & 57.8 & 57.8 & 56.6 & 60.23 \\
\hline
\end{tabular}

The chemical and thermal analyses of the original sludge materials are summarized in Table 2. Exotherms were found for all sludge samples. The exotherms decreased as the sludge sampling depth increased (i.e., exotherms were greatest at the top). The wt water values of the original sludge materials were determined both by weight $10 \mathrm{ss}$, using 1 to $2 \mathrm{~g}$ samples heated to dryness in an oven, and by TGA, using 30 to $50 \mathrm{mg}$ samples.

As shown in Table 2, the oven values for wt\% water were higher than the TGA values. The values derived by oven weight loss are judged to be more reliable than the TGA values because they showed higher precision (better reproducibility in their duplicates), were obtained from larger, more representative samples, and thus were less subject to evaporative weight losses prior to initial weighing. The smaller TGA samples would be apt to lose more weight, on a relative basis, than the larger oven samples because they have a higher surface area to volume ratio. The oven-determined wt\% water duplicate values for particular core/segment samples were averaged for 
Page 6

use in calculation of the water content of the corresponding centrifuged sludge.

Table 2. Analyses of the Original sludge.

\begin{tabular}{|c|c|c|c|c|}
\hline \multirow{2}{*}{ Core/Seg/Dup } & \multicolumn{2}{|c|}{ Wt\% Water } & \multirow{2}{*}{ Density $(\mathrm{g} / \mathrm{mL})$} & Exotherm $(\mathrm{J} / \mathrm{g})$ \\
\cline { 2 - 3 } & Oven & TGA & \multirow{2}{*}{1.24} & 191 \\
\hline $31 / 3 / 1$ & 79.47 & 76.33 & & 112 \\
\hline $31 / 3 / 2$ & 79.60 & 77.10 & & 33.1 \\
\hline $31 / 7 / 1$ & 74.28 & 72.99 & \multirow{2}{*}{1.19} & 10.2 \\
\hline $31 / 7 / 2$ & 75.16 & 75.12 & & 249 \\
\hline $33 / 1 / 1$ & 79.64 & 77.12 & \multirow{2}{*}{1.16} & 254 \\
\hline $33 / 1 / 2$ & 79.48 & 79.04 & & 41.4 \\
\hline $33 / 7 / 1$ & 73.93 & 81.95 & \multirow{2}{*}{1.20} & 37.5 \\
\hline $33 / 7 / 2$ & 74.20 & 74.24 & & \\
\hline
\end{tabular}

The chemical, physical and thermal analyses of the solution samples are summarized in Table 3 . Though the samples (especially the segment 1 and 3 materials) contained organic carbon, no exotherm was noted in the DSC of any of the solutions. Again, both oven and TGA values of wt\% water were determined and, for the same reasons, the oven values judged to be more reliable. The average value of the oven-determined wt\% water duplicate analyses for particular core/segment samples was used to calculate the water content of the corresponding centrifuged sludge.

Table 3. Analyses of Expressed Solution.

\begin{tabular}{|c|c|c|c|c|}
\hline \multirow{2}{*}{ Core/Seg/Dup } & \multicolumn{2}{|c|}{ Wt\% Water } & \multirow{2}{*}{ Tensity (g/mL) } & [TOC] (mg/L) \\
\cline { 2 - 5 } & Oven & TGA & Dens & 1620 \\
\hline $31 / 3 / 1$ & 92.27 & 86.80 & Insuff. samp le & 979 \\
\hline $31 / 3 / 2$ & 91.65 & 85.13 & 1.040 & 210 \\
\hline $31 / 7 / 1$ & 88.87 & 80.80 & 1.065 & 140 \\
\hline $31 / 7 / 2$ & 88.52 & 85.40 & 1.087 & 1010 \\
\hline $33 / 1 / 1$ & 95.41 & 87.02 & 0.990 & 1000 \\
\hline $33 / 1 / 2$ & 94.65 & 92.06 & 1.028 & 180 \\
\hline $33 / 7 / 1$ & 90.02 & 85.50 & 1.089 & 200 \\
\hline $33 / 7 / 2$ & 89.44 & 86.66 & 1.101 & \\
\hline
\end{tabular}

The chemical and physical analyses of the centrifuged sludge samples are given in Table 4. The wt\%s water derived from the TGA are significantiy lower than those found by oven drying. Substantial air-drying of the centrifuged sludge apparently occurred prior to the TGA determinations. The DSC analyses showed that on a dry basis, centrifuged sludges had exotherms somewhat larger than the original siudges. For example, for sludge from 
D. B. Engerman

Page 7

8EI10-PCL94-046

segment I of core 33 (which exhibited the highest exotherm of the four samples studied), the centrifuged material had an exotherm of about $1700 \mathrm{~J} / \mathrm{g}$ dry sludge as compared to $1140 \mathrm{~J} / \mathrm{g}$ dry sludge for the original material. For segment 3 of core 31 , the centrifuged siudge gave about $1150 \mathrm{~J} / \mathrm{g}$ dry sludge (the $1525 \mathrm{~J} / \mathrm{g}$ value was not included in the calculation) while the original sludge gave about $640 \mathrm{~J} / \mathrm{g}$ dry sludge. The centrifuged segment 7 samples showed no measurable exotherms; exotherms for the original segment 7 sludges were about 100 to $200 \mathrm{~J} / \mathrm{g}$ dry siudge.

Table 4. Analyses of Centrifuged Sludge.

\begin{tabular}{|c|c|c|c|c|}
\hline \multirow[b]{2}{*}{ Core/Seg/Dup } & \multicolumn{2}{|c|}{ Wt\% Water } & \multirow[b]{2}{*}{ Density $(\mathrm{g} / \mathrm{mL})$} & \multirow[b]{2}{*}{ Exotherm $(\mathrm{J} / \mathrm{g})$} \\
\hline & Oven & TGA & & \\
\hline $31 / 3 / 1$ & 65.14 & 53.80 & 1.05 & $546.9,465.3$ \\
\hline $31 / 3 / 2$ & 64.78 & 56.92 & 1.12 & $1525.3,544.9$ \\
\hline $31 / 7 / 1$ & 62.28 & 58.94 & 1.16 & 0.0 \\
\hline $31 / 7 / 2$ & 61.83 & 52.71 & 1.24 & 0 \\
\hline $33 / 1 / 1$ & 65.74 & 51.11 & 1.21 & 838.1 \\
\hline $33 / 1 / 2$ & 65.23 & 51.62 & 1.16 & 822.4 \\
\hline $33 / 7 / 1$ & 59.66 & 44.82 & 1.24 & 0 \\
\hline $33 / 7 / 2$ & 60.23 & 45.48 & 1.33 & 0 \\
\hline
\end{tabular}

Please call should you have questions or comments on this work.

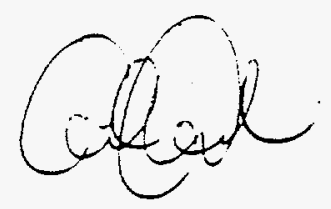

C. H. Delegard, Principle Senior Scientist

Process Chemistry Laboratories 
SAMPLE STATUS REPORT FOR T DISPATCHED: $3 / 5 / 94$ 10:31 RECEIVED :
546. $T-111$ T-111 \#1 TIME: SAMPLE HAS NOT BEEN SLURPED
EXT. DETER.

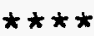

1001

5706

5711

5711

- 5712

5713

5714

5714

5720

5725

5726

5727

5728

5729

5730

5750

5750

5771

5771

5771

5771

5771

5771

5778

5781

5781

5782

5783

5786

5786

9114

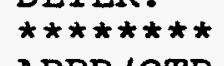

APPR/OTR

SPG

DSC

DSC

TGA

$\mathrm{pH}$

$\% \mathrm{H} 2 \mathrm{O}$

$\% \mathrm{H} 2 \mathrm{O}$

TB

AT

TOC

TIC

$\mathrm{NH} 4$

$\mathrm{OH}$ LIQ

GEA

ICP-LIQ

ICP-LIQ

IC

IC

IC

IC

IC

IC

CN LIQ

Pu239/40

Pu239/40

Am 241

$\mathrm{Np} 237$

$\operatorname{sr} 90$

$\operatorname{Sr} 90$

ARCHIVE
RESULTS OR STATUS

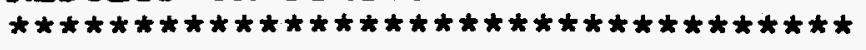

YELLOW CLEAR < $1 \%$ SOLIDS

1.03610E 00 NONE

OUT FOR RERUN

INCOMPLETE

INCOMPLETE

$1.15700 E$ OI NONE

OUT FOR RERUN

INCOMPLETE

$2.21000 \mathrm{E}-01 \mathrm{UCi} / \mathrm{ML}$

$2.31000 \mathrm{E}-03 \mathrm{UCi} / \mathrm{ML}$

$4.73000 E$ O2 UG $\mathrm{C} / \mathrm{ML}$

8.00000E 02 UG C/ML

$3.61000 \mathrm{E} 02 \mathrm{UG} / \mathrm{ML}$

$3.54000 \mathrm{E}$ O3 UG/ML

8.96000E-02 UCi/ML

$2.04000 \mathrm{E}$ 04 UG/ML

$<5.05000 \mathrm{E}$ 0O UG/ML

1.95997E $03 \mathrm{UG} / \mathrm{ML}$

$4.77260 \mathrm{E}$ 02 UG/ML

$1.33501 \mathrm{E} 03 \mathrm{UG} / \mathrm{ML}$

$2.91022 \mathrm{E}$ 04 UG/ML

$8.06644 \mathrm{E}$ 03 UG/ML

$2.78205 E$ O3 UG/ML

2.71000E $00 \mathrm{UG} / \mathrm{ML}$

OUT FOR RERUN

INCOMPLETE

$<3.97000 \mathrm{E}-05 \mathrm{uCi} / \mathrm{ML}$

$<1.38000 \mathrm{E}-05 \mathrm{uCi} / \mathrm{ML}$

OUT FOR RERUN

$7.09000 \mathrm{E}-04 \mathrm{UCi} / \mathrm{ML}$

INCOMPLETE

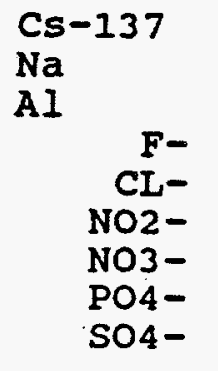

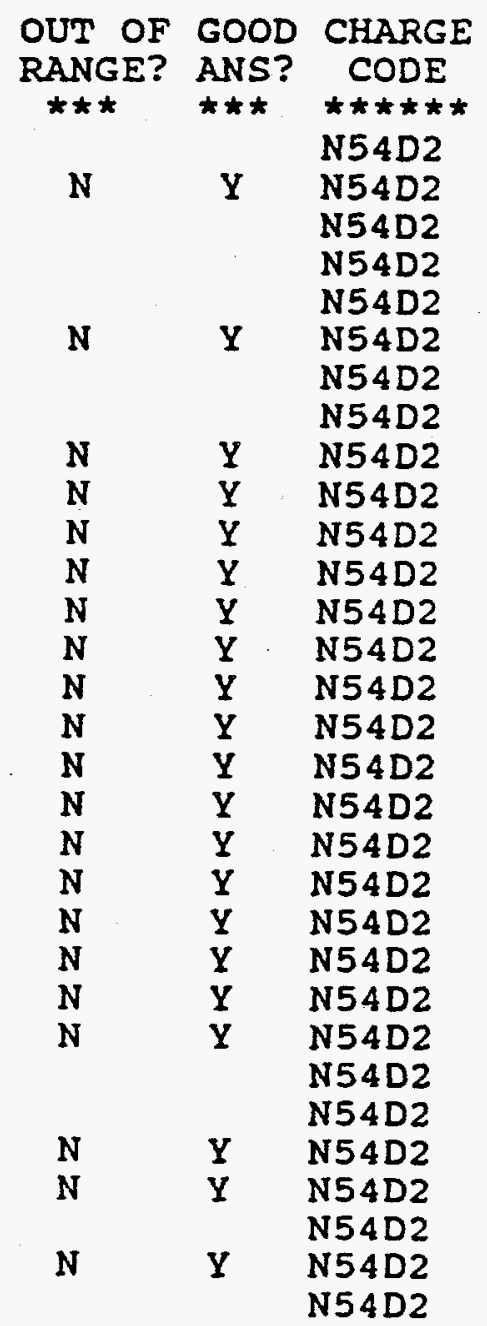

END OF REPORT 
SAMPLE STATUS REPORT FOR T DISPATCHED: $3 / 5 / 94$ 10:48 RECEIVED: $\quad 3 / 5 / 94$ 13:16
548. $T-I I I$ SAMPIE T-111 \#2 TIME:

$\begin{array}{ll}\text { T-III } & \# 2 \text { TIME } \\ \text { T BEEN SLURPED }\end{array}$
EXT. DETER.

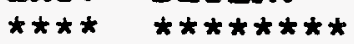

1001 APPR/OTR

5706 SPG

5711 DSC

5711 DSC

5712 TGA

$5713 \mathrm{pH}$

$5714 \% \mathrm{H} 2 \mathrm{O}$

5720 TB

5725 AT

5726 TOC

5727 TIC

$5728 \quad$ NH4

5729 OH IIQ

5730 GEA

5750 ICP-LIQ

5750 ICP-LIQ

5771 IC

5771 IC

5771 IC

5771 IC

5771 IC

5771 IC

5778 CN LIQ

5781 Pu239/40

5781

5782

5783

5786

5786

9114
RESULTS OR STATUS

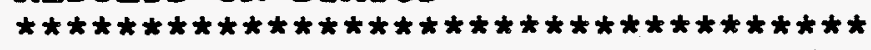

CLEAR YELLOW < $1 \%$ SOLIDS

1.03760E OO NONE

OUT FOR RERUN

INCOMPLETE

INCOMPLETE

$1.15900 E$ O1 NONE

$9.29000 \mathrm{E}$ OI $\% \mathrm{H} 2 \mathrm{O}$

$2.31000 \mathrm{E}-01 \mathrm{uCi} / \mathrm{ML}$

$2.32000 \mathrm{E}-03 \mathrm{uCi} / \mathrm{ML}$

4.18000 E 02 UG C/ML

$7.90000 \mathrm{E} 02 \mathrm{UG} \mathrm{C} / \mathrm{ML}$

$3.70000 \mathrm{E} 02 \mathrm{UG} / \mathrm{ML}$

$2.70000 \mathrm{E} 03 \mathrm{UG} / \mathrm{ML}$

$9.21999 \mathrm{E}-02 \mathrm{UCi} / \mathrm{ML}$

$2.43000 E$ O 04 UG/ML

$<5.05000 \mathrm{E}$ OO UG/ML

2.15977 E 03 UG/ML

4.9764OE $02 \mathrm{UG} / \mathrm{ML}$

$1.37823 \mathrm{E} 03 \mathrm{UG} / \mathrm{ML}$

$3.00138 \mathrm{E} \quad 04 \mathrm{UG} / \mathrm{ML}$

$8.24791 \mathrm{E} 03 \mathrm{UG} / \mathrm{ML}$

$2.85180 \mathrm{E} 03 \mathrm{UG} / \mathrm{ML}$

$1.84000 \mathrm{E}$ OO UG/ML

OUT FOR RERUN

INCOMPLETE

$<2.76000 \mathrm{E}-05 \mathrm{uCi} / \mathrm{ML}$

$<2.89000 \mathrm{E}-05 \mathrm{uCi} / \mathrm{ML}$

OUT FOR RERUN

3.03000E-04 UCi/ML

INCOMPLETE

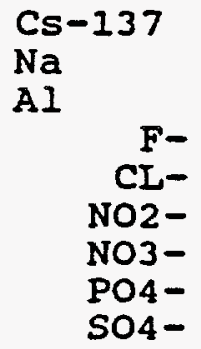

Cs-137

Na

F-
CL-
NO2-
NO3-
PO4-
SO4-
OUT OF GOOD CHAREE RANGE? ANS? CODE

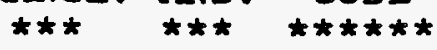

N54D2 -

N $\quad \mathrm{N} \quad \mathrm{N} 54 \mathrm{D2}$

N54D2

N54D2.

N54D2

N54D2

N54D2

N54D2

N54D2

N54D2

N54D2

N54D2

N54D2

N54D2

N54D2

N54D2

N54D2

N54D2

N54D2

N54D2

N54D2

N54D2

N54D2

N54D2

N54D2

$\begin{array}{lll}\mathrm{N} & \mathrm{Y} & \mathrm{N} 54 \mathrm{D2} \\ \mathrm{N} & \mathrm{Y} & \mathrm{N} 54 \mathrm{D2}\end{array}$

N54D2

N $\quad \mathrm{Y} \quad \mathrm{N} 54 \mathrm{D2}$

N54D2

END OF REPORT 
SAMPLE STATUS REPORT FOR T $\begin{array}{lll}\text { DISPATCHED: } & 3 / 5 / 94 & 10: 49 \\ \text { RECEIVED: } & 3 / 5 / 94 & 13: 16\end{array}$

550. $T-111$ SAMPLE HAS NOT BEEN SLURPED

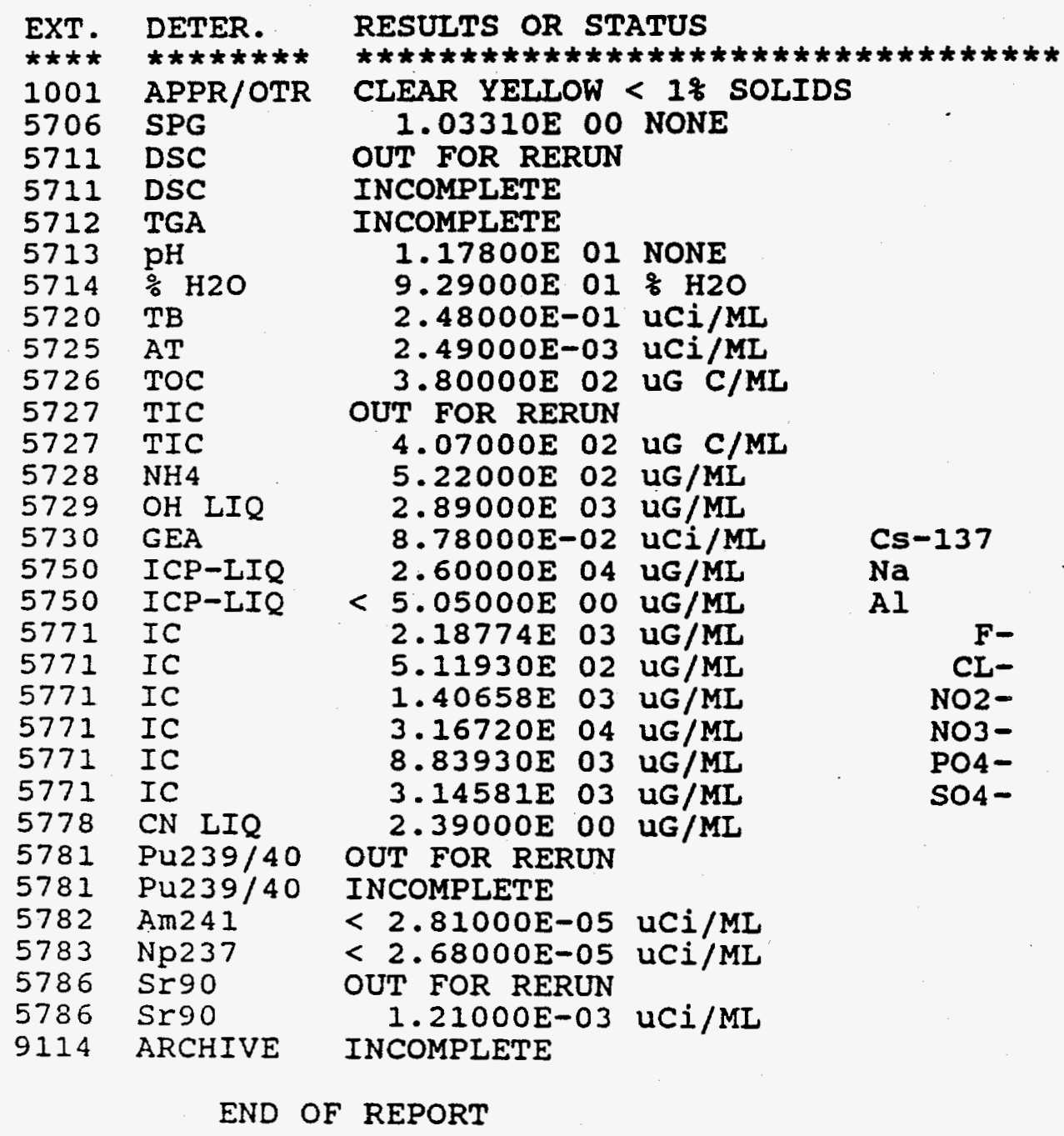

\begin{tabular}{|c|c|c|}
\hline $\begin{array}{l}\text { OUT OF } \\
\text { RANGE? } \\
\star \star \star\end{array}$ & $\begin{array}{l}\text { GOOD } \\
\text { ANS? } \\
\star \star \star\end{array}$ & $\begin{array}{l}\text { CHARGE } \\
\text { CODE } \\
\star \star \star \star \star \star\end{array}$ \\
\hline$N$ & $Y$ & $\begin{array}{l}\text { N54D2 } \\
\text { N54D2 } \\
\text { N54D2 } \\
\text { N54D2 } \\
\text { N54D2 }\end{array}$ \\
\hline $\mathbf{N}$ & $Y$ & N54D2 \\
\hline $\mathrm{N}$ & $Y$ & N54D2 \\
\hline $\mathbf{N}$ & $Y$ & N54D2 \\
\hline $\mathbf{N}$ & $\mathbf{Y}$ & N54D2 \\
\hline $\mathrm{N}$ & $\mathbf{Y}$ & $\begin{array}{l}\text { N54D2 } \\
\text { N54D2 }\end{array}$ \\
\hline $\mathrm{N}$ & $\mathbf{Y}$ & N54D2 \\
\hline $\mathrm{N}$ & $\mathbf{Y}$ & N54D2 \\
\hline $\mathrm{N}$ & $Y$ & N54D2 \\
\hline $\mathbf{N}$ & $Y$ & N54D2 \\
\hline$N$ & $\mathbf{Y}$ & N54D2 \\
\hline $\mathrm{N}$ & $Y$ & N54D2 \\
\hline $\mathrm{N}$ & $\mathbf{Y}$ & N54D2 \\
\hline $\mathrm{N}$ & $Y$ & N54D2 \\
\hline $\mathrm{N}$ & $Y$ & N54D2 \\
\hline $\mathbf{N}$ & $Y$ & N54D2 \\
\hline $\mathbf{N}$ & $Y$ & N54D2 \\
\hline N & $\mathbf{Y}$ & $\mathrm{N} 54 \mathrm{D} 2$ \\
\hline$N$ & $Y$ & $\begin{array}{l}\text { N54D2 } \\
\text { N54D2 }\end{array}$ \\
\hline $\mathbf{N}$ & $Y$ & $\begin{array}{l}\text { N54D2 } \\
\text { N54D2 }\end{array}$ \\
\hline N & $\mathrm{Y}$ & $\begin{array}{l}\text { N54D2 } \\
\text { N54D2 }\end{array}$ \\
\hline $\mathrm{N}$ & $Y$ & $\begin{array}{l}\text { N54D2 } \\
\text { N54D2 }\end{array}$ \\
\hline
\end{tabular}


Estimate of plutonium concentration that would place 241-T-111 out of specification with regard to established inventory limits.

$50 \mathrm{~kg}{ }^{239 / 240} \mathrm{Pu}$ is the standard inventory limit for single-shell tanks ${ }^{9}$.

Therefore, $\quad \frac{50,000 \mathrm{~g}^{239 / 240 \mathrm{Pu}}}{2.171 \mathrm{E}+09 \mathrm{~g} \text { waste }}=\frac{2.303 \mathrm{E}-05 \mathrm{~g}^{239 / 240 \mathrm{Pu}}}{\mathrm{g} \text { waste }}$

Approximate proportion of $\mathrm{Pu}-239=96 \%$

Approximate proportion of $\mathrm{Pu}-240=4 \%$

Specific activity of $\mathrm{Pu}-239=6.2 \mathrm{E}-02 \mathrm{Ci} / \mathrm{g}^{2}$

Specific activity of $\mathrm{Pu}-240=2.27 \mathrm{E}-01 \mathrm{Ci} / \mathrm{g}$

Specific activity for the plutonium in the waste:

$0.96^{*}(6.2 \mathrm{E}-02 \mathrm{Ci} / \mathrm{g})+.04^{*}(2.27 \mathrm{E}-01 \mathrm{Ci} / \mathrm{g})=0.0686 \mathrm{Ci} / \mathrm{g}^{239 / 240} \mathrm{Pu}$

$$
\frac{2.303 E-05 \mathrm{~g}^{239 / 240} \mathrm{Pu}}{\mathrm{g} \text { waste }} * \frac{0.0686 \mathrm{Ci}}{\mathrm{g}\langle 39 / \angle 40 \mathrm{Pu}} * \frac{1 \mathrm{E}+06 \mu \mathrm{Ci}}{\mathrm{Ci}}=\frac{1.58 \mu \mathrm{Ci}}{\mathrm{g} \text { waste }}
$$

The estimates of historical inventory values for selected analytes were derived from Agnew $^{3}$. The estimates for $2 \mathrm{C}$ concentrations were done by taking the average concentrations of the two flowsheet formulations, $2 C \quad 44-51$ and $2 C$ 52-56. The 224 waste concentrations were used as presented. These values were multiplied by their respective volumes to develop the bulk inventory estimates. The buld concentrations presented for he tank were derived by multiplying each analyte's concentration by the fr..tion its waste contributes to the total inventory and adding them together, i.e. $0.526^{*}\left(2 \mathrm{C}_{\text {avg }}\right.$ concentration $)+0.474 *(224$ concentrations $)=$ Bulk analyte concentrat ion

${ }^{1}$ Boyles, V. C. 1992, Operating Specifications for singleShelI Waste Storage Tanks, OSD-T-151-00013, Rev. D-1, Westinghouse Hanford Company, Richland, Washington.

${ }^{2}$ Van Tuyl, H. H., 1962, Fission Product Generation and Decay Calculations, HW-75978, General Electric Company, Richland, Washington.

${ }^{3}$ Agn $=\because$, S. F. 1994, Hanford Defined wastes: Chemical and Radionuc- ie Compositions, LA-UR-2657, Los Alamos National Laborator Los Alamos, Mew Mexico. 


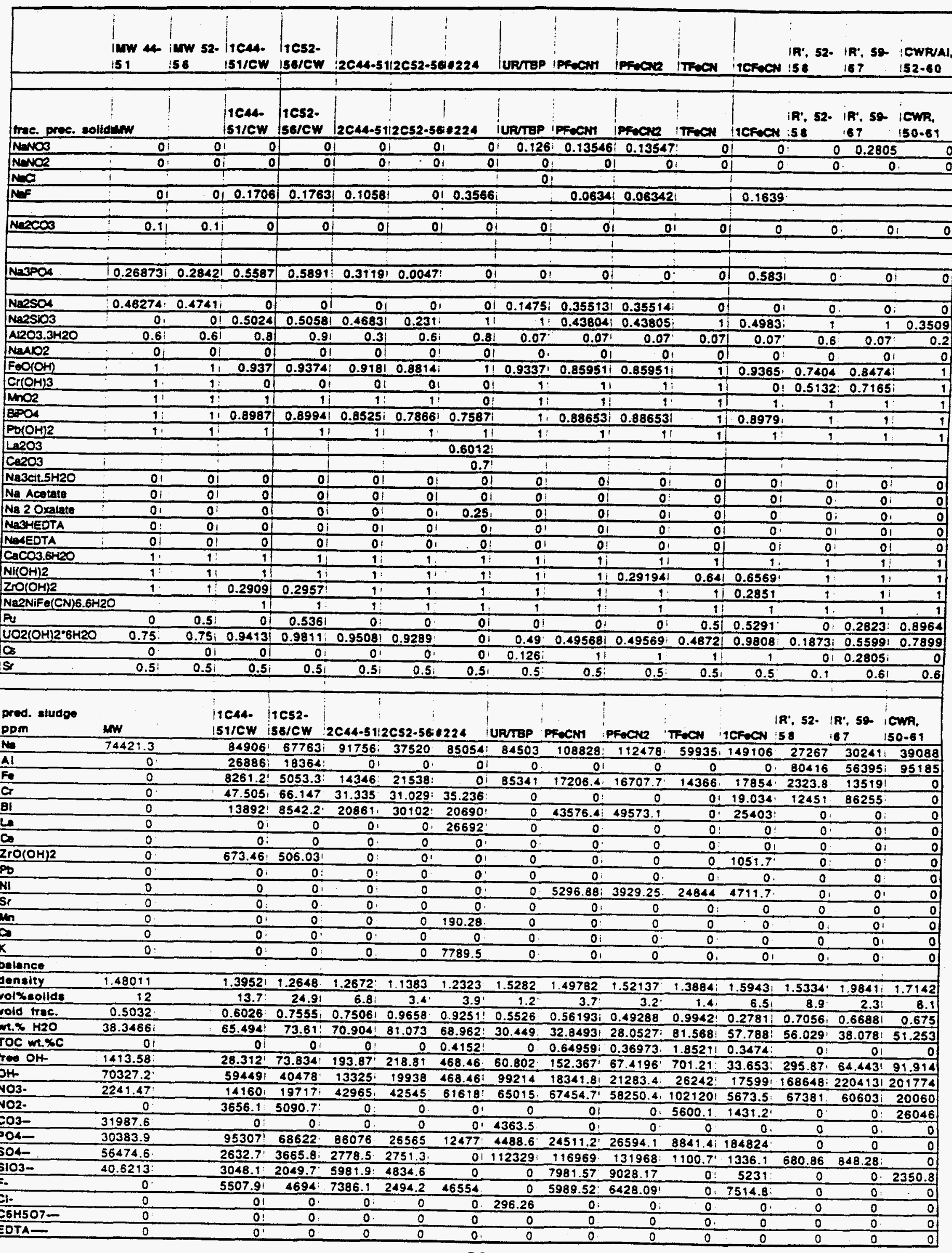




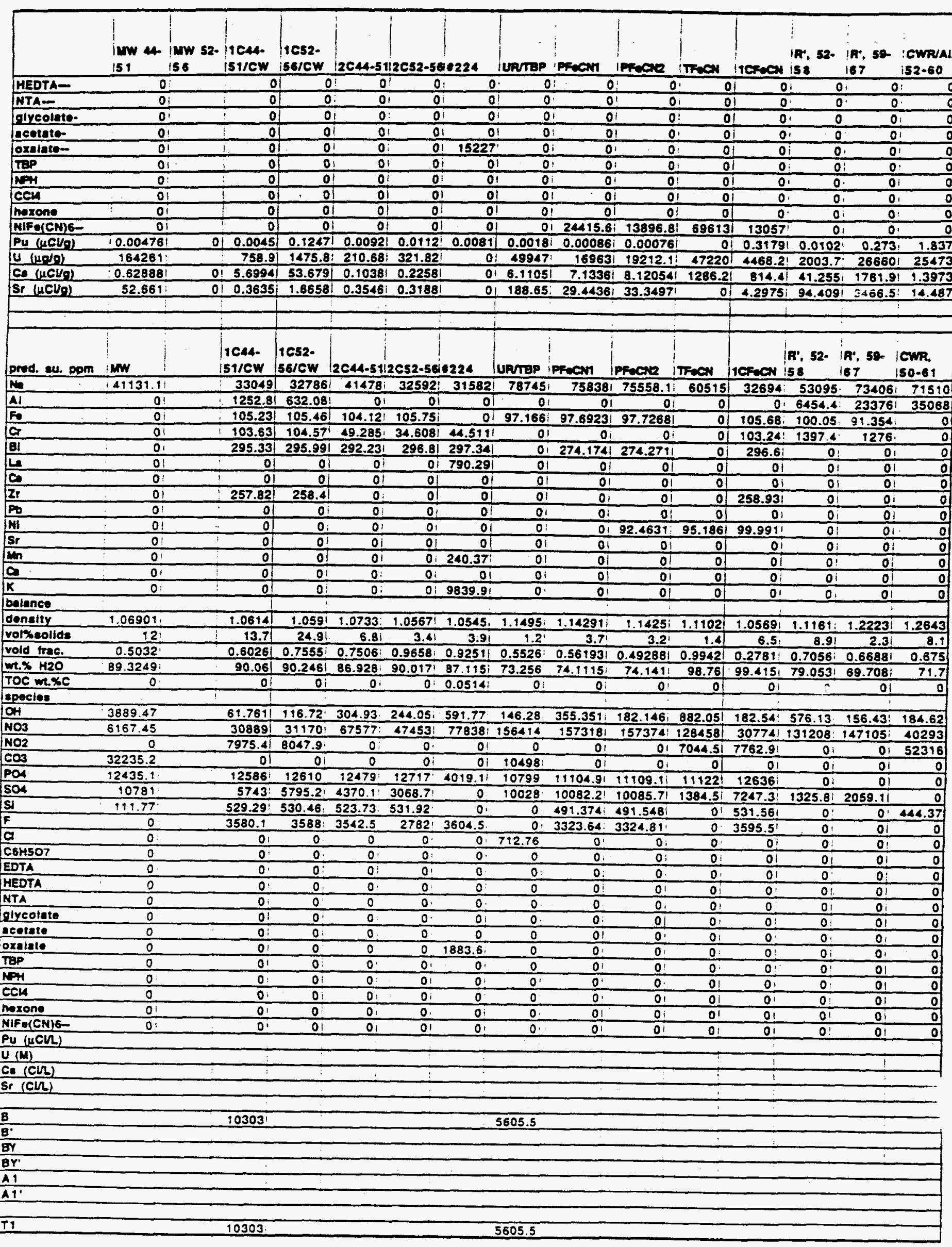


TR: :

)

Iiquid, Gel.

$82 \times 10^{3}$
WHC-EP-0.806

\section{TANK III-T STATUS}

Sluage, Gal.

So. Gr. $(g / c c)$

$430 \times 10^{3}$

1.032

\section{Chemical Anelyses}

\begin{tabular}{|c|c|}
\hline $\begin{array}{l}\text { Free } \mathrm{NaOH} \\
\mathrm{CO}_{3}=(\mathrm{g} / \mathrm{I})\end{array}$ & $0.701 \mathrm{~N}$ \\
\hline $\mathrm{AlO}_{2}(\mathrm{~g} / 1)$ & 0.022 \\
\hline$(g / 1)$ & \\
\hline$C I^{-}(g / 1)$ & 15.8 \\
\hline $\mathrm{Na}^{+}(g / I)$ & 21.0 \\
\hline $\mathrm{NO}_{3}^{-}(\mathrm{g} / 1)$ & 2.47 \\
\hline- & 9.5 \\
\hline Gamma Scen & N.D. \\
\hline$-\mathrm{No} 95$ (uc/1) & $3.48 \times 10^{8}$ \\
\hline$-R b^{106}(\mathrm{uc} / \mathrm{I})$ & $1.21 \times 10^{3}$ \\
\hline $25(\mathrm{uc} / 1)$ & N.D. \\
\hline $134(u c / 1)$ & N.D. \\
\hline $37(\mathrm{uc} / \mathrm{I})$ & $1.15 \times 103$ \\
\hline
\end{tabular}

\section{Boil-Down Studies}

Percent B011-Down

301 ling Polat $\left({ }^{\circ} \mathrm{C}\right)$

Percent Solfas -

at bo1lias point

at room temperature

$\begin{array}{rrrr}0 & 50 & 80 & 90 \\ 105 & 105 & 106 & 107\end{array}$

$\begin{array}{llrr}\text { CI } & =15 & 5 & 7 \\ 01 & 28 & 70\end{array}$ 


\section{$\because Z--三 \quad$ WHC-EP-0805 \\ Atiantic Richfield Hanford Company}

Date: June 7,1974

To: R. L. Walser

From: R. E. Wheeler of Rt Dictin

Subject: ANALYSIS OF TANK FARM SAMPLES

SAMPLE: T-3304 111-T

Vis-0TR: Clear, Yellow, 30\% solids like rust. Filtrate $<10 \mathrm{mrad} / \mathrm{hr}$.

$\mathrm{pH}:$ 13.25

SpG:

1.018

$\mathrm{OH}$ :

$0.254 \underline{M}$

A1:

$<6.48 \times 10^{-4} \mathrm{M}$

Na:

0.446

$\mathrm{NO}_{2}$ :

$4.39 \times 10^{-3} \underline{M}$

$\mathrm{NO}_{3}:$

$0.083 \mathrm{M}$

Pu:

$1.17 \times 10^{-6} \mathrm{~g} / 1$

DTA: No Exotherm

$\mathrm{SO}_{4}:$

$\mathrm{PO}_{4}$ :

F:

$3.79 \times 10^{-3} \mathrm{M}$

$2.16 \times 10^{-2} \bar{M}$

$\mathrm{CO}$

$3.56 \times 10^{-2} \frac{M}{M}$

GEA:

$$
\begin{aligned}
& 0.024 \mathrm{M} \\
& 134 \mathrm{Cs}-1.13 \mathrm{LCi} / \mathrm{gaT} \\
& 137 \mathrm{Cs}=3.69 \times 10^{2} \mathrm{Ci} / \mathrm{g}
\end{aligned}
$$$$
\begin{aligned}
& 137 \mathrm{Cs}-3.13 \times \mathrm{HCi}^{2} \mathrm{gal} \\
& 125 \mathrm{Sb}-4.66 \times 10^{2} \mathrm{HCi} / \mathrm{gal}
\end{aligned}
$$

Water: $98.24 \%$

Cooling Curve: $10^{\circ} \mathrm{C}$ for $45 \mathrm{~min}$. No solids. $5^{\circ} \mathrm{C}$ for $45 \mathrm{~min}$. No solids.

$30 \%$ Reduction - 27.5

$50 \%$ Reduction -50.0

Solids - 0

Solids - $0.5 \%$

REW: jd 


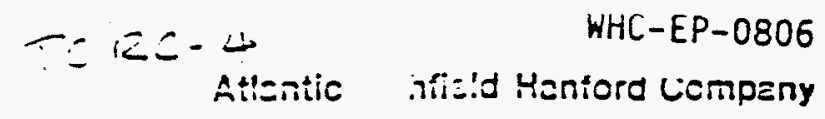

Date: September 24,1974

To: R. L. Walser

From: R. E. litheeler A riticeir

Subject: AIIALYSIS OF.TANK FARM SAIIPLES

SAMPLE: T-4893 111-T

l'is-OTR: Black. 90\% solids. $10 \mathrm{mrac} / \mathrm{hr}$, filtrate

pH: $\quad 12.9$

Sog: $\quad 1.0202$

0.4: $\quad 0.206 \underline{M}$

A1: $\quad 7.75 \times 10^{-4} \mathrm{H}$

i.a: $\quad 0.188 \mathrm{M}$ icN

! $\mathrm{O}_{2}: \quad 5.17 \times 10^{-3} \mathrm{M}$

$105: \quad 0.109$ if

Pu: $\quad<1.41 \times 10^{-6} \mathrm{~g} / 1$

DIA: lio exotherm below $200^{\circ} \mathrm{C}$

SD.: $\quad \quad .43 \times 10^{-3} \underline{\mathrm{M}}$

F.: $\quad 2.33 \times 10^{-2} \underline{M}$

F: $\quad 4.28 \times 10^{-2} \bar{M}$

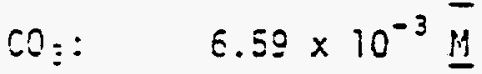

$\exists=\therefore: \quad \therefore: C_{5}-5.72 \times 10^{2} \mathrm{iCi} / \mathrm{gal}$

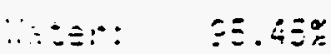

$\because: \vdots ; r: \equiv$ Lrre: $\angle n=C$ for 45 min. onor Solids. $25=C$ for $45 \mathrm{~min}$. $00 \%$ solids.

$3 n=C$ For $45 \mathrm{~min}$. Qn\% solids.

$25=C$ for 45 min. gna solids.

2nc for 45 rin. ang solios.

i:C cor 45 min. gn:s solids.

io:c ier 45 min. goo solics.

$\equiv=C$ For $45 \mathrm{~min}$. $90 \%$ solids.

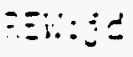

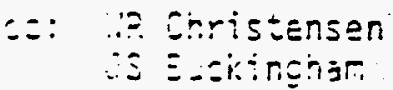

